VISUELLE GESCHICHTSKULTUR | BAND 15

\title{
DAS JAHR 1813, OSTMITTELEUROPA UND LEIPZIG
}

Die Völkerschlacht als (trans)nationaler Erinnerungsort 
Das Jahr 1813, Ostmitteleuropa und Leipzig 


\title{
GWZO
}

Geisteswissenschaftliches Zentrum

Geschichte und Kultur Ostmitteleuropas e.V.

\section{Visuelle Geschichtskultur}

\author{
Herausgebergremium: \\ Stefan Troebst und Arnold Bartetzky \\ in Verbindung mit \\ Steven A. Mansbach und Małgorzata Omilanowska
}

Band 15 


\title{
Das Jahr 1813, \\ Ostmitteleuropa und Leipzig
}

Die Völkerschlacht als (trans)nationaler Erinnerungsort

\author{
Herausgegeben von \\ Marina Dmitrieva und Lars Karl \\ unter Mitarbeit von Paweł Gorszczyński
}

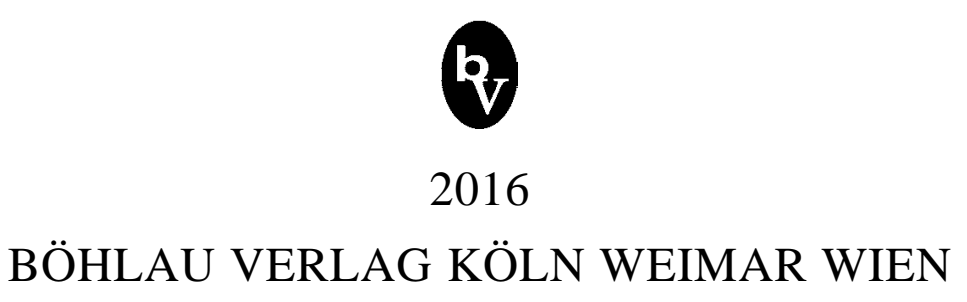


Gedruckt mit Unterstützung des Geisteswissenschaftlichen Zentrums Geschichte und Kultur Ostmitteleuropas e. V. an der Universtität Leipzig.

Das dieser Publikation zugrunde liegende Vorhaben wurde u. a. mit Mitteln des Bundesministeriums für Bildung und Forschung unter dem

Förderschwerpunkt „Geisteswissenschaftliche Zentren“

(Förderkennzeichen 01UG1410) gefördert.

Die Verantwortung für den Inhalt dieser Veröffentlichung liegt bei den Autoren.

Bibliografische Information der Deutschen Nationalbibliothek:

Die Deutsche Nationalbibliothek verzeichnet diese Publikation in der Deutschen Nationalbibliografie; detaillierte bibliografische Daten sind im Internet über http://portal.dnb.de abrufbar.

Umschlagabbildung:

Leipzig, Völkerschachtdenkmal: Kryptapfeiler mit Schicksalsmaske und Totenwächtern. Foto: Matthias Topfstedt.

(C) 2016 by Böhlau Verlag GmbH \& Cie, Köln Weimar Wien Ursulaplatz 1, D-50668 Köln, www.boehlau-verlag.com

Alle Rechte vorbehalten. Dieses Werk ist urheberrechtlich geschützt. Jede Verwertung außerhalb der engen Grenzen des Urheberrechtsgesetzes ist unzulässig.

Korrektorat: Rainer Landvogt, Hanau

Gesamtherstellung: WBD Wissenschaftlicher Bücherdienst, Köln

Gedruckt auf chlor- und säurefreiem Papier

Printed in the EU

ISBN 978-3-412-50399-4 


\section{Inhalt}

Marina Dmitrieva und Lars Karl

Einleitung ............................... 7

\section{Geschichtspolitik und Erinnerungskultur}

Karen Hagemann

Helden, Horror und Hunger.

Die Leipziger Völkerschlacht 1813 - Erfahrungen und Erinnerungen . . . . . . . .

Stefan Troebst

Vom „Vaterländischen Krieg 1812“ zum „Großen Vaterländischen Krieg 1941-1945“. Siegesmythen als Fundament staatlicher Geschichtspolitik in der Sowjetunion, der Russländischen Föderation, der Ukraine und Belarus' . . . . . .

Karsten Holste und Dietlind Hüchtker

Die bewaffnete Heldin 1813-1913-2013: Wahrnehmungen, Deutungen und

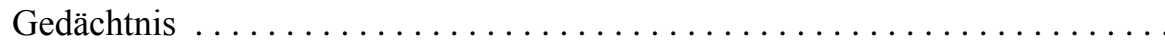

\section{Völkerschlacht als nationales Narrativ}

Hans-Christian Trepte

Zum Poniatowski-Mythos in der polnischen Kultur und Literatur

Ruth Leiserowitz

Die Völkerschlacht im Spiegel des polnischen historischen Romans

Agnieszka Zabłocka-Kos

Stationen der Erinnerung an die Befreiungskriege in Schlesien:

1813-1913-2013

Arnold Bartetzky

Befreiungskriege und Völkerschlacht in der visuellen Erinnerungskultur des

Deutschen Kaiserreichs 


\section{Topografie der Völkerschlacht: Spurensuche}

Thomas Topfstedt

Das Leipziger Völkerschlachtdenkmal: Eine kurze Ideen- und Baugeschichte

\section{Marina Dmitrieva}

Die Russische Gedächtniskirche in Leipzig als Erinnerungsort

an die Völkerschlacht

Christian Forster

Die österreichischen Denkmale um Leipzig zum Gedenken an die

Völkerschlacht

Thomas Westphalen

Die Archäologie der Völkerschlacht bei Leipzig 1813

\section{Bilder der Völkerschlacht: Medien und Erinnerung}

Dagmar Burkhart

Heldensturz. Deutsche, englische und russische Napoleon-Karikaturen zur

Völkerschlacht von Leipzig

\section{Lars Karl}

„Das Volk steht auf, der Sturm bricht los!“ Die Napoleonischen Kriege als Mobilisierungsressource im NS-Spielfilm - das Beispiel „Kolberg“ . .

Stephan Krause

István Széchenyi vor Leipzig. Heldenstory und Soldatengeschwätz . . .

Elena Bukreeva und Ramil Rachimov

Die irreguläre Kavallerie des Zaren Alexander I. in der Leipziger Völkerschlacht und ihre Darstellungen in Beständen des Staatlichen Historischen Museums Moskau . . . . . . . . . . . . . . . . . . . . . . . . . . . . . . . . . . . 267

Autorenverzeichnis ............................... 285

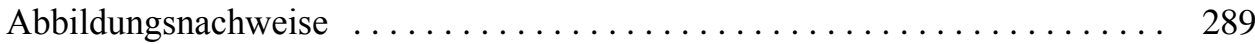

Register ..................................... 291

Personenregister ............................... 291

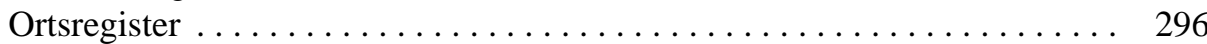




\title{
Einleitung
}

\author{
Marina Dmitrieva und Lars Karl
}

\begin{abstract}
Ich schreibe Dir am Morgen einer Schlacht, wie sie in der Weltgeschichte kaum gefochten ist. Wir haben den französischen Kaiser umstellt. Diese Schlacht wird über das Schicksal Europas entscheiden. (August Neidhardt von Gneisenau, 18. Oktober 1813)
\end{abstract}

Aus diesem kurzen, aus zeitgenössischer Perspektive aber programmatischen Zitat wird ersichtlich, dass der preußische Militärreformer und Generalstabschef der 3. Schlesischen Armee auf einen siegreichen Kampf gegen Napoleon und damit auf ein baldiges Ende einer Epoche der Umwälzungen und Kriege hoffte. Am Tage danach konnte er mitteilen: „Die große Schlacht ist gewonnen, der Sieg ist entscheidend.“1

Für vier Tage stand die Stadt Leipzig mit ihren damals 33.000 Einwohnern im Zentrum einer Schlacht von bis dahin unbekanntem Ausmaß. Sie brachte Blut, Tod und Verderben über fast 100.000 Menschen und zählte mit deutlich mehr als einer halben Million Soldaten zu einer der größten Schlachten der europäischen Geschichte: die sogenannte Völkerschlacht vom 16. bis zum 19. Oktober 1813. Bis heute gilt sie in zahlreichen nationalen Meistererzählungen über die Befreiungs- oder Freiheitskriege als die entscheidende Schlacht zwischen der Grande Armée Napoleon Bonapartes und den Truppen der Verbündeten Österreich, Preußen, Russland und Schweden. Auf beiden Seiten kämpften darüber hinaus Angehörige vieler weiterer Nationen, was ihr das Attribut verlieh, eine Schlacht der Völker gewesen zu sein. Mit der Völkerschlacht bei Leipzig, so das dominierende Narrativ, wurde für weite Gebiete Europas im Zeitalter Napoleons eine Trendwende eingeläutet, die im darauf folgenden Jahr mit dem Wiener Kongress von 1814/1815, der nochmaligen Niederlage Napoleons in der Schlacht von Waterloo und seinem endgültigen Sturz eine politische und territoriale Neuordnung des Kontinents erbrachte, die für viele Jahre das 19. Jahrhundert und die Geschicke der deutschen Staaten, allen voran Preußens, prägen sollte.

Tatsächlich war die militärische Bedeutung trotz der ungeheuren Opfer begrenzt. Der Kaiser der Franzosen hatte zwar eine schwere Niederlage hinnehmen müssen, doch war die Schlacht bei Leipzig, die der napoleonische Armeebericht seinerseits als einen bloßen Rückzug darstellte, nur ein Glied in einer längeren Kette von Niederlagen und

1 Zit. nach: Thamer, Hans-Ulrich: Die Völkerschlacht bei Leipzig. Europas Kampf gegen Napoleon. München 2013, S. 7; zu aktuellen Publikationen über die Schlacht bei Leipzig vgl. auch: Platthaus, Andreas: 1813. Die Völkerschlacht und das Ende der Alten Welt. Berlin 2013; Poser, Steffen: Die Völkerschlacht bei Leipzig. ,In Schutt und Graus begraben‘. Hg. v. Stadtgeschichtlichen Museum Leipzig. Leipzig 2013. 
Abwehrkämpfen, die 1812 in Moskau begannen und erst mit Waterloo und der Verbannung Napoleons auf St. Helena endeten. Während in der französischen historischen Wahrnehmung die Völkerschlacht bei Leipzig daher konsequenterweise kaum Beachtung fand und findet, entstand auf deutscher Seite ein nationaler Gründungsmythos par excellence. Die Völkerschlacht wurde in der kollektiven Erinnerung der Deutschen zu einer nationalen Heilsgeschichte, zur mythischen Urschlacht, zur Geburtsstunde der Nation verklärt. Innerhalb weniger Jahrzehnte stilisierte man das Geschehen auf den Schlachtfeldern von Leipzig nicht selten zu einem manichäisch anmutenden Kampf zwischen Licht und Finsternis, zwischen Gut und Böse - denn die Selbstfindung der deutschen Nation erfolgte nicht zuletzt im Gegenbild des dämonisierten französischen Feindes.

Für mehr als ein Jahrhundert war die Völkerschlacht somit Gegenstand nationaler Mythenbildungen, wobei die geschichtspolitische Instrumentalisierung häufig bis in die Begrifflichkeiten reichte. Sollte die Völkerschlacht nun als Teil und Höhepunkt von „Freiheitskriegen“ oder „Befreiungskriegen“ gelesen werden? Der semantische Streit stellte sich als ein politischer Konflikt um Deutungsmacht heraus. Als die verbündeten Monarchen weder die Freiheitsideale erfüllten noch den Rufen nach einer geeinten deutschen Nation nachkamen, wandelten sich die Gedenkfeiern vom 18. Oktober mancherorts in Demonstrationen national und liberal gesinnter Freiheitskämpfer, wie etwa beim Wartburgfest vom 17. Oktober 1817. So teilte sich die Erinnerung an die Schlacht: Die eine Seite verherrlichte sie als die Geburtsstunde der deutschen Nation, als Volksbewegung für Einheit und Freiheit, die anderen feierten sie als Sieg über die Herrschaft Napoleons und die Revolution auf deutschem Boden. Im Bereich der Denkmalskultur wurden allerdings vorerst nur diejenigen Entwürfe realisiert, welche die monarchisch legitimierte Ordnung feierten. Erst mit dem 1894 begonnenen Völkerschlachtdenkmal, geplant und realisiert vom „Deutschen Patriotenbund“, wurde der Schlacht bei Leipzig als Geburtsstunde der deutschen Nation ein Denkmal gesetzt. Die Erinnerung an die Völkerschlacht kann somit als Gradmesser für die Schwankungen und Gegensätze in der politischen Kultur des deutschen Nationalismus und des Nationalstaates gelten - von 1814 bis 1945 oder, im Hinblick auf die DDR, sogar bis 1989.²

Selbstverständlich ist bis heute umstritten, welchen Anteil die viel beschworene nationale Begeisterung der Massen tatsächlich am militärischen Sieg über Napoleon hatte. Auch in der Namengebung „Völkerschlacht“" wird dieser Konflikt bereits semantisch angezeigt: Während jener Oberst von Müffling, der das neue Wort in seinen Armeebericht einschleuste, es noch in seiner alten, unmetaphorischen Bedeutung verwendete und mit „Völkern“ das Heervolk, also die Truppen absolutistischer Herrscher, umschrieb, wurde es von anderen Zeitgenossen als Benennung einer Schlacht der um nationale Emanzipation von Napoleon ringenden „Völker“ umgedeutet. Als sich die

2 Zur musealen Verarbeitung dieses Erinnerungsdiskurses im Jubiläumsjahr 1813 siehe u.a.: Helden nach Maß. 200 Jahre Völkerschlacht bei Leipzig. Ausst.-Kat. Stadtgeschichtliches Museum Leipzig. Hg. v. Volker Rodekamp. Leipzig 2013; 1813. Auf dem Schlachtfeld bei Leipzig. Ein Rundgang durch das Gemälde „Siegesmeldung“" von Johann Peter Krafft. Ausst.-Kat. Hg. v. Deutschen Historischen Museum (DHM). Berlin 2013. 
Völkerschlacht 100 Jahre später im Leipziger Denkmal monumentalisierte, war die Denotation „Heervolk“ längst vergessen. „Völker“ meinte autonome Kollektivsubjekte der Geschichte.

Welche Rolle das Völkerschlachtereignis für die Erinnerungskulturen der Angehörigen der beteiligten osteuropäischen bzw. ostmitteleuropäischen „Heervölker“ hatte, ist Gegenstand des vorliegenden Sammelbandes. Aus Anlass des Leipziger Doppeljubiläums (Völkerschlacht 1813, Einweihung des Völkerschlachtdenkmals 1913) sowie in Anknüpfung an die vielfältige historische Erforschung der Kommemorierung von Kriegen sowie der damit zusammenhängenden Formen von Erinnerungspolitik widmete das Geisteswissenschaftliche Zentrum Geschichte und Kultur Ostmitteleuropas (GWZO) an der Universität Leipzig seine Jahrestagung 2013 der Thematisierung des Völkerschlachtereignisses in den Gedächtniskulturen Ost(mittel)europas. Im Zentrum standen dabei kultur- und erinnerungsgeschichtliche Perspektiven - mit einem Schwerpunkt auf den jeweiligen nationalen Narrativen und daran hängenden Mythenbildungen. Besondere Berücksichtigung fanden dabei die medialen Aufbereitungen des Ereignisses in Literatur, bildender Kunst und Film. Vor diesem Hintergrund ist das Sammelwerk als Produkt einer angeregten interdisziplinären Diskussion zu verstehen sowie als Versuch, einschlägige Forschungsergebnisse in einen gesamteuropäischen Kontext einzuordnen.

Die Napoleonischen Kriege bedeuteten in mehrfacher Hinsicht eine Zäsur. Sie waren Kriege im Zeichen von Massenmobilisierung und Massenheeren, von neuen Militärstrategien und politischen Ideologien, die unter den Vorzeichen von „Nation“ und „Revolution“ standen. Diese große Akzeptanz im Hinblick auf nationale Symbole und Deutungen erlaubte zudem, das erlebte menschliche Leid, die ungeheuren Opferzahlen und die gewaltigen Schäden zu verarbeiten, welche das Schlachtereignis selbst mit sich brachte. Als Auftakt des Themenabschnitts Geschichtspolitik und Erinnerungskultur geht Karen Hagemann der zentralen Frage nach, wie die Gewalt der offensiven Kriegführung, wie sie vor allem von Napoleon entwickelt wurde, nicht nur den militärischen Gegner, sondern auch die Zivilbevölkerung traf. Diese musste Einquartierung und Requirierung, Plünderung und Raubaktionen erleben und ertragen. Die Entfesselung kriegerischer Gewalt setzte den Versuchen der Einhegung militärischer Konflikte, wie sie im „kleinen Krieg“ des 18. Jahrhunderts praktiziert wurde, ein Ende und nahm das Vernichtungspotenzial des totalen Krieges im 20. Jahrhundert tendenziell vorweg.

Im Hinblick auf die Sowjetunion erfolgte die Namengebung des „Großen Vaterländischen Krieges“ (Velikaja Otečestvennaja vojna) von 1941-1945 sogar im expliziten Rückgriff auf den sogenannten „Vaterländischen Krieg“ (Otečestvennaja vojna) von 1812. Besonders augenfällig werden (national)staatliche Bemühungen um eine politisch motivierte Konstruktion historischer Kontinuitäten daher am Beispiel der Nachfolgestaaten des Sowjetimperiums - der Russländischen Föderation, der Ukraine und Belarus' -, so Stefan Troebst in seinem Beitrag zu den Konstanten und Variablen postkommunistischer Geschichtspolitik. Im Falle der Russländischen Föderation sei der 
2005 erfolgte Rückgriff auf den nur wenig präsenten patriotischen Erinnerungsort „1612“ dabei ebenso erratisch wie der im Jahre 2012 verstärkte Bezug auf den heroischen lieu de mémoire „1812“ nahe liegend. Vielmehr trage der selektive geschichtspolitische Bezug auf die Vergangenheiten von Sowjetunion, Zarenreich, Großfürstentum Moskau und Kiewer Rus dazu bei, das Spannungsverhältnis zwischen multiethnischrussländischem Imperium und monoethnisch-russischem Nationalstaat aufrechtzuerhalten und damit den Prozess der Bildung einer corporate identity unter den Bürgern der Russländischen Föderation zu erschweren.

Im Anschluss daran widmen sich Karsten Holste und Dietlind Hüchtker dem Spannungsverhältnis von „Ausnahme“ und „Normalität“ in Bezug auf die (aktive) Teilnahme von Frauen an kriegerischen Handlungen im geteilten Polen zu Beginn des 19. und 20. Jahrhunderts. So sehr die kämpfende Frau in Polen im Besonderen eine Ausnahme von der herrschenden Geschlechterordnung darstellte, bestätigte sie zugleich die als Ausnahmeerscheinung wahrgenommene Situation Polens im Allgemeinen. Mit der Wiedererlangung der Unabhängigkeit und der daraus resultierenden Etablierung einer gesellschaftlichen „Normalität“ sei umgekehrt die Rechtfertigung für derartige Ausnahmen entfallen, was sich 1922 in der Auflösung von vorher zeitweise etablierten, regulären Fraueneinheiten in der polnischen Armee äußerte. Im Zentrum der Betrachtungen von Holste und Hüchtker steht dabei nicht die Entdeckung der Frau unter Waffen oder eine Entwicklungsgeschichte der Emanzipation, sondern die Relationalität zwischen sich permanent verändernden Geschlechterkonzeptionen und den daran hängenden Vorstellungen von Kriegs- und Friedensordnungen.

In der Tat war für kaum eine andere Nation Ostmitteleuropas das Völkerschlachtereignis für die Konstruktion geschichtsträchtiger Mythen um nationales Heldentum, enttäuschte Hoffnungen und Märtyrertod von größerer Bedeutung als für die polnische. Mit der preußischen Niederlage im Jahre 1806 war die Möglichkeit, die Teilung Polen-Litauens zu überwinden, scheinbar in greifbare Nähe gerückt. Im Juli 1807 hatte Napoleon im neu gebildeten Herzogtum Warschau den Code Napoléon eingeführt und eine Verfassung erlassen, die sich stark an die französische anlehnte. Als im Jahre 1812 die Grande Armée gegen Russland zog, bildeten die polnischen Truppen unter dem Kommando von Fürst Józef Poniatowski ein eigenes Armeekorps. Das Scheitern des Russlandfeldzuges ließ alle weiteren Pläne der Warschauer Regierung hinfällig werden, denn im Februar 1813 wurde die Stadt von russischen Truppen besetzt. Poniatowski und seine Soldaten blieben jedoch an der Seite Frankreichs und nahmen an der Völkerschlacht bei Leipzig teil. Nach dem vollständigen Zusammenbruch des napoleonischen Systems einigten sich die europäischen Mächte in Wien auf die neuen Grenzen zwischen ihren Herrschaftsgebieten - ein Akt, der in Bezug auf Polen später als die Vierte Teilung bezeichnet wurde.

Einführend zu dieser, u.a. dem polnischen Beispiel gewidmeten Themeneinheit Völkerschlacht als nationales Narrativ, analysiert Hans-Christian Trepte den Poniatowski-Mythos in der polnischen Kultur und Literatur. Erste idealisierende Schriften über das wohl prominenteste polnische Opfer der Völkerschlacht erschienen bald nach dem 
Tod des bis heute als Nationalhelden verehrten Poniatowski, der tödlich verwundet in der Hochwasser führenden Elster ertrunken war. Ebenfalls relativ früh setzte aber auch die Dekonstruktion dieses Heldenmythos ein. So sah General Ignacy Prądzyński in Poniatowski zwar einen disziplinierten Helden, der aber an den anderen großen Freiheitskämpfer der Epoche, Tadeusz Kościuszko, nicht herangereicht habe. Als promiz nenter Kritiker eines polnischen Bündnisses mit Napoleon wurde Letzterer auch Poniatowski positiv gegenübergestellt. Weitere an Poniatowski herangetragene Kritikpunkte waren sein vormaliger, ,fragwürdiger“ Lebenswandel als Lebemann, seine ,fremdläne dische“ (österreichische) Erziehung und seine „späte“ Begeisterung für die polnische Sache.

Im Anschluss betrachtet Ruth Leiserowitz die Völkerschlacht im Spiegel des polnischen historischen Romans, in welchem sich das eigentliche historische Ereignis eben kaum oder bestenfalls als Teil einer Reihe von französischen Niederlagen widerspiegele - und das trotz der 16.000 polnischen Soldaten, die allein auf der Seite Napoleons am Kampfgeschehen teilnahmen. Vielmehr avancierte der (Helden-)Tod Poniatowskis zum alles überstrahlenden Topos; ansonsten überwogen andere, mit militärischen Siegen verbundene Themen. Das Ausbleiben eines großen polnischen Völkerschlachtromans selbst zu Zeiten der Konjunktur des Genres erklärt Leiserowitz damit, dass polnische Soldaten auch auf russischer Seite gekämpft hatten und somit kein nationalkonstitutiver Nutzen aus einem solchen Werk gezogen werden konnte.

Entlang der Jahreszahlen 1813, 1913 und 2013 zeigt Agnieszka Zabłocka-Kos die Unterschiede im Gedenken an die Befreiungskriege in Niederschlesien und seiner Hauptstadt Breslau auf. In den Jahren unmittelbar nach der Völkerschlacht stand dort das Gedenken an den erfolgreichen Generalfeldmarschall von Blücher im Vordergrund, dem 1827 als erster weltlicher Person in Breslau ein Denkmal gesetzt wurde. Die (bald abflauende) Blüchereuphorie kann dabei als Gradmesser und Ausdruck der Preußentreue der Schlesier verstanden werden. Höhepunkt des Gedenkens wurde in Form eines Baudenkmals die Breslauer Jahrhunderthalle, welche 1913 in Erinnerung an König Friedrich Wilhelms III. Aufruf „An mein Volk“ eröffnet wurde, den man als Initialzündung des preußischen Kampfes gegen Napoleon verstand. In ihrer auch nach außen getragenen Modernität war die Jahrhunderthalle ein Konkurrenzprojekt zum archaisch wirkenden Leipziger Denkmalsbau und in Hinblick auf die östlichen Nachbarn ein postuliertes Zeichen hoher Zivilisation. Beides, sowohl der Konkurrenz- als auch der Bollwerk-Gedanke, trugen der peripheren Lage Breslaus Rechnung. Bei der 100-JahrFeier des Baudenkmals im Jahre 2013 wurde die Idee eines Hortes der Modernität aufgegriffen, nun aber unter den umgekehrten Vorzeichen einer Moderne im Westen Polens.

Die inhaltliche Sektion um nationale Narrative abschließend, weist Arnold Bartetzky in seinem Beitrag über die Befreiungskriege und die Völkerschlacht in der visuellen Erinnerungskultur des Deutschen Kaiserreiches auf die grundlegende Bedeutung der Parallelisierung der Ereignisse von 1813 und 1871 für das historische Selbstverständnis des jungen deutschen Nationalstaates hin. In dem unter preußischer Führung geeinten Deutschen Reich sei es geschichtspolitisch geboten gewesen, dessen Gründung in 
teleologischer Manier als Erfüllung alter Hoffnungen erscheinen zu lassen. Dementsprechend wurde das 1821 in Berlin errichtete Kreuzberg-Denkmal zur Vorlage für kleinere Denkmäler zum Deutsch-Französischen Krieg. Das erste ausschließlich den Befreiungskriegen gewidmete Monument wurde indes erst im Jahre 1913 in Leipzig errichtet.

Der im Jahre 1894 vom Architekten Clemens Thieme gegründeten „Deutsche Patriotenbund" hatte sich vorgenommen, ein Sinnzeichen zu errichten, das keinerlei Parallelen zu Baustilen der Vergangenheit auswies. Archaisch sollte das Bauwerk wirken, so als stamme es aus einer grauen Vorzeit. Dabei galt es einen typisch „deutschen“ Architektur- und Kunststil zu finden, sodass Anleihen bei der italienischen Renaissance, dem französischen Barock oder dem Klassizismus ausgeschlossen schienen. Nicht nur das Bauwerk selbst, sondern die gesamte Anlage sollte diese Intention ausdrücken. Einleitend zur Themeneinheit Topografie der Völkerschlacht: Spurensuche unternimmt Thomas Topfstedt den Versuch, ausgehend von der Entstehungsgeschichte dieses vielschichtigen Architekturdenkmals dessen Leitbilder, Symbole und ikonografische Bezüge zu decodieren.

Unweit des Völkerschlachtdenkmals und zeitgleich mit diesem anlässlich des 100. Jubiläums der historischen Schlacht eingeweiht, liegt der zweite zentrale Erinnerungsort auf dem Stadtgebiet Leipzigs - die Russische Gedächtniskirche (Hl.-Aleksij-Gedächtniskirche zur Russischen Ehre, Svjato-Aleksievskij chram-pamjatnik Russkoj Slavy). Diese ist als freie Nachbildung der 1530-1532 in Kolomenskoe bei Moskau erbauten Christi Himmelfahrtskirche mit dem dort erstmals verwirklichten Typus einer russischen Turmkirche ausgeführt, als verputzter Ziegelbau mit einem Zeltdach als Eisenbetonbau. Marina Dmitrieva widmet ihren Beitrag der Entstehungsgeschichte und kunsthistorischen Einordung dieses Bauwerks, welches im Gedenken an die 22.000 russländischen Soldaten errichtet wurde, die während der Völkerschlacht in und um Leipzig gefallen sind.

Fortgesetzt wird die Spurensuche durch Christian Forsters Überlegungen zum österreichischen Anteil am Völkerschlachtgedenken. Nachdem bereits ein Denkmal für den Oberbefehlshaber der Verbündeten, Karl Philipp Fürst zu Schwarzenberg, in Meusdorf bei Leipzig errichtet worden war, stand Österreich bei den Feierlichkeiten im Jahre 1913 eher im Abseits. Von Spendensammlungen für das Völkerschlachtdenkmal im kleindeutschen Sinne explizit ausgeschlossen und nach eigenem Verständnis unzureichend repräsentiert, ließ $\beta$ der österreichische Staat hingegen an fünf ehemaligen Kampfstätten nahezu identische Denkmale in Form eines mit ausgebreiteten Schwingen auf einem Obelisken ruhenden habsburgischen Doppeladlers errichten. Die hier angebrachten Gedenktafeln verweisen indes auf alle Opfer der Völkerschlacht.

Diese kann zwar in Planung und Ausgang sowie im Ergebnis der Kampfhandlungen als einheitliche Schlacht angesehen werden, aber sie zerfiel dennoch in eine Reihe von Einzelgefechten, die ihr Eigengewicht besaßen und anfangs auch zu unterschiedlichen täglichen Zwischenergebnissen führten. Dies war indes nicht allein den Koordinationsproblemen der alliierten Planung und Kriegsführung geschuldet, sondern wurde durch die geografische Beschaffenheit des Geländes um Leipzig noch verstärkt. Davon aus- 
gehend vermittelt Thomas Westphalen in seinem Beitrag einen Überblick über die Ergebnisse, Möglichkeiten und Grenzen einer Archäologie der Völkerschlacht. Das ehemalige Schlachtfeld mit einer Fläche von 300 Quadratkilometern entspricht in etwa dem heutigen Stadtgebiet Leipzigs, dessen Norden allerdings heute weitgehend bebaut ist, sodass Funde eher selten und zumeist mit Bauarbeiten verbunden sind. Als Beispiel kann in diesem Zusammenhang ein Massengrab mit den sterblichen Überresten von 30 Menschen gelten, das bei der Umgestaltung des Leipziger Zoos im Jahre 2008 entdeckt wurde.

Die abschließende Themeneinheit Bilder der Völkerschlacht: Medien und Erinnerung ist den medialen Repräsentationen des Völkerschlachtereignisses gewidmet, wobei hier insbesondere zeitgenössische Printmedien, die bildende Kunst sowie der Film im Mittelpunkt der Einzelanalysen stehen. Bereits in den Monaten vor und ganz besonders in der Zeit kurz nach der Völkerschlacht ist eine explosionsartige Zunahme von Napoleon-Karikaturen zu verzeichnen. Weder zuvor noch in den darauf folgenden Jahrzehnten hat es in Deutschland wieder eine solche Fülle satirischer Darstellungen um eine einzelne Persönlichkeit gegeben. Dagmar Burkhart widmet sich in ihrem Beitrag diesem populären und somit äußerst wirkungsmächtigen Massenmedium, wobei englische und deutsche Fallbeispiele im Zentrum der Analyse stehen. Während Erstere durch einen generell liberalen Umgang mit der Presse begünstigt wurden, konnten Letztere erst durch eine Lockerung der Zensur im Zuge der Befreiungskriege zur vollen Entfaltung kommen. Taten sich die englischen Spottbilder durch stärkere Überzeichnungen hervor, so waren die deutschen Gegenstücke vielfach nur im Zusammenspiel mit einem Begleittext verständlich.

Der Beitrag von Lars Karl erweitert das Spektrum der medialen Verarbeitungen um die Dimension des Films. Am 1. Juli 1943 beauftragte Reichspropagandaminister Joseph Goebbels den Regisseur Veit Harlan mit der Produktion eines Spielfilms über die Belagerung der pommerschen Stadt Kolberg (heute Kołobrzeg) im Jahr 1807. Dieses Ereignis im Krieg gegen Frankreich wurde bereits im Laufe des 19. Jahrhunderts zu einem Mythos des erfolgreichen Widerstandes gegen Napoleon. Die preußische Festung unter dem Kommando von Gneisenau war von Soldaten und Bürgern unter ihrem Repräsentanten Nettelbeck erfolgreich bis zum Friedensschluss von Tilsit im Juli 1807 verteidigt worden, auch mit Unterstützung des später zum Volkshelden avancierten Majors von Schill und seiner Freikorps. Die letzte und aufwendigste Spielfilmproduktion des „Dritten Reiches“ wurde in Berlin und in dem zur „Atlantikfestung“ erklärten La Rochelle am zwölften Jahrestag der Machtübernahme durch die Nationalsozialisten uraufgeführt, was sowohl den hohen geschichtspolitischen Stellenwert dieses Films als auch seinen Zweck als „Durchhaltepropaganda“ am Ende des Zweiten Weltkrieges verdeutlicht.

Ebenfalls dem Medium Film gewidmet sind die Überlegungen von Stephan Krause, der die Mythenbildung um István Széchenyi, den „größten Ungarn“, in den Mittelpunkt seiner Analyse stellt. Der Aristokrat und Unternehmer Széchenyi hatte sich - gemäß der bis heute dominierenden nationalen Meistererzählung - im 19. Jahrhundert durch sein kulturelles, wissenschaftliches und (wirtschafts)politisches Engagement als Weg- 
bereiter des modernen ungarischen Staates verdient gemacht. Ungeachtet dieser Meriten existiert allerdings kein hinreichender historischer Beleg für die Umstände des legendären Kurierrittes Széchenyis am Vorabend des 18. Oktober 1813, in dessen Verlauf er im Auftrag Schwarzenbergs Blücher und später auch den schwedischen Thronfolger Bernadotte zu einem koordinierten Angriff bewegt haben soll. Bei aller gebotenen Unterscheidung zwischen der historischen Person und der (Haupt-)Figur verschiedener Helden-Narrative zeigt sich hier einmal mehr die Ungelöstheit - und Unauflösbarkeit - des Widerstreites von Wahrheit, Wirklichkeit und Geschichte(n).

Den Abschluss des Bandes bildet der besonders reich illustrierte Beitrag von Elena Bukreeva und Ramil Rachimov. Dieser stellt in Form und Inhalt eine Ausnahme im vorliegenden Sammelwerk dar, besticht er doch durch seine enthnografische Herangehensweise und exotisierende Nuancen. Gewissermaßen als Quellentext wird er in seiner ganzen faszinierenden Vollständigkeit wiedergegeben. Auch wenn der Begriff „Völkerschlacht“ ursprünglich auf den militärischen Terminus „Heervölker“ rekurriert, machen Bukreeva und Rachimov deutlich, dass das heutige Begriffsverständnis im Sinne von „Völkerschaften“ keineswegs jeglicher Grundlage entbehrt. Die irregulären leichten Kavallerieeinheiten innerhalb der russisch-imperialen Armee - 31 Regimenter mit insgesamt 17.000 Mann - umfassten neben Kosaken und Kalmücken auch Turkvölker wie Baschkiren, Kasachen (zeitgenössisch und nicht im heutigen Sinne als „Kirgisen“ bezeichnet) und Tataren. Neben ihrer Hauptfunktion als Aufklärungseinheiten sorgten diese Formationen häufig allein durch ihre „exotische“ Erscheinung für Verwirrung. Ihre Bewaffung mit Pfeil und Bogen, altertümlichen Lanzen und Krummsäbeln innerhalb einer Schlacht, bei der erstmals auf britischer Seite sogenannte Rocketeers (Raketentruppen) zum Einsatz kamen, wirkte ebenso archaisch wie anachronistisch.

Am Zustandekommen dieses Buches waren zahlreiche Personen und Institutionen beteiligt, denen wir zu Dank verpflichtet sind. Zunächst sei allen Beiträgern gedankt, die hoch motiviert und zügig ihre Vortragsmanuskripte zu Aufsätzen umgearbeitet und eingereicht haben.

Dem GWZO, dessen Jahrestagung 2013 die dem Buch zugrunde liegende Konferenz darstellt und das die Aufnahme in seine Publikationsreihe „Visuelle Geschichtskulturen“ ermöglichte, danken wir ebenso wie dem Bundesministerium für Bildung und Forschung (BMBF), das die Forschungstätigkeit des Zentrums finanziell fördert. Unser Dank gilt ebenso dem Staatlichen Historischen Museum und dem Architekturmuseum in Moskau, dem Stadtgeschichtlichen Museum und dem Stadtarchiv in Leipzig dafür, dass sie Bilder und Fotos aus ihren Beständen für diese Publikation zur Verfügung gestellt haben.

Lars Karl dankt in seiner Eigenschaft als Junior Fellow dem Alfried Krupp Wissenschaftskolleg Greifswald für dessen Unterstützung während der Endredaktion. Weiterhin gilt unser Dank Madlen Benthin für die Erstellung des Registers. Schließlich sei außerdem Dorothee Rheker-Wunsch vom Böhlau Verlag für die unkomplizierte Zusammenarbeit gedankt. 
Geschichtspolitik und Erinnerungskultur 
Open Access @ 2016 by Böhlau Verlag GmbH \& Cie, Köln Weimar Wien 


\title{
Helden, Horror und Hunger
}

\section{Die Leipziger Völkerschlacht 1813 - Erfahrungen und Erinnerungen}

\author{
Karen Hagemann
}

\begin{abstract}
Die Schlacht bei Trafalgar entschied die Herrschaft zur See. Jene bei Leipzig den Sturz Napoleons und damit den Beginn der neuesten Zeit, welche nicht mehr durch den Willen des fürstlichen Gebieters, sondern durch wirtschaftliche und völkische Fragen bestimmt wird. Das gewaltige Massenringen gestaltete sich somit zu einem Marksteine in der Geschichte Europas. ${ }^{1}$
\end{abstract}

Mit diesen Worten begann der Berliner Historiker Julius von Pflugk-Harttung seine 1913 veröffentlichte umfangreiche Dokumentation mit dem Titel Leipzig 1813. Wie zahlreiche andere Publikationen erschien das Buch anlässlich des hundertsten Jahrestages der „Leipziger Völkerschlacht“ - wie sie schon von den Zeitgenossen genannt wurde. Vom 16. bis zum 19. Oktober 1813 kämpften ca. 171.000 Mann unter Napoleons Oberbefehl, darunter viele Soldaten der noch bei ihm verbliebenen deutschen Verbündeten Baden und Sachsen, gegen mehr als 300.000 Soldaten der Alliierten unter dem Kommando des österreichischen Feldmarschalls Fürst zu Schwarzenberg. Ein beträchtlicher Teil der Streitkräfte Europas - über 470.000 Soldaten aus zwölf Ländern - war in Sachsen, im Zentrum Mitteleuropas, zusammengezogen. Damit war diese Schlacht bis zum Ersten Weltkrieg die größte der Weltgeschichte. Die Befreiung Deutschlands, die offiziell bereits am 16. März 1813 mit der Kriegserklärung der preußisch-russischen Koalition begonnen hatte, wurde sicherlich nicht durch diese Schlacht entschieden, noch beendete sie den sechsten Koalitionskrieg. Es dauerte noch ein halbes Jahr, bis Napoleon im April 1814 endgültig besiegt wurde - aber die Leipziger Schlacht war nach dem Russlandfeldzug 1812 seine zweite dramatische Niederlage. Nach Leipzig mussten sich die Überreste seiner Armee zum Rhein zurückziehen, um Frankreichs Grenzen zu verteidigen. Das lange so siegreiche französische Heer erholte sich nicht mehr von diesem Debakel. ${ }^{2}$

1 Pflugk-Harttung, Julius v.: Leipzig 1813. Aus den Akten des Kriegsarchivs des Geheimen Staatsarchivs Berlin, Staatsarchivs in Breslau und des Ministeriums der auswärtigen Angelegenheiten in London. Gotha 1913, S. iii.

2 Zur Leipziger Schlacht vgl. u. a.: Thamer, Hans-Ulrich: Die Völkerschlacht bei Leipzig. Europas Kampf gegen Napoleon. München 2013; Platthaus, Andreas: 1813. Die Völkerschlacht und das Ende der Alten Welt. Berlin 2013; Poser, Steffen: Die Völkerschlacht bei Leipzig. ,In Schutt und Graus begraben'. Hg. v. Stadtgeschichtlichen Museum Leipzig. Leipzig 2013; Hagemann, Karen: ,Unimaginable Horror and Misery‘. The Battle of Leipzig in October 1813 in Civilian Experience and Perception. In: Soldiers, Citizens and Civilians. Experiences and Perceptions of the French Wars, 1790-1820. Hg. v. Alan Forrest, Karen Hagemann und Jane Rendall. Basingstoke 2009, S. 157178. 
In ihrem Urteil über die militärische Bedeutung der Schlacht unterscheidet sich die neue Militärgeschichtsschreibung wenig von der alten. Tausende von Büchern und Aufsätzen sind bis heute zu dieser Schlacht und den sogenannten „Befreiungskriegen“ erschienen. In der Geschichtsschreibung und im nationalen Gedächtnis der beteiligten Nationen nahmen die Kriege gegen Napoleon im 19. Jahrhundert eine Schlüsselstellung ein. ${ }^{3}$ Gut erforscht sind allgemein die militärische und politische Geschichte der „Befreiungskriege“. ${ }^{4}$ Was bemerkenswerterweise fehlt, ist - anders als etwa für den Russlandfeldzug von $1812^{5}$ - eine Alltags- und Sozialgeschichte der Schlacht bei Leipzig wie der Kriege von 1813-1815 und ihrer ökonomischen und sozialen Kosten und Folgen. ${ }^{6}$ Auch gibt es erst wenige Untersuchungen zur umkämpften Konstruktion der kollektiven Erinnerung an die Kriege von 1813-1815. ${ }^{7}$ Seit den späten 1960er Jahren hat sich die Forschung zum napoleonischen Deutschland auf drei Hauptthemen konzentriert: das Militär, die Kriege und die internationale Politik, das Entstehen souveräner Staaten und deren Reformen in den Jahren 1806 bis 1819 sowie das Aufkommen

3 Zur Literatur des 19. Jahrhunderts: KiRCheISEN, Friedrich: Bibliographie des Napoleonischen Zeitalters einschließlich der Vereinigten Staaten von Nordamerika, Bd. 1-2. Berlin, 1908-1912. Zur Analyse der Historiografie des 19. Jahrhunderts: Hagemann, Karen: Revisiting Prussia's War Against Napoleon. History, Culture and Memory. Cambridge, UK 2014, Kap. 13.

4 Neuere militärhistorische Studien sind: Riley, Jonathan P.: Napoleon and the World War of 1813. Lessons in Coalition Warfighting. London 2000; Sмiтн, Digby G.: 1813, Leipzig. Napoleon and the Battle of the Nations. London 2001; Leggiere, Michael V.: Napoleon and Berlin. Franco-Prussian War in North Germany. 1813. Norman, OK 2002; Ders.: The Fall of Napoleon. Cambridge, UK 2007. Zur politischen Geschichte: Iвbeken, Rudolf: Preußen 1807-1813. Staat und Volk als Idee und in Wirklichkeit. Köln 1970; MüNChOw-PoHL, Bernd v.: Zwischen Reform und Krieg. Untersuchungen zur Bewußtseinslage in Preußen 1809-1812. Göttingen 1987; Rowe, Michael: From Reich to State: The Rhineland in the Revolutionary Age, 1780-1830. Cambridge, UK 2003; Hagemann, Karen: „Mannlicher Muth und Teutsche Ehre”. Nation, Militär und Geschlecht zur Zeit der Antinapoleonischen Kriege Preußens. Paderborn 2002.

5 Furrer, Daniel: Soldatenleben. Napoleons Russlandfeldzug 1812. Paderborn 2012; Munlstein, Anka: Der Brand von Moskau. Napoleon in Rußland. Frankfurt/M. 2008; Murken, Julia: Bayerische Soldaten im Russlandfeldzug 1812. Ihre Kriegserfahrungen und deren Umdeutungen im 19. und 20. Jahrhundert. München 2016; Zamoyski, Adam: 1812. Napoleons Feldzug in Russland, München 2012.

6 Ausnahmen, die sich allerdings nicht auf die Kriege von 1813-1815 konzentrieren, sondern den gesamten Zeitraum von 1792 bis 1815 behandeln, sind: Planert, Ute: Der Mythos vom Befreiungskrieg. Der deutsche Süden und die französischen Kriege. Alltag, Wahrnehmung, (Um)Deutung. Paderborn 2007; JAMES, Leighton S.: Witnessing the Revolutionary and Napoleonic Wars in German Central Europe. Basingstoke 2012.

7 Vgl. Hagemann (wie Anm. 3). Weitere Einzelstudien zur deutschen Erinnerungsgeschichte sind: Buchinger, Kirsten: Napoléomanie. Berlin 2013; Koller, Wolfgang: Historienkino im Zeitalter der Weltkriege. Die Revolutions- und Napoleonischen Kriege in der europäischen Erinnerung. Paderborn 2013; Bethan, Angelika: Napoleons Königreich Westphalen. Lokale, deutsche und europäische Erinnerungen. Paderborn 2012; FöRster, Birte: Der Königin Luise-Mythos. Mediengeschichte des „Idealbilds deutscher Weiblichkeit", 1860-1960. Göttingen 2011; Mustafa, Sam A.: The Long Ride of Major von Schill: A Journey through German History and Memory. Lanham, MD 2008. Als Überblick zur europäischen Erinnerungsgeschichte der Zeit der Revolutions- und Napoleonischen Kriege: War Memories. The Revolutionary and Napoleonic Wars in Modern European Culture. Hg. v. Alan ForREST, Etiénne François und Karen Hagemann. Basingstoke 2012. 
eines frühen modernen Nationalismus. Die ökonomische, soziale und kulturelle Geschichte der Napoleonischen Kriege wurde lange ebenso vernachlässigt wie die Dimensionen der Kriegsgewalt und der Kriegserfahrung und deren Verarbeitung im kollektiven Gedächtnis. Eine Änderung setzte hier erst in den späten 1990er Jahren ein. ${ }^{8}$

Eine Folge ist, dass lange der moderne Charakter dieser ersten "totalen Kriege“ wie der amerikanische Historiker David Bell sie jüngst genannt hat - übersehen wurde, der darin bestand, dass sie zum einen erstmals mit riesigen Massenarmeen geführt wurden, für die mit intensiver patriotisch-nationaler Propaganda mobilisiert wurde, und sie zum anderen in ihrer räumlichen Ausdehnung weit über Europa hinausreichten. ${ }^{9}$ Diese Kriege prägten nicht nur die Erfahrung der Soldaten und Offiziere, die daran teilnahmen, sie wirkten sich nachhaltig auch auf das Alltagsleben von Frauen und Männern aller sozialen Schichten aus den unterschiedlichsten Regionen Europas aus. Vor allem das enorme Ausmaß der neuen Massenarmeen hatte weitreichende Folgen nicht nur für das Militär, sondern auch auf Gesellschaft und Wirtschaft, die zudem erheblich unter der intensivierten ökonomischen Kriegführung litten. ${ }^{10}$ Ein Ansatz, der Militär-, Politik-, Sozial- und Kulturgeschichte verbindet und die vielfältigen Kriegserfahrungen sowie deren Bedeutung für die Konstruktion des kollektiven Gedächtnisses in die Analyse einbezieht, kann helfen, den ambivalenten Charakter der Periode und ihrer Nachwirkungen besser zu verstehen.

Aufgrund ihrer außerordentlichen Bedeutung ist die Leipziger Schlacht ein aufschlussreicher Gegenstand für eine solche Studie. Mit einem Fokus auf dem Schlachtgeschehen als dem gewaltvollsten Kulminationspunkt der Kriegshandlungen kann untersucht werden, wie sich die veränderte Kriegführung mit Massenheeren auf die betroffenen Soldaten und Zivilisten auswirkte, wie sich ihre Interaktion gestaltete und wie das Geschehen wahrgenommen und erinnert wurde. Im Folgenden kann allerdings nur ein knapper Überblick über die vielfältigen Erfahrungen der Schlacht und ihres historischen Kontexts - der Entwicklung Sachsens zwischen 1806 und 1816 - sowie die umkämpften Erinnerungskonstruktionen im deutschen Sprachraum gegeben werden.

8 Einen Überblick zum Forschungsstand geben: Hagemann (wie Anm. 3), S. 9-30; Hagemann, Karen/ Aaslestad, Katherine: 1806 and its Aftermath. Revisiting the Period of the Napoleonic Wars in German Central Europe. In: Central European History 39 (2006), S. 547-579; EsDAILE, Charles: Recent Writing on Napoleon and His Wars. In: The Journal of Military History 73 (2009), S. 209-220.

9 BeLl, David: The First Total War. Napoleon's Europe and the Birth of Warfare as We Know It. Boston 2007.

10 Ebd.; BeLl, David: The Limits of Conflict in Napoleonic Europe - And Their Transgression. In: Civilians and War in Europe, 1618-1815. Hg. v. Erica Charters, Eve Rosenhaft und Hannah Smith. Liverpool 2012, S. 201-208; War in an Age of Revolution, 1775-1815. Hg. v. Roger CHICKERING und Stig FörSTER. Cambridge, UK 2010; Fregosi, Paul: Dreams of Empire. Napoleon and the First World War, 1792-1815. London 1989; EsDAiLE, Charles: Napoleon's Wars. An International History, 1803-1815. London 2009. 


\section{Das Königreich Sachsen in den Jahren 1806 bis 1812}

Sachsen gehörte Anfang des 19. Jahrhunderts zu den am dichtesten besiedelten Gebieten Deutschlands. Aufgrund der zentralen Lage war die Messestadt Leipzig mit ihren ca. 40.000 Einwohnern ein wichtiger Handels- und Verkehrsknotenpunkt und zudem das Zentrum des Buchhandels. Die Bevölkerung des Königreichs war seit 1806 unmittelbar in die Napoleonischen Kriege einbezogen. Am 14. Oktober 1806, nur eine Woche nach Beginn des Vierten Koalitionskrieges, wurde die preußisch-sächsische Armee bei Jena und Auerstedt vernichtend geschlagen. Französische Truppen besetzten Sachsen, dessen König Friedrich August I. im Dezember 1806 dem Rheinbund beitrat. Er wurde gezwungen, einen Friedensvertrag zu unterzeichnen, der das Königreich verpflichtete, Napoleon mit Geld, Ausrüstung und Soldaten zu unterstützen. Die sächsische Bevölkerung musste nicht nur die Last der Kriegsfolgen bewältigen, sondern auch Einquartierungen und Requisitionen tragen. ${ }^{11}$

Darüber hinaus litt die sächsische Wirtschaft, wie die anderer mitteleuropäischer Staaten, unter der Kontinentalsperre, die Napoleon am 21. November 1806 erlassen hatte. Diese Blockade beeinträchtigte die landwirtschaftliche und industrielle Produktion sowie den Handel Sachsens erheblich, wenn auch nicht in dem gleichen Ausmaß wie in Preußen, da zumindest der Zugang zu den Märkten des napoleonischen Kaiserreichs offen blieb. Zudem hatten die zunehmenden finanziellen Verpflichtungen als Rheinbundstaat, d.h. die Zahlung von erheblichen Steuern, Abgaben und Tributen sowie die Bereitstellung und Ausrüstung einer großen Armee, wachsende negative Folgen für Finanzen und Wirtschaft der Monarchie. Ab 1810, als Napoleon die Kontinentalblockade verschärfte und in der Folge die ökonomischen Probleme zunahmen, wuchs wie in anderen Regionen die Unzufriedenheit der Bevölkerung mit der französischen Herrschaft merklich. $^{12}$

Nach fünf relativ friedlichen Jahren wurde die Bevölkerung Sachsens im Frühjahr und Sommer 1812 erneut mit Kriegsvorbereitungen konfrontiert. Die Monarchie war neben Preußen Hauptaufmarschgebiet der Grande Armée für den Russlandfeldzug, der am 24. Juni 1812 mit dem Überschreiten der russischen Grenze begann. Frankreich hatte insgesamt 650.000 Mann für diesen Krieg mobilisiert, die aus allen Regionen des Napoleonischen Empires kamen. Über 120.000 Soldaten hatte der Rheinbund zu stellen, Sachsen alleine 25.000, und Preußen weitere 30.000. ${ }^{13}$ Die Bevölkerung Sachsens und

11 KöPPING, Reinhard: Sachsen gegen Napoleon. Zur Geschichte der Befreiungskriege 1913-1915. Berlin 2001; Beachy, Robert: The Soul of Commerce. Credit, Property, and Politics in Leipzig, 17501840. Leiden 2005, Kap. 5 und 6.

12 Aaslestad, Katherine: Paying for War. Experiences of Napoleonic Rule in the Hanseatic Cities. In: Central European History 39 (2006), S. 641-675; Dies.: The Continental System and Imperial Exploitation. In: Napoleon and his Empire. Europe, 1804-1814. Hg. v. Philip G. Dwyer und Alan ForRest. Basingstoke 2007, S. 114-132; Revisiting Napoleon's Continental System. Local, Regional and European Experiences. Hg. v. Katherine AasLestad und Johannes Joor. Basingstoke 2014.

13 Martin, Alexander: The Russian Empire and the Napoleonic War. In: Napoleon and Europe. Hg. v. Philip G. Dwyer. Harlow 2001, S. 243-263, hier S. 258; Mieck, Ilja: Preußen von 1807 bis 1850. 
Preußens hatte zudem für die Einquartierung, Verpflegung und Ausrüstung des durchziehenden Riesenheeres zu sorgen. ${ }^{14}$

Bekanntlich endete der Russlandfeldzug mit einem Desaster für Napoleon. Nur 81.000 Mann machten den Rückmarsch mit. Mindestens 370.000 Soldaten starben während des Feldzuges, 200.000 gerieten in Gefangenschaft, von denen weniger als die Hälfte überlebte. Von den sächsischen Soldaten kehrten nicht mehr als 6.000 lebend zurück. ${ }^{15}$ Das Bild, das die zurückkehrenden Truppen ab Anfang des Jahres 1813 boten, war trostlos. Der Rückzug bedeutete für die Bevölkerung Sachsens nicht nur erneute Einquartierungen, sondern erhöhte auch das Risiko von Krankheiten und Seuchen ganz erheblich. Die Lazarette in Leipzig und anderen Städten Sachsens, die von der französischen Armee eingerichtet worden, füllten sich schnell mit Soldaten, die sich mit Fleckfieber und Ruhr angesteckt hatten und die wiederum die Zivilbevölkerung infizierten. In der Folge starben allein in Leipzig 3.500 Einwohner, d.h. fast 9 Prozent der Stadtbevölkerung. Um die enormen Verluste der napoleonischen Armee auszugleichen, musste Sachsen zudem neue Truppen rekrutieren. Im Januar 1813 war die sächsische Armee bereits wieder 18.300 Mann stark. ${ }^{16}$

\section{Die ersten Schlachten der Kriege in Sachsen, März-Oktober 1813}

Am 16. März 1813 erklärten Preußen und Russland Frankreich den Krieg. Anfang Mai waren Leipzig und sein Umland erstmals seit dem Herbst 1806 wieder ein zentraler Ort von Kriegshandlungen. Die Stadt und die umgebenden Dörfer litten erheblich unter den Folgen der Schlachten bei Lützen und Bautzen im Mai 1813 und den kleineren Gefechten in ihrem Gefolge. An beiden Schlachten waren über 250.000 Soldaten beteiligt. Napoleon besiegte das preußisch-russische Heer, das 40.000 Gefallene zu verzeichnen hatte, und besetzte erneut die Region, die zwischenzeitlich von preußischen und russischen Truppen befreit worden war. Bis Oktober 1813 blieb die Gegend ein zentraler Standort des französischen Heeres in der Mitte Deutschlands. Die Folgen für die Zivilbevölkerung waren einmal mehr ,beständige und sehr drückende Einquartierungen, Lieferungen und Steuern", wie es in einem zeitgenössischen Bericht hieß. ${ }^{17}$ Schon im August 1813 schien den Bewohnern der Region das Maß des Erträglichen weit überschritten zu sein. Ferdinand Heinrich Grautoff, der 1813 Theologiestudent an der Leipziger Universität war, erinnert sich:

Reformen, Restauration und Revolution. In: Handbuch der Preußischen Geschichte. Bd. 2. Hg. v. Otto Büsch. Berlin 1992, S. 3-292, hier S. 38-40.

14 Мieck (wie Anm. 13), S. 38 f.; Münchow-Pohl (wie Anm. 4), S. 352-384.

15 Martin (wie Anm. 13), S. 260; Zamoyski (wie Anm. 5).

16 Gross, J. C.: Die Franzosenzeit in Leipzig. Persönliche Erinnerungen an 1813. Leipzig 1913, S. 5; Naumann, Robert: Die Völkerschlacht bei Leipzig. Nebst Nachrichten von Zeitgenossen und Augenzeugen über dieselbe. Leipzig 1863, S. 5-7; KöPPING (wie Anm. 11), S. 44.

17 SCHLosser, Wilhelm Gottlob: Erlebnisse eines sächsischen Landpredigers in den Kriegsjahren 18061815. Wiesbaden 1914, S. 60; NaumanN (wie Anm. 16), S. 182-183 und 193. 
Nach den ununterbrochenen Durchzügen der Truppen, mit denen der französische Kaiser während des Sommers sein Heer ergänzte, schien schon der Wohlstand der Mittelklasse ganz erschöpft; auch jetzt blieb eine zahlreiche Besatzung der Stadt mehr zur Last als zum Schutze; dazu die vielen Lazarette und ein französisches Gouvernement, das sich selbst in einem feindlichen Orte nicht größere Gewalttaten hätte erlauben können. ${ }^{18}$

Nach dem Ende des Waffenstillstands vom 4. Juni bis 10. August, den beide Seiten für die Wiederaufrüstung nutzten, traten Österreich, Großbritannien und Schweden der antinapoleonischen Koalition bei. Der Raum zwischen Berlin, Leipzig, Dresden und Breslau wurde zum Hauptaufmarschgebiet der Massenheere und zum Zentrum des Herbstfeldzuges 1813. Am 23. August erlitt Napoleon seine erste schwere Niederlage in der Schlacht von Großbeeren bei Berlin. Bis Anfang Oktober folgten fünf weitere Niederlagen. Die verwundeten Soldaten dieser Schlachten wurden auf Befehl der napoleonischen Militäradministration zu einem erheblichen Teil nach Leipzig transportiert, das neben Halle zu einem Hauptlazarettstandort ausgebaut wurde. ${ }^{19}$ Bereits Anfang September musste die Stadt Platz für 18.000 Verwundete und Kranke schaffen. Alle größeren öffentlichen Gebäude wurden als Lazarette benutzt. In den wenigen Wochen zwischen Ende August und Anfang Oktober 1813 zogen 90.000 verwundete und kranke Soldaten durch Leipzig. ${ }^{20}$ Die Bewohner Leipzigs sahen täglich lange Kolonnen von Kranken, Verwundeten und Versprengten durch die Stadttore ziehen. Grautoff schildert deren Bild:

\begin{abstract}
Sie brachten den schrecklichsten Anblick! - Seinen Eindruck hat auch das spätere Elend nicht bei mir wieder vertilgt, und noch sehe ich diese erbarmungswürdigen Gestalten, ebenso ekelhaft wie schrecklich, an elenden Krücken, kaum halb bedeckt von den zerlumpten Kleidern, den nahen Tod auf ihren hohlwangigen Gesichtern, sich mühsam durch die Strassen schleppen und laut jammern vor Hunger und Schmerz. ${ }^{21}$
\end{abstract}

Da der Stadt die Mittel fehlten, wurden die verwundeten und kranken Soldaten weder ordentlich verpflegt noch sorgfältig verbunden und betreut. Zusätzlich hatten die Bürger die Kriegsgefangenen der gegnerischen Verbündeten zu verpflegen, die vor der Stadt kampierten, darunter 8.000 Österreicher. ${ }^{22}$

Not und Elend in der Stadt und dem Umland nahmen rasch zu. Ungeachtet dessen stieg die Zahl der Einquartierungen weiter, da Napoleon, bedrängt von den Alliierten, immer mehr Truppen im Leipziger Raum und in der Stadt selbst zusammenzog. Mit der Zahl der Soldaten vervielfachten sich die Versorgungsprobleme, denn die Grande Armée verpflegte sich ausschließlich durch Requisitionen. Weil die geforderten Natu-

18 GrautofF, Ferdinand: In Leipzig während der Völkerschlacht. Leipzig 1913, S. 69.

19 Ebd., S. 15-18.

20 Ebd., S. $75 \mathrm{f}$.

21 Ebd., S. 74.

22 Ebd., S. 73 und 77-78. 
ralien immer häufiger nicht mehr geliefert werden konnten, kam es zunehmend zu gewaltsamen Plünderungen. Zwar wird in vielen Berichten betont, dass die höheren Offiziere der napoleonischen Armee sich bemühten, „Mannszucht“ zu halten und Plünderungen zu verhindern, doch je größer Hunger und Not der Soldaten wurden, desto geringer war ihr Erfolg. Am ehesten konnten noch Französisch sprechende Einwohner mit Milde rechnen, da sie sich mit den Offizieren und Soldaten verständigen konnten. Dies war vor allem bei Wohlhabenden und Gebildeten der Fall, denen die Bewirtung der einfallenden Soldaten ohnehin leichter fiel..$^{23}$

In seinen 1914 erstmals veröffentlichten Erinnerungen schildert Ludwig Wilhelm Gottlob Schlosser, langjähriger Pfarrer des Dorfes Großzschocher bei Leipzig, wie Anfang Oktober 600 württembergische und 600 französische Soldaten ohne Warnung im Ort einfielen ,und ihr Lager in einem großen Feldgarten vor dem Dorf und auf den Pflanzbeeten aufschlugen“. Sie nahmen den Dorfbewohnern buchstäblich alles weg, was sie tragen konnten, und kamen fünf Tage lang wieder. Einfälle dieser Art hielten bis zur Schlacht bei Leipzig an. Nicht alle durchziehenden Einheiten begnügten sich mit einem Feldlager vor dem Dorf. Andere, wie etwa eine Einheit von 1.200 französischen Soldaten, verlangten Quartier in den Höfen und Hütten der Dorfbewohner, was dazu führte, dass manche Haushalte 80 oder sogar 100 Mann zu beherbergen und beköstigen hatten. ${ }^{24}$

Die Niederlagen, die Napoleon seit August hinnehmen musste, motivierten Bayern, den Rheinbund am 8. Oktober zu verlassen. Alle anderen Staaten des Bündnisses folgten dem Beispiel mit der Ausnahme von Baden und Sachsen. Im Verlauf des Oktobers wurden von beiden Seiten mehr und mehr Truppen in der Region um Leipzig zusammengezogen. Mit den vielen durchziehenden Einheiten änderten sich die Frontlinien fast täglich. In der Wahrnehmung der Dorfbewohner machte es im Alltag allerdings wenig Unterschied, ob sie „,befreundete” oder ,feindliche” Truppen zu beherbergen und zu versorgen hatten. In den Wochen vor der Schlacht kulminierte die Abneigung aber zunehmend vor allem gegen Napoleon und seine Vielvölkerarmee. ${ }^{25}$ Der Grund hierfür war der Befehl Napoleons, dass durch seine Truppen beim Rückzug „,alles Vieh der Bewohner mitgenommen, die Wälder verbrannt, die Fruchtbäume umgehauen und alle anderen Nahrungsmittel zerstört werden sollen“, um diese Gegenden „möglichst von jedem Unterhaltsmittel zu entblößen und in eine Wüste zu verwandeln." ${ }^{\text {"26 }}$ Ziel dieser Politik der „verbrannten Erde“, die nach Zeitzeugenberichten auch auf dem Rückzug des französischen Heeres nach Frankreich so weit wie möglich weiter praktiziert wurde, war es, dem Gegner keinerlei Mittel für die Reproduktion der Armee zu hinterlassen. Diese Politik war ein wichtiges Motiv für das Überlaufen sächsischer Truppen während

23 GraF, Gerhard: Die Völkerschlacht bei Leipzig in zeitgenössischen Berichten. Berlin 1988, S. 265; SChlosser (wie Anm. 17), S. 54-56.

24 Schlosser (wie Anm. 17), S. 77 und 80.

25 Naumann (wie Anm. 16), S. 86, 209 und 213.

26 Aster, Karl Heinrich: Die Gefechte und Schlachten bei Leipzig im Oktober 1813. Dresden 1852, S. 48. Aster war im Jahr 1813 Leutnant bei der sächsischen Armee und lehrte an der Militärakademie in Dresden. 
der Leipziger Schlacht, die sich damit gegen ihren Monarchen stellten, der zu Napoleon hielt und nach dessen Niederlage bei Leipzig von den Alliierten schlicht abgesetzt wurde. Die sächsischen Soldaten wollten sich nicht an der Zerstörung ihrer Heimat beteiligen. ${ }^{27}$

Je mehr Truppen in der Region um Leipzig zusammengezogen wurden, je enger sich der Kreis der napoleonischen Armee um die Stadt schloss und je näher die verbündeten Einheiten kamen, desto klarer wurde den Bewohnern der Stadt und der Dörfer ihres Umlandes, dass in ihrer Gegend eine große Schlacht bevorstand. Angesichts anschwellender Gerüchte nahm die Angst zu. ${ }^{28}$

\section{Die Leipziger Schlacht in der Erfahrung der Zivilbevölkerung}

Für die Dorfbevölkerung der Region um Leipzig begann das Kampfgeschehen bereits Anfang Oktober. Mit der Zusammenballung der Truppen in der Region nahmen die vielen kleineren Gefechte um einzelne Ortschaften stetig zu, deren Bewohner sich glücklich schätzen konnten, wenn sie vorab von den jeweiligen Besatzungssoldaten gewarnt wurden, dass es Kämpfe um ihren Ort geben würde. Dieser Warnung folgte in der Regel der Befehl zur Evakuierung und nicht selten die Zerstörung weiter Teile des Dorfes im Gefecht. ${ }^{29}$ Der Pfarrer zu Liebertwolkwitz und Großpösna, Karl August Goldschab, berichtete Folgendes von den Erlebnissen seines Dorfes am 14. Oktober, das noch von französischen Truppen besetzt war, aber von den Alliierten an diesem Tag überraschend belagert und beschossen wurde:

In dieser großen Noth wussten wir nicht, wohin wir uns wenden sollten, um Schutz zu finden, welchen wir in unseren Häusern nicht mehr fanden, und eine große Zahl der hiesigen Einwohner flüchtete sich in die Kirche, weil sie sich da wegen des starken Mauerwerks vor den Kugeln gesichert hielten; andere verbargen sich in den Kellern ihrer Häuser. ${ }^{30}$

Goldschab berichtete weiter, dass andere sich in den nahe gelegenen Gutshof flüchteten und sich dort im Keller versteckten. Um den Ort wurde den gesamten Tag gekämpft. Die Bombardierung verstärkte sich; auch die Kirche wurde nicht verschont:

Herzzerreißend war das Jammern und Wehklagen in der Kirche, besonders da die Kirchenthüren ausgesprengt wurden und die Kugeln durch die Fenster in die Kirche fielen ... Noch mehr aber

27 Ebd., S. 48; Naumann (wie Anm. 16), S. 91 f. und 283.

28 Naumann (wie Anm. 16); Rochlitz, Friedrich: Tage der Gefahr. Ein Tagebuch der Leipziger Schlacht. Leipzig 1875, S. 8-19.

29 Naumann (wie Anm. 16), S. 232.

30 Abgedruckt in: Ebd., S. 145-152, hier S. 147 f. 
steigerte sich unser Jammer, als einige Männer durch die schmalen Öffnungen des Thurmes gewahr wurden, wie der größte Theil der Häuser auf der Windmühlengasse in Feuer aufging. ${ }^{31}$

Die Kirche war am Ende heftig umkämpft. Bevor der Beschuss einsetzte, wurden die Bewohner, die sich in die Kirche gerettet hatten, von einem französischen Offizier aufgefordert, das Gotteshaus zu verlassen und nach Leipzig zu fliehen. Goldschab schilderte seine Empfindungen in dieser Situation:

Ein schreckliches Schauspiel bot sich nun auch vor der Kirche unseren Blicken dar. Todte und im Todeskampf begriffene Krieger lagen hier umher und das Würgen und Wüthen währte besonders auf dem Markte und dem unteren Theile des Ortes immer noch fort, während ein großer Theil unserer Wohnungen uns als rauchende Ruinen erschienen. Höher konnte menschliches Elend wohl nicht steigen, als es hier der Fall war. Von Allem, auch dem Allernöthigsten entblößt, getrennt von den Unsrigen, indem der Gatte die Gattin, Aeltern ihre Kinder und Kinder ihre Aeltern verloren hatten, befanden wir uns nun auf der Flucht nach Leipzig und hinter uns sahen wir, wie in dem Orte ein Gebäude nach dem anderen in Flammen aufging. ${ }^{32}$

Ähnliche Berichte von örtlichen Pastoren, seltener auch Gutsbesitzern oder Dorflehrern, liegen aus anderen Orten vor, die vom Schlachtgeschehen um Leipzig betroffen waren. Der „Verein zur Feier des 19. Oktober in Leipzig“ begann ab 1843 Augenzeugenberichte zu sammeln und veröffentlichte diese in einer umfangreichen Dokumentation anlässlich des fünfzigsten Jahrestages der Schlacht. ${ }^{33}$ Diese Berichte deuten darauf hin, dass die Plünderungen und Zerstörungen im Zuge der Kämpfe die Existenzgrundlage vor allem der Ärmsten in der ländlichen Region um Leipzig vernichteten.

Die Bewohner Leipzigs erlebten das unmittelbare Kriegsgeschehen zunächst nur aus der Entfernung. Denjenigen, die Zugang zu einem Dachgeschossfenster hatten, bot sich ein bemerkenswertes Bild: Die anschwellenden Kolonnen der heranrückenden Alliierten bedeckten ganze Höhenzüge. ${ }^{34}$ Zudem war die schnell wachsende Zahl von Flüchtlingen aus den umliegenden Dörfern ein unübersehbarer Vorbote der bevorstehenden Schlacht. Jeder, der einen Zweitwohnsitz in der Stadt, zumindest aber Verwandte oder Freunde dort hatte, verließ sein Dorf und flüchtete entweder nach Leipzig oder in eine weiter entfernt liegende Stadt. Christian Hussell, ein in Leipzig lebender Gelehrter und Publizist, schilderte das jammervolle Bild der Flüchtlinge in einem nur ein Jahr nach der Schlacht veröffentlichten Erlebnisbericht:

Sobald die vorderen Kolonnen in den Biwaks an den nahen Dörfern angekommen waren, fehlte es nicht an tausend Boten ... Jammernde Mütter mit Betten in Tragkörbe gepackt und zwei, drei fast völlig nackende Kinder an der Hand, den Säugling auf dem Rücken; Väter, die Frau und

31 Ebd., S. 148.

32 Ebd.

33 Ebd., III-VIII. Robert Naumann war der erste Vorsitzende des Vereins.

34 Rochlitz (wie Anm. 28), S. 36; Steffens, Heinrich: Was ich erlebte. Leipzig 1938, S. 359. 
Kinder suchten; Kinder, die im Gewühl ihre Eltern verloren hatten; Kranke, die man auf Schubkarren durch das Pferdegewühl drängte; überall Heulen und Wehklagen - dies waren die Herolde und Posaunen. ${ }^{35}$

Auch andere Augenzeugen beschrieben in ihren Memoiren das bemitleidenswerte Schicksal der Flüchtlinge. Diese mussten von den Bewohnern Leipzigs ebenso untergebracht und verpflegt werden wie die schnell wachsende Zahl von verwundeten und kranken Soldaten, die in die Stadt gebracht wurden. Dies verschärfte den ohnehin schon erheblichen Platz- und Nahrungsmangel weiter. Alle Lebensmittel waren rationiert, und Brot als eines der Hauptnahrungsmittel durfte nur an die französische Besatzungsarmee ausgegeben werden.

In den Tagen vor dem offiziellen Beginn der Schlacht konnte die Bevölkerung Leipzigs Feuer und Rauch schnell näher kommen sehen. Der Schlachtenlärm wurde unüberhörbar. Die Hauptschlacht begann am 16. Oktober mit einer Offensive der Koalitionstruppen, die wenig erreichte und schnell zurückgeschlagen wurde. Allerdings waren Napoleons zahlenmäßig unterlegene Truppen auch nicht in der Lage, die Linien der Koalition zu durchbrechen, was zu einem verlustreichen Stillstand führte. Die Dörfer in der Umgebung von Leipzig waren an diesem Tag der Hauptschauplatz der Kampfhandlungen und wurden schwer in Mitleidenschaft gezogen. Eine Lithografie des Leipziger Zeichners Ernst Wilhelm Straßberger, der die Schlacht als Augenzeuge miterlebte, veranschaulicht die Eindrücke der Zeitgenossen (Abb. 1). Am 17. Oktober ruhten die Kämpfe weitgehend. Die Verbündeten erhielten weitere Verstärkung und bekamen nun die Übermacht. Ihr Vorteil wurde durch die Desertion vieler sächsischer Einheiten verstärkt. Insgesamt sollen ca. 5.000 deutsche Deserteure während der Schlacht die Seiten gewechselt haben. Zusätzlich verlor Napoleon in den Schlachttagen 30.000 Kriegsgefangene, die in der Region festgehalten worden waren. Am 18. Oktober rückte der Kaiser mit seinen Truppen noch dichter an Leipzig heran und in die Stadt hinein und fing zugleich mit der Sicherung seines Rückzuges nach Westen an. Die Alliierten begannen mit heftigen Angriffen. Es setzte ein erbittertes Ringen um eine Vielzahl einzelner Ortschaften in unmittelbarer Nähe der Stadt ein, die der französischen Armee nach und nach verloren gingen. Nach Einbruch der Dunkelheit befahl Napoleon schließlich den Rückzug durch Leipzig in Richtung Saale. ${ }^{36}$

Am 19. Oktober griffen die Verbündeten Leipzig an, drangen trotz des erbitterten französischen Widerstandes in die Stadt ein und verfolgten den Feind. Heftig umkämpft war vor allem die Vorstadt außerhalb der Stadtmauern, die weitgehend zerstört wurde. Die Stadt selbst, deren Repräsentanten um „Gnade“ gebeten hatten, wurde von den Alliierten zwar so weit wie möglich verschont, doch eine Bombardierung war notwendig, da die Franzosen die Stadt nicht kampflos räumen wollten. Granaten und Kano-

35 Hussell, Christian: Leipzig während der Schreckenstage der Schlacht im Monat Oktober 1813 [...]. Leipzig 1814 (Nachdruck: Leipzig 1896, S. 20-27).

36 Steffens (wie Anm. 34), S. 107-108. 


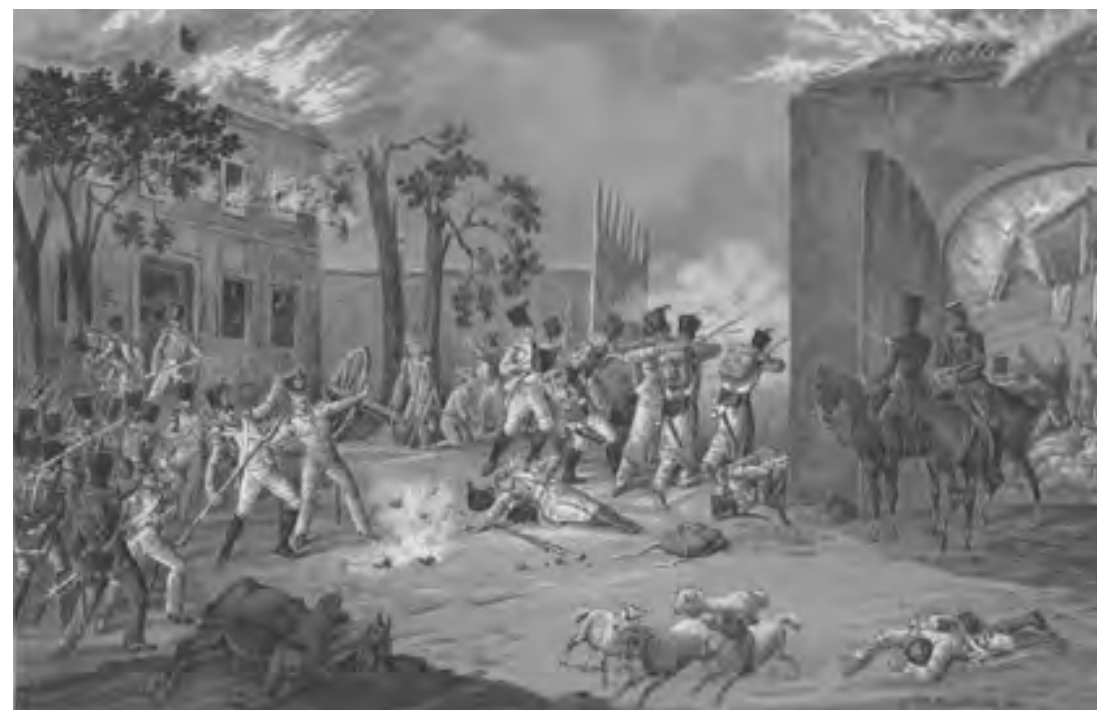

Abb. 1 Ernst Wilhelm Straßberger (1796-1866): Erstürmung der Schäferei Auenhayen bei Leipzig 1813, Zeichnung. Stadtgeschichtliches Museum Leipzig.

nenkugeln schlugen sogar in der Stadtmitte ein und trafen viele Wohnhäuser. ${ }^{37}$ Aber anders als in den verlassenen Dörfern, wo niemand mehr zum Löschen zurückgeblieben war, konnten die Leipziger einen größeren Feuersturm verhindern, obwohl in der völlig überfüllten Stadt wie im fliehenden französischen Heer chaotische Zustände herrschten. Während die napoleonischen Truppen flohen und an vielen Stellen noch bekämpft wurden, um ihnen möglichst große Verluste zuzufügen, zogen die Monarchen der Verbündeten bereits in Leipzig ein und wurden mit Glockengeläut von der jubelnden Bevölkerung begrüßt. ${ }^{38}$

Am 22. Oktober wurde der Sieg auf dem zentralen Marktplatz Leipzigs in Gegenwart der österreichischen, preußischen und russischen Monarchen offiziell gefeiert. Nach einhelliger Ansicht der Zeitgenossen trug deren Anwesenheit entscheidend dazu bei, dass die Stadt von den siegreichen Truppen schonend behandelt wurde. Die Heerführer hatten strengste militärische Disziplin befohlen, die notfalls mit Gewalt durchzusetzen war, und zudem angeordnet, dass die Truppen ihre Lager außerhalb der Stadt aufzuschlagen hatten. Marodeure, die das Chaos in der Stadt und im Umland nutzen wollten, waren zu verhaften. Anders als andere gestürmte Städte wurde Leipzig nicht geplündert, und es gab auch keine gewaltsamen Ausschreitungen. ${ }^{39}$

37 Gross (wie Anm. 16), S. 42-45; Grautoff (wie Anm. 18), S. 119.

38 Naumann (wie Anm. 16), S. 129-130 und 139-140.

39 Gross (wie Anm. 16), S. 55; Pflugk-Harttung (wie Anm. 1), S. 419-420. 


\section{Die militärischen und zivilen Opfer der Schlacht}

Napoleon blieben 60.000 Mann, mit denen er sich nach Frankreich zurückzog. Von den ca. 470.000 auf beiden Seiten eingesetzten Soldaten waren etwa 120.000 gefallen. Die Verbündeten schätzten ihre Gesamtverluste auf 54.000 Mann, die Franzosen auf 66.000. Der Transport aller Verwundeten und die Beseitigung der Leichen von den Schlachtfeldern um Leipzig dauerten mehrere Wochen. Hierzu wurden Kriegsgefangene eingesetzt und auch Bürger der Stadt und des Umlandes zwangsverpflichtet. ${ }^{40}$ Die Angaben zur Zahl der infolge der Schlacht verwundeten und erkrankten Soldaten in Leipzig variieren beträchtlich. Sie schwanken zwischen 20.000 und 38.000. Zudem wurden ca. 5.000 Verwundete nach Halle gebracht. Was immer die genaue Zahl gewesen sein mag, sie wurde aufgrund der hohen Sterberate schnell kleiner. Jeden Tag starben 600 bis 800 Verwundete. Trotzdem befanden sich noch Ende November mehr als 18.000 verwundete und kranke Soldaten in Leipzig. ${ }^{41} 54$ größere private und öffentliche Gebäude waren zu Hospitälern umfunktioniert worden, in denen über 800 Männer und Frauen als Ärzte und Pflegepersonal tätig waren. Weniger schwer verwundete Offiziere wurden in Privatquartieren untergebracht, was die Seuchengefahr weiter erhöhte. ${ }^{42}$

Trotz der Hilfeleistungen aus anderen Teilen Deutschlands, die nach und nach eintrafen, hatte die Bevölkerung Leipzigs größere Schwierigkeiten denn je, mit den zahlreichen Verwundeten fertigzuwerden. Es fehlte nicht nur an ausreichender medizinischer Hilfe, sondern auch an Unterbringungsmöglichkeiten und Lebensmitteln. Einer der vielen Zeitgenossen, die die fürchterliche Situation der kranken und verwundeten Soldaten in den improvisierten Krankenhäusern beschrieben, war der preußische Arzt Johann Christian Reil, dem nach dem Sieg über Napoleon die Leitung der Militärhospitäler in Leipzig und Halle oblag. Er schrieb in einem offiziellen Bericht vom 26. Oktober:

Die zügelloseste Phantasie ist nicht im Stande, sich ein Bild des Jammers in so grellen Farben auszumalen, als ich es hier in der Wirklichkeit vor mir fand. Das Panorama würde selbst der kräftigste Mensch nicht anzuschauen vermögen. [...] Man hat unsere Verwundete an Orte niedergelegt, die ich der Kaufmännin nicht für ihren kranken Möppel anbieten möchte. Sie liegen entweder in dumpfen Spelunken, in welchen das Amphibien-Leben nicht Sauerstoffgas genug finden würde, oder in scheibenleeren Schulen und wölbischen Kirchen, in welchen die Kälte der Atmosphäre in dem Maaße wächst, als ihre Verderbniß abnimmt, bis endlich einzelne Franzosen noch

40 Leggiere, Napoleon (wie Anm. 4), S. 276; Die Franzosenzeit in deutschen Landen, 1806-1815. Hg. v. Friedrich Schulze. Leipzig 1906, S. 191.

41 Johann Christian Reil an Freiherr v. Stein, Leipzig, 26. Oktober 1813, in: Pflugk-Harttung (wie Anm. 1), S. 426; Graf (wie Anm. 23), S. 138; Naumann (wie Anm. 16), S. 138 und 421 f.

42 Naumann (wie Anm. 16), S. 421 f. und 431-433. 


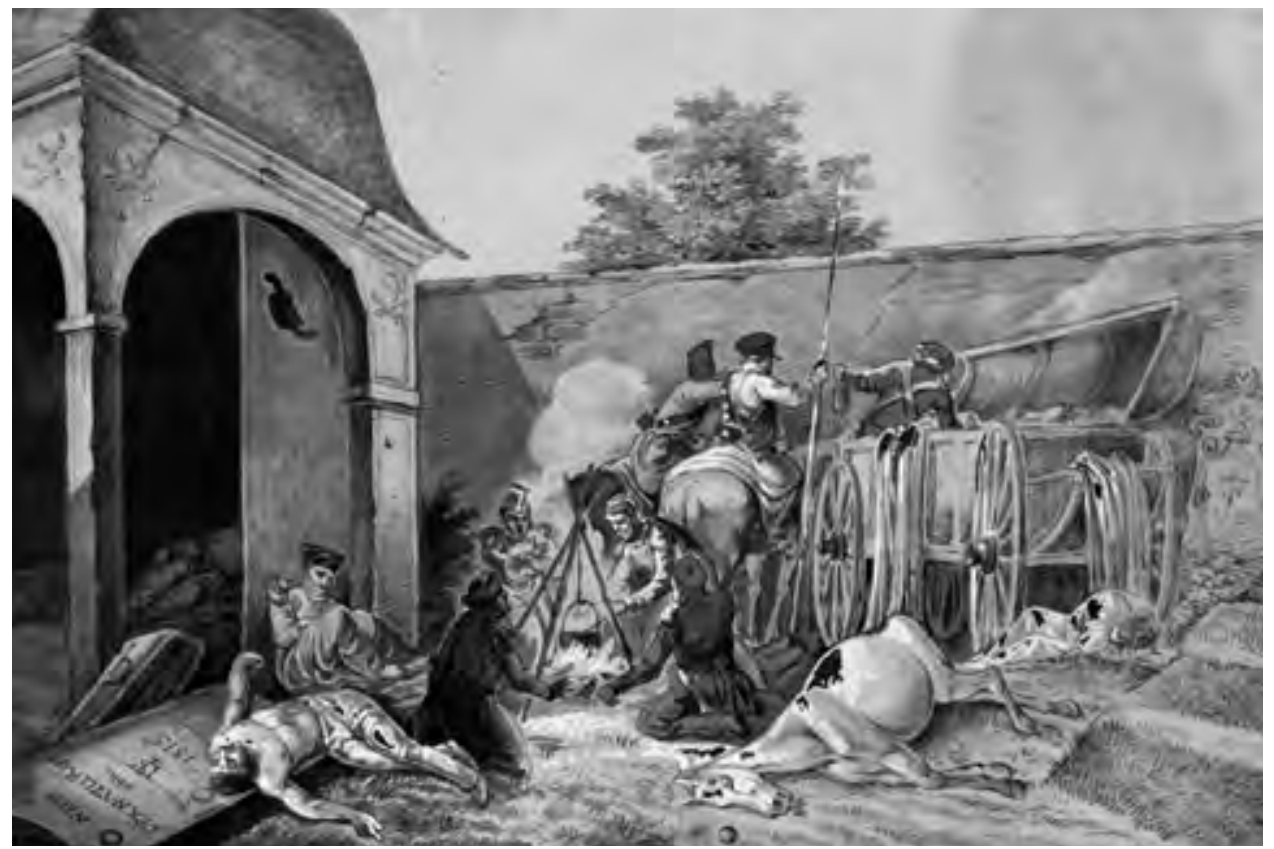

Abb. 2 Ernst Wilhelm Straßberger: Lagerszenen auf dem Alten Johannisfriedhof nach der Schlacht 1813, 1813, Tusche über Kreide und Bleistift. Stadtgeschichtliches Museum Leipzig.

ganz ins Freye hinausgeschoben sind, wo der Himmel das Dach macht, und Heulen und Zähneklappen herrscht. ${ }^{43}$

Die Situation der in der Stadt gebliebenen verwundeten französischen Soldaten und Kriegsgefangenen war besonders schrecklich. Ihre Lage war nicht nur deshalb so desolat, weil es allgemein an allem fehlte und auch die Mehrzahl der Zivilisten Hunger litt, sondern auch weil die Soldaten der Koalitionstruppen grundsätzlich als Erste und besser versorgt wurden. Straßberger hielt die desolate Lage der verwundeten und kranken Soldaten in der Zeichnung einer Lagerszene auf dem Alten Johannisfriedhof in Leipzig fest (Abb. 2). ${ }^{44}$

Die gewaltige Zahl verwundeter und kranker Soldaten brachte erneut Seuchen in die Stadt. Immer mehr Einwohner erkrankten in den letzten drei Monaten des Jahres 1813, durchschnittlich 700 bis 800 pro Woche, von denen 5 bis 10 Prozent starben. Besonders hoch war die Zahl der Toten unter Ärzten und Pflegepersonal, die sich zu fast 50 Prozent infizierten und in überdurchschnittlich hoher Zahl verstarben. Insgesamt erkrankte 1813 ein Drittel der Bevölkerung Leipzigs an Typhus, ca. 13.500 Einwohner, von denen 2.700 starben. Bis Juni 1814 wurden weitere 1.000 Menschen Opfer der

43 Reil an Stein, Leipzig, 26 Oktober 1813 (wie Anm. 41); vgl.: Graf (wie Anm. 23), S. 138.

44 Graf (wie Anm. 23), S. 140; Grautoff (wie Anm. 18), S. 163-164. 


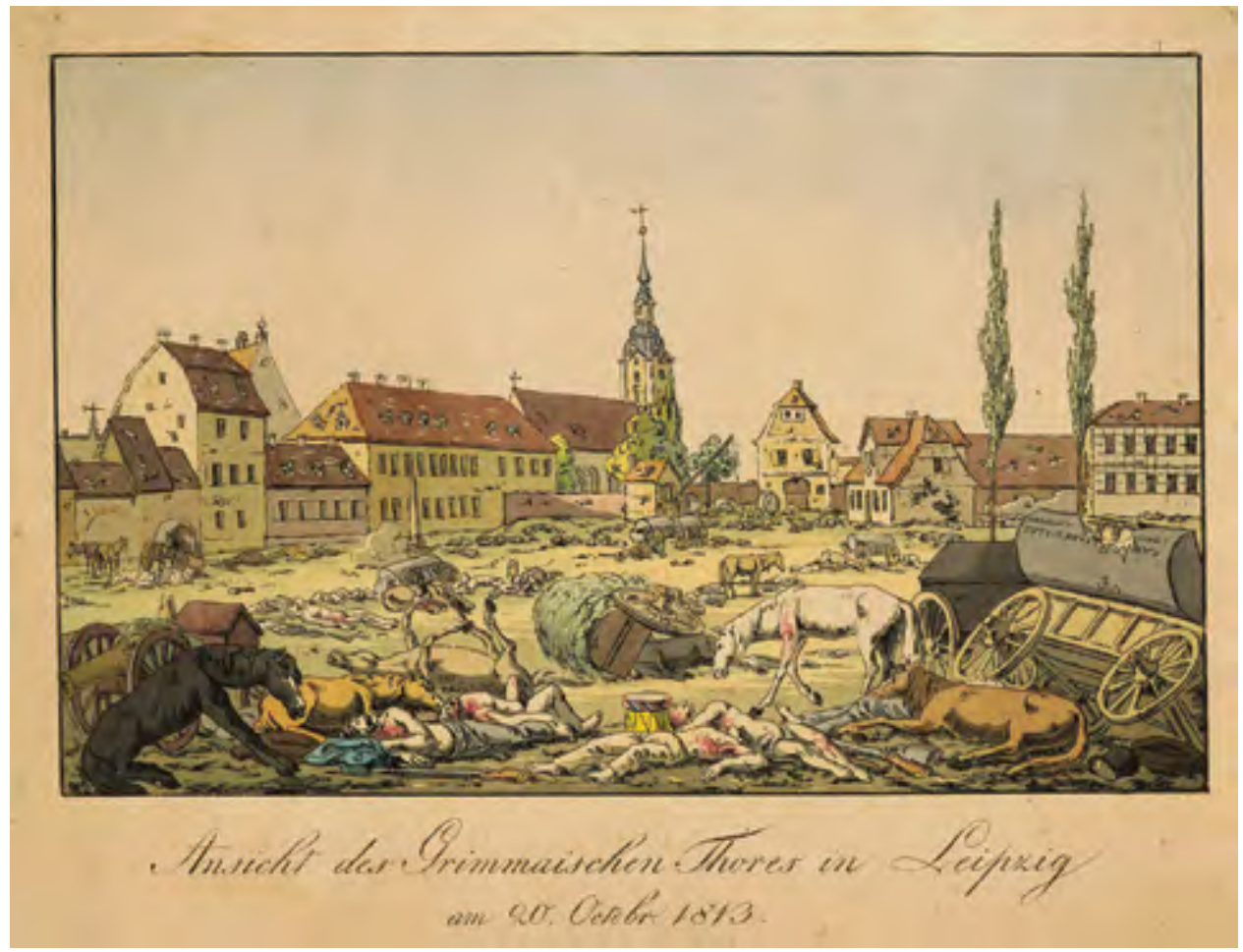

Abb. 3 Ernst Wilhelm Straßberger: Ansicht des Grimmaschen Thores am 20. Oktober, Leipzig 1813, Radierung. Stadtgeschichtliches Museum Leipzig.

Seuche, die insgesamt ein Zehntel der Bevölkerung in Stadt und Umland tötete. Die Epidemie konnte sich nicht zuletzt deshalb so ausbreiten, weil in der Bevölkerung selbst noch Monate nach der Schlacht die „größte Not und der äußerste Mangel herrschten“ und vor allem Kinder und Alte erheblich geschwächt waren..$^{45}$

Insgesamt wurden mindestens 60 Dörfer der Region erheblich zerstört. Allein 20 waren während der Kämpfe schwer bombardiert worden und weitgehend abgebrannt. Straßberger dokumentierte die Lage in und um die Stadt Leipzig in den Tagen der Schlacht in eindrucksvollen Bildern (Abb. 3) ${ }^{46}$ Baugut für den Wiederaufbau fehlte. Es dauerte fast ein Jahr, bis die gröbsten Spuren der Kämpfe beseitigt waren und die Mehrzahl der Flüchtlinge zurückkehren konnte. Auch die meisten Felder und Gärten der Region waren bis zur Unkenntlichkeit verwüstet. Ernte und Viehbestände waren vernichtet. Saatgut war Mangelware. Als im Frühjahr die Felder zum ersten Mal wieder

45 Grautoff (wie Anm. 18), S. 423-424 und 429-430; Graf (wie Anm. 23), S. 138; Naumann (wie Anm. 16), S. 153.

46 Naumann (wie Anm. 16), S. 139-140; Obermüller, Karl Friedrich: Aus der Zeit der Fremdherrschaft und der Befreiung. Erinnerungen. Karlsruhe o.D., S. 29; Graf (wie Anm. 23), S. 144. 
gepflügt wurden, brach die Seuche erneut aus, denn die Bauern fanden Tausende von halb verwesten Toten, die während der Gefechte nur eilig verscharrt worden waren. Vor allem in den Dörfern des Umlandes von Leipzig, die am meisten unter der Schlacht gelitten hatten, dauerte der Wiederaufbau Jahre. Die Stadt selbst hingegen, deren Zerstörungen sich in Grenzen gehalten hatten, erholte sich nach Kriegsende relativ schnell vom Trauma der Schlacht und des Krieges. ${ }^{47}$

Da König Friedrich August I. bis zuletzt bei Napoleon geblieben war, wurde Sachsen nach der Niederlage von den Alliierten unter preußische Verwaltung gestellt. Das Schicksal des Königreichs sollte zu einem der Hauptkonfliktpunkte auf dem Wiener Kongress 1814/15 werden. Am Ende erhielt Friedrich August I. seinen Thron zurück, verlor aber 40 Prozent seines Herrschaftsbereichs an Preußen. Sachsen wurde eines der 39 Mitglieder des Deutschen Bundes. Diese politische Entwicklung hatte zusammen mit den Kriegserfahrungen lang andauernde Auswirkungen auf die Ausformung der regionalen Erinnerungen an den Krieg.

\section{Politik, Kultur und Erinnerungen}

Schon die knappe Skizze der Kriegserlebnisse in Sachsen zwischen 1806 und 1815 verdeutlicht die massiven Auswirkungen, die die neue, durch Massenheere von bis dahin unbekannter Größe geprägte Kriegführung nicht nur auf das Militär, sondern auch auf die Zivilbevölkerung hatten. Natürlich gab es Kriegsprofiteure wie Kreditgeber, Kriegslieferanten und Schmuggler. Andere machten Karriere in der napoleonischen Armee oder Verwaltung. Aber die Mehrzahl der Menschen litt mehr oder weniger stark, für kürzere oder längere Zeit auf eine Weise unter den Napoleonischen Kriegen, die sich deutlich von Kriegserfahrungen im 18. Jahrhundert unterschied. Die Zahl der Toten ist nur einer von vielen Indikatoren. Wie der britische Historiker David Gates hervorhob, neigen Historiker dazu zu vergessen, dass die Gesamtzahl der Kriegstoten zwischen 1792 und 1815 mit fünf Millionen - gemessen an der Einwohnerzahl die Dimensionen des Ersten Weltkrieges erreichte. ${ }^{48}$ Solange die Historiografie der Napoleonischen Kriege die Gewaltdimension nicht stärker in den Blick nimmt, die sehr unterschiedlichen Kriegserfahrungen nicht ernsthaft berücksichtigt und nicht akzeptiert, dass die neuen Formen der Kriegführung weitreichende Auswirkungen für Zivilisten wie für Soldaten hatten, können wir nicht hoffen, den modernen Charakter dieser Kriege zu erfassen oder zu verstehen, warum die Napoleonischen Kriege und mit ihnen Ereignisse wie die Schlacht von Leipzig einen derart bedeutenden Platz in der populären regionalen, nationalen und europäischen Erinnerung haben. Die spezifischen und oft sehr gewaltvollen Kriegserlebnisse waren aber nur ein wichtiger Faktor, der die Kriegserinnerungen prägte. Im deutschsprachigen Mitteleuropa waren die konkurrierenden politischen Interpretationen der Kriege von 1813 bis 1815 und

47 Graf (wie Anm. 23), S. 140 und 144.

48 Gates, David: The Napoleonic Wars, 1803-1815. London 1997, S. 272. 
die unterschiedliche Entwicklung in den verschiedenen Regionen zwischen 1792 und 1815 ebenfalls von erheblicher Bedeutung.

Die Frage, ob die Kriege von 1813-1815 „Befreiungskriege“ oder „Freiheitskriege“ waren, wurde bereits hitzig in der zeitgenössischen Presse diskutiert. Diese beiden konkurrierenden Interpretationen bildeten die Grundlage für die hoch kontroverse Konstruktion des politischen Gedächtnisses im Deutschen Bund und im Kaiserreich und damit auch für die Erinnerung an die Schlacht von Leipzig. Die konservative preuBisch dominierte Meistererzählung sprach von „Befreiungskriegen“, ausgefochten von „Untertanen“, die „monarchisch bis ins Mark“ dem Ruf ihres Königs gefolgt seien und angeführt von seinen Generälen für die Befreiung gekämpft hätten. ${ }^{49}$ In Sachsen und anderen monarchisch regierten Staaten des ehemaligen Rheinbundes herrschte ebenfalls eine monarchisch-konservative Interpretation der Kriege vor, die aber die Rolle Preußens herunterspielte und den regionalen Patriotismus betonte. Die liberale deutschnationale Meistererzählung dagegen sprach von „Freiheitskriegen“, in denen „das deutsche Volk“ in „,freier, autonomer Bewegung“ einen „Kampf für die äußere und innere Freiheit“ geführt habe..$^{50}$ Die Diskussion um Name und Bedeutung der Kriege von 1813-1815 hatte vor allem bis zur Reichsgründung erhebliche politische Brisanz, da ihr Vermächtnis herangezogen wurde, um deutschnationale Einigungswünsche sowie liberale und demokratische Forderungen nach mehr politischen Rechten zu legitimieren. Die Debatte thematisierte zudem Preußens Rolle in einem vereinigten Deutschland..$^{51}$ Der Konflikt prägte die Konstruktion der kollektiven Erinnerungen bis zum Ersten Weltkrieg, aber nach der Einigung durch „Blut und Eisen“, die 1871 zu einem deutschen Nationalstaat ohne Österreich führte, gewann die monarchisch-konservative Interpretation zunehmend die Oberhand und prägte auch die Erinnerung an die Schlacht von Leipzig.

Die erheblich divergierende Entwicklung in den verschiedenen Regionen Kontinentaleuropas zwischen 1792 und 1815 war ein dritter wichtiger Faktor, der die Erinnerungskonstruktion beeinflusste. Für Sachsen, das länger als irgendein anderer deutscher Staat mit Napoleon alliiert blieb und das zunächst von Preußen besetzt und später teilweise annektiert worden war, waren Erinnerungen an die Kriege äußerst konfliktbeladen, mehr noch als in den meisten anderen Regionen, die zum Rheinbund gehört hatten. Wie in Sachsen musste sich die Erinnerungskonstruktion in allen ehemaligen Rheinbundstaaten mit der Tatsache auseinandersetzen, dass sie Alliierte Napoleons gewesen waren und erst sehr spät die Fronten gewechselt hatten, um den Kampf für die Befreiung Deutschlands und Europas zu unterstützen. Das Beispiel Sachsens ist nicht nur wegen des spezifischen Zusammenspiels der drei bisher genannten Faktoren bei

49 Treitschke, Heinrich von: Deutsche Geschichte im Neunzehnten Jahrhundert, Bd. 1-5. Leipzig ${ }^{4} 1886$ [11879], hier Bd. 1, S. 269, 417, 429-430 und 434-445.

50 Roттеск, Karl von: Allgemeine Geschichte. Vom Anfang der historischen Kenntnis bis auf unsere Zeiten, Bd. 1-10, hier Bd. 9. Braunschweig 1851, S. 425-426.

51 Vgl. Berding, Helmut: Das geschichtliche Problem der Freiheitskriege, 1813-1814. In: Historismus und moderne Geschichtswissenschaft. Europa zwischen Revolution und Restauration, 1797-1815. Hg. v. Karl Otmar Freiherr von Aretin und Gerhard A. Ritter. Wiesbaden 1987, S. 201-215; HAgEMANN (wie Anm. 3), Kap. 13. 
der Konstruktion des kollektiven Gedächtnisses interessant. Er erlaubt uns zudem, den Einfluss der sich wandelnden politischen Kultur, des sich kommerzialisierenden Literaturmarktes und des Zusammenspiels verschiedener Erinnerungsmedien auszuloten.

Die zeitgenössische Presse und autobiografische Erinnerungen deuten darauf hin, dass die meisten Sachsen, ähnlich wie die Bewohner anderer deutscher Regionen, den Sieg über Napoleon in der Schlacht von Leipzig ebenso wie den Triumph der antifranzösischen Koalition im April 1814 begrüßten. Ein Beispiel hierfür sind die 1845 vom Leipziger „Verein zur Feier des 19. Oktober" veröffentlichten Memoiren von Auguste Vater mit dem Titel „Was wir erlebten im Oktober 1813“. Der Text ist zugleich das seltene Beispiel einer publizierten autobiografischen Erinnerung von einer Frau. Die Pastorentochter war 16, als ihre Familie ihr Dorf in der Nähe Leipzigs wegen der Kämpfe verlassen musste. Trotz all des Leids und der Verluste, die ihre Familie zu ertragen hatte, schrieb sie:

Wir erhoben uns gemeinschaftlich in dem freudenvollen Gedanken, befreit zu sein vom französischen Joche, den großen Kampf glücklich und siegreich beendigt zu sehen und betrachteten die vielfachen Verluste werthvoller Sachen als ein Opfer für's große Ganze, das wir in der That ohne Murren mit einer so ruhigen Ergebung brachten ... ${ }^{52}$

An ihrer Haltung änderte die politische Nachkriegsgeschichte Sachsens wenig. Wie die meisten anderen autobiografischen Erinnerungen von Zivilisten aus der Region betont ihr Text hauptsächlich die großen Opfer, die die sächsische Bevölkerung während des Krieges erbracht hatte.

Die Berichterstattung in der lokalen Presse und die sächsische Regionalgeschichtsschreibung legen hingegen nahe, dass nach der Teilung des Königreichs eine ausgeprägt antipreußische Stimmung in der Öffentlichkeit um sich griff. Die Regionalgeschichtsschreibung setzte, wie die Historiografie zu den Napoleonischen Kriegen allgemein, unmittelbar nach Kriegsende ein und versuchte Sachsen nicht nur als Opfer Napoleons und der Kriege, sondern zugleich Preußens zu stilisieren. ${ }^{53}$ Diese Interpretation schlug sich in den meisten publizierten autobiografischen Texten sächsischer Autoren, wie beispielsweise den Erinnerungen von Auguste Vater, jedoch nicht nieder. Werke von Zivilisten berichteten vor allem über die Ereignisse im Zusammenhang mit der „Völkerschlacht" und ihre Auswirkungen auf die Bevölkerung. Militärs schilderten den verheerenden Russlandfeldzug und betonten Heroismus, militärische Ehre und Selbstaufopferung der sächsischen Soldaten. ${ }^{54}$

Zudem konkurrierten diese sächsischen Stimmen in der Öffentlichkeit mit Erinnerungen der Kriege von Autoren aus anderen Rheinbundstaaten und Preußen. Einen ganz erheblichen Einfluss hatten preußische Autoren, deren veröffentlichte autobiografische Texte zu den Napoleonischen Kriegen fast 40 Prozent der 211 ausgewerteten Titel

52 Auguste Vater. In: Zeugen des Schreckens. Erlebnisberichte aus der Völkerschlacht in und um Leipzig. Hg. v. Thomas NABERT. Leipzig 2012, S. 12-61, hier S. 52.

53 Töppel, Roman: Die Sachsen und Napoleon. Ein Stimmungsbild, 1806-1813. Köln 2008, S. 308-317.

54 Hagemann (wie Anm. 3), Kap. 14. 
stellen, die vor $1871 \mathrm{im}$ deutschen Sprachraum veröffentlicht wurden. Diese Autobiografien stammen hauptsächlich von Offizieren, Regierungsvertretern und Patrioten sowie Freiwilligen und betonen die herausragende Rolle Preußens im „Befreiungskampf“. Nur zehn Prozent der erfassten autobiografischen Texte stammen von sächsischen Autoren, der Rest verteilt sich auf die übrigen Regionen. Frauen fanden sich sowohl unter den Verfassern von Geschichtsbüchern als auch unter den Autoren von veröffentlichten autobiografischen Erinnerungstexten an die Napoleonischen Kriege kaum. Ihre bedeutende Rolle während der Kriege von 1813-1815 wurde in diesen Erinnerungstexten zumeist völlig ausgeblendet. ${ }^{55}$

Auch in den vielen bildlichen Darstellungen dieser Kriege, die von sächsischen Künstlern geschaffen wurden, vor allem den kolorierten Lithografien, dominierten die Gräuel des „Russlandfeldzugs“ und vor allem der „Völkerschlacht“. Besonders produktiv waren hier Christian Gottfried Heinrich Geißler und Ernst Wilhelm Straßberger, beide Zeichner und Lithographen aus Leipzig, die die Schlacht in Leipzig selbst mite erlebt hatten. Geißler war auch ein eifriger Produzent der sehr populären antinapoleonischen Karikaturen, die nach den Kriegen wiederholt nachgedruckt und in den Schaufenstern der Buchhandlungen sowie auf Märkten gezeigt wurden. Eine seiner populärsten war „Das grosse Rabengastmahl bey Leipzig“, eine Radierung, die er unmittelbar nach der Schlacht schuf (Abb. 4). Wie viele andere Karikaturen auch, kommentierte er mit ihr Napoleons Niederlage bei der „Völkerschlacht“. Karikaturen wurden zu einem wichtigen Bestandteil des visuellen Gedächtnisses der Kriege von 1813 und der Schlacht bei Leipzig, da sie breite Bevölkerungskreise ansprachen. ${ }^{56}$

Ihre visuelle Sprache der Ironie und Satire wurde von der dokumentieren Bildsprache der zeitgenössischen Lithografien ergänzt. Hinzu kam eine wachsende Zahl großer historischer Gemälde zu den Kriegen und der „Völkerschlacht“, die zu einem ganz zentralen Thema der bildlichen Erinnerung an die Napoleonischen Kriege im 19. Jahrhundert wurde, nicht nur im deutschen Raum, sondern in ganz Europa. Immer wieder stellten Künstler aus den verschiedensten Ländern diese beeindruckende Schlacht dar. Im Vordergrund standen dabei zumeist der Heroismus der Kämpfenden, die enormen Dimensionen der Schlacht und die damit einhergehenden unvorstellbaren Verluste unter den Soldaten. Bis weit in das 20. Jahrhundert hinein wurde dem Leiden der Zivilbevölkerung in dieser Form der Darstellungen wenig Beachtung geschenkt. Dies galt auch für die Alltagskultur, wie Postkarten, Sammelkarten, Spielkarten, illustrierte Magazine und Populärliteratur zeigen. Sie betonten ebenfalls den Heroismus der Völkerschlacht und des Kampfes gegen und Sieges über Napoleon. ${ }^{57}$

55 Ebd.

56 Das Zeitalter der Befreiungskriege und die Leipziger Völkerschlacht in Malerei, Graphik, Plastik. Ausstellung anlässlich des 175. Jahrestages der Völkerschlacht bei Leipzig 1989. Ausst.-Kat. Museum der Bildenden Künste Leipzig. Hg. v. Renate HАRтLeв. Leipzig 1988; Patriotische Flugblätter, 18001815 und ihr Umfeld. Ausst.-Kat. Braunschweigisches Landesmuseum. Hg. v. Gerd BiegeL und Christof RöMER. Braunschweig 1990; sowie der Beitrag von Dagmar Burkhart im vorliegenden Band.

57 Viele dieser historischen Gemälde waren in den jüngsten Ausstellungen zu sehen: Napoleon und Europa. Traum und Trauma. Ausst.-Kat. Kunst- und Ausstellungshalle der Bundesrepublik in Bonn. 


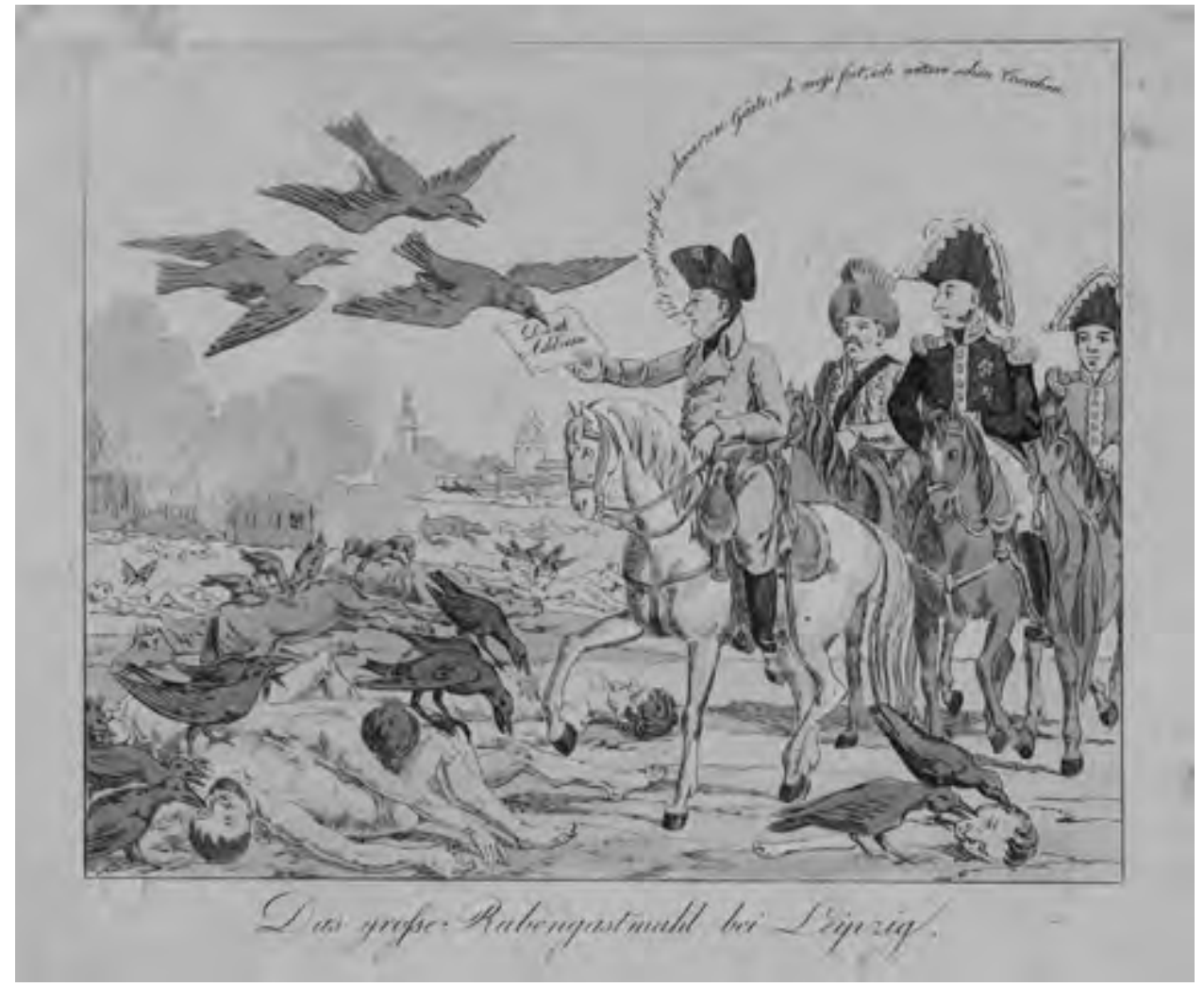

Abb. 4 Christian Heinrich Geißler (1770-1844): Das grosse Rabengastmahl bey Leipzig, 1813, kolorierte Radierung. Stadtgeschichtliches Museum Leipzig.

Zudem nahm die „Völkerschlacht“ im 19. Jahrhundert einen zentralen Platz in der regionalen und nationalen Fest- und Denkmalskultur ein, die gleichfalls die politischen und regionalen Konfliktlinien der Erinnerungsproduktion widerspiegelt. Der Jahrestag der Schlacht von Leipzig wurde zum ersten Mal am 18. und 19. Oktober 1814 als „Nationalfest der Teutschen“ gefeiert. Der Vorschlag zu dieser Feier stammte von einem Kreis deutschnationaler Patrioten um den populären Dichter und Publizisten Ernst Moritz Arndt und wurde mit der auflagenstarken Schrift ,Ein Wort über die Feier der Leipziger Schlacht“, die im August 1814 erschien, schnell weit verbreitet. Von Anfang an war mit dem Vorschlag der Gedanke des Baus eines „Nationaldenkmals“" verbunden. ${ }^{58}$

Hg. v. Bénédicte SAvoy. München 2011; 1813. Auf dem Schlachtfeld bei Leipzig. Ein Rundgang durch das Gemälde „Siegesmeldung“ von Johann Peter Krafft. Ausst.-Kat. Hg. v. Deutschen Historischen Museum (DHM). Berlin 2013; Blutige Romantik. 200 Jahre Befreiungskriege - Essays. Ausst.Kat. Militärhistorisches Museum Dresden. Hg. v. Gerhard BAuer, Gorch PIEken und Matthias RogG. Dresden 2013; Helden nach Maß. 200 Jahre Völkerschlacht bei Leipzig. Ausst.-Kat. Stadtgeschichtliches Museum Leipzig. Hg. v. Volker RodeKamp. Leipzig 2013.

58 ARndt, Ernst Moritz: Ein Wort über die Feier der Leipziger Schlacht. Frankfurt/M. 1814. 
Die Idee des „Nationalfestes“ wurde in weiten Teilen des deutschsprachigen Raumes aufgegriffen. Ein umfangreicher Festreport, der 1815 erschien, berichtete von über 780 Feiern vor allem in West- und Mitteldeutschland einschließlich Sachsen sowie in Preußen und dem übrigen Norddeutschland. ${ }^{59}$ Auch in den folgenden zwei Jahren fanden wieder Gedenkfeiern im Oktober statt. Im Rahmen der Restaurationspolitik wurden die „Nationalfeste“ jedoch mehr und mehr von den Obrigkeiten unterdrückt, denen die häufig deutschnationale Ausrichtung der Feierlichkeiten nicht passte, mit denen allerorts an den „Anteil des Volkes“ am „Freiheitskrieg“ erinnert wurde. Das „Nationalfest“ mit Festumzügen, Dankesgottesdiensten, Turnvorführungen, Freudenfeuern und einer Fülle von patriotischen Reden und Liedern gilt als „Matrix der deutschen Nationalfeste im 19. Jahrhundert" und bildete mit seinen Zeremonien und seiner Symbolik auch die Vorlage für die späteren Feierlichkeiten anlässlich des 25., 50. und 100. Jubiläums der Leipziger Schlacht. ${ }^{60}$ Vor allem die Feierlichkeiten von 1838 und 1863 standen noch ganz im Zeichen der Konkurrenz um die Deutungshoheit über die Erinnerungen.

Im Rahmen der regionalen Feierlichkeiten zum 25. Jahrestag begannen Leipzig und die umliegenden Dörfer 1838 mit der Errichtung lokaler Denkmäler an den wichtigsten Erinnerungsorten der Schlacht. Initiator war der bereits 1814 gegründete Leipziger „Verein zur Feier des 19. Oktober“. Sein erklärtes Ziel war es, die großen Opfer, die die Region erbracht hatte, ins Gedächtnis zu rufen und ihren Beitrag zur Nationalgeschichte der Befreiung mit lokalen Denkmälern zu betonen, die an herausragende Militärs und Patrioten sowie umkämpfte lokale Kriegsschauplätze erinnerten. Die Einweihungsfeierlichkeiten der ersten acht Denkmäler, die zwischen 1845 und 1863 errichtet wurden, organisierte der Verein stets gemeinsam mit der örtlichen Obrigkeit, der evangelischen Kirche und lokalen Assoziationen. Aus Anlass des 50. Jahrestages errichtete der Verein weitere 44 „Marksteine“ auf dem Schlachtfeld. ${ }^{61}$

Leipzig war 1863 der zentrale Gedenkort einer großen nationalen Feier, zu der mit Duldung der sächsischen Regierung die deutschen Städte, allen voran Berlin und Leipzig, eingeladen hatten. Diese Feier war nach der gescheiterten Revolution von 1848/49 eine deutliche politische Willensbekundung des nationalliberalen Bürgertums, mit der die unerfüllten Forderungen von 1813 nach Einheit und Freiheit unterstrichen wurden. Dementsprechend griffen die Organisatoren sehr bewusst auf die Festformen, Bilder und Symbole der „Freiheitskriege“ zurück und integrierten die Burschenschaften sowie Turn- und Gesangsvereine in das Festprogramm, die bereits 1814 aktiv bei der Gestaltung des „Nationalfestes der Teutschen“ mitgewirkt hatten. Selbstverständlich war auch

59 Des Teutschen Volkes feuriger Dank- und Ehrentempel oder Beschreibung wie das aus zwanzigjähriger französischer Sklaverei durch Fürsten-Eintracht und Volkskraft gerettete Teutsche Volk die Tage der entscheidenden Völker- und Rettungsschlacht bei Leipzig am 18. und 19. October zum erstenmale gefeiert hat. Hg. v. Karl HofFmann. Offenbach 1815.

60 Hagemann, Karen: Celebration, Contestation and Commemoration: The Battle of Leipzig in German Memories of the Anti-Napoleonic Wars of 1813-1815. In: War, Demobilization and Memory: The Legacy of War in the Era of Atlantic Revolutions. Hg. v. Alan Forrest, Karen Hagemann und Michael Rowe. Basingstoke 2016, S. 335-353.

61 Hartleb (wie Anm. 56), S. 36-39. 


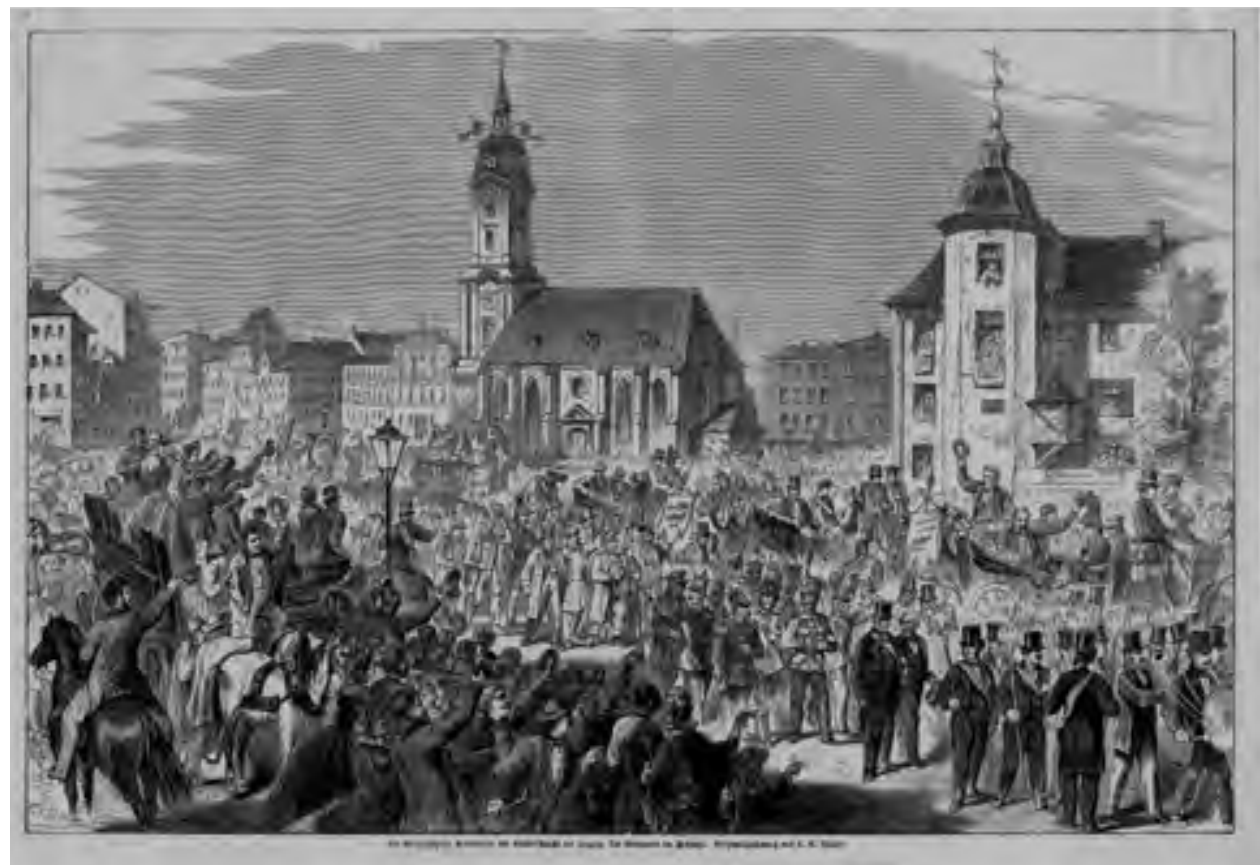

Abb. 5 „Die Veteranen von 1813-15 im Festzug anläßlich der Nationalfeiern der Leipziger Völkerschlacht", Blatt aus der Illustrirte Zeitung, Leipzig, Oktober 1863. Stadtgeschichtliches Museum Leipzig.

das Liedgut der „Freiheitskriege“ Teil der Feiern. Bei den Teilnehmern waren - wie bereits 1813 - die Lieder von Ernst Moritz Arndt und Theodor Körner besonders populär. Der zentrale Umzug in Leipzig gewährte den noch lebenden Veteranen der Kriege von 1813-1815 einen prominenten Platz in seinen Reihen, ohne dabei nach militärischem oder sozialem Rang zu unterscheiden, was symbolisieren sollte, dass sie alle gleichermaßen „Kameraden, Kämpfer und Sieger in Deutschlands größter Schlacht“ gewesen waren. ${ }^{62}$ Insgesamt nahmen ca. 20.000 Menschen an dem Festumzug selbst teil; die Zahl der Zuschauer wird auf ca. 100.000 geschätzt. Die technischen Innovationen des Pressewesens erlaubten nun Sonderdrucke mit Illustrationen zu solchen Großereignissen, die mit der Post bis in die entferntesten Regionen des Deutschen Bundes transpor-

62 Hoffmann, Stefan: Sakraler Monumentalismus um 1900. Das Leipziger Völkerschlachtdenkmal. In: Der politische Totenkult. Kriegerdenkmäler in der Moderne. Hg. v. Reinhart KoselLeCK und Michael Jeismann. München 1994, S. 249-280; Hoffmann, Stefan: Mythos und Geschichte. Leipziger Gedenkfeiern der Völkerschlacht im 19. und frühen 20. Jahrhundert. In: Nation und Emotion. Deutschland und Frankreich im Vergleich 19. und 20. Jahrhundert. Hg. v. Etienne FrançoIs, Hannes Siegrist und Jakob Vogel. Göttingen 1995, S. 111-132, hier S. 119; Puschner, Uwe: 18. Oktober 1813. „Möchten die Deutschen nur alle und immer dieses Tages gedenken!“ - Die Leipziger Völkerschlacht. In: Erinnerungstage. Wendepunkte der Geschichte von der Antike bis zur Gegenwart. Hg. v. Etienne François und Uwe Puschner. München 2010, S. 145-162. 
tiert wurden. Ein nach der Leipziger Nationalfeier veröffentlichtes „Blatt aus der Illustrierte Zeitung“ zeigte etwa „Die Veteranen von 1813-15 im Festzug anläßlich der Nationalfeiern der Leipziger Völkerschlacht“ (Abb. 5). Die Presse berichtete auch darüber, dass zum Abschluss der Leipziger Feierlichkeiten der bereits 1815 propagierte Gedanke eines Nationaldenkmals wieder aufgegriffen und ein Grundstein vor den Toren der Stadt gelegt wurde. Es sollte jedoch noch weitere 50 Jahre dauern, bis dieses Denkmal eingeweiht werden konnte. ${ }^{63}$

Das Jubiläum von 1913 sah dann allerdings vollkommen anders aus. Mehr als 40 Jahre nach der Reichgründung stand der konservativ-monarchische Mythos von der „Völkerschlacht" als „Geburtsstunde des deutschen Volkes“, die die „edelsten Kräfte“ des „Volkstums, des deutschen Volksbewußtseins“ entfesselt hätte, im Zentrum. Dieser Mythos hatte seit der Reichsgründung, die als „Vollstreckung“ von 1813 interpretiert wurde, vor allen Dingen in weiten Teilen des nationalliberalen Bürgertums zunehmend an Einfluss gewonnen. ${ }^{64}$ Er fand seinen Niederschlag auch in der massiven Architektur des Leipziger „Völkerschlachtdenkmals“, dessen Errichtung 1894 vom „Deutschen Patriotenbund" initiiert worden war und 1913 endlich abgeschlossen wurde. Der 91 Meter hohe Klotz ist bis heute das höchste Denkmal Europas. „Der trutzige Koloss war ein steinernes Symbol des ,unheiligen Deutschen Reiches preußischer Nation““”, wie Thomas Mann das Kaiserreich genannt hat. Schon während der langen Bauzeit besuchten 600.000 Menschen die Stätte. ${ }^{65}$ Sonderdrucke der Presse, Illustrationen in Magazinen und Zeitungen, Plakate und Postkarten (Abb. 6) machten das „Völkerschlachtdenkmal" schnell in allen Teilen des Deutschen Reiches bekannt und transportierten zugleich die mit ihm verknüpfte, nach wie vor umstrittene Erinnerung an die Kriege von 18131815. Zwar hatte sich nun eine nationalkonservative Deutung dieser Kriege durchgesetzt, aber es gab nach wie vor Opposition. Die Sozialdemokratische Partei mobilisierte ihre Anhänger in Leipzig gar zu einer Gegendemonstration gegen die pompöse Einweihung des Nationaldenkmals, die am 18. Oktober 1913 mit einer gigantischen Prozession und unter Beteiligung von Kaiser Wilhelm II. gefeiert wurde.

$\mathrm{Zu}$ den ,edelsten Kräften“, die aus Anlass der Einweihung in Festreden und in der Presse gepriesen wurden, gehörte die bedingungslose nationale Opferbereitschaft. Diese Eigenschaft war am Vorabend des Ersten Weltkrieges wieder besonders gefragt. Die Feierlichkeiten von 1913 vermittelten ein Kriegsbild, das mental auf eine neue große Völkerschlacht einstimmte und den Krieg als Katalysator nationaler Einigung und Erneuerung anpries. ${ }^{66}$ Dieses Kriegsbild fand nun selbst in liberalen bildungsbürgerlichen Kreisen breite Akzeptanz. So knüpfte der Historiker Friedrich Meinecke in der kurz

63 Hoffmann, Mythos (wie Anm. 62), S. 118.

64 SpitzNer, A.: Deutschlands Denkmal der Völkerschlacht. Das Ehrenmal seiner Befreiung und nationalen Wiedergeburt. Weiheschrift des Deutschen Patriotenbundes. Leipzig 1913, S. 14.

65 Der Klotz der Nation. In: Tagesspiegel, 20.10.2013.

66 Siemann, Wolfgang: Krieg und Frieden in historischen Gedenkfeiern des Jahres 1913. In: Öffentliche Festkultur. Politische Feste in Deutschland von der Aufklärung bis zum Ersten Weltkrieg. Hg. v. Dieter Düding, Peter Friedemann und Paul Münch. Reinbek 1988, S. 298-320, hier S. 313-315; Vom Kult zur Kulisse. Das Völkerschlachtdenkmal als Gegenstand der Geschichtskultur. Hg. v. Kat- 


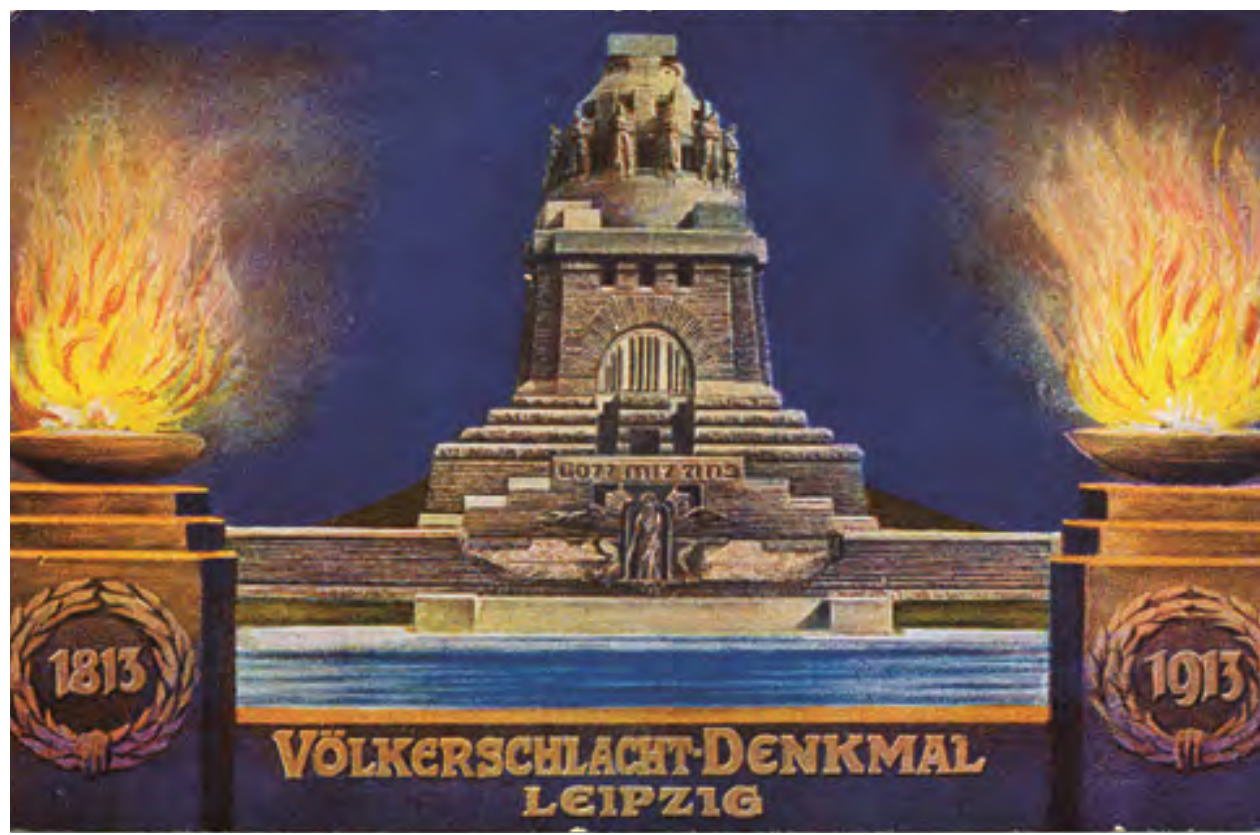

Abb. 6 Völkerschlachtdenkmal Leipzig, 1813-1913, Postkarte, Leipzig 1913. Stadtgeschichtliches Museum Leipzig.

nach Kriegsbeginn 1914 erschienenen Schrift „Die deutsche Erhebung von 1914“ in dem Kapitel „Die deutschen Erhebungen von 1813, 1848, 1870 und 1914“ bewusst an die Kriegstradition von 1813-1815 an. Er betonte, dass ,der Tod für das Vaterland, dieses uralte Opfer ... wieder einen neuen und ewigen Sinn erhalten“ habe und ,einen heiligen Frühling für ganz Deutschland“" bedeute:

Wir waren in den Jahren vorher anscheinend ganz unheilbar gespalten und oft ganz müde und verzagt über den unseligen Klassen- und Konfessionshaß und die Bedrohungen unseres Geisteslebens. Nun sind wir mit einem Schlage hinausgehoben über alle Schranken, eine einzige, mächtige, tief atmende Gemeinschaft des Volkes auf Leben und Tod. ${ }^{67}$

Und damit schloss sich 1914 für ihn und viele andere gebildete nationalliberale Männer des Mittelstandes, die den neuen Krieg begrüßten, der Kreis zu den Kriegen von 1813-1815. In der Tat setzte mit dem Ersten Weltkrieg eine neue Runde der heroi-

rin Keller und Hans-Dieter Schmid. Leipzig 1995; Mosse, George: Fallen Soldiers. Reshaping the Memory of the World Wars. New York 1990, S. 53-158.

67 Meinecke, Friedrich: Die deutschen Erhebungen von 1813, 1848, 1870 und 1914. In: Ders., Die deutsche Erhebung von 1914. Stuttgart 1914, S. 9-38, hier S. 28 f.; Ders.: Das Zeitalter der deutschen Erhebung (1795-1815). Leipzig 1906 (Nachdruck: Göttingen 1957). 
schen Erinnerungsproduktion ein, in der das Gedächtnis der Leipziger Schlacht und der Kriege von 1813-1815 einmal mehr für gegenwartsbezogene, insbesondere nationalistische und militaristische, Zwecke genutzt wurde, wobei die Leiden der Soldaten und der Zivilbevölkerung in diesen Kriegen und dieser Massenschlacht mehr und mehr in Vergessenheit gerieten. 


\title{
Vom „Vaterländischen Krieg 1812“ zum „Großen Vaterländischen Krieg 1941-1945“
}

\author{
Siegesmythen als Fundament staatlicher Geschichtspolitik \\ in der Sowjetunion, der Russländischen Föderation, der Ukraine \\ und Belarus'
}

\author{
Stefan Troebst
}

Die mediale, visuelle und repräsentationsmäßige Verwertung des russischen Sieges über Napoleon 1812 und seiner „Architekten“, der Generäle Aleksandr Suvorov und Michail Kutuzov, stellte eine Neuausrichtung in der Geschichtspolitik des Zarenreiches dar. Denn bis dahin waren die imperial propagierten Erinnerungsorte sämtlich religiös konnotiert, was auch und gerade für militärische Ereignisse galt: Die Schlacht auf dem Peipus-See 1242 gegen den Deutschen Orden oder der Sieg auf dem Schnepfenfeld über die Tataren 1380 wurden im Moskauer Staat wie im petrinischen Russland als Triumphe der Orthodoxie über Ketzer und Ungläubige kanonisiert, die Sieger Aleksandr Nevskij und Dmitrij Donskoj als Heilige verehrt. Hinzu kam, dass beide als Vertreter russischer Staatsmacht - des Großfürstentums Vladimir-Suzdal' der eine, des Großfürstentums Moskau der andere - agierten und damit in eine Traditionslinie zu den späteren Zaren gestellt wurden.

Anderen siegreichen Befreiern ,russischer Erde“ wurde diese Qualität nicht beigemessen, sodass sie als Heroen höchstens zweiter Klasse eingestuft wurden. Dies galt etwa für das opolčenie, also für das Aufgebot eines Volksheeres gegen die polnischlitauische Besetzung Moskaus der Jahre 1610 bis 1612, in der sogenannten „Zeit der Wirren“, der smuta. Mit dem Sieg der Insurgenten wurde der Weg frei für die Krönung Michail Romanovs 1613 zum Zaren durch seinen Vater Patriarch Filaret. Die Dynastie Romanov, die bis 1917 herrschte, war damit begründet. Zwar war einer der Anführer der Aufständischen, Dmitrij Požarskij, ein Fürst aus dem Haus der Rjurikiden, doch sein Partner, der Kaufmann (oder Metzger?) Kuz'ma Minin aus Nižnij Novgorod, war nichtadliger, überdies wohl auch nichtrussischer, mutmaßlich tatarischer Herkunft. Das 1818 auf dem Roten Platz in Moskau aufgestellte Minin-und-Požarskij-Denkmal ging folglich nicht auf die Initiative der Monarchie, sondern auf diejenige der Bürger Nižnij Novgorods zurück. Und seine Aufstellung wäre ohne die geschichtspolitische Wende im Zuge des Sieges von 1812 - jetzt in Richtung Reichspatriotismus und Russentum statt, wie bisher, Orthodoxie und Dynastie - nicht möglich gewesen. Überdies waren am russländischen Sieg über Napoleon nicht zuletzt russische Freischärler beteiligt, die wie exakt 200 Jahre zuvor unter der Bezeichnung opolčenie, Landwehr, firmierten und deren Zahl auf nicht weniger als 400.000 (bei einer nur geringfügig höheren Zahl regulärer zarischer Truppen) geschätzt wird. 
Allerdings bestand Zar Aleksandr I. darauf, den in der Folgezeit als „Vaterländischen Krieg" bezeichneten Waffengang gegen Frankreich und seine Verbündeten religiös einzubinden. In seinem Manifest ,über die Erstattung der Dankbarkeit für die Befreiung Russland vom feindlichen Angriff an Gott den Herrn" vom 25. Dezember 1812 dekretierte er:

Von nun an soll der 25. Dezember, der Tag der Geburt Christi, im kirchlichen Kontext auch der Tag der Dankbarkeitsfeier sein - unter der Bezeichnung: Geburt unseres Erlösers Jesus Christus sowie Erinnerung an die Errettung der Kirche und des Russländischen Staates vor dem Angriff der Gallier mit ihren zwölf Völkern. ${ }^{1}$

Der Sieg über Napoleon 1812 ist seitdem ein zentraler staatlicher Erinnerungsort, wie nicht zuletzt die aufwendigen Feiern zum 100. Jubiläum 1912 im Zarenreich, zum 150. 1962 in der Sowjetunion und zum 200. 2012 in der Russländischen Föderation belegen, die jeweils mit Medienkampagnen, Publikationsoffensiven sowie (partei) politischen und militärischen Inszenierungen unter dem Rubrum „Vaterländischer Krieg" einhergingen.

In mehrfacher Hinsicht ein Geniestreich von Stalins Chefpropagandisten Emel'jan Jaroslavskij war die bereits am Tag nach dem Angriff NS-Deutschlands auf die Sowjetunion, am 22. Juni 1941, in einer in der Parteizeitung „Pravda“ veröffentlichten Rede getroffene Sprachregelung vom „Großen Vaterländischen Krieg“(Velikaja Otečestvennaja vojna). Jaroslavskij, damals Vorsitzender der „Gesellschaft der Gottlosen“, also des sowjetischen Atheistenverbandes, knüpfte damit zum einen an den „Vaterländischen Krieg" gegen Napoleon an, stellte aber zum anderen durch das Adjektiv velikaja (groß) implizit die Sowjetunion über das Zarenreich und damit Stalin über Aleksandr I. Unterschwellig unterstrich er damit den russischen Charakter der Sowjetunion und gab zugleich den Startschuss zur Propagierung des neuen Konzepts eines „Sowjetpatriotismus“, der bald durch eine „allslavische“ Komponente sowie durch eine propagandistische Instrumentalisierung der zuvor repressierten russisch-orthodoxen Kirche ergänzt wurde. In Stalins berühmter Rede zum 24. Jahrestag der Oktoberrevolution vor Soldaten der Roten Armee auf dem Roten Platz in Moskau am 7. November 1941 hörte sich die neue Linie wie folgt an:

Möge Euch in diesem Krieg das heldemütige Vorbild eurer großen Vorfahren beseelen - Aleksandr Nevskijs, Dmitrij Donskojs, Kuz'ma Minins, Dmitrij Požarskijs, Aleksandr Suvorovs, Michail Kutuzovs. Möge Euch das siegreiche Banner des großen Lenin Kraft verleihen!?

1 Polnoe sobranie Zakonov Rossijskoj Imperii [Vollständige Sammlung der Gesetze des Russländischen Reiches]. Bd. 32. Peterburg 1830, S. 486-487.

2 Stalin, I.: Reč‘ na parade Krasnoj Armii 7 nojabrja 1941 goda na Krasnoj ploščadi v Moskve [Rede auf der Parade der Roten Armee am 7. November 1941 auf dem Roten Platz]. In: Ders.: O Velikoj Otečestvennoj vojne Sovetskogo Sojuza. Moskva 1943, S. 34-37, hier S. 37. 
Die Kontinuitätslinie von 1242 und 1380 über 1612 und 1812 zu 1917 und 1941 war damit gezogen.

Was Jaroslavskij bei seiner Prägung der Formel vom „Großen Vaterländischen Krieg“ Ende Juni 1941 nicht ahnen konnte, war der Umstand, dass das zweite Adjektiv otečestvennaja (vaterländisch), und nicht, wie zu erwarten gewesen wäre, sovetskaja (sowjetisch) - den russländischen, ukrainischen und belarusischen Nachfolgestaaten der Sowjetunion die reibungslose Weiternutzung der sowjetischen Formel vom „Großen Vaterländischen Krieg“" auch in postkommunistischer Zeit ermöglichte. Zwar war mit „Vaterland“ ursprünglich die UdSSR gemeint, aber da diese eben nicht beim Namen genannt wurde, konnte nach 1991 problemlos ein „Vaterlandstransfer“ zum neuen Russland und sogar zur neuen Ukraine und zur neuen Belarus' hergestellt werden. Und die seit der bedingungslosen Kapitulation des Deutschen Reiches am 8. bzw. (nach Moskauer Uhrzeit) 9. Mai 1945 in Berlin-Karlshorst dem dreiteiligen Standardbegriff angehängten Jahreszahlen ,1941-1945“ ermöglichten der Russländischen Föderation, der Ukraine und Belarus' wie zuvor der Sowjetunion die Ausblendung der Anfangsphase des Zweiten Weltkriegs vom 1. September 1939 bis zum 21. Juni 1941. In das jetzt auch russländische Narrativ vom heldenhaften Kampf der Völker der Sowjetunion gegen den nationalsozialistischen „Drang nach Osten“ mussten folglich der Hitler-Stalin- bzw. Molotov-Ribbentrop-Pakt samt Geheimem Zusatzprotokoll über die Aufteilung Ostmitteleuropas vom 23. August 1939, der Einmarsch der Roten Armee in Polen am 17. September 1939, der Deutsch-Sowjetische Grenz- und Freundschaftsvertrag vom 28. September 1939, die zwischen Berlin und Moskau koordinierte deutsch-sowjetische Okkupation Polens samt Kooperation von Wehrmacht und Roter Armee sowie von Gestapo und NKVD, die gewaltsame Einverleibung Estlands, Lettlands, Litauens, Ostpolens, der Bukovina und Bessarabiens in die UdSSR, die Lieferung kriegswichtiger Rohstoffe aus der Sowjetunion ins „Dritte Reich“ und andere sperrige Tatbestände nicht eingepasst werden. In der Geschichtspolitik der Ukraine hingegen wurde vor allem unter dem Präsidenten Leonid Kučma der aus Sowjetzeiten stammende Terminus „Goldener September“ für die Annexion Südostpolens durch die UdSSR bei Angliederung an die Ukrainische Sozialistische Sowjetrepublik im Herbst 1939 weiterverwendet. Und unter dem belarusischen Präsidenten Lukašenkả wurde die Proklamierung des 17. September, an dem 1939 die Rote Armee in Polen einfiel, zum staatlichen Feiertag „der Wiedervereinigung der belarusischen Lande" ernsthaft erwogen. Gemeint war natürlich der gewaltförmige Anschluss Nordost-Polens an die Weißrussische Sozialistische Sowjetrepublik.

Die Geschichtspolitik in Zarenreich, Sowjetunion und Russländischer Föderation gleicht der Echternacher Springprozession: Nach jedem Regimewandel - und dazu sind auch die innersowjetischen Brüche von 1929, 1953 und 1985 zu rechnen - wurden zuvor ausrangierte Erinnerungsorte reaktiviert sowie bisher gültige abgeschaltet. Frithjof Benjamin Schenk hat in seinem fulminanten Buch über Aleksandr Nevskij als „Erinnerungsfigur im russischen kulturellen Gedächtnis“ die „Entthronung“ dieses Nationalhelden durch die Bol'ševiki sowie seine umgehende „Rehabilitierung“ durch 
Stalin beschrieben, ${ }^{3}$ und Jutta Scherrer hat ihre 2005 vorgenommene und mit „Siegesmythos versus Vergangenheitsaufarbeitung " überschriebene Analyse sowjetischer wie postsowjetischer Geschichtspolitik mit folgendem skeptischem Fazit beendet:

Rußland [gemeint ist die heutige Russländische Föderation - S. T.] hat sich in erstaunlich kurzer Zeit von dem Mythos der „Großen Sozialistischen Oktoberrevolution“ befreit. Wird es sich jemals von dem Mythos des Großen Vaterländischen Krieges, der heroischen Heldentat des Siegs befreien können oder wollen? ${ }^{4}$

Aus heutiger Sicht muss die Antwort lauten: weder - noch. Der Sieg über HitlerDeutschland im Zweiten Weltkrieg ist der Gründungsmythos des Putin'schen Russland und wird es auf absehbare Zeit hinaus auch bleiben. Dafür sprechen mindestens drei gewichtige Gründe:

Erstens, ein Alternativmythos ist nicht in Sicht. Die Entstalinisierungspolitik Chruščëvs, die bezüglich Lebensstandard und Konsum „goldenen“, politisch und kulturell aber verlorenen Jahre unter Brežnev, die halbherzige Perestrojka unter Gorbačëv, die Gründung der Russländischen Föderation durch El'cin oder die abgewehrten Putschversuche gegen die beiden Letztgenannten taugen dafür sowohl aus der Sicht der „Vertikale der Macht" als auch aus derjenigen der Bevölkerungsmehrheit nicht.

Zweitens, die Stalin'sche Formel von der „Befreiung der Völker Europas vom Faschismus“ 1945 durch die Rote Armee festigt den imperialen wie globalen Machtanspruch des Russlands Putins. So gering das internationale Prestige der Russländischen Föderation auch ist, so unbestritten ist selbst im Westen der sowjetische Beitrag zum gemeinsamen Sieg über Hitler. Indirekter Beleg dafür ist etwa die Proklamierung des 27. Januar zum internationalen Gedenktag für die Opfer des Holocaust, denn an diesem Tag befreiten 1945 Sowjettruppen das NS-deutsche Vernichtungslager AuschwitzBirkenau.

Und drittens, die Traditionslinie vom „Vaterländischen Krieg 1812“ zum „Großen Vaterländischen Krieg 1941-1945“ wirkt als ,allrussische“ Kontinuitätsbrücke sowohl zum zarischen Russland als auch zum neuen Russland, denn sowohl El'cin wie Putin haben den „Sieg über den Faschismus“ zum Gründungsmythos der Russländischen Föderation stilisiert. Die Sowjetperiode und mit ihr Stalin als „Führer“ (russ. vožd") sind damit in die russländische Meistererzählung sowie das amtlicherseits propagierte Geschichtsbild integriert.

All dies heißt aber nicht, dass der umgangssprachlich mit „VOV“ abgekürzte lieu de mémoire - für russisch Velikaja Otečestvennaja vojna (Großer Vaterländischer Krieg) auf einem gesellschaftlichen Konsens basiert, im Gegenteil: Die innerrussländischen

3 Schenk, Frithjof Benjamin: Aleksandr Nevskij. Heiliger - Fürst - Nationalheld. Eine Erinnerungsfigur im russischen kulturellen Gedächtnis (1263-2000). Köln-Weimar-Wien 2004, S. 226-287.

4 SCHERRER, Jutta: Sowjetunion/Rußland: Siegesmythos versus Vergangenheitsaufarbeitung. In: Mythen der Nationen. 1945 - Arena der Erinnerungen. Hg. v. Monika FlacKE. Bd. 2. Mainz 2004, S. 619670, hier S. 655. 
geschichtspolitischen Debatten der letzten Jahre kreisten eben um dieses Thema. Die rudimentäre Zivilgesellschaft hat ihren fundamentalen Dissens zur staatlichen Geschichtspolitik in die Formel „, pobeda bez Stalina “ gefaßt - „Sieg ohne Stalin“. Der Sieg ist zu feiern, so diese Sichtweise, aber nicht der Diktator. Nach der Abwicklung des Medvedev'schen Konzepts einer „zweiten Entstalinisierung“ lautet die aktuelle Sprachregelung des Kremls wie folgt: Ja, Stalin war ein Mensch mit gewissen Schwächen und Defiziten, die indes durch seine politischen wie militärischen Leistungen im Kampf gegen den Faschismus mehr als aufgewogen werden. Jutta Scherrers Skepsis ist daher auch zehn Jahre später vollauf berechtigt.

Dennoch ist die Putin'sche Geschichtspolitik weniger starr, als es auf den ersten Blick scheinen mag. Auf Initiative des Kremls wurde 2005 der von El'cin in „Tag der Eintracht und Versöhnung" umbenannte sowjetische Staatsfeiertag am 7. November, damals der „Jahrestag der Großen Sozialistischen Oktoberrevolution“, abgeschafft und durch einen neuen, zeitlich nahe gelegenen Feiertag am 4. November ersetzt. Dieser neue „Tag der nationalen Einheit“" rekurriert auf das Jahr 1612, als das besagte Volksaufgebot unter Minin und Požarskij in der „Zeit der Wirren“ von Nižnij Novgorod nach Moskau zog und die polnischen Besatzer aus der Hauptstadt vertrieb.

Die Konstanzer Historikerin Isabelle de Keghel hat 2009 in einem Band über "Geschichtspolitik und Erinnerungskultur im neuen Russland“ eine eindringliche Analyse der zahlreichen Konnotationen zivilgesellschaftlicher, EU-feindlicher, multiethnischer, nationalistisch-rechtsextremer, sozialkohäsiver und anderer Art dieses neuen russländischen Staatsfeiertages geliefert. Der machtpolitische Kern, den ihre Untersuchung zur beabsichtigten und tatsächlichen Wirkung des neuen „Tags der nationalen Einheit" herausarbeitet, lautet:

In den Vergangenheitsdiskurs der Transformationszeit schrieb sich dieser Vorschlag insofern gut ein, als die „Zeit der Wirren“ dort ein Schlüsselbegriff gewesen war. Häufig war dieser Terminus, der [...] zur Bezeichnung einer historischen Entwicklungsphase im frühen 17. Jahrhundert diente, auch zur Beschreibung der Umbruchsituation im Russland der Transformationszeit benutzt worden. Diese Periode raschen und verunsichernden Wandels sollte nun offiziell für beendet erklärt werden.

Und weiter:

Der neue Feiertag transportierte also zugleich die Aussage, Putin habe das Chaos der Ära El'cin beseitigt und Russland konsolidiert. Implizit wurde dabei eine Analogie zwischen dem ersten Romanov und Präsident Putin hergestellt: So wie das Land [1613] mit der Inthronisierung von Mihail Romanov erstmals nach der „Zeit der Wirren“ wieder einen starken Herrscher bekam, ging Putin nun in seinem Selbstverständnis gegen Anarchie und Regionalismus vor, indem er die „Machtvertikale“ und eine starken Staat forcierte. ${ }^{5}$

5 Keghel, Isabelle de: Verordneter Abschied von der revolutionären Tradition: Der „Tag der nationalen Einheit" in der Russländischen Föderation. In: Geschichtspolitik und Erinnerungskultur im neuen Russland. Hg. v. Lars Karl und Igor J. Polianski. Göttingen 2009, S. 119-140, hier S. 124-125. 
Der siegreiche Widerstand gegen ausländische Militärinterventionen ist gemeinsamer Nenner zarischer, sowjetischer und russländischer Geschichtspolitik. Gemäß sowjetischer Tradition ist dabei auch zu postsowjetischer Zeit der „Tag des Sieges“ am 9. Mai als Apotheose des „Großen Vaterländischen Krieges 1941-1945“ zentraler Fluchtpunkt, der wiederum in direkter historischer wie terminologischer Traditionslinie zum „Vaterländischen Krieg 1812“ steht. Eine Putin'sche Innovation ist die Proklamierung des 4. November zum „Tag der nationalen Einheit“, mit dem der Vertreibung der polnisch-litauischen Interventen 1612 gedacht wird. Eine zu zarischen wie sowjetischen Zeiten aus unterschiedlichen Gründen nur halbherzig gefeierte weitere erfolgreiche militärische Beendigung einer feindlichen Intervention ist damit geschichtspolitisch beträchtlich aufgewertet. Stützpfeiler des auf einem Unbesiegbarkeitsmythos beruhenden neuen russländische Gedenkkanons ist somit neben 1812 (Abb. 1) und 1945 jetzt auch 1612, nicht länger hingegen das Revolutionsjahr 1917 und noch nicht 2000, das Jahr des Beginns der ersten Präsidentschaft Vladimir Putins.

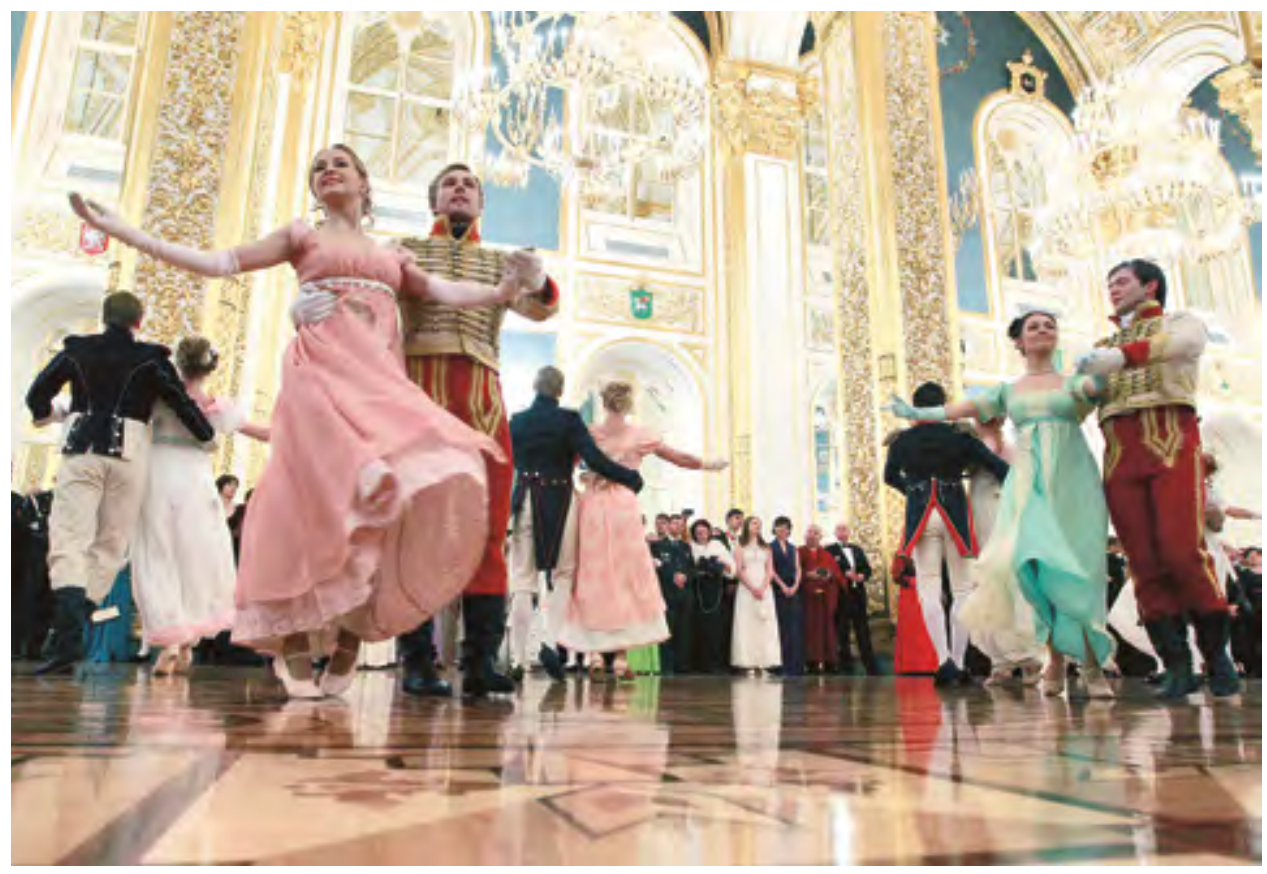

Abb. 1 Mit dem Vaterländischen Ball im Kreml (Moskau) wird in historischen Kostümen des 200. Jahrestages des Krieges von 1812 gedacht (C picture-alliance/dpa). 


\title{
Die bewaffnete Heldin 1813-1913-2013: Wahrnehmungen, Deutungen und Gedächtnis
}

\author{
Karsten Holste und Dietlind Hüchtker
}

Die Kombination „Waffen und Frauen“ ist immer wieder eine Schlagzeile wert. Im Januar 2013 gewann eine US-amerikanische Soldatin gegen das Verteidigungsministerium einen Prozess. Künftig dürfen Frauen an allen Kampfeinsätzen teilnehmen: „Ich habe darum gekämpft, gleichberechtigt behandelt zu werden, selber entscheiden zu dürfen“, wird die Soldatin im Magazin der „Süddeutschen Zeitung“ vom 11. Oktober 2013 unter dem Titel „Waffengleichheit“ zitiert. ${ }^{1}$ Was macht die bewaffnete Soldatin so interessant? Es geht offenbar um das Aufbrechen einer tradierten und hierarchischen Geschlechterordnung, um Gleichberechtigung und die Aneignung von Bereichen, die als althergebrachtes Refugium von Männlichkeit gelten: Militär und Waffen. Es geht auch um Souveränität. Mit dem Recht auf eigenständige Entscheidung über die Teilnahme an Kampfeinsätzen beansprucht die US-amerikanische Soldatin die Position eines souveränen Subjekts, das gegen seinen Willen weder geschützt noch verteidigt werden soll. Allerdings bleibt ihre Entscheidung über die Teilnahme an Kampfeinsätzen ein Privileg, das Soldaten meist nicht haben. Solange Frauen freiwillig kämpfen, würde dies daher nicht Geschlechtergleichheit bedeuten. Es geht also um mehr als um eine lang andauernde Emanzipationsgeschichte. Es geht auch um den Zusammenhang von Krieg und Souveränität, um die Ordnung einer Gesellschaft in Krieg und Frieden. Der zitierte Zeitungsartikel suggeriert darüber hinaus, dass die Kombination „Frauen und Waffen“ etwas Exzeptionelles sei, ein außergewöhnlicher, letzter Schritt der Gleichberechtigung oder unausgesprochen der implizite Beweis ihrer Unmöglichkeit - was schon allein der ironische Titel „Waffengleichheit“" nahelegt. ${ }^{2}$

Die Spannung zwischen bewaffneten Kämpferinnen als Besonderheit und als Normalität tritt noch deutlicher in Berichten über militärische Formationen im Nahen Osten hervor. Die Frauenverbände der kurdischen „Volksverteidigungseinheiten“ werden als Zeichen des Wandels dessen gesehen, was als Normalität der Geschlechterordnung in nahöstlichen Gesellschaften gilt. ${ }^{3}$ Wenn dagegen Frauen in der al-Kaida nahestehenden

1 Baumann, Marc: Waffengleichheit. In: Magazin der Süddeutschen Zeitung, 11.10.2013, S. 66. Besonders danken möchten wir Iwona Dadej (Berlin), die uns viele Hinweise gab und Material zur Verfügung stellte.

2 Unter dem Titel „Waffengleichheit“ sind auch andere Artikel über Frauen im Militär erschienen, beispielsweise als Frauen in die Bundeswehr aufgenommen wurden. S.: Waffengleichheit für Frauen. In. faz.net, 29.12.2000: http://www.faz.net/aktuell/politik/bundeswehr-waffengleichheit-fuer-frauen127654.html (07.01.2015).

3 Hermann, Rainer: Zwischen Front und Frauenrechten. In: faz.net, 21.11.2014. http://www.faz. net/aktuell/politik/ausland/naher-osten/widerstand-der-syrischen-kurden-gegen-islamischenstaat-13268000.html (18.01.2015); NordHausen, Frank: Kurden in Syrien. Die Frau, die Al-Kaida das 
al-Nusra-Front und in den Einheiten des sogenannten Islamischen Staates am bewaffneten Kampf teilnehmen, so wird dies meist mit der exzeptionellen Bedeutung des Konfliktes begründet. ${ }^{4}$

Obwohl es so scheint, als sei der Schritt zur „Waffengleichheit“ eine aktuelle Errungenschaft, ist dies nicht der Fall. Bewaffnete Frauen hat es immer wieder gegeben, und sie wurden schon von den Zeitgenoss/innen diskutiert, sowohl als Exzeption als auch als Teil einer Geschichte, die Gleichberechtigung als einen fortschreitenden Prozess der Aneignung von männlich konnotierten Räumen versteht. Schon die Kriege zu Beginn des 19. und zu Beginn des 20. Jahrhunderts markierten Zeitfelder, in denen Debatten über militärische Mobilisierung mit Debatten über Geschlechterordnungen und ihre (zeitweise) Auflösung einhergingen. Diskutiert wurden nicht nur Familien- und Hausarbeit, Wahlrecht und Bildung, sondern auch die Beteiligung der Geschlechter am Krieg sowie der Zusammenhang von Waffen und Staatsbürgerschaft. Die Aufstände im geteilten Polen und der antinapoleonische Befreiungskrieg in Preußen, wahrgenommen als außergewöhnliche Herausforderungen, mobilisierten Frauen, die nicht nur Gaze zupften, Söhne und Männer in den Krieg schickten oder Verwundete pflegten, sondern auch zur Waffe griffen, zum Teil offen als Frauen, zum Teil als Männer verkleidet. Im Ersten Weltkrieg kämpften polnische Frauen in den „Polnischen Legionen“(Legiony Polskie) und engagierten sich bei der Verteidigung und Sicherung der Front.

Von Karen Hagemann und Helen Watanabe-O'Kelly ist eingehend untersucht worden, wie die neue nationale Mobilisierung während der antinapoleonischen Kriege Preußens Frauen zwar aufgrund der Ausnahmesituation Möglichkeiten zur Beteiligung am Kampf eröffnete, gleichzeitig aber die Konstruktion von als normal geltenden dichotomen Geschlechterräumen, den separate spheres, vorantrieb. ${ }^{5}$ In der polnischen Nationalgeschichte nahmen bewaffnete „Heldinnen“ immer einen wichtigen Platz ein. Dies könnte so gedeutet werden, dass die als Ausnahme wahrgenommene Situation des unter den Nachbarmächten aufgeteilten Polens eine als außergewöhnlich angesehene Mobilisierung von Frauen dauerhaft gerechtfertigt hätte. Entsprechend sahen die dortigen Frauenbewegungen in der Beteiligung an Aufständen eine Legitimation für ihre

Fürchten lehrt. In: fr-online.de, 28.2.2014. http://www.fr-online.de/syrien/kurden-in-syrien--die-frau-die-al-kaida-das-fuerchten-lehrt-,24136514,26418628.html (18.01.2015).

4 StRYJAK, Jürgen: Frauen für den „Heiligen Krieg“. tagesschau.de, 08.11.2014. In: http://www.tagesschau.de/ausland/dschihadistinnen-101.html (18.01.2015); ABouzeID, Rania: Syrian Al-Qaeda Women: Searching for Combat, Martyrdom on the Front Lines. In: america.aljazeera.com, 20.7.2014. http:// america.aljazeera.com/articles/2014/7/20/syrian-women-qaedarebels.html (18.01.2015).

5 Hagemann, Karen: Heldenmütter, Kriegerbräute und Amazonen. Entwürfe patriotischer Weiblichkeit zur Zeit der Befreiungskriege. In: Militär und Gesellschaft im 19. und 20. Jahrhundert. Hg. v. Ute Frevert. Stuttgart 1997 (Industrielle Welt 58), S. 174-200; Watanabe-O'Kelly, Helen: Beauty or Beast? The Woman Warrior in the German Imagination from the Renaissance to the Present. Oxford 2010, S. 156-177; Hagemann, Karen: „Mannlicher Muth und Teutsche Ehre“. Nation, Militär und Geschlecht zur Zeit der Antinapoleonischen Kriege Preußens. Paderborn 2002 (Krieg in der Geschichte 8), S. 304-393; Dies.: „Heroic Virgins“ and „Bellicose Amazons“: Armed Women, the Gender Order and the German Public During and After the Anti-Napoleonic Wars. In: European History Quarterly 37 (2007), S. 507-527. 
Forderung nach Gleichberechtigung und damit nach einem Aufbrechen der tradierten Geschlechterordnung. Das Ziel der polnischen Aufstände im 19. Jahrhundert und der Aufstellung polnischer Legionen im Ersten Weltkrieg war es jedoch, einen „normalen“ Staat mit regulärer Armee zu schaffen, was zugleich eine Reetablierung dessen erwarten lassen würde, was als normale Geschlechterordnung galt. Doch was als normal und was als außergewöhnlich angesehen wurde, hatte sich inzwischen gewandelt, und die Einführung des Frauenwahlrechts bei Wiedergründung des polnischen Staats nach dem Krieg wurde - wie vielfach von der geschlechtergeschichtlichen Forschung festgestellt als Herstellung von Normalität und nicht als Umwälzung der Geschlechterordnung wahrgenommen. ${ }^{6}$

Im Folgenden werden wir einige Überlegungen zu bewaffneten Frauen in Preußen und Polen vom Anfang des 19. bis zum Anfang des 20. Jahrhunderts anstellen. Wir beginnen mit einem Blick auf das für die militärische Beteiligung der Bevölkerung Preußens prägende Jahr der Völkerschlacht 1813 und auf die Erinnerungen an die für Preußen bewaffnet kämpfenden Frauen. Dieser Einstieg erlaubt es, anschließend das polnische nationalgeschichtliche Narrativ mit dem preußisch-deutschen abzugleichen. Auch hinsichtlich des bewaffneten Engagements polnischer Frauen und dessen Erinnerung werfen wir zunächst einen Blick auf die Napoleonischen Kriege, gehen dann auf die Aufstände im 19. Jahrhundert ein und stellen ausführlicher die paramilitärischen und militärischen Organisationen kurz vor und während des Ersten Weltkriegs dar. Am Beispiel der polnischen Geschichte diskutieren wir Erinnerung und Gedächtnis an Frauen in bewaffneten Auseinandersetzungen. Dabei geht es uns um die Beziehungen zwischen sich verändernden Geschlechterkonzeptionen und sich verändernden Vorstellungen von gesellschaftlicher Normalität und Ausnahme - der einleitende Ausflug in die Gegenwart zeigt, dass das Thema weiterhin Bedeutung hat. Die „Entdeckung“ der Frau mit Waffe, die bereits vielfach entdeckt und gebührend in der Forschung gewürdigt worden ist, ist dagegen nicht unser Fokus. ${ }^{7}$

Unsere These ist, dass bewaffnete Frauen die Ausnahme des Krieges und des bewaffneten Aufstands symbolisierten und damit auch eine Ausnahme für die Geschlechterordnung. Sie waren weniger ein Zeichen für deren Aufweichung, sondern bestätigten vielmehr ihre Bedeutung für die Ordnung der Gesellschaft.

6 S. z.B. Rouette, Susanne: Sozialpolitik als Geschlechterpolitik. Die Regulierung der Frauenarbeit nach dem Ersten Weltkrieg. Frankfurt/M.-New York 1993 (Geschichte und Geschlechter 6).

7 A Soldier and a Woman. Sexual Integration in the Military. Hg. v. Gerard J. DeGroot und Corinna Peniston-Bird. Harlow 2000 (Women and Men in History); Goldstein, Joshua S.: War and Gender. How Gender Shapes the War System and Vice Versa. Cambridge 2001; Soldatinnen. Gewalt und Geschlecht im Krieg vom Mittelalter bis heute. Hg. v. Klaus Latzel, Franka Maubach und Silke SatJukow. Paderborn 2011 (Krieg in der Geschichte 60); Waffenschwestern. Hg. v. Dagmar ElLERBRock und Ulrike WECKEL. 


\section{Nach 1813: „Heldenjungfrauen" und Soldatinnen in Preußen und Polen. Ein- und Ausblendungen im nationalen Gedächtnis}

In den Armeen der Frühen Neuzeit waren - in Männerkleidung - kämpfende Frauen zwar keine Einzelfälle, aber doch Ausnahmen. Und gerade als Ausnahmen, die militärische Ausnahmesituationen unterstrichen, wurde ihnen besondere Bedeutung zugemessen. ${ }^{8}$ Bei sozialen Protesten und Aufständen war die Beteiligung von Frauen hingegen Normalität, ${ }^{9}$ sie repräsentierte die Normalität der Ausnahmesituation. Für die Einbeziehung von Frauen in die sich im Kontext von Protest und Aufstand neu formierenden Armeen des Revolutionszeitalters sprach die Logik des fortgesetzten Ausnahmehandelns. Sie schlug sich in den intensiven Debatten der ersten Jahre des revolutionären Frankreichs um ihre Aufnahme in die Streitkräfte nieder, die mit ihrem Ausschluss aus der neu geordneten Wehrpflichtarmee endeten. ${ }^{10}$ Dieselbe Entwicklung zeigte sich bei der Beteiligung von Frauen an der Freiwilligenbewegung von 1813 in Preußen.

Die neuere Forschung betont, dass die Auseinandersetzungen des Jahres 1813 vor allem von regulären Truppen ausgetragen wurden. ${ }^{11}$ Aber unbestreitbar fand der Krieg in größeren Teilen der preußischen Gesellschaft starke Unterstützung, die sich in einer hohen Spendenbereitschaft sowie einer verhältnismäßig hohen Zahl von Freiwilligen niederschlug und so die aggressive Kriegführung Preußens ermöglichte. ${ }^{12}$ In der Bewegung zur Unterstützung der Kriegsbemühungen waren in großem Ausmaß Frauen aktiv, vor allem bei der Organisation von Spenden und in der Krankenpflege. ${ }^{13}$ Ihre Bemü-

8 CRIM, Brian: Silent Partners: Women and Warfare in Early Modern Europe. In: A Soldier and a Woman (wie Anm. 7), S. 18-32; Füssel, Marian: Frauen in der Schlacht? Weibliche Soldaten im 17. und 18. Jahrhundert zwischen Dissimulation und Sensation. In: Soldatinnen (wie Anm. 7), S. 159-178; LyNN II, John A.: Essential Women, Necessary Wives, and Exemplary Soldiers. The Military Reality and Cultural Representation of Women's Military Participation (1600-1815). In: A Companion to Women's Military History. Hg. v. Barton C. Hacker und Margaret Vining. Leiden 2012 (History of Warfare 74), S. 93-136.

9 Farge, Arlette: Frauen im Aufstand. In: Geschichte der Frauen. Hg. v. Georges Duby und Michelle Perrot. Bd. 3: Frühe Neuzeit. Hg. v. Arlette Farge und Natalie Zemon Davis. Frankfurt/M. 1994, S. 507-524; Ulbrich, Claudia: Frauen im Aufstand. Möglichkeiten und Grenzen ihrer Partizipation in frühneuzeitlichen Bauernbewegungen. In: Schlaglichter Preußen - Westeuropa. Festschrift für Ilja Mieck zum 65. Geburtstag. Hg. v. Ursula Fuhrich-Grubert und Angelus H. Johansen. Berlin 1997 (Berliner historische Studien 25), S. 335-348.

10 Harten, Elke/Harten, Hans-Christian: Frauen - Kultur - Revolution 1789-1799. Pfaffenweiler 1988 (Frauen in Geschichte und Gesellschaft 3), S. 23-28; OpITz, Claudia: Aufklärung der Geschlechter, Revolution der Geschlechterordnung. Studien zur Politik- und Kulturgeschichte des 18. Jahrhunderts. Münster-New York 2002, S. 173-191.

11 Bleyer, Alexandra: Auf gegen Napoleon! Mythos Volkskriege. Darmstadt 2013.

12 Ibbeken, Rudolf: Preußen, 1807-1813. Staat und Volk als Idee und in Wirklichkeit. Köln 1970 (Veröffentlichungen aus den Archiven Preußischer Kulturbesitz 5), S. 398-429; LegGiere, Michael V.: Napoleon and Berlin. The Franco-Prussian War in North Germany 1813. Norman 2002 (Campaigns and Commanders 1), S. 291-296.

13 Hagemann, Heldenmütter (wie Anm. 5), S. 192-195; Dies., „Mannlicher Muth“ (wie Anm. 5), S. 374-383 und 416-427. 
hungen, sich auch direkt an den militärischen Auseinandersetzungen zu beteiligen, stellten die Militärbehörden vor das Problem, wie mit diesem Engagement umzugehen sei. Am Ende wurden die sich zahlreich freiwillig meldenden Frauen - wie 20 Jahre zuvor in der Französischen Revolution - zurückgewiesen. Nur einigen gelang es mitzukämpfen, indem sie ihr Geschlecht verbargen. ${ }^{14}$

$\mathrm{Zu}$ den bewaffnet Kämpfenden zählten Eleonore Prochaska und Frederike Krüger, die beide jenen kleinbürgerlichen Schichten entstammten, die den größten Teil der Freiwilligen stellten. ${ }^{15}$ Prochaska wurde relativ rasch, nachdem sie einer Freiwilligeneinheit beigetreten war, schwer verwundet und erst kurz, bevor sie starb, von dem sie behandelnden Arzt als Frau erkannt. Frederike Krüger hatte sich hingegen als August Lübeck vor Bekanntwerden ihres Geschlechts im Kampf derart ausgezeichnet, dass ihr Verbleib bei der Armee bis Kriegsende geduldet wurde. Im Verlauf des Krieges wurde sie zum Unteroffizier befördert und sowohl mit dem Eisernen Kreuz als auch mit dem russischen St.-Georgs-Orden ausgezeichnet. Nach dem Krieg ehrenvoll verabschiedet, ging sie eine Ehe mit einem Unteroffizier ein. ${ }^{16}$

Insgesamt ließ nach Ende der militärischen Auseinandersetzungen das Interesse an der während des Krieges intensiv diskutierten Beteiligung von Frauen rasch nach. ${ }^{17}$ Dies lässt sich nicht zuletzt auf die sich durchsetzende Deutung des Krieges als Befreiungsund nicht als Freiheitskrieg zurückführen: Gerade die (Wieder-)Herstellung von Ordnung, nicht der Bruch mit ihr, trat im Zuge der diskursiven Demobilisierung der Gesellschaft in den Mittelpunkt der offiziellen Erzählung. ${ }^{18}$ Die dem restaurativen Bestreben um Einhegung der Kriegserinnerung entgegengesetzte, zunächst oppositionelle liberale und nationale Traditionsbildung bot Anknüpfungspunkte für die weibliche Beteiligung an Wohltätigkeits- und Unterstützungsvereinen, entwarf aber zugleich ein neues, auf den Kriegsdienst bezogenes nationales Männlichkeitsbild. Aus diesem Grunde ließ sie wenig

14 Hagemann, „Heroic Virgins“ (wie Anm. 5), S. 520 f.; Dies., „Mannlicher Muth“ (wie Anm. 5), S. $383 \mathrm{f}$.

15 Dies., „Heroic Virgins“ (wie Anm. 5), S. 514. Zur sozialen Zusammensetzung der Freiwilligen vgl. IBBEKEN (wie Anm. 12), S. 405-410.

16 Hagemann, „Mannlicher Muth“ (wie Anm. 5), S. 384-386; Dies., „Heroic Virgins“ (wie Anm. 5), S. 515 f.; RAuchfuss, Thoralf: „Doch ich müsste mich schämen, ein Mann zu heißen ...“. Über verkleidete Kämpferinnen der Befreiungskriege. In: Blutige Romantik. 200 Jahre Befreiungskriege Essays. Ausst.-Kat. Militärhistorisches Museum Dresden. Hg. v. Gerhard BAuER, Gorch Pieken und Matthias Rogg. Dresden 2013, S. 148-155.

17 Hagemann, „Mannlicher Muth“ (wie Anm. 5), S. 386 und 426.

18 Zur Diskussion nach 1815 siehe Clark, Christopher M.: The Wars of Liberation in Prussian Memory: Reflections on the Memorialization of War in Early Nineteenth-Century Germany. In: Journal of Modern History 68 (1996), S. 550-576. Zur Entstehung der Begriffsgegenüberstellung BERDING, Helmut: Freiheitskriege. In: Sowjetsystem und demokratische Gesellschaft. Eine vergleichende Enzyklopädie. Hg. v. Claus D. Kernig. Bd. 2. Freiburg 1968, Sp. 681-693, hier Sp. 685 f. Franz Schnabel verweist darauf, dass der preußische König Friedrich Wilhelm III. angeordnet habe, in der Geschichtsschreibung den Begriff Befreiungs- statt Freiheitskrieg zu benutzen, datiert und belegt diese Äußerung allerdings nicht. Schnabel, Franz: Deutsche Geschichte im neunzehnten Jahrhundert. Bd. 2: Monarchie und Volkssouveränität. Freiburg 1933, S. 216 mit Anm. auf S. 394; vgl. auch HagemanN, „Mannlicher Muth“ (wie Anm. 5), S. 427. 
Raum für eine Heraushebung der bewaffnet kämpfenden Frauen. Die national-patriotisch legitimierte Kriegführung hatte zwar, wie Karen Hagemann konstatiert, für Frauen und Männer neue Handlungsfelder eröffnet, zugleich aber einen Geschlechterrollendiskurs ermöglicht, der Frauen außerhalb der Sphäre von Öffentlichkeit, Politik und Militär verortete. ${ }^{19}$ Daran änderte auch die politische und militärische Beteiligung von Frauen während der Revolution von 1848/49 wenig. ${ }^{20}$

Eine Ausnahme bildete die Erinnerung an die 1813 jung gefallene Eleonore Prochaska. Deren Andenken wurde das ganze 19. Jahrhundert hindurch aufrechterhalten als Ansporn für die männliche Jugend und als Zeichen für die Besonderheit der „nationalen Erhebung “. ${ }^{21}$ Nach dem Zweiten Weltkrieg kam allerdings die Erinnerung an Prochaska wie an den weiblichen Anteil bei der gesellschaftlichen Mobilisierung von 1813 überhaupt weitgehend zum Erliegen und setzte erst in den letzten Jahrzehnten wieder ein. ${ }^{22}$ Dies ist möglicherweise im Kontext zu der nach 1945 in der deutschen Öffentlichkeit zunächst vorherrschenden Verdrängung weiblicher Beteiligung an Gewalt und Verbrechen während der Weltkriege zu sehen. ${ }^{23}$

Das polnische nationalgeschichtliche Narrativ setzte für die militärischen Auseinandersetzungen des 19. Jahrhunderts andere Schwerpunkte als das preußisch-deutsche. Die Verflechtungen von adligem Selbstverständnis, nationaler Organisation und revolutionärer Projektion bildeten die Grundlage für die Vorstellung einer Kontinuität des nationalen Befreiungskampfes seit dem 18. Jahrhundert. ${ }^{24}$ Eine entscheidende Rolle einzelner Frauen bei kriegerischen Ereignissen wurde bereits im frühneuzeitlichen Polen-Litauen überliefert, ${ }^{25}$ aber erst die Auseinandersetzungen von 1792 um die Ver-

19 Ebd., S. 427; Dies., Heldenmütter (wie Anm. 5), S. 200.

20 Hauch, Gabriella: „Bewaffnete Weiber“. Kämpfende Frauen in der Revolution 1848/49. In: Landsknechte, Soldatenfrauen und Nationalkrieger. Militär, Krieg und Geschlechterordnung im historischen Wandel. Hg. v. Karen Hagemann und Ralf Pröve. Frankfurt/M.-New York 1998 (Geschichte und Geschlechter 26), S. 223-246; TACKE, Charlotte: Geschlecht und Nation. In: Geschlecht und Nationalismus in Mittel- und Osteuropa 1848-1918. Hg. v. Sophia KemLeIN. Osnabrück 2000 (Einzelveröffentlichungen des Deutschen Historischen Instituts Warschau 4), S. 15-32, hier S. 26 f.; ElLERBRock, Dagmar: Warum Germania bewaffnet war und trotzdem nicht wählen durfte. Zur Geschlechterkonstruktion des politischen Waffendiskurses im 19. Jahrhundert. In: Waffenschwestern (wie Anm. 7), S. 31-54.

21 Watanabe-O’Kelly (wie Anm. 5), S. 156-177; Rauchfuss (wie Anm. 16), S. 154 f.

22 Hagemann, Heldenmütter (wie Anm. 5), S. 174-176.

23 Zur Erinnerung an die Weltkriege Hagemann, Karen: „Jede Kraft wird gebraucht“. Militäreinsatz von Frauen im Ersten und Zweiten Weltkrieg. In: Erster Weltkrieg - Zweiter Weltkrieg. Ein Vergleich. Krieg, Kriegserlebnis, Kriegserfahrung in Deutschland. Hg. v. Bruno Thoss und Hans-Erich VolKmann. Paderborn 2002, S. 79-106, hier S. 103-106; Latzel, Klaus/Maubach, Franka/Satjukow, Silke: Soldatinnen in der Geschichte: Weibliche Verletzungsmacht als Herausforderung. In: Soldatinnen (wie Anm. 7), S. 11-49, hier S. 40.

24 MülleR, Michael G.: Deutsche und polnische Nation im Vormärz. In: Polen und die polnische Frage in der Geschichte der Hohenzollernmonarchie 1701-1871. Hg. v. Klaus Zernack. Berlin 1982, S. 69-95.

25 Bogucka, Maria: Gender in the Economy of a Traditional Agrarian Society: The Case of Poland in the XVI $^{\text {th }}-X V I^{\text {th }}$ Centuries. In: Dies.: Baltic Commerce and Urban Society, 1500-1700. Gdańsk/Danzig and Its Polish Context. Aldershot 2003 (Variorum Collected Studies Series 760), S. 5-19, hier S. 9. 
teidigung der Verfassungsgesetze des Vorjahres und der Kościuszko-Aufstand von 1794 gingen mit einem öffentlichen, organisierten und als bedeutend erinnerten Engagement von Frauen einher. Im Vordergrund standen vor allem Spendensammlungen und moralische Unterstützung, seltener Lazarettdienst. Daneben gibt es einige Hinweise auf direkt an Kampfhandlungen beteiligte Frauen, die jedoch nicht traditionsbildend wirkten. ${ }^{26}$

Auch für das polnische Militär ist erst für die Napoleonischen Kriege eine offiziell als Soldatin anerkannte und für Tapferkeit ausgezeichnete Frau durch eine Vielzahl von Quellen belegt. ${ }^{27}$ Joanna Żubrowa, häufig ohne die weibliche Namensendung nur Żubr genannt, trat 1807 als Volontär der Armee des Herzogtums Warschau bei. Sie hatte zunächst ihren Ehemann, der sich wie viele junge polnische Adelige für den großpolnischen Aufstand sowie die sich neu formierenden polnischen Streitkräfte begeisterte, aus dem russischen Teilungsgebiet nach Warschau begleitet. Nachdem dieser sich der Armee angeschlossen und sie mittellos zurückgelassen hatte, meldete sie sich bei derselben Einheit als sein Bruder. Aufgrund ihrer Beteiligung bei der Erstürmung von Zamość 1809 wurde Żubrowa der militärische Verdienstorden Virtuti Militari zugesprochen. Die Ordensverleihung erfolgte jedoch nicht, da ihr Geschlecht bekannt wurde. Sie wechselte gemeinsam mit ihrem zum Offizier beförderten Mann zu einer anderen Einheit, in der ihr gestattet wurde, offiziell als Frau ihren Dienst als Soldat fortzusetzen. Wenig später wurde sie zum für Verpflegung zuständigen Unteroffizier befördert. Während des Russlandfeldzuges 1812 wurde Żubrowa als Marketenderin eingesetzt, behielt aber ihren militärischen Rang und zeichnete sich durch eigenmächtiges Eingreifen erneut im Kampf aus. Es folgte ihre Beförderung in einen höheren Unteroffiziersrang und die nachgeholte Verleihung des militärischen Verdienstkreuzes. Im Frühjahr 1813 geriet sie bei der Verteidigung von Częstochowa in Gefangenschaft. ${ }^{28}$

Die Erinnerungen Joanna Żubrowas, von denen leider nur der erste Teil überliefert ist, ${ }^{29}$ geben einige Einblicke in ihre schwierige Position bei der kämpfenden Einheit. So klagt sie einerseits darüber, dass ihre Beförderung lange ausgeblieben sei, während weit weniger erfahrene und gebildete Männer Karriere gemacht hätten, rechtfertigt diese Ungleichbehandlung gleichzeitig aber dennoch, indem sie die gute Arbeit der Beförderten als Ausbilder der jungen Rekruten betont. ${ }^{30}$ Besonders eindrücklich ist eine Episode, die angesichts der zumindest inoffiziell weiter üblichen Leibesstrafen für

Wawrzykowska-Wierciochowa, Dionizja: Rycerki i samarytanki [Ritterinnen und Samaritinnen]. Warszawa 1988, S. 24-139.

26 Kleinmann, Yvonne: Die Verfassung vom 3. Mai 1791 - Inhalt, Kontroversen, nationale und internationale Bedeutung. In: Polen in der europäischen Geschichte. Ein Handbuch in vier Bänden. Hg. v. Michael G. MülLer. Bd. 2: Frühe Neuzeit. Hg. v. Hans-Jürgen Bömelburg. Stuttgart 2011, S. 567605, hier S. 551-554; WaWrZYKowska-Wierciochowa (wie Anm. 25), S. 140-193.

27 Vgl. ebd., S. $223 \mathrm{f}$.

28 Zur Biografie vgl. ebd., S. 225-263.

29 Żubrowa, Joanna: Pamiętnik Joanny Żubr [Die Erinnerungen von Joanna Żubr]. In: Księga Świata 9 (1860), Bd. 2, S. 195-199. Die angekündigte Fortsetzung der nur bis 1809 reichenden Erinnerungen ist offensichtlich nie erschienen. Vgl. Wawrzy ówSKa-Wierciochowa (wie Anm. 25), S. 262.

30 Żubrowa (wie Anm. 29), S. 199. 
Mannschaftsdienstgrade auf den Konflikt zwischen ständischen Ehrvorstellungen und dem Militärdienst einer adligen Frau unterhalb des Offiziersranges verweist. ${ }^{31}$ Nachdem Żubrowa, durch ein Gespräch aufgehalten, die Lebensmittel- und Unterkunftsorganisation ihrer Einheit vernachlässigt hatte, ,begannen die durchnässten Soldaten [...] zu murren: ,wenn dies jemand anderes getan hätte, wüssten wir, was mit ihm geschehen würde, aber es ist die Ehefrau, das ist immer unser Elend“"32. Als kommandierender Offizier drohte Żubrowas Mann ihr daraufhin Prügel an und musste von den Unteroffizieren beruhigt werden. Żubrowa notierte: ,[E]inige Tage konnte ich den Kopf nicht bewegen, da er mir den Hals verdreht hatte. “33

Den zeitgenössischen Bekanntheitsgrad von Joanna Żubrowa verdeutlichen die ihr 1817 durch den polnische König und russländischen Zaren Alexander I. verliehene Ehrenpension, ihr öffentlicher Aufruf an die polnischen Frauen zur Beteiligung am Novemberaufstand 1830 und der 1852 in der viel gelesenen Krakauer Zeitung Czas (Die Zeit) gedruckte Nekrolog. ${ }^{34}$ In der zweiten Jahrhunderthälfte wurde ihre Geschichte allerdings weitgehend vergessen, bis sie von Włacław Gąsiorowski 1902 literarisch verarbeitet wurde. Die fiktive Marketenderin Joanna Żubr des sowohl im Original als auch in einer Bearbeitung als Jugendbuch vielfach aufgelegten Romans Huragan (Hurrikan) ${ }^{35}$, die die polnischen Legionen bei ihren Kämpfen in Italien und Spanien begleitete, überlagert bis heute die historische Soldatin, wie unter anderem die Diskussion um ein Straßenschild in Łódź zeigt, das nur auf die Marketenderin hinweist. ${ }^{36}$

Zum Sinnbild der mit der Waffe in der Hand für die polnische Unabhängigkeit kämpfenden Frau wurde nicht die öffentlich als Unteroffizierin ausgezeichnete Żubr(owa), sondern die Gräfin Emilia Plater, die sich am Novemberaufstand ohne militärischen

$31 \mathrm{Zu}$ Diskussionen in der preußischen Armee vor 1800 über den Vollzug von Leibesstrafen bei Soldaten, die sich als Frauen herausstellten, vgl. Füssel (wie Anm. 8), S. 168.

32 Żubrowa (wie Anm. 29), S. 199: „Żolnierze zmoczeni [...] zaczęli ze sobą szemrać: ,żeby to kto inny zrobił, to wiemy jakby mu było, ależe to żona, to zawsze nam bieda‘."

33 ,[J]a parę dni głowę nie mogłam ruszyć, bo mi karku nakręcił.“ Ebd.

34 Wawrzykowska-Wierciochowa (wie Anm. 25), S. 251, 255-257 und 262. Vgl. auch Czas. Nr. 205, 7.9.1852, S. 3: „W liczbie ofiar epidemii, w czasie grasowania jéj w m. Wieluniu, zabraną także została i śp. Joanna Żubr, niegdy sierżant 17 go pułku piechoty liniowéj b[yłego] w[ojska] p[olskiego] b[yłego] Księstwa Warszawskiego, a następnie wdowa pod nadleśnym, znana powszechnie z otrzymanego w r. 1809 krzyża wojskowego Virtuti militarii. [...] była jedyną z żyjących niewiast kraju naszego, którój pierś ozdabiał znak honorowy, jako dowód męztwa okazanego przez nią na polu sławy.” [,Zu den Opfern der in der Stadt Wieluń grassierenden Epidemie wurde auch Joanna Żubr, einst Unteroffizier des 17. Linienregiments der ehem. poln. Streitkräfte des ehem. Herzogtums Warschau, danach Försterwitwe, allgemein bekannt, da sie 1809 das Militärkreuz Virtutis militariis erhielt. [...S] ie war die einzige der lebenden Frauen unseres Landes, deren Brust ein Ehrenzeichen schmückte, als Beweis ihres Mutes, den sie auf dem Feld des Ruhms gezeigt hatte."]

35 Sclavus, Wiesław [Gąsiorowski, Wacław]: Huragan. Powieść historyczna [Hurrikan. Ein historischer Roman]. Lwów ${ }^{1} 1902$ (Warszawa ${ }^{7} 1936$, Neuausg. Warszawa 1959); Ders.: Huragan. Powieść historyczna z epoki napoleońskiej. W przeróbce dla młodzieży dokonanej przez autora [Hurrikan. Ein historischer Roman aus napoleonischer Zeit. Bearbeitet für die Jugend durch den Autor]. Warszawa ${ }^{1} 1904$ (Warszawa ${ }^{10} 1948$, Neuausg. 1955, Warszawa ${ }^{7} 1984$ ).

36 JAGIEŁŁo, Michał: Żubrowa, żona Żubra [Żubrowa, Ehefrau von Żubr]. 29.10.2008. In: http://lodz.wyborcza.pl/lodz/1,35153,5863847,Zubrowa_zona_Zubra.html (02.02.2016). 
Rang und offizielle Auszeichnungen beteiligte. Der Aufstand von 1830 und der anschließende, bis 1831 anhaltende Polnisch-Russische Krieg wurden wie bereits 1794 der Kościuszko-Aufstand von einer Unterstützungsbewegung unter massiver Beteiligung von Frauen begleitet. ${ }^{37}$ Der Übergang zu Kampfhandlungen war dabei im Kurierdienst, bei der Truppenversorgung und bei der Versorgung Verwundeter fließend. ${ }^{38}$ Józefa Kluczycka, die als Feldscher diente, wurde nach mehrfacher Verwundung als zweiter Frau nach Żubrowa das militärische Verdienstkreuz zuerkannt. ${ }^{39}$

Von mehr als zehn Frauen ist eine direkte Beteiligung an Kampfhandlungen im Dienst polnischer Einheiten bekannt, noch einmal so viele engagierten sich in den Partisaneneinheiten, die in Litauen aktiv waren, wobei der Eintritt in militärische Formationen teils aus patriotischer Begeisterung, teils aus Verlangen nach Rache für gefallene oder hingerichtete männliche Verwandte, teils aus konkreter Notlage erfolgte. Barbara Bronisława Czarnowska, die im Zuge ihres Dienstes die Beförderung zum Unteroffizier erreichte und als dritte Frau mit dem militärischen Verdienstkreuz ausgezeichnet wurde, kämpfte in der polnischen Kavallerie ebenso wie Waleria Dębicka und deren namentlich nicht bekannte Begleiterin offen als Frau. Die Mehrzahl der in reguläre Kampfeinheiten eintretenden Frauen diente hingegen bis zum Kriegsende in männlicher Kleidung und mit männlichem Namen. ${ }^{40}$

Unter den während des Novemberaufstandes bewaffnet kämpfenden Frauen nimmt Emilia Plater aufgrund ihrer aristokratischen Herkunft und der noch während des Kampfes einsetzenden Legendenbildung eine Sonderstellung ein. ${ }^{41}$ Sie hatte sich im März 1831 in Litauen zusammen mit den Bauern ihres Cousins dem Aufstand angeschlossen, wechselte im weiteren Verlauf mehrfach die Einheiten und verstarb, nachdem die Aufständischen Litauen verlassen hatten, im Dezember 1831 auf dem Weg nach Warschau ${ }^{42}$ Während ihre Anwesenheit bei den kämpfenden Einheiten und mehrfache erfolglose Versuche, sie zur Rückkehr zu bewegen, durch eine Vielzahl von Berichten

37 Vgl. allgemein BARAŃSKA, Anna: Kobiety w powstaniu listopadowym 1830-1831 [Frauen im Novemberaufstand von 1830-1831]. Lublin 1998 (Źródła i monografie/Towarzystwo Naukowe Katolickiego Uniwersytetu Lubelskiego 168). Zu einer der berühmtesten Organisatorinnen und Krankenpflegerinnen vgl. RezLer, Marek: Emilia Sczaniecka 1804-1896. Poznań 1996 (Biblioteka „Kroniki Wielkopolski“), S. 29-56.

38 Barańska (wie Anm. 37), S. 301 f. und 305-314.

39 PezdA, Janusz: Rostkowska Józefa (Józefina) 1. v. Kluczycka, pseud. Józef Kluczycki. In: Polski Słownik Biograficzny 32 (1989-1991), S. 157-159.

40 BARAŃsKa (wie Anm. 37), S. 293-302; eine neuere biografische Erzählung zu Barbara Czarnowska: NADOLSKI, Artur: Z szablą na Moskala. Barbara Czarnowska (1810-1891), żołnierz Powstania Listopadowego [Mit dem Säbel gegen den Moskowiter. Barbara Czarnowska (1810-1891), Soldat des Novemberaufstands]. Warszawa 2011.

41 Nachrichten über Emilia Plater führte die erwähnte Barbara Bronisława Czarnowska als einen Grund für ihren Eintritt in die polnische Kavallerie 1831 an. Vgl. BARAŃSKa (wie Anm. 37)., S. 293.

42 Kieniewicz, Stefan: Plater (Broel-Plater) Emilia (1806-1831). In: Polski Słownik Biograficzny 26 (1981), S. 652 f. Neuere biografische Darstellungen: WaWrZYKowsKa-Wierciochowa, Dionizja: Sercem i orężem ojczyźnie służyły. Emilia Plater i inne uczestniczki Powstania Listopadowego 1830 1831 [Mit Herz und Waffe dienten sie dem Vaterland. Emilia Plater und andere Teilnehmerinnen am Novemberaufstand 1830-1831]. Warszawa 1982; ŻARYN, Małgorzata: Emilia Plater. Warszawa 1989. 
belegt sind, ist das Ausmaß ihrer konkreten Kampfbeteiligung schwer einzuschätzen. ${ }^{43}$ Im Pariser Exil bauten Freunde und Verwandte ihre Geschichte zu einer Heldinnenlegende aus. Für den Aufstieg ihrer Figur zu einem zentralen Symbol der Hoffnung auf nationale Erneuerung sorgte endgültig das 1832 von Adam Mickiewicz verfasste, den Namen Platers aufgreifende Gedicht Śmierć putkownika (Der Tod des Obersts). ${ }^{44}$ Erst im Moment des Todes ihres im Kampf verwundeten, bis zuletzt die Massen begeisternden Kommandeurs erkennen die Untergebenen in ihm die Frau Emilia Plater. Mickiewicz hatte eine Möglichkeit gefunden, das Bild einer idealen Führungspersönlichkeit zu zeichnen, die sich grundlegend von der tatsächlichen, nach der Niederlage in der Kritik stehenden Führungsschicht des Aufstandes unterschied. ${ }^{45}$

Anders als die übrigen bekannten bewaffneten Aufstandsteilnehmerinnen zählte Plater zum engen Kreis der aristokratischen Gesellschaft, was es in der publizistischen Bearbeitung nahelegte, ihr die von der Aristokratie generell als angeboren beanspruchten Führungsfähigkeiten zuzusprechen. Gleichzeitig gehörte sie als Frau nicht zum tatsächlichen, hauptsächlich ebenfalls aristokratischen Führungspersonal, dem nach dem Aufstand vorgeworfen wurde, durch zu konventionelles und schulmäßiges Vorgehen militärisch und durch das Ausbleiben einer Mobilisierung der Bauern politisch versagt zu haben. Die trotz aller ihr widersprechenden Erfahrungen aufrechterhaltene Hoffnung der adlig-intellektuellen nationalen Bewegung, dass eine erfolgreiche patriotische Mobilisierung der ländlichen Bevölkerung möglich sei, und die ebenso aller Erfahrung widersprechende Erwartung, durch Enthusiasmus militärische Professionalität ausgleichen zu können, fanden ein Sinnbild in der sich für die nationale Erhebung begeisternden jungen Frau, die durch ihre Reden die Bauern mobilisierte und sich in kürzester Zeit zur militärischen Führerin entwickelte. Die Geschichte Emilia Platers wurde zum Teil der romantischen Deutung des Aufstandes. ${ }^{46}$

43 Zur kritischen Auseinandersetzung mit der Überlieferung vgl. BAchóRz, Józef: O Emilii Plater i Śmierci pułkownika. Narodziny i dzieje legendy [Über Emilia Plater und den Tod des Obersts. Geburtsstunde und Geschichte einer Legende]. In: Ders., Jak pachnie na Litwie Mickiewicza i inne studia o romantyzmie. Gdańsk 2003, S. 7-60 [frühere Fassung in: Zeszyty Naukowe Wydziału Humanistycznego Uniwersytetu Gdańskiego, Prace Historycznoliterackie 2 (1973), S. 17-54]. Die Überzeugungskraft von Bachórz' Argumentation wird allerdings beeinträchtigt durch seinen Versuch, hinter den Legenden eine „eigentliche“ Geschichte zu entdecken, die er durch den Verweis auf schlechte Heiratsaussichten der Gräfin sowie allgemeine Zweifel an der militärischen Leistungsfähigkeit von Frauen zu stärken meint. Ebd., S. 32-35; vgl. Filipowicz, Halina: The Daughters of Emilia Plater. In: Engendering Slavic Literatures. Hg. v. Pamela Chester und Sibelan Forrester. BloomingtonIndianapolis 1996, S. 34-58, hier S. $38 \mathrm{f}$.

44 Mickiewicz, Adam: Śmierć pułkownika [Der Tod des Obersts]. In: Ders., Dzieła. Bd. 1: Wiersze. Hg. v. Czesław ZGorzelski. Warszawa ${ }^{2} 1998$ [11979], S. 346 f.

45 Bachórz (wie Anm. 43), S. 54-60; Filipowicz (wie Anm. 43), S. 44.

46 Bachórz (wie Anm. 43), S. 12-15; Filipowicz (wie Anm. 43), S. 44; Barańska (wie Anm. 37), S. 302-304. Zur bis ins 20. Jahrhundert anhaltenden kaum überwindbaren kulturellen Differenz zwischen Bauern und polnischen Oberschichten vgl. Tomaszewski, Nikodem Bończa: Polskojęzyczni chłopi? Podstawowe problemy nowoczesnej historii chłopów polskich [Polnischsprachige Bauern? Grundprobleme der Geschichte der polnischen Bauern in der Neuzeit]. In: Kwartalnik Historyczny 112 (2005), S. 91-111. Zur Hoffnung auf eine Mobilisierung der Bauern vgl. KULAK, Teresa: Mit 
Die Figur wurde in der Folge - ähnlich wie die von Eleonore Prochaska in Preußen, jedoch mit unvergleichlich größerer Breitenwirkung - in Literatur und Historiografie vor allem als Vorbild für nationale Opferbereitschaft inszeniert, als Opferung der Weiblichkeit, nicht als weibliches Rollenmodell. ${ }^{47}$ Als Beleg für die generelle Fähigkeit von Frauen, sich in jeder Form politisch und militärisch zu beteiligen, wurde die Geschichte Emilia Platers 1845 hingegen in den Vereinigten Staaten von Margaret Fuller aufgegriffen und fand so Eingang in die Traditionsbildung der dortigen Frauenbewegung. ${ }^{48}$ Die in der polnischen literarischen und historiografischen Behandlung des Themas vorherrschende Einbindung von Platers Biografie in das Narrativ nationalen Opfers stand allerdings auch in Polen ihrer Verwendung als Berufungsinstanz für weibliches militärisches Engagement nicht grundsätzlich entgegen, was sich in der Namensgebung einer weiblichen Militäreinheit der in der Sowjetunion 1943 gebildeten polnischen Streitkräfte niederschlug. ${ }^{49}$

Am Januaraufstand im Königreich Polen 1863/64 beteiligte sich erneut eine große Zahl von Frauen. Dass deren Organisationen nun auch von der Aufstandsführung eine zentrale Bedeutung zugemessen wurde, schlug sich in ihrer Eingliederung in die Strukturen der Aufstandsverwaltung nieder, die allerdings mit der Unterordnung der beteiligten Frauen unter ausschließlich mit Männern besetzte Führungsgremien einherging. ${ }^{50}$ Die Aufnahme von Frauen in Kampfeinheiten - nicht jedoch ihre Beauftragung mit Kurier- und sonstigen Hilfsdiensten - wurde von der Aufstandsregierung im April 1863 ausdrücklich verboten, nachdem die aus der bekannten Adelsfamilie Rogaliński stammende, schwangere Marja Piotrowiczowa zusammen mit ihren Begleiterinnen im Februar bei einem Gefecht nahe Dobra gefallen war. ${ }^{51}$ Dennoch gelang einer Reihe von

narodowej siły polskiego ludu [Der Mythos von der nationalen Stärke des polnischen Volks]. In: Polskie mity polityczne XIX i XX wieku. Hg. v. Zofia SmYK. Wrocław 1994 (Polska myśl polityczna XIX i XX wieku 9), S. 153-166.

47 Filipowicz (wie Anm. 43), S. 39 f. und 45-53.

48 Ebd., S. $37 \mathrm{f}$.

49 Bachórz (wie Anm. 43), 7; Szmagaj, Bożena: Samodzielny Batalion Kobiecy i jego akta z lat 19431945 [Das Unabhängige Frauenbataillon und seine Akte aus den Jahren 1943-1945]. In: Biuletyn Wojskowej Służby Archiwalnej 10 (1980). http://archiwumcaw.wp.mil.pl/biuletyn/b10/b10_6.pdf (15.01.2015).

50 KuLAK, Teresa: Polityka powstańczego Rządu Narodowego wobec aktywności organizacyjnej kobiet w Królestwie Polskim w latach 1863-1864 [Die Politik des Nationalrats des Aufstands im Hinblick auf die Organisationsaktivitäten von Frauen im Königreich Polen in den Jahren 1863-1864]. In: Postawy i aktywność kobiet w czasie powstania styczniowego 1863-1864 (na tle polskich konspiracji i działalności powstańczej doby zaborowej). Hg. v. Ders., Joanna Dufrat und Monika PiotrowskaMarchewa. Wrocław 2013, S. 57-86.

51 Bruchnalska, Marja: Ciche bohaterki. Udział kobiet w Powstaniu Styczniowym. Materjały [Stille Heldinnen. Die Beteiligung von Frauen am Januaraufstand. Materialien]. Miejsce Piastowe 1933, S. 236-241; KozŁowski, Eligiusz: Piotrowiczowa z Rogalińskich Maria (1839-1863). In: Polski Słownik Biograficzny 26 (1981), S. 454. Für den Hinweis danken wir Anna Barańska (Lublin). 
Frauen die Beteiligung am bewaffneten Kampf, ${ }^{52}$ von denen die als Adjutantin eingesetzte Anna Henryka Pustowójtówna den größten Bekanntheitsgrad erreichte. ${ }^{53}$

An den Beispielen aus dem 19. Jahrhundert - etwa der weitgehenden Reduktion der Rolle Żubrowas auf die einer Marketenderin, der Aufwertung der militärischen Verdienste Platers und der vergleichsweise geringen Beachtung von Frauen wie Barbara Bronisława Czarnowska - wird deutlich, dass die Traditionsbildung von bewaffneten Kämpferinnen weniger vom jeweiligen historischen Geschehen abhängig ist als vielmehr vom Kontext der Rahmennarrative über Ausnahme und Normalität: Für die gesamte polnische Aufstandsgeschichte des 19. Jahrhunderts lassen sich bekannte Frauengestalten aufzeigen, die sich bewaffnet an den militärischen Auseinandersetzungen beteiligt hatten und die zu verschiedenen Zeiten sowie in unterschiedlichem Ausmaß als Symbolfiguren des nationalen Widerstandes gegen die Teilung des Landes dienten. Dennoch bedeutete dies nicht, dass sich in der polnischen Gesellschaft mehr und mehr ein weibliches Rollenmodell der bewaffneten Kämpferin durchgesetzt hätte. Vielmehr blieb die Wahrnehmung der bewaffneten Frauen als Heldinnen an die Ausnahmesituation des Aufstandes gekoppelt und wurde nur in diesem Rahmen und als Sonderfall legitimiert. Wachsende Akzeptanz und Institutionalisierung erfuhren hingegen die zivilen Unterstützungsorganisationen von Frauen. ${ }^{54}$

\section{Um 1913: Polnische (para)militärische Fraueneinheiten, Patriotismus und Gleichberechtigung}

$\mathrm{Zu}$ Beginn des 20. Jahrhunderts gewannen Unabhängigkeitsbestrebungen und nationale Politik in allen drei Teilungsgebieten Polens an Bedeutung. ${ }^{55}$ Im Kontext der Zuspitzung der gesamteuropäischen Krisen während der letzten Jahre vor dem Ersten Weltkrieg ${ }^{56}$ führten Radikalisierung und Nationalisierung in den Teilungsgebieten zu einer Verengung der Politik auf den Kampf um Unabhängigkeit und zu einer Stär-

52 Kulak, Polityka (wie Anm. 50), S. 83 f.

53 Kieniewicz, Stefan: Pustowojtow (Pustowoitoff, Pustowójtowna) zamężna Loewenhardtowna Anna Henryka (1838-1881) [Pustowojtow (Pustowoitoff, Pustowójtowna), verheiratete Loewenhardtowna, Anna Henryka (1838-1881)]. In: Polski Słownik Biograficzny 29 (1986), S. 432-434. Eine belletristische Bearbeitung der Biografie: WawrzyKowska-Wierciochowa, Dionizja: Najdziwniejszy z adiutantów. Opowieść o Annie Henryce Pustowójtównie [Der außergewöhnlichste der Adjutanten. Eine Erzählung über Anna Henryka Pustowójtowna]. Warszawa 1968.

54 Vgl. BarańsKa, Anna: Wpływ powstań na ewolucję ról społecznych kobiet [Der Einfluss der Aufstände auf die Entwicklung der sozialen Rollen von Frauen]. In: Polskie powstania narodowe na tle przemian europejskich w XIX wieku. Hg. v. Ders., Witold MATwiEjczyk und Jan ZióŁek. Lublin 2001, S. 275-285.

55 Zur Zunahme des Nationalismus um 1900 siehe Porter, Brian: When Nationalism Began to Hate: Imagining Modern Politics in Nineteenth Century Poland. Oxford 2000, S. 219-227.

56 Hingewiesen werden muss an dieser Stelle auf CLARK, Christopher: Die Schlafwandler. Wie Europa in den Ersten Weltkrieg zog. München 2013 (engl. 2012). 
kung illegaler und paramilitärischer Organisationen. ${ }^{57} \mathrm{Zu}$ den wichtigsten Fraktionen gehörten die „Nationaldemokratie“ (Narodowa Demokracja, Endecja) unter Führung von Roman Dmowski, die staatliche Souveränität mit Unterstützung Russlands anstrebte, und die „Polnische Sozialistische Partei“ (Polska Partia Socjalistyczna, PPS) unter Józef Piłsudski, die auf eine Lösung der „Polnischen Frage“ durch ÖsterreichUngarn baute..$^{58}$ Die PPS ebenso wie die Endecja operierten im russischen Teilungsgebiet, ihre Basis aber hatten sie vor allem in Galizien mit seinen im Vergleich größeren Spielräumen zur politischen Betätigung. Dort bauten beide Fraktionen konspirative Organisationen mit paramilitärischen Einheiten auf. Die PPS gründete den „Verband des aktiven Kampfs“ (Związek Walki Czynnej), aus dem 1911 der „Schützenverband“ (Związek Strzelecki) unter Leitung von Piłsudski hervorging. Die Endecja bildete 1911 die „Polnische Schützenstaffel“ (Polskie Drużyny Strzeleckie) sowie die illegale „Polnische Armee“ (Armia Polska), ebenfalls eine militärisch operierende Organisation. Hinzu kamen paramilitärische Einheiten der „Polnischen Bauernpartei“ (Polskie Stronnictwo Ludowe). ${ }^{59}$

In der Hoffnung auf einen antirussischen Aufstand marschierte Piłsudski 1914 mit den Einheiten des Schützenverbandes in das russische Teilungsgebiet ein. Der Aufstand blieb aus, und die Einheiten wurden in die neu gegründeten und dem österreich-ungarischen Oberkommando unterstellten Polnischen Legionen integriert. ${ }^{60}$ Mit dem Namen knüpfte man an die Legionen an, die an der Seite Napoleons gekämpft hatten, und stellte sich in die romantische Tradition des Freiheitskampfs. ${ }^{61}$ In ihrer Mischung aus regulärer militärischer Einheit und Aufstandsarmee bezeugten die Legionen den Anspruch der polnischen Nationalbewegung auf einen eigenen Staat. Entsprechend wurde insbesondere die Erste Brigade unter dem Kommando von Piłsudski verehrt, auch wenn die konkrete Unterstützung gerade zu Beginn des Kriegs nicht groß war. ${ }^{62}$

An den geschilderten Aktivitäten zur Vorbereitung nationaler Unabhängigkeit beteiligten sich auch Frauen. 1913 gründete sich in Warschau die konspirative „Frauenliga zur Kriegsvorbereitung“" (Liga Kobiet Pogotowia Wojennego). Die Parallele in Lemberg, die „Frauenliga von Galizien und Schlesien“(Liga Kobiet Galicji i Śląska), wurde 1915 ins Leben gerufen, allerdings nicht als unabhängige Organisation, sondern auf Initiative

57 Dufrat, Joanna: Kobiety w kręgu lewicy niepodległościowej. Od Ligi Kobiet Pogotowia Wojennego do Ochotniczej Legii Kobiet (1908-1918/1919) [Frauen in den Kreisen der Unabhängigkeits-Linken. Von der „Frauenliga zur Kriegsvorbereitung“ bis zur „Freiwilligen Frauenlegion“ (1908-1918/1919]. Toruń 2001, S. 35.

58 Jaworski, Rudolf/LÜBke, Christian/Müller, Michael G.: Eine kleine Geschichte Polens. Frankfurt/M. 2000, S. $293 \mathrm{f}$.

59 Chwalba, Andrzej: Historia Polski 1795-1918 [Die Geschichte Polens 1795-1918]. Kraków 2001, S. $529 \mathrm{f}$.

601916 kämpften 1.000 Offiziere und ca. 20.000 Soldaten in den Legionen. HoEnsch, Jörg K.: Geschichte Polens, 2. neu bearb. und erw. Aufl. Stuttgart 1990 [11983], S. 238.

61 Stegmann, Natali: „Wie die Soldaten im Feld“: Der widersprüchliche Kampf polnischer Frauen für „Vaterland“ und Frauenrechte. In: Geschlecht und Nationalismus (wie Anm. 20), S. 197-216, hier S. 205.

62 Chwalba (wie Anm. 59), S. $571 \mathrm{f}$. 
des „Oberen Nationalrats“ (Naczelny Komitet Narodowy) ${ }^{63}$ der auf diese Weise die Frauenvereine und -aktivitäten zur Unterstützung der Polnischen Legionen bündeln wollte. ${ }^{64}$ Die Ligen organisierten Wohltätigkeitseinrichtungen, die sich um Soldaten und ihre Familien kümmerten, pflegten Verwundete und fühlten sich für eine nationale Erziehung verantwortlich. Auch bestanden Verbindungen zu den bildungspolitischen, pädagogischen und sozialreformerischen Projekten der Frauenbewegung und Frauenorganisationen - an der Spitze der Warschauer Liga stand beispielsweise Iza Moszczeńska, die in der Frauenbildungsbewegung aktiv war. ${ }^{65}$ Ziel der Ligen war die Mobilisierung von Frauen, die ihren Anteil an den Unabhängigkeitsaktivitäten leisten und sich in der romantischen Aufstandstradition verorten sollten. ${ }^{66}$ Der Akzent der Aktivitäten lag auf der Unterstützung von Krieg und Nation, ${ }^{67}$ während - wie Natali Stegmann betont Forderungen der Frauenbewegung zurückgestellt wurden. ${ }^{68} \mathrm{Im}$ Zuge der sich seit 1916 konkretisierenden Staatsgründung formierte sich die Frauenbewegung erneut. 1917 hielt sie in Warschau einen Kongress ab, der die Forderung nach Frauenwahlrecht wieder auf die Tagesordnung setzte und mit dem Engagement im Krieg und für die Nation begründete. ${ }^{69}$

Manchen der in nationalen Organisationen aktiven Frauen genügte es nicht, sich um Familien, Hinterbliebene und Verwundete zu kümmern. Ab 1910 bei den Polnischen Schützenstaffeln und ab 1912 auch im Schützenverband, der sich zunächst geweigert hatte, entstanden paramilitärische Frauenabteilungen - zunächst in Krakau und Lemberg. ${ }^{70}$ Insgesamt waren es einige Hundert meist junge Frauen ${ }^{71}$ vor allem der inteli-

63 Der Obere Nationalrat fungierte als Oberkommando der polnischen militärischen Aktivitäten in Österreich-Ungarn und beanspruchte eine nationale Vertretung entsprechend der austro-polnischen Idee. Dmowski gründete drei Monate später in Warschau ein Polnisches Nationalkomitee (Komitet Narodowy Polski), das die russisch-polnische Option repräsentierte. Beide Institutionen existierten den gesamten Krieg gegen- und nebeneinander. Vgl. JAWORSKI (wie Anm. 58), S. 295 f.

64 Dufrat, Joanna: Ligi Kobiet Królestwa, Galicji i Śląska. Próba politycznej aktywizacji kobiet w okresie I wojny światowej [Die Frauenligen des Königreichs, Galiziens und Schlesiens. Der Versuch der politischen Aktivierung der Frauen während des Ersten Weltkriegs]. In: Działaczki społeczne, feministki, obywatelki ... Samoorganizowanie się kobiet na ziemiach polskich do 1918 roku (na tle porównawczym). Hg. v. Agnieszka JaniaK-JasińSKa, Katarzyna SierakowsKa und Andrzej Szwarc. Warszawa 2008, S. 113-130, hier S. 120.

65 Rzepecki, Jan: Moszczeńska (Moszczeńska-Rzepecka) Iza. In: Polski Słownik Biograficzny 22 (1977), S. 80-85.

66 Dufrat (wie Anm. 64), S. 114.

67 Chwalba (wie Anm. 59), S. 573.

68 Stegmann (wie Anm. 61), S. 209.

69 Siehe z.B. Słowo wstępne [Einleitung]. In: Pamiętnik zjazd kobiet polskich w Warszawie w roku 1917. Hg. v. J[ustyna] BudzińsKa-TyLICKa. Warszawa 1918, S. 1-4, hier S. 1.

70 NAŁĘCZ, Tomasz: Kobiety w walce o niepodległość w czasie pierwszej wojny światowej [Frauen im Unabhängigkeitskampf während des Ersten Weltkriegs]. In: Kobieta i świat polityki. Polska na tle porównawczym w XIX i w początkach XX wieku. Hg. v. Anna ŻARnowska und Andrzej Szwarc. Warszawa 1994, S. 72-79, hier S. 76.

71 Dufrat (wie Anm. 57), S. 69; BAgiŃski, Henryk: U podstaw organizacji wojska polskiego 1908 1914 [An der Basis der polnischen Militärorganisationen 1908-1914]. Warszawa 1935 (Materijały 
gencja: Lehrerinnen, Schülerinnen und Studentinnen aus Einrichtungen für höhere Frauenbildung, Gymnasien und Universitäten. Auch die neuen Frauenberufe, Angestellte und Verkäuferinnen, waren vertreten. Das heißt, die Freiwilligen stammten aus Kontexten, aus denen der Großteil der Feministinnen ebenfalls stammte und in denen schon in den letzten Jahren vor dem Krieg die nationalpolitischen Aktivitäten zugenommen hatten ${ }^{72}$ Sie gehörten einer neuen Generation an, der der Zugang zu Universität, Ausbildung und Berufstätigkeit bereits offenstand, für den sich die vorhergehende, die der Frauenrechtlerinnen um 1900, eingesetzt hatte. Viele der sich ab 1910 in den paramilitärischen Verbänden organisierenden Frauen kamen aus dem russischen Teilungsgebiet, wo sie die Revolution von 1905 und die folgenden Repressionen erlebt hatten. Einige von ihnen hatten sich schon damals im Umfeld der PPS an den illegalen Aktivitäten der Kampfbünde beteiligt, zu denen auch Attentate gehörten, hatten also Erfahrung im Umgang mit Waffen. ${ }^{73}$ Andere waren im Umfeld der Falkenbewegung Sokot mit Sport und Körperertüchtigung in Berührung gekommen.

Wie die Gründung der Polnischen Legionen war auch der Einsatz von Frauen in paramilitärischen Organisationen ein Zeichen für die Besonderheit des nationalen Engagements und gleichzeitig für die Normalität, die für den anvisierten neuen Staat beansprucht wurde. Die Rolle der Beteiligten war sowohl die von Ausnahmeheldinnen als auch die von ,ihren Mann stehenden“ Soldatinnen. 1927 berichtete Janina Bendekówna über ihr Engagement und die Entstehung der Frauenabteilung des Schützenverbands: Sie sei 1911 nach Lemberg an die Universität gekommen, wo sie Piłsudski habe sprechen hören - was sie in der Seele getroffen habe. Daher habe sie Kontakt zur Konspiration und zum Schützenverband gesucht, aber zunächst seien Frauen nicht zugelassen gewesen. Erst 1912 hätten sie durchgesetzt, dass der Offiziersrat die Gründung einer Frauenabteilung gestattete - so Bendekównas Bericht. ${ }^{74}$

Die Fraueneinheiten erhielten Unterricht in Sanitätsdienst, Erster Hilfe, Nachrichtenermittlung und Kurierdienst, über Heeresstruktur, Taktik und Strategie, Waffen- und Sprengstoffkunde, Geländekunde, Geografie. Sie führten Manöver durch, teilweise zusammen mit Männereinheiten, und übten sich in Kartenlesen, Biwakieren, Marschieren, Schießen, Umgang mit Sprengstoffen. Die Schulungen endeten mit Examina zu Sanitätsoffizierinnen und -unteroffizierinnen. ${ }^{75}$ Die Frauen wurden folglich professionell

do historji ruchu niepodległościowego: „Zarzewie“, Polskie Drużyny Strzeleckie i tajny skauting 1), S. 664.

72 Leszczawski-Schwerk, Angelique: „Töchter des Volkes“ und „stille Heldinnen“. Polnische und ukrainische Legionärinnen im Ersten Weltkrieg. In: Soldatinnen (wie Anm. 7), S. 179-205, hier S. 188; NALĘCZ (wie Anm. 70), S. 75.

73 Ponichtera, Robert M.: Feminists, Nationalists, and Soldiers: Women in the Fight for Polish Independence. In: The International History Review XIX (1997), S. 16-31, hier S. 20.

74 Bendekówna, Janina: Nasz oddział macierzysty we Lwowie [Unsere Heimatabteilung in Lemberg]. In: Wierna służba. Wspomnienia uczestniczek walk o niepodległość 1910-1915 [Treuer Dienst. Erinnerungen der sich am Kampf um Unabhängigkeit Beteiligenden 1910-1915]. Hg. v. Al[eksandra] PItSUDSKA u.a. Warszawa 1927, S. 6-9, hier S. 6.

75 BAgińsKi (wie Anm. 71), S. 655-664. 
ausgebildet und in militärische Strukturen eingegliedert. Allerdings sollten sie vor allem hinter der Front, im Sanitäts- und Kurierdienst, als Hilfstruppen eingesetzt werden, was sie, so die Erinnerung von Bendekówna, „stillschweigend akzeptierten“. Dennoch lernten sie schnell, mit Waffen umzugehen: „laden, wieder laden, zusammensetzen, reinigen von Brauning, Mauser und Karabiner" ${ }^{\text {"76 }}$. Leistung und Diskriminierung waren auch in anderen Berichten Thema. Eine weitere Mitstreiterin schildert ein gemeinsames Manöver von Frauen- und Männerabteilungen im Frühling 1914. Die Frauenabteilung sei zum Sanitäts- und Küchendienst abkommandiert worden, dennoch habe sich niemand beschwert. ${ }^{77}$ Die Frauen hatten ihre Fähigkeit zu militärischem Gehorsam und Disziplin bewiesen, die Normalität ihrer Anwesenheit. Aus der Demonstration von Normalität und Professionalität leiteten die Berichte immer wieder einen Anspruch auf Gleichberechtigung ab - so auch die Memoiren von Aleksandra Piłsudska, Piłsudskis Ehefrau. ${ }^{78}$

Während allerdings die paramilitärischen Organisationen die Frauenabteilungen eingliederten, konnten Frauen in die reguläre Armee Österreich-Ungarns ebenso wenig eintreten wie beispielsweise in die englische. Wie schon im 19. Jahrhundert taten es einige dennoch als Männer verkleidet. Zu den bekanntesten gehört Wanda Gertzówna (häufig Gertz), die in den Polnischen Legionen mehr als sechs Monate unentdeckt an der Ostfront kämpfte. ${ }^{79}$ Über sie sind in letzter Zeit einige, auch populärwissenschaftliche Bücher und Artikel erschienen, was - abgesehen vom Kontext des 100. Jahrestags des Kriegsausbruchs - die Frage nach dem Warum aufwirft. ${ }^{80}$ Wenn vor allem Wanda Gertzówna als Symbol für kämpfende Frauen wiederbelebt wird, so ist zu vermuten, dass dies eben nicht für damaligen Handlungsmöglichkeiten von Frauen oder Hoffnung auf Gleichberechtigung, sondern vor allem für Exzeption und Differenz steht und damit unterstreicht, dass die polnische Geschichte als Ausnahmegeschichte zu erzählen ist.

1919 wurde die Zweite Republik Polen gegründet und Frauen erhielten aktives und passives Wahlrecht. In den anschließenden Kriegen um die Grenzen im Osten, dem polnisch-ukrainischen Kampf um Lemberg und dem Polnisch-Sowjetischen Krieg, wurden die bewaffneten Fraueneinheiten eingesetzt, zwar nicht an der eigentlichen

76 „Zgadzałyśmy się bez dyskusji“; „ładowanie i rozładowanie, składanie i czyszczenie brauningów, mauzerów, czy karabinów“. BENDEKównA (wie Anm. 74), S. 7 f.

77 Kossuthówna, Barbara St.: Manewry [Manöver]. In: Wierna służba (wie Anm. 74), S. 16-21, hier S. 17.

78 PiŁsudska, Aleksandra: Wspomnienia [Erinnerungen]. Londyn 1989 (11985), S. 125 f; zuerst auf Englisch erschienen als Dies.: Memoirs of Madame Pilsudski. London 1940.

79 Dass Nałęcz dies für „Folklore (folklora)“, nicht für ein „soziales Phänomen (zjawisko społeczne)“ hält, für nicht weiter erwähnenswert, ist insofern aufschlussreich und wohl mehr über den Autor aussagend als über das Phänomen, weil er ihm dennoch immerhin drei Sätze widmet. Siehe NAŁĘCZ (wie Anm. 70), S. 77.

80 Jankowski, Stanisław M.: Dziewczęta w maciejówkach [Mädchen mit Männermützen]. Warszawa 2012; Smoleński, Pawel: Dziewczyna, która chciała być żołnierzem [Das Mädchen, das Soldat sein wollte]. In: Gazeta wyborcza, 25.8.2014. http://wyborcza.pl/alehistoria/1,140246,16516978,Dziewczyna_ktora_chciala_byc_zolnierzem.html (21.09.2014); NowAKowsKa, Anna: Wanda Gertz. Opowieść o kobiecie żołnierzu [Wanda Gertz. Eine Erzählung über eine Soldatin]. Kraków 2009. 
Front, aber doch zur Bewachung von Sicherheitszonen und Verteidigungslinien. Aleksandra Zagórska, ein aus den Kampfeinheiten der PPS kommendes Mitglied des Schützenverbandes Lemberg, gründete dort eine Frauenabteilung, deren Aufgabe es war, vor Ort Männer zu rekrutierten, Nachrichten zu analysieren und Soldaten durch feindliches Territorium zu führen. Aus dieser Abteilung ging eine reguläre militärische Einheit hervor, das „Frauen-Freiwilligenkorps“ (Ochotnicza Legia Kobiet), das militärische Einrichtungen bewachte und bewaffnet in der Sicherheitszone Lembergs patrouillierte. 1919 wurde es direkt dem Hohen Militärkommando unterstellt.

Insgesamt gab es sechs Frauenbataillone, die an Fronthandlungen beteiligt waren. Im Polnisch-Sowjetischen Krieg beispielsweise hatte das Wilnaer Bataillon einen 25 Kilometer langen Frontabschnitt zu verteidigen. ${ }^{81}$ Die Angaben zur Zahl der Frauen in diesen militärischen Einheiten schwanken zwischen 2.500 und 10.000. ${ }^{82}$ 1922, mit dem Ende der Kriege, wurden alle Frauenabteilungen aufgelöst. Für den sich etablierenden polnischen Staat war das Frauenwahlrecht zwar wie für viele andere Staaten Europas unabwendbare Normalität, aber er benötigte keine bewaffneten Fraueneinheiten mehr, die zuvor die Ausnahmesituation des Kampfes um staatliche Unabhängigkeit legitimiert hatten.

Was motivierte die Frauen, sich an bewaffneten Auseinandersetzungen zu beteiligen? Nach dem Krieg erschienen mehrere Gedächtnisschriften, die den Beitrag der Kämpferinnen zur Erlangung der Unabhängigkeit dokumentieren sollten und in denen sich dessen vielfache Kontexte und Deutungen niederschlugen. ${ }^{83}$ Gertzówna beispielsweise erinnert sich: „Seit meiner frühesten Kindheit war mein Traum, ein Soldat der polnischen Armee zu werden. Mein Vater, ein Aufständischer von 1863, lebte mit der Hoffnung auf ein unabhängiges Polen. Die Aufständischen trafen sich oft bei uns zu Hause und träumten von einem freien Polen. Und ich träumte von den Geschichten des Heldentums. “84 Mit dieser Vater-Tochter-Tradition schreibt sich Gertzówna in das Aufstandsnarrativ ein und legitimiert ihr außergewöhnliches Tun, ihre Beteiligung am Kampf. ${ }^{85}$ Sie bezieht sich nicht - und dies scheint uns bemerkenswert - auf Emilia Plater und andere am Kampf beteiligte Frauen, und zwar trotz der wachsenden Zahl von Publikationen über diese vor und nach dem Weltkrieg, nicht auf weibliche Heldinnen, sondern auf eine männlich-patriarchale Tradition des Heldentums, personifiziert im Vater.

81 Ponichtera (wie Anm. 73), S. 25.

82 Ebd., S. 26.

83 Wierna służba (wie Anm. 74); Służba ojczyźnie. Wspomnienia uczestniczek walk o niedpodległość 1915-1918 [Dienst am Vaterland. Erinnerungen der Teilnehmerinnen am Kampf um Unabhängigkeit 1915-1918]. Hg. v. Al[eksandra] PiŁsudska u.a. Warszawa 1929; PiŁsudska (wie Anm. 78).

84 „Od najmłodszych lat marzeniem mojem było zostać żołnierzem w wojsku polskim. Ojciec mój, powstaniec 1863 roku, żył nadzieją ujrzenia niepodległej Polski. Często też zbierali się u nas powstańcy, aby snuć nić rojeń o Polsce wolnej. I ja marzyłam, wychowywana na opowiadaniach bohaterskich.“ GertzównA, Wanda (Żuchowicz, Kazik): W pierwszym pułku artylerji [Im ersten Artillerieregiment]. In: Służba ojczyźnie (wie Anm. 83), S. 49.

85 Stegmann, Natali: Die Töchter der geschlagenen Helden. „Frauenfrage“, Feminismus und Frauenbewegung in Polen 1863-1919. Wiesbaden 2000, S. 112-133. 
Für viele Frauen war das Engagement für Unabhängigkeit ein Beweis ihres Könnens. Die Töchter folgten den väterlichen Vorbildern, den Aufständischen, und so auch Piłsudski. Auf diese Weise verorteten sie sich in einer romantischen Aufstandsgeschichte. Die Erinnerungen dagegen zeichnen sich vor allem durch detaillierte Berichte aus, durch wenig Romantik, eher durch Bezug auf das Genre der Kriegsliteratur, wenn beispielsweise in den Schilderungen des Kampfs um Lemberg mit wörtlicher Rede Spannung, Tapferkeit, Glück und Erschöpfung beschrieben werden. ${ }^{86}$ Schikanen, Beschränkungen von Männern und Vorgesetzten in Manöver und Kampf wurden hingenommen, zum Beweis militärischer Disziplin und Gleichwertigkeit mit den männlichen Soldaten. Die Berufung auf frühere Heldinnen wie Plater diente dagegen eher zur Durchsetzung der Forderungen nach Kampfbeteiligung gegenüber männlichen Entscheidungsträgern. Heldinnen waren weniger Vorbilder als Wegbereiter.

Die Erinnerungen der Frauen berichten von Ausnahmen und von Normalität, von Traditionen und von Besonderheiten. Sie heben die besonderen Leistungen polnischer Frauen vor dem Hintergrund des geteilten Polens hervor, schildern besondere Visionen der Aufstandsgeschichte und väterliche Vorbilder. Sie bemühen sich aber auch um den Nachweis der Normalität politischer Arbeit und militärischer Disziplin. Alle teilen sie mehr oder weniger explizit ein Narrativ vom Anspruch auf Gleichberechtigung und Anerkennung.

Im Engagement, in der Hoffnung auf gleiche Beteiligung, in der Begeisterung, der Nation oder dem Vaterland zu dienen, waren die polnischen Frauen nicht allein: Versuche der Einrichtung militärischer Fraueneinheiten, sei es in der Etappe zur Verteidigung, sei es an der Front, gab es unter anderem in Russland, in Großbritannien und in Frankreich. Wie das österreich-ungarische Heer verweigerten das britische und französische Frauen die formelle Eingliederung. ${ }^{87}$ In Russland wurden angesichts großer Zahlen von Freiwilligen im Sommer 1917 wie in Polen reine Frauenbataillone gebildet, die als Ausnahme galten und die exzeptionelle Situation der ausbrechenden Revolution spiegelten. ${ }^{88}$

Die Mobilisierung der Frauen bezog sich in erster Linie nicht auf die militärische Front, sondern auf die in den Krieg einbezogene Heimatfront. ${ }^{89}$ In Russland wie auch in den USA, in Italien oder in Serbien wurden während des Ersten Weltkriegs patriotische Einheiten gebildet, die paramilitärische Übungen abhielten und sich zur Verteidi-

86 Paleolog, Stanisława: Służba kurjerska [Kurierdienst]. In: Wierna służba (wie Anm. 74), S. $241 \mathrm{f}$.

87 ThÉBAud, Françoise: Der Erste Weltkrieg. Triumph der Geschlechtertrennung. In: Geschichte der Frauen. Hg. v. Georges Duby und Michelle Perrot. Bd. 5: 20. Jahrhundert. Hg. v. Françoise ThéBAUD. Frankfurt/M. 1992, S. 33-91, hier S. 59 f.

$88 \mathrm{Zu}$ Russland siehe Stoff, Laurie S.: They Fought for Russia: Female Soldiers of the First World War. In: A Soldier and a Woman (wie Anm. 7), S. 66-82; Dies.: They Fought for the Motherland: Russia's Women Soldiers in World War I and the Revolution. Lawrence 2006 (Modern War Studies).

89 Zur Totalisierung des Kriegs vgl. Hagemann, Karen: Heimat - Front. Militär, Gewalt und Geschlechterverhältnisse im Zeitalter der Weltkriege. In: Heimat - Front. Militär und Geschlechterverhältnisse im Zeitalter der Weltkriege. Hg. v. Ders. und Stefanie SchÜlER-Springorum. Frankfurt/M.-New York 2002 (Geschichte und Geschlechter 35), S. 13-52; ThÉBAud (wie Anm. 87), S. 35-63. 
gung der Heimat bereithielten. Britische Ärztinnen, unter ihnen viele, die eng mit den Stimmrechtsorganisationen verbunden waren, beteiligten sich freiwillig an der medizinischen Betreuung Verwundeter und leiteten zwei Frauenmilitärhospitäler im Ausland, davon eins in Paris. Sie erhielten Lohn und Vergütung wie Leutnants, aber keine Titel, keine Ränge, keine Uniformen, da die britische Militärführung es ablehnte, sie regelgerecht aufzunehmen. Die professionell ausgebildeten und zwangsrekrutierten Krankenschwestern dagegen wurden in das Militär eingegliedert, allerdings mit eigenen Uniformen, also eindeutig von Männern unterscheidbar. Daneben entstanden in der Heimat paramilitärische Frauenfreiwilligenorganisationen, die vom Heereskommando zusammengeführt, ausgebildet und zur Verteidigung eingesetzt wurden. Ziel war vor allem ihre Bündelung und Kontrolle. ${ }^{90}$ Obwohl also dem Militär unterstellt, dienten die Organisationen eher einer Militarisierung der Heimat als der Durchbrechung der „Demarkationslinie zwischen den Geschlechtern “91. Der Einsatz uniformierter Soldatinnen wurde nicht nur in Großbritannien sowohl von Männern als auch von Frauen heftig kritisiert.

Auf den ersten Blick erscheinen die kämpfenden polnischen Fraueneinheiten in der Erinnerung weitaus präsenter als beispielsweise die britischen paramilitärischen Organisationen, die nicht einmal in die Nähe der Front gekommen waren. Der Einsatz britischer Frauen hatte vor allem im Kontext der umfassenden Kriegsmobilisierung gestanden, die zwischen Front und Heimat nicht mehr grundlegend unterschied. Dazu gehörte die militärische Ausbildung, die aus Heldinnen pflichtbewusste Bürgerinnen machte. Der gezielte, aggressive Einsatz an der Front blieb in jedem Fall Männern vorbehalten, darüber hinaus war der Einsatz von Frauen, soweit er die Waffe betraf, überall freiwillig.

Vergleicht man die polnische Praxis mit der von anderen europäischen Ländern, so fällt für Erstere die Mischung aus Freiwilligenmobilisierung und regulärer Kriegführung auf - ein Phänomen, das nicht nur Frauen, sondern auch Männer betraf. Diese Situation war es, in der die Mobilisierung der Frauenbataillone erfolgte. Sie ist vergleichbar mit Aufständen oder Revolutionen, in denen die Beteiligung von bewaffneten Frauen auf den Barrikaden wenig Aufregung hervorrief. Dagegen wurden in den beiden Weltkriegen mit ihrer Mobilisierung der gesamten Gesellschaft - wie Angelique LeszczawskiSchwerk und andere gezeigt haben - die Frontlinien zwischen den Geschlechtern zwar verschoben, aber nicht aufgehoben.$^{92}$ Die Geschlechterordnung blieb bestehen, auch wenn oder gerade weil der Krieg die Auflösung der Normalität mit sich brachte. Nicht vergessen werden sollte allerdings, dass die Frauenbataillone wie die der Männer regulär ausgebildet wurden. Die Manöver, die Ausbildung und der Einsatz mit der Waffe bis hinter die kämpfenden Frontlinien stärkten das master narrative der Frauenbewe-

90 Jensen, Kimberly: Volunteers, Auxiliaries, and Women's Mobilization: The First World War and Beyond (1914-1939). In: Women's Military History (wie Anm. 8), S. 189-231; THÉBAud (wie Anm. 87), S. 46 f. Dort finden sich auch Hinweise auf serbische und russische Frauenbataillone.

91 Latzel (wie Anm. 23), S. 14.

92 Leszczawski-Schwerk (wie Anm. 72), S. 205; Latzel (wie Anm. 23), S. 14. 
gungen, das Professionalisierung als zentrales Moment einer Emanzipation ansah, die vor Kriegführung nicht haltmachen sollte.

\section{Schluss}

Es gab in Kriegen und Aufständen zu allen Zeiten Heldinnen mit und Heldinnen ohne Waffen und eine ganze Reihe Frauen, die sich auf verschiedene Weisen beteiligten, ohne zu Heldinnen zu werden. Die Kriege in Nachfolge der Französischen Revolution bildeten dabei insofern einen Wendepunkt, als nun in weiten Teilen Europas reguläre Kriegführung mit Aufrufen zur militärischen Beteiligung aller verbunden wurden Frauen aber explizit ausgeschlossen waren.

Für Preußen war 1813 das entscheidende Jahr, dessen Ausnahmecharakter im preuBisch-deutschen nationalgeschichtlichen Narrativ bis zum Ende des Zweiten Weltkrieges auch durch die Erinnerung an die Beteiligung bewaffnet kämpfender Frauen unterstrichen wurde. Das polnische nationalgeschichtliche Narrativ ist hingegen durch eine als Kontinuität gedeutete Kette von Aufständen zur Wiedererlangung der staatlichen Unabhängigkeit geprägt, in die die Napoleonischen Kriege eingeordnet wurden. Der Ausnahmecharakter der militärischen Auseinandersetzung wurde noch stärker als im preußischen Fall durch die Erinnerung an die beteiligten bewaffneten Heldinnen unterstrichen.

Die Integration einer kleinen Gruppe von Frauen in die polnischen paramilitärischen Organisationen vor und während des Ersten Weltkrieges sowie der Einsatz von militärischen Fraueneinheiten während der folgenden Grenzkriege kann im Zusammenhang mit der Wahrnehmung als Befreiungskampf oder Unabhängigkeitskrieg verstanden werden. In mancher Hinsicht wurden die Kriege in der Tradition der polnischen Aufstände des 19. Jahrhunderts gesehen und waren in dieser Mischung von Kriegsmobilisierung und Aufstandsrhetorik der antinapoleonischen „Erhebung“ Preußens von 1813 ähnlich. Kriege, die sich im Befreiungs- und Revolutionskontext politisieren und emotionalisieren ließen, begünstigten offenbar die Beteiligung von Frauen und vor allem deren Überlieferung sowie Heroisierung. Diese ist also vom Motiv der Ausnahme geprägt, nicht dem der Regel.

An die in die Legionen integrierten Frauen erinnert man sich ebenso wie an Emilia Platers Beteiligung am Novemberaufstand vor allem, weil sie sich in die polnische Aufstandstradierung einfügen und weil sie die polnische Geschichte als Ausnahmegeschichte untermauern - ein Narrativ, das für Preußen so nicht oder nicht mehr existiert. Die Ausnahme der bewaffneten Frau und die Ausnahme der polnischen Geschichte bestätigen sich gegenseitig.

Dennoch: Nicht so sehr das Überschreiten einer Demarkationslinie zwischen den Geschlechtern, die Aneignung von separate spheres, machte für Frauen die Bedeutung der bewaffneten Fraueneinheiten aus als vielmehr die Professionalität ihres Einsatzes. Aus der Perspektive des master narrative der Frauenbewegungen wird die Professionalisierung, die Normalität der Beteiligung, zum entscheidenden Argument. Die polni- 
sche Entwicklung lässt sich daher gleichzeitig als Teil der Geschichte der sich wandelnden Arbeitsteilung zwischen den Geschlechtern und als Teil der sich immer wieder neu etablierenden Geschlechterordnungen verstehen. Wie in einer Reihe anderer europäischer Nachkriegsverfassungen wurde Frauen in der 1921 verabschiedeten Verfassung der Zweiten Republik Polen das Wahlrecht erteilt, und dies signalisierte nun nicht mehr die Ausnahmesituation, sondern eine neu gewonnene Normalität.

Wenn heute erneut intensiv über die Einbeziehung von Frauen in Militär und Kampf diskutiert wird, stellt sich die Frage, inwiefern dies angesichts der zunehmenden Professionalisierung des Militärischen nur die Normalität der Diskussionen um Gleichberechtigung im Berufsleben spiegelt oder inwiefern es nach wie vor einen Ausnahmezustand der besonderen Mobilisierung angesichts von als fundamental wahrgenommenen Herausforderungen signalisiert. 
Open Access @ 2016 by Böhlau Verlag GmbH \& Cie, Köln Weimar Wien 


\section{Völkerschlacht als nationales Narrativ}


Open Access @ 2016 by Böhlau Verlag GmbH \& Cie, Köln Weimar Wien 


\title{
Zum Poniatowski-Mythos in der polnischen Kultur und Literatur
}

\author{
Hans-Christian Trepte
}

„Der Elbe Herr bist Du geworden, doch eine Elster wird dich morden“" - so soll die tragische Prophezeiung einer Zigeunerin gelautet haben, nachdem Fürst Józef Anton(i) Poniatowski, hoch zu Ross und in voller Rüstung, die Elbe erfolgreich durchquert hatte. Diese Redewendung wird durch einen weiteren, im polnischen kollektiven Bewusstsein bis heute lebendig gebliebenen Phraseologismus ergänzt: „Von der Elster besiegt, von den Polen geliebt.“2 Beide Redewendungen können u.a. auch für den Beginn der Poniatowski-Legende über das tragische Ende eines Nationalhelden stehen, die von der polnischen Literatur maßgeblich mit konstruiert, popularisiert, letztendlich aber auch dekonstruiert wurde. Darauf haben im polnischen wie im deutschen historischen und literaturwissenschaftlichen Kontext zahlreiche Wissenschaftler verwiesen. ${ }^{3}$ Fürst Józef Anton(i) Poniatowski, Neffe des letzten polnischen Königs, Stanisław August Poniatowski, gehört zweifelsohne zu den polnischen Nationalhelden; er ist zu einem Sinnbild des polnischen Freiheitskämpfers, geradezu zu einer Verkörperung des polnischen Heldenmythos geworden. Damit steht er in einem engen Zusammenhang mit dem romantischen Muster vom heldenhaften Tod im Sinne von: dulce et decorum est pro patria mori (Horaz). Józef Poniatowski ist von einem besonderen Nimbus, einer speziellen Aura umgeben, in Polen gilt er als Symbol für Treue und Ehre. Für mehrere Generationen, die nicht nur für die Unabhängigkeit und Freiheit ihres Landes im 19. und 20. Jahrhundert bereit waren, ihr Leben zu opfern, ist er ein nacheifernswertes Vorbild geblieben. Die Gestalt des Fürsten steht aber auch für eine gewisse historische Zwangslage: „Mit Napoleon oder gegen ihn. Das Dilemma

1 „Zwyciężyłeś Łabę, a zginiesz od sroki“. Polnisches Sprichwort. WóYcicki, Kazimierz Władysław: Przysłowia narodowe [Nationale Sprichwörter]. Warszawa 1830, S. 224. Übersetzung: Hans-Christian Trepte. S. auch: Z polskich dziejów. Śmierć Józefa Pioniatowskiego [Aus der polnischen Geschichte. Der Tod Józef Poniatowskis] (ohne Angabe des Autors). In: Rodzina. Miesięcznik Katolicki 19/1801 (Neuauflage: 2013), S. 12.

2 „Pokonała go sroka, ale zyskał miłość Polaków“. Polnisches Sprichwort. Wóycicki (wie Anm. 1), S. 224. Übersetzung: Hans-Christian Trepte.

3 Zernack, Klaus: Die Geschichte Preußens und das Problem der deutsch-polnischen Beziehungen. In: Ders.: Preußen - Deutschland - Polen. Aufsätze zur deutsch-polnischen Geschichte. Hg. v. Wolfram Fischer und Michael G. MülLer. Berlin 1991, S. 105-133; Nieuważny, Andrzej: My z Napoleonem [Wir mit Napoleon]. Wrocław 1999, S. 12; KufeL, Sławomir: W poszukiwnia bohatera. U źródeł legendy literackej Józefa Księcia Poniatowskiego [Auf der Suche nach einem Helden. An den Quellen der literarischen Legende von Fürst Josef Poniatowski]. In: Zeszyty Naukowe Uniwersytetu Rzeszowskiego 65 (2010), 6-8; Paluszewski, Jan: Legenda literacka Księcia Józefa Poniatowskiego [Die literarische Legende von Fürst Josef Poniatowski]. Pruszków 2006; WĄSACZ, Agata: Epoka napoleońska w literaturze [Die napoleonische Epoche in der Literatur]. In: http://napoleon.org.pl/ polska/xj.php (17.11.2015). 
der Polen zu Beginn des 19. Jahrhunderts“, so lautete das Thema einer öffentlichen Diskussion, die am 15. Oktober 2013 im Geschichtsmuseum der Stadt Krakau im Pałac Krzysztofory stattfand. ${ }^{4}$ Diskutiert wird bis heute die von Fürst Józef Radziwiłł vertretene Option einer möglichen preußisch-polnischen Personalunion, der zunächst auch Józef Poniatowski nahegestanden haben soll. Ein Angebot Preußens und Russlands, Napoleon die Treue zu kündigen, lehnte Poniatowski allerdings zu Beginn des Jahres $1813 \mathrm{ab}$. Anders als sein ehemaliger Waffengefährte, Tadeusz Kościuszko, der ebenfalls zum polnischen Nationalhelden avancierte, sprach sich Poniatowski für ein enges militärisches Bündnis mit Napoleon aus, um auf diesem Wege dem Ziel der polnischen nationalen Eigenstaatlichkeit näher zu kommen. Anfänglich traute der französische Imperator Poniatowski kaum. Dazu hatten u.a. negative Stimmen polnischer Emigranten in Paris beigetragen. Nach der Absage von Tadeusz Kościuszko war Poniatowski für Napoleon allerdings zu einer wichtigen Bezugsperson geworden. Mit ihm wollte er nicht nur die Herzen, sondern vor allem die Säbel der polnischen Soldaten gewinnen. So wurde Fürst Józef Poniatowski letztendlich zu einem loyalen Partner des französischen Imperators. Unter den polnischen Soldaten erfreute er sich eines vorzüglichen Rufs, in der polnischen Gesellschaft spielte er allerdings eine noch untergeordnete Rolle. ${ }^{5}$ Poniatowskis ca. 14.000 Mann zählende Truppe wurde im Juni 1813 als VIII. Korps in die Grande Armée Napoleons eingegliedert, er selbst wurde dabei, als erster Ausländer, den französischen Marschällen gleichgestellt. Am 16. Oktober 1813, kurz vor seinem Tod, hatte Napoleon Józef Poniatowski zum Maréchal d'Empire, also zum Reichsmarschall von Frankreich ernannt. Obwohl König Friedrich August von Sachsen als Herzog des Großherzogtums Warschau eingesetzt worden war, galt Poniatowski als der eigentliche Herrscher Polens, als aussichtsreichster Anwärter auf den polnischen Thron. ${ }^{6}$ Die ca. 100.000 unter Poniatowskis Kommando an der Seite Napoleons kämpfenden Polen stellten das weitaus größte nichtfranzösische Kontingent in der Grande Armée. ${ }^{7}$

Zwischen der historischen Person Poniatowskis, seiner Legende und seinem Mythos bestand eine deutliche Diskrepanz. Sie zeigte sich in der Geschichtsschreibung ebenso wie in der Kultur und Literatur. Mythos und literarische Legende sind dabei kaum voneinander zu trennen, sie bedingen und ergänzen sich gegenseitig. Gemeinsam trugen sie zu einer nachhaltigen Verklärung Poniatowskis bei, der seine letzte Ruhestätte, polnischen Königen gleich, in der Fürstengruft auf dem Krakauer Wawel fand. Neben der Literatur waren die Malerei wie auch die bildende Kunst an der Festigung der Poniatowski-Legende beteiligt. In der Malerei trugen u.a. die Gemälde von January Suchodolski, wie etwa „Fürst Józef Antoni Poniatowski zu Pferde vor der Front der Grenadiere“(Ö1 auf Leinwand, 1857, Nationalmuseum, Warschau) und „Der Tod des

4 In: http://www.mhk.pl/aktualnosci/z-napoleonem-czy-przeciwko-niemu-dylematy-polakow-na-poczxix-w (01.04.2014).

5 Grochulska, Barbara: Księstwo Warszawskie [Das Herzogtum Warschau]. Warszawa 1991.

6 NieuwaŻny (wie Anm. 3), S. 12; Zernack (wie Anm. 3), S. 106.

7 Ebd., S. 106-107. 
Abb. 1 Juliusz Kossak: Fürst Józef Poniatowski zu Pferde, Aquarell, 1879. Sammlung Schloss Lańcut.

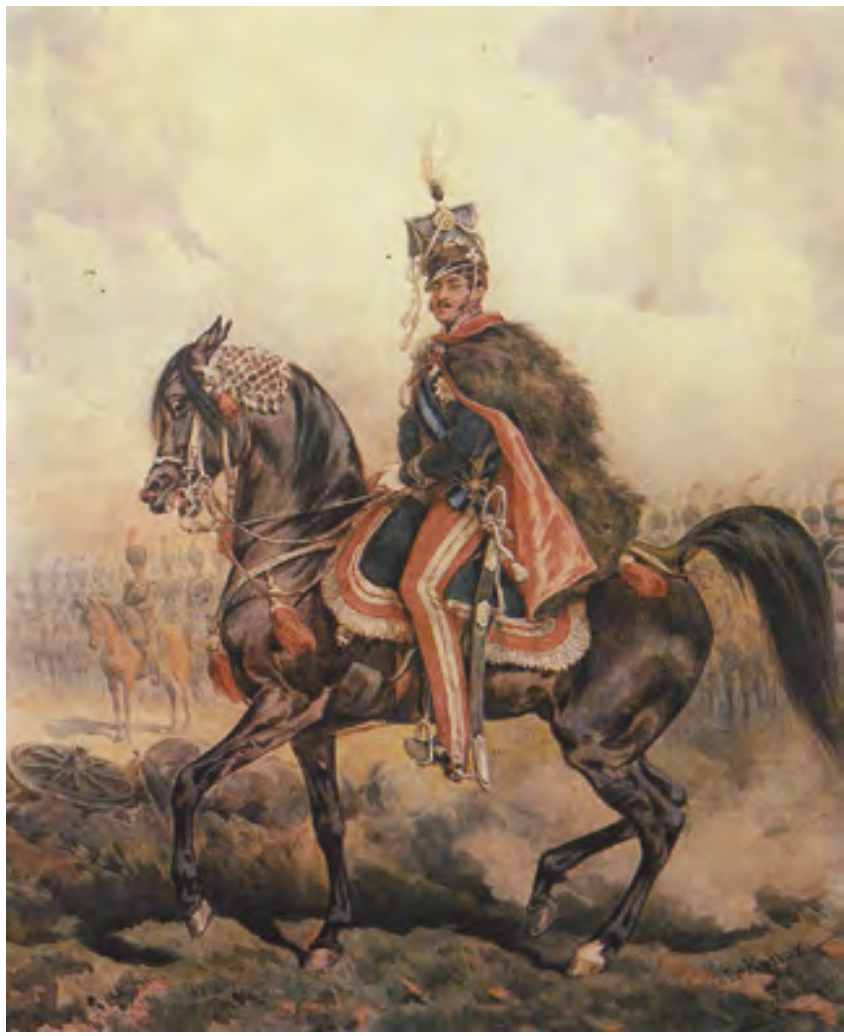

Fürsten Józef Poniatowski in der Elster“ (Öl auf Leinwand, 1859, Nationalmuseum, Warschau) sowie das oft reproduzierte Aquarell von Juliusz Kossak, „Fürst Józef Antoni Poniatowski zu Pferde“ (1879, Sammlung Schloss Lańcut) dazu bei (Abb. 1). Eine ähnliche Rolle spielte auch die vom dänischen Bildhauer Bertel Thorvaldsen geschaffene Statue Poniatowskis (1826-1832), die bis zu ihrer Zerstörung durch die Nazis vor dem Sächsischen Palais im Herzen Warschaus gestanden hatte. Nach dem Ende des Zweiten Weltkriegs hatte sich im August 1946 die Regierung Dänemarks entschieden, der polnischen Hauptstadt ein neues Poniatowski-Denkmal zum Geschenk zu machen, das nach einem sich im Thorvaldsen-Museum in Kopenhagen befindenden Modell gegossen wurde. Das großzügige dänische Geschenk hatte allerdings die kommunistischen Machthaber in Polen in große Verlegenheit gebracht, was den Standort des Denkmals in der polnischen Hauptstadt betraf. Nach langen Diskussionen entschied man sich schließlich für einen Platz im Warschauer Łazienki-Park, außerhalb des historischen Zentrums von Warschau.

In den sechziger Jahren des 20. Jahrhunderts war die Zeit des Empire, ebenso wie die Rolle Polens in den Napoleonischen Kriegen, erneut ins öffentliche polnische Bewusstsein gerückt. Dazu hatten u.a. Andrzej Wajdas Verfilmung von Stefan Żeromskis 


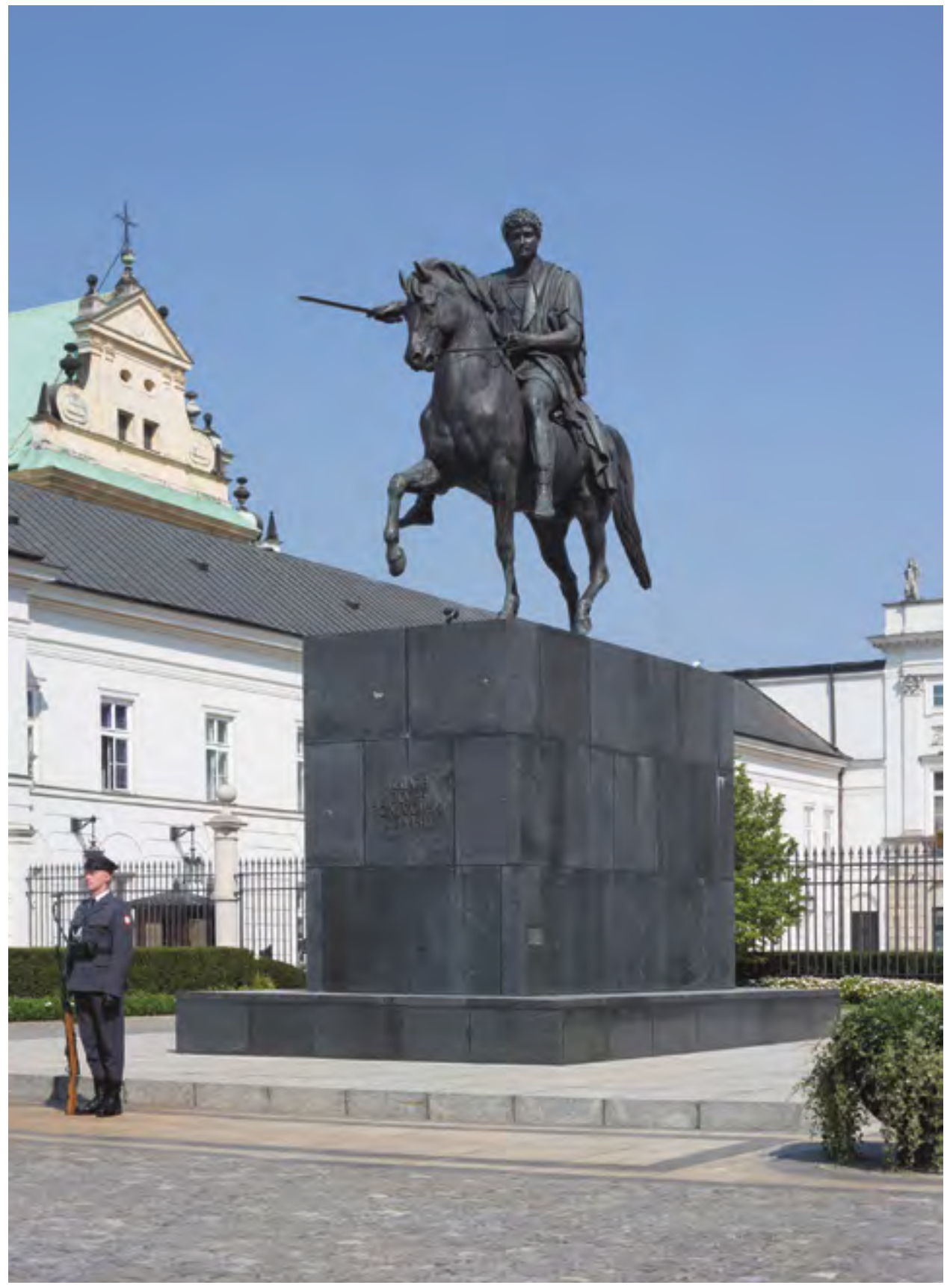

Abb. 2 Józef-Poniatowski-Denkmal in Warschau (Kopie der Statue von Bertel Thorvaldsen, 1826-1832). Foto: Artur Korczak-Siedlecki, 2015. 


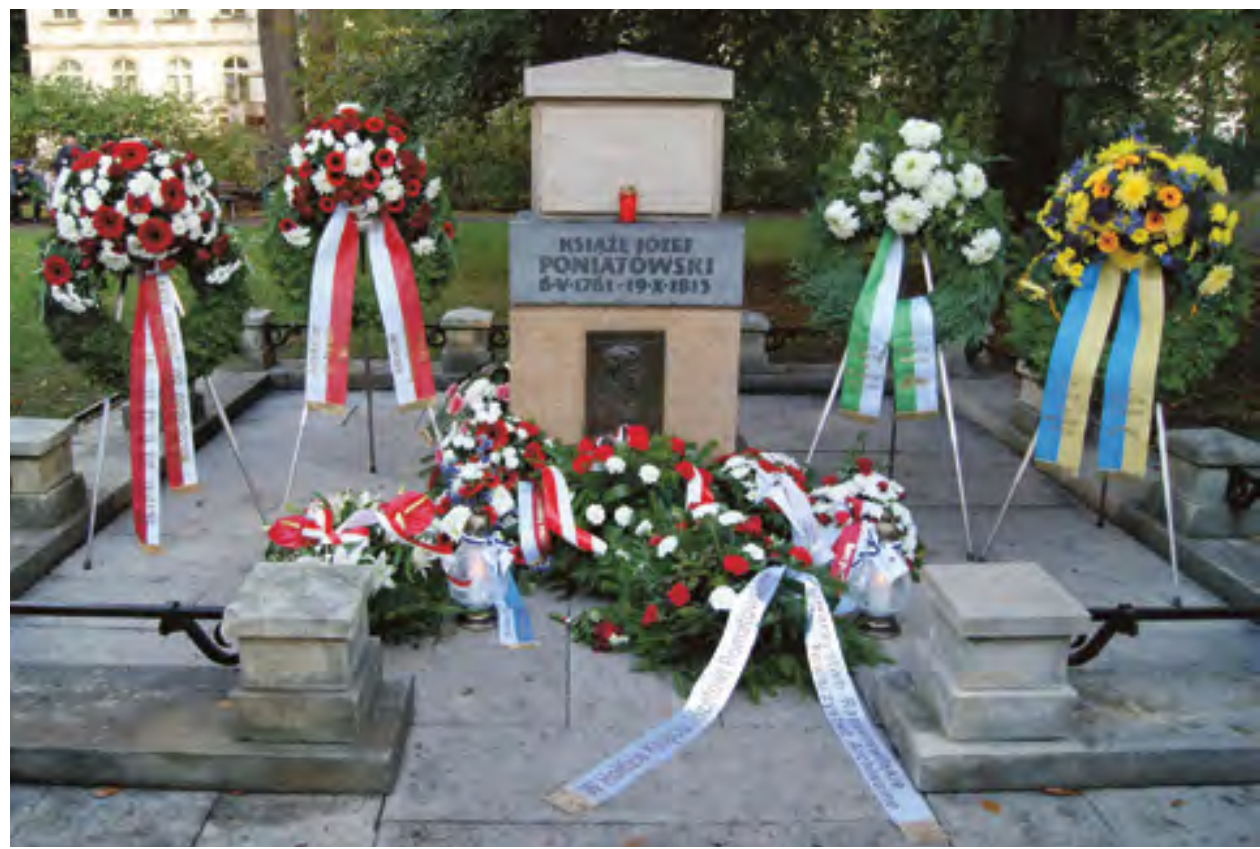

Abb. 3 Feierliche Einweihung des Denkmals Poniatowski am 19. Oktober 2013, zum 200. Jahrestag seines Todes, am Poniatowski-Plan in Leipzig. Foto: Paweł Gorszczyński, 2013.

historischem Roman „In Schutt und Asche“8 wie auch Marian Brandys’ historischer Roman „Der unbekannte Fürst Poniatowski“"9 und sein Essay über den „Offizier höchster Hoffnungen“10, Józef Sułkowski, den polnischen Adjutanten Napoleons, beigetragen. Am 16. Oktober 1965, anlässlich des 152. Jahrestages der Völkerschlacht bei Leipzig, kehrte die Statue Poniatowskis wieder in die Innenstadt Warschaus zurück (Abb. 2). Allerdings wurde dieser erneut infrage gestellt, als nach der Flugzeugkatastrophe von Smolensk Stimmen in der nationalkonservativen PiS-Partei laut wurden (u.a. des Abgeordneten Artur Górski), die forderten, das Poniatowski-Denkmal ,zurück in den (Łazienki-)Park“ zu verlagern oder aber in der Nähe des Poniatowski-Denkmals ein zweites Denkmal für den ums Leben gekommenen polnischen Präsidenten Kaczyński zu errichten. ${ }^{11}$ Das erste Poniatowski-Denkmal wurde im Dezember des Jahres 1813 in Leipzig errichtet, ganz in der Nähe jenes Ortes, an dem der Marschall, nach der vorzei-

8 Żeromski, Stefan: Popioły [Asche]. Warszawa 1904. (Deutsche Ausgabe: In Schutt und Asche. Zürich 1988).

9 Brandys, Marian: Nieznany książę Poniatowski [Der unbekannte Fürst Poniatowski]. Warszawa 1960.

10 Ders.: Oficer największych nadziei [Offizier größter Hoffnungen]. Warszawa 1966.

11 In: http://wiadomosci.gazeta.pl/wiadomosci/1,114873,8335593,Gorski_Przed_palacem_pomnik_ Lecha_Kaczynskiego.html? $\mathrm{v}=1 \&$ obxx $=8335593 \&$ order=najfajniejsze\&page $=4(15.11 .2015)$. In diesem Kontext steht auch der Spott: Der Politiker Palikot macht sich über Lech Kaczyński lustig. In: http://www.fakt.pl/Palikot-drwi-z-Lecha-Kaczynskiego-,artykuly,78764,1.html (15.11.2015). 
tigen Sprengung der Brücke am 19. Oktober 1813 durch die Franzosen, schwer verwundet die Hochwasser führende Elster zu durchqueren versuchte und dabei ums Leben kam. ${ }^{12}$ Das rekonstruierte Denkmal ist am 19. Oktober 2013, zum 200. Jahrestag des Todes Poniatowskis, feierlich eingeweiht worden (Abb. 3).

Zumeist idealisierende Publikationen über das Leben des Fürsten erschienen bereits unmittelbar nach dem Tode Poniatowskis. Ausschlaggebend für die Apotheose und den einsetzenden Kult waren in erster Linie seine militärischen Erfolge. Einen unmittelbaren Anlass dafür bot die Überführung seines Leichnams von Leipzig, wo er in der Ratsgruft auf dem Johannisfriedhof beigesetzt worden war, nach Polen. Interessant und aufschlussreich ist in diesem Zusammenhang die von Kanonikus Jan Paweł Woronicz (1757-1829) gehaltene Trauerrede in Warschau. Woronicz vertrat darin die Auffassung, dass Poniatowski für das Wohl des Vaterlandes gelebt habe, demzufolge gehöre auch sein Tod ausschließlich dem polnischen Volke, das daraus seine Lehren zu ziehen habe. Grundfesten dieses sich auf Józef Poniatowski stützenden polnischen Patriotismus seien das Streben nach ritterlichen Tugenden, nach Mut und Tapferkeit, nach Größe, nach Edelmut der Seele und einem empfindsamen Herzen als wichtigstem Quell wahren Heldentums und echter Vaterlandsliebe, die Woronicz übrigens als „,unheilbare Krankheit der Polen" charakterisierte. ${ }^{13}$ Mit seiner Grabesrede schuf Woronicz einen für mehrere Generationen gültigen Kanon jener positiven Werte, mit denen der Fürst von nun an immer wieder assoziiert werden sollte. Das nächste große nationale Ereignis, das zur weiteren Festigung der Poniatowski-Legende beigetragen hatte, war die feierliche Überführung des Leichnams auf den Krakauer Wawel. Die Traueransprache hielt Wincenty Łańcucki (1756-1841), der die Könige von Polen inständig bat, den großen polnischen Helden doch in ihre ehrwürdige Gemeinschaft aufzunehmen, habe er doch durchaus diese große Ehre verdient, mit ihnen gemeinsam an einem so heiligen Ort zu ruhen.$^{14}$ Gleichzeitig verwies der Trauerredner auf Poniatowskis Vorbildwirkung, auf die großen Potenzen einer wirklich nationalen, patriotischen Erziehung. Er rief die polnischen Mütter auf, mit ihren Kindern diesen Ort zu besuchen, um ihnen so die Liebe

12 Schäfer, Kirstin Anne: Die Völkerschlacht. In: Deutsche Erinnerungsorte. Bd. 2. Hg. v. Etienne FrançoIs und Hagen SchULZE. München 2001, S. 187-201.

13 Woronicz, Jan Paweł: Kazanie na pogrzebie sprowadzonych do Warszawy zwłoków ś.p. JO Xiążęcia Jozefa Poniatowskiego [...] w kościele Warszawskim Ś. Krzyża dnia 10 Września roku 1814 [Predigt zur Beisetzung der nach Warschau überführten Gebeine des seligen Herrn Fürsten Josef Poniatowski [...] in der Warschauer Kirche zum Heiligen Kreuz am 10. September des Jahres 1814]. Warszawa 1814, S. 34.

14 ŁaŃCUCKI, Józef Wincenty: Kazanie podczas religiyjnych obrzędów przy złożeniu zwłoków Xęcia Józefa Poniatowskiegona czelnego wodza woysk polskich, ministra woyny, marszałka państwa francuskiego, wielu orderów, kawalera w kościele katedralnym krakowskim [Predigt während der religiösen Zeremonie anlässlich der Beisetzung der Gebeine von Fürst Josef Poniatowski, oberster Befehlshaber der polnischen Armeen, des Kriegsministers, Marschalls des französischen Staates, Träger zahlreicher Orden und Chevalier in der Wawel-Kathedrale zu Krakau]. Kraków 1817, S. 12.; Buszko, Józef: Uroczystości patriotyczne na Wawelu w latach Rzeczypospolitej Krakowskiej i w dobie autonomii galicyjskiej [Patriotische Feierlichkeiten auf dem Wawel zu Zeiten der Krakauer Republik und in der Zeit der galizischen Autonomie]. Lublin 1996, S. 36. 
zum Vaterland beizubringen, um an dieser Stelle an den Triumph polnischer Waffen, an die Tugenden tapferer und redlicher Polen in Zeiten der Unfreiheit und Fremdherrschaft zu erinnern. ${ }^{15} \mathrm{Im}$ Jahr der Überführung der sterblichen Überreste Poniatowskis auf den Wawel hatte der polnische Dichter Julian Ursyn Niemcewicz ein wichtiges Gedicht verfasste: „Das Begräbnis des Fürsten Józef Poniatowski“, das in sein Werk „Historische Gesänge“"16 aufgenommen wurde:

[...] Sie beklagen ihn [Poniatowski; HCT] in letzter Tiefe, hat doch der Tod über die Hoffnung das Verderben gebracht, du stürztest mit dem Pferd, die Waffe in der Hand, in die schäumenden Fluten. ${ }^{17}[\ldots]$ Die dankbaren Landsleute, die dein Ableben und deinen Tod zu schätzen wissen, erlauben es den Jahrhunderten nicht, dass deine Taten ausgelöscht werden: Sie errichten ein stolzes Grabmal und krönen dessen Spitze mit einem Kranz aus Lorbeer. ${ }^{18}$

Über den stolzen, ja hochmütigen Poniatowski, vor allem in seiner Warschauer Zeit, hatte Niemcewicz Folgendes geschrieben: ,[... [ Göttern gleich, in seiner Karosse stehend, jagte er durch die Straßen, vorbei an prächtigen Gebäuden, mit seinem Haupt fast Laternen und Dächer streifend. "“19 Einen großen polnischen Helden, wie ihn Kleriker und Literaten unisono forderten, brauchte das dreigeteilte polnische Land dringend, und so begann die Legende Poniatowskis zunehmend die historischen Tatsachen zu verdrängen. Dazu trugen u.a. auch Veröffentlichungen, u.a. in polnischen Schulbüchern, bei, die der patriotischen Erziehung dienten. Trotz aller Unterschiede in den drei Teilungsgebieten Polens wurde in diesen stets die edle Herkunft wie auch die militärische Karriere, vor allem aber der heroische Tod Poniatowskis in der Elster hervorgehoben. Verschwiegen wurde dagegen all das, was einer Idealisierung und Verklärung abträglich sein konnte. So wurde das patriotische Wort zunehmend auch durch Illustrationen, durch Porträts und Gemälde über die Schlachten, vor allem aber über Poniatowskis Tod, ergänzt und bereichert; es kam es zu einer deutlichen Visualisierung der Poniatowski-Legende. ${ }^{20}$ Was die Literatur betraf, waren es zunächst vor allem Gedichte, denen zahlreichen Biografien, Erzählungen und historische Romane

15 Brynkus, Józef: W nurtach historii. W 200. rocznicę śmierci księcia Józefa Poniatowskiego [In den Fluten der Geschichte. Zum 200. Todestag von Fürst Josef Poniatowski]. Kraków 2013, S. 36.

16 Niemcewicz, Julian Ursyn: Pogrzeb Xęcia Józefa Poniatowskiego [Das Begräbnis von Fürst Josef Poniatowski]. In: Śpiewy historyczne Juliana Niemcewicza. Lwów 1895, S. 199.

17 „[...] Wyryją na nim jak w ostatniej toni, Śmierć nad nadzieje przenosząc zgubione, Runąłeś z koniem i z orężem w dłoni, W nurty spienione“. Ebd., S. 199. Übersetzung: Hans-Christian Trepte.

18 Ebd., S. 199.

$19, \ldots[\ldots]$ tak podobny do bogów w powozie stojący, przelatywał ulice wśród przepysznych gmachów, sięgając prawie głową latarni i dachów.“ Ebd., S. 200-201. Übersetzung: Hans-Christian Trepte.

20 Benn, Gottfried: „Finis Poloniae“. In: Odra 1 (1989), S. 64-65; AnATolski, Zdzisław: Śmierć księcia (komentarz do obrazu) [Der Tod des Fürsten (Kommentar zum Bild)]. In: PAL 10 (1986), S. 8-89; Paś, Monika/ŻymiaŁowska, Małgorzata: Książę Józef Poniatowski (1763-1813) - pamiątki i wizerunki [Fürst Josef Poniatowski (1763-1813) - Erinnerungen und Darstellungen]. Kraków 2013; Narodziny legendy [Geburtsstunden einer Legende] (ohne Angabe des Autors). In: Mówią Wieki, 5/245 (1978), S. 2-5. http://www.krzemieniewo.net/viewpage.php?page_id=994 (17.11.2015). 
folgten, die das Leben und den Tod Poniatowskis thematisierten. So lesen wir beispielsweise in Franciszek Arnsztayns Gedicht „Auf den 18. Oktober“: „Gott selbst hat Dir die Ehre der Polen anvertraut. / Und Du hast sie Gott zurückgegeben." ${ }^{\text {"21 }}$ Tadeusz Miciński, auch unter dem Pseudonym Miriam bekannt, schrieb in seinem „Hymnus eines Verbannten“: „Ich ziehe Finis Poloniae aus dem Munde eines tapferen Führers vor, / als die Lüge - dass wir überdauert haben! Eine Lüge, bös und tränenreich!“‘22 Unter dem Pseudonym Śpiewak erschienen um das Jahr 1940 die Verse „Keine Kraft der Erde vermag uns zu vernichten“: „Mit Verachtung weisen wir zurück, inmitten von Sturm und Angst, / die nichtigen Signale der Verzweiflung, / denn die Ehre der Menschheit hat doch anvertraut uns Polen Gott allein ..." ${ }^{\text {"23 }}$ Der in der Tradition der polnischen (Neo-)Romantik stehende polnische Dichter Jan Lechoń schrieb in seiner „Legende“: „All die erhabenen Worte, die du (noch) aus der Schule kanntest, / die Musik der alten Gesänge, der Freiheit Engel, / hoch zu Ross Fürst Poniatowski, der über dem Schreibtisch hing ... [...] Und du vernimmst [...] - die ach so schönen Wort / Wie

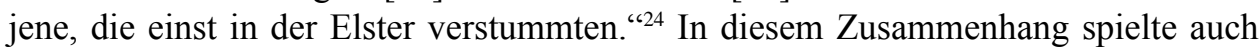
der Schriftsteller Artur Oppman, auch Or-Ot genannte, eine wichtige Rolle. Sein 1918 erschienener Gedichtband, „Lieder über Fürst Joseph“25, kennzeichnet ein „romantischer Heldenkult aus nationaler Vergangenheit““. ${ }^{26} 1913$ hatte Or-Ot aus Anlass des Sterbetags von Poniatowski eine „Elegie in Andenken an Fürst Joseph Poniatowski“'27 geschrieben, in welcher der romantischen Wandlung im Sinne von Adam Mickiewiczs kontemplativem Protagonisten Gustaw hin zum aktiven, tätigen Helden Konrad, in seinem Drama „Totenfeier“ (Dziady), vom Lebemann und Liebling der Salons zum polnischen Heroen, eine entscheidende Bedeutung beigemessen wird. Dieser Wandel geschah in einem engen Zusammenhang mit der berühmten Schlacht von Raszyn, als Poniatowski, ungeachtet des feindlichen Kugelhagels, seine Soldaten zum siegreichen

21 Arnsztayn, Franciszek: Na dzień 18 października Księcia Poniatowskiego [Auf den Tag des 18. Oktobers des Fürsten Poniatowski]. „Sam Bóg Ci powierzył honor Polaków. / Tyś oddał go Bogu.“ In: Kufel (wie Anm. 3), S. 19. Übersetzung: Hans-Christian Trepte.

22 „Wolę Finis Poloniae z ust mężnego wodza, / niż kłamsto - żeśmy przetrwali! Kłamstwo złe kaprawe!“ In: Tadeusz Miciński: Hymn banity [Hymnus eines Verbannten]. In: Kufel (wie Anm.3), S. 20. Übersetzung: Hans-Christian Trepte.

23 „Z pogardą odrzucim, wśród burzy i trwóg, / Nikczemne sygnały rozpaczy, / Bo honor ludzkości powierzył nam Bóg, Polacy..." In: ŚPIEwAK: Żadna siła z ziemi nas nie zetrze [Keine Macht wird uns von dieser Erde tilgen]. In: http://www.bibliotekapiosenki.pl/Zadna_sila_z_ziemi_nas_nie_zetrze (17.11.2015). Übersetzung: Hans-Christian Trepte.

24 „Wszystkie słowa podniosłe, któreś znał ze szkoły, / Muzyka starych pieśni, wolności anioły, / Książę Józef na koniu, wiszący nad biurkiem... [...] I słyszysz - (czyś mógł myśleć?) - równie piękne słowa / Jak tamte, które kiedyś umilkły w Elsterze.“ In: LeChoŃ, Jan: Legenda [Legende]. Warszawa 1924. Übersetzung: Hans-Christian Trepte.

25 Oppman, Artur: Pieśni o Księciu Józefie. [Lieder über Fürst Josef Poniatowski]. Warszawa 1918, S. 4; WąSACZ (wie Anm. 3).

26 Bartnicka, Józefa: Artur Opmann. In: Literatura polska. Przewodnik encyklopedyczny. Bd. II. Red. Czesław Hernas. Warszawa 1985, S. 87. Zit. nach: WĄSACZ (wie Anm. 3).

27 Oppman, Artur: Elegia poświęcona pamięci księdza Józefa Poniatowskiego [Elegie dem Andenken Fürst Josef Poniatowskis gewidmet]. In: OppMan (wie Anm. 25), S. 5; WĄSACZ (wie Anm. 3). 
Angriff gegen den Feind anführte. Allerdings widersprach dem entstehenden Mythos die Tatsache der Kapitulation Warschaus, empfohlen von Poniatowskis Stab. Der Held bewährte sich jedoch auf dem Rückzug als hervorragender und mutiger Kämpfer, als strategischer Denker und siegreicher Feldherr. Die sorglose Zeit der Vergnügungen im Warschauer „Pałac Pod Blachą“ (Palast unter dem Blechdach) schienen vergessen zu sein. Und so war Poniatowski zum Hoffnungsträger der Polen aufgestiegen. Im Geiste des altpolnischen Sarmatismus war ein neuer Held geboren worden, der für die Freiheit seiner Landsleute im geteilten polnischen Land einstand. Von nun an wurde Józef Poniatowski als ein großer Held des polnischen Volkes gesehen, begann sein Mythos, wurde seine Legende aufgeschrieben. Ganz in diesem Sinne legte z.B. Artur Oppman dem Fürsten folgende Worte in den Mund: „Aber im Herzen meines Volkes / möchte ich bleiben in ungebrochenem Andenken / Weiterleben im Gedenken an das Feld des Krieges / Mit erhobenem Säbel, auf fliehendem Ross / Und so durch die Jahrhunderte getragen / einem Morgenrot entgegen - einem großartigen, wenngleich (noch) weiten..." “28

Die heroische Legende von Poniatowskis Tod lebte in der Zeit der Niederschlagung des Novemberaufstandes und der ihr folgenden Polenbegeisterung in Deutschland wieder auf. Das zeigte sich u.a. im programmatischen Motiv des Abschiedes, das sich fast immer mit einer Totenklage verband. Das galt für die Literatur, aber auch für die Malerei. Der deutsche Historienmaler Dietrich Heinrich Maria Monten schuf unter dem Eindruck des niedergeschlagenen Aufstandes von 1830 und des leidvollen Exils der polnischen Truppen zwei Gemälde, „Finis Poloniae 1831“ und „Der Polen Abschied vom Vaterland““. ${ }^{29}$ In der symbolischen Bildkonstruktion ist der Reiter auf dem Schimmel im Zentrum der Szene mit „,dem Porträt des legendären Fürsten Józef Poniatowski versehen $[\ldots]]^{“ 3} .^{30}$ Die sich auf der Grenzsäule befindende Inschrift ist im Kontext der „polnischen Historienlegende“ zu deuten: „,Finis Poloniae“ - Das Ende Polens [...] wird dem letzten polnischen Oberbefehlshabers, Tadeusz Kościuszko, nach der verlorenen Schlacht von Maciejowice zugeschrieben, der die letzte Teilung Polens von 1795 folgte. “"31 Seitdem begleitet dieser Ausruf immer wieder die im martyrologisch-messianischen Sinne interpretierte Geschichte Polens.

Eine zunächst vorsichtige Dekonstruktion von Mythos und Legende setzte relativ früh ein und begann gegen Ende der Teilungen Polens. Begonnen wurde sie durch die Warschauer Historiker Tadeusz Korzon (1839-1918) und Władysław Smoleński (18511926) sowie den Lemberger Historiker Adam Szelągowski (1873-1961). Zu den ersten

28 „Alebym w sercu mojego narodu / Pragnął pamiątką zostać nieustanną / Żyć w jego myśli na wojennym błoniu, Z szablą wzniesioną, na lecącym koniu, / I tak go sobą prowadzić przez wieki / Do jakieś zorzy - wielkiej choć dalekiej...“. In: Oppman (wie Anm. 25), S. 29. Übersetzung: Hans-Christian Trepte.

29 Vanja, Konrad/Weiduschat, Gerhard: Vom Sieg der guten Sache. Über die deutsche Polenbegeisterung. In: Tür an Tür. Polen - Deutschland 1000 Jahre Kunst und Geschichte. Hg. v. Małgorzata OMILANOWSKA. Köln 2011, S. 444-449, hier S. 446.

30 Ebd., S. 446.

31 Ebd., S. 446. 
literarischen Vertretern gehörte Ignacy Prądzyński, der bereits mit 15 Jahren in der Armee Napoleons wie auch im Novemberaufstand von 1830 gekämpft hatte. In seinem Buch „Die letzten vier großen polnischen Führer vor den Jüngsten Gericht“"32 lobpreist Prądzyński Fürst Józef Poniatowski als einen überaus disziplinierten und edlen Helden, der freilich Tadeusz Kościuszko nicht ganz das Wasser reichen konnte, weil ihm dafür angeblich der erforderliche starke Charakter fehle. Prądzyński war überzeugt, dass das Bündnis mit Napoleon den Fürsten zu einem bloßen Werkzeug des Imperators gemacht hätte. Polnische Kritiker thematisierten auch die Herkunft Poniatowskis wie auch seine anfängliche patriotische Untätigkeit. Zunächst in Wien wie auch auf zahlreichen Reisen durch Europa hatte sich Poniatowski nicht durch ein besonderes Interesse für polnische Angelegenheiten ausgezeichnet. Das sollte sich erst nach seiner Ankunft in Polen ändern. Bis dahin galt er als Bonvivant und Playboy, als Liebhaber leichtsinniger Vergnügungen. ${ }^{33}$ Aus jener Zeit stammt auch Poniatowskis Spitzname, Pepi, eine Verkleinerungsform von Joseph/Józef. Der polnische Schriftsteller Marian Brandys legte ein im polnischen kulturellen Kontext wichtiges Buch vor, „Der unbekannte Fürst Poniatowski“‘34, das in Deutschland weitgehend unbeachtet blieb. Anders verhielt es sich mit einem Werk von Jan Dobraczyński. Der Publizist, Politiker und Schriftsteller hatte sich in Volkspolen eingehend mit der Völkerschlacht bei Leipzig beschäftigt. In seinem auch ins Deutsche übertragenen historischen Roman „Vor den Toren Leipzigs - Leben und Tod des Józef Poniatowski ${ }^{\text {“35 }}$ beschrieb Dobraczyński die letzten Tage Poniatowskis vor seinem Tod in der Elster. In zahlreichen Rückblicken ging er auf die europäische Verwandtschaft des Fürsten ein und stellte die These auf, dass Poniatowskis Mutter und die Mutter des österreichischen Generals Karl Philipp zu Schwarzenberg Schwestern gewesen seien; demzufolge wären Schwarzenberg und Poniatowski Vettern gewesen. Entsprechende Familienchroniken bestätigen diesen Tatbestand allerdings nicht. Der Auffassung Dobraczyńskis zufolge wuchs der junge Poniatowski zunächst deutschsprachig auf, Polnisch hatte er nur sporadisch mit seinem Vater, Andrzej Poniatowski, gesprochen, der als Divisionsgeneral in österreichischen Diensten gestanden hatte. Auf Einladung seines Onkels, des letzten polnischen Königs Stanisław August Poniatowski, hatte sich Józef Poniatowski 1789 nach Warschau begeben. Es war das Jahr, in dem die Beratungen des Großen Sejms begonnen hatten. Im Zusammenhang mit den großen historischen Umwälzungen im Polen jener Zeit war der junge Poniatowski bald zu einem eifrigen

32 PrąDZyŃski, Ignacy: Czterej ostatni wodzowie polscy przed sądem historyi. Wstęp historyczny I. Moszczeński [Die letzten vier polnischen Befehlshaber vor dem Gericht der Geschichte. Einführung I. Moszczeński]. Poznań 1865.

33 WawryszuK, Bartosz: Książę Józef Poniatowski - XVIII-wieczny playboy, który nie bał się kul wrogów i szarżował z fajeczką w zębach [Fürst Josef Poniatowski - ein Playboy aus dem 18. Jahrhundert, der keine feindliche Kugel fürchtete und mit der Pfeife im Munde attackierte]. In: http://menstream. pl/wiadomosci-reportaze-i-wywiady/ksiaze-jozef-poniatowski---xviii-wieczny-playboy-ktory-niebal-sie-kul-wrogow-i-szarzowal-z-fajeczka-w-zebach,0,1401606.html (17.11.2015).

34 Brandys (wie Anm. 9).

35 DobraczyŃski, Jan: Vor den Toren Leipzigs - Leben und Tod des Józef Poniatowski. Berlin 1985 (Polnische Ausgabe: Ders.: Bramy Lipska. Warszawa 1976). 
Verfechter des polnischen Reformwerkes geworden. Bereits vor Dobraczyński hatte der polnische Komödienschriftsteller Aleksander Graf Fredro jene Besonderheiten, jene Ambivalenz des Poniatowski'schen Heldentums auf einen Nenner gebracht:

Fürst Poniatowski verfügte tatsächlich nicht über besondere Fähigkeiten eines (militärischen) Anführers, das wussten wir, und dennoch gelang es ihm, die Herzen seiner Soldaten ganz für sich zu gewinnen. Vielleicht auch nur aus dem Grunde, der den Polen stets zu begeistern weiß: Mut, Haltung, Bewegung, Ausdrucksstärke, sie waren ganz von nationaler Art, zugleich vom Glanz des westlichen Rittertums durchdrungen. Auf einem wackeren Pferd ein tapferer Reiter, von standhafter Männlichkeit, von aufrichtigem Ehrgefühl, eine attraktive Gestalt, schwarzer Schnauzbart, die Mütze schief aufgesetzt, das war das Ideal eines polnischen Anführers. Und wenn er am Rande der Hölle geschrien hätte: Mir nach, Landsleute! In die Hölle wären sie für ihn gesprungen. In anderen Augenblicken wiederum stand er für die Verwirklichung der Vorstellung von den erhabenen, reinen, schönen, ritterlichen Tugenden. ${ }^{36}$

In der Zweiten Republik Polen, zwischen den beiden Weltkriegen, wurde in den Schulen und Hochschulen des Landes besonderer Wert auf eine patriotische polnische Erziehung gelegt. Julia Kisielewska (1874-1943) stellte z.B. in ihrem für polnische Schüler geschriebenen Lehrbuch, „Im Dienste des Vaterlandes“637, Poniatowski sogar auf eine Stufe mit derart herausragenden Persönlichkeiten der polnischen Geschichte wie Jan Kiliński, Tadeusz Kościuszko, Jan Henryk Dąbrowski und Romuald Traugutt. Allerdings verweist die Autorin darauf, dass der junge Poniatowski ,po cudzoziemsku“, also fremdländisch erzogen wurde, immerhin hatte er seine militärische Karriere in der österreichischen Armee begonnen und war mit dem Polnischen nur wenig vertraut, das er Kisielewska zufolge erst während seiner Besuche bei seinem Onkel, dem polnischen König Stanisław August Poniatowski, zunehmend verwendet hätte. Die kommunistischen Machthaber Polens waren bemüht, einen Neuzugang zur polnischen Geschichte und ihren großen Helden zu finden. Dabei unterlag auch Józef Poniatowski einer starken politisch-ideologischen Vereinnahmung. So wurde der Fürst zu einem Patrioten, zu einem fortschrittlichen Vertreter des polnischen Volkes gemacht. Auch nach dem demokratischen Umbruch von 1989/1990 gab es, was die Verklärung Poniatowskis betraf, zunächst kaum größere Veränderungen. Allerdings versucht man sich der historischen Gestalt Poniatowski zunehmend auf rationale Weise

36 „Książę Józef Poniatowski nie miał wprawdzie znamiennitych zdolności jako wódź, wiedzieliśmy o tym, a jednak pociągał ku sobie silnie serce żołnierza. Może w części i dlatego że to, co Polaka zawsze zachwyca: odwaga, postawa, ruch, sposób wyrażania się, były czysto narodowe, przeciągnięte wszakże połyskiem zachodniego rycerstwa. Na dzielnym koniu, dzielny jeździec, nieugiętego męstwa, świetnego honoru, pięknej postaci, wąs czarny, czapka na bakier, był idealem polskiego wodza. Gdyby był nad brzegiem piekła krzyknął: za mną dzieci! W piekło skoczono by za nim. W innych zaś chwilach życia urzeczywistniał wyobrażenie wyniosłych, czystych i pięknych cnót rycerskich.“ Zit. nach: PAluszewski (wie Anm. 3), S. 24-25. Übersetzung: Hans-Christian Trepte.

37 KisielewsKa, Julia: W służbie ojczyzny. Pogadanki historyczne dla IV oddziału [Im Dienste des Vaterlandes. Historische Vorträge für die 4. Abteilung]. Warszawa 1932. 
zu nähern. Neben wichtigen Werken der Historiografie war es erneut die Literatur, die sich der Figur des Józef Poniatowski annahm. Literarische Werke gingen gezielt auf Ambivalenzen in Poniatowskis Leben ein. Während es bei Józef Brynkus noch „Józef Poniatowski - ein interessantes und würdevolles Leben, ein ehrenvoller Tod als Passierschein in das vaterländische Pantheon ${ }^{\text {“38 }}$ heißt, gehen andere Schriftsteller gezielt auf Poniatowskis Leben ein, eine Biografie, die genügend Stoff für einen zunehmend universellen Mythos von einem Lebemann, Verschwender, Dandy, Playboy und Weltbürger bot. So lautet der Titel von Sławomir Leśniewskis Buch kennzeichnenderweise „Fürst Joseph - Führer und Liebhaber“39, ein Artikel Leśniewskis wird überschrieben mit: „Fürst Joseph. Ein Dandy als Führer. Vom Lebemann zum Held“، ${ }^{40}$ Die jüngste Veröffentlichung des Schriftstellers, „Fürst Józef Poniatowski - Führer und Dandy“", kann als ein weiterer Höhepunkt in der Entmystifizierung des polnischen Nationalhelden angesehen werden. ${ }^{41}$ In diesem Zusammenhang bleibt allerdings ein wichtiges Buch weitgehend unbeachtet. Es wurde in Leipzig von einem polnischen Vertragsarbeiter geschrieben. Henryk Sekulski: „Przebitka“ (deutsch etwa: Gewinn, Marge) ${ }^{42}$ In diesem Roman wird, ganz in der Tradition der polnischen literarischen Spötter, der polnische Patriotismus verlacht. So wird Poniatowskis Heldentod u.a. in einem Zusammenhang mit der heroischen polnischen Romantik gesehen, einem 1832 in Dresden entstandenen Gedicht von Adam Mickiewicz, „Ordons Redoute“ (Reduta Ordona). Darin, im Widerspruch zur historischen Wahrheit stehend, sprengt der Held Ordon, angesichts der russischen Übermacht, die Redoute und kommt ums Leben:

Zu Beginn (der Stadtbesichtigung) das Denkmal für Fürst Józef, der hier heldenhaft ums Leben gekommen ist, als wir mit Napoleon bei Leipzig ordentlich eins aufs Maul gekriegt haben, und, er, ganz Pole eben, erpicht darauf war, bis zum Schluss zu kämpfen. So kämpfte und kämpfte er, bis er vom schaumbedeckten Pferd in die Fluten der Elster stürzte, und damit gab's einen Patrioten weniger. Das Denkmal - nichts Besonderes, nicht besonders groß, vornehm [...]. - Und diese Elster - fragen wir - ist die weit von hier weg? - Nein, nicht weit. - Die sollte man sich doch angucken. - Kein Problem. Nach kurzer Fahrt steigen wir am Ufer aus und können unseren Augen kaum trauen: Das Wasser reicht bis an die Knöchel! Na, höchstens bis an die Knie. - Wie kann man hier bloß ertrinken? - Noch dazu auf einem Pferde? - Vielleicht war's gar nicht dieser Fluss? Vielleicht hat er vor der Schlacht ordentlich einen gehoben? - Die Dolmetscherin erklärt, dass das Gewässer damals sicher noch nicht begradigt worden war und etwas tiefer gewesen sein muss. - Aber selbst wenn ... Und hat ihn tatsächlich die Strömung weggerissen? Vielleicht weil er schwer verwundet war, eine andere Erklärung gibt's nicht. [...] Schließlich hat ein Verwunde-

38 Brynkus (wie Anm. 15), S. 33-48.

39 LeŚNIEwski, Sławomir: Książę Józef - wódz i kochanek [Fürst Josef - Anführer und Liebhaber]. Warszawa 2012.

40 Ders.: Książę Józef Poniatowski - z hulaki bohater. Dandys wodzem [Fürst Josef - vom Lebemann zum Helden. Ein Dandy als Anführer]. In: Polityka 57/19 (2013), S. 53-55.

41 Ders.: Książę Józef Poniatowski - Wódz i Dandys [Fürst Josef Poniatowski - Anführer und Dandy]. Gdańsk 2012.

42 Sekulski, Henryk: Przebitka [Gewinn]. Olsztyn 2001. 
ter das Recht darauf, dort zu ertrinken, wo er will, andernfalls wär's schon etwas blöd, wenn unser Nationalheld in so einer Pfütze ersoffen sein soll. Na ja, mit diesen reißenden Fluten der Elster, das ist schon 'ne Übertreibung. Sicher hat sich irgendein Dichter, der den Fluss gar nicht gesehen hat, daran aufgegeilt und in seiner Beschreibung ordentlich übertrieben, aus einer Mücke einen Elefanten gemacht! So wie dieser Mickiewicz, der hat geheult und wegen der Redoute herumgejammert, dass diese in die Luft geflogen ist, dass dabei die Verteidiger heldenhaft ums Leben gekommen sind, und dann hat sich's doch herausgestellt, dass dieser Ordon, munter wie ein Fischlein, am Leben ist. ${ }^{43}$

Zusammenfassend kann festgestellt werden, dass Poniatowskis Tod in der polnischen Literatur, Kultur und Kunst nicht nur ehrenhaft und heroisch, sondern auch entsprechend „effektiv“ dargestellt wurde. Poniatowski hatte an der Seite Napoleons, eines großen westlichen Imperators, gekämpft, er endete nicht wie viele andere polnische Widerstandskämpfer am Galgen oder in der Verbannung. Poniatowski hatte vielmehr das „Privileg“, heldenhaft im Kampf zu sterben. Seinem Tod in der Völkerschlacht bei Leipzig kommt eine große nationale Symbolik zu. Dem polnischen Historiker Szymon Askenazy zufolge könnte es tatsächlich so gewesen sein, dass Poniatowski jene in Polen kursierenden Worte zu General Mikołaj Bronikowski geäußert hat. Dieser hatte Poniatowski gebeten, ihm das Oberkommando in der Schlacht zu Leipzig zu übergeben. Darauf habe der Fürst geantwortet: „Gott hat mir die Ehre der Polen anvertraut, und Gott allein werde ich sie zurückgeben“"44, schließlich gelte es „mannhaft zu sterben!“45 „Im nassen Herbst, im sich ausbreitenden Rauch und Feuer, inmit-

43 „Na początku pomnik księcia Józefa, który zginął tutaj bohaterską śmiercią, kiedy razem z Napoleonem dostaliśmy pod Lipskiem porządnie po dupie, a Poniatowski, jak to Polak, uparł się, żeby walczyć do ostatka. Walczył, walczył, aż na spienionym koniu wpadł w nurty Elstery i po nim, jednego patrioty mniej. Posąg niczego sobie, nieduży, elegancki, przyczepić się do niego nie można. - A ta cała Elstera - pytamy - daleko stąd? - Niedaleko. - Warto by ją zobaczyć. - Kajn problem. Podjechawszy kawałek, wysiadamy przy brzegu i oczom swoim uwierzyc nie możemy: wody po kostki! Najwyżej po kolana. - Jak tu utonąć? - Do tego na koniu! - Może tu nie ta rzeka? - Może przed bitwą porzadnie wypił? Tłumaczka wyjaśnia, że pewnie kiedyś strumień nie był zmeliorowany i musiało być trochę głębiej. - No nawet jakby... Ale żeby od razu prąd go porywał? Chyba, że był ciężko ranny, innego wythumaczenia nie ma. [...] Ranny ma prawo utonąć gdzie zechce, bo w przeciwnym razie jakoś głupio, gdyby bohater narodowy miał się topić w takiej kałuży. $Z$ tym, że z tymi bystrymi nurtami Elstery to spora przesada. Pewnie jakiś poeta, co sam rzeki nie widział, podniecił się, w opisie poszedł na całość i zrobił z igły widły. Tak samo jak Mickiewicz, napłakał się, nawyrzekał nad redutą, że wysadzona w powietrze, że jej obrońcy bohatersko polegli, a później okazało się, że ten cały Ordon żyje zdrów jak ryba." SEKULSKI (wie Anm. 42), S. 26-27. Übersetzung: Hans-Christian Trepte.

44 „Bóg mi powierzył honor Polaków, Bogu tylko go oddam.“ In: Askenazy, Szymon: Książę Józef Poniatowski [Fürst Josef Poniatowski]. In: Ders.: Szkice i portrety. Biblioteka Polska. Warszawa 1937, S. 231-245, hier S. 245. Übersetzung: Hans-Christian Trepte.

45 „Trzeba umrzeć mężnie!“ [Es gilt mannhaft zu sterben!]. In: AskenAzy (wie Anm. 44), S. 244-245. „W szarudze jesiennej, w ścielących się dymach i ogniu, śród grzmotu dział, trzasku ręcznej broni, huku pękającego mostu, jęku rannych, krzyku tonących, wściekłego zamieszania ucieczki i pościgu, odcięty od uchodzącej armii napoleońskiej, - on stał na koniu spienionym, osłabły śmiertelnie, zgorączkowany, zziębły, przemokły, okrwawiony cały, omdlejący z ran, znużenia i rozpaczy“. In: Askenazy (wie Anm. 44), S. 244. Übersetzung: Übersetzung: Hans-Christian Trepte. 
ten des Donnerns der Abteilungen, des Knallens der Handwaffen, des Getöses der berstenden Brücke, des Stöhnens der Verwundeten, des Schreiens der Ertrinkenden, des wirren Durcheinanders von Flucht und Verfolgung, von Napoleons abziehender Armee abgeschnitten, richtete er sich auf dem schäumenden Pferd auf, zu Tode erschöpft, fiebernd, durchfroren, durchnässt, völlig mit Blut bedeckt, infolge von Verwundungen, Erschöpfung und Verzweiflung das Bewusstsein verlierend.“46 Poniatowskis Ruf „Es gilt mannhaft zu sterben!“ kann ebenso wie das angeführte Zitat als symbolisches Ende der napoleonischen Ära interpretiert werden. In seiner Bedeutung scheint er dem legendären Ausspruch von Tadeusz Kościuszko „Finis Poloniae“ nahezustehen, der wahrscheinlich eine preußische Interpretation des Sachverhalts gewesen ist und ganz und gar nicht der ,polnischen romantischen Legende mit ihrem Heldentypus" entspricht. ${ }^{47}$

46 In: Askenazy (wie Anm. 44), S. 244-245.

47 Skowronek, Jerzy: Książę Józef Poniatowski [Fürst Josef Poniatowski]. Wrocław 1986. 


\title{
Die Völkerschlacht im Spiegel des polnischen historischen Romans
}

\author{
Ruth Leiserowitz
}

Es lässt sich kurz und ohne Umschweife sagen: Die große dreitägige Schlacht bei Leipzig im Oktober 1813 ist kein Thema des polnischen historischen Romans. Das mag auf den ersten Blick verwundern, haben doch polnische Streitkräfte in beträchtlicher Zahl daran teilgenommen - allein 16.000 Soldaten, die als VIII. Korps im Juli 1813 in die Grande Armée Napoleons eingegliedert worden waren. Darüber hinaus kam in der Völkerschlacht ein überaus prominenter Pole ums Leben, der Feldherr und Fürst Józef Poniatowski (1763-1813). Insofern sind Ort und Zeitpunkt für die polnische Erinnerungskultur a priori markiert. Mustert man die gesamten polnischen historischen Romane über die Ära der Napoleonischen Kriege, fällt - jedoch erst nach genauerer Betrachtung - auf, dass es keine qualifizierte belletristische Auseinandersetzung mit der Völkerschlacht gibt. Auch der Terminus Bitwa narodów (Völkerschlacht) scheint eine spätere Übernahme zu sein. Genuin sprach man in Polen von der Bitwa pod Lipskiem (Schlacht bei Leipzig).

Es bedarf allerdings einiger Erklärungen, warum die Völkerschlacht keinen Weg in den polnischen historischen Roman gefunden hat. Diese sollen hier dargelegt werden, da sie einerseits ein interessantes Licht auf das Phänomen des polnischen historischen Romans über die Ära der Napoleonischen Kriege werfen und andererseits einige Hintergründe über die Wahrnehmung der Völkerschlacht aus der polnischen Perspektive vermitteln. ${ }^{1}$ Es lassen sich zu den Geschehnissen in Leipzig weder eindeutige Deutungen im polnischen kollektiven Gedächtnis aufzeigen, noch existiert jenseits des Heldentodes von Józef Poniatowski eine sinnstiftende patriotische Erzählung. Das polnische Kapitel der Napoleonischen Kriege ist in Polen in erster Linie von Militärhistorikern ausführlich untersucht worden. ${ }^{2}$ Es liegt aber auch eine aktuelle Arbeit von Jarosław Czubaty vor, die sich mit dem gesamten Phänomen des Herzogtums Warschau ausein-

1 Der Beitrag basiert auf der Forschung innerhalb des Internationalen Forschungsprojektes „Nations, Borders, Identities. The Revolutionary and Napoleonic Wars in European Experiences and Memories (1815-1945)“. Die von der Deutschen Forschungsgemeinschaft und dem Arts and Humanities Research Council geförderte deutsch-britische Projektgruppe unter der Leitung von Karen Hagemann und Etienne François „Nations, Borders, Identities: The Revolutionary and Napoleonic Wars in European Experiences and Memories" (NBI) schließt mit einer komparativen und transfergeschichtlichen Analyse europäischer Erfahrungen und Erinnerungen an die Revolutions- und Napoleonischen Kriege eine Forschungslücke.

2 Nieuważny, Andrzej: Czasy napoleońskie [Napoleonische Zeiten]. Wrocław 2001; Morawski, Ryszard/NieuważNy, Andrzej: Wojsko Księstwa Warszawskiego. Artyleria, inżynierowie, saperzy [Das Heer des Herzogtums Warschau. Artillerie, Ingenieure, Pioniere]. Warszawa 2004. 
andersetzt. ${ }^{3}$ Darin resümiert er, dass die Kriege Anfang des 19. Jahrhunderts wichtig für die Ausformung der politischen Mentalität der Polen gewesen sind. ${ }^{4}$ Sie fanden damals aufgrund der entstandenen Bedingungen Möglichkeiten, Verwaltungs- und Regierungsfähigkeiten auszubauen sowie ihre Staatstugenden zu vervollkommnen. Kulturgeschichtliche Aspekte dieses Zeitabschnitts sind in Polen vor allem von Literaturwissenschaftlern untersucht worden. Dazu zählen vor allem die Arbeiten von Maria Janion $^{5}$ und Zdzisław Libera. ${ }^{6}$

\section{Polnische Erfahrungen und Erinnerungen aus der Völkerschlacht}

Da die Analysen, die die Autorin in den vergangenen Jahren bei der Untersuchung der polnischen belletristischen Literatur zu den Napoleonischen Kriegen vorgenommen hat, zeigen, dass zur Abfassung der historischen Romane überwiegend Erfahrungsberichte und Erinnerungen zum Thema herangezogen wurden, gilt es als Erstes zu fragen, inwieweit polnische Zeugnisse über die Völkerschlacht in den polnischen Teilgebieten kursierten. Es gibt sie, so z.B. von Antoni Białkowski, ${ }^{7}$ den Stabsoffizieren Dezydery Chłapowski ${ }^{8}$ und Józef Grabowski ${ }^{9}$ sowie den Generälen Jan Henryk Dąbrowski und Klemens Kołaczkowski ${ }^{10}$. Allerdings sind sie zu diesem Thema nicht besonders umfangreich, eher einsilbig, denn sie schildern die allseits bekannten Tatsachen in relativ kurzen Zusammenfassungen. Darüber hinaus können sie keine weite Verbreitung aufweisen. In der Regel werden diese Texte, obwohl gedruckt vorliegend, nur herangezogen, wenn sie sich als nötig erweisen, d.h., wenn der literarische Nachweis der polnischen Präsenz bei der Schlacht geführt werden soll. Bei der Lektüre fällt durchweg auf, dass die Völkerschlacht bei den polnischen Verfassern und Litera-

3 Czubaty, Jarosław: Księstwo Warszawskie (1807-1815) [Das Herzogtum Warschau (1807-1815)]. Warszawa 2011 (Biblioteka humanisty).

4 Ebd., S. 568.

5 Janion, Maria/Żmigrodzka, Maria: Romantyzm i historia [Romantik und Geschichte]. Gdańsk 2001.

6 Libera, Zdzisław: Od Sejmu Czteroletniego do Napoleona [Vom vierjährigen Sejm bis zu Napoleon]. Warszawa 2004.

7 BiaŁkowski, Antoni: Wspomnienia starego żołnierza [Erinnerungen eines alten Soldaten]. WarszawaKraków 1903.

8 Chlapowski, Adam Dezyderisz: Pamiętniki. cz. 1. Wojny napoleońskie 1806-1813 [Erinnerungen. T. 1. Die Napoleonischen Kriege 1806-1813]. Poznań 1899.

9 Grabowski, Józef (auch Goetzendorf-Grabowski): Pamiętniki wojskowe Józefa Grabowskiego oficera sztabu cesarza Napoleona I; 1812-1813-1814 opracował Waclaw Gąsiorowski [Die Kriegserinnerungen von Józef Grabowski, Stabsoffizier des Kaisers Napoleon I; 1812-1813-1814 in der Bearbeitung von Waclaw Gąsiorowski]. Warszawa 1905.

10 KoŁaczkowski, Klemens: Henryk Dąbrowski twórca legionów polskich we Włoszech 1755-1818. Wspomnienie historyczne / Klemens Kołaczkowski; z francuskiego rękopisu przeł ... [autor] [Henryk Dąbrowski Gründer der polnischen Legionen in Italien 1755-1818. Historische Erinnerungen / Klemens Kołaczkowski; aus der französischen Handschrift übersetzt ... [vom Verfasser]]. Kraków 1901; Ders.: Wspomnienia jenerała Klemensa Kołaczkowskiego. Ksiega I, od roku 1793 do 1813 [Erinnerungen des Generls Klemens Kołaczkowski. Band I, von 1793 bis 1813]. o.O. 1898. 
ten nicht als singuläres Ereignis erfahren wurde, sondern als Endpunkt des von ihnen so genannten „sächsischen Feldzuges“ (kampania saska) Darüber hinaus fällt dem kritischen Leser die folgende Stelle in den Erinnerungen des Stabsoffiziers Dezydery Chłapowski auf. Die Fassung der Textpassage stammt aus der deutschen Übersetzung, die 1910 unter dem Titel: „Als Ordonnanzoffizier Napoleons in den Kriegen 18061813“ in Berlin erschien:

Die russischen Ulanen kamen, als sie angaloppiert hatten, etwas auseinander [...]. Die Ulanen flohen noch schneller, als sie attackiert hatten. Einige blieben in unseren Händen. Es berührte mich schmerzlich, als die schwer Verwundeten jammernd polnisch sprachen. Ein Ulan wollte sich nicht ergeben und wehrte sich mit seinem Säbel, bis ihm ein Chevauxleger zurief: „Bruder, wir sind Polen wie Du!“, worauf er seinen Säbel fortwarf; jedenfalls war ihm gesagt worden, wir wären zwar Ulanen, aber Franzosen. ${ }^{11}$

Es war davon auszugehen, dass das russische Heer auf seinem Weg durch das Herzogtum Warschau Polen für die Armee rekrutiert hatte. Genauere Untersuchungen liegen dazu jedoch bisher nicht vor. Zwar wird die Polnische Reservearmee unter General Leontij (Levin August) von Bennigsen mehrfach in der Literatur angeführt, jedoch sind keine Quellen bekannt, die über die Rekrutierung Auskunft geben. ${ }^{12}$

Von den Erfahrungen zu den Erinnerungen: Die kollektive Erinnerung an die Völkerschlacht gab es im polnischen Kontext nicht. Der Ort Leipzig und der Herbst des Jahres 1813 verdichteten sich für die Polen rasch auf das Ereignis, während dessen der Fürst Józef Poniatowski sein Leben verloren hatte.

Als belletristische Lektüre, die nicht auf den polnischen Fokus ausgerichtet war, aber lebhaft und eindrücklich von den Kämpfen um Leipzig berichtete, diente der polnischen Gesellschaft seit 1881 das Buch des Autorenpaares Émile Erckmann und Alexandre Chatrian Histoire d'un conscrit de 1813 (Geschichte eines Konskribierten Anno 1813) ${ }^{13}$, das in jenem Jahr in einer polnischen Übersetzung unter dem Titel Historia rekruta z 1813 roku erschien und auch mehrmals wieder aufgelegt wurde. ${ }^{14}$ Insgesamt aber war Leipzig als Erfahrungsort der polnischen Soldaten innerhalb der Napoleonischen Kriege nicht präsent.

11 Chlapowski, Dezydery Baron: Aus der Umgebung Bonapartes. Als Ordonnanzoffizier Napoleons in den Kriegen 1806-1813. In: http:/www.polona.pl/dlibra/doccontent?id=12894\&from=FBC (04.06.2014 Link abgeschaltet).

12 Bogdanovič, Modest Ivanovič: Geschichte des Krieges im Jahre 1813 für Deutschlands Unabhängigkeit: Nach zuverlässigen Quellen. Auf Allerhöchsten Befehl 1868. Bd. 2, Abschnitt 2. St. Petersburg 1868, S. 56. Auch Dominic Lieven wiederholt nur bereits Bekanntes: Lieven, Dominic: Russland gegen Napoleon. Die Schlacht um Europa. München 2011 (englische Originalausgabe: Russia against Napoleon - The Battle for Europe, 1807 to 1814. London 2009), S. $398 \mathrm{f}$.

13 Chatrian, Alexandre/Erckmann, Émile: Histoire d'un conscrit de 1813. Paris u.a. 1864.

14 Dies.: Historia rekruta z 1813 roku [Die Geschichte eines Rekruten aus dem Jahr 1813]. o.O. 1881. 


\section{Der polnische historische Roman}

Der historische Roman war die zentrale Literaturgattung des 19. Jahrhunderts. Dieses Genre trat „einen beispiellosen europäischen Siegeszug“ an. ${ }^{15}$ Mit ihm erschien erstmals ein auf die Erinnerungsbedürfnisse der Neuzeit zugeschnittenes Genre. ${ }^{16}$

In Polen entwickelte sich der historische Roman überaus zögerlich. Am Ende des 18. und am Anfang des 19. Jahrhunderts war eine einheimische polnische Belletristik eher eine Seltenheit. Die Bedürfnisse in dieser Richtung wurden hauptsächlich durch den französischen, teilweise durch den deutschen und ein wenig durch den englischen Roman befriedigt. ${ }^{17}$ Allerdings hatte die Lesekultur im Polen des 19. Jahrhunderts elitären Charakter und war gleichzeitig auch durch die breit gehandhabte Zensur, die ebenfalls importierte Literatur betraf, in der Isolation verhaftet. ${ }^{18}$ Noch 1870 betrug die Anzahl der nicht Lesefähigen im Königreich Polen und in Galizien ca. 80 Prozent der Gesamtbevölkerung, während der Prozentsatz in der Provinz Posen bei ca. 30 Prozent lag. ${ }^{19}$

Aufgrund der Teilungsgeschichte des Landes konnte sich der Buchmarkt im 19. Jahrhundert nur schwer entwickeln. Es gab über einen langen Zeitraum hinweg lediglich drei Buchmärkte mit gewollten Vermischungen, Überlappungen sowie starken ausländischen Mischformen, da polnische Bücher mit imitiertem polnischem Impressum im Ausland gedruckt wurden. Dies ermöglichte deren Zirkulation im Königreich Polen, wo eine starke politische Zensur herrschte. So kam es, dass sich der historische Roman nur sehr allmählich als polnisches Genre etablierte. Erste Höhepunkte erlebte diese Gattung kurz vor der Jahrhundertwende mit den Werken von Henryk Sienkiewicz und Bolesław Prus. Allerdings widmeten sie sich historischen Themen anderer Jahrhunderte, wie z.B. Ereignissen des 15. und des 17. Jahrhunderts oder Motiven der römischen Geschichte, wie etwa „Quo vadis“ oder der „Pharao“. Diese Erzählungen weisen jedoch auch allegorischen Charakter auf. ${ }^{20}$

Ende des 19. Jahrhunderts entstand der polnische historische Jugendroman. Dieses Genre bildete sich gleichzeitig europaweit heraus, wobei in jedem Land Werke zu eigenen Topoi entstanden. Während der polnische historische Roman zu dieser Zeit nur allmählich seine Bedeutung erlangte, verlief die Entwicklung des polnischen historischen Jugendromans dagegen rasant. Diese Werke wurden vorrangig zur „Stärkung der Herzen“ (ku pokrzepeniu serc) verfasst. Dieser Ausdruck bezieht sich auf eine Aussage des polnischen Schriftstellers Henryk Sienkiewicz, der seinem Volk die nationale Würde

15 Humphrey, Richard: Literarische Gattung und Gedächtnis. In: Gedächtniskonzepte der Literaturwissenschaft. Theoretische Grundlegung und Anwendungsperspektiven. Hg. v. Astrid ERLL und Asgard NüNNING. Berlin-New York 2005, S. 73-95, hier S. 89.

16 Humphrey (wie Anm. 15), S. 88.

17 Авст, Stanisław: Okruchy wspomnień [Reste von Erinnerungen]. Warszawa 1962, S. 198.

18 Szynder, Bartłomiej: Dzieje cenzury w Polsce do 1918 roku [Die Geschichte der Zensur in Polen bis 1918]. Kraków 1993, S. 66.

19 MaleczyŃsKa, Kazimiera: Książki i biblioteki w Polsce okresu zaborów [Bücher und Bibliotheken in Polen zu Zeiten der Teilung]. Wrocław 1987, S. 51.

20 Sienkiewicz, Henryk: Quo vadis. Kraków 1896; Prus, Bolesław: Faraon [Pharao]. Warszawa 1897. 
wiedergeben wollte und somit in den 1880er Jahren seine große Trilogie über Zeiten schrieb, in denen der Patriotismus der Polen ihr bedrohtes Vaterland gerettet habe. ${ }^{21}$ Diese „Geschichte zur Stärkung der Herzen“ hob, laut der Historikerin Halina KozińskaWitt, ,die siegreichen und großartigen Momente der polnischen Vergangenheit hervor, unterstrich die kontinuierliche Existenz des Polentums, die Einheit der polnischen Provinzen sowie die gesellschaftliche Solidarität aller Schichten und Stände. Die Vermittlung dieser Tradition diente der Schaffung der polnischen modernen Nation, was die Wiedergewinnung der Staatlichkeit unterstützten sollte.“22

\section{Die Erinnerung an die Napoleonischen Kriege im polnischen Jugendroman}

Es soll noch einmal unterstrichen werden, dass es viele andere Themen für polnische historische Romane gab und die Napoleonischen Kriege nicht den Hauptfokus der Erzählung bildeten. Diese Tatsache war u.a. auch auf die starke politische Zensur zurückzuführen, die seit 1819 im Königreich Polen herrschte. ${ }^{23} 1823$ wurde von der zuständigen Behörde in einer politischen Richtlinie verfügt, dass der Kampf gegen den Gebrauch des Namens Napoleon die wichtigste Aufgabe sei. Das Komitee für Zensur war der Meinung, dass jedwede Publikation von „Erinnerungen an den ehemaligen Herrscher Frankreichs“ verboten werden müsse, da „seine Absichten in hohem Maße radikal-revolutionär-reformerisch" gewesen seien. ${ }^{24}$

Demzufolge konnte für eine gewisse Zeit das Thema der Napoleonischen Kriege weder publizistisch noch literarisch verwirklicht werden. Allerdings gab es später eine Zeit, in der das Thema Konjunktur hatte. Von den 142 ausgewerteten polnischen historischen Romanen, die sich hauptsächlich mit Narrativen zu den Napoleonischen Kriegen beschäftigen und die zwischen 1833 und 1945 erschienen, wurden 86, also mehr als die Hälfte, der Erstauflagen zwischen 1895 und 1914 herausgegeben, was beweist, dass die Lockerung der Zensur ein großes Potenzial von Literatur freisetzte.

Für Schriftsteller und Leser war es wichtig, dass die Handlung an Orten spielte, die sich stark mit einer patriotischen Erzählung verbinden ließen. So wurden Geschichten aus Spanien erzählt oder von polnischen Orten unter österreichischer Besatzung, die nach dem Feldzug 1809 an das Herzogtum Warschau kamen. Dabei ging es vorrangig um die Geschichte von Siegen, es gab keine „Niederlagenkultur“ im Roman.

Militärische Handlungen, die sich an deutschen Orten abspielten, wurden höchst selten für Romane ausgewählt. So existiert ein (!) bescheidener Roman zu der Schlacht

21 Sienkiewicz, Henryk: Pan Wołodyjowski. ${ }^{1}$ Warszawa 1888, hier Warszawa 1970, S. 547.

22 KoziŃSKA-Witt, Hanna: Zeremonielle Landschaften. Das Beispiel Krakau. In: Stadt und Öffentlichkeit in Ostmitteleuropa 1900-1939. Beiträge zur Entstehung moderner Urbanität zwischen Berlin, Charkiv, Tallinn und Triest. Hg. v. Andreas R. Hofmann und Anna Veronika Wendland. Stuttgart 2002 (Forschungen zur Geschichte und Kultur des östlichen Mitteleuropa 14), S. 97-110, hier S. 99.

23 SzyndLer (wie Anm. 18), S. 66.

24 Ebd., S. 74. 
von Jena, ${ }^{25}$ für Preußisch Eylau ist kein einziger bekannt. Die Völkerschlacht ist hier nur äußerst marginal vertreten - durch wenige Seiten in zwei historischen Jugendromanen, zum einen in dem Werk von Walery Przyborowski Bóg mi powierzył honor Polaków. Opowiadanie młodego Krakusa (Gott hat mir die Ehre der Polen anvertraut. Die Erzählung eines jungen Krakauers), ${ }^{26}$ erschienen 1912 in Warschau, sowie in dem Band von Zuzanna Morawska Na posterunku (Auf Posten), erschienen 1914 in Posen. ${ }^{27}$ Auf beide Werke wird im Folgenden eingegangen.

Im Gegensatz zu den allgemeinen Themen des polnischen historischen Romans waren die Napoleonischen Kriege das beliebteste Thema des historischen Jugendromans. Augenscheinlich verlieh auch der in erster Linie an die Fachkollegen gerichtete Appell des Historikers Szymon Askenazy auf dem Dritten Polnischen Historikerkongress 1900 in Krakau, sich stärker mit der Geschichte der Legionen und der Napoleonischen Kriege zu beschäftigen, den Jugendbuchautoren Ansporn, ${ }^{28}$ denn innerhalb der nächsten Dekade wurden dazu 23 Werke veröffentlicht. ${ }^{29}$ Hier trafen die Entwicklung des Genres und die Folgen der Entschärfung der Zensur nach 1905 aufeinander, sodass Jugendbücher zu diesem Thema überhaupt erst möglich wurden. ${ }^{30}$

Dieser Lektüre, die heute nicht mehr rezipiert wird und fast vollkommen in Vergessenheit geriet, gebührt besondere Aufmerksamkeit, denn sie leistete einen wesentlichen Beitrag zur patriotischen Erziehung der Kinder und Jugendlichen, die die erste Generation der Staatsbürger im ab 1918 wieder unabhängigen Polen darstellte. Darüber hinaus lasen auch Erwachsene diese Literatur; die Forschung hat nachgewiesen, dass jene, die nicht besonders gut lesen konnten, häufig auch zu Jugend- und Kinderbüchern griffen. ${ }^{31}$

Morawskas Roman Na posterunku wurde 1943 in dem Warschauer Verlag Tajne Wojskowe Zakłady Wydawnicze (Geheime Militärische Verlagsgesellschaft) neu aufge-

25 Przyborowski, Walery: Było to pod Jeną ... Opowiadanie legjonisty [Es war bei Jena ... Die Erzählung eines Legionärs]. Warszawa 1903.

26 Ders.: Bóg mi powierzył honor Polaków. Opowiadanie młodego Krakusa [Gott hat mir die Ehre der Polen anvertraut. Die Erzählung eines jungen Krakauers]. Warszawa 1912.

27 Morawska, Zuzanna: Na posterunku: powieść historyczna na tle życia ks. Józefa Poniatowskiego [Auf Posten: Historischer Roman vor dem Hintergrund des Lebens des Fürsten Józef Poniatowski]. Poznań 1914.

28 Stasiak, Arkadiusz Michał: Przyborowski między prawdą semantyczną i prawdą artystyczną [Przyborowski zwischen semantischer und künstlerischer Wahrheit]. In: Walery Przyborowski i Józef Brandt [Walery Przyborowski und Józef Brandt]. Hg. v. Krzysztof StĘPNIK und Monika Gabryś. Lublin 2007 (Obrazy kultury polskiej), S. 69-78, hier S. 77.

29 SкотNіска, Gertruda: Tradycje narodowo-kulturowe w literaturze dla dzieci i młodzieży: materiały z sesji, Jachranka 30 XI-2 XII 1994 r [Nationalkulturelle Traditionen in der Kinder- und Jugendliteratur: Seminarmaterialien, Jachranka 30. November-2. Dezember 1994]. Warszawa 1996, S. 175.

30 Olszewska, Maria Jolanta: Powieści historyczne Wiktora Gomulickiego - pasje i poszukiwania [Die historischen Romane von Wiktor Gomulicki - Passion und Suche]. In: Ostrołęckie Towarzystwo Naukowe im. Adama Chętnika, Zeszyty naukowe T. XX, S. 9-42, hier S. 29.

31 Dunin, Janusz: Papierowy bandyta. Ksiażka kramarska i brukowa w Polsce [Der Papierbandit. Gebrauchs- und Schundliteratur in Polen]. Łódź 1974, S. 284. 
legt, da dessen patriotischen Bildungsinhalte augenscheinlich immer noch sehr hoch bewertet wurden.

\section{Heldinnen und Helden}

Welche Figuren wurden in den Romanen angesiedelt? Fiktive oder reale Helden? Kollektive oder individuelle? Als ideal galt die Verbindung von beiden Heldentypen. Wesentliche Aufgabe der Autoren war, mittels der Kombination von fiktiven und realen Helden eine sinnstiftende patriotische Erzählung zu konstruieren.

Vorrangig war es ein romantisches Heldenmuster. Es wurden polnische Männer dargestellt, die um Freiheit kämpften und ihr Leben auf dem Altar des Vaterlandes und der Menschheit opferten. Kampf, Heldentum, Militärdienst waren also die notwendigen Elemente der Heldenbiografie. ${ }^{32}$ In vielen Werken wurde das Leben fiktiver Legionäre oder Soldaten erzählt und dazu Episoden mit Napoleon und Kościuszko oder Józef Poniatowski und Jan Henryk Dąbrowski eingebaut. ${ }^{33}$ In den Jugendromanen handelte es sich immer um sehr junge Soldaten, die häufig auch eine Verlobte zu Hause hatten. Dadurch wurden Identitätsvorlagen auch für Leserinnen geliefert. Kriegswaisen beider Geschlechter waren ebenfalls beliebte Heldinnen und Helden im Jugendroman, wodurch sich militärische Erzählstränge und jugendliche Rezipienten in der Konstruktion gut kombinieren ließen. Unter den polnischen Prominenten war besonders Poniatowski wichtig, bildeten doch seine Legenden einen laut Maria Janion ,integralen Bestandteil des Mythos der nationalen Armee“.34

Die Polen erinnerten sich 1912 an das Jahr 1812 als eine Zeit großer Hoffnungen, aber auch der Enttäuschungen und der Trauer. Damals wurde die Jugend von polnischen patriotischen Literaten und Publizisten dazu angehalten, sich mit der Geschichte zu beschäftigen:

[...] dieses Jahr 1812, dessen hundertste Wiederkehr wir begehen, sollte uns anregen, in den Geschichten jener großen Kriege nachzulesen, und unsere heilige und große Vergangenheit zu überdenken. ${ }^{35}$

Darüber hinaus wurde die polnische Öffentlichkeit aufgefordert, über ihre zeitgenössischen patriotischen Verpflichtungen nachzudenken und ,sich im Geiste bereit[zu] halten für zukünftige Kämpfe und Opfer, welche Überraschungen uns auch treffen mögen." 36

32 JANION, Maria: Bohater, spisek, śmierć. Wykłady żydowskie [Held, Verschwörung, Tod. Jüdische Vorträge]. Warszawa 2009, S. 5.

33 JANION/ŻMigrodZKa (wie Anm. 5), S. 322.

34 Ebd., S. 304.

35 KrólińsKi, Kazimierz: Rok 1812 [Das Jahr 1812]. Stanisławów 1913, S. 29.

36 Ebd. 
Dieser Konditionierung für die Zukunft Polens diente die patriotische Literatur mit ihren Helden. Sie alle sollten weiterhin eine Stärkung im kulturellen Gedächtnis erfahren. 1913 war für die Polen ausschließlich das Jahr des Gedenkens an den Tod Poniatowskis. Die Völkerschlacht und andere polnische Gefallene rückten dagegen deutlich in den Hintergrund.

\section{Der Held Józef Poniatowski}

Wer war der viel bedachte Held? Józef Antoni Poniatowski war ein polnischer Aristokrat, der 1807 nach dem Tilsiter Frieden Kriegsminister des neu entstandenen Herzogtums Warschau und Oberbefehlshaber der polnischen Truppen wurde. In der Folgezeit baute er eine neue polnische Armee auf und führte 1809 erfolgreich Krieg gegen Österreich. Im Juni 1812 übernahm Poniatowski innerhalb des Russlandfeldzugs den Oberbefehl über das V. Korps der Grande Armée. 1813 begann er in Krakau mit dem Aufbau einer neuen Streitmacht, die dann das VIII. Korps der Armee Napoleons bildete. In der Völkerschlacht bei Leipzig standen die Truppen am südlichen und südöstlichen Saum des napoleonischen Heeres. Während der Völkerschlacht wurde Poniatowski von Napoleon zum französischen Marschall ernannt. Nachdem die Schlacht verloren war, deckten die Einheiten Poniatowskis den Rückzug Napoleons und seiner Truppen. Poniatowski ertrank währenddessen bei der Durchquerung der Weißen Elster durch irrtümlich abgegebene französische Schüsse (häufig auch als friendly fire bezeichnet). Erst 1814 wurde der Sarg nach Polen überführt, kurzzeitig in Warschau bestattet und schließlich 1817 feierlich in der Kathedrale des Wawels in Krakau beigesetzt. Poniatowski war der erste nichtmonarchische Pole, der dort Platz fand. Immerhin war er aber ein Neffe des letzten Königs. Mit diesem Ereignis manifestierte sich der beginnende Personenkult um ihn. Józef Poniatowski wurde zum Symbol für soldatischen Mut und Treue, für Kampf bis zum Ende und zur Aufopferung für das Vaterland. $^{37}$

\section{Bücher über Józef Poniatowski auf dem polnischen Buchmarkt}

Besonders nach der Überführung der Leiche nach Polen und den Beisetzungsfeierlichkeiten gab es zahlreiche Gedichte sowie Zeitzeugenberichte über den Helden und seinen Tod, die veröffentlicht wurden. ${ }^{38}$ Der Warschauer Politiker und Freimaurer Graf Stanisław Kostka Potocki, der 1816 einen Nachruf auf Poniatowski hielt und

37 S. hierzu auch den Beitrag von Hans-Christian Trepte in diesem Band.

38 Świderski, Jedrzej: Jozefada. W sześciu pieniach nad zgonem św. p. Xiazecia Józefa Poniatowskiego N. W. W. P. Roku 1813 przypadlym [Die Josefiade. In sechs Stücken über das Ableben des Fürsten Józef Poniatowski im Jahre 1813]. Warszawa 1818; Niemcewicz, Julian Ursyn: Śpiewy historyczne, do których przydane są dodatki proza, zawieraiące krótki zbiór historyi polskiéj [Historische Gesänge, denen Prosa hinzugefügt wurde mit einem kurzen Abriss der polnischen Geschichte]. Warszawa 1816. 
diesen auch veröffentlichte, zitierte den Toten mit seinem angeblich letzten Satz: „Gott hat mir die Ehre der Polen anvertraut, und Gott gebe ich sie zurück““. ${ }^{39}$ In den Text des langen Epos, das Jędrzej Świderski 1818 über den Tod Poniatowskis veröffentlichte, wurde dieses Zitat ebenfalls eingebettet. Interessant ist, dass der Verfasser innerhalb der vielen Verse keine Beschreibung der Schlacht lieferte und auch auf die Episode mit dem Marschallstab verzichtete. ${ }^{40}$ So wurde in kurzer Zeit mehrfach dieses Zitat, wie auch weitere vermeintliche Sätze von Poniatowski aus seinen letzten Tagen, schriftlich in Umlauf gesetzt, die sich fest im polnischen kollektiven Gedächtnis verankerten.

Ein neuer Schub von Werken über Poniatowski wurde durch die Biografie von Szymon Askenazy ausgelöst, die erstmals 1904 erschien und noch vor dem Ersten Weltkrieg mehrfach aufgelegt wurde ${ }^{41}$ Dieser romantische Lebenslauf wurde vielfach abgeschrieben und immer wieder unter neuer Autorenschaft ediert. Allein 1913 erschienen sechs Biografien über Poniatowski, wovon die Hälfte von Schriftstellerinnen verfasst worden war. ${ }^{42}$ Alle Biografien trugen denselben Titel. Die Autoren schienen nicht zu befürchten, dass ihr Werk mit dem eines anderen verwechselt werden würde.

Über die Jubiläen hinaus war Poniatowski eine Person, die lang anhaltend die Gemüter beschäftigte, so erschien noch 1931 eine neue Biografie des Helden von Jan Adolf Hertz, Ksiązę Józef Poniatowski (Fürst Józef Poniatowski). ${ }^{43}$

Zwei Schriftsteller, die für den historischen Jugendroman vor dem Ersten Weltkrieg in den polnischen Teilungsgebieten wichtig waren, befassten sich ebenfalls stark mit der Figur Poniatowskis. An erster Stelle steht hier Zuzanna Morawska (1840-1922), die als Kinder- und Jugendbuchautorin sowie im Bildungsbereich tätig war, über 15 historische Jugendromane verfasste und für Zeitschriften wie Przyjaciel dzieci (Kinderfreund) und Bluszcz (Efeu. Wochenzeitschrift für Frauen) schrieb.

Wie sie gab es Anfang des 20. Jahrhunderts mehrere polnische Pädagoginnen im russisch verwalteten Teilungsgebiet, die ihre Schülerinnen zu glühendem Patriotismus

39 Kostкa Ротоскі, Stanisław: Pochwały, mowy i rozprawy [Lobreden, Ansprachen und Ausführungen]. Warszawa 1816, S. 455.

40 Libera, Zdzisław: Zapomniane poematy o księciu Józefie Poniatowskim [Vergessene Gedichte über den Fürsten Józef Poniatowski ]. In: Romantyzm, Janion, fantazmaty. Prace ofiarowane Profesor Marii Janion na jej siedemdziesięciolecie [Romantik, Janion, Phantasien. Arbeiten gewidmet Professor Maria Janion zu ihrem siebzigsten Geburtstag]. Hg. v. Maria JANION, Dorota SiwICKa und Marek BIEŃCZYK. Warszawa 1996, S. 89-99, hier S. 96.

41 Askenazy, Szymon: Ksiażę Józef Poniatowski 1763-1813 [Fürst Józef Poniatowski 1763-1813]. Warszawa-Kraków 1904.

42 Gębarski, Stefan: Książę Józef Poniatowski [Fürst Józef Poniatowski]. Warszawa 1913; Jaworski, Franciszek: Książę Józef Poniatowski [Fürst Józef Poniatowski]. Lwów 1913; OczYKowski, Romuald: Książe Józef Poniatowski [Fürst Józef Poniatowski]. Łowicz 1913; Mossoczowa, Michalina: Książę Józef Poniatowski, obrońca honoru Polaków [Fürst Józef Poniatowski, der Verteidiger der Ehre der Polen], Kraków 1913; BogusŁawska, Emma: Książę Józef Poniatowski [Fürst Józef Poniatowski]. Tarnów 1913 (Wydawnictwo Przystępnych Odczytów do Obrazów Świetlnych, 3); PrzewósKa-CzARNOCKA, Zofia: Książę Józef Poniatowski [Fürst Józef Poniatowski]. Warszawa 1914; JuRCZYKowsKi, Józef: Książę Józef Poniatowski [Fürst Józef Poniatowski]. Warszawa 1923.

43 Hertz, Jan Adolf: Książę Józef Poniatowski [Fürst Józef Poniatowski]. Warszawa 1931. 
und gesellschaftlichen Aktivitäten erzogen und zu diesem Zweck zahlreiche Erzählungen aus dem Stoff der polnischen Geschichte „für Familie und Schule“ verfassten. Aus Gründen der Zensur erschienen einige ihrer Werke zuerst außerhalb des russischen Teilungsgebietes.

Ein anderer wichtiger Autor historischer Jugendliteratur, Walery Jerzy Przyborowski (1845-1913), war von Hause aus studierter Historiker und betätigte sich ebenfalls als Übersetzer der Romane von Émile Zola und Alexandre Dumas aus dem Französischen, wodurch er sich Schreibtechniken aneignete und schriftstellerische Kniffe übernahm. Er veröffentlichte mehrere historische Arbeiten, besonders zum polnischen Januaraufstand, und zahlreiche historische Jugendromane, u.a. auch zu der polnischen Beteiligung an den Napoleonischen Kriegen, die sich großer Beliebtheit erfreuten.

In allen polnischen Jugendromanen zu den Napoleonischen Kriegen, die vor dem Ersten Weltkrieg von Schriftstellerinnen verfasst wurden, so etwa von der bereits erwähnten Zuzanna Morawska und von Tereza Papi, war der Auftritt von Poniatowski zwingend vorgesehen. In der Regel kulminierte die Romanhandlung in der persönlichen Begegnung mit Poniatowski. Dieser Held eignete sich aufgrund zahlreicher Zuschreibungen auch für die weibliche Leserschaft. So wird in dem Roman Na Posterunku die jugendliche Hauptheldin Jagusia mit anderen jungen Mädchen bei Poniatowski vorstellig, da sie auch als Soldaten kämpfen wollen. ${ }^{44}$ In den historischen Romanen für die erwachsene Leserschaft kam Poniatowski nur als Nebenfigur vor, insbesondere als Heerführer, vor allem im Feldzug von 1809.

Außerhalb des Untersuchungszeitraums existiert lediglich ein historischer Roman über Józef Poniatowski während der Völkerschlacht, den Jan Dobraczyński 1976 unter dem Titel Bramy Lipska (Die Tore Leipzigs) herausgebracht hat ${ }^{45}$ und der 1985 in der deutschen Übersetzung unter dem Titel „Vor den Toren Leipzigs. Leben und Tod des Józef Poniatowski“ in der DDR erschien. ${ }^{46}$ Über die Motivation des Autors, sich gerade diesem Thema zu widmen, ist nichts bekannt. Die Veröffentlichung in der DDR hatte indes einen politischen Grund. Das Kulturministerium der DDR beschloss 1982, nach der Ausrufung des Kriegsrechts in der Volksrepublik Polen, weiterhin Bücher und Filme aus dem Polnischen übersetzen zu lassen, jedoch nur von jaruzelskitreuen Autoren. Die Werke von Dobraczyński, der zu diesem Zeitpunkt als Vorsitzender der Dachvereinigung PRON, Patriotyczny Ruch Odrodzenia Narodowego (Patriotische Front für die Nationale Wiedergeburt), fungierte, standen da an erster Stelle. Das Werk hat jedoch kein größeres Echo hervorgebracht.

44 Morawska (wie Anm. 27), S. 82-84.

45 Dobraczyński, Jan: Bramy Lipska [Die Tore Leipzigs]. Warszawa 1976.

46 Ders.: Vor den Toren Leipzigs. Leben und Tod des Józef Poniatowski. Roman. Berlin 1985. 


\section{Die Thematisierung der Völkerschlacht}

Die Autoren Zuzanna Morawska und Walery Przyborowski haben je einen historischen Jugendroman verfasst, in dem Leipzig einen Nebenschauplatz darstellt. Die Art und Weise, wie sie das Schlachtereignis in die Handlung einflechten bzw. vernachlässigen, ist geradezu exemplarisch für die Rolle, die die Völkerschlacht im polnischen kollektiven Gedächtnis spielte.

Bei Morawska wird die Völkerschlacht als Ganzes gar nicht eingeführt. Sie baut in ihrem Roman Na posterunku das gesamte Geschehen ausschließlich um ihren Haupthelden Poniatowski auf. Eine Spezifik ihrer Werke besteht darin, dass sie Zitate einfügt und diese auch im Text kenntlich macht, um die Authentizität der Erzählung zu unterstreichen. So schildert sie auch die Verleihung des Marschallstabes an den Polen: „Poniatowski zog die Augenbrauen hoch: ,Ich kämpfe nicht für Ruhm und Auszeich-

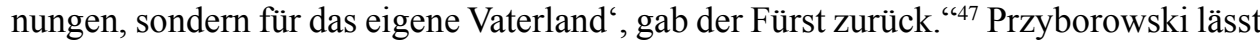
seine Erzählung, die in der ersten Person Singular eines 18-jährigen Krakus (wie man die von Poniatowski in Krakau rekrutierten Soldaten nannte) vorgetragen wird, zwar in der Völkerschlacht zu Leipzig kulminieren, beschreibt oder interpretiert dieses Ereignis aber nicht. Zum einen meint er, dass das Ereignis schon beschrieben sei, zum anderen will er nur die enge Perspektive des jugendlichen Haupthelden und Erzählers darstellen. So heißt es bei ihm:

Soll ich diesen riesigen Kampf beschreiben, an dem fast alle Völker Europas teilnahmen und der zu Recht von den Deutschen „Völkerschlacht“ genannt wurde? Das haben bessere und talentiertere Federn geleistet, vor allem, da ich ja nur das weiß, was ich mit eigenen Augen gesehen habe, während das, was sich anderswo abspielte, mir völlig fremd ist. Da ich immer im Gefolge des Heerführers war, konnte ich ihn auch immer besser als andere beobachten, aber ich war damals ein junger Bursche, der nicht daran gewohnt war, die sich rundherum abspielenden Ereignisse aufmerksam zu betrachten, die ich manchmal nicht gänzlich verstand. Ich weiß nur, dass sich unser Korps tapfer schlug, keinen Schritt zurückwich, dass der Kampf wild war und das Getöse so groß, dass die Erde zitterte und dass der Pulverdampf einen geradezu schmoren ließ. ${ }^{48}$

Allerdings weist seine kurze Passage darauf hin, dass es augenscheinlich keine erwähnenswerte populärwissenschaftliche polnische Schilderung dieses Großereignisses in der Zeit vor dem Ersten Weltkrieg gab, sonst hätte Przyborowski zwingend darauf verwiesen, wie es sonst sein Stil war.

Typisch für beide Autoren ist auch, dass der Handlungsbogen mit dem Tod des Haupthelden endet. Zwar finden auf den letzten Seiten die eingeführten Personen, wie der Militärarzt Zygmunt Szerski in Morawskas Roman und der junge Krakus bei Przybyszewski, wieder nach Hause zurück, aber diese wenigen Sätze stehen in beiden Erzählungen nur als Nachklang. Bei Morawska lautet das Ende wie folgt:

47 Morawska (wie Anm. 27), S. 211.

48 Przyborowski (wie Anm. 25), S. 205. 
Geendet. So. Das Leben des großen Helden hatte geendet. Die große Geschichte des Kampfes unseres Volkes hatte geendet. Seine großen Hoffnungen. Fünfzehntausend Soldaten, darunter viele Generäle und Kommandeure gerieten in Gefangenschaft. Viele gingen ins Exil. Die Treuesten gingen, um das Schicksal des besiegten Herrschers ... Napoleons zu teilen. Nur eine Handvoll kehrte in das Land zurück. Sie kehrten zurück, um dessen Elend zu sehen und Gräber für die anzulegen, die in fernen Ländern gefallen waren. Sie brachten große Erinnerungen mit und lebten mit diesen Erinnerungen. Auch Zygmunt Szerski kehrte zurück. ${ }^{49}$

Morawska, die innerhalb ihrer Erzählungen gerne mit Detailtreue trumpft, wird gegen Abschluss allgemein patriotisch auf Kosten der historischen Genauigkeit, wie in diesem Fall, wo es um die angebliche Gefangenschaft der Angehörigen des V. Korps geht. Diese kehrten ab dem 1. Juni 1814 mit ihrer Ausrüstung, ihren Uniformen und militärischen Auszeichnungen unter freiem Geleit nach Polen zurück. ${ }^{50}$

Bei Przyborowski wird das individuelle Geschehen des Icherzählers mit der Perspektive auf den großen Helden verknüpft:

Gleichgültig schaute ich zu, wie ich vom Pferd geholt wurde, ich fühlte keine Hiebe und Knuffe, mit denen nicht gespart wurde, ich ließ mir mein Geld und meine Uhr nehmen. Was konnte mich das alles noch berühren, wenn der, der stolz die Ehre der Polen trug, in den Wellen eines grimmigen deutschen Flüsschens umgekommen war. Ich wiederholte mir die Worte, die er ausgesprochen hatte, als er sich durch die Gärten längs des fatalen Flusses manövriert hatte, und diese waren mir in dieser Katastrophe, die uns alle und mein Volk betraf, der einzige Trost: „Gott hat mir die Ehre der Polen anvertraut, und Gott gebe ich sie zurück“. ${ }^{51}$

Am Ende der Erzählung erweist sich Przybyszewski wieder einmal als Historiker. Er platziert das berühmte letzte Zitat von Poniatowski und vermeidet wortreiche Allgemeinplätze. Der Leser dieser Jugendromane erhält keine konkreten Informationen über die Völkerschlacht. Das Schicksal der vielen polnischen Soldaten bleibt blass, da die Tragik des individuellen Helden absolut im Vordergrund steht und keine anderen Handlungsstränge zulässt.

\section{Fazit}

Theoretisch hätten polnische Schriftsteller auf der Basis der vorhandenen Erfahrungsund Erinnerungsberichte am Anfang des 20. Jahrhunderts direkt zum 100. Jubiläum einen großen Roman über die Völkerschlacht aus polnischer Sicht abfassen können. Dazu kam es jedoch nicht. Die These liegt nahe, dass das Thema vor allem deswegen nicht aufgegriffen wurde, weil es bis dahin keine Deutung dieses kollektiven Ereignis-

49 Morawska (wie Anm. 27), S. 203.

50 Grabowski (wie Anm. 9), S. 186.

51 Przyborowski (wie Anm. 25), S. 216. 
ses gab, an dem polnische Soldaten auf beiden Seiten beteiligt waren. Somit ließ sich keine sinnstiftende patriotische Erzählung konstruieren. Hinzu kam, dass das zeitliche und örtliche Umfeld durch die ausgiebigen Publikationen über Fürst Józef Poniatowski und seinen Tod anscheinend ,ausgeschöpft“ schien. Drittens war der Heldentod des polnischen Heerführers zu einem derart alle und alles überstrahlenden Topos geraten, dass in dessen Radius keine weiteren Handlungsstränge angesiedelt werden konnten. Diese hätten den Heldenmythos unweigerlich banalisiert bzw. trivialisiert, was innerhalb der damaligen polnischen patriotischen Erinnerungskonstruktion keinesfalls erwünscht war.

Erst 1990 wurde auf dem Warschauer Grab des Unbekannten Soldaten eine Tafel mit den Namen der wichtigen Orte, an denen Polen vor 1914 gekämpft hatte, angebracht. Jetzt stehen hier für die Zeit der Napoleonischen Kriege die Ortsnamen Somosierra, Raszyn, Smoleńsk, Borodino, Zamość, Leipzig und Arcis-sur-Aube.

Damit ist die Leipziger Völkerschlacht in den Kanon der Erinnerung aufgenommen worden und wird aus polnischer Perspektive nicht mehr ausschließlich auf den Ort des Todes von Józef Poniatowski reduziert. 


\title{
Stationen der Erinnerung an die Befreiungskriege in Schlesien: 1813-1913-2013
}

\author{
Agnieszka Zabłocka-Kos
}

\begin{abstract}
Keinen andern Ausweg gibt es, als einen ehrenvollen Frieden, oder einen ruhmvollen Untergang. Auch diesem würdet Ihr getrost entgegen gehen, um der

Ehre willen; weil ehrlos der Preuße und der Deutsche nicht zu leben vermag. Allein wir dürfen mit Zuversicht vertrauen: Gott und unser fester Wille werden unserer gerechten Sache den Sieg verleihen, mit ihm einen sichern, glorreichen

Frieden und die Wiederkehr einer glücklichen Zeit. ${ }^{1}$
\end{abstract}

Mit diesen vom preußischen König Friedrich Wilhelm III. am 17. März 1813 in Breslau geäußerten Worten und dessen zeitgleicher Stiftung des Eisernen Kreuzes begann die am Ende siegreiche Erhebung der Preußen gegen Napoleon. Die ersten Kämpfe fanden in Schlesien statt, wo der Sieg in der Schlacht an der Katzbach bei Liegnitz und Wahlstatt dem Preußengeneral Gebhard Leberecht von Blücher zu Ruhm verhalf. Mit ihr begann die Verehrung für den „Marschall Vorwärts“, der zu einem der wichtigsten deutschen Kriegshelden werden sollte. Die Schlacht bei Leipzig sieben Monate darauf war eine entscheidende Station dieses Krieges. Ihr zweihundertstes Jubiläum bietet Anlass genug, um auf die Vergangenheit zurückzublicken und die Frage zu stellen, was der Beginn der Befreiungskriege für Breslau und Schlesien bedeutete - für die Zeitgenossen sowie 100 Jahre später - und wie die Jahre 1813 und 1913 im heutigen, polnischen Breslau des Jahres 2013 wahrgenommen werden, ob und wie ihrer gedacht wird. Diese drei Stationen der Erinnerung - 1813, 1913, 2013 - besitzen ihre je eigene Aussagekraft, die im politischen und kulturellen Kontext zunächst Preußens, dann Deutschlands und schließlich des heutigen Polens analysiert werden soll. ${ }^{2}$

1 In: http://www.documentarchiv.de/nzjh/preussen/1813/an-mein-volk_friedrich-wilhelmIII-aufruf.html (20.04.2014).

2 EIDEN, Maximilian: Gedächtnisgeschichte. In: Historische Schlesienforschung. Methoden, Themen und Perspektiven zwischen traditioneller Landesgeschichtsschreibung und moderner Kulturwissenschaft. Hg. v. Joachim BAHLCKE. Köln u.a. 2005 (Neue Forschungen zur Schlesischen Geschichte 11), S. 477-510. 


\section{3 - „Als Gott uns Vater Blücher gab“}

Bereits anhand dieses Postulats wird die deutsche Geschichte Schlesiens für das Jahr 1813 als Erinnerungsort klar ersichtlich. ${ }^{3}$ Zunächst kam für die Breslauer und alle anderen Schlesier die Bedeutung des Jahres 1813 in den beiden „Anrufen“ des preußischen Königs, „An mein Volk“ und „An mein Kriegsheer", sowie in der Formierung der schlesischen Landwehr (Freikorps) zum Ausdruck. ${ }^{4}$ Nach dem Ende des Krieges wurden diese jedoch durch die Person und Taten des Feldmarschalls Gebhard Leberecht von Blücher ergänzt bzw. ersetzt. ${ }^{5}$ Als Oberbefehlshaber der Schlesischen Armee begann er seinen Siegeszug mit der Schlacht bei Wahlstatt an der Katzbach am 26. August 1813 und vollendete ihn 1815 in der Schlacht bei Waterloo. Bereits kurz nach der triumphalen Parade der Gegner Napoleons in Paris am 31. März 1814 in Anwesenheit von König Friedrich Wilhelm III. und Zar Alexander I. kündigte die schlesische Presse an, Blücher ein Denkmal widmen zu wollen. Der Hintergrund war vermutlich, dass Blücher am 3. Juni 1814 vom König der Titel eines Fürsten von Wahlstatt ${ }^{6}$ und damit einhergehend die 1810 säkularisierten Güter der Prämonstratenser von Krieblowitz sowie der Zisterzienserinnen von Trebnitz verliehen wurden und er auf diese Weise zum Schlesier gemacht wurde. ${ }^{7}$ Durch die Verleihungen stieg Blücher in schlesische Adelskreise auf, die nicht nur hoch vermögend waren, sondern

3 SснÜск, Robert: Das Blücher Denkmal in Breslau. Ein Beitrag zur Provinzial-Geschichte. Breslau 1884, S. 27.

4 Zur Formierung des Lützow'schen Freikorps und der Rolle des Zobtenbergs als Erinnerungsort: KunicKI, Wojciech: Die Lützower am Zobtenberg. Facetten der Erinnerungskultur. In: Schlesische Erinnerungsorte. Gedächtnis und Identität einer Mitteleuropäischen Region. Hg. v. Marek CzAPLIŃSKI, Hans-Joachim HaHN und Tobias WegER. Görlitz 2005, S. 138-176, sowie in erweiterter Form KUNICKI, Wojciech: Korpus Lützowa w Sobótce. Dzieje pewnego kultu [Das Lützow'sche Freikorps in Zobten. Geschichte eines Kultes]. In: Od patriotyzmu do nacjonalizmu. Rok 1813 w Sobótce i jego rola w świadomości narodowej Niemców. Hg. v. Wojciech KunICKI. Wrocław 2014, S. 9-66.

5 In: http://de.wikisource.org/wiki/ADB:Bl\%C3\%BCcher_von_Wahlstatt,_Gebhard_Leberecht_F\% C3\%BCrst (20.04.2014).

6 Dieser Titel erinnerte nicht allein an die Schlacht an der Katzbach, sondern weckte durch den Ort Wahlstatt auch starke Assoziationen zur Schlacht gegen die Mongolen im Jahr 1241, durch welche deren weiteres Vordringen nach Westen aufgehalten wurde. Wahlstatt ist als spezifisch schlesischer Erinnerungsort, als ein Ort der Verteidigung - des Christentums im Mittelalter, des Katholizismus zur Zeit der Gegenreformation sowie schließlich des Staates und der Nation während der Befreiungskriege - konnotiert. Vgl. Wahlstatt 1241 - Beiträge zur Mongolenschlacht bei Liegnitz und zu ihren Nachwirkungen. Hg. v. Ulrich Schmilewski. Würzburg 1991; Wrabec, Jan: Legnickie Pole [Wahlstatt]. Wrocław 1991. Vgl. auch EIDEN, Maximilian: Das Nachleben der schlesischen Piasten. Dynastische Tradition und moderne Erinnerungskultur vom 17. bis 20. Jahrhundert. Bd 22. Köln-WeimarWien 2012 (Neue Forschungen zur Schlesischen Geschichte), S. 92-110, 127-134.

7 Mempel, Hans Christian: Die Vermögenssäkularisation 1803/10. Verlauf und Folgen der Kirchengutenteignung in verschiedenen deutschen Territorien. Teil II Text. Bd. 15. München 1979 (tuduv-Studien: Reihe Sozialwiss.), S. 31-32. 
sich auch teilweise als Nachfahren der Teilnehmer der Schlacht gegen die Mongolen im Jahr 1241 und somit als Elite unter den Adelsgeschlechtern begriffen. ${ }^{8}$

Im Kontext der Befreiungskriege und der sich in ihnen ausformenden Nationsidee vermochte jedes Handeln, das auf ,ruhmreiche Taten der Vergangenheit“ Bezug nahm, der deutschen Identitätsbildung zu dienen. Für Schlesien war dies von besonderer Bedeutung. Es war in dem halben Jahrhundert preußischer Herrschaft seit 1741 nicht vollständig in Preußen integriert worden, und die während der Napoleonischen Kriege vor allem vonseiten der Katholiken geäußerten prohabsburgischen Sympathien hatten Zweifel an der vollen Loyalität der Untertanen gegenüber dem Monarchen und dem Staat aufkommen lassen. ${ }^{9}$ Der Titel eines Fürsten von Wahlstatt reihte Blücher und seine Kriegstaten unter die bedeutendsten historischen Gestalten und Ereignisse Schlesiens ein. Auch die Verleihung der säkularisierten Güter zweier großer mittelalterlicher Klöster an den preußischen Heerführer im Jahr 1814 lässt sich als symbolischer Akt lesen - als eine Art Sieg über die katholische Welt und daher indirekt auch über Frankreich. Auch andere preußische Generäle und hochrangige Beamte wie z.B. Wilhelm von Humboldt oder Staatskanzler Karl August von Hardenberg erhielten für ihre Verdienste säkularisierte katholische Besitztümer in Schlesien verliehen. ${ }^{10}$ Mit dieser Art Auszeichnung für bedeutende Preußen betrieb der König eine Politik, die Schlesien enger an Preußen anbinden und in der schlesischen Gesellschaft eine propreußische Identitätsbildung befördern sollte. Hier wäre zu fragen, wie sich diese spezielle Politik in Bezug auf Schlesien mit der in den folgenden Jahrzehnten besonders ausgeprägten „Aneignung“ des Jahres 1813 und vor allem des Sieges bei Leipzig durch die Hohenzollern verband. ${ }^{11}$

Blücher wurde in Deutschland und besonders in Schlesien als „Befreier Deutschlands, ja Europas“ zum eigentlichen Helden der Befreiungskriege stilisiert. ${ }^{12}$ Diese Euphorie

8 ConRads, Norbert: Adelsgeschichte. In: Historische Schlesienforschung. Methoden, Themen und Perspektiven zwischen traditioneller Landesgeschichtsschreibung und moderner Kulturwissenschaft. Hg. v. Joachim BAHLCKE. Köln u.a. 2005 (Neue Forschungen zur Schlesischen Geschichte 11), S. 364 365.

9 ZABŁocKA-Kos, Agnieszka: Zrozumieć miasto. Centrum Wrocławia na drodze ku nowoczesnemu city 1807-1858 [Die Stadt verstehen. Das Zentrum Breslaus auf dem Weg zu einer modernen City, 18071858]. Wrocław 2006, S. 19-53.

10 Mempel (wie Anm. 7), S. 31-32.

11 Puschner, Uwe: 18. Oktober 1813: „Möchten die Deutschen nur alle und immer dieses Tages Gedenken" - die Leipziger Völkerschlacht. In: Erinnerungstage. Wendepunkte der Geschichte von der Antike bis zur Gegenwart. Hg. v. Etienne François und Uwe Puschner. München 2010, S. 145-163; Siemann, Wolfram: Krieg und Frieden in historischen Gedenkfeiern des Jahres 1913. In: Öffentliche Festkultur. Politische Feste in Deutschland von der Aufklärung bis zum Ersten Weltkrieg. Hg. v. Dieter Düding, Peter Friedemann und Paul Münch. Reinbek bei Hamburg 1988, S. 298-320.

12 So etwa in einer einflussreichen, in Stuttgart und Tübingen herausgegebenen Zeitschrift „Morgenblatt für gebildete Stände“. Vgl. Hagen, August Heinrich von der: Denkmal der Kraft. In: Morgenblatt für gebildete Stände. Kunst-Blatt Nr. 101, 18.12.1820, S. 402 (In: http://digi.ub.uni-heidelberg. de/diglit/kunstblatt1_1820/0414?sid=e0f6d3e8db56c9f3c049cc6c55e170b9, 15.10.2014). Schon ab 1815 erschienen ihm gewidmete panegyrische Texte wie z.B. GNeIsenau, August Wilhelm Anton Graf Neidhardt von: The life and campaigns of Field-Marshal Prince Blücher, of Wahlstatt. London 1815; 
war zweifelsohne Teil des sehr früh unternommenen Versuchs, aus den preußischen Generälen Gneisenau, Scharnhorst und Blücher deutsche Nationalhelden zu machen, denen die Deutschen ihre Befreiung verdankten. Eine spezielle Rolle spielte hierbei Ernst Moritz Arndt, aber beim gegenwärtigen Forschungsstand bleibt einstweilen die Frage offen, welchen Einfluss seine Publikationen in Schlesien hatten und inwiefern sie insbesondere in Breslau eine ,problüchersche“ Stimmung beförderten. ${ }^{13}$ Unterdessen publizierten die einflussreichen „Schlesischen Provinzialblätter“ schon im Mai 1814 den Artikel des Grafen von Zedlitz-Trützschler „Wie könnten wir Schlesier unsere Helden und Retter ehren?" ${ }^{\prime 14}$ und schlugen ,ein Denkmal von Eisen“ für Blücher vor. ${ }^{15}$ In derselben Zeitschrift erschienen zwischen 1813 und 1816 zahlreiche Artikel über Blücher, und sie spielten sicher eine Schlüsselrolle für die Mythenbildung um Marschall Blücher und die Befreiungskriege sowie für die Stärkung patriotischer Stimmungen in Schlesien. ${ }^{16}$

Als ersten Schritt schlug man die Umbenennung der zentralen Breslauer Plätze Ring, Salzring und Neumarkt in Blücherplatz, Gneisenauplatz bzw. Yorckplatz vor (schließlich wurde der Salzring 1827 in Blücherplatz umbenannt und sollte bis 1945 diesen Namen behalten). ${ }^{17}$ Das Schweidnitzer Tor als Überrest der eben abgetragenen alten Stadtbefestigung wollte man mit einer Blücherstatue versehen. Diese Idee wurde vom Direktor der Breslauer Provinzialkunstschule, Karl Daniel Bach, unterstützt, der sich der Verschönerung der Stadt verpflichtet fühlte und sich zugleich als Patriot etablieren wollte. ${ }^{18}$ Durch kleine Veränderungen wie einen pyramidenförmigen Aufsatz mit vergoldeter Kugel und Siegesadler, Siegeszeichen, Darstellungen von Blüchers ,vorzüglichen Schlachten“ sowie Inschriften an den Seiten sollte der gotische Turm zu einem „würdigen, nicht kostspieligen Helden-Tempel“, einem Triumphbogen in gotischer Gestalt werden. „Dies von tausend Menschen täglich gesehene und durchwandelte

FÖRSTER, Friedrich Christoph: Der Feldmarschall Fürst Blücher von Wahlstatt und seine Umgebungen. Leipzig 1821; BuRкhaRd, Wilhelm: Gebhard Leberecht v. Blücher, preussischer Feldmarschall und Fürst von Wahlstatt. Stuttgart 1835.

13 Gruner, Wolf D.: Ernst Moritz Arndt - die nationale Frage der Deutschen und ihre Instrumentalisierung für die historische Legitimierung des preußisch-kleindeutschen Kaiserreichs. In: Ernst Moritz Arndt (1769-1860): Deutscher Nationalismus, Europa - transatlantische Perspektiven. Bd. 112. Hg. v. Arne Koch und Walter ERHARt. Tübingen 2007 (Studien und Texte zur Sozialgeschichte der Literatur), S. 31-65, hier S. $48 \mathrm{f}$.

14 Gerber, Michael Rüdiger: Die Schlesischen Provinzialblätter 1785-1849. Sigmaringen 1995, S. 57-61, 77-80, 108.

15 Schlesische Provinzialblätter 59 (1814), S. 449-452. Es wäre auch zu fragen, ob man Blücher auch im restlichen Preußen, insbesondere in seiner Heimat Pommern, so wie in den übrigen deutschen Staaten als Nationalhelden aufbaute. Bildete Schlesien diesbezüglich womöglich eine Ausnahme?

16 Dieser Gesichtspunkt ist bislang unerforscht geblieben.

17 Malicki, Patrycjusz: Pomnik feldmarszałka Blüchera we Wrocławiu [Das Denkmal des Feldmarschalls Blücher in Breslau]. In: Studia z dziejów XIX i XX wieku. Hg. v. Teresa KulaK. Wrocław 2005 (Prace Historyczne XXXVII), S. 69-92.

18 Hölscher, Petra: Die Akademie für Kunst und Kunstgewerbe zu Breslau: Wege einer Kunstschule 1791-1932. Kiel 2003, S. 26 f.; WiedemanN, Franz: Zur Vorgeschichte der Blücher-Ehrung in Schlesien. In: Schlesische Geschichtsblätter 2 (1927), S. 33-39. 
Monument sollte mit dem bedeutenden Namen Blücher benannt werden, und erhält zur Vollendung der Lebendigkeit eine Schlage-Uhr [...] um das Werk gleichsam durch sich unsterblich zu machen" ${ }^{19}$ In den Jahren 1814 und 1815 vorgeschlagene Entwürfe sahen weitere Ideen vor: eine Umbenennung des mit heidnischen, vorgermanischen Ritualen konnotierten Zobtenbergs in Blücherberg, ${ }^{20}$ die Umgestaltung des dortigen Kreuzweges zu „Siegesstationen“ ${ }^{21}$ die Errichtung einer kolossalen Blücherstatue auf dem Gipfel der Schneekoppe, des höchstens Bergs Schlesiens, oder gar die Umbenennung des Sternbilds „Orion“ in „Blücher“. Auch der Bau eines Kranken- oder Invalidenhauses in einem Hain an der Katzbach wurde erwogen..$^{22}$ Diese insgesamt wenig realistischen Ideen müsste man den Bestrebungen zur Errichtung eines Nationaldenkmals in Leipzig gegenüberstellen, insbesondere dem von Ernst Moritz Arndt in seiner Schrift „Ein Wort über die Feier der Leipziger Schlacht" aus dem Jahr 1814 formulierten Appell, dort ein „Monumental Memorial“" zu schaffen. ${ }^{23}$ Womöglich war der Vorschlag, in der Breslauer Vorstadt einen „Heldensaal“ mit einer kolossalen marmornen Blücherstatue zu errichten, eine Reaktion auf Arndts Appell. Nach dem Vorbild der Schinkel'schen Architektur als griechischer Tempel entworfen, sollte dieser, so der Urheber der Idee, in seinem Innern auch Nischen für weitere schlesische Helden erhalten und mit als „lebendige Geschichtstafel“" gedachten Gemälden ausgestattet werden. ${ }^{24}$ Dieses möglicherweise ebenfalls von Bach oder vom Stadtarchitekten Johann Friedrich Knorr stammende Projekt ${ }^{25}$ hätte ein genuines Pendant zum Denkmal Alexandre Pierre Vignons für die Grande Armée in Paris (der späteren Kirche Sainte-Marie-Madeleine) und ein Vorläufer der Walhalla an der Donau werden können. ${ }^{26}$ Auch hätte es einen bleibenden schlesischen Erinnerungsort für die Befreiungskriege und andere Kämpfe der Schlesier schaffen können. $\mathrm{Zu}$ einer Realisierung kam es jedoch nicht.

Es ist beim bisherigen Forschungsstand schwer zu beurteilen, ob all diese Initiativen eher als spontane Äußerungen des Zeitgeistes zu verstehen sind oder ob sie durch einflussreiche Presseorgane wie die quasi staatsoffiziellen „Schlesischen Provinzialblätter“

19 Schlesische Provinzialblätter 62 (1815), S. 319-327, hier S. 324-325.

20 Hagen (wie Anm. 12), S. 402; Kunicki (wie Anm. 4), S. 50-51.

21 Schlesische Provinzialblätter 63 (1816), S. 427.

22 Wiedemann, Franz: Geschichte des Blücherdenkmals in Breslau als Zeitbild, 1827 bis 1927. In: Zeitschrift des Vereins für die Geschichte Schlesiens 61 (1927), S. 220-244.

23 Poser, Steffen: Soll es gesehen werden, so muß es groß und herrlich seyn ... Völkerschlacht-Erinnerung und Ideen für ein Völkerschlachtdenkmal. In: Völkerschlachtdenkmal. Hg. v. Volker RodeKAMP. Leipzig ${ }^{3} 2009$ ['2003], S. 49; Puschner (wie Anm. 11), S. 145-163.

24 Ein Vorschlag, Blüchers Denkmahl in Blüchers Geist auszuführen. In: Schlesische Provinzialblätter 63 (1816), S. 419-430, hier S. 425-426..

25 BıŃKowsKa, Iwona: Natura i miasto. Publiczna zieleń miejska we Wrocławiu od schyłku XVIII do początku XX wieku [Stadt und Natur. Die öffentlichen Grünflächen Breslaus vom ausgehenden 18. bis zum frühen 20. Jahrhundert]. Wrocław 2006, S. 110-111 präsentiert den Entwurf eines Belvedere auf der Taschenbastion in Gestalt eines antiken Tempels. Dabei handelt es sich möglicherweise um einen der in der Presse erwähnten Vorschläge für das Blücherdenkmal.

26 Bischoff, Ulrich: Denkmäler der Befreiungskriege in Deutschland 1813-1815. Berlin 1977. 
gelenkt wurden. ${ }^{27}$ Eine zweifelsohne große Rolle bei der Mythenbildung um den Kriegshelden Blücher spielten jedoch Künstler, Intellektuelle sowie der propreußisch eingestellte schlesische Adel. Sämtliche Bestrebungen, Blücher in Schlesien zu ehren, kulminierten letzlich in der ,trivialen“ Idee, ihm auf dem Salzring, einem der Breslauer Hauptplätze, ein „Standbild zu Fuß“ zu setzen. ${ }^{28}$ Die anfangs vom Bürgertum getragene Idee wurde sehr schnell vom schlesischen Adel übernommen und in ein konservativ-monarchistisches Bekenntnis transformiert. Das Blücherdenkmal wurde eine der Hauptstationen eines Triumphwegs, der über die Schweidnitzer Straße und den Ring zum Salzring führte und im Königsschloss endete. Zugleich war es das erste öffentliche Breslauer Denkmal, das man einer weltlichen Persönlichkeit widmete.

Anfangs wurden für das Denkmal zwei mögliche Standorte in Betracht gezogen: der in der Nähe des Königsschlosses an der eben erst anstelle der alten Stadtbefestigung angelegten Promenade geplante Exerzierplatz oder das Stadtzentrum. Da das Gelände der ehemaligen Befestigungsanlagen, die nach der Einnahme der Stadt im Januar 1807 auf Befehl der französischen Militärführung geschleift worden waren, immer noch nicht vollständig geräumt worden war, fiel die Wahl auf den Salzring. Man diskutierte lange über die Gestalt des Denkmals. Dabei ließ man die vorausgehenden Fantastereien zur Umgestaltung des Schweidnitzer Tors außer Acht und präferierte stattdessen ein Anknüpfen an antike Traditionen. Dies äußerte sich in - wiederum kritisierten - Vorschlägen, es in Gestalt einer Säule (nach dem Vorbild der Trajanssäule), eines Triumphtors oder eines antiken Tempels zu errichten.

1817 beendete Friedrich Wilhelm III. die Auseinandersetzungen und beschloss die Errichtung einer Blücherstatue in Form eines Standbildes. Es begannen langwierige Verhandlungen mit verschiedenen Künstlern, darunter Thorvaldsen und Schinkel, schließlich fiel die Wahl jedoch auf den deutschen Bildhauer Christian Daniel Rauch. Damit hatte sich die von Barthold Georg Niebuhr vertretene Auffassung durchgesetzt: „Ein Nationaldenkmal darf nur in dem unglücklichen Falle Fremden aufgetragen werden, wenn der Nation selbst ein Künstler fehlt; ja man möchte sagen, dass in diesem Falle die Sache sogar besser ganz unterlassen würde, indem es dann ein fremdartiges

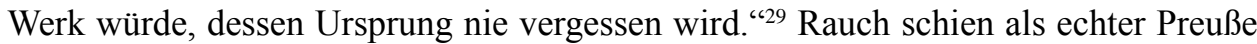
und Schöpfer einer 1815 entstandenen und in Dutzenden von Kopien verkauften BlücherBüste der adäquateste Künstler zu sein. Das Standbild sollte aus Bronze gegossen werden, während der Sockel, dessen Entwurf man dem bekannten schlesischen Architekten Karl Ferdinand Langhans anvertraute, aus Granit geschlagen wurde. Ein Alternativvorschlag kam von Karl Friedrich Schinkel. Anhand der von Rauch und Langhans vorgelegten Entwürfe wurde letztlich ein Denkmal realisiert, dass ein in erster Linie

27 Gerber (wie Anm. 14), S. 108 und in: Exkurs: Die Diskussion um Denkmäler für die Helden der Befreiungskriege 1813/15, ebd., S. 353-355. Dabei handelt es sich um ein Verzeichnis sämtlicher Artikel zum Thema.

28 ZABŁOCKA-Kos (wie Anm. 9), S. 118-129, hier eine gründliche Beschreibung der Entstehungsgeschichte sowie eine kunsthistorische Analyse des errichteten Denkmals nebst vollständiger Bibliografie; Malicki (wie Anm. 17).

29 Sснӥск, (wie Anm. 3), S. 8. 


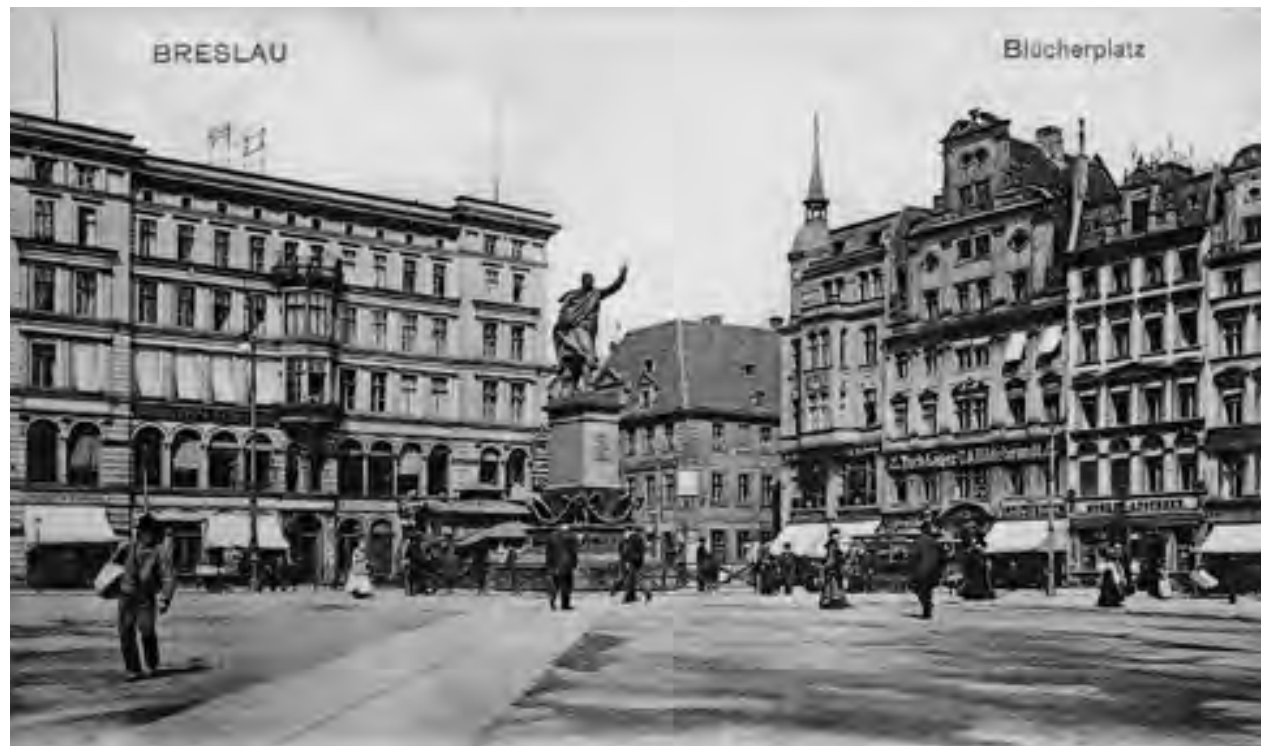

Abb. 1 Blücherdenkmal am Blücherplatz in Breslau, Postkarte um 1910. Sammlung Verlag Via Nova, Wrocław.

aus mangelnden finanziellen Mitteln resultierender Kompromiss war. Übrig blieben zwei sich zum Flug erhebende, Girlanden und den Wahlspruch des Eisernen Kreuzes haltende Preußenadler; auf die schon hergestellten Reliefs mit historischen Szenen verzichtete man jedoch. Dank einer Reduzierung der Sockelhöhe erhielt das Denkmal günstigere Proportionen als ursprünglich vorgesehen. Die Figur Blüchers, in Anspielung auf dessen Spitznamen „Marschall Vorwärts“ im leichten Ausfallschritt und mit erhobener Linker dargestellt, fügte sich gut in das Ensemble des Platzes ein und mischte sich gleichsam unter die dort flanierenden Spaziergänger. Der siegreiche Armeeführer erschien nicht als unnahbarer Heros, seine Gestalt und Taten wurden dem Bürger nahegebracht, er selbst fast als einer von ihnen präsentiert (Abb. 1).

Die lange Zeit, die es dauerte, bis das Denkmal schließlich errichtet wurde, zeugt jedoch davon, wie schnell die anfängliche Blücher-Euphorie verflogen war. Ein Beleg dafür war u.a. die geringe Bereitschaft der Schlesier, Gelder für diesen Zweck zu spenden. Erst eine großzügige Spende des Fürsten Henckel von Donnersmarck ermöglichte schließlich die Aufstellung des seit zwei Jahren fertigen Standbildes auf seinem Granitsockel. Die erst 1827, am 14. Jahrestag der Schlacht an der Katzbach und acht Jahre nach dem Tod Blüchers, stattfindende Denkmalsenthüllung soll eine „klanglose Feier“ gewesen sein. Blücher, den man 1814 noch als „vom Himmel geschenkt" gefeiert hatte, war nur 13 Jahre später kein Objekt kultischer Verehrung mehr. Die Blücherbegeisterung kurz nach Kriegsende war ein Ausdruck der Preußentreue der Schlesier gewesen, deren Loyalität man nach der französischen Eroberung Schlesiens 1807 in Zweifel gezogen 
hatte. 1808 hatte Schlesien seine Sonderstellung innerhalb Preußens verloren und war mehrfach Gegenstand der Kriegshandlungen und der darauf folgenden Friedensverhandlungen gewesen. Die daraus resultierende Ungewissheit über seine politische und staatliche Zugehörigkeit zwischen 1807 und 1815 hatte großen Einfluss auf die späteren Denkmalsinitiativen vor allem adliger Kreise, die so ihre Loyalität zum Hause Hohenzollern artikulieren und unterstreichen wollten. Blücher stellte als ,guter Preuße und für Schlesien gewonnener Pommeraner“, der für einen ,glorreichen Frieden“ kämpfte und „die Wiederkehr einer glücklichen Zeit“ versprach, bis etwa 1820 eine geeignete Helden- und Identifikationsfigur für die Schlesier dar. ${ }^{30}$

1827 befand sich Schlesien jedoch in einer veränderten politischen und gesellschaftlichen Lage. Nach 1815 war es eine administrativ und politisch gut integrierte Provinz des reformierten preußischen Staates, der (einstweilen) weder Rebellion noch ein „Feilschen“ um ihr Territorium drohte. Breslau entwickelte sich außerordentlich dynamisch, und seine Stellung in der Hierarchie der preußischen Städte war zweifelsohne stabil und sehr hoch. Die nach 1815 mit dem Nimbus des Sieges umgebene Gestalt Blüchers musste nicht länger die Rolle der Integrationsfigur, des alle Schlesier um sich scharenden, unbesiegbaren Anführers ausfüllen. Blücher wurde einer von ihnen, wie auch die schließliche Form des Denkmals zeigt. Einziger Verweis auf die einstige Euphorie war die bereits 1814 vorgeschlagene Umbenennung des Salzrings in Blücherplatz, die 1827 zusammen mit der Denkmalsenthüllung erfolgte und bis 1945 bestehen bleiben sollte (inzwischen ist man zum ursprünglichen Namen in seiner polnischen Form „Plac Solny“ zurückgekehrt). Der Platz wurde binnen Kurzem Teil des sich schnell modernisierenden Stadtzentrums, befand sich aber gleichzeitig am zum Königsschloss hinführenden Triumphweg. Das Denkmal stellte also einen Schnittpunkt zweier semantischer Ebenen im öffentlichen Stadtraum dar: Es markierte einerseits den bürgerlichen Platz, in dessen Kontext Blücher gleichsam zu einem unter vielen Breslauer Bürgern wurde, ein buchstäblich ,eingebürgerter“ Kriegsheld in Friedenszeiten. Andererseits repräsentierte es als Bestandteil der städtischen Hauptachse zwischen Königsresidenz und Rathaus die preußische Monarchie, deren Fortbestand von Persönlichkeiten wie Blücher als einem ihrer herausragenden Militärführer garantiert wurde.

Daher erstaunt es nicht, dass die Monarchie im Moment ihrer Bedrohung durch den Vormärz erneut auf die Figur Blüchers zurückgriff. ${ }^{31} 1842$ beschloss König Friedrich Wilhelm IV. anlässlich von Blüchers 100. Geburtstag, ihm ein monumentales Mausoleum in Krieblowitz, wo er 1819 beigesetzt worden war, zu errichten. Für diese Aufgabe engagierte man den Berliner Architekten Johann Heinrich Strack, der nach den Wün-

30 Es ist bislang nicht untersucht worden, inwiefern Blüchers Tod im Jahr 1819 genutzt wurde, um den Schlesiern seine Gestalt erneut in Erinnerung zu rufen, und ob dabei Blüchers „Schlesiertum“ hervorgehoben wurde.

31 Wiedemann, Franz: Blüchers Grabstätte in Krieblowitz. In: Zeitschrift des Vereins für Geschichte Schlesiens 65 (1931), S. 473-501; KunN, Jörg: Das Mausoleum Blüchers in Krieblowitz. In: Mitteilungen des Vereins für die Geschichte Berlins, 88/4, Oktober 1992, S. 79-88. In: http://www.zlb. de/fileadmin/user_upload/berlin_portal/MVGB/MVGB_1992-1995.pdf (15.10.2014 Link nicht mehr aktiv). 


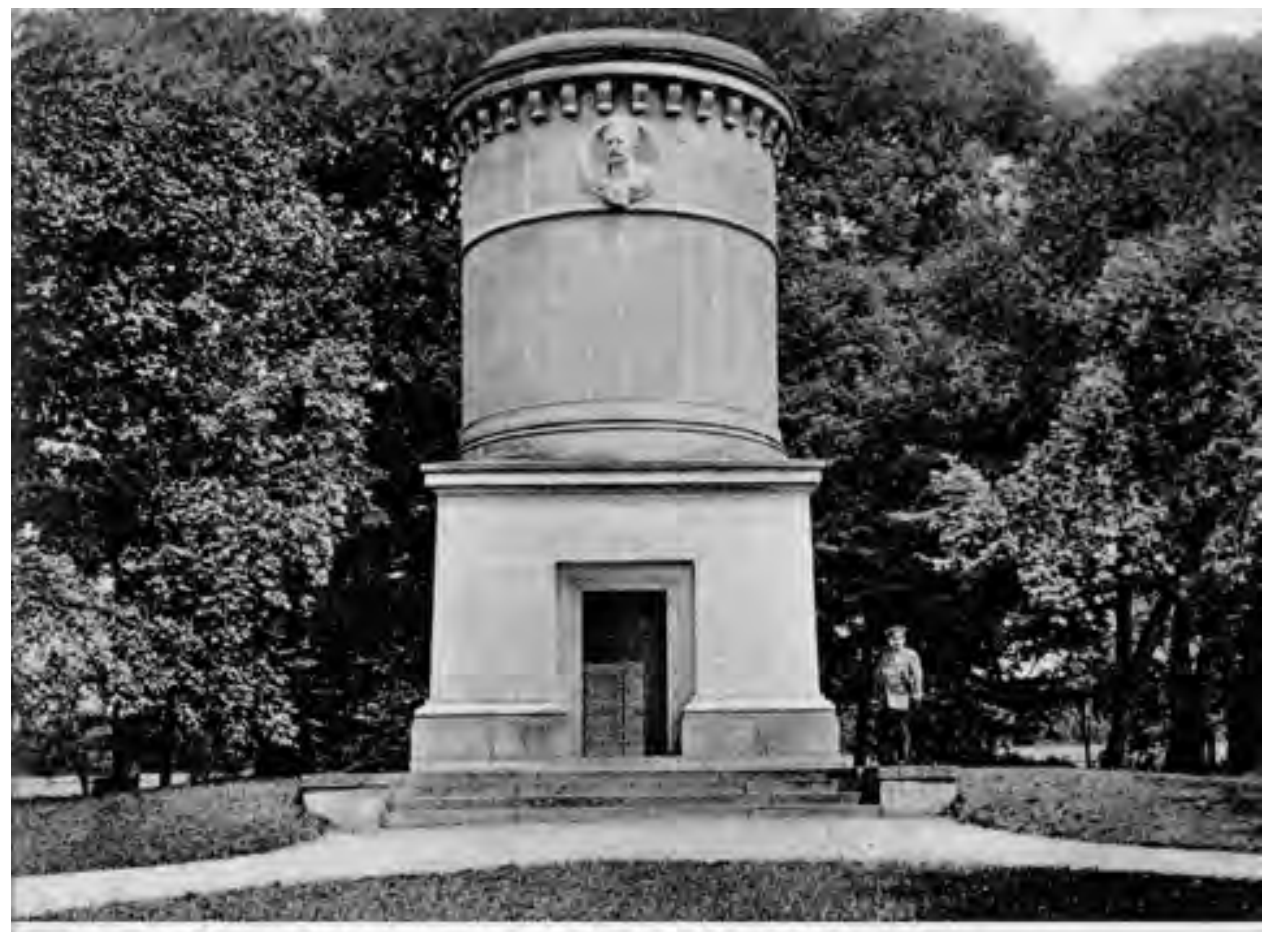

Dem Fursten Blücter von Wahlstalt.

Die Könige Friedrià Wilhelm III., Friedrich Wilhelm IV. und das Heer. Vollendel 1853.

Abb. 2 Krieblowitz in Schlesien, Blücher-Mausoleum, um 1910, Postkarte. Privatsammlung.

schen des Königs architektonisch an das antike Vorbild des aus dem 1. Jahrhundert n. Chr. stammenden Grabmals der Plautier an der Villa Tiburtina in Tivoli anknüpfte, dabei jedoch das Vorbild deutlich modifizierte (Abb. 2). Die politische und gesellschaftliche Situation in Schlesien war zu dieser Zeit angespannt. Als 1840 der neue König den Thron bestieg, erhoben sich hier Stimmen für eine Liberalisierung der Regierung und für das Verabschieden einer Verfassung. Das wiederbelebte Blücher-Gedenken und das Mobilisieren der öffentlichen Meinung für die Errichtung eines Denkmals waren vor diesem Hintergrund zweifelsohne politisch motiviert. Gleichwohl zog sich der Bau auch diesmal hin, und die feierliche Einweihung der neuen Grabstätte Blüchers fand erst am 26. August 1853 zum 40. Jahrestag der Schlacht an der Katzbach statt. Das Gedenken an Blüchers großen Sieg im Befreiungskrieg war von besonderer symbolischer Bedeutung angesichts der nach der Märzrevolution von 1848 etablierten neuen Ordnung, in der der König einen Teil seiner Herrscherprärogative abgeben und in erheblichem Maße von seiner Idee der Monarchie abrücken musste. Der Errichtung des Krieblowitzer Mausoleums waren frühere Initiativen vorausgegangen, möglicherweise hatte sich 
1835 sogar Zar Nikolaus I. in die Diskussionen eingemischt. Während Friedrich Wilhelm III. jedoch in der Endphase seiner Herrschaft bei der Verbreitung des BlücherMythos relativ zurückhaltend gewesen war, da dieser, so Kunicki, „eine mit dem Hohenzollern-Kult konkurrierende Legende" darstellte, ${ }^{32}$ betrachtete sein Nachfolger ihn als „Stütze der Monarchie“. „Die Hohenzollern versuchten, sich beide [...] (Lützow und Blücher) einzuverleiben: indem sie bei den jeweiligen Jubiläen nicht bloß anwesend waren, sondern deren Regie selbst übernahmen, außerdem durch die Aufschriften auf Denkmälern, Grabmälern und Gedenktafeln [...] ordneten sie diese beiden Erinnerungslinien der dominierenden, durch das Königshaus gelenkten Erinnerung unter. ${ }^{\text {"33 }}$ Diese Erinnerung sollte sich angesichts des 1913 in Breslau begangenen Jubiläums wandeln.

\section{3 - „Der alte Marschall sinkt entseelt nieder“: Ein modernes Bauwerk ersetzt den Mythos des Kriegshelden}

Einhundert Jahre nach dem Beginn der Befreiungskriege tauchte Blücher in einem von Gerhart Hauptmann anlässlich des Jubiläums verfassten „Festspiel in deutschen Reimen" noch einmal auf:

Direktor:

Was bist du für ein Eisenfresser?

Blücher:

Der Marschall Vorwärts [...]

Direktor:

Wer - ich kenn dich besser [...] du bist ein Püppchen meines Personals, der Schatten eines toten Generals [...] in deine Kiste.

Blücher:

Wie? Was? Kiste? Zieh!

Direktor:

Du wackrer Graukopf, lieg an deinem Ort!

Was Leben bleiben soll, das sei dein Wort.

Ich schenk es Deutschland - brenn es in sein Herz,

nicht deine Kriegslust, aber dein: Vorwärts.

Der alte Marschall, vom Stab des Direktors berührt, sinkt entseelt nieder. ${ }^{34}$

Mit diesen Worten endet das von Max Reinhardt inszenierte und in der neuen Breslauer Jahrhunderthalle uraufgeführte Stück.

Der Held und Sieger der Befreiungskriege wurde von Hauptmann als Marionette dargestellt, die nichts zu sagen und nichts zu bedeuten hat. Die patriotische Hochstim-

32 Kunicki (wie Anm. 4), S. 52.

33 Ebd., S. 54.

34 In: http://archive.org/details/festspielindeuts00haup (20.11.2015), S. 110-111. 
mung des Jahres 1813 ließ sich im Breslau des Jahres 1913 nicht wieder beleben. Als Gemeinsamkeit blieb der Wille der Protagonisten, ein Identifikationssymbol zu schaffen, mittels dessen man die nationalen Kräfte zusammenführen und einen konnte. Das Jubiläum war ein guter Anlass, um die Schlesier an ein verschwundenes Geschichtsbild zu erinnern - doch Blücher, der nationale und militärische Mythos der Befreiungskriege, musste ,in die Kiste“. 35

Die Feierlichkeiten sollten in erster Linie dazu dienen, die Position der schlesischen Hauptstadt auf der kulturellen und mentalen Landkarte Deutschlands zu stärken. Um 1913 gehörte Breslau sicher zu den wichtigsten Städten im Deutschen Reich, doch drohte es aufgrund seiner Randlage, insbesondere aber durch seinen kulturellen und wirtschaftlichen Bedeutungsverlust in Konkurrenz zu Berlin und vor allem zu Leipzig in Provinzialität zu versinken. Eine neue Messe- und Veranstaltungshalle konnte einen Impuls zur Wiederherstellung von Breslaus starker Position innerhalb Preußens und Ostdeutschlands geben und in der Konkurrenz vor allem zu Leipzig ein Zeichen setzen, um wieder mehr Messen, Veranstaltungen und mit ihnen Gäste in die Stadt zu holen. Um Breslaus Position unter den Metropolen Deutschlands zu stärken, waren neue Großbauten und Institutionen notwendig, aber auch eine kollektive Erinnerung, die geeignet war, die deutsche Identität der Schlesier zu bekräftigen.

Nach 1900 ergriff der Staat, gedrängt durch eine Lobby schlesischer Intellektueller und Industrieller, eine Reihe von Initiativen, um das Prestige von Breslau zu heben. Sie mündeten u.a. in der Anhebung des Status der existierenden städtischen Hochschulen und in der Gründung einer neuen Technischen Hochschule (eröffnet 1910). Diese Initiativen wurden von der Stadtregierung, an deren Spitze zwischen 1891 und 1912 der energische Oberbürgermeister Georg Bender stand, aktiv unterstützt. Die erstmals 1907 geäußerte Idee, in Breslau ein großes Ausstellungsgelände zu schaffen, war zweifelsohne die kommunale Antwort auf die staatlichen Initiativen und verknüpfte sich mit einer breit angelegten Modernisierung der städtischen Infrastruktur, durch die man zu anderen europäischen Metropolen aufschließen wollte. Bisher hatten Industrie- und andere Messen an verschiedenen Stellen am Rand der schlesischen Hauptstadt stattgefunden. ${ }^{36}$ Doch keiner der Standorte eignete sich für eine ständige Ausstellung oder um eine ständige Messe zu organisieren. Breslau fehlte insbesondere eine für solche Zwecke geeignete Festhalle. Mit dem Erwerb des Geländes der ehemaligen Pferderennbahn im sich schnell entwickelnden nordöstlichen Stadtteil Scheitnig durch die Stadt im Jahr 1907 eröffnete sich eine realistische Perspektive für die Einrichtung eines Messegeländes an dieser Stelle. Der Direktor des Schlesischen Museums für Kunstgewerbe und Alterthümer, Karl Masner, stellte damals in der viel gelesenen und einflussreichen

35 Über das Festspiel im bürgerlichen Kontext: Hetrling, Manfred: Politische Bürgerlichkeit. Der Bürger zwischen Individualität und Vergesellschaftung in Deutschland und der Schweiz von 1860 bis 1918. Göttingen 1999, S. 317-330.

36 ZwIERz, Maria: Dziewiętnastowieczne wystawy rzemiosła i przemysłu we Wroclawiu [Die Ausstellungen für Handwerk und Industrie im 19. Jahrhundert in Breslau]. In: Hans Poelzig we Wrocławiu. Architektura i sztuka 1900-1916. [Hans Poelzig in Breslau, Architektur und Kunst 1900-1916]. Hg. v. Jerzy Ilkosz und Beate StöRTKuHL. Wrocław 2000, S. 307-324. 
Kulturzeitschrift „Schlesien“ die Frage „Braucht Breslau ein Ausstellungsgebäude?“37 Gleichzeitig schlug er vor, den 100. Jahrestag des „Aufrufs an mein Volk“ Friedrich Wilhelms III. vom 17. März 1813 zum Anlass für die Errichtung eines solchen Gebäudes zu nehmen. Max Berg, der leitende Architekt des Hallenbaus, ergänzte rückblickend in einem Aufsatz in der „Deutschen Bauzeitung“ im Eröffnungsjahr 1913: „Es kam hinzu, dass Breslau, die Stadt des ,Aufrufs an mein Volk', als Ausgangsstätte der Erhebung Preußens vor hundert Jahren sich verpflichtet fühlte, im Jahre 1913 durch eine besonders groß angelegte Feier die Erinnerung an diese große Zeit seiner Geschichte und der Geschichte Preußens und Deutschlands zu pflegen. “38

Bergs Berufung zum Breslauer Stadtbaurat im Jahr 1909 gab dem Projekt eine ganz neue Wendung. Der junge und außergewöhnlich ehrgeizige Architekt griff Masners Initiative auf und verknüpfte sie mit der Vision von Breslau als künftigem Zentrum des deutschen Ostens. ${ }^{39}$ Das Ausstellungsgelände wurde in einen schnell wachsenden und prestigereichen neuen Stadtteil von Breslau eingebunden, dessen Kern die seit den achtziger Jahren des 19. Jahrhunderts errichteten Universitätskliniken, die Gebäude der neuen Technischen Hochschule sowie der 1865 eröffnete Zoologische Garten waren. Es wurde durch eine repräsentative Allee, die Kaiserstraße, an das Stadtzentrum angebunden, die 1910 durch die moderne Kaiserbrücke eine direkte Verbindung zur Altstadt erhielt. 1909 begann in der regionalen Fachzeitschrift für Architektur „Ostdeutsche Bauzeitung“ eine Diskussion zur Gestaltung des künftigen Ausstellungsgeländes. „Den meisten Anklang dürfte wohl der Gedanke finden, hier einen großzügig angelegten Festplatz zu schaffen, der für Ausstellungen und zur Abhaltung festlicher und geselliger Veranstaltungen großen Stils, namentlich solcher künstlerischer und sportlicher Art, geeignet ist. “40 Die veröffentlichten Pläne zu dieser „hervorragenden Sehenswürdigkeit“" präsentierten ganz im Geist des Historismus entworfene Pavillons. ${ }^{41}$ Im Dezember 1910 rief man einen nationalen Architekturwettbewerb für das Ausstellungsgelände und dessen Anbindung an den benachbarten Zoologischen Garten aus. Die ausgezeichneten Entwürfe wurden im April 1911 öffentlich präsentiert. Die Teilnehmer des Wettbewerbs hatten Bergs bereits bekannten Entwurf der Ausstellungshalle in ihre Pläne eingearbeitet, was vermuten lässt, dass man eher Werbewirksames als urbanistisch und architektonisch Innovatives erwartete. Es scheint, als sei es weniger um neue Ideen für die Gestaltung des Ausstellungsgeländes denn um eine Werbekampagne gegangen, mit der man Architekten, aber auch die Eliten im weitesten Sinne über den geplanten Hallenbau

37 Schlesien 2 (1908-1909), S. 36-38.

38 Berg, Max: Die Jahrhunderthalle und das neue Ausstellungsgelände der Stadt Breslau. In: Deutsche Bauzeitung XLVII/42 (1913), 24. Mai 1913, S. 385-389, hier S. 385.

39 Zur Entstehungs- und Baugeschichte ausführlich: Ilkosz, Jerzy: Die Jahrhunderthalle und das Ausstellungsgelände in Breslau - das Werk Max Bergs. München 2006 (Schriften des Bundesinstituts für Kultur und Geschichte der Deutschen im östlichen Europa, Bd. 28). Unlängst auch STÖRTKUHL, Beate: Moderne Architektur in Schlesien 1900 bis 1939. Baukultur und Politik. München 2013 (Schriften des Bundesinstituts für Kultur und Geschichte der Deutschen im östlichen Europa, Bd. 45), S. 96-107.

40 BeCK, Carl: Breslauer Festplatz. In: Ostdeutsche Bauzeitung 7/2 (1909), S. 9 und 11 (Plan).

41 Ebd. 
und die Feierlichkeiten zum Jahrestag informieren wollte. Zugleich ging es wohl darum, die Breslauer und den Stadtrat, letztlich aber auch die zentralen staatlichen Instanzen und den Kaiserhof von diesem ziemlich kostspieligen Vorhaben zu überzeugen. ${ }^{42}$

Doch die Ratsherren, die eine entscheidende Stimme bei der Finanzierung des Vorhabens hatten, waren nicht hundertprozentig von Masners und Bergs Ideen überzeugt. Anfangs dachte man sogar darüber nach, in Breslau zum Jahrestag lediglich ein kleines Denkmal aufzustellen. Doch nach einigem Zögern fand die Vision des Stadtbaurats die Zustimmung vor allem liberaler Stadtverordneter. Sie verteidigten die geplante Halle als „Denkmal der Technik“, während die Sozialdemokraten ihrer Errichtung unter der Bedingung zustimmten, dass sie von allen Parteien für politische Veranstaltungen genutzt werden könne. Am Ende sollten die Stadtoberen dieses Versprechen nicht halten. ${ }^{43}$ Anfang 1912 brachte der Direktor der Akademie der Bildenden Künste, Hans Poelzig, auf Veranlassung von Karl Masner die Idee auf, für die ursprünglich innerhalb der Festhalle geplante historische Ausstellung einen separaten Pavillon zu errichten. ${ }^{44}$ Nach langen Debatten und anfänglich heftigem Widerstand des Oberbürgermeisters Bender ${ }^{45}$ stimmte der Stadtrat auch dieser Änderung zu und genehmigte gleichzeitig zusätzliche Finanzmittel. Dadurch erlebte die gesamte Anlage ein Jahr vor ihrer Eröffnung eine weitere grundsätzliche, räumliche wie auch inhaltliche Metamorphose. Man beschloss nämlich, einen speziellen Pavillon für eine ungewöhnlich große historische Schau zu bauen, die in Leipzig nicht vorgesehen war. Dass ließ die Breslauer Feierlichkeiten im Vergleich zur Leipziger Denkmalsenthüllung in ganz neuem Licht erscheinen. Auch das Timing war von Bedeutung: Die Breslauer Ausstellung wurde im Mai eröffnet, das Leipziger Denkmal dagegen bekanntlich erst im Oktober. Im Mai 1912 verlieh Hans Poelzig dem um 75 Hektar vergrößerten Ausstellungsgelände seine (fast) endgültige räumliche und architektonische Gestalt. ${ }^{46}$

1913 veröffentlichte Max Berg einen Plan, der in seiner schließlichen Umsetzung noch einige finanziell motivierte Modifizierungen erfuhr (so wurde etwa der Haupteingang zum Ausstellungsgelände etwas bescheidener als ursprünglich geplant). ${ }^{47}$ Das Zentrum der Anlage bildete die von einem quadratischen Platz umgebene Jahrhunderthalle, an den vier Ecken des Platzes waren bekuppelte Pavillons vorgesehen. Das Gelände

42 Ilkosz (wie Anm. 39), S. 72, 75. Die eingereichten Entwürfe wurden 1911 in einem eigens zu diesem Zweck entworfenen Saal auf der Ostdeutschen Ausstellung in Posen gezeigt: STÖRTKUHL, Beate: Ausstellungsarchitektur als Mittel nationaler Selbstdarstellung: Die „Ostdeutsche Ausstellung“ 1911 und die „Powszechna Wystawa Krajowa“ 1929 in Posen/Poznań. In: Nation, Style, Modernism. Hg. v. Jacek Purchla und Wolf Tegethoff mit Christian Fuhrmeister und Łukasz Galusek. KrakówMünchen 2006 (CIHA [Comité international d histoire de l'art] Papers 1), S. 237-255. GrzeszczuKBrendel, Hanna: Ausstellung, Stadt und Land. Die Architektur der Posener Ausstellungen 1911 und 1929. In: Zeitschrift für Ostmitteleuropa-Forschung 1-2/2009, S. 77-100.

43 Hettling (wie Anm. 35), S. 318, 329.

44 Ausführlich dazu Ilkosz (wie Anm. 39), S. 180-190.

45 Ilkosz (wie Anm. 39), Anmerkung 467, S. 282 und 82 f.

46 Ausführlich dazu ebd., S. 76-95, dort auch sämtliche Pläne.

47 Deutsche Bauzeitung 47/42 (1913), S. 386-387; Ilkosz (wie Anm. 40), S. 123 f., mit einer Rekonstruktion sämtlicher Entwurfsphasen. 
südlich und nördlich des zentralen Platzes erhielt jeweils eine halb elliptische Gestalt. Für den nördlichen Teil entwarf Poelzig einen Teich mit Springbrunnen, umgeben von einer Pergola, die von einfachen dorischen Säulen aus Gussbeton getragen wurde. Hallenseitig sah Berg ein großes Restaurantgebäude vor. Die Südseite sollte mit den Pavillons des Lunaparks der „leichten Unterhaltung“ gewidmet werden. Auf der Westseite, wo sich der Haupteingang zum Ausstellungsgelände befand, errichtete man den Pavillon für die historische Ausstellung und ihm gegenüber den Pavillon für den „Künstlerbund Schlesien“, auf der Ostseite entstand das zweigeschossige Weinlokal „Rheingold“ (die beiden letzteren Bauten wurden nach dem Ende der Ausstellung wieder abgetragen). $\mathrm{Zu}$ den Jubiläumsfeierlichkeiten wurden zahlreiche Veranstaltungen organisiert: die Aufführung des eingangs zitierten Festspiels von Gerhart Hauptmann sowie weiterer Theaterstücke und Konzerte, die historische Ausstellung in dem eigens für sie errichteten Pavillon, eine Ausstellung über historische Gärten und eine über Friedhofskunst, die Kunstausstellung im Pavillon des „Künstlerbundes Schlesien“ und schließlich die Präsentation der nach den Plänen von Paul Schmitthenner neu entstandenen Gartenstadt Carlowitz. Die anlässlich des Jahrestages produzierten Postkarten illustrieren die Botschaft, die das gesamte Vorhaben vermitteln sollte: Man gab sich modern mit einem Nimbus von Tradition (Abb. 3).

Die Baugeschichte der Jahrhunderthalle, ihre Bedeutung für die Architekturgeschichte sowie der Ablauf der Jubiläumsfeierlichkeiten sind gut bekannt und sollen an dieser Stelle lediglich anhand der wichtigsten Fakten rekapituliert werden. Der von Max Berg

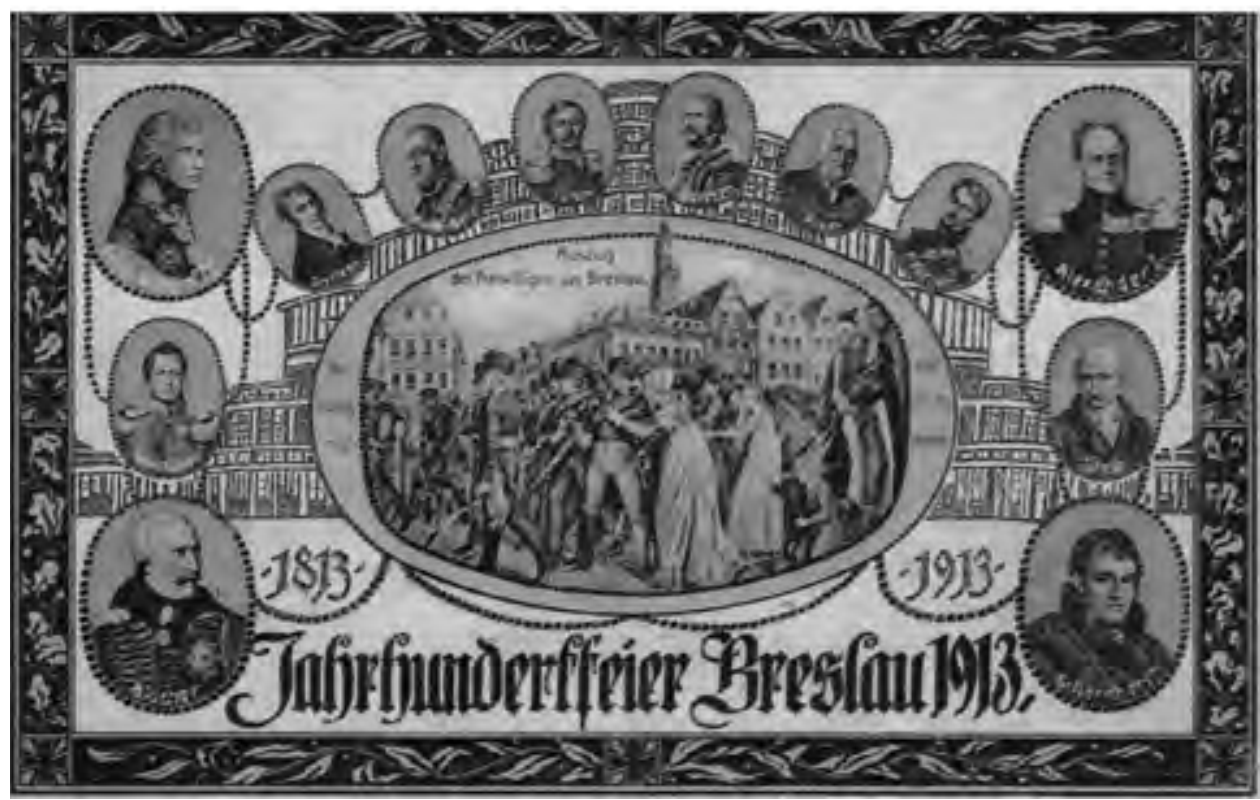

Abb. 3 Jahrhundertfeier, „Patriotische Postkarte“, 1913. Sammlung Ma gorzata Urlich-Kornacka, Wrocław. 
entworfene Bau wurde vollständig in Stahlbeton ausgeführt. Seine innovative Konstruktionsweise und Form, aber vor allem die Spannweite der mit 65 Meter Durchmesser damals weltweit größten Kuppel waren für die Architektur jener Zeit bahnbrechend. Die Basis des symmetrischen Grundrisses bildet eine Vierkonchenanlage, d.i. ein Kreis mit vier Apsiden. Auf diesem Grundriss errichtete man eine umlaufende, eingeschossige Galerie, auf den Achsen befinden sich die insgesamt drei rechteckig angelegten Eingänge. Der Haupteingang wurde mit einer skulpturalen Darstellung des mit dem Drachen kämpfenden Erzengels Michael, des Schutzpatrons von Deutschland, bekrönt (der Künstler war Alfred Vocke). Zu seinen Füßen befand sich das Breslauer Stadtwappen. Eingefasst wurde die Figur von zwei Zitaten aus dem „Anruf an mein Kriegsheer“, der am 17. März 1813 zusammen mit dem „Anruf an mein Volk“veröffentlicht worden war und sich an das preußische Heer richtete: Linker Hand befand sich die Inschrift „Wer für das Vaterland fühlt, denkt nicht an sich“, rechter Hand „Folgt dem Beispiel Eurer Vorfahren, seyd ihrer würdig und Eurer Nachkommen eingedenk“. Dies ließ sich auf die Befreiungskriege und ihre Breslauer Anfänge beziehen, aber ebenso als Anspielung auf die Gegenwart und die wachsende Kriegsbereitschaft lesen. Die Darstellung des Erzengels Michael ließ sich als Symbol für die Bezwingung des napoleonischen Frankreichs interpretieren; aber gleichzeitig auch als Inbild des kampfbereiten deutschen Soldaten und Vaterlandsverteidigers, was durch die Zitate aus dem königlichen „Anruf“ zusätzlich unterstrichen wurde. ${ }^{48}$ Der Haupteingang mit dem ihm vorgesetzten halbrunden dorischen Portikus war das einzige historisierende Element in der Architektur der Jahrhunderthalle, die ihn bekrönende Skulptur das einzige baudekorative Element der gesamten Anlage, das an den eigentlichen Anlass der hier begangenen Feierlichkeiten erinnerte. Das architektonische Konzept der Halle selbst brach dagegen vollständig mit der Tradition des Historismus und eröffnete ein neues, die Moderne vorwegnehmendes Kapitel der Architekturgeschichte.

Teils im Widerspruch dazu stand der von Hans Poelzig entworfene Pavillon der historischen Ausstellung (Abb. 4). Wenngleich man auch hier den neuen Werkstoff Stahlbeton verwendete, so war die architektonische Form doch eher konservativ und der Vergangenheit verhaftet. Dies hing mit der Funktion des Baues zusammen und war bewusst gewählt. In den Fassaden dominierte das Motiv der Säule bzw. Halbsäule in stilisierter dorischer Ordnung. Der Rückgriff auf die als heroisch, aber auch bürgerlich konnotierte dorische Ordnung sowohl im Pavillon der historischen Ausstellung als auch

48 In der Literatur wird übereinstimmend betont, dass es sich dabei um ein Zitat aus dem „Anruf an mein Volk“ handelte. Die Berufung auf den zweiten Appell des Königs „An mein Kriegsheer“ verändert dagegen erheblich die politische Aussage des Skulpturenschmucks über dem Eingang. In: http://www.documentarchiv.de/nzjh/preussen/1813/an-mein-kriegsheer_friedrich-wilhelmIII-aufruf. html (15.10.2014). Eine Darstellung des Erzengels Michael flankiert auch den Eingang zum Völkerschlachtdenkmal in Leipzig. Zur Interpretation der beiden Darstellungen Eiden, Maximilian: Jahrhundertdenkmäler und Jahrhundertfeiern der Befreiungskriege in Leipzig und Breslau - zwei gegenläufige nationale Erinnerungsprojekte? In: Visuelle Erinnerungskulturen und Geschichtskonstruktionen in Deutschland und Polen 1800 bis 1939. Bd. III. Hg. v. Robert Born, Adam S. Labuda und Beate StöRTKUнL. Warszawa 2006 (Das gemeinsame Kulturerbe - Wspólne dziedzictwo. Hg. v. Małgorzata OmiLANowsKa), S. 205-229, hier S. 210-211, 213-214. 


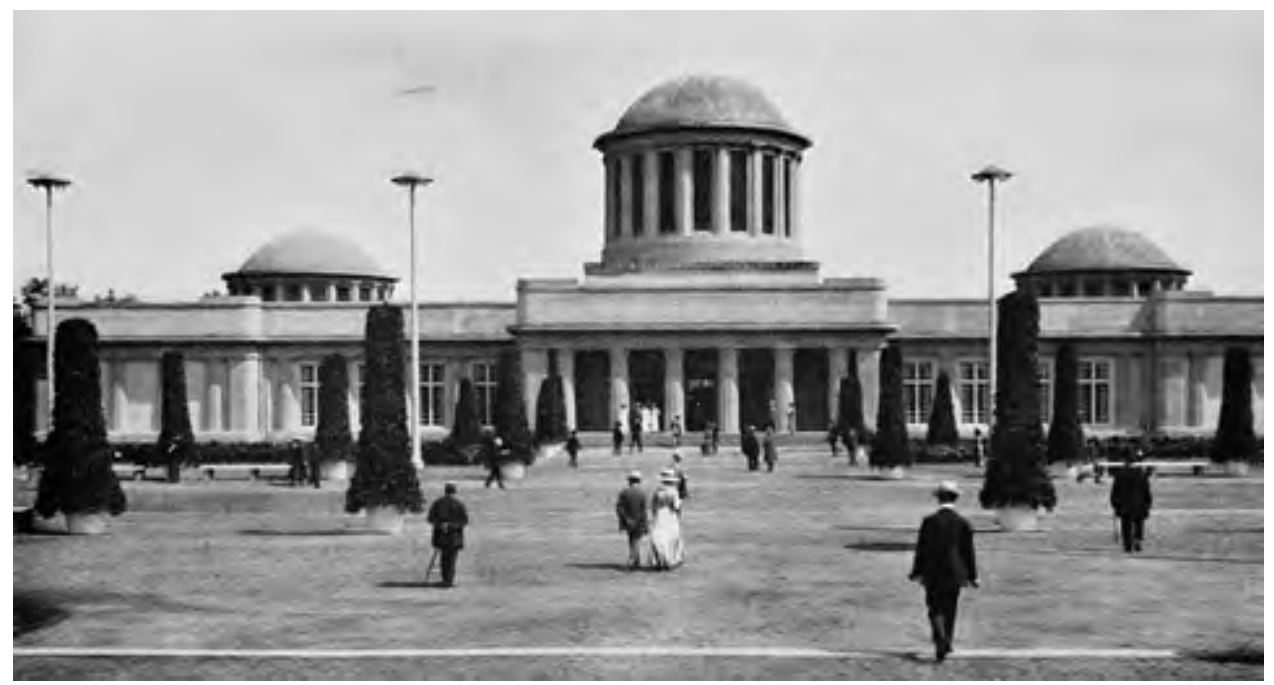

Abb. 4 Hans Poelzig: Das Gebäude der Historischen Ausstellung. Historische Aufnahme.

am Eingangsportikus der Jahrhunderthalle und an der Pergola war zweifelsohne wohldurchdacht. Die Dorik unterstrich die Funktion der Gebäude und deren ,patriotische“ Aussage und spielte in subtiler Weise auf die Kunst um 1813 an. Die architektonische Form des Pavillons wurde dem Ausstellungskonzept untergeordnet. Es handelt sich um einen rund um einen quadratischen Innenhof angelegten vierflügeligen Bau mit vier kuppelbekrönten hohen Sälen auf den Achsen sowie eingeschossigen, mit Oberlichtern versehenen Pavillons dazwischen. Poelzig hatte damit einen hervorragenden Ausstellungsbau mit großen Sälen und kleineren Kabinetten entworfen.

Die Ausstellung selbst besaß eine wohldurchdachte Dynamik mit einer sich steigernden Spannung und klug gesetzten Kulminationspunkten. In der „Deutschen Bauzeitung“ schilderte Max Berg den Aufbau folgendermaßen: „Der Kuppelraum am Eingang enthält als Repräsentationsraum die lebensgroßen Bildnisse der verbündeten Monarchen, der zweite Kuppelraum ist dem Heereswesen gewidmet, ein dritter ovaler Kuppelraum in der Achse der ersten gelegen, wurde der Darstellung der Stadt Breslau im Jahre 1813 vorbehalten, ein vierter Kuppelsaal ist als Gedenkhalle für die Gefallenen errichtet. ${ }^{\text {499 }}$ Ein rundes Dutzend weiterer Ausstellungskabinette war den Militärführern,

49 Berg, Max: Die Jahrhunderthalle und das neue Ausstellungsgelände der Stadt Breslau. In: Deutsche Bauzeitung XLVII/51 (1913), S. 462-466, hier S. 466; Jahrhundertfeier der Freiheitskriege Breslau 1913. Katalog der historischen Ausstellung. Ausst.-Kat. Breslau 1913. Beschreibung der einzelnen Säle in Gussone, Nicolaus: Wystawa Historyczna w setną rocznicę wojen wyzwoleńczych we Wrocławiu (1913). Przyczynek do kultu pamięci i polityki historycznej w Cesarstwie Niemieckim [Historische Ausstellung zum 100. Jahrestag der Befreiungskriege in Breslau (1913). Beitrag zum Erinnerungskult und der Geschichtspolitik im Kaiserreich]. In: Hans Poelzig in Breslau (wie Anm. 36), S. 427-444. 
den am Konflikt beteiligten Staaten sowie den Kriegshandlungen von 1813-1815 gewidmet. Das architektonisch herausgehobene Zentrum bildete ein ovaler Saal mit dorischen Säulen, die ihm einen sakralen Charakter verliehen. Hier brachte man den wichtigsten Teil der Ausstellung über den Beginn der Befreiungskriege und über Breslau im Jahr 1813 unter. Der Saal wurde von Kabinetten flankiert, die der russischen Armee und dem Feldzug von 1812 sowie der Völkerschlacht gewidmet waren. Man präsentierte also eine Triade der wichtigsten Ereignisse: den mit dem Moskaufeldzug einsetzenden Niedergang Napoleons, die preußische Reaktion und den Beginn der Befreiungskriege in Schlesien sowie die Völkerschlacht bei Leipzig als Kulminationspunkt der Kriegshandlungen. Dieser Teil der Ausstellung wurde mit der Präsentation von Napoleon-Karikaturen beschlossen. Ein Kabinett mit Modellen und Zeichnungen verschiedener Denkmäler der Befreiungskriege bildete den Übergang zur bekuppelten „Gedenkhalle für die gefallenen Preußen“. Sie war das Pendant zur Halle „Das preuBische Heereswesen“ im Westflügel. Die beiden architektonisch identischen Hallen waren gleichsam die ideologischen, den toten und lebenden Helden gewidmeten Pylone der Ausstellung. Die „Gedenkhalle“ bildete den Schlussakkord des betont patriotischen historischen Ausstellungsteils. Ein wesentlich kleinerer, lediglich ein Viertel der Gesamtausstellung umfassender Teil war der Kunst und dem Alltagsleben zur Zeit der Napoleonischen Kriege gewidmet. ${ }^{50}$ Komposition und Dramaturgie der Ausstellung erinnerten an die Musik des Klassizismus - sie ließe sich also auch aus diesem Blickwinkel analysieren. ${ }^{51}$

Das elaborierte, von Karl Masner erdachte Ausstellungskonzept wies weit über Breslau und Schlesien hinaus. Es präsentierte die Befreiungskriege nicht allein aus preußischer Perspektive, sondern berücksichtigte auch die anderen deutschen Länder (auch die mit Napoleon verbündeten Sachsen, Bayern und Württemberg) sowie die europäischen Koalitionäre Russland und Schweden. Das Konzept entsprach nur zum Teil der militaristischen Stimmungslage des wilhelminischen Deutschlands des Jahres 1913 und war in gewisser Hinsicht mit Hauptmanns Stück kompatibel, das nicht die Befreiungs-, sondern die Freiheitskriege, nicht den Krieg, sondern den Frieden glorifizierte. „Nicht der blutige Höhe- und vorläufige Endpunkt der ,Befreiungskriege “ wurde hier begangen, sondern ein Anfang. "52 Dies drückte sich vor allem in der Benennung der Feierlichkeiten als „Jahrhundertfeier der Freiheitskriege. Breslau 1913“ aus. Die Figur der Pallas Athene (ausgeführt von Robert Bendorz), die den Springbrunnen im Zentrum des offenen, als Empiregarten gestalteten Innenhofs zierte, lässt sich dann auch eher als Verkörperung der Weisheits- denn der Kriegsgöttin interpretieren. Auch Hauptmanns Stück gründet seine Kernaussage auf eine Kritik an Krieg, Chaos, Zerstörung und sinnlosem Tod. Die allegorische Figur der „Furie des Krieges“ verwandelt sich am

50 Deutsche Bauzeitung 47/42 (1913), ausführlicher Ausstellungsplan auf S. 388.

51 Dabei handelte es sich um eine subtile Anspielung auf die Musik der Zeit um 1813. Max Berg äußerte sich 1913 zu diesem musikalischen Aspekt in einem privaten Brief an den Breslauer Oberbürgermeister Matting, veröffentlicht in: Hans Poelzig in Breslau (wie Anm. 36), S. 544.

52 EIDEN, Jahrhundertdenkmäler (wie Anm. 48), S. 208-209. 
Ende des Stückes in eine „Athene Deutschland“, die sich mit folgenden Worten an das Publikum wendet: „Die Tat des Friedens ist es, nicht die Tat des Krieges! Die Wohltat ist es! Nimmermehr die Missetat!“53 Die Breslauer Feierlichkeiten waren keine Glorifizierung der Hohenzollern und besaßen, wie in der Forschung vielfach betont, einen antimonarchistischen Charakter. Die patriotische Grundaussage von Masners Ausstellung konnte nicht verhindern, dass der Kaiser sich weigerte, die Schirmherrschaft zu übernehmen, und dass der Hof die Absetzung von Hauptmanns Stück anordnete. Der dezidiert promonarchistisch begangene 100. Jahrestag des Lützow'schen Freikorps wurde in Zobten und Umgebung gefeiert. Er war es, der das staatlich verordnete, offizielle „historische Gedenken“ repräsentierte.

Der Bau der Jahrhunderthalle sollte also mehreren Zwecken dienen: Mit der Errichtung der Festhalle wollte man die Bedeutung und das Prestige Breslaus unter den Städten Deutschlands erhöhen; und mit den Feierlichkeiten zum Beginn der Befreiungskriege sollte ein neues kollektives Bewusstsein geschaffen werden. Der Beginn der Befreiungskriege und der nationalen Erhebung gegen Napoleon im Jahr 1813 eben hier, in Schlesien, war ein willkommener Vorwand, um die Rolle Breslaus in der deutschen Geschichte hervorzuheben. Sicher muss man die Jahrhunderthalle im Zusammenhang mit dem Völkerschlachtdenkmal und als dessen Konkurrenzprojekt im Rahmen der nationalen Jubiläumsfeierlichkeiten interpretieren. Beide Objekte wurden als politische Architektur konzipiert und markierten Anfang und Ende zweier unterschiedlicher Epochen. Das Leipziger Denkmal ließ sich als „Krönung“ des wilhelminischen Deutschlands und des Historismus verstehen. ${ }^{54}$ Seine Botschaft kommt in der Einweihungsrede des Denkmalsinitiators Clemens Thieme sehr gut zum Ausdruck: „Gewaltiger Zeiten gewaltiges Zeichen, - den gefallenen Helden ein Ehrendenkmal, - dem deutschen Volk ein Ruhmesmal, kommenden Geschlechtern ein Mahnzeichen “55.

53 Hettling (wie Anm. 35), S. 320-321; Sprengel, Peter: Die inszenierte Nation. Deutsche Festspiele 1813-1913. Tübingen 1991, S. 69-104. Während Hauptmanns Stück bereits ausgiebig analysiert wurde, sind die historische Ausstellung und ihre Aussage bislang nicht grundlegend untersucht worden.

54 Ein sorgfältiger Vergleich der Feierlichkeiten in: EIDEN, Jahrhundertdenkmäler (wie Anm. 48), S. 205-228. Außerdem Eiden, Maximilian: Ein Erinnerungsort für Deutsche und Polen. Jahrhunderthalle und Ausstellungsgelände in Breslau (Wrocław). Unveröffentlichte Magisterarbeit, Institut für Geschichtswissenschaften an der Humboldt-Universität zu Berlin 2004; DyrofF, Stefan: 1813-1913: Patriotische Jahrhundertfeiern in Leipzig und Breslau. In: Europas Mitte. Mitteleuropa. Europäische Identität? Geschichte, Literatur, Positionen. Hg. v. Barbara Brezsach. Berlin 2003, S. 32-46. Im Jahre 2014, nach der Anfertigung dieses Textes, ist das Buch: Von Breslau nach Leipzig. Wahrnehmung, Erinnerung und Deutung der antinapoleonischen Befreiungskriege. Hg. v. Roland GeHrKe. Köln-Wien 2014 erschienen. Das Buch konnte ich in diesem Text leider nicht mehr berücksichtigen.

55 Puschner (wie Anm. 11), S. 155. Zur Interpretation des Denkmals in unterschiedlichen Kontexten liegt bereits eine umfangreiche Literatur vor, so z.B. TорFSTEDT, Thomas: Erhaben, von jeglicher persönlicher Beziehung und von jedem kleinen Zweck entbunden, steht das Werk in ruhiger Schönheit da. Das Völkerschlachtdenkmal als Gesamtkunstwerk. In: Völkerschlachtdenkmal (wie Anm. 23), S. 8-43, hier S. 40-41 (in überarbeiteter Fassung als Beitrag von Thomas Topfstedt in diesem Band). Gleichzeitig war das Völkerschlachtdenkmal auch im wörtlichen Sinne ein Baudenkmal, denn ebenso wie in Breslau verwendete man hier eine damals neuartige Betonkonstruktion - allerdings mit dem Unterschied, dass sie hier vollkommen unsichtbar bleibt. Inwiefern Berg die Bauarbeiten in Leipzig 
Das Breslauer Projekt erscheint noch einmal in anderem Licht, wenn man es nicht allein im lokalen Kontext analysiert, sondern vor dem Hintergrund der staatlichen und kommunalen Aktivitäten zur sogenannten „Hebung der Ostprovinzen“ seit dem Ende des 19. Jahrhunderts betrachtet, die insbesondere in Breslau, Posen, Stettin und Danzig entfaltet wurden.

Besonders instruierend ist ein Vergleich der Konzeption der Breslauer Festhalle mit dem zwischen 1902 und 1910 in Posen errichteten Kaiserforum, dem Letzten seiner Art in Europa. Dessen Bauten sollten die Legitimität der Kaiserherrschaft bekräftigen; die deutsche Kolonisation der „Ostprovinzen“ würdigen; die Bedeutung von Wissenschaft und Kunst für die nationale Identitätsbildung und die Entwicklung der Provinz Posen hervorheben; und schließlich die Deutschen dazu ermutigen, die Randgebiete des Reiches zu besiedeln und so einer historischen Verpflichtung gerecht zu werden. ${ }^{56}$ Nur wenige Jahre vor dem Ausbruch des Ersten Weltkrieges wollte man Posen zum Bollwerk des Deutschtums im national umkämpften Osten des Reiches machen. Die gesamte Anlage wurde in strikt historisierenden Formen entworfen, die die Funktionen der einzelnen Gebäude hervorheben sollten. Die Jahrhunderthalle war dagegen von einer solchen architektonischen Formensprache befreit. Gleichwohl war ihr Zweck letztlich dem der Posener Bauten ähnlich. Beide Anlagen sollten die deutsche Mission im Osten gleichsam als deren Ecksteine veranschaulichen, die eine (in Posen) als Ausdruck der Tradition, die andere (in Breslau) als Monument der Moderne.

Die schwierige und angespannte Situation in den Ostprovinzen hielt jedoch nur wenige Jahre an und wurde mit dem Ausbruch des Ersten Weltkrieges beendet bzw. umgedeutet: Nach 1918 wurde Posen polnisch, die preußischen Bauten wurden polonisiert und für neue Zwecke adaptiert. ${ }^{57}$ Nach 1945 wandelte sich die Bedeutung der hier besprochenen Bauten wiederum radikal. Auch die Jahrhunderthalle wurde umgedeutet. Sie wurde in „Volkshalle“ (Hala Ludowa) umbenannt und ihrer Konnotationen mit den Napoleonischen Kriegen entledigt. Stattdessen sollte sie nun - insbesondere mit einer Ausstellung zu den „Wiedergewonnenen Gebieten“ im Jahr 1948 - die Stärke des sozialistischen Polens rühmen. Ihr symbolischer Bauschmuck wie der Erzengel Michael oder das aus der Zeit des Dritten Reichs stammende Hakenkreuz wurde entfernt und durch eine fast 100 Meter hohe Stahlspitze, die sogenannte „Nadel“ (Iglica) ersetzt, die der Gesamtanlage einen völlig neuen Akzent verlieh und die drei Pfeiler - Arbeiter, Bauern und Intelligenz - des neuen sozialistischen Staates symbolisieren sollte. Erst mit der Aufnahme der Halle in die UNESCO-Weltkulturerbeliste im Jahr 2006 wurde

und deren technische Details verfolgte, ist im Zusammenhang mit der Jahrhunderthalle noch nicht untersucht worden.

56 PaŁat, Zenon: Architektura a polityka. Gloryfikacja Prus i niemieckiej misji cywilizacyjnej w Poznaniu na początku XX wieku [Architektur und Politik. Die Glorifizierung Preußens und der deutschen Kulturmission im Osten in Posen zu Beginn des 20. Jahrhunderts]. Poznań 2011, besonders S. 188197.

57 Moskal, Anna: Die Polonisierung der Stadt Posen nach 1918 und 1945: Im Spannungsfeld von Region und Nation. Wiesbaden 2013 (Studien zur Sozial- und Wirtschaftsgeschichte Ostmitteleuropas, Bd. 23). 
sie wieder zur Jahrhunderthalle (Hala Stulecia), wobei nur wenige in Breslau heute noch wissen, worauf sich diese Benennung ursprünglich bezog.

\section{3 - Ein Fürst ersetzt den anderen: Zwischen deutscher und polnischer Geschichte}

Aus polnischer Sicht ist der Feldzug von 1813 eine von vielen Niederlagen in der polnischen Geschichte, an die man sich bis heute nicht erinnern mag. Deshalb gab es 2013 in Breslau auch keine Feierlichkeiten zum Gedenken an die Völkerschlacht und die preußischen Befreiungskriege. Zwar luden im September 2013 deutsche Plakate zur Fahrt nach Leipzig und zur Besichtigung des Völkerschlachtdenkmals ein, sodass auch den Breslauern das Jubiläum in Erinnerung gerufen wurde. Dem Erinnerungsort Jahrhunderthalle wurde allerdings eine neue Bedeutung zugeschrieben: Im Mai 2013 beging man deren hundertsten Geburtstag, und viele waren der Meinung, dass die Benennung der Halle ebendiesem Umstand - ihrem hundertjährigen Bestehen zu verdanken sei. Im Architekturmuseum gab es eine kleine Ausstellung zur Baugeschichte der Jahrhunderthalle; sie war allerdings lediglich als Ergänzung zur zeitgleich stattfindenden Ausstellung zu Pier Luigi Nervi gedacht. Am 16. Oktober 2013, also fast am Jahrestag der Völkerschlacht, wurde in der Jahrhunderthalle der 90. Geburtstag des Breslauer Kardinals emeritus Henryk Gulbinowicz gefeiert. Er ist einer der verdienstvollsten kirchlichen Würdenträger Polens und eng mit der Geschichte der Solidarność-Bewegung verbunden. Seine Ehrung in der Jahrhunderthalle war ein Beleg für seine Bedeutung. Gleichzeitig zeigte sie, dass die Jahrhunderthalle heute ein völlig anderer Erinnerungsort ist als vor 1945 und sich in ihrer symbolischen Bedeutung weit von den Ursprüngen entfernt hat.

Eine Art Zwischenposition nahm im Jubiläumsjahr das Breslauer Stadtmuseum im einstigen Schloss der preußischen Könige ein. Dort wurden vor einigen Jahren einige Gemächer Friedrich Wilhelms III. rekonstruiert. Allerdings erinnerte man dort 2013 in den Tagen des Jubiläums der Leipziger Völkerschlacht nicht an Lützow oder Blücher, sondern zeigte, wie in vielen anderen polnischen Geschichtsmuseen auch, eine Poniatowski-Ausstellung. Die deutschen Befreiungskriege wurden in Polen und besonders in Breslau kaum erwähnt - schließlich bedeutete Napoleons Niederlage für Polen den Verlust der Hoffnung auf die Wiedergeburt eines freien und unabhängigen polnischen Staates. Folgerichtig gedachte man im Jubiläumsjahr vor allem des Fürsten Józef Poniatowski, der in der Leipziger Völkerschlacht an der Seite Napoleons kämpfte und am 19. Oktober 1813 in der Elster ertrank. 2013 war in Polen ein Poniatowski-Jahr, in dem man seinen 250. Geburts- und 200. Todestag mit zahlreichen Ausstellungen, Konferenzen, Medaillen und Banknoten beging. In diesem Kontext stand auch die Ausstellung im ehemaligen Breslauer Königsschloss gleich neben den rekonstruierten Gemächern Friedrich Wilhelms III., die zwar die Völkerschlacht bei Leipzig thematisierte, aber dabei Poniatowski in den Mittelpunkt stellte. An Blücher, den Fürsten von Wahlstatt, wurde hier nicht mehr erinnert. Der deutsche Fürst und Nationalheld Blücher wurde im 


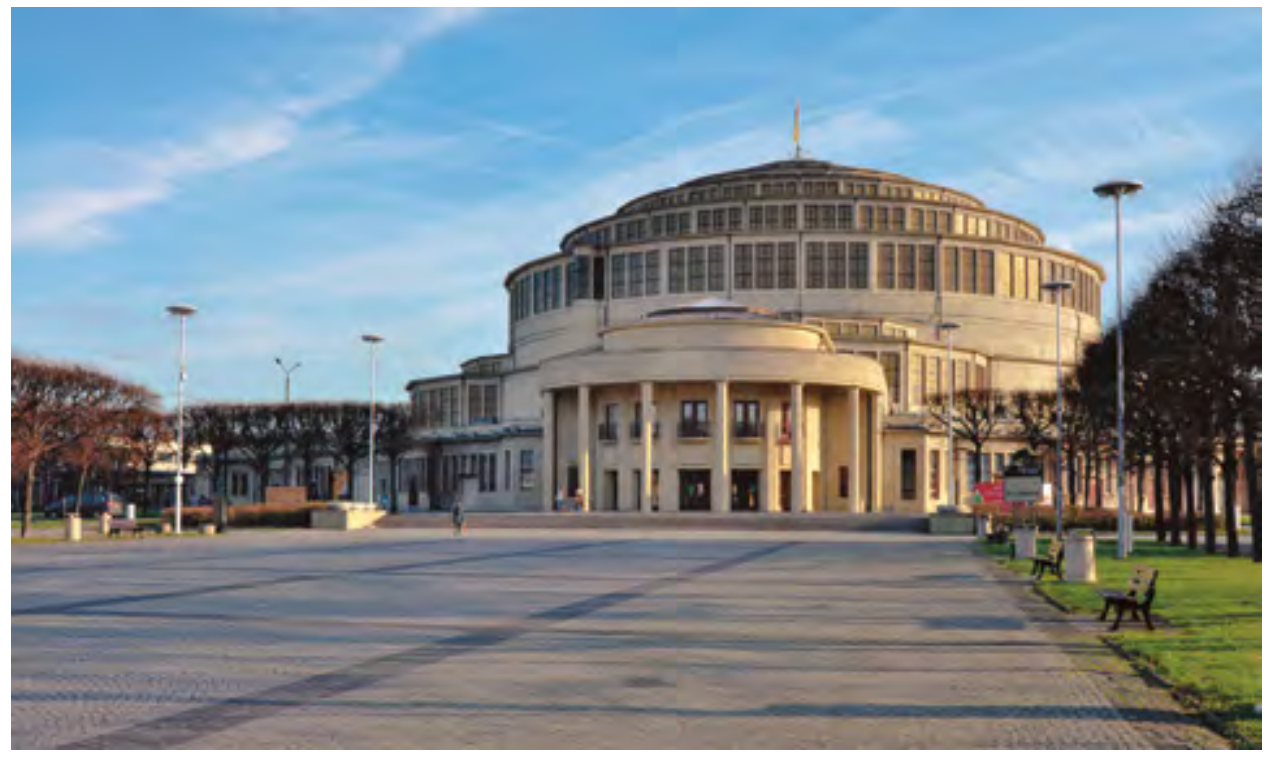

Abb. 5 Jahrhunderthalle (Hala Stulecia), 2015. Foto: Jerzy Kos.

kollektiven Gedächtnis durch den polnischen Fürsten und Nationalhelden Poniatowski ersetzt.

Im heutigen Polen steht die Jahrhunderthalle wiederum für Modernität und eine sich dynamisch entwickelnde Gesellschaft. Ihre von der Stadtverwaltung betriebene Aufnahme in die Weltkulturerbeliste dokumentiert den Willen, Fremde und Touristen nach Breslau zu holen. Umfangreiche Umbau- und Renovierungsarbeiten an der Halle haben dazu beigetragen, die Odermetropole erneut als Messestadt und Konferenzort zu etablieren (Abb. 5). Auch Poelzigs Ausstellungspavillon wird zu diesem Zweck umgebaut. Er hatte nach 1945 als Filmstudio gedient, wird nun aber komplett renoviert und wieder in einen Ausstellungsort umgewandelt. Ab 2016 soll er als Zweigstelle des Nationalmuseums moderne Kunst präsentieren. Das gesamte ehemalige Ausstellungsgelände wird wieder zu einer Sehenswürdigkeit mit Mehrzweckhalle, Ausstellungsgebäude, Konferenzzentrum und Grünanlagen. Ein Ausbau des Zoologischen Gartens soll weitere Gäste in diesen Teil von Breslau ziehen. Damit wird das Gelände ganz ähnlichen Zwecken dienen wie vor 100 Jahren bei seiner Einweihung, doch nunmehr frei von politischen Konnotationen sein. Breslau verfolgt wie vor 100 Jahren das Ziel, nicht bloß die Hauptstadt von Niederschlesien, sondern auch die Drehscheibe zwischen Ost und West darzustellen. Wo es vor 100 Jahren als ein Vorposten der Moderne im Osten Deutschlands dienen sollte, da will es heute Vorposten der Moderne im Westen Polens sein.

Die Daten 1813, 1913 und 2013 haben für die Breslauer bei der Suche nach ihrer kollektiven Identität eine wichtige Rolle gespielt, wenngleich dies in jeder Epoche eine andere Ausprägung fand. Die Zeit der Befreiungskriege sah den vom preußischen König Friedrich Wilhelm III. und dem schlesischen Adel unternommenen Versuch, den Kriegs- 
helden Blücher zum Symbol für eine propreußische schlesische Identität zu machen, die von den für diese Provinz so typischen sozialen und religiösen Problemen unbelastet ist. Dies gelang für eine kurze Zeit, doch Blüchers Heldentaten verblassten schnell, und er blieb nur als einer von vielen Generälen des Feldzugs von 1813-1815 im Gedächtnis. Dieser war allerdings schon in der zweiten Hälfte des 19. Jahrhunderts kaum mehr von Bedeutung.

So stellte der Marschall bereits am Vorabend des Ersten Weltkrieges keine zentrale Figur mehr dar, und auch die in Deutschland zu jener Zeit so machtvolle Kriegsrhetorik fand während der Breslauer Feierlichkeiten zum 100. Jahrestag keinen entsprechenden Widerhall. Der Kaiser übernahm nicht die Schirmherrschaft über die Breslauer Ausstellung, und der Skandal um die Aufführung von Hauptmanns Stück sowie dessen vorzeitige Absetzung vom Spielplan bewirkten, dass die Jubiläumsfeierlichkeiten in einer gegen die Hohenzollern und gegen den kommenden Krieg gestimmten Atmosphäre stattfanden. Der moderne, seiner Zeit vorausgreifende Bau der Jahrhunderthalle wurde zum Symbol dieser Jubiläumsfeiern. Die Rezeption der Halle durch die Bewohner Breslaus und Schlesiens ist gleichwohl bisher nicht eingehend erforscht worden. Vermochte ihre Modernität als kollektives Identifikationsangebot zu funktionieren? Zweifelsohne war dies die Absicht ihrer Erbauer, doch der weitere Verlauf der Geschichte sollte die Richtung, in welche sich die Suche nach einer schlesischen Identität bewegte, alsbald ändern. Der Erste Weltkrieg, die auf ihn folgenden schlesischen Aufstände und die Teilung von Oberschlesien bewirkten, dass in dieser Region von Deutschland die Moderne nicht länger en vogue war. Poelzig verließ 1916 Breslau und übernahm das Amt des Dresdner Stadtbaurats, nach dem Krieg ging er nach Berlin. Auch Berg, unzufrieden mit der mangelnden Anerkennung für seine Ideen zur Umgestaltung Breslaus in eine moderne europäische Metropole mit Hochhäusern und Schnellstraßen, resignierte und verließ 1925 die Stadt. Die Keimzelle der Moderne, die die Jahrhunderthalle hatte sein sollen, besaß im Deutschland der Zwischenkriegszeit keine Chance zur Weiterentwicklung. Viele Modernisierungsprojekte wurden, trotz der Bemühungen von Künstlern und teilweise auch der kommunalen Verwaltung sowie des jüdischen Wirtschaftsbürgertums, bloß auf dem Papier verwirklicht. Breslau wurde zu einer Bastion des Deutschtums, das man um jeden Preis und auf allen Gebieten zu verteidigen gedachte - unter anderem, indem man traditionelle architektonische Formen präferierte. ${ }^{58}$

Der Zweite Weltkrieg, die Zerstörung der Stadt und der vollständige Austausch der Bevölkerung im Zusammenhang mit der veränderten staatlichen Zugehörigkeit führten dazu, dass die vor dem Ersten Weltkrieg formulierten Ideen wieder aktuell wurden. Die Realitäten der sozialistischen Ökonomie verhinderten jedoch die Schaffung der modernen Metropole, von der die Architekten der Nachkriegszeit zunächst träumten. ${ }^{59}$ Erneut schafften es viele Projekte nicht über den Zeichentisch hinaus.

58 Vgl. etwa das Projekt von Sarah SchlachetZKi. In: http://p3.snf.ch/Project-151223 (03.12.2015).

59 GABIŚ, Agata: Koncepcje i rzeczywistość. Wrocławska architektura 1956-1970 [Entwurf und Wirklichkeit. Breslauer Architektur 1956-1970] (im Druck). 
1989 wurde ein neues Kapitel aufgeschlagen. Erst jetzt - und insbesondere seit 2005 - war die Metropole an der Oder so weit, dass sie sich nicht länger nur damit beschäftigen musste, Rückständigkeiten aufzuholen und die Folgen der Nachkriegsordnung zu beseitigen. Erst jetzt können Max Bergs Pläne wirklich Gestalt annehmen, können die vor 100 Jahren von ihm formulierten Ziele umgesetzt werden. Die Breslauer identifizieren sich immer weniger ausschließlich mit dem piastischen Erbe der Stadt, wie es ihnen die Nachkriegspropaganda vorgegeben hatte, sondern zunehmend auch mit einer lange herbeigesehnten und von historischem Ballast befreiten Moderne. Breslau möchte ein Flaggschiff der Moderne sein und ist auf dem besten Wege, um die Ideen und Träume von Poelzig und Berg nun endlich zu verwirklichen.

Für die Bevölkerung des niederschlesischen Umlandes von Breslau dagegen sind die Befreiungskriege eines von vielen Ereignissen aus der Vergangenheit, das sich für das Tourismusmarketing nutzbar machen lässt - gestützt im Übrigen durch eine solide wissenschaftliche Forschung ${ }^{60}$. Besonders interessant war das Gedenken an den antinapoleonischen Feldzug in Bunzlau. Wenn es um die Erinnerung an 1813 geht, ist diese Stadt etwas Besonderes. Hier starb am 28. April 1813, zu Beginn des Feldzugs, Feldmarschall Michail Kutuzov, Heerführer der mit Preußen verbündeten russischen Armee, an Typhus. 1819 enthüllte man hier zu seinen Ehren ein von Johann Gottfried Schadow und Karl Friedrich Schinkel entworfenes Denkmal (Abb. 6). Nach 1945 war es eines der wenigen deutschen Denkmäler in Schlesien, die nicht demontiert wurden - ganz im Gegenteil wurde es im Kontext der polnisch-sowjetischen Freundschaft zu einem identitätsbildenden Element des „,neuen“, polnischen Schlesien. Bereits 1945 richteten die Sowjets in Kutuzovs Sterbehaus ein ihm gewidmetes Museum ein. Es war das einzige exterritoriale Museum in Schlesien und unterstand ausschließlich der sowjetischen Militärkommandantur. Paradoxerweise blieb hier also dank Kutuzovs Krankheit und Tod in Schlesien die Erinnerung an den Feldzug von 1813 auch nach dem Zweiten Weltkrieg lebendig - auch wenn sie dies der Polen aufgezwungenen politischen Ordnung verdankte. 1991 wurde das Kutuzov-Haus vom Keramik-Museum übernommen. ${ }^{61} 2010$ eröffnete man hier einen Ableger des stadthistorischen Museums, der u.a. auch Säle zum Feldzug von 1813 erhielt. Die Bunzlauer Feierlichkeiten am 6. und 7. September 2013 bildeten den eigentlichen Höhepunkt des Gedenkens an den antinapoleonischen Feldzug in Schlesien. Man organisierte eine internationale Konferenz sowie eine Ausstellung und führte ein Reenactment der Schlacht um Bunzlau auf. Dabei präsentierte man die die Befreiungskriege eröffnenden schlesischen Kriegshandlungen in ihrem internationalen Kontext und knüpfte damit (wahrscheinlich eher unbewusst) an das

60 OlczaK, Mariusz: Kampania 1813. Śląsk i Łużyce [Der Feldzug von 1813. Schlesien und die Lausitz]. Warszawa 2004; MALICKI, Patrycjusz: Wielka Armia Napoleona na Śląsku 1806-1808 [Napoleons Grande Armée in Schlesien 1806-1808]. Warszawa 2008.

61 Die Sammlung wurde zusammen mit der Roten Armee abgezogen und wird heute in Teilen in einem St. Petersburger Militärmuseum ausgestellt. Das Bunzlauer Museum hat - bislang erfolglos - eine Rückgabe der Sammlung gefordert. In: http://www.istotne.pl/a10491.php (15.10.2014). 
Abb. 6 Kutuzovdenkmal in Bunzlau (Boleslawiec), Postkarte von 1913. Sammlung Muzeum Ceramiki, Boleslawiec.

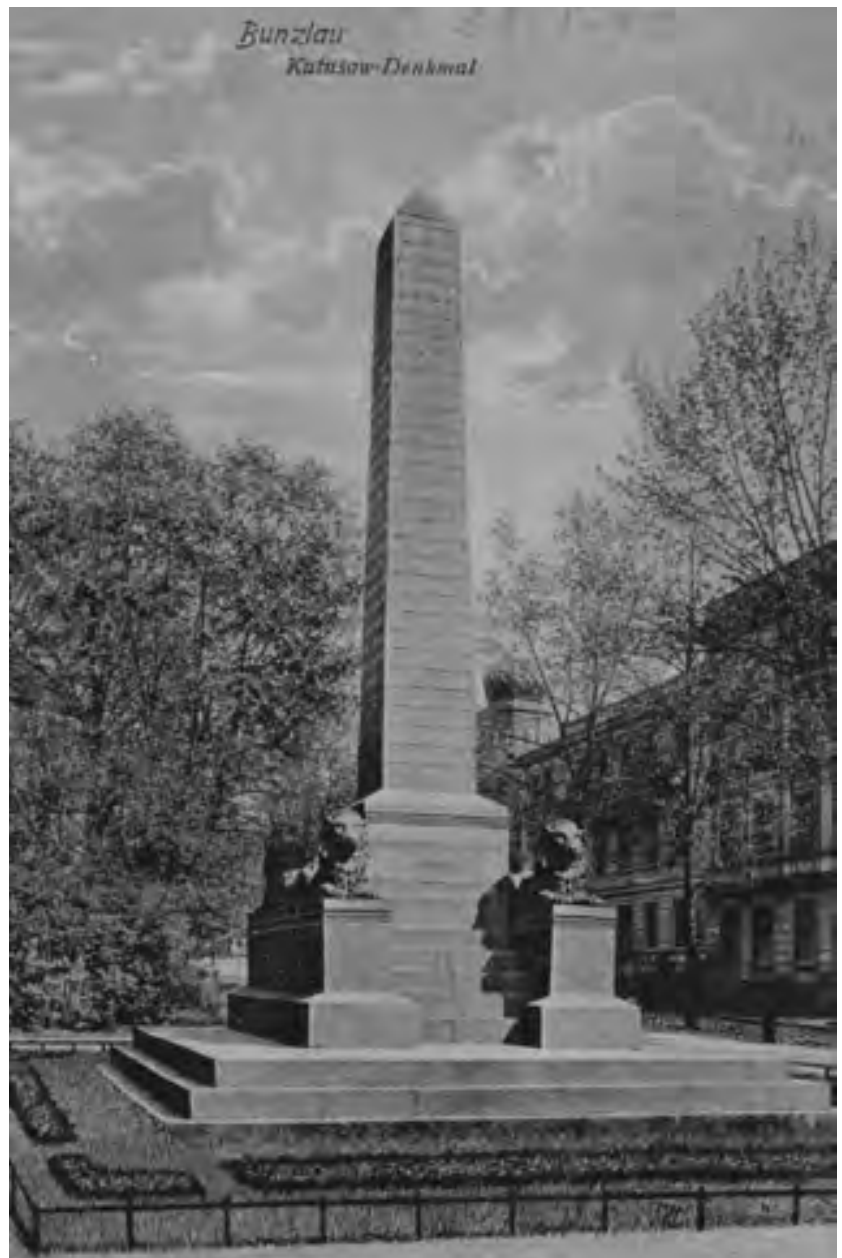

Konzept der historischen Ausstellung von 1913 an. ${ }^{62}$ So war 2013 nicht Breslau, sondern Bunzlau der Erinnerungsort der Befreiungskriege in Schlesien.

Der Jahrestag des Feldzugs von 1813 wurde im Schlesien des Jahres 2013 also auf vielschichtige Weise begangen: In Breslau hielt man sich mit der Poniatowski-Ausstellung einerseits an die offizielle Linie staatlicher Geschichtspolitik, andererseits folgte man der Politik der Stadtregierung und ihrem Bestreben, Breslau als europäische Metropole zu etablieren. Kleinere schlesische Städte dagegen nutzten das Jubiläum in erster Linie, um Touristen anzuziehen. Reenactment, Ausstellung und Konferenz in Bunzlau brachten die Suche der niederschlesischen Bevölkerung nach einer regionalen

62 1813-2013. Dwusetna rocznica kampanii napoleońskiej na Śląsku [1813-2013. 200 Jahre des napoleonischen Feldzuges in Schlesien]. Hg. v. Jerzy MaroŃ, Grzegorz Strauchold und Andrzej OlejNICZAK. Bolesławiec 2013. Ausgabe in deutscher, polnischer und russischer Sprache. 
Identität zum Ausdruck. Das Zentrum, die Hauptstadt Niederschlesiens setzt mit dem Slogan „Wrocław - The Meeting Place“ auf Europäizität (auch im historischen Kontext). Die Peripherie dagegen sucht ihre Identität immer häufiger in der reichen und vielfältigen, aber nach wie vor nicht wirklich ,angeeigneten“ Geschichte der Region. Als symptomatisch für diesen Prozess lässt sich folgende Äußerung des Bunzlauer Stadtpräsidenten Piotr Roman verstehen: „Er [Kutuzov] ist für uns kein Held. Aber die Erinnerung an ihn ist trotzdem wichtig für die Stadt."63

Übersetzt aus dem Polnischen von Heidemarie Petersen

63 In: http://wroclaw.gazeta.pl/wroclaw/1,35771,6369318,Boleslawiec_walczy_o_pamiatki_po_Kutuzowie.html (15.10.2014). - Abschließend sei unterstrichen, dass sich obige Ausführungen auf die deutsche Wahrnehmung des Jubiläums von 1913 als Erinnerungsort beschränken. Ebenso müsste man die Rezeption der schlesischen Anfänge der Befreiungskriege in Deutschland im Jahr 2013 näher betrachten. Die Ausstellung „Helden nach Maß. 200 Jahre Völkerschlacht“ im Stadtgeschichtlichen Museum in Leipzig im Jahre 2013 hat sich diesem Aspekt mit besonderer Hervorhebung des Blücher-Mythos gewidmet. Der eine wie der andere Aspekt bedürfen weitergehender vergleichender Untersuchungen. Im Oktober 2015 wurde von einer der polnischen Parteien im Wahlkampf vorgeschlagen, die Jahrhunderthalle in „Poniatowski-Halle“ umzubenennen. 


\title{
Befreiungskriege und Völkerschlacht in der visuellen Erinnerungskultur des Deutschen Kaiserreichs
}

\author{
Arnold Bartetzky
}

Anlässlich des zweihundertsten Jahrestages der Völkerschlacht zeigte das Stadtgeschichtliche Museum Leipzig eine Ausstellung, die unter dem Titel „Helden nach Maß" vor Augen führte, in welchem Maße die Produktion von Erinnerungen an die Napoleonischen Kriege in Deutschland wirkungsmächtige Bilder, Symbole und kulturelle Muster hervorgebracht hatte. ${ }^{1}$ In zwei Jahrhunderten transformiert und für die jeweiligen Bedürfnisse der Gegenwart anverwandelt, wirken sie vielfach bis heute nach, auch wenn ihre Herkunft ohne Vorwissen größtenteils nicht mehr erkennbar ist. In der Geschichtskultur des 19. Jahrhunderts waren die Erinnerungen an die napoleonische Zeit dagegen noch allgegenwärtig. Mit der Gründung des Deutschen Reichs von 1871 erhielten sie zudem eine neue Aktualität und sinngebende Bedeutung, auf die im Folgenden anhand von Denkmälern, illustrierten Geschichtswerken und Festdekorationen einige Schlaglichter geworfen werden.

Für das neue Kaiserreich gehörten die napoleonische Besatzung und die Befreiungskriege mit der Völkerschlacht als Höhepunkt zu den zentralen historischen Referenzpunkten. Ihre Vergegenwärtigung hatte eine mobilisierende, integrative und legitimatorische Funktion. Das liegt wesentlich an den Umständen der Entstehung dieses Reichs.

So unverhofft wie der siegreiche Krieg gegen Frankreich von 1870/71 und in dessen Folge die Gründung des Kaisertums gekommen war, so wurde es zu einer zentralen Aufgabe der Geschichtspolitik, die Ereignisse in eine Tradition zu stellen, die das neue Reich als Lohn langen nationalen Einheitsstrebens und als Erfüllung alter Hoffnungen erscheinen ließ. Zum letzten Mal waren diese Hoffnungen eine Generation zuvor, im Zuge der Revolution von 1848/49, aufgeflammt. Doch diese war für die Gründer des Kaiserreichs unter Preußens Führung als Traditionsspender aus mehreren Gründen tabu. Wegen ihrer parlamentarisch-demokratischen Bestrebungen war sie nicht kompatibel mit der obrigkeitlichen Konzeption des neuen Reichs. Zudem waren die Einheitshoffnungen seinerzeit gerade an der Haltung Preußens gescheitert: König Friedrich Wilhelm IV., der Bruder des neuen Kaisers und sein Vorgänger auf dem preußischen Königsthron, hatte 1849 die ihm von der Frankfurter Nationalversammlung angetragene Kaiserkrone abgelehnt.

1 Helden nach Maß. 200 Jahre Völkerschlacht bei Leipzig. Ausst.-Kat. Stadtgeschichtliches Museum Leipzig. Hg. v. Volker RodeKamp. Leipzig 2013. 


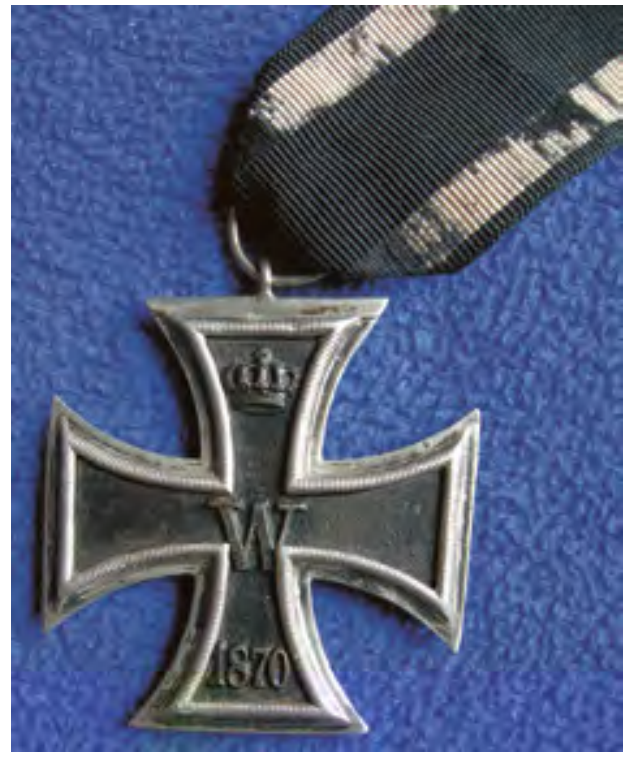

Abb. 1 Eisernes Kreuz II. Klasse von 1870.
Dagegen war der Sieg über Napoleon als historische Präfiguration hervorragend geeignet. $^{2}$ Als unübersehbare Parallele galt die siegreiche Waffenbrüderschaft Preußens mit anderen Staaten im Kampf gegen Frankreich, der nun als gesamtdeutsche Erhebung, angeführt vom preuBischen König, interpretiert wurde - auch wenn Preußen in den Befreiungskriegen bekanntlich nicht die später von ihm behauptete Rolle einer treibenden Kraft gespielt hatte. Eine weitere Parallele wurde darin gesehen, dass in beiden Fällen die militärischen Erfolge zum Sturz eines französischen Kaisers mit dem Namen Napoleon geführt hatten. Als Vorbild für 1870/71 galten auch die patriotische Begeisterung und legendäre Opferbereitschaft der Bevölkerung während der Befreiungskriege. Der Idealismus von damals, so die gängige Geschichtsdeutung der Reichsgründungszeit, habe erst in der Kaiserproklamation seine volle Erfüllung gefunden.

Schon zu Beginn des Deutsch-Französischen Krieges sollte die Beschwörung des Erbes der Befreiungskriege die Kampfbereitschaft der Soldaten steigern. Nach der französischen Kriegserklärung erneuerte König Wilhelm von Preußen, der künftige Kaiser Wilhelm I., das Eiserne Kreuz, das sein Vater Friedrich Wilhelm III. 1813 für den Krieg gegen Napoleon gestiftet hatte (Abb. 1). Die von Karl Friedrich Schinkel gestaltete, in ihrer Einfachheit markante Auszeichnung für alle Dienstgrade hatte es damals rasch zur Prominenz in Preußens visueller Kultur gebracht. Nach der Rückkehr der von Napoleon geraubten Quadriga auf das Brandenburger Tor im Jahr 1814 ersetzte ein eichenlaubumkränztes, von einem preußischen Adler bekröntes Eisernes Kreuz sogar den Lorbeerkranz in der Hand der nunmehr als Siegesgöttin gedeuteten Wagenlenkerin. Im Kaiserreich wurde es zu einem gesamtdeutschen Symbol, das nun an den Krieg von 1870/71 erinnerte und diesen zugleich in die Tradition des Kampfes gegen Napoleon stellte.

Diese Verbindung kam bereits deutlich in der Festdekoration des monatelang vorbereiteten Einzugs von Kaiser Wilhelm I. mit seinen Truppen in Berlin am 16. Juni

2 Zur Bedeutung der Befreiungskriege für die visuelle Geschichtskultur im Deutschland des 19. Jahrhunderts zusammenfassend: FLACKE, Monika: Die Begründung der Nation aus der Krise. In: Mythen der Nationen: Ein europäisches Panorama. Hg. v. Monika Flacke. München-Berlin ${ }^{2} 2001$ [11998], S. 101-128, hier S. 116-120. 
Abb. 2 Festdekoration am Pariser Platz zum Einzug von Kaiser Wilhelm I. mit seinen Truppen in Berlin, 16. Juni 1871.

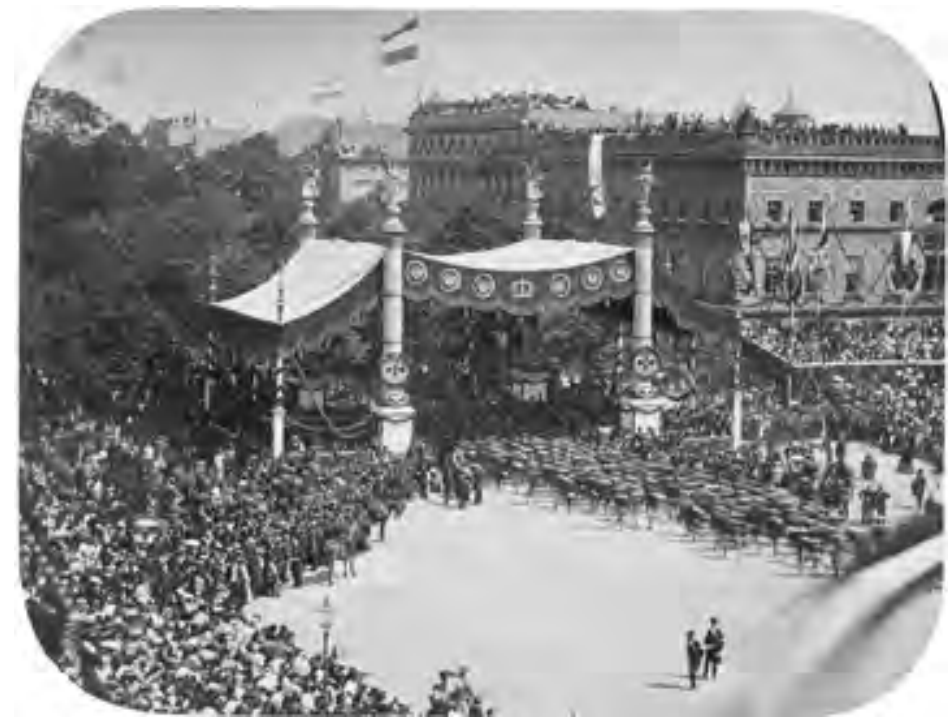

1871, einer der größten Massenveranstaltungen des 19. Jahrhunderts, zum Ausdruck. ${ }^{3}$ Zwei Säulen des Ehrenbaldachins am Pariser Platz waren mit je einem eichenumkränzten Eisernen Kreuz geschmückt worden (Abb. 2). Den Inschriften zufolge stellte eines von ihnen das von 1813, das andere das von 1870 dar. ${ }^{4}$ In der Folgezeit gehörte das Eiserne Kreuz zu den meistverwendeten Motiven an Gefallenen- und Siegesdenkmälern.

Die emphatische Betonung der Parallelen zwischen 1870/71 und 1813 wurde natürlich auch zu einem Topos der preußischen Geschichtsschreibung. So heißt es etwa in dem auf Initiative des preußischen Unterrichtsministeriums publizierten, opulent illustrierten Buch „Der Krieg gegen Frankreich und die Einigung Deutschlands“ von Theodor Lindner:

Zweimal in unserm Jahrhundert sind dem deutschen Volke große Zeiten beschieden gewesen; zweimal haben seine Führer und seine Söhne Thaten verrichtet von unübertrefflichem Heldentum.

3 Einige der unzähligen Berichte über den Truppeneinzug und seine Dekoration: EgGERs, Karl: Die Siegesstrasse in Berlin beim Einzuge des Kaisers Wilhelm mit den Deutschen Truppen am 16. Juni 1871. Berlin 1871; Meyer, Bruno: Der künstlerische Theil der Berliner Siegesfeier. 16. Juni 1871. In: Kunst-Chronik. Beiblatt zur Zeitschrift für Bildende Kunst 6 (1871), Nr. 20, S. 161-164, Nr. 21, S. 169-172, Nr. 22, S. 177-181, Nr. 23, S. 186-189; S., H.: Kaiser Wilhelm und seine Paladine. Eine Erinnerung an den 16. Juni 1871. In: Die Gartenlaube (1871), Nr. 40, S. 670-674; WernER, Anton von: Erlebnisse und Eindrücke 1870-1890. Berlin 1913, S. 57-60; Die Gründung des Deutschen Reiches 1870/71 in Augenzeugenberichten. Hg. v. Ernst DeuerLein. München 1977, S. 340-344; Das Tagebuch der Baronin Spitzemberg geb. Freiin v. Varnbüler. Aufzeichnungen aus der Hofgesellschaft des Hohenzollernreiches. Hg. v. Rudolf VIERHAus. Berlin ${ }^{5} 1989$ [ $\left.{ }^{1} 1960\right]$, S. 126-127; Berlin wird Kaiserstadt. Panorama einer Metropole 1871-1890. Hg. v. Ruth Glatzer. Berlin 1993, S. 25-32 (mehrere Textauszüge).

4 Eggers (wie Anm. 3), S. 13-14. 


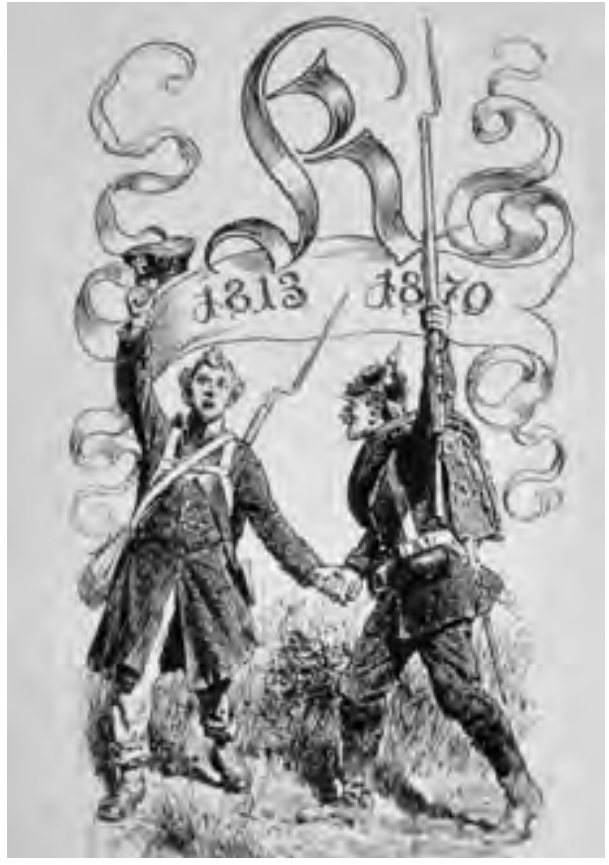

Abb. 3 Theodor Lindner: Der Krieg gegen Frankreich und die Einigung Deutschlands. Berlin 1895, Schmuckinitiale am Anfang des Buches.

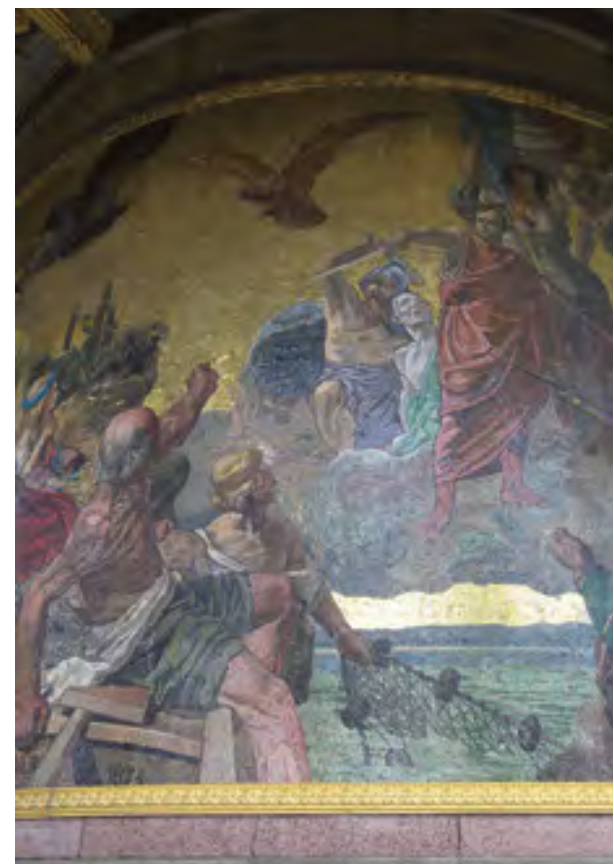

Abb. 4 Berlin, Mosaikbild an der Siegessäule, Detail, um 1872. Foto: Arnold Bartetzky.

In den Befreiungskriegen wurde das von dem ersten Napoleon zerschmetterte Volk wieder aufgerichtet, aus den Kämpfen gegen den dritten Napoleon ging eine geeinte Nation, ein neues Reich hervor. ${ }^{5}$

Eine Schmuckinitiale am Anfang des Buches zeigt an der Stelle den symbolischen Händedruck zwischen einem preußischen Soldaten von 1813 und einem von 1870 (Abb. 3). In einem panegyrischen Werk über die Hohenzollern von Rudolf Graf von Stillfried-Alcántara, dem Oberzeremonienmeister des preußischen Hofes, und Bernhard Kugler werden sogar Parallelen im Schlachtverlauf konstruiert: „Die Kämpfe um Metz gleichen der Leipziger Völkerschlacht. Beide Male ringen ungeheure Heeresmassen drei Schlachttage lang mit einander, und 1813 wie 1870 wird in diesen drei Tagen die Hauptmacht des französischen Kaiserreichs vernichtet.“ In ihrem Kommentar zur Gefangennahme Napoleons III. nach der Schlacht von Sedan bringen die Autoren auch die Idee der Rache für die Verwüstungen durch Napoleon Bonaparte zum Ausdruck: „,Der Kaiser, der Kaiser gefangen“ - und gefangen allein durch deutsche

5 LindNER, Theodor: Der Krieg gegen Frankreich und die Einigung Deutschlands. Zur 25jährigen Wiederkehr der Gedenktage von 1870/71. Berlin 1895, S. 1. 
Kraft - das klang wie die wundersamste Vergeltung für Alles, was die Napoleoniden jemals am Vaterlande gesündigt hatten." ${ }^{\text {66 }}$

Mit bildlichen Mitteln formulierte der Maler Anton von Werner dieselbe Idee auf dem umlaufenden Mosaik der Berliner Siegessäule, die 1864-1873 als Denkmal für die drei preußischen Siege im Deutsch-Dänischen Krieg, im Deutschen Krieg gegen Österreich und im Deutsch-Französischen Krieg errichtet wurde. ${ }^{7}$ Auf einer dunklen Wolke schwebt hier der französische Aggressor mit ausgestrecktem Schwert dem unschuldigen deutschen Volk entgegen (Abb.4). Werner stellte ihn als einen „Cäsarentypus"8 mit den Zügen Napoleon Bonapartes dar, nachdem ihm Kaiser Wilhelm entsprechend seinem monarchischen Pietätssinn verboten hatte, ihn als Napoleon III. darzustellen. Hinter dem Angreifer schwingt Marianne, die Personifikation Frankreichs, die Trikolore. Die Geißeln der Menschheit - Krieg, Hunger und Tod - bilden das Gefolge.

Deutlicher noch als an der Siegessäule wurde die Verbindung zwischen dem DeutschFranzösischen Krieg und den Befreiungskriegen an anderen Denkmälern hergestellt. ${ }^{9}$ So fand anlässlich der Berliner Einzugsfeier vom 16. Juni 1871 die Einweihung des damals noch nicht fertiggestellten Reiterstandbilds für Friedrich Wilhelm III. statt. ${ }^{10}$ Durch die vorgezogene Denkmalsenthüllung wurde es möglich, den Vater des Kaisers mit einer feierlichen Niederlegung eroberter französischer Fahnen postum als Sieger über Napoleon und Wegbereiter des Triumphs von Versailles zu ehren. „So schließt sich in der Geschichte Glied an Glied“, schreibt dazu Lindner. „Das vom Vater ruhmreich begonnene Werk hatte der Sohn herrlich vollendet." ${ }^{\text {"11 }}$

Eine Aufwertung erfuhr nach der Reichsgründung das den Befreiungskriegen gewidmete, 1821 eingeweihte Kreuzbergdenkmal in Berlin, ein von Schinkel entworfener neugotischer, turmartiger Baldachin aus Gusseisen mit eingestellten Genien der Hauptschlachten und bekrönendem Eisernem Kreuz. Um seine seit Langem als unbefriedigend geltende Fernwirkung zu verbessern, wurde das knapp 20 Meter hohe, unter Friedrich Wilhelm III. errichtete Denkmal 1878 auf Anordnung des Kaisers auf einen mächtigen Unterbau gehoben (Abb. 5). ${ }^{12} \mathrm{Zu}$ dieser Zeit stand es noch nicht im Schatten der vielen ungleich größeren Monumente, die im späten 19. und frühen 20. Jahrhundert in ver-

6 Stillfried-Alcántara, Rudolf/Kugler, Bernhard: Die Hohenzollern und das Deutsche Vaterland. München ${ }^{4} 1886$ [11884], S. 364-366.

7 Alings, Reinhard: Die Berliner Siegessäule. Vom Geschichtsbild zum Bild der Geschichte. Berlin 2000.

8 Werner (wie Anm. 3), S. 72.

9 Zur Programmatik nationalpolitischer Denkmäler im Kaiserreich grundlegend: Auıngs, Reinhard: Monument und Nation. Das Bild vom Nationalstaat im Medium Denkmal - zum Verhältnis von Nation und Staat im deutschen Kaiserreich 1871-1918. Berlin-New York 1996.

10 ARndt, Karl: Denkmaltopographie als Programm und Politik. Skizze einer Forschungsaufgabe. In: Kunstverwaltung, Bau- und Denkmal-Politik im Kaiserreich. Hg. v. Ekkehard MAI und Stephan WAETzoldT. Berlin 1981, S. 165-190, hier S. 176.

11 Lindner (wie Anm. 5), S. 162.

12 Die Erhöhung des Krieger-Denkmals auf dem Kreuzberge zu Berlin. In: Zeitschrift für Bauwesen 29 (1879), S. 417-424; Nungesser, Michael: Das Denkmal auf dem Kreuzberg von Karl Friedrich Schinkel. Berlin 1987, S. 68-75. 


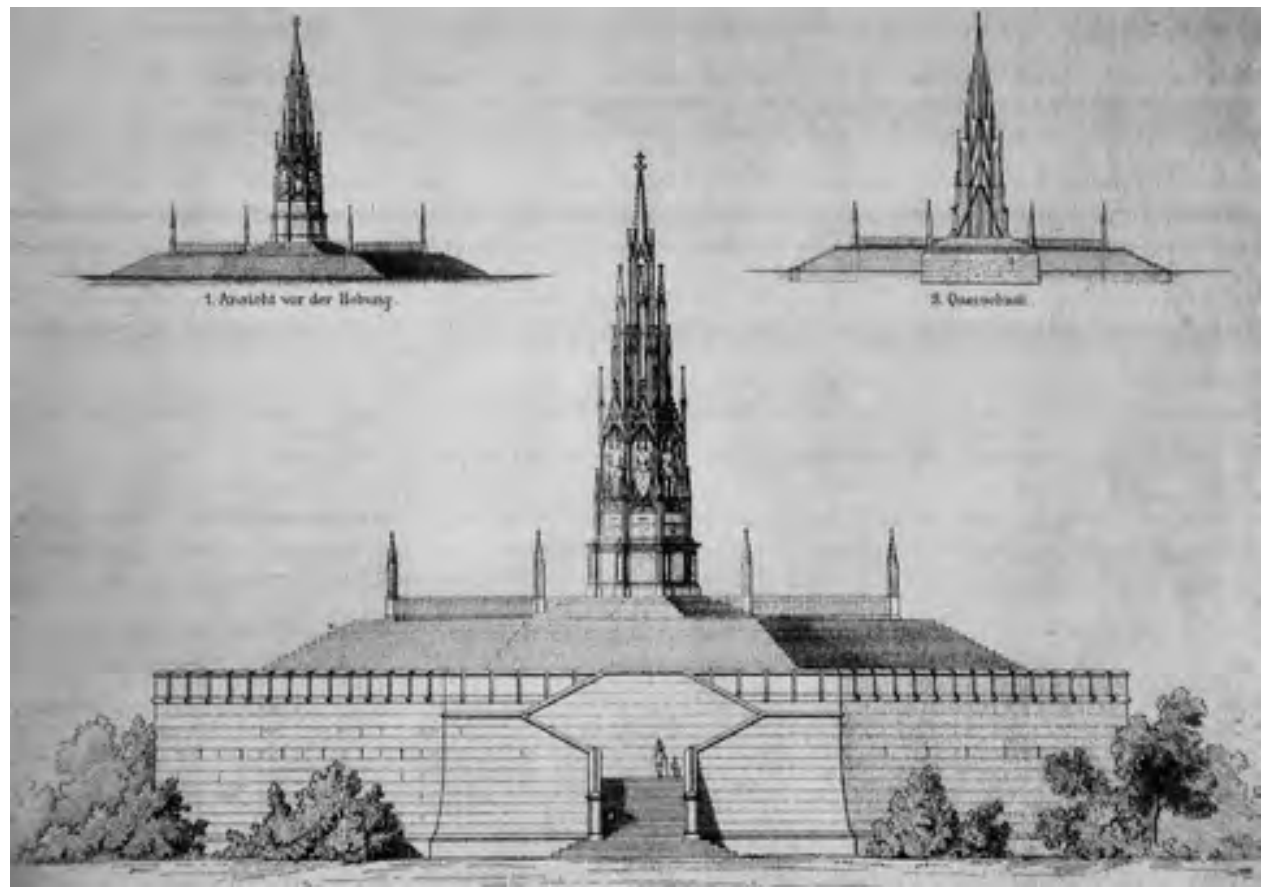

Abb. 5 Berlin, Kreuzbergdenkmal, Ansichten vor und nach der Erhöhung von 1878. Zeitschrift für Bauwesen 29 (1879).

schiedenen Teilen Deutschlands entstehen sollten. Seine große Bedeutung für die Erinnerungskultur der Reichsgründungszeit zeigt sich in der Vorbildfunktion für einige kleinere Denkmäler für den Krieg von 1870/71 und vor allem in einer Reverenz am Niederwalddenkmal, dem 1883 eingeweihten Hauptmonument für die deutsche Einigung von $1871 .{ }^{13}$ An dessen Terrassenmauer sind die Worte Kaiser Wilhelms anlässlich der Grundsteinlegung im Jahr 1877 angebracht: „Wie mein koeniglicher Vater einst dem preussischen Volke an dem Denkmale bei Berlin zurief, so rufe ich heute an dieser bedeutungsvollen Stelle dem deutschen Volke zu: Den Gefallenen zum Gedaechtnis, den Lebenden zur Anerkennung und den kuenftigen Geschlechtern zur Nacheiferung."

Durch den Deutsch-Französischen Krieg und die Reichsgründung wurde nicht nur die Erinnerung an Friedrich Wilhelm III. wiederbelebt, sondern auch und in einem vielleicht noch höheren Maße die an seine Ehefrau, Königin Luise von Preußen. Bereits seit ihrem frühen Tod im Jahr 1810 hatte sich ein Personenkult um die Mutter des späteren Kaisers Wilhelm entwickelt, in dessen Zentrum der ihr zugeschriebene aufopferungsvolle Patriotismus während der napoleonischen Besatzung stand. ${ }^{14}$ Sie wurde zu

13 Tittel, Lutz: Das Niederwalddenkmal 1871-1883. Hildesheim 1979.

14 Auswahl jüngerer Publikationen zum Luisenkult: Speth, Rudolf: Königin Luise von Preußen - deutscher Nationalmythos im 19. Jahrhundert. In: Mythos Diana - von der Princess of Wales zur Queen 
einer Symbolfigur des antinapoleonischen Widerstands in Preußen, und ihr Tod nach Fluchten vor französischen Truppen galt als Opfertod für das Vaterland. Nach 1871 konnte er neu gedeutet werden: Luise wurde fortan nicht nur als Märtyrerin, sondern auch, wie es der Kunsthistoriker Friedrich Eggers 1873 formulierte, als „Ahnfrau des neuen deutschen Reiches ${ }^{\text {“15 }}$ verehrt. In dem 1890 erschienenen, von Adolf Bär und Paul Quensel herausgegebenen Prachtband „Bildersaal deutscher Geschichte“ stellen die ihr in den Mund gelegten letzten Worte an ihre Söhne diesen Bezug zur Gegenwart her:

Es gibt keinen preußischen Staat, keine preußische Armee, keinen preußischen Nationalruhm mehr [...] Ach, meine Söhne, [...] ruft künftig, wenn eure Mutter und Königin nicht mehr lebt, diese unglückliche Stunde in euer Gedächtnis zurück [...] Aber begnügt euch nicht mit den Tränen allein; handelt - entwickelt eure Kräfte; vielleicht läßt Preußens Schutzgeist sich auf euch nieder; befreiet dann euer Volk von der Schande [...]; suchet den jetzt verdunkelten Ruhm eurer Vorfahren von Frankreich zurückzuerobern $[\ldots]$.

Die politische Bedeutung dieser Worte für die wilhelminische Zeit war wohl für jeden zeitgenössischen Leser offenkundig. Trotzdem wird im Anschluss noch gesagt, was eigentlich gar nicht gesagt werden musste: „Hätte sie ahnen können [...], daß sich auf Wilhelm Preußens Schutzgeist niederlassen, ihn zum Befreier seines Volkes von der Schande und Erniedrigung erwählen und dereinst zum Kaiser eines großen mächtigen Deutschland erheben werde!“"16 Wilhelm, so die aktualisierte Botschaft der Luisenlegende, hat die Hoffnungen seiner Mutter nicht nur erfüllt, sondern übererfüllt.

Zum Andenken an die Königin wurde 1880 im Berliner Tiergarten ein von Erdmann Encke geschaffenes Standbild enthüllt (Abb. 6). ${ }^{17}$ Das Kaiser Wilhelm gewidmete, von der Stadt Berlin und privaten Spendern finanzierte Denkmal zeigt Luise als Schönheit von jugendlicher Anmut und zugleich schwermütiger Erhabenheit. Um den Rundsockel läuft ein Relief herum, das der Erhebung des Volkes in den Befreiungskriegen gewidmet ist. Zu sehen sind Szenen des Abschieds der Soldaten, der Armenfürsorge und Pflege von Verwundeten, der Beweinung von Gefallenen und schließlich der glücklichen Heimkehr der Sieger. Entsprechend der Vorbildfunktion Luises ist hier die Rolle der leidenden und sich aufopfernden Frau besonders akzentuiert.

of Hearts. Hg. v. Sabine Berghahn und Sigrid Koch-Baumgarten. Gießen 1999, S. 265-285; De BruYn, Günter: Preußens Luise. Vom Entstehen und Vergehen einer Legende. Berlin 2001; MüLLER, Friedrich Ludwig: Luise. Aufzeichnungen über eine preußische Königin. Bonn 2001; DemandT, Philipp: Luisenkult: Die Unsterblichkeit der Königin von Preußen. Köln-Weimar-Wien 2003; ScHORNSchÜtTE, Luise: Königin Luise. Leben und Legende. München 2003; ThIELE, Johannes: Luise, Königin von Preußen. Das Buch ihres Lebens. München 2003; Schönpflug, Daniel: Luise von Preußen. Königin der Herzen. Eine Biographie. München 2010.

15 Zitiert nach: Simson, Jutta von: Das Denkmal der Königin Luise in Berlin. Ein Beitrag zur Luisenverehrung im 19. Jahrhundert. In: Festschrift für Otto von Simson zum 65. Geburtstag. Hg. v. Lucius Grisebach und Konrad Renger. Frankfurt/M.-Berlin-Wien 1977, S. 516-530, hier S. 523.

16 Bildersaal deutscher Geschichte. Zwei Jahrtausende deutschen Lebens in Wort und Bild. Hg. v. Adolf BÄr und Paul Quensel. Stuttgart-Berlin-Leipzig 1890. Nachdruck: Wiesbaden 2004, S. 360.

17 Simson (wie Anm. 15), S. 516-530. 


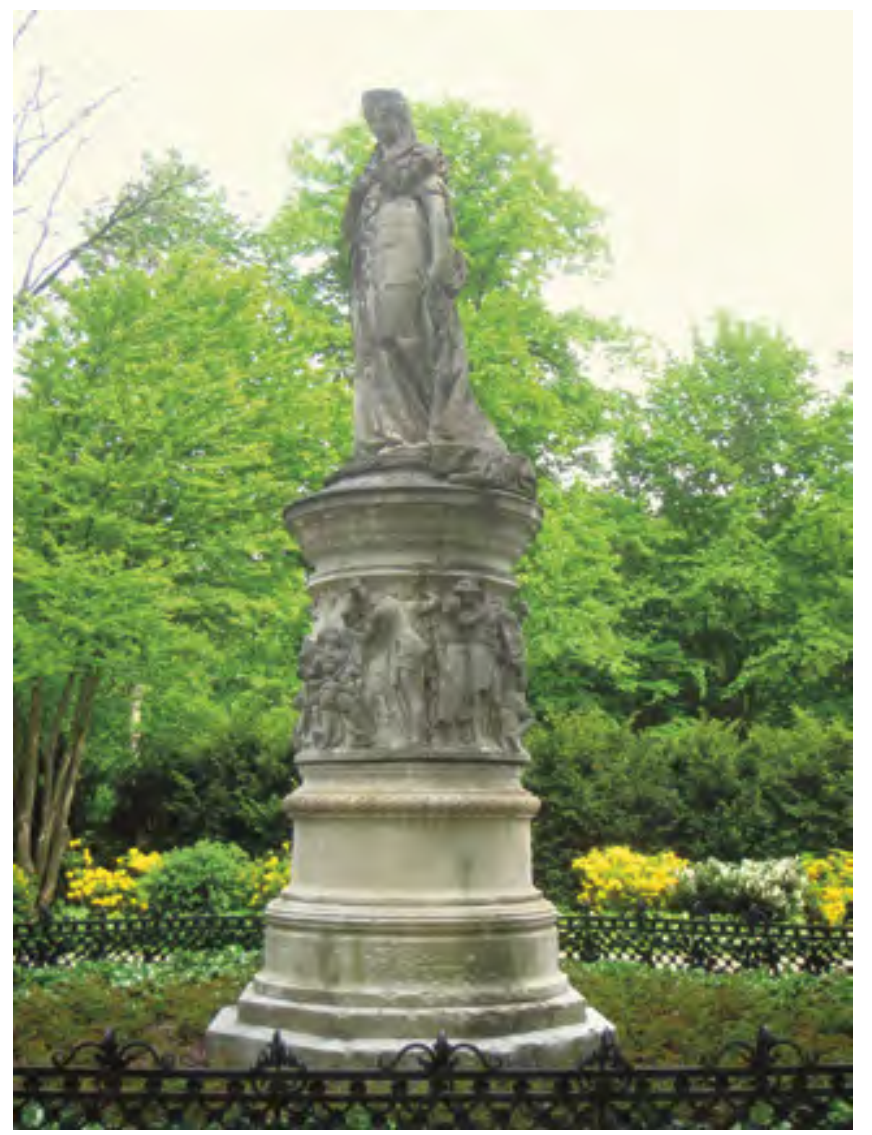

Abb. 6 Berlin, Denkmal der Königin Luise, 1880 eingeweiht.

Die Parallelisierung von napoleonischer Besatzung und Befreiungskriegen mit dem Deutsch-Französischen Krieg und der Reichsgründung war einer der tragenden Pfeiler im Geschichtsgebäude des Kaiserreichs. Ebenso wie einige andere Geschichtskonstruktionen - darunter vor allem der Bezug zum Heiligen Römischen Reich Deutscher Nation mit dem Stauferkult und die Mythisierung germanischer Frühgeschichte mit dem Hermannskult - sollte die Berufung auf die Befreiungskriege historische Kontinuität simulieren und damit dem Kaiserreich, einem Parvenü unter den Großmächten, eine Tradition verschaffen, die ihm tatsächlich fehlte. Sie war damit von staatstragender Bedeutung.

Es waren aber nicht nur staatliche Institutionen, sondern wohl vor allem Initiativen aus dem Bürgertum - Bürgerinitiativen, würde man heute sagen -, die für die entsprechende Erinnerungsproduktion sorgten. Das spektakulärste Beispiel dafür lieferten die Aktivitäten des 1894 von dem Architekten Clemens Thieme gegründeten „Deutschen Patriotenbundes zur Errichtung eines Völkerschlacht-Denkmals bei Leipzig“. 
Der 1913 fertiggestellte, von Bruno Schmitz entworfene Turmbau von über 90 Metern Höhe (Abb. 7) war das erste große, ausschließlich den Befreiungskriegen gewidmete Denkmal seit der Reichsgründung. Er konnte aber auf eine reiche ältere Tradition von Denkmälern zu diesem Thema aufbauen - von dem erwähnten Kreuzbergdenkmal in Berlin über die annähernd 100, überwiegend sehr bescheidenen Erinnerungsmale in und um Leipzig bis zur wuchtigen, 1863 fertiggestellten Befreiungshalle im niederbayerischen Kelheim. Darüber hinaus stellten weitere Denkmäler in verschiedenen Kontexten Bezüge zu den Befreiungskriegen her. So bildet eine Figurengruppe am Südgiebel der 1842 eröffneten Walhalla bei Donaustauf eine Allegorie auf „Teutschlands Befreyung im Jahr 1814“. An dem seit den 1830er Jahren erbauten, aber erst 1875 eingeweihten Hermannsdenkmal bei Detmold feiert eine Inschrift die Wiedergewinnung deutscher Einheit im Kampf gegen Napoleon, wobei entsprechend den aktuellen politischen Erfordernissen die vermeintlich führende Rolle Preußens besonders akzentuiert wird: „Nur weil deutsches Volk verwelscht und durch Uneinigkeit machtlos geworden, konnte Napoleon Bonaparte, Kaiser der Franzosen, mit Hülfe Deutscher Deutschland unterjochen. Da endlich 1813 scharten sich um das von Preußen erhobene Schwert alle deutschen Staemme, ihrem Vaterlande aus Schmach die Freiheit erkämpfend." Eine weitere Inschrift schlägt den Bogen zur Gegenwart: „Am 17. Juni 1870 erklärte Frankreichs Kaiser, Louis Napoleon, Preußen Krieg, da erstunden alle mit Preußen verbündeten deutschen Volksstaemme und züchtigten vom August 1870 bis Januar 1871 immer siegreich französischen Uebermuth unter Führung des Koenigs Wilhelm von Preußen, den das deutsche Volk am 18. Januar 1871 zu seinem Kaiser erhob.“ Zu den zahlreichen Denkmälern mit Bezug zu den Befreiungskriegen kamen unrealisiert gebliebene Entwürfe, Visionen und Luftschlösser hinzu, die bereits kurz nach der Völkerschlacht aufgekommen waren, darunter der berühmte Befreiungsdom von Schinkel und ein nicht minder ambitionierter Entwurf für ein „teutsches Nationaldenkmal“ von Friedrich Weinbrenner, der als Inspirationsquelle für das Völkerschlachtdenkmal von besonderer Bedeutung war. In Leipzig hatte zudem bereits zum 50. Jubiläum der Völkerschlacht ein Wettbewerb für ein größeres Denkmal stattgefunden. 1863 wurde sogar ein Grundstein gelegt, doch das Projekt versandete.

Die komplizierte Planungs- und Baugeschichte, Baugestalt und Ikonografie des Völkerschlachtdenkmals werden im Beitrag von Thomas Topfstedt in diesem Band behandelt. An dieser Stelle sei nur kurz auf die nationalpolitische Bedeutung eingegangen, die das größte Monument Europas für seine Initiatoren hatte. Der Deutsche Patriotenbund, heißt es in einer von Alfred Spitzner verfassten Schrift zur Denkmalweihe im Jahr 1913, stellte sich ,auf den rein nationalen Standpunkt und richtete den Blick auf die einfache, große Linie, die von Jena" - gemeint ist die preußische Niederlage gegen Napoleon in der Schlacht bei Jena und Auerstedt im Jahr 1806 - „über Leipzig nach Sedan und Versailles führte. [...] Man wußte nun, daß Deutschlands Denkmal der Völkerschlacht der Ehrung seiner Befreiung und seiner nationalen Wiedergeburt gelten sollte, daß es sich darum handelte, mit ihm die tieferliegenden Fäden zu erfassen, die 1813 und 1871 verknüpfen, und mit ihm die segenvolle Wandlung des deutschen Schicksals in der Leipziger Schlacht zu verherrlichen, da die schmachvolle Fremdherrschaft 


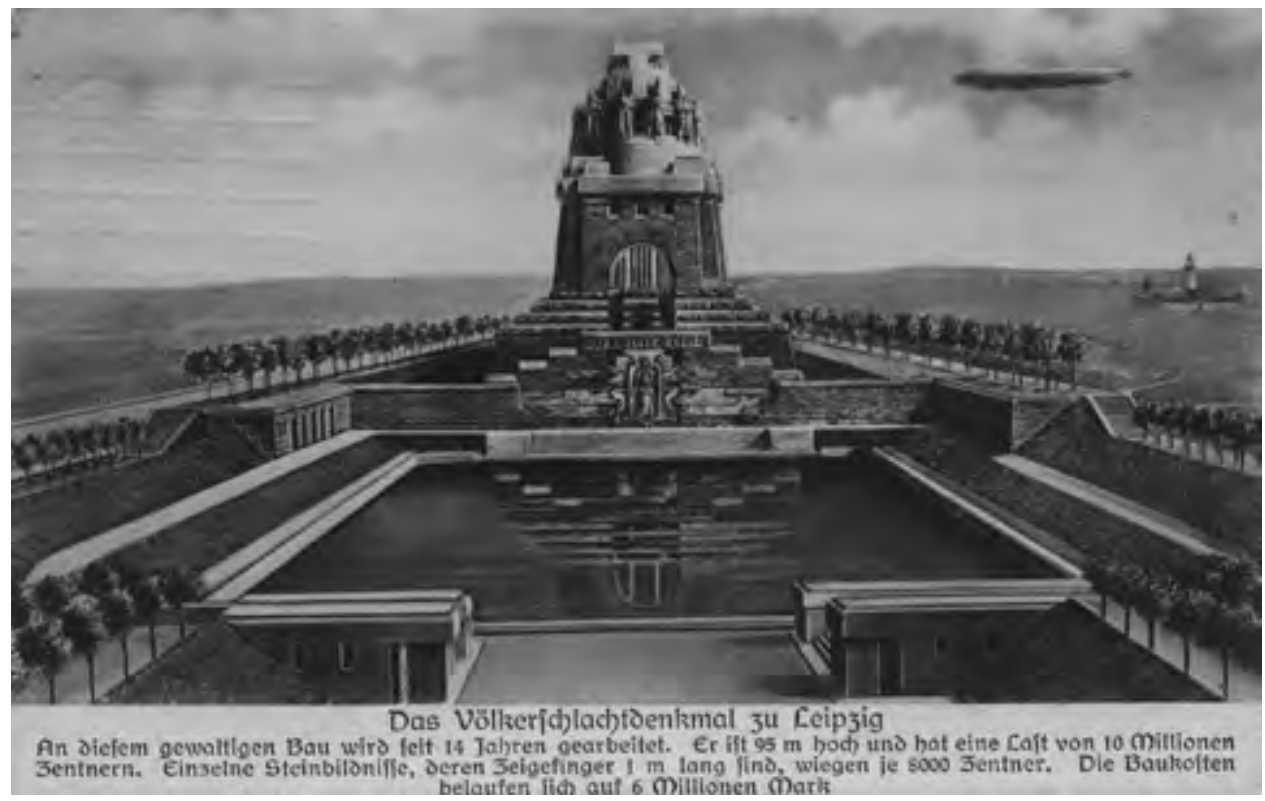

Abb. 7 Leipzig, Völkerschlachtdenkmal. Postkarte um 1912.

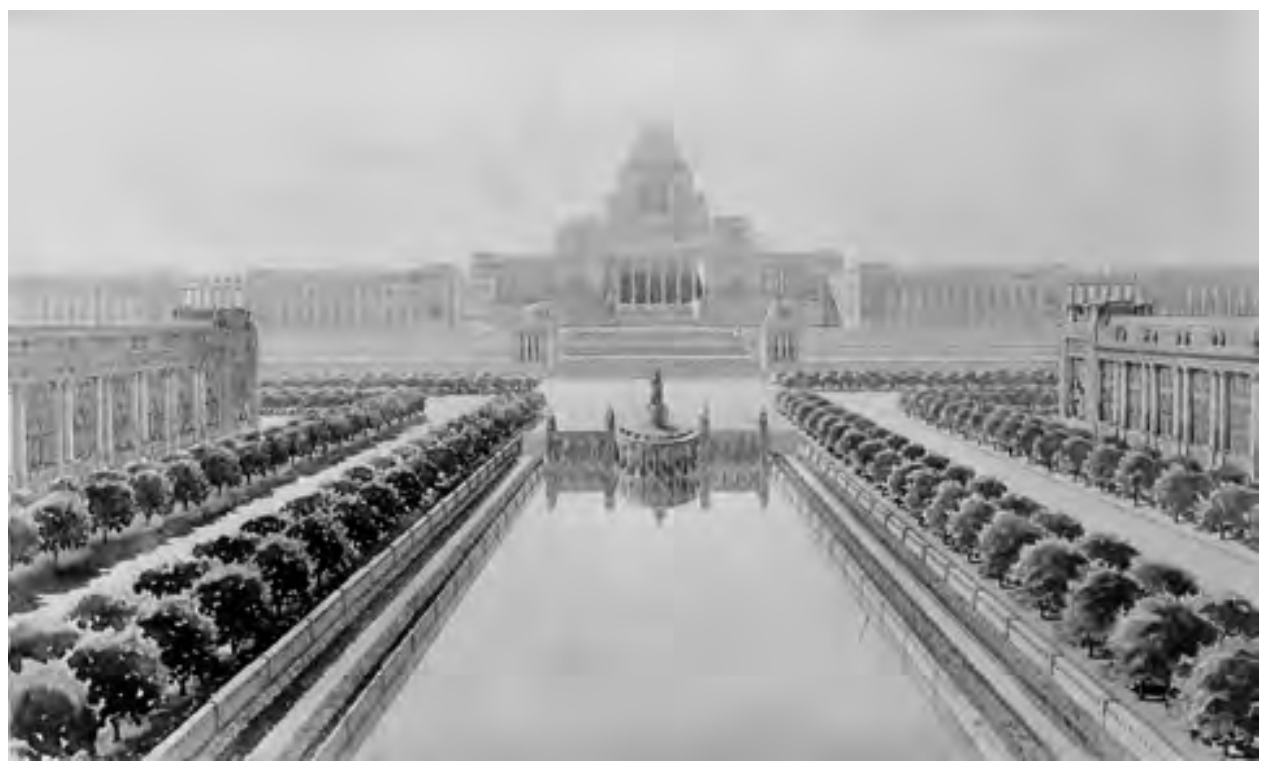

Abb. 8 Eliel Saarinen, Entwurf für das australische Parlament in Canberra, 1912. 
gebrochen und die neue Zeit eingeleitet wurde: die frei nach eigener Art sich vollziehende Entwicklung Deutschlands unter Preußens Führung.“

Der Verfasser, der als Zweiter Vorsitzender des Deutschen Patriotenbundes figurierte, sah in dem Koloss ein „Ruhmesmal der deutschen Volksart“, in dem „die echt germanische Kraft und die malerische Einstimmung in die Natur der Umgebung [...] aufs höchste gesteigert" seien. ${ }^{18}$

Der martialische, unter anderen von altägyptischen Vorbildern inspirierte Zyklopenstil galt den Vätern des Denkmals als urgermanische Architektursprache und damit als baulicher Ausdruck eines wiederzuerweckenden, urwüchsig-kraftstrotzenden Volkscharakters. „In dem Denkmalbau [...] hat das deutsche Nationalbewußtsein sich seine Form geschaffen", hieß es in einer Festrede zum Richtfest. ${ }^{19}$ Allerdings erwies sich der die deutsche Einheit feiernde Bau selbst nicht gerade als einheitsstiftend, war er doch bereits unter den Zeitgenossen höchst umstritten. Feierten ihn völkisch-nationalistische Kreise als „,die größte Leistung aller Kunst aller Völker des 20. Jahrhunderts“" ${ }^{\text {“20, so war }}$ er für deren Gegner, darunter nicht zuletzt die Sozialdemokraten, ein bloßer „Steinhaufen“21 und „Ausdruck einer nationalen Unkultur“, der „mit Kunst nichts zu tun“ habe. ${ }^{22}$

Die Zuordnung des Völkerschlachtdenkmals zu einer spezifisch deutschen National(un)kultur durch Befürworter wie Gegner sollte allerdings nicht darüber hinwegtäuschen, dass sein himmelstürmender und zugleich raumgreifender, archaisierender Monumentalismus nichts Urdeutsches war, sondern eher die Radikalisierung einer internationalen Architekturströmung des frühen 20. Jahrhunderts, für die sich der Begriff Nationalromantik eingebürgert hat. Dass diese auch für andere Staaten und andere Ideologien als passend empfunden werden konnte, zeigt beispielhaft der etwa zeitgleich mit der Fertigstellung des Völkerschlachtdenkmals entstandene Entwurf des finnischen Architekten Eliel Saarinen für das Parlamentsgebäude im australischen Canberra (Abb. 8).

Umgekehrt konnte im späten Kaiserreich das vom nationalistischen Getöse begleitete Gedenken an 1813 auch ein Werk von einer ganz anderen ästhetischen Haltung wie die ebenfalls 1913 eröffnete Jahrhunderthalle in Breslau von Max Berg, hervorbringen, eine Inkunabel der Moderne, die im Beitrag von Agnieszka Zabłocka-Kos ausführlicher besprochen wird. Die beiden Bauten - hier der düstere gedrungene Steinkoloss, dort die lichtdurchflutete Halle - wirken wie zwei Antipoden, die idealtypisch vor Augen führen, dass es in der Architekturgeschichte keine starre Zusammengehörigkeit von Inhalt und Form gibt. Dass sie bei allen vordergründigen Gegensätzen verwandter sind, als es auf den ersten Blick scheint, wäre eine eigene Betrachtung wert, die allerdings den Rahmen dieses Beitrags sprengen würde.

18 Spitzner, Alfred: Die Entstehungsgeschichte des Völkerschlachtdenkmals. In: Deutschlands Freiheitsdom. Gedenkblatt zur Weihe des Völkerschlachtdenkmals. Sonderdruck der Leipziger Neuesten Nachrichten, 18.10.1913, S. 6-7, hier S. 6.

19 Mitteilungen des Deutschen Patriotenbundes 18 (1911), Nr. 1, S. 1, zitiert nach: Hutter, Peter: „Die feinste Barbarei“. Das Völkerschlachtdenkmal bei Leipzig. Mainz 1990, S. 13.

20 Hans Schliepmann, zitiert nach: Hutter (wie Anm. 19), S. 183.

21 Kommentar der SPD, zitiert nach: Hutter (wie Anm. 19), S. 185.

22 Wilhelm Hausenstein, zitiert nach: Hutter (wie Anm. 19), S. 185. 
Völkerschlachtdenkmal und Jahrhunderthalle wurden zu den aufsehenerregendsten und zugleich zu den letzten dem Triumph gegen Napoleon gewidmeten Monumenten in Deutschland. Die Berufung auf die Befreiungskriege sollte zwar weiterhin immer wieder eine mobilisierende Rolle spielen. So erneuerte Kaiser Wilhelm II. bereits wenige Monate nach der Einweihung der beiden Denkmäler abermals das Eiserne Kreuz, um Deutschlands Kampfkraft im beginnenden Ersten Weltkrieg zu erhöhen. Nach Deutschlands Niederlage und dem Zusammenbruch des Kaiserreichs in dessen Folge wurde aber die Feier siegreicher Schlachten gegen Frankreich anachronistisch. 
Topografie der Völkerschlacht: Spurensuche 
Open Access @ 2016 by Böhlau Verlag GmbH \& Cie, Köln Weimar Wien 


\title{
Das Leipziger Völkerschlachtdenkmal: Eine kurze Ideen- und Baugeschichte
}

\author{
Thomas Topfstedt
}

Die Freiraumanlage und der gigantische Bau des Völkerschlachtdenkmals ${ }^{1}$ bilden den abschließenden Höhepunkt einer sich über das gesamte Leipziger Stadtgebiet verteilenden Denkmallandschaft, deren Monumente von unterschiedlichen Stiftern zur Erinnerung an die Orte und Akteure der Völkerschlacht gesetzt worden sind. ${ }^{2}$ In seiner langen und wechselvollen Ideengeschichte reicht es bis in die Zeit unmittelbar nach den Befreiungskriegen zurück. Mit dem Bau des Monumentes ist gegen Ende des 19. Jahrhunderts begonnen worden, und dies in Dimensionen, die der Initiator des Denkmalprojektes, der 1894 gegründete „Deutsche Patriotenbund zur Errichtung eines Völkerschlacht-National-Denkmals bei Leipzig“, anfänglich überhaupt nicht ins Auge gefasst hatte. Mit 91 Metern Gesamthöhe galt das Leipziger Völkerschlachtdenkmal bei seiner Einweihung 1913 als das größte Denkmal Europas. Sehr wahrscheinlich aber ist es bis heute das größte architektonische Denkmal der Welt (Abb. 1).

Der Faszination, die von der schieren Größe und Massigkeit des Monumentes und seines Skulpturenprogramms ausgeht, kann sich kein Betrachter entziehen, ganz gleich, ob er den Denkmalsbau als Gesamtkunstwerk und bautechnische Bravourleistung anerkennt oder ob er dem primär vom völkischen Gedankengut am Vorabend des Ersten Weltkrieges getragenen inhaltlichen Konzept des Denkmals eher distanziert gegenübersteht. Einen adäquaten Zugang zum Verständnis der Architektur und der skulpturalen Ausstattung des Völkerschlachtdenkmals gewinnt man jedoch nur über die genauere Kenntnis seiner wechselvollen Planungs- und Baugeschichte. Im Leipziger Völkerschlachtdenkmal sind sowohl lang wirkende Denkmalsideen der Zeit nach den Befreiungskriegen wie auch prototypische Gestaltvorstellungen der wilhelminischen Nationaldenkmäler und unverkennbar auch bereits moderne künstlerische Tendenzen der Architektur und der Monumentalplastik nach 1900 zum Tragen gekommen. Diese

1 Dieser Beitrag ist die geringfügig überarbeitete Fassung eines Aufsatzes, den der Verfasser unter dem Titel „,Erhaben, von jeglicher persönlicher Beziehung und von jedem kleinen Zweck entbunden, steht das Werk in ruhiger Schönheit da. ' Das Leipziger Völkerschlachtdenkmal als Gesamtkunstwerk" veröffentlicht hat in: Völkerschlachtdenkmal. Hg. v. Volker RodekAmp, Leipzig 2003, S. 8-43.

2 ApeL, Theodor: Führer auf die Schlachtfelder Leipzigs im October 1813 und zu den Marksteinen. Leipzig 1863; Denkmale der Völkerschlacht. Hg. v. Kulturbund Leipzig. Leipzig 1988; Poser, Steffen: Hiob 38,11, Bis hierher sollst du kommen und nicht weiter; hier sollen sich legen deine stolzen Wellen. Denkmäler erzählen über die Leipziger Völkerschlacht. Beucha 1998 (Leipziger Hefte 13); MÜNCH, Reinhard: Marksteine und Denkmäler der Völkerschlacht in und um Leipzig. Panitzsch 2000; Poser, Steffen: Denkmale zur Völkerschlacht. Leipzig 2008. 


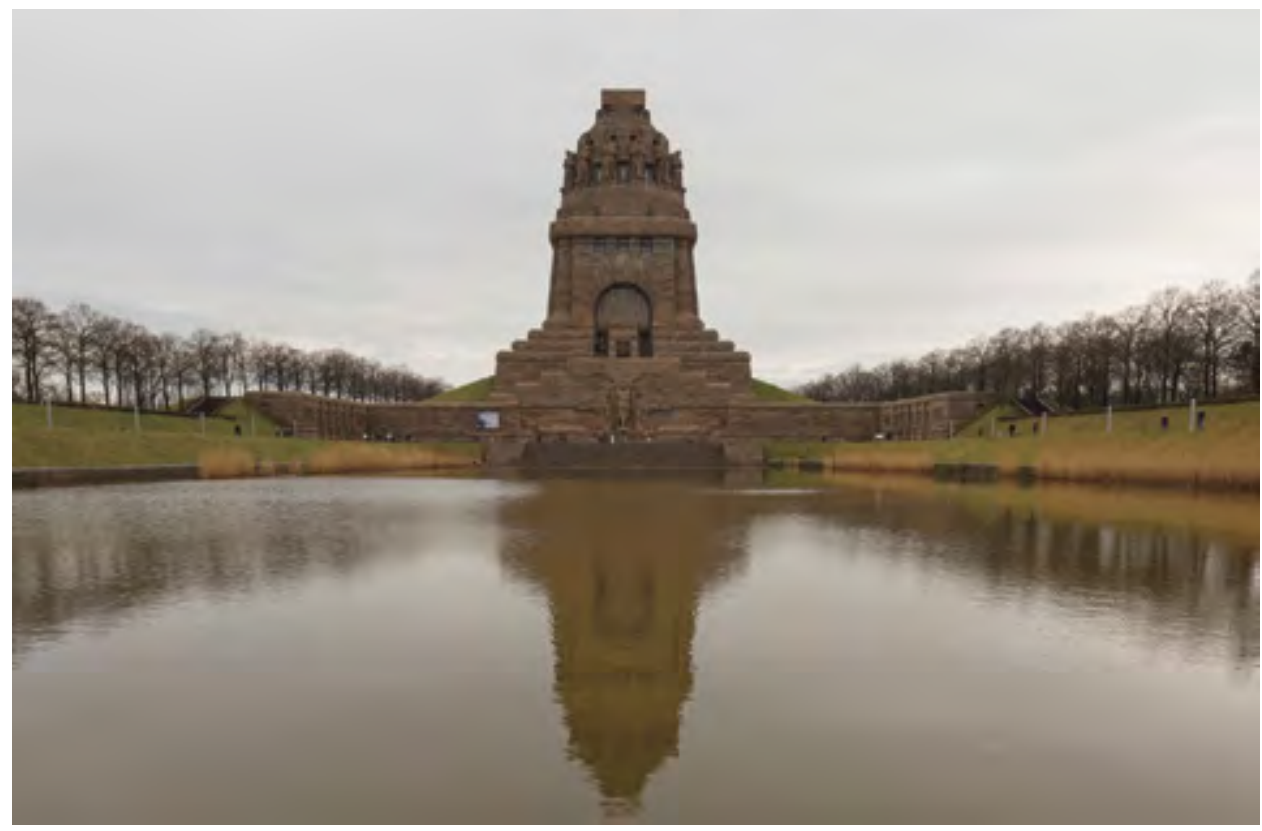

Abb. 1 Leipzig, Völkerschlachtdenkmal, Gesamtansicht von Nordwesten mit Wasserbecken.

Vielschichtigkeit der verarbeiteten Gestaltungsideen sowie die Entwicklung des Denkmalsprogramms soll im Folgenden aufgezeigt werden. ${ }^{3}$

Als eigentlicher Auftakt zur Entwurfs- und Ideengeschichte des Leipziger Völkerschlachtdenkmals sind zwei Projekte aus dem Jahr 1814 hervorzuheben: der Denkmalsentwurf von Friedrich Weinbrenner und die Flugschrift „Ein Wort über die Feier der Leipziger Schlacht“ von Ernst Moritz Arndt. Wie andere Architekten, hatte sich auch Weinbrenner schon bald mit der Frage eines großen Denkmalbaues, der zum immerwährenden Gedenken an die siegreiche Schlacht am historischen Ort errichtet werden sollte, auseinandergesetzt und diesen Vorschlag publiziert. ${ }^{4}$ Er hielt seinen Entwurf in

3 Literatur zum Leipziger Völkerschlachtdenkmal (Auswahl): SPITZnER, Alfred: Das VölkerschlachtNational-Denkmal. Denkschrift des Deutschen Patrioten-Bundes. Leipzig 1897; Ders./HÈroux, Bruno: Das Völkerschlacht-Denkmal. Weiheschrift. Leipzig 1913; LurTz, Meinhold: „Lieblich ertönt der Gesang des Sieges“. In: kritische berichte, Heft 3/1988, S. 17-32, Heft 1/1989, S. 22-38; HutTER, Peter: „Die feinste Barbarei“. Das Völkerschlachtdenkmal bei Leipzig. Mainz 1990; Vom Kult zur Kulisse. Das Völkerschlachtdenkmal als Gegenstand der Geschichtskultur. Hg. v. Katrin Keller und Hans-Dieter Schmidt. Leipzig 1995; Topfstedt, Thomas: „Erhaben, von jeglicher persönlicher Beziehung und von jedem kleinen Zweck entbunden, steht das Werk in ruhiger Schönheit da." (wie Anm. 1); Hoffmàn, Stefan Ludwig: Sakraler Monumentalismus um 1900. Das Leipziger Völkerschlachtdenkmal. In: Der politische Totenkult. Kriegerdenkmäler in der Moderne. Hg. v. Reinhard Kosellek und Michael Jeismann. München 1994, S. 249-280.

4 Weinbrenner, Friedrich: Ideen zu einem teutschen Nationaldenkmal des entscheidenden Sieges bei Leipzig. Karlsruhe 1814. 
pathetischen und strengen, dem Repertoire der französischen Revolutionsarchitektur entlehnten Formen und entwickelte Gestaltungsideen, die in mancher Hinsicht wie ein Vorgriff auf das viel später ausgeführte Völkerschlachtmonument anmuten. Verwiesen sei auf die monumentale, sich in drei Stufen aufbauende pyramidale Gesamtform des Denkmals, den sockelartigen quadratischen Unterbau, den als Sieges- und Ruhmestempel gedachten und durch massige Eckpfeiler straff eingefassten Mittelbau und die sich darüber erhebende kuppelbekrönte Feierhalle. Auch der große Relieffries am Sockel mit der Schilderung der Schlacht findet sich bereits in Weinbrenners Entwurf. Den triumphalen Abschluss des Bauwerkes sollte eine Stufenpyramide mit einer Quadriga bilden. Der Entwurf bezog seine Hauptwirkung nicht aus dem beziehungsreichen Programm seiner Inschriften und Bildwerke, sondern aus der suggestiven Wucht gestufter Baumassen. Als ,vaterländisches“ Baumaterial bestimmte der Architekt deutschen Granit. Dass Weinbrenner für sein aufsehenerregendes Projekt eines Leipziger Völkerschlachtdenkmals nichts wirklich Neues schuf, sondern einen nicht ausgeführten Entwurf umarbeitete, den er bereits einige Jahre zuvor für ein riesiges, ebenfalls mit einer Quadriga zu bekrönendes Mausoleum zu Ehren Napoleons I. in Paris entwickelt hatte, ${ }^{5}$ entbehrt nicht einer gewissen Pikanterie.

Ebenso wirkungsmächtig wie Weinbrenners architektonischer Entwurf und sogar noch erhabener in der Idee war Ernst Moritz Arndts Vision eines Leipziger Völkerschlacht-Denkmals, zu deren Verwirklichung er die deutsche Nation aufrief, unverzüglich alle Kräfte anzuspannen:

Dass auf den Feldern bei Leipzig ein Ehrendenkmal errichtet werden muss, das dem spätesten Enkel noch sagt, was daselbst im Oktober des Jahres 1813 geschehen, darüber ist in ganz Teutschland, ja wohl fast in der ganzen Welt nur Eine Stimme. Aber wie und in welcher Art dieses Denkmal errichtet werden soll, darüber werden die Stimmen gewiss ebenso verschieden lauten, als sie über das Erste einig sind. Ein kleines unscheinbares Denkmal, das sich gegen die Natur umher in nichts gleichen kann, thut es nicht; ein zierliches und blankes, etwa in Leipzig selbst auf irgend einem Platz hingestellt, würde in seiner Armseligkeit von der großen That, wodurch die Welt von dem abscheulichsten aller Tyrannen und dem tückischesten aller Tyrannenvölker befreit ward, zu sehr beschämt werden.. Das Denkmal muss draußen stehen, wo soviel Blut floss; es muss so stehen, dass es ringsum von allen Straßen gesehen werden kann, auf welchen die verbündeten Heere zur blutigen Schlacht der Entscheidung heranzogen. Soll es gesehen werden, so muss es groß und herrlich seyn, wie ein Koloss, eine Pyramide, ein Dom in Köln. Aber solches in großer Kraft und in großem Sinne zu bauen, fehlt uns das Geld und das Geschick, und ich fürchte, wenn man bei kleinen Mitteln etwas Ähnliches machen will, kömmt etwas Erbärmliches heraus. Ich schlage deshalb etwas ganz Einfaches und Ausführliches vor, ein Denkmal, wobei die Kunst keine Äffereien anbringen und wogegen unser nordischer, allen Denkmälern so feindseliger Himmel nichts ausrichten kann. Ich befehlige einige tausend Soldaten oder Bauern in die Ebene von Leipzig hin und lasse auf der Mitte des meilenlangen Schlachtfeldes einen Erdhügel von 2000 Fuß Höhe aufthürmen. Auf den Erdhügel werden Feldsteine gewälzt, und über diesen wird ein kolos-

5 Scharf, Helmut: Kleine Kunstgeschichte des deutschen Denkmals. Darmstadt 1984, S. 151. 
sales, aus Eisen gegossenes und mit mancherlei Anspielungen und Zeichen geziertes Kreuz errichtet, ein Zeichen des Heils und der Herrscher des neuen Erdballes. Das Kreuz trägt eine große vergoldete Kugel, die weit in die Ferne leuchtet. Das Land rings um den Hügel, etwa 10 bis 15 Morgen weit, wird für heiliges Land erklärt, mit Wall und Graben eingefasst und mit Eichen bepflanzt. Dieser Hügel, dieses Kreuz, und diese Bäume wären zugleich ein ächt germanisches und ein ächt christliches Denkmal, wohin unsere Urenkel noch wallfahrten gehen würden. ${ }^{6}$

Weinbrenners Entwurf und Arndts flammende Worte wurden gegen Ende des 19. Jahrhunderts wieder lebhaft erinnert. Sie gaben in ideeller und zweifellos auch in gestalterischer Hinsicht den Maßstab vor, an dem sich die Erbauer des Leipziger Völkerschlachtdenkmals schließlich orientiert haben. Es sollten jedoch noch viele Jahrzehnte vergehen, bevor die politischen und kulturellen Voraussetzungen für die Realisierung eines solchen Denkmalvorhabens gegeben waren. Zwar wurde 1863 zur Fünfzigjahrfeier der Völkerschlacht der Grundstein für ein Denkmal durch den Leipziger Oberbürgermeister Dr. Karl Wilhelm Otto Koch gelegt, doch blieb dies ein symbolischer Akt, dem keine weiteren Taten folgten. Erst nachdem 1871 mit der Gründung des wilhelminischen Kaiserreichs die Einigung Deutschlands „von oben“ herbeigeführt worden war, hatte ein als Sinnbild der nationalen Integration angedachtes Projekt eines Leipziger Völkerschlachtdenkmals eine reale Aussicht, errichtet zu werden.

Die politische Funktion von Nationaldenkmälern erfüllten zunächst die in rascher Folge ab 1889 nach Entwürfen von Bruno Schmitz errichteten Kaiser-Wilhelm-Denkmäler auf dem Kyffhäuser, an der Porta Westfalica bei Minden und am Deutschen Eck bei Koblenz sowie das in repräsentativen Neubarockformen gehaltene Kaiser-WilhelmDenkmal von Reinhold Begas (1893-1897) in Berlin. Im Gegensatz zu diesen Monumenten wurde der Bau des Leipziger Völkerschlachtdenkmals staatlicherseits weder angeregt noch finanziell gefördert, wohl weil in seinem Darstellungsprogramm das monarchische Element völlig ausgespart blieb. Statt des Hohenzollern'schen Herrscherhauses sollte die mythisch beschworene deutsche Volksgemeinschaft als das handelnde Subjekt der Geschichte und als der eigentliche Held der Befreiungskriege von 1813 geehrt werden. Das Denkmal verkörperte damit das auf Befreiung von der napoleonischen Fremdherrschaft gerichtete Ideengut der Zeit um und nach 1813, allerdings überlagert von Intentionen, die zum Teil im wilhelminischen Denkmalskult wurzelten, zunehmend aber von den deutschvölkischen Bestrebungen der Jahrhundertwende getragen wurden.

Die Initiative zum Denkmalsbau ging von dem Leipziger Architekten Clemens Thieme (1861-1945) aus. Er war Mitglied der Deutsch-Nationalen Partei, die er als Abgeordneter im Leipziger Stadtparlament vertrat. Am 26. April 1894 wurde auf sein Betreiben hin der Deutsche Patriotenbund zur Errichtung eines Völkerschlachtdenkmals bei Leipzig gegründet. Thieme übernahm von Anbeginn das Amt des Vereinsvorsitzen-

6 ARndt, Ernst Moritz: Ein Wort über die Feier der Leipziger Schlacht (1813), Zitat aus: Deutschlands Denkmal der Völkerschlacht, das Ehrenmal seiner Befreiung und nationalen Wiedergeburt. Weiheschrift des Deutschen Patriotenbundes. Hg. v. Alfred Spitzner. Leipzig 1913, S. 43 f. 
den. Er war nicht nur ein geschickter Politiker und glänzender Organisator, sondern nahm auch einen entscheidenden Einfluss auf die Klärung wesentlicher baukünstlerischer Fragen des Denkmalsentwurfs. Dass sich das Völkerschlachtdenkmal in seiner ausgeführten Gestalt so ostentativ von den anderen Nationaldenkmälern der wilhelminischen Ära abhebt, ist nicht in erster Linie das Verdienst von Bruno Schmitz. Zwar wurde Schmitz vom Deutschen Patriotenbund in der Öffentlichkeit immer als Autor des Ausführungsentwurfs präsentiert, doch hatte er sich während aller Phasen des langwierigen, weit in die Bauausführung hineinreichenden Entwurfsgeschehens bedingungslos den Vorstellungen und Anweisungen Thiemes zu fügen.

Wie konfliktreich und mühselig der Weg von den ersten Entwürfen bis zum Ausführungsprojekt war, zeigt die Abfolge der verschiedenen Denkmalskonzeptionen. Eingeleitet wurde dieser Prozess der Ideenfindung mit der vom Deutschen Patriotenbund im August 1895 ausgeschriebenen Vorkonkurrenz, zu der nur deutsche Architekten zugelassen waren. Der Auslober forderte, dass das Denkmal eine landschaftsbeherrschende Stellung einnehmen und ,mehr architektonischen als bildkünstlerischen Schmuck enthalten ${ }^{\text {"7 }}$ solle. Die Reaktion auf die Ausschreibung war recht mäßig. Es gingen nur 32 Entwürfe ein, die am 15. November 1895 juriert wurden. Den ersten Preis erhielt Karl Doflein (Berlin); der zweite Preis ging an Bernhard Schaede (Charlottenburg), der dritte Preis an die Architekten Engel und Wenk (Berlin). Bezeichnend für die anfangs noch sehr unentschlossene Haltung des Deutschen Patriotenbundes ist die Tatsache, dass der zweite Preis - Schaedes nicht gerade originelle Paraphrase des Kyffhäuserdenkmals - vom Vorstand als die „bemerkenswerteste Arbeit“" favorisiert wurde. Um das Denkmalprojekt über Leipzigs Grenzen hinaus bekannt zu machen, ließ der Deutsche Patriotenbund eine farbige Abbildung dieses Entwurfes in einer Auflage von 20.000 Exemplaren drucken. Nach dieser ersten groß angelegten Werbekampagne hat Thieme den Vorstand recht bald davon überzeugen können, dass keiner der preisgekrönten Entwürfe dem Charakter der gestellten Aufgabe, nämlich ein in seiner Gestalt und in seinem monumentalen Anspruch singuläres Monument zu schaffen, auch nur annähernd gerecht wurde.

Weitaus größere Resonanz hatte die im August 1896 ausgeschriebene Hauptkonkurrenz, sodass die Wettbewerbsjury am 21. und 22. Dezember 1896 über insgesamt 71 Entwürfe zu befinden hatte. Wiederum waren die Preisträger Wilhelm Kreis, Otto Rieth, Spaeth und Usbeck und Bruno Schmitz keine Leipziger, sondern Architekten aus Berlin und Charlottenburg, und wieder orientierten sich die meisten Teilnehmer am Prototyp des Kyffhäuserdenkmals. Unübersehbar ist dies auch beim Entwurf des ersten Preisträgers, des damals noch unbekannten jungen Architekten Wilhelm Kreis, der Fall gewesen, dessen turmartiges Denkmalsprojekt sich allerdings durch seine schlanken Konturen von den massiger erscheinenden Entwürfen der meisten Bewerber unterschied. Mit keinem Preis ausgezeichnet wurde der bemerkenswerte, geometrisch strenge Entwurf von Paul Pfann aus München, obwohl dieser in seiner neuartigen monumentalen

7 Deutsche Konkurrenzen VII./73, Heft 1 (1897), S. 1.

8 Spitzner (wie Anm. 3), S. 39. 
Formensprache dem Charakter des schließlich ausgeführten Völkerschlachtdenkmals am nächsten kam. Bruno Schmitz hatte unter dem Kennwort „St. Michael“ den Entwurf eines wehrhaft anmutenden Rundturms eingereicht, der sich auf einem hohen Erdkegel erheben und in einem an das Theoderichgrabmal in Ravenna erinnernden Kuppelaufsatz ausklingen sollte. Eine kreisförmige Vorhalle umgab den Turmfuß. An der Vorderseite des Baues sollte eine als Hochrelief auszuführende Kolossalfigur des Erzengels Michael angebracht werden. Dieses nur mit dem vierten Preis bedachte Projekt hat der Deutsche Patriotenbund damals als ,zu wuchtig ${ }^{\text {“9 }}$ bezeichnet. Vermutlich bestand auch zu diesem Zeitpunkt noch keine klare Vorstellung über die endgültige Größe und Gestalt des Denkmals, wie man überhaupt mit dem Gesamtergebnis auch dieses Wettbewerbes nicht zufrieden war. Der Deutsche Patriotenbund erwog darauf hin, die Preisträger und einige weitere Architekten nochmals zu einem begrenzten Wettbewerb aufzufordern. Um aber nicht noch mehr Zeit zu verlieren und das Interesse der Öffentlichkeit am Denkmalvorhaben nicht durch allzu langes Zögern zu ermüden, wurde im Februar 1897 die definitive Entscheidung getroffen, auf eine dritte Konkurrenz zu verzichten und stattdessen den Auftrag zur Erarbeitung des Ausführungsprojektes an Bruno Schmitz (1858-1916), den seinerzeit berühmtesten deutschen Denkmalarchitekten, zu vergeben.

Ohne zu ahnen, welchen Verdruss er sich für die kommenden Jahre mit diesem so lukrativ erscheinenden Auftrag einhandeln sollte, machte sich Schmitz unverzüglich an die Arbeit. Er präsentierte bereits im Juni 1897 auf der Sächsisch-Thüringischen Gewerbeausstellung zu Leipzig einen völlig neuen Entwurf, in dem erstmals die Grundkonturen des Völkerschlachtdenkmals in seiner später realisierten Gestalt deutlich fassbar wurden. Nun ruht das Gebäude auf einem breiten Postament mit seitlich hinaufführenden Treppenanlagen. An der Stirnseite dieses monumentalen abgeschrägten Sockels findet sich ein großes Schlachtenrelief mit der zentral platzierten Michaelfigur. Darüber erhebt sich der stark geböschte, von vier gewaltigen Bogenöffnungen durchbrochene Mittelbau des Denkmals, welcher die Feierhalle enthält. Bekrönt wird das Gebäude von einem säulenumkränzten Rundbau, dessen mehrfach gestufter Kuppelaufsatz ein großes Eisernes Kreuz trägt. Dieser obere Bauteil ist durch reichen bauplastischen Schmuck besonders hervorgehoben und birgt in seinem Inneren die Kuppel der Feierhalle. Aus der Rundbogenöffnung der Hauptfront tritt ein halbkreisförmiger Einbau hervor. Er korrespondiert mit der schweren Pfeilerpergola, die den breiten Umgang auf dem Denkmalssockel allseitig umfassen sollte. Im Wesentlichen war mit diesem Entwurf die Grundgestalt des Denkmals fixiert als eine gewaltige, sich nach oben stetig verjüngende Baumasse aus drei klar voneinander abgesetzten Teilen, die allerdings in der Fassung von 1897 noch ein relativ selbstständiges Dasein führen.

Am 18. Oktober 1897 bestätigte der Deutsche Patriotenbund auf seiner Jahreshauptversammlung den Schmitz'schen Entwurf, der nach einer nochmaligen Überarbeitung Kaiser Wilhelm II. zur Begutachtung vorgelegt und im August 1898 auf der Internationalen Kunstausstellung in Berlin mit der Großen Goldenen Medaille prämiert wurde.

9 LANGE, Reinhard: Die preisgekrönten Entwürfe für das Völkerschlacht-National-Denkmal bei Leipzig. In: Mitteilungen des Deutschen Patriotenbundes 3/3 (1897), S. 3. 
Abb. 2 Leipzig, Völkerschlachtdenkmal, Aufriss der Hauptfassade (nach einer Zeichnung von Max Naumann).

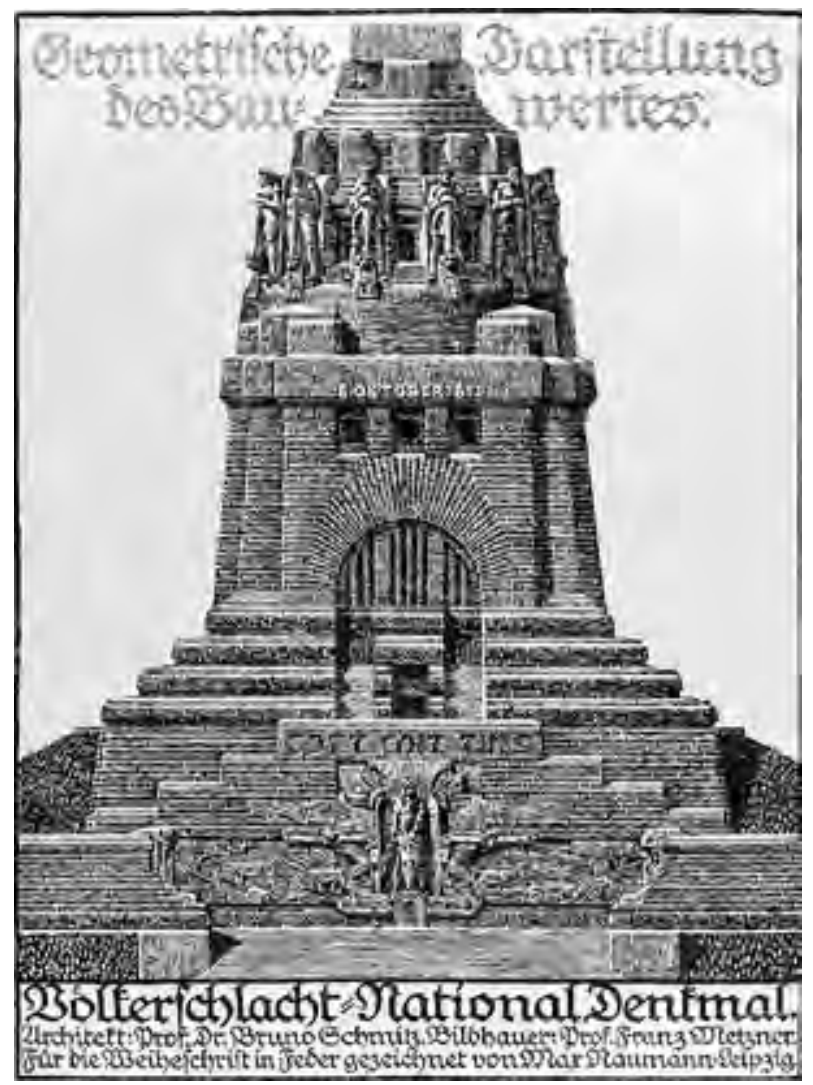

Als zeitgenössische Stimme, die das qualitativ Neue des Entwurfs damals sehr zutreffend beschrieben hat, sei Cornelius Gurlitt zitiert:

Es herrscht hier vor allem ein bildnerisches Planen, ein großer Zug im Verteilen der Massen, ein Hinwirken auf einfachen Umriss, auf klare, einfache Linienführung. Die stilistischen Beengungen sind völlig überwunden. Wenn auch Anklänge an alte Formen nicht vermieden sind, so ist doch der Entwurf immer völlig frei von der Oberherrschaft geschichtlicher Grundgedanken. Es liegt das Schwergewicht auf der Erzielung eines starken einheitlichen Eindrucks, auf einer entschiedenen Betonung der Größe gegenüber dem bisher namentlich in der Nachahmung des Barock vorherrschenden Reichtum. ${ }^{10}$

Dank Thiemes Einflussnahme besaß das Denkmal jetzt tatsächlich eine sehr eindrucksvolle Silhouette durch die Verschleifung von Sockel, Mittelteil und Kuppel zu

10 GurlitT, Cornelius: Die deutsche Kunst des 19. Jahrhunderts. Ihre Ziele und Thaten. Berlin 1900, S. 667. 
einer monumentalen Großform. ${ }^{11}$ Allerdings erweckte die Kuppel - trotz spürbarer Vereinfachung gegenüber dem Entwurf von 1897 - in ihrer Außenbaugestaltung noch immer Assoziationen an einen kronenartigen Aufsatz, wie er als vergrößertes und stilisiertes Abbild der deutschen Kaiserkrone die Nationaldenkmäler auf dem Kyffhäuser und an der Porta Westfalica tatsächlich abschloss. In der nach 1900 sich herauskristallisierenden endgültigen Gestalt des Völkerschlachtdenkmals trat an die Stelle dieses Gebildes die formal und ikonografisch angemessenere Lösung der Kuppel mit Freiheitswächtern und Gipfelstein (Abb. 2).

Der Entwurf von 1898 ist nicht allein in architektonischer, sondern ebenso in bildkünstlerischer Hinsicht wegweisend geworden, da in ihm das Skulpturenprogramm des Denkmals schon zu einem großen Teil festgelegt worden war. Verbindlich blieb fortan die Gestaltung der Stirnwand des Denkmalssockels mit der Figur des heiligen Michael, dem Schlachtenrelief und der Inschrift „GOTT MIT UNS“, ebenso die vier kolossalen Sitzfiguren in den Ecken der Feierhalle. Es wird auch schon das Bestreben deutlich, die Feierhalle mit der Kuppel zu einem einheitlich durchformten Zentralraum von steilem Zuschnitt zu verklammern. Eine Krypta war allerdings noch nicht geplant; sie wurde erst 1903 auf Anregung von Clemens Thieme in das Bauprogramm aufgenommen. Ursprünglich war vorgesehen, im Unterbau des Denkmals ein Museum zur Erinnerung an die Geschichte der Befreiungskriege zu installieren. Dieses Vorhaben wurde zugunsten einer Krypta zur Ehrung der gefallenen Helden der Völkerschlacht aufgegeben, wobei das ehrende Heldengedächtnis nicht ausgewählten Persönlichkeiten, sondern dem deutschen Volk als kollektivem Subjekt und „Schicksalsgemeinschaft“ galt. Diese Kryptenanlage, die in den Einzelformen auf alle klassischen Elemente verzichtet und in ihrer kruden Massigkeit den Geist einer angeblich vorantiken germanischen Monumentalarchitektur beschwören will, ist jedoch keine originäre Bauschöpfung gewesen. Bei wesentlichen Elementen - so z.B. der kreisrunden Grundform, dem konzentrischen Umgang hinter einer Pfeilerstellung und der Öffnung des Kryptabereiches nach oben zu dem höher gelegenen Raum der Feierhalle - sind die typologischen Parallelen zu der nach 1840 im Pariser Invalidendom eingerichteten Kaisergruft mit dem Grab Napoleons I. unübersehbar. Es war gewissermaßen eine „heimliche“ Ideenanleihe, die öffentlich nicht thematisiert wurde, weil sie den vom Deutschen Patriotenbund propagierten Leitgedanken eines nur aus germanischen und deutschen Quellen schöpfendenden Denkmalskonzeptes zuwiderlief.

11 „Die betonte Abstufung der einzelnen Denkmalzonen wurde zugunsten kaum wahrnehmbarer Übergänge zurückgenommen und das ganze Denkmal zu einer kompakten Masse zusammengefasst, wodurch der Umriss dem einer Pyramide angenähert wurde. Die Anlehnung an den Entwurf Weinbrenners ist deshalb nur noch typologisch und an wenigen dekorativen Einzelheiten des Inneren erkennbar. Hingegen ist eine Annäherung an den Entwurf Pfanns festzustellen. Alle klassischen Struktur- und Dekorationselemente sind eliminiert. Der neue Entwurf weist deshalb am Außenbau keine einzige Säule und keine Pilaster mehr auf und gibt so der völkischen Vorstellung des Germanischen als des von der antiken Kultur noch Unberührten in aller Konsequenz Ausdruck." In: Hutter (wie Anm. 3), S. $109 \mathrm{f}$. 
Mit einem symbolischen Spatenstich wurde am 18. Oktober 1898 das gewaltige Werk begonnen. Zwei Jahre nahmen die aufwendigen Gründungsarbeiten in Anspruch; der Grundstein konnte am 18. Oktober 1900 gelegt werden. In den folgenden Jahren wuchsen die massigen Betonsubstruktionen, auf denen das Denkmal ruht, in die Höhe. Parallel dazu begannen die Vorbereitungen für den Entwurf und die Ausführung der Bildwerke.

Der Auftrag für das gesamte Skulpturenprogramm wurde vom Deutschen Patriotenbund an den Breslauer Bildhauer Christian Behrens (1852-1905) vergeben. Seine Zusammenarbeit mit Bruno Schmitz war bereits erprobt durch einen gemeinsamen Entwurf anlässlich des deutschlandweit Aufsehen erregenden, 1901 veranstalteten Wettbewerbs für das Hamburger Bismarck-Denkmal. ${ }^{12}$ Bemerkenswert ist, dass die von Behrens entworfene, von einem Harnisch umhüllte und sich auf einen großen Schild stützende Bismarckfigur in mancher Hinsicht die später von ihm entworfene Michaelfigur des Völkerschlachtdenkmals geradezu vorwegzunehmen scheint. Überdies hatte Behrens im Auftrag der Stadt bereits einige nicht unbedeutende Arbeiten ausgeführt (u.a. die sechs Reliefs am Haupteingang des Neuen Rathauses und etliche Plastiken für die im Zweiten Weltkrieg zerstörte Markthalle). Er war in Leipzig schon ein geschätzter Künstler, bevor er für den Deutschen Patriotenbund tätig wurde. Wann genau seine Mitwirkung am Völkerschlachtdenkmal begann, lässt sich nicht mehr exakt belegen. Offenbar hat Christian Behrens nur die Modelle der Michaelsfigur, des Schlachtenreliefs und der sogenannten Barbarossaköpfe an den Treppenaufgängen fertigstellen können. Diese Modelle wurden am 18. Oktober 1904 am Völkerschlachtdenkmal ausgestellt. Noch im gleichen Jahr sind die Stützmauer mit den im Gesamteindruck wie in ihrer scharfgratigen Binnenzeichnung noch recht dem Jugendstil verhafteten Barbarossaköpfen vollendet worden. Des Weiteren begannen damals die Steinmetzarbeiten am Schlachtenrelief.

Christian Behrens starb am 14. September 1905. Vom Deutschen Patriotenbund aufgefordert, einen Nachfolger zu benennen, entschied sich Bruno Schmitz für den deutsch-österreichischen Bildhauer Franz Metzner (1870-1919). Die „Deutsche Bauzeitung“" gab dazu im Januar 1906 folgenden Kommentar ab:

Wir halten diese Wahl für eine außerordentlich glückliche; durch sie ist der rechte Mann an die rechte Aufgabe gestellt. Das Völkerschlachtdenkmal ist keine monumentale Aufgabe im landläufigen Sinne des Wortes, es stellt an seine Künstler Anforderungen ganz besonderer Art. Für den bildnerischen Teil vermöchte ihnen Metzner voraussichtlich in vollem Maße gerecht zu werden,

12 Das Hamburger Bismarck-Denkmal wurde nach dem gemeinsamen Entwurf von Emil Schaudt und Hugo Lederer von 1903 bis 1906 ausgeführt. Der Unterbau des Denkmals und die 14,8 Meter hohe Kolossalfigur folgen dem gleichen künstlerischen Konzept einer umfassenden architektonischen Stilisierung wie das Leipziger Völkerschlachtdenkmal. Obwohl auf diese verwandtschaftlichen Züge zwischen beiden Denkmälern in der zeitgenössischen Literatur kein Bezug genommen wurde, sind die Parallelen nicht nur formal, sondern auch inhaltlich klar fassbar, vor allem im typologischen Vorbild der mittelalterlichen Rolandsstatue, das sowohl in der Bismarckfigur des Hamburger Denkmals wie auch bei den Freiheitswächtern des Leipziger Völkerschlachtdenkmal rezipiert wurde. 
denn seine bisherigen Arbeiten vereinigen in gleicher Weise unabhängig persönliche Empfindung, monumentale Gesinnung und architektonische Strenge der Komposition und Formgebung. Seine Kunst ist groß und neu. ${ }^{13}$

Metzners Ruf als wegweisender Formneuerer war bereits gefestigt. Als er die Arbeit an den Figurenmodellen für das Völkerschlachtdenkmal aufnahm, konnte er auf Gestaltungsideen zurückgreifen, die er schon aus anderen Anlässen und für andere Aufgaben während seiner Wiener Schaffensperiode ausgiebig erprobt hatte. ${ }^{14}$ Der Künstler war 1903 auf Betreiben der Wiener Sezessionisten als Professor für figurales Gestalten an die Wiener Kunstgewerbeschule berufen worden. Enge persönliche Kontakte verbanden ihn insbesondere mit Josef Hoffmann, für dessen berühmtes Palais Stoclet in Brüssel er das Modell der Turmfiguren geschaffen hat. Trotz des sehr beachtlichen Erfolges seiner Arbeiten auf den Wiener Sezessionsausstellungen blieb aber der praktische Wirkungsradius des Bildhauers recht begrenzt. An bauplastischen Arbeiten konnte er in Wien nur die Steingut-Atlanten des Zacherl-Hauses (erbaut 1903-1905 nach Plänen von Jože Plečnik) realisieren; Aufträge von öffentlicher Hand blieben völlig aus. Umso willkommener muss ihm daher das Angebot aus Leipzig, fast alle Modelle für die Figuren des Völkerschlachtdenkmals auszuführen, gewesen sein. Es sollte die dem Umfang nach größte Aufgabe werden, die Metzner je gestellt wurde.

Im Protokollbuch der Vorstandssitzungen des Deutschen Patriotenbundes findet sich mit Datum vom 8. September 1907 eine von Schmitz und Metzner unterzeichnete Eintragung, ${ }^{15}$ die in Vorbereitung des endgültigen Arbeitskontraktes folgende Vereinbarung enthält: Metzner verpflichtet sich, für das Resthonorar des verstorbenen Christian Behrens das Schlachtenrelief zu überarbeiten. Für 100.000 Mark soll er sämtliche Modelle und Hilfsmodelle der Bildwerke im und am Denkmal schaffen (im Einzelnen aufgeführt: die Figuren an der Außenkuppel, die vier Figuren in der Halle, die Modelle der Krypta). Zur inhaltlichen Konzeption des Denkmals konnte er kaum mehr eigene Ideen beisteuern, sondern hatte sich strikt an das vom Bauherrn vorgegebene Programm zu halten. Es ist auch nicht zu klären, in welchem Umfang sich Metzner bereits während seiner letzten Wiener Jahre mit Vorstudien für die Modelle befasst hat. Außer Zweifel steht nur, dass er 1906 mit der Überarbeitung des „Totenfeldes“ auf der 60 Meter breiten und 19 Meter hohen Reliefwand begonnen hat, doch sind die Ausführungsmodelle laut Protokollbuch des Deutschen Patriotenbundes erst 1909 in Leipzig eingetroffen.

13 Die bildnerischen Arbeiten des Völkerschlachtdenkmals. In: Deutsche Bauzeitung 40/3 (1906), S. 18.

14 Pötzl-Malikova, Maria: Franz Metzner und die Wiener Secession. In: Alte und moderne Kunst 21/Heft 148/49 (1976), S. 30-39; Dies., Maria: Franz Metzner, Leben und Werk. In: Franz Metzner - Ein Bildhauer der Jahrhundertwende in Berlin - Wien - Prag. Ausst-Kat. Museum Villa Stuck, München 1977, S. 12-23; TopFsTEDT, Thomas: Anmerkungen zur Monumentalskulptur des Leipziger Völkerschlachtdenkmals. In: Protokollband des XXXV. Internationalen Kunsthistorikerkongresses CIHA 1983 Wien, Sektion 8 (Wien und die Architektur des 20. Jahrhunderts). Wien-Köln-Graz 1986, S. 65-71.

15 Protokollbuch der Vorstandssitzungen des Deutschen Patriotenbundes, Stadtarchiv Leipzig, Kap. 35, Nr.1175, S. 207 f. 
Endgültig fertiggestellt war das Schlachtenrelief im Juli des Jahres 1910. In Erfüllung dieser Aufgabe hatte Franz Metzner auch den Kopf des heiligen Michael nach eigenen Entwürfen nochmals überarbeiten lassen und ihm eine merklich strengere, um nicht zu sagen aggressivere Physiognomie gegeben (Abb. 3).

Die folgenden Monumentalskulpturen - beginnend mit dem Figurenzyklus in der Denkmalskrypta - haben wichtige Arbeiten der Wiener Schaffenszeit zur künstlerischen Voraussetzung. So scheint in dem auf der Frühjahrsausstellung der Wiener Sezession 1904 von Metzner präsentierten „Tempel der Erde“ ${ }^{\text {“16 }}$ die räumliche und bauplastische Konzeption der etwa zur gleichen Zeit in das Programm des Leipziger Völkerschlachtdenkmals aufgenommenen Krypta geradezu vorweggenommen zu sein. Die obere Wandzone des rotundenartigen Tempelraums wurde durch acht überlebensgroße, von breiten Lisenen hinterfangene Atlanten in gemessenem Rhythmus gegliedert (vergleichbar der Achtzahl der Kryptapfeiler des Völkerschlachtdenkmals). Mit ungeheurer Kraftanspannung gaben diese Atlanten vor, das Gebälk des Tempels zu stützen, ohne dass sie tatsächlich eine tragende Funktion zu erfüllen hatten. Erstmals nahm Metzner hier die Gelegenheit wahr, seine ureigene Vorstellung von monumentaler, symbolistisch aufgeladener Bauplastik in einem größeren Ensemble zu realisieren. Insbesondere die Reihung gleich gebildeter, streng symmetrisch angelegter Figuren sowie die gewaltsame Architektonisierung der menschlichen Anatomie mittels blockhaft „,versteinerter“ Körperformen waren Charakterzüge, die wenige Jahre später in Metzners Skulpturen für das Leipziger Völkerschlachtdenkmal eine Weiterentwicklung erfahren sollten. Dabei war aber Metzner nie daran gelegen, die jugendstilartig dekorative Grundkomponente seiner künstlerischen Handschrift völlig zu eliminieren.

Im Jahr 1906 schuf Franz Metzner die Plastiken für das von Bruno Schmitz entworfene, 1906/07 als exklusives Konzert- und Gesellschaftshaus erbaute „Haus Rheingold“ in Berlin. Unter anderem gestaltete er dort die Gewölbepfeiler des sogenannten Steinsaales und gab ihnen die ungewöhnliche Form großer Masken, die, vom Fußboden bis zum Gewölbeansatz aufragend, von schlanken Figuren flankiert wurden. Unverkennbar ist der Versuch, sezessionistische Elemente zurückzudrängen, ohne jedoch auf dekorative Effekte zu verzichten, sodass sich in Metzners Gestaltung Ornamentales auf seltsame Weise mit einer dumpf archaischen Note mischt. Zwei Jahre später hat er diese zwitterhaften Gebilde in einer strengeren Fassung als „Schicksalsmasken“ an den Kryptapfeilern des Leipziger Völkerschlachtdenkmals wiederholt. Obwohl diese „Schicksalsmasken“ im Vergleich mit ihren Vorläufern im Steinsaal des „Rheingold“ wesentlich zusammengenommener im Umriss, sparsamer in der Binnengliederung und mächtiger im Volumen sind, erweist sich das Maskenmotiv bei näherer Betrachtung als austauschbare Formel: Metzner hatte bei der Ausstattung der Berliner „Weihestätte höherer Geselligkeit ${ }^{\text {“17 }}$ ein so hoch gestimmtes Pathos entfaltet, dass ihm bei der Gestaltung der Kryptafiguren

16 Hackelsberger, Berthold: Die Bildnerei des Jugendstils. Diss. Freiburg/Br. 1952, S. 52 f.

17 Schliepmann, Hans: Haus „Rheingold“ in Berlin - Eine Meisterschöpfung von Bruno Schmitz. In: Deutsche Kunst und Dekoration XX (1907), S. 2. 


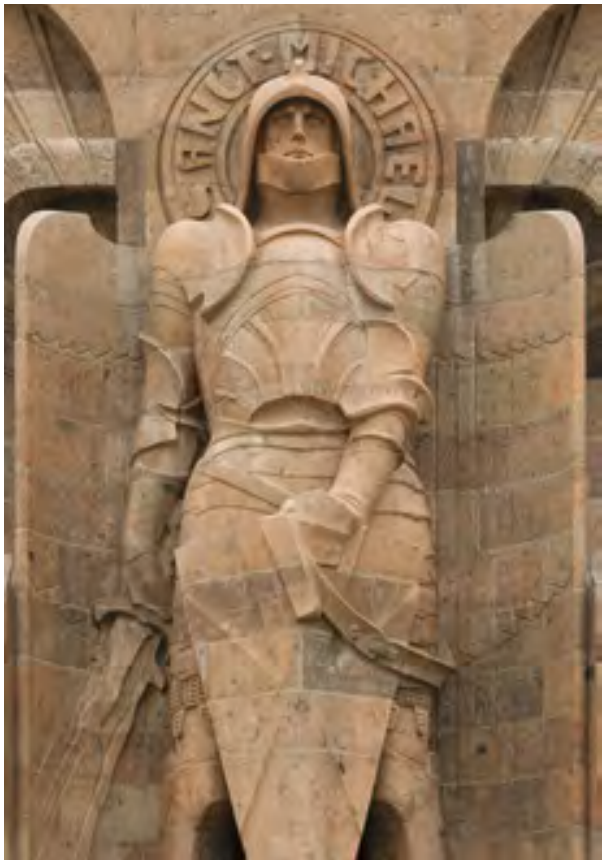

Abb. 3 Leipzig, Völkerschlachtdenkmal, Hauptfassade, Michaelfigur.

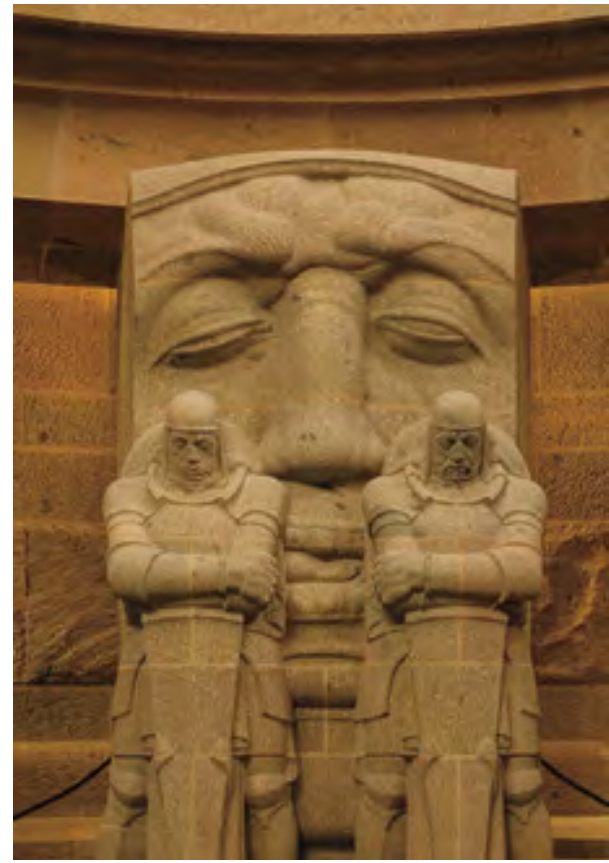

Abb. 4 Leipzig, Völkerschlachtdenkmal, Kryptapfeiler mit Schicksalsmaske und Totenwächtern.

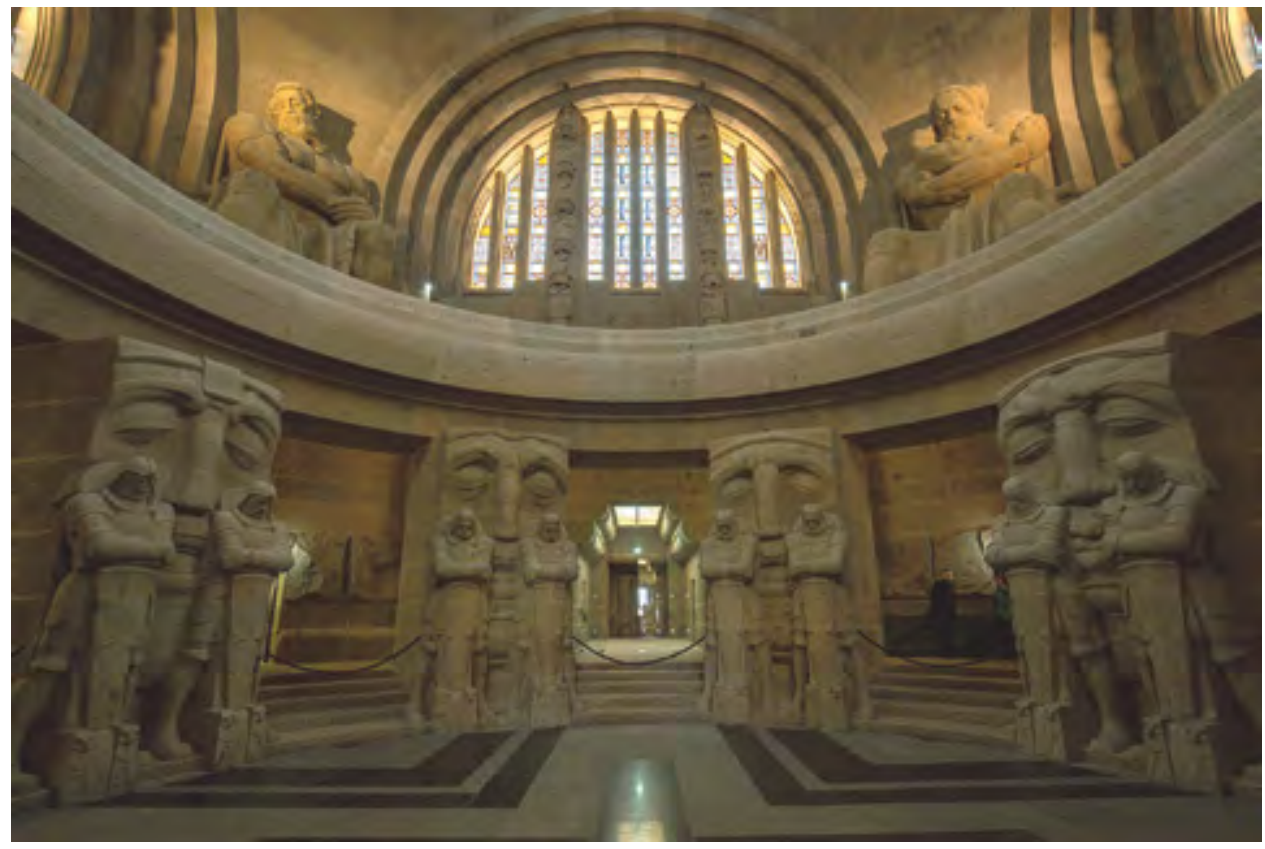

Abb. 5 Leipzig, Völkerschlachtdenkmal, Krypta und Feierhalle. 
in der nationalen Weihestätte des Leipziger Völkerschlachtdenkmals nur noch geringer Spielraum blieb, den Ausdruck seiner Bildwerke zu vertiefen (Abb. 4).

Mit der Ausarbeitung der Kryptafiguren wurde im Winter 1908 begonnen. Sie ragen weit in den kreisrunden, wie ein skulptiertes Stonehenge anmutenden Raum hinein, der sich nach oben zur Feierhalle und zur Kuppel hin öffnet (Abb. 5). Zugleich erwecken die Plastiken den Eindruck, als ob sie unmittelbar aus den Pfeilerblöcken herauswüchsen. Vor jeder Maske stehen zwei massige, auf ihre Schilde sich stützende Ritterfiguren, die zu einem schwermütigen Reigen von 16 Totenwächtern formiert sind. Einen Eindruck der allgemeinen Begeisterung, die diese Bildwerke damals hervorriefen, vermitteln noch heute die euphorischen Sätze des Kunstkritikers Franz Servaes:

Wir sind in einem Reiche der Unwirklichkeiten, in einem von religiösen Schauern durchwehten Phantasieraum, in dem alles, was menschliches Maß heißt, fremdartig überragt wird. Die Figuren, die hier vor den Innenmauern sich aufbauen, die gleichsam aus den Mauern hervorgequollen sind und an ihnen festkleben wie korallenartige Gewächse, haben zwar menschliche Formen und sind doch keine Menschen. Sie sind Schicksalsträger, dämonische Halbgottheiten, symbolhaft tiefsinnige Traumerscheinungen, [...] doch stets auch gerüstet zu grimmiger Abwehr. ${ }^{18}$

Solch mythischer Ausstrahlung wegen wurde ein in seiner Monumentalität vergleichbarer Figurenzyklus auch bei der Gestaltung des Denkmal-Außenbaues ausgeführt. Es sind die zwölf gepanzerten Kriegergestalten, welche die Kuppel umkränzen (Abb. 6).

Wiederum knüpfte Metzner beim Entwurf dieser Skulpturen unmittelbar an ein Hauptwerk der Wiener Zeit an, indem er die 1904 in erster Fassung vollendete RüdigerFigur für einen Nibelungenbrunnen ${ }^{19}$ in Wien zum kolossalen Stereotyp der Freiheitswächter des Völkerschlachtdenkmals umprägte. Das Ausführungsmodell für die Freiheitswächter war 1909 vollendet. Bereits am 18. Oktober 1910 waren die seriell gefertigten Skulpturen am Denkmal bis Armhöhe versetzt. Während das Michaelrelief sowie die Figuren in der Krypta und in der Feierhalle an Ort und Stelle aus den zuvor aufgemauerten Steinquadern herausgemeißelt wurden, musste man sich bei den Freiheitswächtern einer anderen Technologie bedienen. Im Steinbruch wurde eine Figur vollständig ausgearbeitet und danach in große Blöcke zerlegt. Von jedem Block wurden elf weitere Exemplare angefertigt. Dies geschah mit einer solchen Präzision, dass die Steinmetze beim Versatz der Figurenteile am Kuppelaußenbau nur noch geringfügige Überarbeitungen vornehmen mussten.

Das gleiche Prinzip der Serie kennzeichnet die in elf Reihen übereinander angeordneten Reiterfriese an der Innenwand der Hauptkuppel. Ihre 324 Einzelfiguren bilden eine scheinbar endlose, hoch über der Feierhalle schwebende und sich im Dämmerlicht

18 Servaes, Franz: Franz Metzner in seinen neueren Werken. In: Die bildenden Künste 1 (1916-1918), Heft 10/11, S. $94 \mathrm{f}$.

19 Pötzl-Malikova, Maria: Die Plastik der Ringstraße, künstlerische Entwicklung 1890-1918. In: Die Wiener Ringstraße, Bild einer Epoche. Hg. v. Renate WAgNER-RIEgER. Bd. IX, Teil 2, Wiesbaden 1976, S. 87-89 und 91-92. 


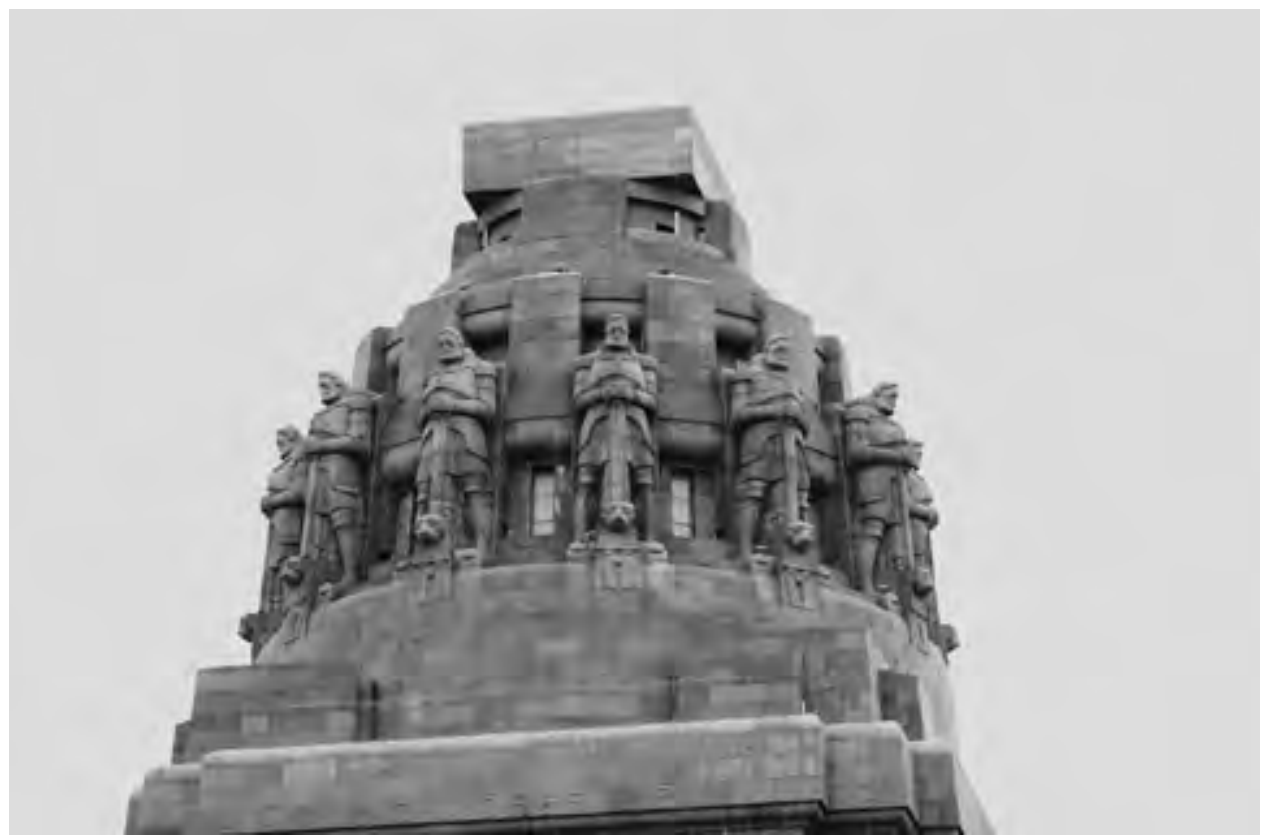

Abb. 6 Leipzig, Völkerschlachtdenkmal, Freiheitswächter am Außenbau der Kuppel.

des gewaltigen Raumtrichters verlierende Prozession. Ursprünglich war beabsichtigt, die Kuppelinnenwand mit Glasmosaiken, später dann mit Steinmosaiken auszugestalten. Davon wurde aus Kostengründen Abstand genommen. Im Jahre 1909 schuf Metzner die Modelle der Reiterfiguren. Sie sind also erst während seiner Mitarbeit am Denkmal in das Bildprogramm aufgenommen worden, vielleicht sogar auf seinen Vorschlag hin. Gleichzeitig mit dem Bau der Kuppel (1909-1911) entstanden in einem einheitlichen Arbeitsgang die Reiterfriese. Das technisch bemerkenswerte Verfahren ihrer Ausführung hat der Bauführer des Völkerschlachtdenkmals, Otto Rudolph, sehr anschaulich beschrieben:

Hierzu hatte Prof. Metzner zwei Modelle, allerdings auf ebenem Grunde, anstatt auf Kuppelfläche geliefert. Jetzt galt es diese Reiter in die kreisrunden sich auch nach oben verjüngenden Ringteile einzufügen. Hierzu wurde erst ein entsprechend großes Stück der Gewölbefläche in Gips hergestellt, dann von dem Reitermodell ein Leimabguss hergestellt, der dann in die Gipsform des Gewölbeteils hineingebogen werden konnte. Hiernach konnten erst die richtigen Gipsfiguren hergestellt werden. Dieses umständliche Verfahren wiederholte sich in jeder einzelnen Schicht. Nachdem die Formen für eine Schicht ringsum nach vorher berechneten Maßen sorgfältig aufgestellt und stark versteift waren, konnte mit der Hinterbetonierung begonnen werden. ${ }^{20}$

20 Rudolph, Otto: Plaudereien vom Bau des Völkerschlachtdenkmals. Bibliothek des Stadtgeschichtlichen Museums Leipzig, 14 Blatt (masch. schr. Man.), verfasst 1937, (Signatur: IG 147 a), S. 9. 
Metzner schuf demnach nur die Gipsmodelle der Figuren und kümmerte sich offenbar nicht um die technischen Details der Ausführung. Wie sie in Originalgröße dem Bau eingefügt und in mühsamer, jahrelanger Arbeit in Stein umgesetzt wurden, war ganz allein die Sache der Leipziger Bauführer und Steinmetzen.

Eine ebenso beeindruckende bautechnische und logistische Leistung war die Verkleidung des Denkmalaußenbaus mit gewaltigen, die „vaterländische“ Anmutung des Bauwerkes ganz im Sinne von Weinbrenners Forderung verstärkenden Quadern aus Granitporphyr (Diorit). Dieses Gestein wurde in einem Steinbruch des nahe bei Leipzig gelegenen Dorfes Beucha abgebaut. In der 1913 erschienenen Weiheschrift des Deutschen Patriotenbundes finden sich die folgenden Angaben:

Die Aufschichtung der riesigen Quadermassen geschah in der Weise, dass jedes Mal nach der Versetzung einer waagerecht verlaufenden Stufe der dahinter liegende Stein mit Beton ausgestampft wurde. Dieses Verfahren ersparte die Schalung und bewirkte die innigste Verbindung der beiden Baustoffe. Eine besondere Verankerung der Steine mit dem Beton war darum nicht nötig. Im ganzen wurden 26500 Granitwerkstücke mit zusammen $12500 \mathrm{cbm}$ Rauminhalt versetzt und 120 $000 \mathrm{cbm}$ Zementstampfbeton hergestellt, wozu gegen 20 Millionen $\mathrm{kg}$ Zement notwendig waren. Dies bedeutete einen Erddruck von 300 Millionen kg oder reichlich 6 kg auf 1 qcm der 4900 qm großen Grundfläche der Pyramide. Die ungeheuren Lasten - die Granitquader wogen bis zu 10 $000 \mathrm{~kg}$ - wurden von elektrisch betriebenen Maschinen gehoben und an Ort und Stelle geleitet. Es waren darum verhältnismäßig nur wenig Arbeiter nötig - durchschnittlich 40 Mann - um den Bau flott zu fördern. ${ }^{21}$

Ab Winter 1910 waren die Steinmetzarbeiten an den vier zyklopischen Sitzfiguren der Feierhalle im Gange. Skizzenhaft sind sie bereits im Denkmalsentwurf von 1898 angelegt. In ihnen, insbesondere in der götzenhaft thronenden „Volkskraft“ (Grundsteinlegung am 18. Oktober 1911) hat Metzners nun regelrecht ins Amorphe auswuchernde Formensprache ihren Gipfel erreicht. Noch deutlicher als in den Skulpturenzyklen in der Krypta und am Kuppelaußenbau wird hier die Intention der Denkmalstifter und des Bildhauers fassbar, mit Rückgriff auf archaische bzw. vorklassische Vorbilder eine neuartige völkisch-nordische Monumentalkunst zu schaffen, die sich nachdrücklich von der humanistisch fundierten Bau- und Bildkunst des 19. Jahrhunderts abhob. Da es keine monumentale germanische Plastik gab und im Übrigen auch die Geschichte der nachantiken europäischen Plastik keine geeigneten Vorgaben bereithielt, bot sich als Rezeptionsfeld nur die altorientalische und insbesondere die altägyptische Bildhauerkunst an. Die Sitzfiguren in der Feierhalle des Völkerschlachtdenkmals lassen sich mit den ästhetischen Maßstäben des akademischen Historismus nicht beschreiben. Typologisch und formal korrespondieren sie mit kolossalen Sitzfiguren altägyptischer Pharaonen wie den um 1400 v. Chr. geschaffenen Memnonsäulen in Theben und den 22 Meter hohen Bildwerken am großen Felsentempel von Abu Simbel (um 1250

21 Spitzner (wie Anm. 3), S. 100. 


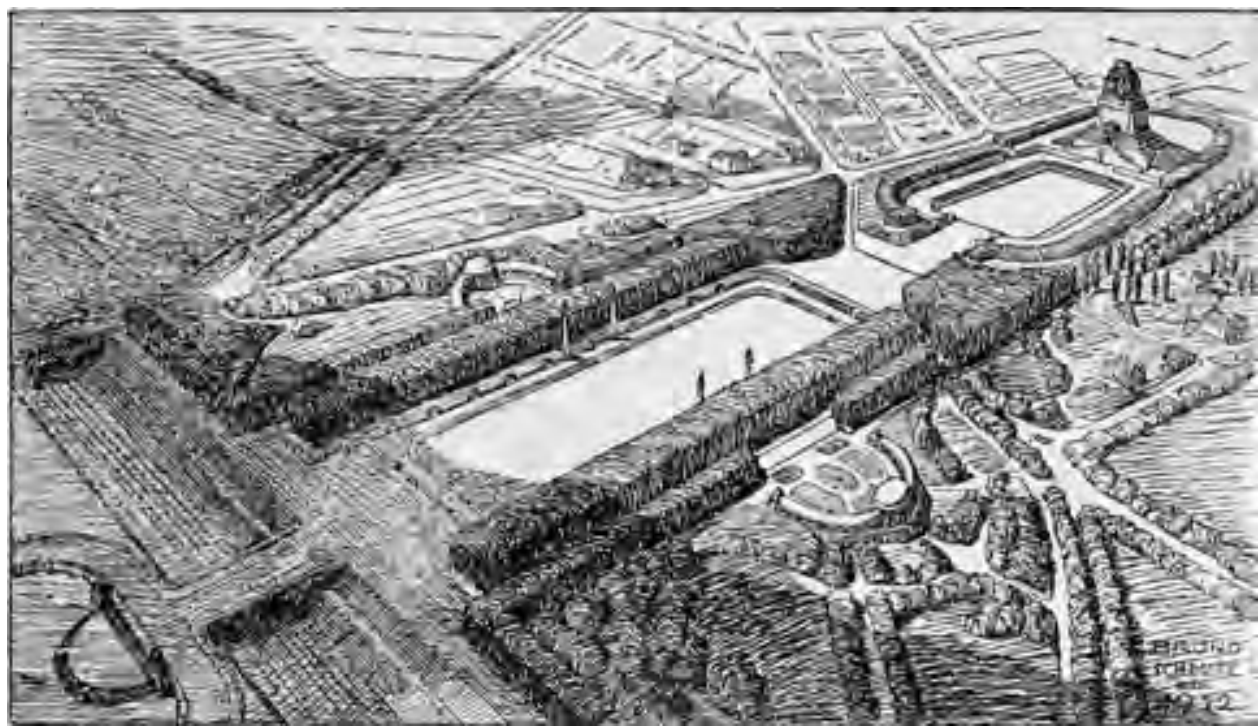

Abb. 7 Leipzig, Völkerschlachtdenkmal, Vogelschaubild mit dem Wasserbecken und der nicht ausgeführten Deutschen Kampfbahn (nach einer Zeichnung von Rudolph Müller-Gerhardt).

v. Chr.). Es ist dies ein Zusammenhang, auf den der Deutsche Patriotenbund in seinen Schriften wiederholt hingewiesen hat. ${ }^{22}$

Die im Frühjahr 1913 endgültig fertiggestellten Bildwerke bilden ikonografisch in ihrer Verkörperung der „Volkstugenden“ Glaubensstärke, Heldenmut, Volkskraft und Opferwilligkeit den eigentlichen Angelpunkt des Denkmalprogramms. Künstlerisch aber sind sie die mit Abstand schwächsten Leistungen und fielen auch bald nach ihrer Fertigstellung der Kritik anheim. ${ }^{23}$ Sie sind höchst lehrreiche Beispiele dafür, dass allein

22 „Die Steinriesen des Denkmals werden an Größe nur von den bekannten Kolossalfiguren des ägyptischen Königs Amenophis III und seiner Gemahlin bei Theben, den sogenannten Memnonsäulen, übertroffen. Im Übrigen wetteifern ihre Maße aber durchaus mit denen aller anderen Bildwerke in ägyptischen Tempeln und Palästen.“ In: Mitteilungen des Deutschen Patriotenbundes Nr. 9, Juli 1913, S. 4.

23 „Man machte Athleten und meinte, Athleten seien formal etwas Kolossales, zweimal, wenn man ihre Muskulatur und ihre Haltung , stilisiert" - das heißt kunstgewerblich abplattet. [...] Der Kultus der Muskulatur, die plastische Verherrlichung maßloser Kräfte, [...] die Begeisterung für die äußerst materiellen Dimensionen, die sich an assyrischen und ägyptischen Vorbildern erregte und sie auf die Epoche nach 1900 zu übertagen versuchte: dies alles ist Ausdruck eines üblen neudeutschen Imperialismus in Politik und Wirtschaft. Die österreichische Herkunft Metzners gab den Tendenzen seiner Plastik nur eine Spannung mehr. Das persönliche Talent Metzners stand außer Frage. Es war sein Unglück, in eine grobe, stofflich expansive Zeit hineingeboren zu werden. Seiner Begabung würden unter anderen Verhältnissen edlere Dinge entsprungen sein. Er war ein Opfer der Epoche. Notwendiger Wunsch: dass diese Situation begriffen werde und dass die Einsicht andere abhalte, auf dieser Bahn weiterzugehen. Die Gefahr ist - leider - noch groß.“ In: Hausenstein, Wilhelm: Die bildende Kunst der Gegenwart, Berlin-Leipzig ${ }^{2} 1923$ [1914], S. 234 f. 
durch megalomane Material- und Formhäufung wahre Monumentalität nicht erreicht werden kann. Dies gilt nicht nur für die spannungs- und kraftlose Durchbildung der Skulpturen selbst, sondern ebenso im Hinblick auf ihr Verhältnis zum Raum. Gerade hier fällt die viel gepriesene Einheit von Plastik und Raum auseinander, denn trotz einer Größe von ca. 9,50 Metern können sich die Figuren nicht als dominierende Elemente behaupten. In der Nahsicht kaum für den Betrachter ganzheitlich erfassbar, verlieren sie sich andererseits in der Weite des nach unten zur Krypta und nach oben zur Kuppel geöffneten Zentralraumes.

Am 13. Mai 1912 wurde die feierliche Schlusssteinlegung des Völkerschlachtdenkmals von Clemens Thieme vollzogen, doch war damit der Bau noch nicht vollendet. So fiel im September 1912 die Entscheidung, die vier großen, fast 14 Meter hohen Rundbogenöffnungen der Feierhalle zu verglasen, um das Innere des Denkmals vor Witterungsunbilden zu schützen und den starken Gegenlichteinfall zu dämpfen, der auch heute noch die Sitzfiguren in ihrer plastischen Wirkung erheblich beeinträchtigt. Für Metzner ergab sich damit die Gelegenheit, an den Hauptstreben der Bogenfenster noch einen weiteren, umfangreichen Zyklus aus insgesamt 94 Einzelfiguren bzw. Figurenpaaren anzubringen. Im Mai 1913 fertiggestellt, sind diese Bildwerke dem Gedenken an die Leiden der vom Krieg betroffenen Bevölkerung gewidmet.

Den Dimensionen und der Formensprache des Denkmals entspricht die Gestaltung des weiträumigen Vorgeländes (Abb. 7). Es ist ein durch hohe terrassierte Wälle vom flachen Umland abgehobener Bezirk, dessen eigentliche Funktion darin besteht, den Besucher auf einem langen vorgeschriebenen Weg zum Denkmal hinzuführen. Bunkerartig anmutende, in ihrer Gestalt altägyptischen Mastaba-Gräbern nachgebildete Bauten flankieren den Zugang in den Freiraum. Ein leicht trapezoider Grundriss verstärkt den optischen Tiefenzug der Anlage, an deren Ende der massige Denkmalsbau aufragt. Diese Inszenierung erfährt eine letztmögliche Steigerung durch das 162 Meter lange Wasserbecken, in dem sich das Bauwerk in voller Größe spiegelt. Nicht ausgeführt wurde der schon seit 1896 vom Deutschen Patriotenbund erwogene Plan, die Achse des Denkmalvorgeländes durch die Anlage der Deutschen Kampfbahn zu verlängern.

Nach einer Bauzeit von insgesamt 15 Jahren erfolgte die Einweihung des Denkmals am 18. Oktober 1913 mit großem vaterländischem Pomp. ${ }^{24}$ Realisiert worden war ein Monument, in dem sich Architektur und Plastik zu einem beeindruckenden Gesamtkunstwerk vereinigen. Auch in bautechnischer Hinsicht ist das Völkerschlachtdenkmal ein kühnes Unternehmen gewesen, denn es gehört, wie die zur Säkularfeier der Befreiungskriege 1913 eingeweihte Jahrhunderthalle in Breslau (Architekt: Max Berg) und die Betonhalle von Wilhelm Kreis auf der Leipziger Internationalen Bauausstellung 1913, zu den Inkunabeln des monumentalen Betonbaus in Deutschland. Mit der Konzeption dreier architektonisch und bauplastisch differenzierter, doch inhaltlich und baulich-räumlich untrennbar zusammengehöriger Denkmalsbereiche gelang es Bruno Schmitz und Clemens Thieme, die vom Deutschen Patriotenbund angestrebte komplexe

24 Deutschlands Freiheitsdom. Gedenkblatt zur Weihe des Völkerschlachtdenkmals. In: Leipziger Neueste Nachrichten, 18.10.1913. 


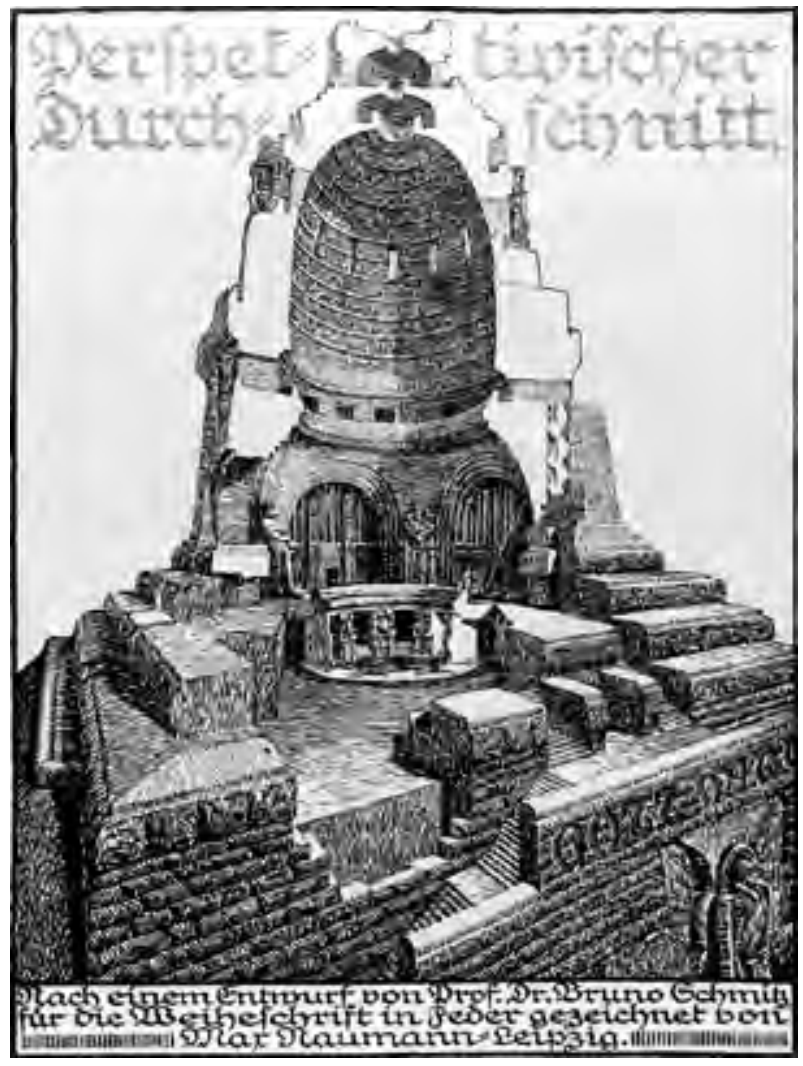

Abb. 8 Leipzig, Völkerschlachtdenkmal, perspektivischer Schnitt (nach einer Zeichnung von Max Naumann).

Aussage des Monuments überzeugend zu artikulieren. Es ist als ein Ehrenmal für die Gefallenen der Völkerschlacht (Krypta), als Ruhmesmal für das deutsche Volk (Feierhalle und Innenkuppel) und als ein Mahnmal für kommende Geschlechter (Freiheitswächter) konzipiert worden (Abb. 8). Diese Botschaft ist auch heute noch in Kenntnis des Darstellungsprogramms ohne Schwierigkeiten nachvollziehbar. An eine Würdigung der Völkerschlacht in ihrer europäischen Bedeutung war freilich nie gedacht worden, wie überhaupt im und am Denkmal jeder Hinweis auf den Beitrag der anderen an der Völkerschlacht beteiligten Nationen, ohne die der Sieg über Napoleon nicht möglich gewesen wäre, vermieden wurde. So kam als Adressat des als Nationaldenkmal konzipierten Monumentes allein das deutsche Volk in Betracht, wobei die Begriffe „Volk“ und „Nation“ eine für die Situation am Vorabend des Ersten Weltkrieges bezeichnende ideologische Modellierung erfuhren. Thomas Nipperdey hat diesen Kontext in einer wegweisenden, schon 1968 erschienenen Studie über Nationalidee und Nationaldenkmal in Deutschland im 19. Jahrhundert untersucht. Sein zusammenfassendes Urteil über das Leipziger Völkerschlachtdenkmal sei deshalb an den Schluss des vorliegenden Aufsatzes gestellt: 
Die Größe und Gewalt der Nation soll in der Bauform anschaulich werden. Damit bleibt das Denkmal architektonisch dem Wilhelminismus, dem Gestus des Imponierenwollens verhaftet; das Denkmal der deutschen Erhebung ist eben auch Denkmal der deutschen Macht. Aber die Bauform ist mehr als Darstellung von Macht und Geschlossenheit, auch sie ist vom schweren und lastenden Ernst der Plastik erfüllt, auch sie bezieht sich auf ein Unendliches, dem sie in festem Trotz entgegentritt. [...] Die das Denkmal leitende Idee der nationalen Sammlung zeigt sich endlich darin, wie mit der Bauform das Verhältnis von Individuum und Nation neu bestimmt wird. Das architektonische Denkmal ohne individuelles Standbild will die Beschauer als nationale Gemeinschaft zusammenbinden. [...] Die Nation, die sich im Denkmal mit sich selbst identifizieren soll, ist nicht mehr Kultur- und Glaubensgemeinschaft, sondern Kampf-, Schicksals- und Opfergemeinschaft; sie ist nicht mehr in einem konkreten Sinn politisch, nämlich monarchisch und demokratisch verfaßte Gemeinschaft, sondern sie ist im Mythos der Innerlichkeit und der - antisozialistisch gerichteten - Solidarität zusammengefaßte Nation. Der demokratische Begriff der Nation, der am Anfang der Idee eines Leipziger Denkmals gestanden hatte, ist zum integralen Begriff der Nation geworden, das Denkmal zum Denkmal der nationalen Konzentration, das zwar 1913 durchaus noch den herrschenden politischen Zuständen entsprach, aber davon auch ablösbar war. ${ }^{25}$

25 NipPERDEY, Thomas: Nationalidee und Nationaldenkmal in Deutschland im 19. Jahrhundert. In: Historische Zeitschrift, Bd. 206/Heft 3 (1968), S. 576 f. 


\title{
Die Russische Gedächtniskirche in Leipzig als Erinnerungsort an die Völkerschlacht
}

\author{
Marina Dmitrieva
}

Die Kirche macht nach ihrer Vollendung jetzt einen prachtvollen Eindruck, namentlich bei hellem Sonnenschein, und ist jedermann, den ich darüber gesprochen habe, ganz entzückt von dem Bau. Die Kirche ist auf alle Fälle eine Zierde des neuen Stadtviertels,

schrieb Friedrich Wilhelm Dodel (1861-1933), Leipziger Rauchwarenhändler und Mitglied des Baukomitees der Russischen Gedächtniskirche, am 17. September 1913 an den St. Petersburger Architekten Vladimir Pokrovskij. ${ }^{1}$

Mit ihrer schlanken Silhouette, weiß getünchten Wänden und golden glänzendem Dekor aus venezianischen Mosaiksteinen ist die Russische Gedächtniskirche in der Leipziger Stadtlandschaft fest verankert. Durch ihre Errichtung am Windmühlenweg (der heutigen Philipp-Rosenthal-Straße), etwas seitlich gelegen von der zum 100. Jahrestag der Völkerschlacht angelegten Straße des 18. Oktober, die zum Völkerschlachtdenkmal hinausführte, entstand ein wichtiger Orientierungspunkt in einem neu angelegten Stadtviertel. Dieses sollte ein paar Jahre später durch den Bau der Deutschen Bücherei gegenüber der Kirche noch weiter aufgewertet werden. Der feierliche Gottesdienst in der einen Tag davor eingeweihten Kirche fand am 18. Oktober 1913 statt, unmittelbar nach der Eröffnung des Völkerschlachtdenkmals und im Beisein des Kaisers Wilhelm II., des sächsischen Königs Friedrich August III., des österreichischen Thronfolgers Kronprinz Franz Ferdinand und des Vertreters des russischen Zaren, Großfürst Kyrill Vladimirovič.

Der kommemorative Charakter des Denkmals, seine städtebauliche Einfügung sowie sein ,„̈sthetisch befriedigender und überraschend schöner Anblick“ sind in der zeitgenössischen Leipziger Presse positiv konstatiert worden. ${ }^{2}$

Das Doppeljubiläum der Völkerschlacht und der Gedächtniskirche im Oktober 2013 bot einen Anlass, über die Rolle dieses Denkmals in beiden Erinnerungskulturen - der russischen und der deutschen - erneut nachzudenken. Die gemeinsam mit dem Erzpriester der Russischen Kirche Aleksej Tomjuk organisierte Konferenz und die daraus erfolgte Publikation versammelte Historiker, Theologen und Kunsthistoriker aus beiden Ländern. ${ }^{3}$ Im Architekturmuseum Moskau fand sich zudem ein Konvolut von Zeichnungen und Entwürfen für die Leipziger Kirche. ${ }^{4}$ Die im Archiv der Gedächtniskirche

1 Archiv Russische Gedächtniskirche, Korrespondenz von Friedrich Wilhelm Dodel, Mappe 16 (Brief vom 17. September 1913).

2 Illustrirte Zeitung, Nr. 3669, 23.10.1913, S. 717-721, hier S. 720.

3 Russkij chram-pamjatnik v Lejpcige [Die Russische Gedächtniskirche in Leipzig]. Hg. v. Marina DMITRIEVA. St. Petersburg 2015.

4 Ivanova, Tatjana: Chudožestvennoe nasledie V.A.Pokrovskogo v sobranii Gosudarstvennogo naučnoissledovatel'skogo muzeja architektury im. A.V.Ščuseva [Der Nachlass von V.A.Pokrovskij in den 
versammelten Dokumente, betreffend das Bauvorhaben und die Geschichte der Kirche, deren Einsicht von Erzpriester Tomjuk großzügig gewährt wurde, warten noch auf ihre gründliche Auswertung. Im Leipziger Bauordnungsamt und im Stadtarchiv befinden sich darüber hinaus Dokumente und Pläne hinsichtlich der Russischen Gedächtniskirche, ihrer Entstehungsgeschichte und Realisierung, auf die zunächst Hartmut Mai aufmerksam geworden war. ${ }^{5}$ Nicht zuletzt aufgrund dieser Archivfunde ergibt sich ein neuer, facettenreicher Blick auf das Leipziger Bau- und Kulturdenkmal.

Einleitend sei zu konstatieren, dass sich in Gestalt der Russischen Gedächtniskirche in Leipzig ein Bauwerk von seltenem künstlerischem Wert befindet. ${ }^{6}$ Das Projekt stammt von einem seinerzeit sehr bekannten und geschätzten, aber später fast vergessenen Architekten - Vladimir Aleksandrovič Pokrovskij (1871-1931). ${ }^{7}$ Zu seinen realisierten Projekten in Russland zählen die Peter-und-Pauls-Kirche der Pulverfabriken in Schlüsselburg (1906-1907) und die Theodorkirche in Zarskoe Selo bei St. Petersburg (1910). An der Seite seines Mentors Leontij N. Benois (1856-1928) hat er am Bau und an der Ausstattung der Alexander Newski-Kathedrale in Warschau mitgewirkt (1894-1912, zerstört 1924-1926). Der nicht verwirklichte Entwurf des militärgeschichtlichen Museums in St. Petersburg (1907-1910) in einem märchenhaft historisierenden russischen Stil besticht durch seine erfinderische Vielfalt und Kenntnis von Details der altrussischen Architektur. Von Pokrovskijs hohem Prestige zeugen Aufträge der Zarenfamilie in Zarskoe Selo und anderen prominenten Orten, die Präsenz in einer Vielzahl von Komitees und Gremien sowie nicht zuletzt auch die Aufforderung, dieses für die zeitgenössische, russisch-imperiale Geschichtspolitik zentrale Bauwerk in Leipzig zu errichten. Zugleich handelte es sich dabei auch um das letzte von staatlichen und kirchlichen Instanzen realisierte Auslandsprojekt des Zarenreiches vor Ausbruch des Ersten Welt-

Sammlungen des Staatlichen wissenschaftlichen A.V.Ščusev Architekturmuseums. In: Russkij chrampamjatnik v Lejpcige (wie Anm. 3), S. 127-133.

5 MaI, Hartmut, unter Beteiligung von Mathias Gretschel u.a.: Russisch-orthodoxe Kirche des hl. Alexi. In: Die Bau- und Kunstdenkmale von Sachsen, Stadt Leipzig. Die Sakralbauten. Hg. v. Landesamt für Denkmalpflege Sachsen. München, Berlin 1995, S. 761-770.

6 Hervorzuheben sind in diesem Zusammenhang vor allem die Publikationen von Hartmut Mai, der schon in den 1970er Jahren die ersten wissenschaftlichen Abhandlungen zu diesem Denkmal verfasste. Ich danke Prof. Mai an dieser Stelle für die großzügige Bereitschaft, sein Wissen zu teilen: MAI, Hartmut: Die russische Gedächtniskirche in Leipzig, ein Denkmal der Befreiungskriege. In: Sächsische Heimatblätter 23 (1977), H. 1, S. 39-43; Ders./Flemming, Johanna: Die russischen orthodoxen Kirchen in Potsdam, Weimar, Dresden und Leipzig. Berlin 1983; Ders.: Russkij chram-pamjatnik Svjatitelja Alekseja v Leipzige (1910-1913) [Russische Hl.-Aleksij-Gedächtniskirche in Leipzig (1910-1913)]. In: Russkij chram-pamjatnik v Lejpcige (wie Anm. 3).

$7 \mathrm{Zu}$ Pokrovskij: KIRIČENKo, Evgenija I.: Poiski nacional'nogo stilja $\mathrm{v}$ tvorčestve architektora V.A.Pokrovskogo [Die Suche nach einem Nationalstil im Schaffen des Architekten V.A. Pokrovskij]. In: Architekturnoe nasledstvo (1973), Vyp. 21, S. 69-82; GavriLov, Sergej A.: Zodčij V.A. Pokrovskij v Peterburge - Petrograde - Leningrade [Der Architekt V.A. Pokrovskij in St. Petersburg, Petrograd, Leningrad]. In: Nevskij archiv. St. Petersburg 2003, Vyp. VI, S. 471-497; Ders.: Iz istorii sozdanija chrama-pamjatnika vo imja Svjatitela Aleksija v Leipzige [Aus der Entstehungsgeschichte der Hl.-Aleksij-Gedächtniskirche in Leipzig]. In: Russkij chram-pamjatnik v Lejpcige (wie Anm. 3), S. 39-58. 


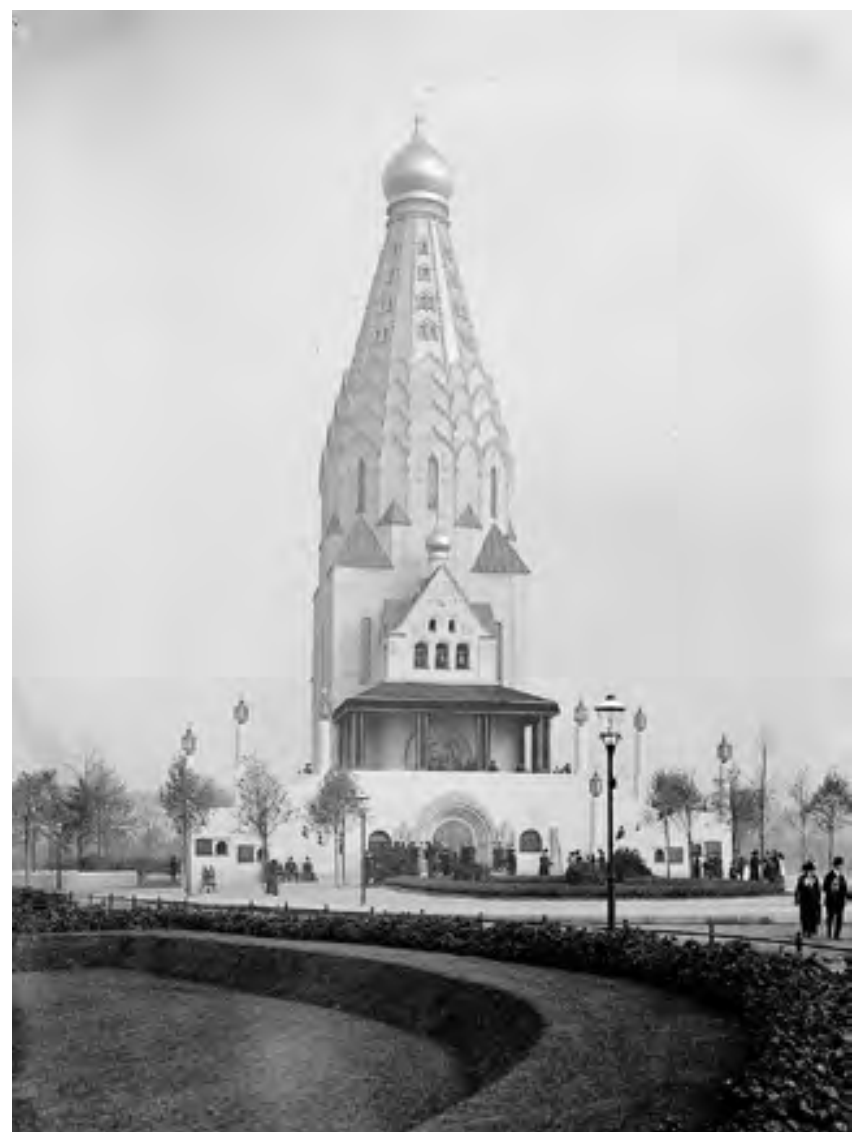

Abb. 1 Die Russische Gedächtniskirche in Leipzig, 18. Oktober 1913. Foto: Ernst Hoenisch, 1913. Stadtarchiv Leipzig.

kriegs. Auch die Pokrovskij erteilten Aufträge für russische Nationalpavillons auf der Hygieneausstellung in Dresden (1911) und der Internationalen Buch- und Grafikausstellung in Leipzig (1914) zeugen von seiner offiziellen Wertschätzung. Pokrovskijs Verdienste in Deutschland sollten eine besondere Würdigung erfahren: Vom sächsischen König erhielt er den Albrecht-Orden sowie den Titel eines Professors; vonseiten des Zaren erfolgte die ehrenvolle Ernennung zum „Architekten des Zarenhofs“. Insgesamt gesehen war Pokrovskij somit ein führender Vertreter des sogenannten neorussischen Stils in der Architektur um die Jahrhundertwende. ${ }^{8}$

Im Gegensatz zu den meisten seiner Werke in Russland ist die Leipziger Gedächtniskirche mit ihrer vom Architekten selbst entworfenen aufwendigen Ausstattung fast

8 Kiritschenko, Ewgenia I.: Zwischen Byzanz und Moskau. Der Nationalstil in der russischen Architektur. München 1991; KeYPEn-VARDIC, Diana: Charmovoe zodčestvo neorusskogo stilja [Sakrale Architektur des neorussischen Stils]. In: Russkij chram-pamjatnik v Lejpcige (wie Anm. 3), S. 144170 . 
Abb. 2 Christi Himmelfahrtskirche in Kolomenskoe, 1532. Foto: Marina Dmitrieva, 2013.

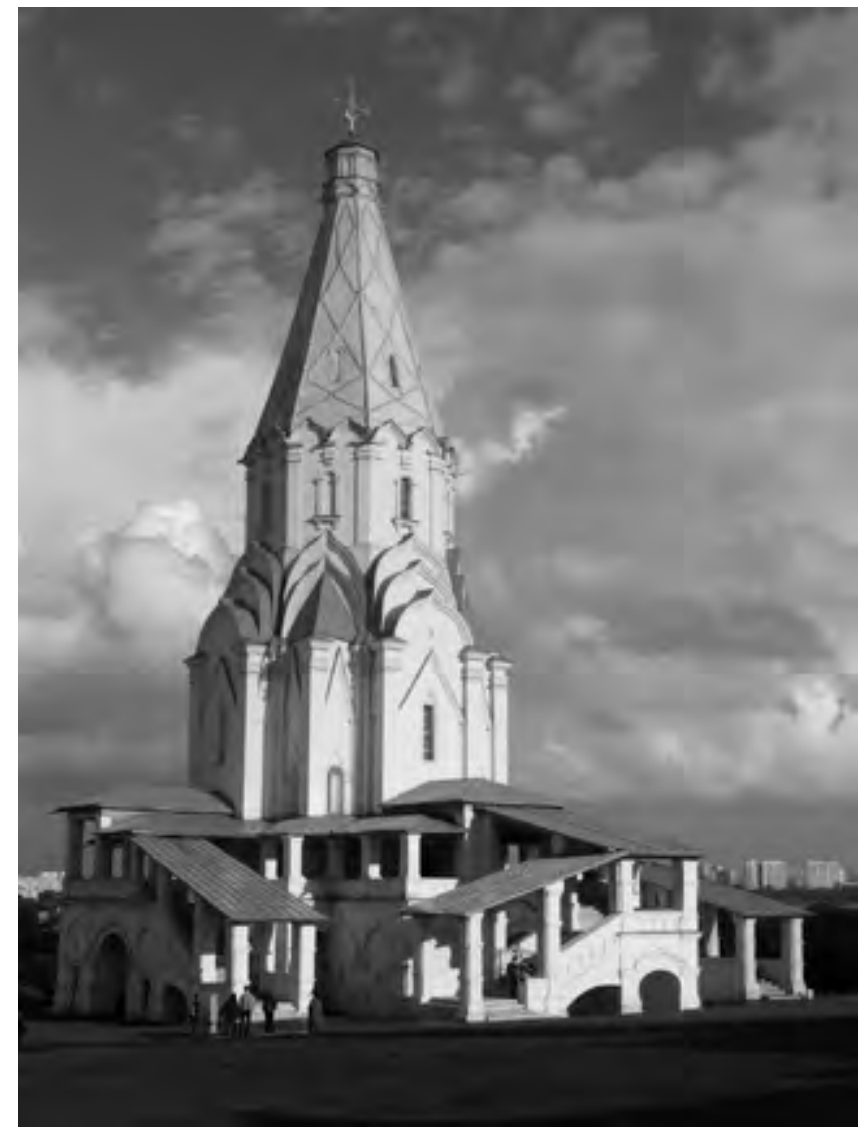

komplett erhalten geblieben. Die Oberleitung des Bauvorhabens lag, in enger Zusammenarbeit mit dem russischen Architekten, in den Händen der Leipziger Baumeister Georg Weidenbach und Richard Tschammer, mit denen er zuvor im Rahmen der Hygiene-Ausstellung zusammen gearbeitet hatte.

Noch in seiner Entstehungsphase geriet das Projekt in den Fokus eines komplexen deutsch-russischen Erinnerungskonflikts, welcher die kleine russische Kirche zu Leipzig in ihrer Bedeutung weit über ihren nationalen und regionalen Deutungskontext hinausführte. Die dichte Überlappung von memorialen Diskursen und aktuellen geschichtspolitischen Interessen am Vorabend des Ersten Weltkrieges macht dieses Denkmal zu einem spannenden Untersuchungsobjekt in einer transnationalen Forschungsperspektive. Diese Optik verschiebt den Blick von Pierre Noras Konzept eines national konnotierten lieu de mémoire sowie der daraus konstatierten Erinnerungskulturen, der containered memories, hin zu solchen Deutungsaspekten, die sich auf das Zusammenwirken von Gedächtniskulturen konzentrieren. Die folgenden Ausführungen sollten daher dem Ansatz Astrid Erlls folgen, nach dem der Blick des ,transnationalen 
Gedächtnisses“ („transnational memory“) „towards mnemotic processes unfolding across and beyond cultures" gerichtet ist. ${ }^{9}$

\section{Form und Funktion}

Die dem Moskauer Metropoliten Aleksij geweihte Kirche ist zugleich ein Ort der Erinnerung an die in der Völkerschlacht gefallenen Soldaten. Diese doppelte Funktion als Kirche und Gedenkstätte - kann sowohl anhand der Ausstattung als auch anhand der Architekturform abgelesen werden.

Der Kirchenbau, der mit seiner gotisch anmutenden, aufstrebenden Turmkuppel und einer zentralbaulichen Komposition zum relativ selten benutzten altrussischen Typus der sogenannten Turm- oder Zeltdachkirchen gehört und sich an der Christi Himmelfahrtskirche von Kolomenskoe in Moskau (1528-1532) orientiert (Abb. 1-2), besteht aus zwei Teilen. Im breiteren unteren Teil sollten nach dem Plan des Architekten ein Museum der Völkerschlacht und eine Bibliothek untergebracht werden. Als Vorbild diente vermutlich das zum opulent begangenen 100. Jubiläum des Sieges über Napoleon eröffnete „Museum des Jahres 1812“ in Moskau. Auch im Unterbau des Völkerschlachtdenkmals war ursprünglich vorgesehen, ein Museum zu installieren. Seit Ende der 1920er Jahre besteht dieser Unterbau allerdings aus einer dem hl. Panteleimon gewidmeten „unteren“ Kirche. Zur oberen (eigentlichen) Kirche führt eine repräsentative Treppe, die an einer breiten Terrasse endet und zum gewölbten Rundgang für österliche Prozessionen führt. Acht schlanke Laternen flankieren Treppe und Terrasse. Auf ebendieser mit einem provisorischen Baldachin überdachten Terrasse stand der Erzpriester Georgij Šavel'skij vor dem feierlichen Gottesdienst am 18. Oktober 1913, in Erwartung der Staatsgäste, die nach der Einweihung des Völkerschlachtdenkmals zum Tedeum in die russische Kirche kommen sollten. Die erhöhte Terrasse (russ. papert') erwies sich somit als hervorragender Beobachtungsort für vorbeiziehende Prozessionen. Als Erzpriester der russisch-imperialen Armee und Marine wurde Šavel'skij diese Aufgabe zugeteilt, denn die Kirche stand in der Zuständigkeit des russischen Kriegsministeriums.

An beiden Seiten des mit plastischen Reliefs reich dekorierten Sandsteinportals zum geplanten Museum befinden sich zwei Marmortafeln mit Texten in stilisierter Schrift, sowohl in russischer als auch in deutscher Sprache (Abb. 3). Sie, wie auch fast die komplette Innenausstattung der Kirche, sind von Pokrovskij entworfen worden. Die deutschsprachige Inschrift lautet:

Dem Gedenken der 22000 russischen Krieger, gefallen für die Befreiung Deutschlands 1813 bei Leipzig. An der Völkerschlacht zu Leipzig vom 16. - 19. Oktober nahmen teil:

9 ERLL, Astrid: Travelling Memory. In: Parallax 17/H. 4 (2011), S. 4-18. In: http://dx.doi.org/10.1080 /13534645.2011.605570 (23.12.2015). S. auch: Welsch, Wolfgang: Transculturality - the Puzzling Form of Cultures Today. In: Spaces of Culture: City, Nation, World. Hg. v. Mike Featherstone und Scott Lash. London 1999, S. 194 f. 


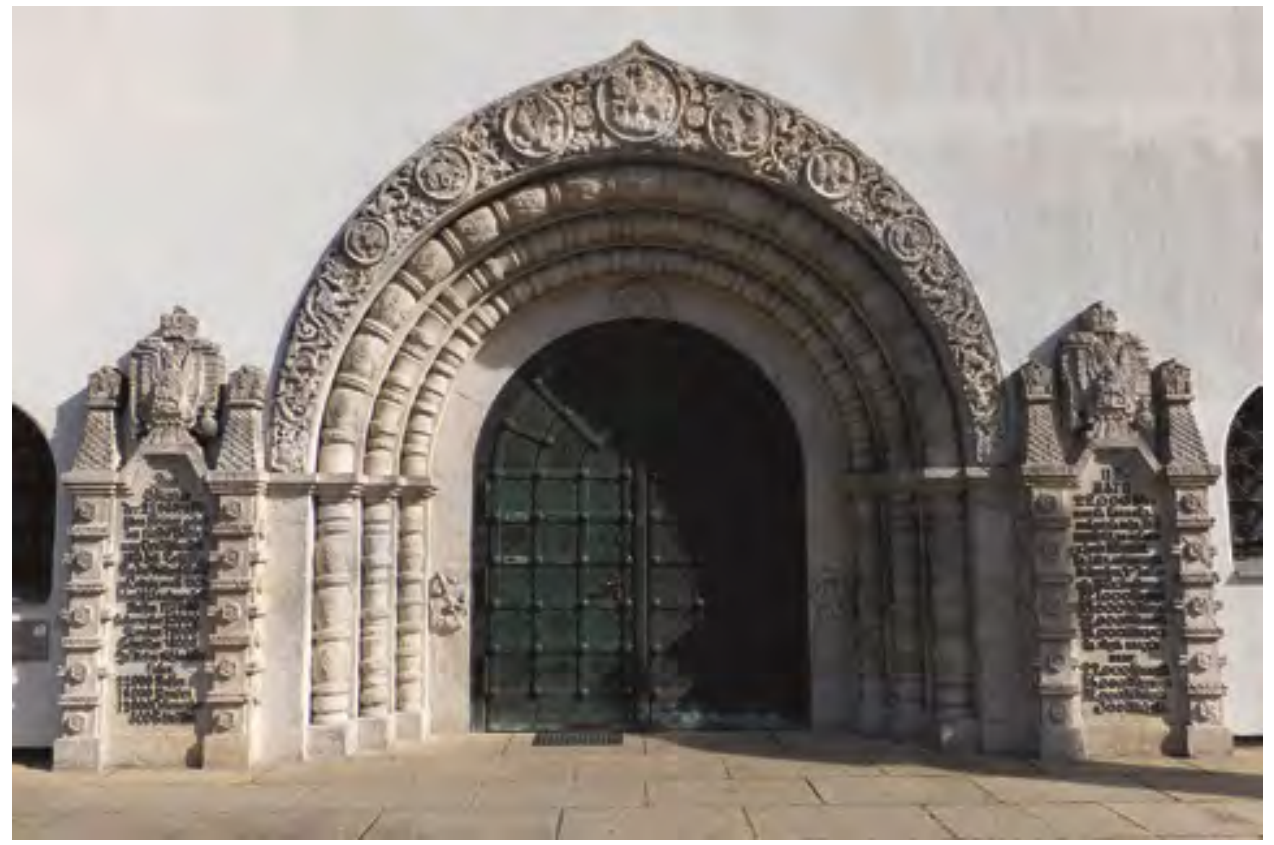

Abb. 3 Portal der Russischen Gedächtniskirche. Foto: Rainer Krumrey, 2013.

\author{
Russen 127000 \\ Oesterreicher 89000 \\ Preußen 72000 \\ Schweden 18000 \\ In diesen Schlachten fielen: \\ 22000 Russen \\ 16000 Preußen \\ 12000 Oesterreicher \\ 300 Schweden
}

Im Gegensatz zu den von der Habsburgermonarchie ebenfalls im Zusammenhang mit dem Jubiläum als Zeichen staatlicher Erinnerungspolitik in Leipzig aufgestellten Denkmälern ${ }^{10}$ und auch im Vergleich zum Völkerschlachtdenkmal gilt die Erinnerung in der Russischen Gedächtniskirche nicht nur den Russen, sondern allen in der Schlacht gefallenen Soldaten: Preußen, Österreichern und Schweden. ${ }^{11}$ Somit kann sie als das einzige Denkmal zur Völkerschlacht gelten, welches nicht nur die eigene nationale Kriegserinnerung, sondern auch diejenigen der Verbündeten pflegte.

10 S. dazu den Beitrag von Christian Forster in diesem Band.

11 Die russischen Verluste waren am zahlreichsten, da russisch-imperiale Einheiten in allen vier Armeen der Verbündeten vertreten waren. 
Ein weiterer wichtiger Aspekt der Erinnerung an die Leipziger Schlacht kam in der Begründung der Duma für die finanzielle Unterstützung dieses Projektes zum Ausdruck. Die Memorierung gebühre nicht nur den Russen, sondern auch ,vielen Völkern, die das Territorium Russlands besiedeln, die in der Schlacht von Leipzig zusammengekommen sind". ${ }^{12}$ Somit bedeutete es, nicht nur den russisch-nationalen, sondern auch den supranationalen Charakter der russisch-imperialen Erinnerungspolitik zu betonen.

Seitlich rechts ist eine weitere Tafel zu sehen. Die von einem stilisierten Olivenzweig dekorierte schlichte Bronzetafel ist auf Anordnung des sowjetischen Stadtkommandanten Generalmajor Nikolaj I. Trufanov im September 1945 angebracht worden. Ihre Inschrift lautet: „Ewiger Ruhm den Helden, die im Kampf für die Freiheit und Unabhängigkeit unserer Heimat gefallen sind. 1813-1945“. Mit der Erweiterung des geschichtspolitischen Deutungsgehalts auf die im Zweiten Weltkrieg gefallenen sowjetischen Soldaten und der damit einhergehenden Überlappung von historischen Ereignissen ${ }^{13}$ erfolgte eine legitimierende Umcodierung einer Stätte des christlich-orthodoxen Kultes zu einem Sieges- und Gedächtnismahnmal der russischen Armee. Eine im Jahre 1949 publizierte russischsprachige Broschüre über die Gedächtniskirche trägt den martialisch anmutenden Titel „Denkmal des russischen Waffenruhmes zu Leipzig“ (Pamjatnik slavy russkogo oružija v gor. Lejpcige) und evoziert eine Parallelität des historischen Geschehens. Nach dieser teleologischen Argumentation sei die Niederlage des „undankbaren“ Deutschlands anno 1945 bereits durch den ersten Sieg im Jahre 1813 prädestiniert gewesen und habe dadurch zusätzlich eine sakral-mystische Bedeutung erhalten:

Die Zeit verging, und es marschierten entlang des Heiligen Ortes erneut Regimenter der Räuber. ... Die Heimat unserer großen Vorfahren ist nun abermals, ähnlich wie während Napoleons Invasion, von den undankbaren Söhnen Deutschlands angegriffen und verwüstet worden. Aber es geschah ein ewiges Recht. Die tapferen russischen Soldaten, würdige Nachkommen ihrer heldenhaften Vorfahren, haben den Feind in ihrer Heimat zerschlagen und sind erneut in das undankbare deutsche Land gekommen. ${ }^{14}$

Unweit der Kirche befand sich bereits seit Kriegsende ein Stein mit einer auf Halbmast gesetzten sowjetischen Fahne. Der Kirchenbau und das ganze Areal um ihn herum waren somit zum offiziellen Pilgerort für Exkursionen, Kranzniederlegungen von Delegationen in Erinnerung an die gefallenen russischen Soldaten beider Kriege erklärt worden. Die eigentliche, dem Sowjetregime ideologisch nicht konforme christliche Kultstätte war dadurch als offizielles „Denkmal“ legitimiert worden. Gleichzeitig ging das Bauwerk 1945 von der Zuständigkeit der russisch-orthodoxen Kirche

12 Beschluss der Duma vom 6. Februar 1913 bezüglich der finanziellen Unterstützung des Baus der Russischen Kirche zu Leipzig. Zit. in: GavriLov: Iz istorii sozdanija chrama-pamjatnika (wie Anm. 7), S. 67.

13 S. dazu den Beitrag von Stefan Troebst in diesem Band.

14 Šulenin, Michail: Pamjatnik slavy russkogo oružija. Ohne Ortsangabe 1949, S. 14. 
im Ausland in die des Moskauer Patriarchats über und behielt ihre Funktion als orthodoxes Gotteshaus. Vor der Gedächtniskirche fand im Jahr 1994 die letzte Parade der in Leipzig stationierten sowjetischen (russischen) Truppen vor ihrem Abzug aus Deutschland statt. ${ }^{15}$

An der westlichen Rückseite der Kirche ist eine Mosaikikone des thronenden Christus angebracht. Vom Kreuzgang aus sichtbar ist der in die Gemäuer der zentralen Apsis eingemeißelte Gründungsstein, der in der feierlichen Zeremonie am 28. Dezember 1912 gelegt wurde. Von unten führt eine Treppe in die Krypta hinein. Dort, in den Wandnischen, befinden sich vier Sarkophage mit sterblichen Überresten von drei Offizieren dem Oberstleutnant des Taurischen Grenadierregiments Andrej Jurgenev, Generalleutnant Ivan Ševič, Generalmajor Fürst Nikolaj Kudašev - und einem unbekannten Soldaten. Die Überreste sind am 16. Oktober 1913 vom Johannesfriedhof in die Gruft überführt worden. Die zentrale Ikone der Ikonostasis ist dem Typus des „Christus im Limbus" gewidmet - passend zur Funktion einer Grabeskapelle (Abb. 4).

Über die Haupttreppe kommt man durch das ebenfalls üppig verzierte, jetzt stark abgedunkelte Sandsteinportal in die Hauptkirche. Über dem Portal befindet sich eine Heiland-Ikone aus Glasmosaiksteinen. Dank der hohen Turmkuppel mit durchbrochenen Fenstern wirkt der nicht sehr große, aber hohe (39 Meter) Raum geräumig. Dies wird zusätzlich durch eine prachtvolle fünfreihige Lampe (panikadilo) aus 68 Schalen von gelber Smalte betont, die von der Kuppel an einer langen Kette herunterhängt. Die 18 Meter hohe Ikonostasis, gestiftet von einem Donkosakenregiment, welches an der Schlacht teilgenommen hatte, ebenso wie die Brüstung auf dem Sängerpodium, Schränke in der Sakristei, den Kronleuchter und die Kerzenständer fertigte nach Skizzen Pokrovskijs eine bekannte, auf Kirchenutensilien und Artefakte spezialisierte Moskauer Firma (Ivan P. Chlebnikov). Pokrovskij schuf auch Skizzen für einen großen Teppich (jetzt im Grassimuseum zu Leipzig). Der Teppich ist von dem bereits erwähnten Friedrich Wilhelm Dodel gespendet worden. ${ }^{16}$ Die altertümlich wirkenden Ikonen sind im Stil des 17. Jahrhunderts in der Ikonenwerkstatt Nikolaj S. Emeljanovs für die Kirche angefertigt worden. Die über dem Portal und an der Rückseite angebrachten Mosaikikonen, ebenso wie Engelfiguren mit Posaunen, stammen aus der Werkstatt von Vladimir Frolov in St. Petersburg. Mit Frolov und Chlebnikov verbanden Pokrovskij langjährige private und berufliche Beziehungen. Die gesamte Ausstattung wurde somit in Russland gefertigt und anschließend mit der Eisenbahn nach Leipzig transportiert. Dies alles geschah im Zeichen beidseitiger diplomatischer Bemühungen: Der Transport in Russland erfolgte nach einem

15 Foto: „Das Bild“, 8. Mai 1994. Zit. nach: Zeittafel zur Geschichte der Russischen Gedächtniskirche zu Leipzig (Anhand von Artikeln und Pressemitteilungen). Leipzig 2008. Manuskript, zusammengestellt vom Erzpriester Aleksej Tомлuк. Ich danke Erzpriester Tomjuk für die Nutzung der Materialsammlung.

16 In einem Brief vom 13./26. August 1913 aus St. Petersburg schrieb Pokrovskij an Dodel: „Dafür, dass dank Ihrer Spende zugunsten der Kirche es meinem Teppich gegönnt ist, sich zu verwirklichen, bringe ich Ihnen, hochverehrter Herr Dodel, meinen aufrichtigen tiefen Dank dar.“ Archiv der Russischen Gedächtrniskirche, Briefwechsel von Dodel und Pokrovskij. 


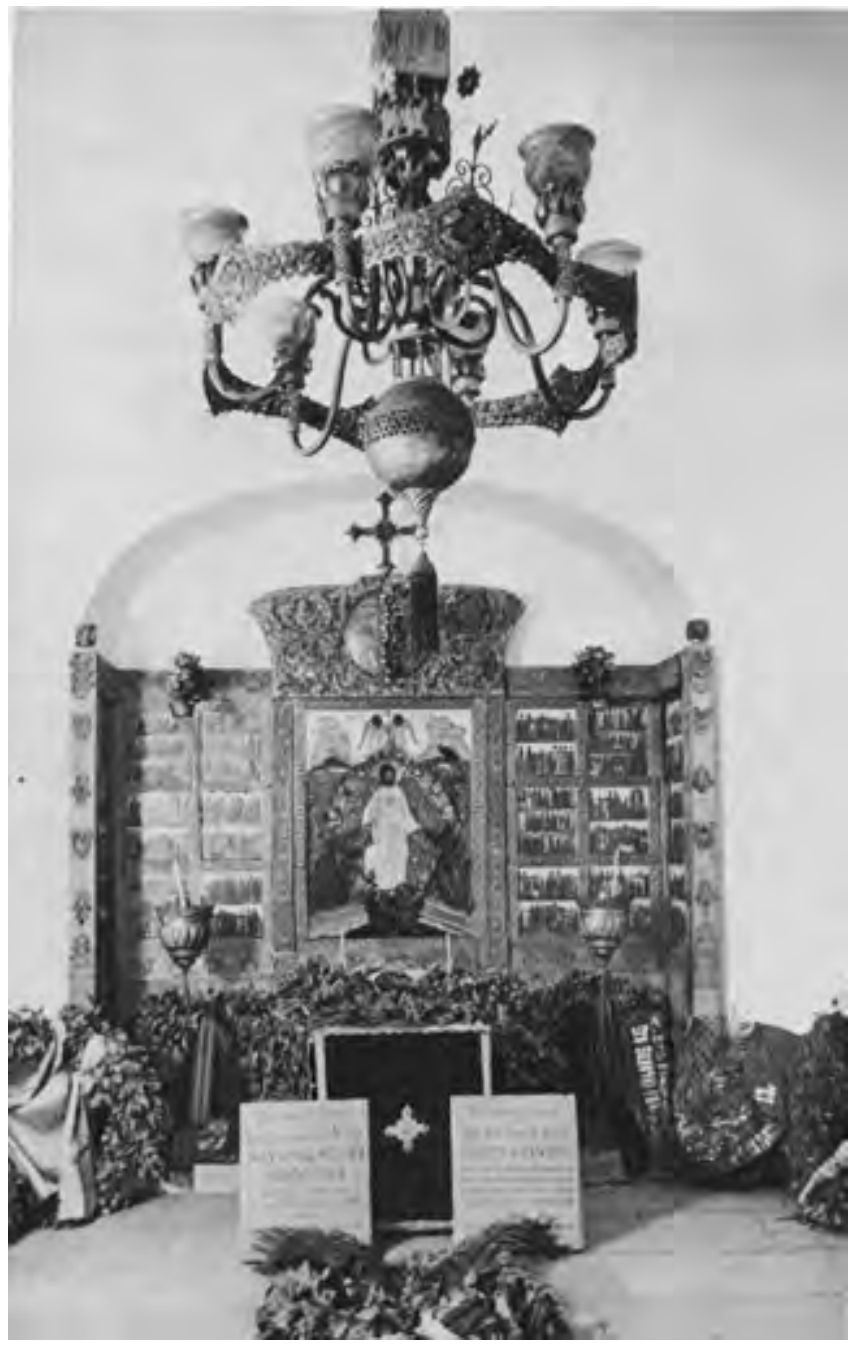

Abb. 4 Grabkapelle mit der Ikonostasis. Foto, vermutlich 1913. Stadtarchiv Leipzig.

verbilligten Tarif, in Deutschland war er gar vollkommen kostenlos und steuerfrei. ${ }^{17}$ Die acht Bronzeglocken in der Narthex über dem Portal zur oberen Kirche goss die Firma Olovjanišnikov in Jaroslawl. Die erst kürzlich dank russischer Spenden von Leipziger Spezialisten restaurierte Ikone des hl. Georg war eine Gabe des Orenburger Kosakenheeres, dessen Einheiten an der Völkerschlacht bei Leipzig teilnahmen. Auch im offenen Arkadengang des Unterbaus befinden sich Tafeln mit Namen einzelner russischer Regimenter, die an der Völkerschlacht beteiligt waren (Abb. 5).

Rechts und links von der Altarwand sind die Standarte der Donkosaken sowie acht Bronzetafeln mit Namen russischer Regimenter befestigt. Somit ist das Gedenken an

17 GaVRILov: Iz istorii sozdanija chrama-pamjatnika (wie Anm. 7), S. 69. 


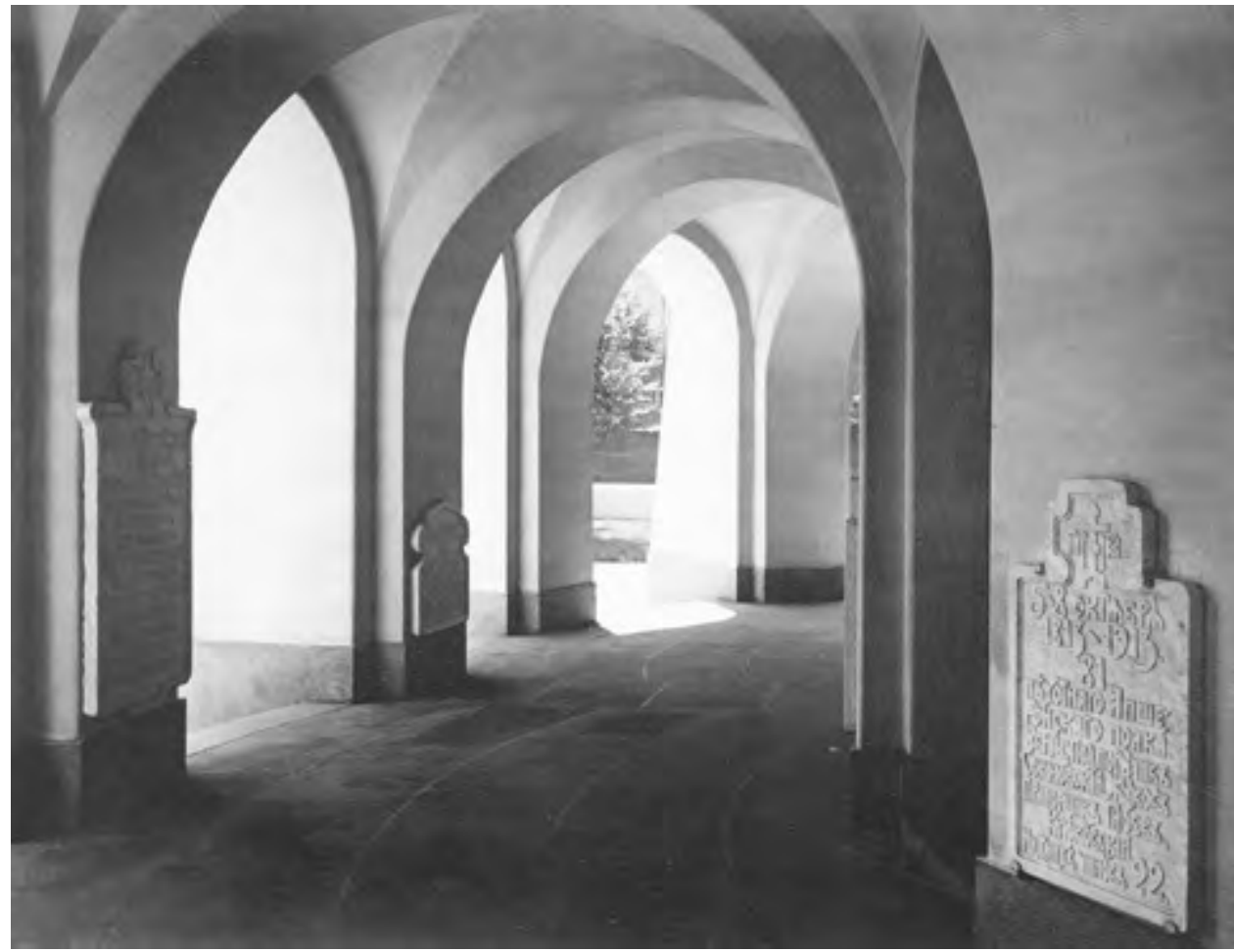

Abb. 5 Unterer Kreuzgang der Gedächtniskirche. Foto, vermutlich 1913. Stadtarchiv Leipzig.

ein Ereignis der Militärgeschichte in der Ausstattung der Kirche sehr präsent, obwohl sie in ihrer primären Funktion ein Gotteshaus darstellt. Teilweise hängt dies mit dem nicht realisierten Projekt eines Museums zusammen, dessen Idee jetzt in einer kleinen Ausstellung im Vorraum der Kirche angedeutet wird. An der Westwand der Narthex ist eine Anfang der 2000er Jahre gemalte Darstellung der Völkerschlacht als Wandmalerei zu sehen. Einige Memorabilia und auch ein Originalmodell der Kirche, nebst Standarten aus dem sowjetischen Monumentalfilm „Krieg und Frieden“ (Vojna i mir; Regie: Sergej Bondarčuk, 1967), sind dort als profane Ausstellungsstücke zu besichtigen. Somit treten künstlerische Fiktion und ,reale“ Zeugnisse der Geschichte in eine etwas anachronistisch wirkende Beziehung zueinander. Laut der Interpretation Aleksandr Musins greift das Konzept der Leipziger Gedächtniskirche eine althergebrachte, mittelalterliche Tradition des kirchlichen Gedenkens an die im Krieg Gefallenen auf. ${ }^{18}$ Zeitgleich bezog man sich auf die zeitgenössische, im 19. Jahrhundert entstandene Tradition der Errichtung von Gedächtniskirchen. Das bekannteste Beispiel ist die Christus-Erlöser-Kathe-

18 Musin, Aleksandr: Chram-pamjatnik v Leipcige v kontekste zerkovnoj tradicii uvekovečenija voinskoj pamjati [Gedächtniskirche in Leipzig im Kontext der kirchlichen Tradition der Kommemorierung des Militärgedächtnisses]. In: Russkij chram-pamjatnik v Lejpcige (wie Anm. 3), S. 181-228. 
drale in Moskau, die in Erinnerung an den Sieg über Napoleon und zum Gedenken an die gefallenen russischen Soldaten entstanden war. Die nach einer Idee des Zaren Alexander I. und dem Entwurf von Konstantin Ton gebaute und 1882 geweihte Kirche war 1931 gesprengt und von 1995 bis 1999 wieder aufgebaut worden. Sie dient heute als Kathedrale. Die rekonstruierten Reliefs an den Außenseiten sind einzelnen Schlachten gegen Napoleon gewidmet, u.a. auch der Schlacht bei Leipzig.

\section{Baugeschichte}

Die Russische Gedächtniskirche in Leipzig ist innerhalb eines extrem kurzen Zeitraumes errichtet worden. Als die Wände bereits 30 Meter hoch waren, erfolgte am 28. Dezember 1912 die Grundsteinlegung, und im September 1913 war der Bau, wie im zitierten Brief Dodels konstatiert wurde, in seinen Grundzügen bereits fertiggestellt. ${ }^{19}$ Aus der kurzen Bauzeit resultierten nicht zuletzt einige technische Mängel, die schon bald nach der Fertigstellung augenfällig waren und nach mehreren Renovierungen und Sanierungen verlangten. Im Jahre 1923 war die erste Renovierung nötig, weitere Sanierungen sind 1945, 1963, 1981, 1978, 1988 sowie 2013-2014 (also jeweils zu anstehenden Jubiläen) durchgeführt worden (Abb. 6).

Die Idee, ein Gotteshaus für die in Leipzig lebende russische Gemeinde zu schaffen, entstand noch 1907-1908, aber erst ab 1910 gründete sich in St. Petersburg ein Baukomitee zur Errichtung einer Gedächtniskirche oder, wie es anfangs hieß, einer Kapelle in Leipzig..$^{20}$ Den Ehrenvorsitz hatte der Bruder des Zaren, Großfürst Michail Aleksandrovič, Vorsitzende waren die jeweiligen, im Vorfeld des Kriegs rasch wechselnden, Generalstabchefs, da sich die Leipziger Kirche unter der Obhut des Verteidigungsministeriums befand. Zudem bestand das Komitee aus weiteren hochrangigen Vertretern des Militärs, der führenden politischen Elite und den Vertretern der russischorthodoxen Kirche sowie aus zwei Architekten - Leontij Benois und Vladimir Pokrovskij. In Leipzig vertrat das Komitee der Vorsitzende der Handelskammer, Rauchwarenhändler Friedrich Wilhelm Dodel. Dank seiner russischen Frau verfügte er über gute persönliche und geschäftliche Kontakte nach Russland. Bis zu seiner Ausreise in die USA in den 1920er Jahren war er als der alleinige Repräsentant des (seit der Revolution von 1917 nicht mehr existierenden) Komitees für den Erhalt der Kirche zuständig. Als Schatzmeister war Ivan P. Leljanov ernannt worden. Der im Archiv der Gedächtniskirche aufbewahrte Briefwechsel von „Friedrich Vladimirovič“ Dodel und Ivan Pavlovič Leljanov sowie Briefe an und von Pokrovskij bieten faszinierende Einblicke in viele

19 Zur Baugeschichte und Komitee: Stadtarchiv Leipzig, Kap. 42-0 Nr. 2: Akten die Russische Kirche betreffend, Bd. 1, 3-5; 16; Stadt Leipzig, Bauordnungsamt. Akten des Rats der Stadt Leipzig in Baupolizeifragen, 1907-1971; Akten über das Grundstück Philipp-Rosenthal-Str. 51 a, mit Bauplänen, Bd. I-III, 1907-1995. S. dazu: Mai/Flemming (wie Anm. 6), S. 4-9.

20 GAVRILov: Iz istorii sozdanija chrama-pamjatnika (wie Anm. 7), S. 64-75. 
Abb. 6 Restaurierung des Kuppelkreuzes der Gedächtniskirche. Foto: Marina Dmitrieva, 2013.

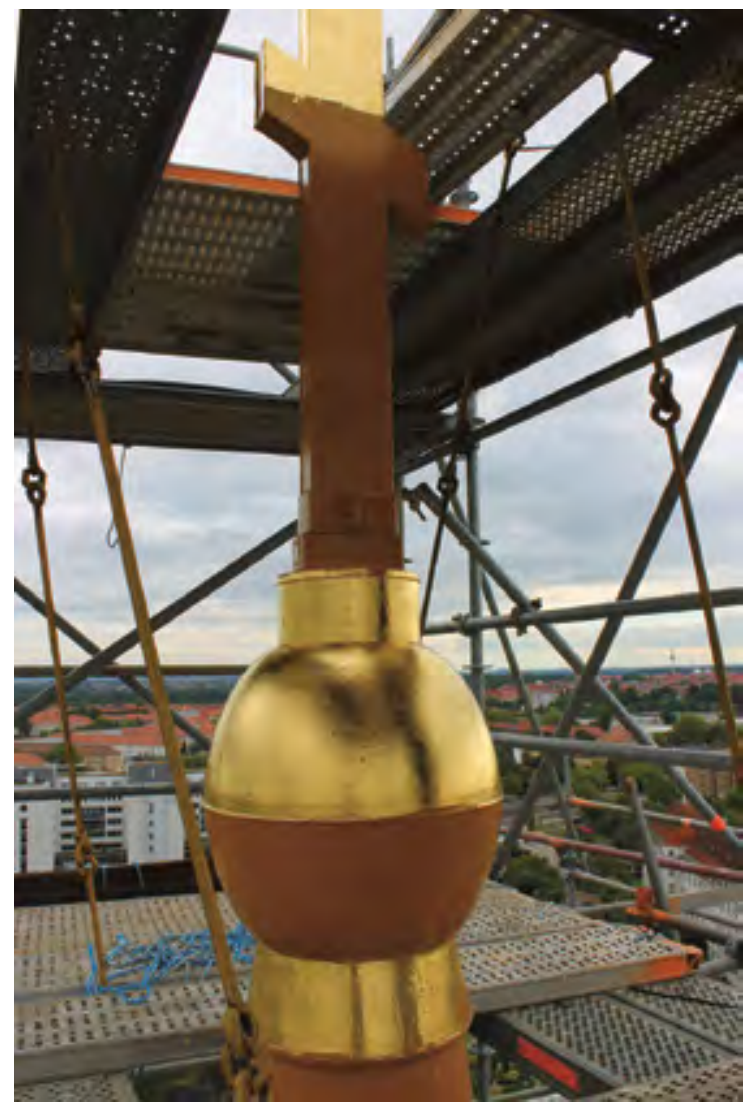

Details der Planung und Realisierung des Projekts, mit allen persönlichen Emotionen, Missverständnissen und zahlreichen zu lösenden Problemen.

Wie russische Archivdokumente belegen, ging die Initiative, in Leipzig eine Gedächtniskirche zu Ehren der russischen Gefallenen zu errichten, auf die adlige Großgrundbesitzerin Ol'ga Petrovna Dmitrieva aus Südrussland zurück. Während ihrer Reisen durch Deutschland besuchte sie Leipzig und konnte beobachten, mit wie viel Aufwand und Engagement der Plan zur Realisierung des Völkerschlachtdenkmals voranschritt. So verlangte sie ebenfalls vehement nach einem Mahnmal, welches der Rolle der russischen Armee bei diesem historischen Ereignis gerecht werden könne. Das Unternehmen sollte, ähnlich wie bereits das Völkerschlachtdenkmal, durch Spenden finanziert werden.

Der Beschluss des Komitees, „,eine Gedächtniskirche am Schlachtfeld zu errichten, bescheidener Größe, aber in ihrer Schönheit und Proportionen der Würde Russlands und Bedeutung der russischen Architektur entsprechend“, kam am 5. März 1911.21 Vladimir Pokrovskij war aufgefordert, drei Skizzen vorzulegen, von denen der Zar

21 Ebd., S. 65. 


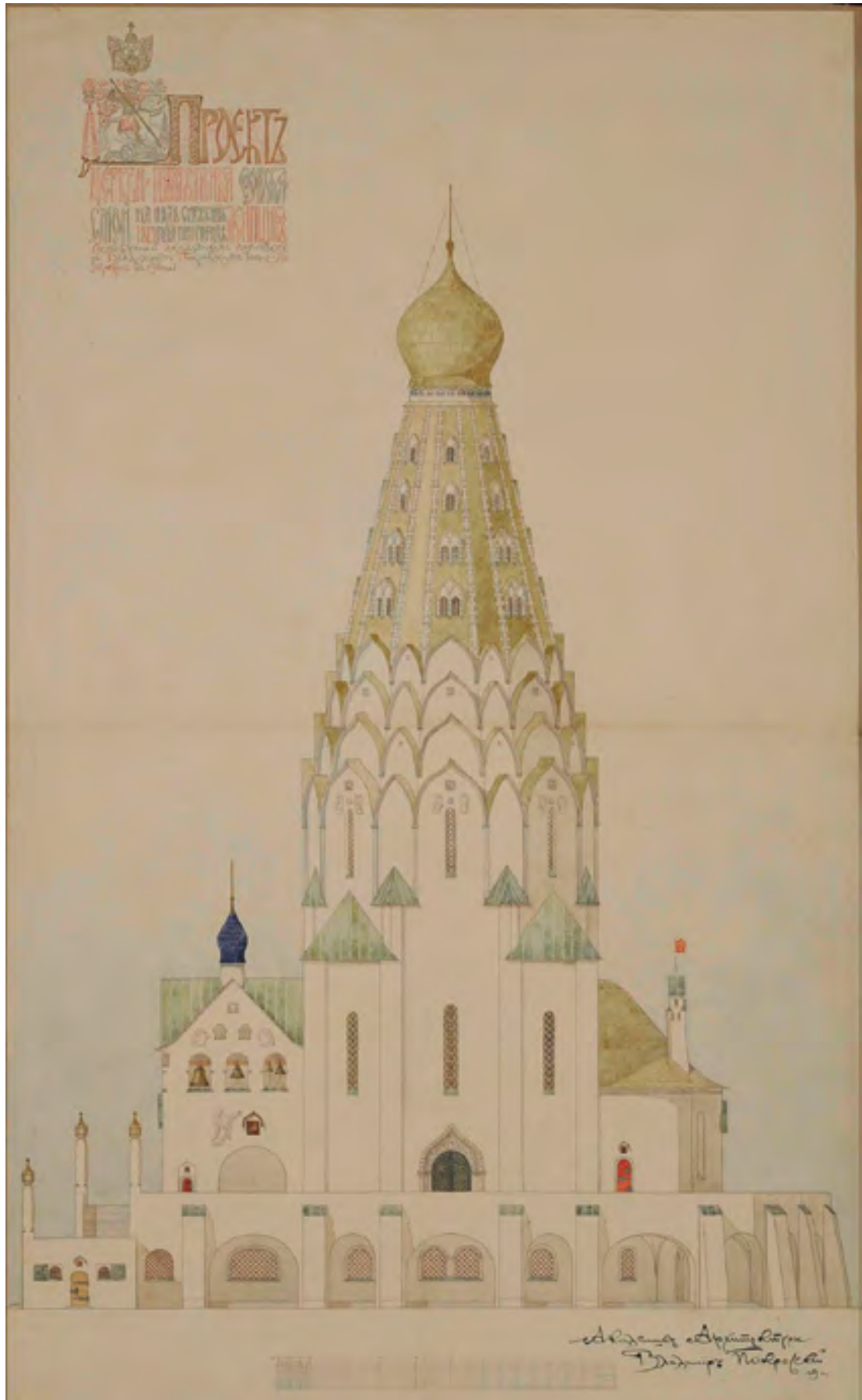

Abb. 7 Skizze der Südseite der Gedächtniskirche in Leipzig. Ursprüngliches Projekt von Vladimir Pokrovskij, 1911. Staatliches Architekturmuseum Moskau. 


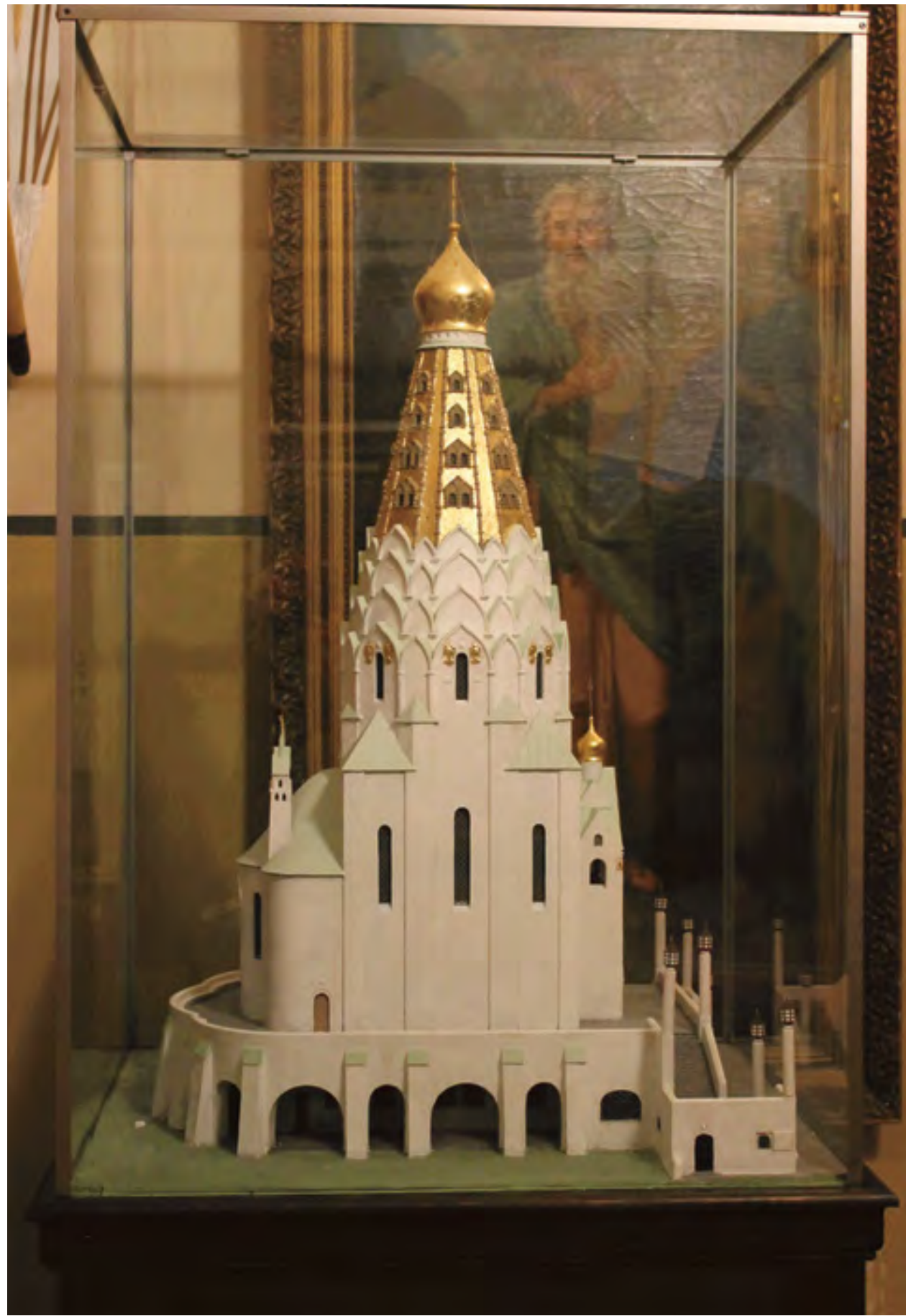

Abb. 8 Modell der Gedächtniskirche. Vorhalle der HI.-Aleksij-Kirche. Foto: Marina Dmitrieva, 2013. 
persönlich am 5. Juni einen an die Christi Himmelfahrtskirche in Kolomenskoe angelehnten Entwurf auswählte. Durch den Beschluss der Leipziger Stadtverordneten vom 6. September 1911 wurde daraufhin ein Grundstück im Gesamtwert von ca. 25.000 Mark kostenfrei zur Verfügung gestellt, gepaart mit der Auflage einer kontinuierlichen zweckmäßigen Nutzung als Kirche für nicht weniger als fünf Jahre. Betont wurde, dass die neue Kirche „eine Ergänzung des uns am Herz liegenden Völkerschlachtdenkmals und eine erwünschte Bereicherung der Silhouette unserer Stadt" darstelle. ${ }^{22}$

Mit dem Bau wurde die Leipziger Architekturfirma Weidenbach und Tschammer beauftragt. Allerdings erwies sich die von ihr erstellte Kalkulation von 980.000 Mark als zu teuer. Nach einer Reise von Weidenbach nach St. Petersburg im Februar 1912 und dortiger Abstimmung mit Pokrovskij wurde daraufhin ein neues Projekt vereinbart. Der Bau wurde günstiger, aber auch entschieden kleiner und kompakter in der Form und wirkte durch die Betonung der Vertikalen etwas ,westlicher" als der ursprüngliche Entwurf mit seinen stämmigen Formen (Abb. 7-8). Der äußere Durchmesser betrug 12,50 Meter (früher 17,50 Meter) und die Höhe 55 Meter (statt 65 Meter). Außerdem entfielen die geplanten Seitenportale, und die Narthex ist kürzer und somit enger an den Körper der Kirche angelehnt als ursprünglich vorgesehen. Eine wichtige Ergänzung bestand zudem in der modernen Eisenbetonkonstruktion des sehr komplizierten Zeltdaches, die von der Leipziger Firma Otto Enke (Eisenbetonbau) ausgeführt wurde. Nach den Plänen Pokrovskijs bestand das Dach aus 16 Bahnen, von außen durchzogen mit Streifen aus Sandstein, und dekoriert durch übereinander gereihte Arkaden (Kokoschniki) und Goldmosaik.

Die Mittel für den Bau der Gedächtniskirche sollten durch Kollekten in russischen Gemeinden und Spenden von Einzelpersonen erwirtschaftet werden. Zusätzlich beschloss die Duma, das „Bauprojekt der Gedächtniskirche am Grab der gefallenen russischen Soldaten" mit 120.000 Rubel zu unterstützen, weil die Spenden allein nicht ausreichend waren. Als Begründung wurde die offizielle Notwendigkeit postuliert, die „entscheidende Rolle Russlands bei der Befreiung der Völker Europas“ zu betonen, welche ansonsten der Vergessenheit anheimzufallen drohe. ${ }^{23}$

\section{Feierlichkeiten und Diplomatie}

Die Grundsteinlegung am 28. Dezember 1912 wurde zugleich zu einem wichtigen diplomatischen Ereignis. In der Leipziger „Illustrirten Zeitung“ beschrieb Dr. Ludwig Stettenheim die auf ihn exotisch wirkenden Gewänder der orthodoxen Priesterschaft und „stattliche Gestalten russischer Offiziere in ihren Uniformen““. ${ }^{24}$ Anwesend waren alle drei Architekten, Vertreter des Baukomitees und Kriegsminister Vladimir A.

22 Stadtarchiv Leipzig (wie Anm. 19), Kap. 42-0 Nr. 2, 16.

23 GAVRILov: Iz istorii sozdanija chrama-pamjatnika (wie Anm. 7), S. 67-69.

24 Stettenheim, Ludwig: Die Russische Gedächtniskirche in Leipzig. In: Illustrirte Zeitung, Nr. 3627, 2.01.1913, S. 15. 
Suchomlinov. Das „Leipziger Tageblatt“ berichtete am 30. Dezember, „dass Rußland eine aufrichtige Gesinnung gegenüber Deutschland hege ... und dass es sein herzlicher Wunsch sei, den Frieden dauernd zu erhalten “ ${ }^{25}$ Die später im Exil aufgezeichneten Erinnerungen Suchomlinovs halten ebenfalls diesen feierlichen Moment fest. Für ihn waren es „die letzten Minuten der Diplomatie“. Noch bestünde eine Hoffnung, „die Katastrophe zu vermeiden.“ Allerdings sei ihm bei diesem Besuch im Leipzig des ausgehenden Jahres 1912 klar geworden, dass eine Konfrontation mit der Habsburgermonarchie möglich sei und dass Deutschland folglich „die Seite der Habsburger einnehmen“" würde“. ${ }^{26}$ Es sei eine „scheinbare Bruderschaft" (mnimoe bratanie), die in Leipzig demonstriert werde. Ab März 1913, also noch vor den großen Feierlichkeiten zur Einweihung beider Leipziger Denkmäler, begannen in Russland, wie Suchomlinov schrieb, die Vorbereitungen für die Kriegsmobilisierung.

Diese angespannte Stimmung und schwierige Allianzen waren vermutlich der Grund für die schwache russische Präsenz bei den Leipziger Feierlichkeiten im Oktober 1913. Der Zar verbrachte diese Zeit des Jahres in seiner Residenz Livadia auf der Krim. Auch der Großfürst Michail Aleksandrovič, der als Vorsitzender des Baukomitees anwesend sein sollte, erschien nicht. Vertreten war der Zar durch seinen Cousin, Kyrill Vladimirovič (1876-1938), Abb. 9). Obgleich ein Held des Russisch-Japanischen Krieges (er überlebte einen Schiffsbruch infolge der Seeschlacht bei Tsushima), geriet Kyrill durch eine nicht standesgemäße Heirat innerhalb der Zarenfamilie in eine Abseitsposition. Gleichwohl wurde er als legitimer Vertreter der Familie nach der Oktoberrevolution Oberhaupt des Hauses Romanov. Kriegsminister Suchomlinov nahm an den Feierlichkeiten im Oktober 1913 nicht mehr teil - vertreten wurde er durch den Chef des Generalstabs und hohe Offiziere.

Zusammenfassend stellt sich somit die Frage, warum die Gedächtniskirche so plötzlich die Bedeutung für die russische Diplomatie und Geschichtspolitik verlor, die ihr noch kurz zuvor beigemessen worden war. Die Zusammensetzung des Baukomitees wie auch die Unterstützung der Duma sowie die Wahl eines renommierten Architekten sprachen für den hohen Stellenwert dieses Projekts innerhalb der offiziellen monarchischen Erinnerungspolitik. Auch die vom Zar persönlich bestimmte Form sowie das Patrozinium sind bedeutsam. Die Christi Himmelfahrtskirche in Kolomenskoe, den Prototypus der Leipziger Kirche, ließ der Moskauer Großfürst Vasilij III. zu Ehren der Geburt seines Erben, des zukünftigen Zaren Ivan des Schrecklichen, von einem italienischen Architekten als repräsentatives Werk der damaligen Architektur erbauen. Auf der Rückseite der Kirche, in dem erhöhten Kreuzgang, welcher zugleich als Aussichts-

25 Leipziger Tageblatt, 30.12.1913.

26 Vospominanija generala Suchomlinova [Erinnerungen des Generals Suchomlinov]. Berlin 1924. In: http://dugward.ru/library/xxvek/suhomlinov_vospom.html (27.12.2015). Vladimir Aleksandrovič Suchomlinov (1848-1926) wurde im Jahre 1909 zum Kriegsminister ernannt. Nach ersten Niederlagen im Ersten Weltkrieg, die er unter Verweis auf die Unfähigkeit der Vertreter des Zarenhauses in Militärangelegenheiten zurückwies, wurde er der Spionage beschuldigt, abgesetzt und verhaftet. Später folgten der Freispruch und das Exil. 
plattform am hohen Ufer des Moskva-Flusses diente, befindet sich ein reichlich mit italienischer Ornamentik verzierter Thron.

Geistiger Patron der Leipziger Kirche war der hl. Aleksij, der Metropolit von Moskau und eine bedeutende historische Figur in der Geschichte der russischen Staatlichkeit. ${ }^{27}$ Und dieses Patrozinium war von besonderer Bedeutung. Wie der Schatzmeister des Komitees, Leljanov, an Dodel schrieb: „Die Kirche wird im Namen des Moskauer Metropoliten Hl. Alexij geweiht". Und in der Fußnote: „Zu Ehren unseren Thronfolgers “ (Hervorhebung: MD). ${ }^{28}$ Am 5. (18. Oktober), am letzten Tag der Schlacht, war der Tag des hl. Aleksij und zugleich Namenstag (russ. tesoimenitstvo) des Zarevič. Beide Feiertage wurden im Rahmen der Einweihung der Kirche zelebriert.

Das Programm der Feierlichkeiten wurde im Vorfeld detailliert durchgeplant. Nach langer Abstimmung mit dem Komitee schrieb am 27./14. August 1913 Leljanov an Dodel:

3/16 Oktober am Tage. Überführung der Überreste der Russischen Generale und Offiziere aus dem Bruder-Grabe in die Gruft der Gedächtniskirche. Um 6 abends Nachtliturgie.

4/17 Oktober. Einweihung der Kirche und Liturgie.

5/18. Liturgie und Zarengebet anlässlich des Namenstages der Kaiserlichen Hoheit des Thronfolgers Zessarewitsch Alexis Nikolajewitsch.

Anzug - bei der Überführung und Liturgie gewöhnlich, bei den übrigen Gottesdiensten - Gala. ${ }^{29}$

Das Tedeum erfolgte am 18. Oktober in Anwesenheit des Kaisers, des sächsischen Königs und des österreichischen Kronprinzen Franz Ferdinand (Abb. 10). Die Festgottesdienste waren begleitet vom Synodalchor unter Leitung des berühmten Protodiakons Konstantin Rosov, dessen gewaltige Bassstimme bei Wilhelm II. einen bleibenden Eindruck hinterlassen haben sollte. ${ }^{30}$

Diese Events sind aufgrund des Einsatzes neuer Medien, der Fotografie und des Films, hervorragend dokumentiert und einschlägige Postkarten vom Leipziger Hoffotografen Ernst Hoenisch vervielfältigt worden. Ein prächtiges Album wurde seitdem in der Gedächtniskirche aufbewahrt und ein weiteres Exemplar direkt an den Zaren geschickt. Trotz dieser, nicht zuletzt als diplomatische Bemühungen der deutschen Seite

27 S. LÜвKE, Christian: Svjatitel' Aleksij, mitropolit Moskovskij. Ego žizn` i trudy [Der Hl. Aleksij, Metropolit von Moskau. Sein Leben und Werk]. In: Russkij chram-pamjatnik v Lejpcige (wie Anm. 3), S. 171-180.

28 Archiv der Russischen Gedächtniskirche, Mappe 14 (Brief vom 8. Oktober/25. September 1912).

29 Archiv der Russischen Gedächtniskirche, Briefwechsel von Dodel und Leljanov, Mappe 15 (Brief von Leljanov, am 27./14. August 1913).

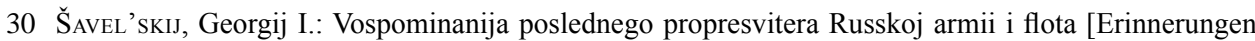
des letzten Protopresbyter der Russischen Armee und Flotte]. New York 1954. In: http://militera.lib. ru/memo/russian/shavelsky (23.12.2015). 

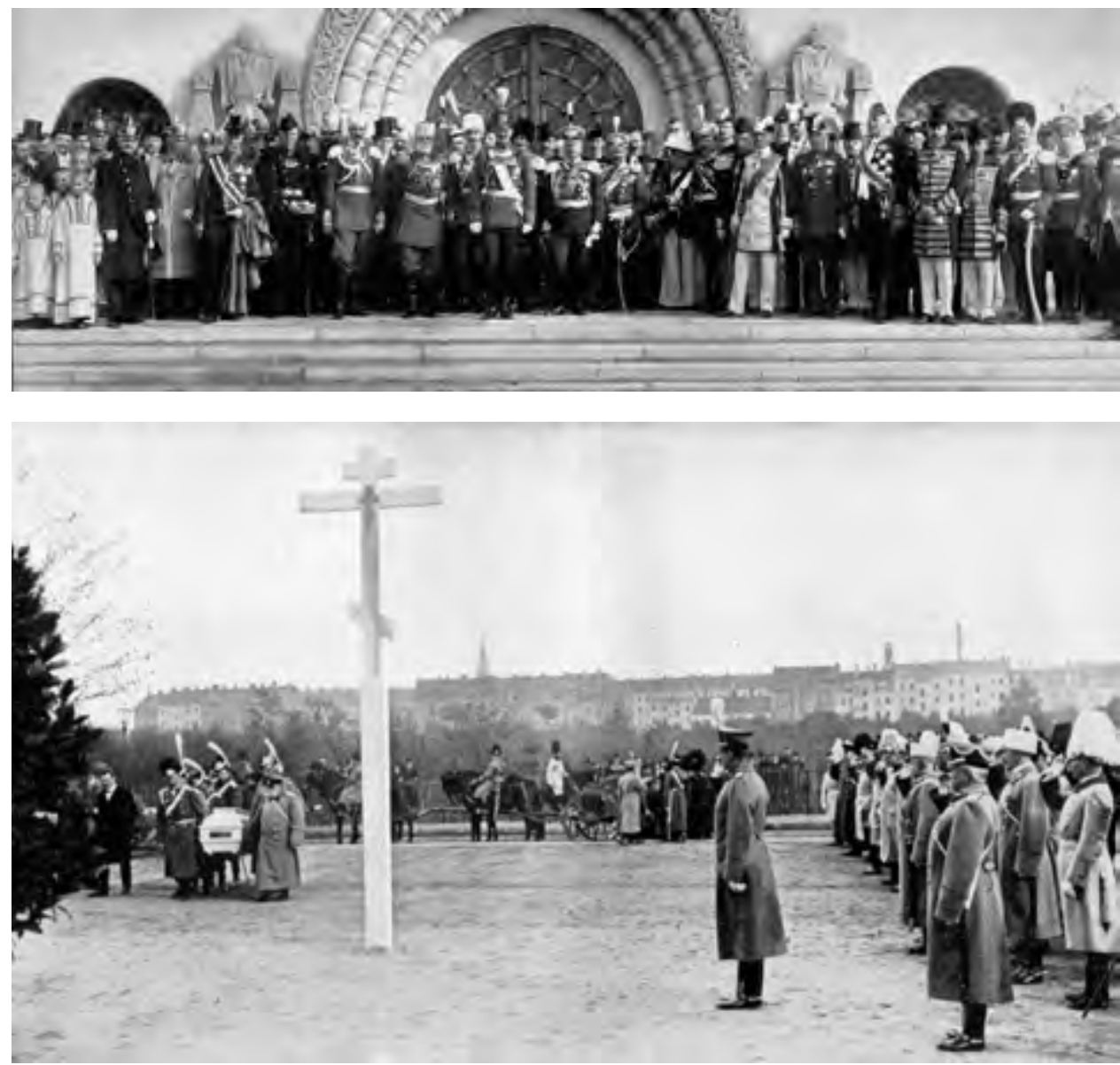

Abb. 9 Feierliche Zeremonien am 16. (unten) und am 17. Oktober. In der Mitte der Großfürst Kyrill Vladimirović. Illustrirte Zeitung, 23. Oktober 1913.

zu interpretierenden Aktivitäten blieb die Stimmung zwischen den beiden Großmächten angespannt.

Die Memoiren des Erzpriesters der Russisch-Imperialen Armee und Flotte, Georgij Šavel'skij, verfasst im New Yorker Exil, vermitteln einen umfassenden Eindruck sowohl von der zeitgenössischen Architektur der Kirche als auch von den zwiespältigen Eindrücken der russischen Teilnehmer dieses Ereignisses:

Frühmorgens, am 18. Oktober, fingen die Leipziger Feierlichkeiten an. Nie werde ich diesen 18. Oktober vergessen. Da ich lange vor dem Beginn des Gottesdienstes gekommen war, konnte ich von der hohen Vorhalle der Kirche eine Beobachtungsposition einnehmen: Die Kirche besteht aus zwei Stockwerken, dabei ist die Fläche des unteren Stocks viel größer als die des oberen. Unten ist die Grabeskapelle, oben - die Kirche. Die Kirche steht also wie auf einem Sockel, und der nicht von der Kirche besetzte Teil dieses Sockels bildet eine offene Vorhalle und einen Rundgang 


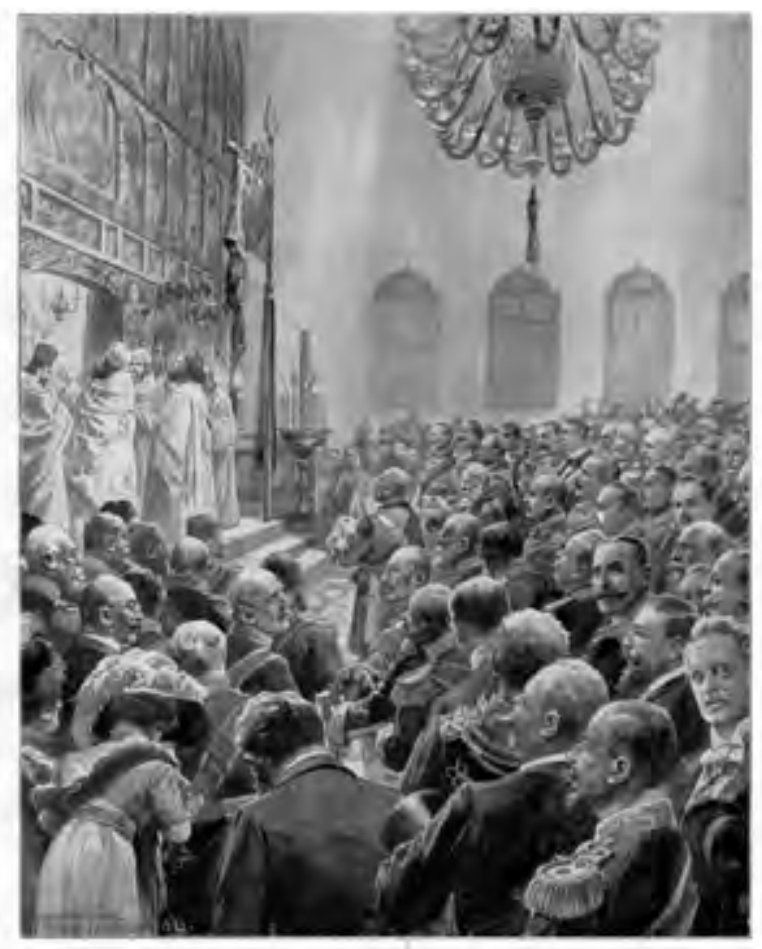

Abb. 10 Tedeum in der Russischen Gedächtniskirche (nach einer Originalzeichnung von Hans B. Schmidt, Weimar). Illustrirte Zeitung,

23. Oktober 1913.

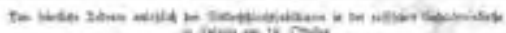

ain - to cost

t-

für Kreuzgänge. Ich beobachtete das unendlich lange, bunte, wie ein vielfarbiger Teppich und wie im Kinematografen sich dauernd veränderte Streifen der vorbeiziehenden Armeeeinheiten, Prozessionen und verschiedenen Organisationen. Es marschierten die Armeeeinheiten: Kavallerie, Infanterie und Artillerie. Danach zogen Studenten vorbei. Sie waren nach Verbindungen eingeteilt, mit Fahnen und Abzeichen, jede Verbindung in eigener Uniform - schön, manchmal zu gekünstelt. Die Studenten bewegten sich in geordneten Reihen, wie gut abgerichtete Regimenter. Die Ordnung wurde nirgendwo und nie verletzt. Das Volk folgte wohlgesittet am Rande des Weges, bildend eine Umrahmung des schönen, prachtvollen Streifens der Armeeeinheiten und Studentenverbindungen. [...]

Mein Herz blieb kurz stehen: Das ist Deutschland! Geordnet, zusammen gerückt, diszipliniert, patriotisch! [...]

Und bei uns reden alle vom Kampf gegen dieses Land ... Wie schwer ist es für uns - den Vereinzelten, durch Propaganda auseinander gebrachten - mit ihm zu wetteifern. Dieser Gedanke verfestigte sich in mir, je länger ich den Fortgang der Feierlichkeiten beobachtete. ${ }^{31}$

31 Ebd. 
Wie für den Kriegsminister Suchomlinov einige Monate davor, blieben die Leipziger Feierlichkeiten für Šavel'skij ein „unvergessliches Ereignis“: Es war vielleicht die letzte symbolische Repräsentation der alten Ordnung einer „Heiligen Allianz“, die nach dem Sieg über Napoleon in Leipzig und Europa etabliert worden war. Aber für die russische Seite waren die geteilten Erinnerungen an den gemeinsamen Sieg bereits durch die Vorahnung der kommenden Katastrophe getrübt, bei der die ehemaligen Verbündeten zu Feinden werden sollten.

\section{"Ein würdiges Seitenstück“}

Schon bei der Planung hatten die Stadtverordneten die Nähe und Korrespondenz der neuen Kirche zum schon fast fertigen deutschen Monument gesucht und beachtet. Es sollte „eine Ergänzung des uns am Herzen liegenden Völkerschlachtdenkmals“ werden. ${ }^{32}$ Als ein „würdiges Seitenstück“ des Denkmals ist es in der zeitgenössischen Presse verortet worden. ${ }^{33}$ Auch die „,charakteristische Denkmalsform“ der Kirche wurde in diesem Zusammenhang betont. ${ }^{34}$ Zugleich schienen auch die Unterschiede gravierend: Die Größe, das Material (der „,vaterländische“ Granit und der als „russisch" konnotierte, weiß getünchte Backstein), aber vor allem die Funktion unterschieden die beiden Denkmäler. Im Kontrast zu anderen Denkmälern der Schlacht war die Gedächtniskirche ein sakraler und kein profaner Bau. Ihr fehlte das monumentale nationale Pathos, das im Völkerschlachtdenkmal so dominierend ist. ${ }^{35}$ Als ein sakraler Bau sollte die Gedächtniskirche einen Anspruch auf die würdige Memorierung aller in der Leipziger Schlacht gefallenen Soldaten erhalten - nicht nur der Russen, sondern auch der Vertreter anderer Nationalitäten des Russischen Reiches, die in der Schlacht von Leipzig gekämpft haben. Trotz betonten Wohlwollens angesichts eines russischen Denkmals wurde jedoch in der öffentlichen Wahrnehmung nicht selten sein - obwohl „imposanter“ - doch „eigenartiger“ Charakter hervorgehoben. ${ }^{36}$

Ein wichtiger Kompromiss im deutsch-russischen Erinnerungskonflikt wurde in der DDR ab den 1960er Jahren gefunden. ${ }^{37}$ Dort wurde die Russische Gedächtniskirche zunehmend zu einer „Brücke zwischen den Völkern“ uminterpretiert - ganz ähnlich wie das Völkerschlachtdenkmal, welches noch lange Zeit mit dem Manko des Militarismus und des monumentalen Geschmacks der Wilhelminischen Epoche behaftet blieb. Der DDR galt das Denkmal als Zeichen des Bemühens um eine Wiederherstellung des deutschen Nationalstaates, der nun als sozialistischer Nationalstaat definiert wurde.

32 Illustrirte Zeitung (wie Anm. 2), S. 720.

33 Stadtarchiv Leipzig (wie Anm. 19).

34 Illustrirte Zeitung (wie Anm. 24), S. 15.

35 Zur nationalen Bedeutung des Völkerschlachtdenkmals vgl. den Beitrag von Thomas Topfstedt in diesem Band.

36 Illustrirte Zeitung (wie Anm. 2).

37 Bauordnungsamt Leipzig (wie Anm. 19). 
Zunehmend sollte das Memorial an die Befreiungskriege als Erinnerungsort des vorgeblich seit 1813 bestehenden deutsch-russischen Freundschaftsverhältnisses dienen, dessen Kern bald als „deutsch-sowjetische Waffenbrüderschaft" beschrieben wurde, ebenso wie die benachbarte Russische Gedächtniskirche. Kurz vor dem Zusammenbruch der DDR, im Jahr 1989, hieß es noch, dass ,die Russische Kirche das Gesicht der Messestadt unverwechselhaft prägt. Sie ist als völkerverbindende Stätte ein Denkmal unserer Heimat, das es zu bewahren gilt“ “ ${ }^{38}$ Die letzte, von der Stadt Leipzig betriebene Sanierung der Gedächtniskirche wurde vonseiten der Regierung der Russländischen Föderation mit 250.000 Euro (bei einem Gesamtbetrag von insgesamt mehr als einer Million) bezuschusst. Nicht zuletzt dies könnte zugunsten einer Fortsetzung dieser Tradition sprechen.

So stellt die Russische Gedächtniskirche, entworfen von einem russischen Architekten, gebaut von Leipziger Baumeistern mit Unterstützung der Stadt Leipzig und vielen Spenden, aufgrund ihrer 100-jährigen Geschichte ein sowohl vertrautes als auch exotisches Artefakt gemeinsamer deutsch-russischer Erinnerungskulturen dar. Vielleicht ist es gerade dadurch ein würdiges Denkmal des ersten gesamteuropäischen militärischen Großereignisses - der Völkerschlacht bei Leipzig. In ihrer harmonischen Gestalt und wechselhaften Geschichte verkörpert sie eine sowohl geteilte und versöhnende als auch kontroverse und störende Erinnerung an Kriegsgeschehnisse und Regimewechsel.

38 Die Union/Leipzig, 1.9.1989, S. 6 (Sammlung H. Mai). 


\title{
Die österreichischen Denkmale um Leipzig zum Gedenken an die Völkerschlacht
}

\author{
Christian Forster
}

Am 18. Oktober 1913 verließ Erzherzog Franz Ferdinand die Einweihungsfeier des Leipziger Völkerschlachtdenkmals vorzeitig, um an einer österreich-ungarischen Zeremonie am Schwarzenberg-Denkmal teilzunehmen. Den Programmpunkt „Besichtigung der Krypta durch die Fürstlichkeiten" ließ er aus, um die von ihm organisierte Gedenkstunde an jenem Monument in Leipzig-Meusdorf zu leiten, das dem Andenken an den Oberkommandierenden der Verbündeten Armeen, Karl Philipp Fürst zu Schwarzenberg, im Jahre 1838 von seiner Familie gestiftet worden war (Abb. 1). Am frühen Morgen des 18. Oktober hatte er eine Ehrenwache zum Denkmal befohlen, die aus einem Wachtmeister und vier Ulanen des k. k. Ulanen-Regiments Nr. 2 bestand, eines Regiments, das den Namen „Fürst zu Schwarzenberg“ trug. Um Viertel nach 12 Uhr traf der österreichische Thronfolger selbst in Begleitung des sächsischen Kriegsministers, des Leipziger Oberbürgermeisters Rudolf Dittrich und des Prinzregenten von Bayern ein. Mit ihnen hatten sich Vertreter der Familien der an der Völkerschlacht beteiligten Offiziere eingefunden, darunter Generalstabschef Franz Conrad von Hötzendorf und Fürst Karl V. zu Schwarzenberg. Das Gefolge, das Franz Ferdinand nach Leipzig begleitete, umfasste 44 Personen. Zudem war am Schwarzenberg-Denkmal eine kleine Abordnung des Vereins nichtaktiver österreichisch-ungarischer Offiziere im Königreich Sachsen erschienen. Auf dem weitläufigen Gelände des Meusdorfer Vergnügungsparks, auf dem das Denkmal steht, hatte sich eine Menschenmenge versammelt, um der Gedenkfeier beizuwohnen. ${ }^{1}$

Nachdem auch Kaiser Wilhelm II. in Begleitung des Königs von Sachsen und des Königs von Württemberg eingetroffen war, hielt der junge Schwarzenberg eine kurze Rede. Die Kranzniederlegung durch Franz Ferdinand begleitete eine Militärkapelle mit der österreichischen Volkshymne. „Dann legte auch Kaiser Wilhelm einen Kranz nieder und ließ sich vom Erzherzog die Mitglieder der Familie Schwarzenberg vorstellen, mit denen er sich einige Minuten unterhielt. Dann [...] drückte er jedem der Generäle die Hand. Dann war die Feier zuende" und alle fuhren ab, um am Tedeum in der Russischen Gedächtniskirche teilzunehmen (Abb. 2). ${ }^{2}$

Franz Ferdinand hatte auf dieser gesonderten Veranstaltung bestanden, und die Stadt Leipzig, die zuerst wegen des personellen Aufwands an Polizei zögerte, hatte sie schließlich ermöglicht. Aus den Akten der deutschen Behörden geht hervor, dass der Thron-

1 Leipziger Neueste Nachrichten, 19.10.1913, S. 14; Neues Wiener Tagblatt, 20.10.1913, S. 10.

2 Leipziger Tageblatt, 18.10.1913, S. 2. Allgemein: Poser, Steffen: Die Jahrhundertfeier der Völkerschlacht und die Einweihung des Völkerschlachtdenkmals zu Leipzig 1913. In: Feste und Feiern. Zum Wandel städtischer Festkultur in Leipzig. Hg. v. Katrin KelLeR. Leipzig 1994, S. 196-213. 


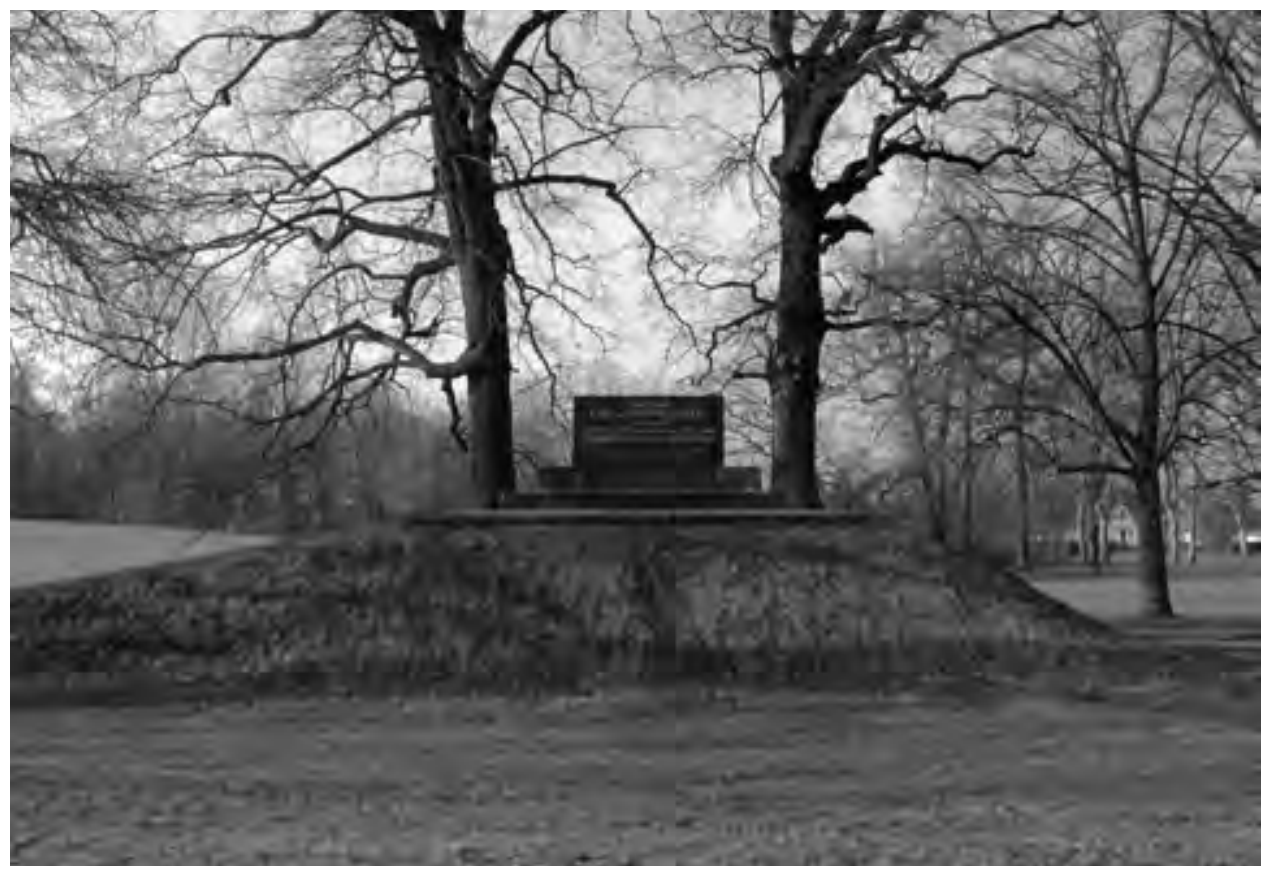

Abb. 1 Denkmal für Karl Philipp Fürst zu Schwarzenberg in Leipzig-Meusdorf. Foto: C. Forster.

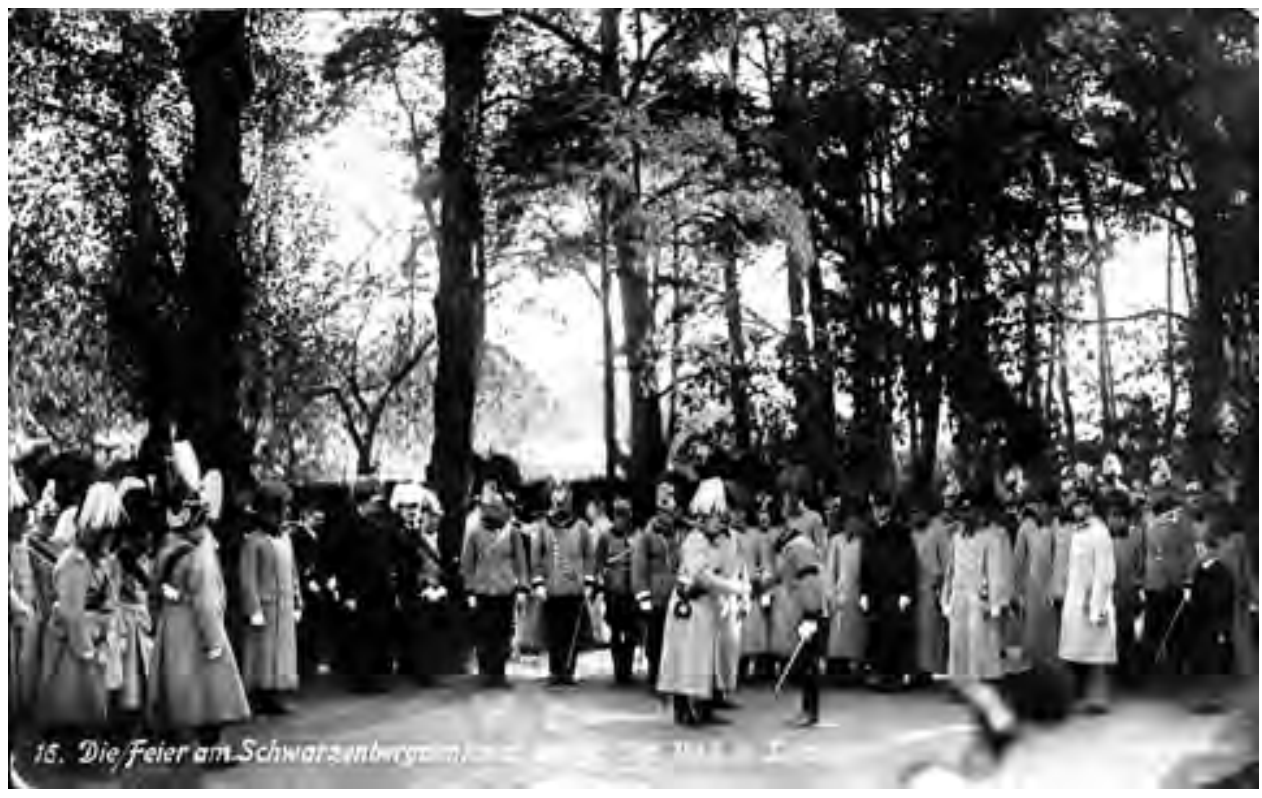

Abb. 2 Der deutsche Kaiser Wilhelm Il. begrüßt Karl Fürst zu Schwarzenberg am Schwarzenberg-Denkmal in Leipzig am 18. Oktober 1913. Foto: Österreichisches Staatsarchiv, Haus-, Hof- und Staatsarchiv. 
folger Wert darauf gelegt habe, dass ,eine österreichische Feier mit Rücksicht auf die russische Feier zustande komme“ und dass der deutsche Kaiser an ihr teilnehme. ${ }^{3}$ Just am 18. Oktober 1913 drohte der österreichische Geschäftsträger in Belgrad der serbischen Regierung mit Krieg, sollte Albanien nicht binnen acht Tagen geräumt worden sein. ${ }^{4}$ Vor dem Hintergrund eines drohenden Konflikts Österreich-Ungarns mit dem Königreich Serbien, das in die territoriale Konstitution eines albanischen Staates zu seinen Gunsten eingriff und sich dabei der Unterstützung durch Russland sicher war, schien es Franz Ferdinand notwendig, auf dem Feld symbolischer Akte nicht hinter dem Zaren zurückzubleiben und die Waffenbrüderschaft mit dem deutschen Kaiser zu untermauern. Zugleich sah sich Österreich-Ungarn ebenso wie Russland und Schweden aus dem Gedenken an die Völkerschlacht, wie es 100 Jahre nach dem Ereignis auf deutscher Seite mit der Einweihung eines gigantischen Monuments begangen wurde, ausgeschlossen. Das war absehbar gewesen. Als ,reindeutsches“ Denkmal wollte sein Initiator, zugleich Vorsitzender des Deutschen Patriotenbundes, Clemens Thieme, das Leipziger Bauwerk verstanden wissen, weshalb er es ablehnte, Geld zu seiner Errichtung unter den einstigen Verbündeten zu sammeln. ${ }^{5}$ Deren höchste Repräsentanten waren zwar zur Einweihungsfeier eingeladen worden, aber nur, so musste es ihnen vorkommen, um sich vor Ort durch Thiemes chauvinistische Rede brüskieren zu lassen. ${ }^{6}$, Thieme sprach bei der Einweihung des Völkerschlachtdenkmals stets mit sattem Behagen nur von Deutschland“, berichtete „Danzer’s Armee-Zeitung“ nach Wien, ${ }^{7}$ während die „Reichspost“" kritisierte, dass des Fürsten Schwarzenberg mit keiner Silbe gedacht worden sei und übrigens auch nicht der Russen und Schweden, um diplomatisch einzulenken, dass dies in der Rede des sächsischen Königs, der im Anschluss an Thieme sprach, nachge-

3 Protokoll einer Besprechung der Organisatoren der Einweihungsfeier des Völkerschlachtdenkmals am 3.10.1913, Staatsarchiv Leipzig, 20024 Kreishauptmannschaft Leipzig, Nr. 164, fol. 106-108.

4 Österreich-Ungarns Außenpolitik von der Bosnischen Krise 1908 bis zum Kriegsausbruch 1914. Diplomatische Aktenstücke des österreichisch-ungarischen Ministerium des Äußern. Bd. 1-9. Hg. v. Ludwig Bittner und Hans Uebersberger. Wien 1930, hier Bd. 7, S. 453, Nr. 8850, S. 464 f., Nr. 8866; Die Große Politik der Europäischen Kabinette 1871-1914. Sammlung der Diplomatischen Akten des Auswärtigen Amtes. Hg. v. Johannes Lepsius, Albrecht Mendelssohn Bartholdy und Friedrich Thimme. Bd. 1-40. Berlin 1922-1927, hier Bd. 36 (1926), S. 397 f., Nr. 14174, S. 398 f., Nr. 14176 und S. 387 f., Nr. 14161 (Anm. zu einem Gespräch Kaiser Wilhelms II. mit Conrad während des Frühstücks im Leipziger Rathaus am 18.10.1913); ConRad von HöTZEndorf, Franz: Aus meiner Dienstzeit 1906-1918. Bd. 1-5. Wien 1921-1925, hier Bd. 3 (1922), S. 469 f.

5 Poser (wie Anm. 2), S. 200 f. verweist auf den Beschluss der 69. Vorstandssitzung am 18.12.1902, Stadtarchiv Leipzig, Deutscher Patriotenbund zur Errichtung eines Völkerschlachtdenkmals bei Leipzig 1 (ehem. Kap. 35, Nr. 1775), fol. 163.

6 Rede abgedruckt in Leipziger Tageblatt, 18.10.1913, Abend-Ausgabe, S. 1.

7 Danzer's Armee-Zeitung, 23.10.1913. Vgl. auch ConRAD von Hötzendorf (wie Anm. 4), S. 469: „Aber die Veranstaltungen trugen ein ausgesprochen reichsdeutsches, ich möchte sagen, internes Gepräge. Den österreichisch-ungarischen, russischen und schwedischen Gästen schien nur die Rolle als Zuseher zugemessen zu sein [...] Der rein deutsche Charakter der Feier kam insbesondere in der Festrede zum Ausdruck, die am 18. Oktober bei der imposant inszenierten Einweihung des Denkmals gehalten wurde." 
holt worden sei. ${ }^{8}$ Tatsächlich aber hatte König Friedrich August keineswegs über den militärischen Anteil der Verbündeten im Jahre 1813 gesprochen, sondern nur dem Wunsch Ausdruck verliehen, dass das Denkmal von 1913 „späteren Geschlechtern“ erzählen möge, ,,wie in dieser Stunde Russen und Deutsche, Oesterreicher, Ungarn und Schweden ihre Knie in Verehrung beugen vor Gott, dem allmächtigen Lenker der Weltgeschichte". 9 .

Die österreichisch-ungarische Erinnerungspolitik rückte 1913 in Leipzig die Tatsache in den Vordergrund, dass ohne die Offiziere und Truppen des Habsburgerreiches Napoleon nicht geschlagen worden wäre. Dazu verfolgte man zwei Konzepte: Dem seit 1838 auf der Leipziger Flur existierenden privaten Schwarzenberg-Denkmal wurde durch den feierlichen Akt, den der Thronfolger an ihm vollzog, die Ehre höchster staatlicher Anerkennung zuteil. Darüber hinaus wurden eigens fünf neue Denkmale im weiteren Umkreis aufgestellt, die man aus militärhistorischen Erwägungen für geeignete Orte des Gedenkens hielt. Die Überlegungen, die der Standortwahl zugrunde lagen, sollen hier nachgezeichnet werden.

\section{Das Schwarzenberg-Denkmal auf dem Monarchenhügel}

Am frühen Nachmittag des 18. Oktober 1813 hatten die verbündeten Monarchen und ihr Oberbefehlshaber Schwarzenberg das Standquartier gewechselt und, mit der 2. Kolonne gegen Leipzig vorrückend, auf dem später so genannten Monarchenhügel in Meusdorf Aufstellung genommen, während Napoleon seinen Feldherrnposten weiter stadteinwärts, nahe der Quandt'schen Tabaksmühle eingerichtet hatte (Abb. 3). An diesem 18. Oktober konnten die Verbündeten die meisten um verschiedene Dörfer geführten Gefechte zu ihren Gunsten entscheiden und am kommenden Tag schließlich die mehrtägige Schlacht mit der Einnahme Leipzigs beenden. Als Schwarzenberg fast auf den Tag genau sieben Jahre später (am 15. Oktober 1820) in Leipzig verstarb, kam der Gedanke auf, ihn am Ort seines größten Triumphes beizusetzen. Besagten Ort auf dem Monarchenhügel verkaufte Major i. R. Johann Ernst von Winckler, Eigentümer des Geländes westlich der Chaussee nach Grimma, das zum Vorwerk Meusdorf und damit zum Rittergut Dölitz gehörte, der Familie Schwarzenberg am 17. Oktober $1820 .{ }^{10}$ Dann war aus dem Testament des Verstorbenen bekannt geworden, dass er in seinem Schloss in Worlik (Orlík nad Vltavou) begraben sein wolle. Daher wurde der Leichnam des Feldherrn am 19. Oktober zur Einsegnung nach Prag gebracht und

8 Reichspost (Wien), 20.10.1913.

9 Leipziger Tageblatt, Nr. 531, 18.10.1913, Abend-Ausgabe, S. 1.

10 Zit. bei Rainold, Karl Eduard: Denkmal dem großen Helden unsrer Zeit [...]. Prag 1820, S. 29. Erwähnt im Situationsplan Staatsarchiv Leipzig, 20024 Kreishauptmannschaft Leipzig, Nr. 164, fol. $35 / 2$ (,Kaufvertrag vom 17. Oktober $1820^{\circ)}$ ); nicht erhalten in der Sammlung von Kaufverträgen 1640-nach 1835, Staatsarchiv Leipzig, 20373 Rittergut Dölitz, Nr. 110. 


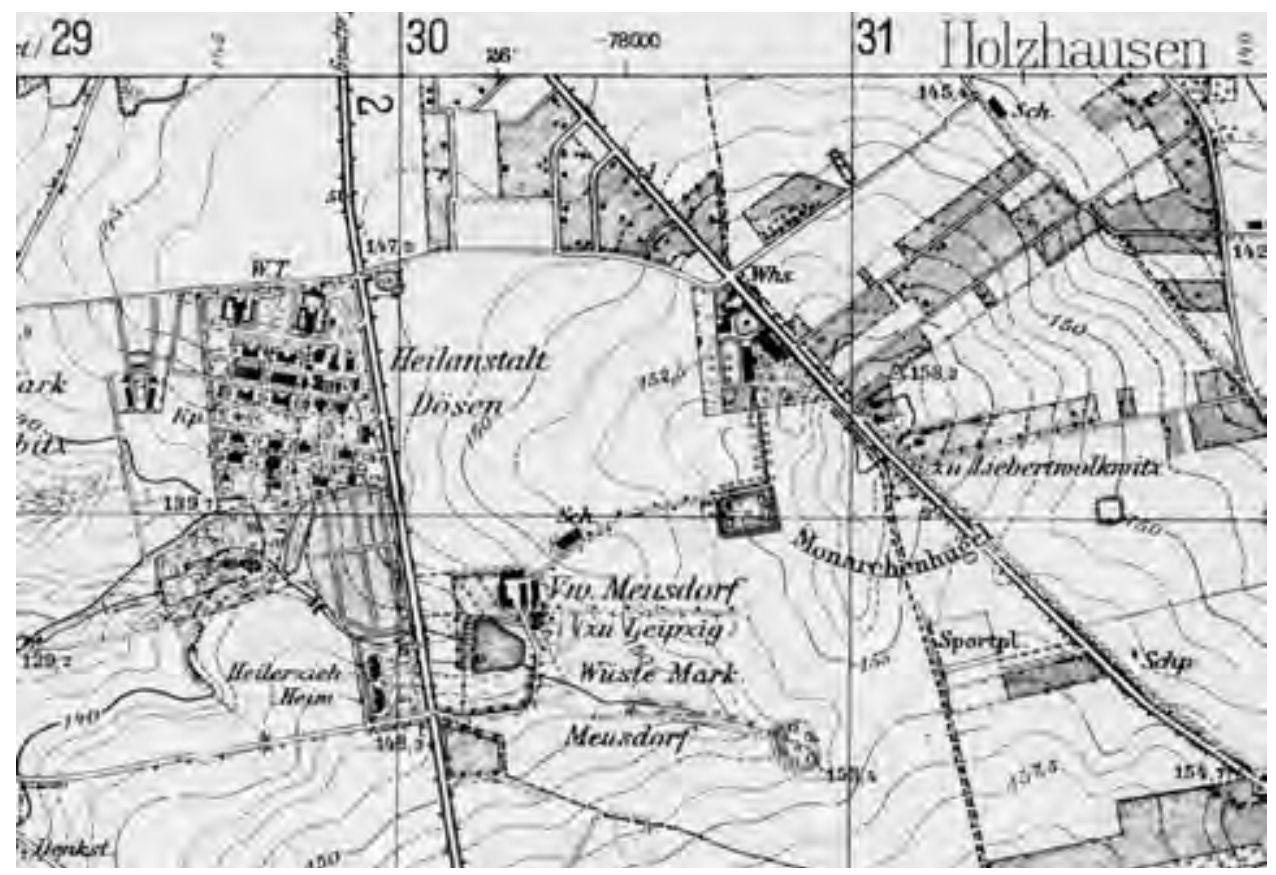

Abb. 3 Messtischblatt Liebertwolkwitz, Kartenausschnitt Monarchenhügel. Foto: GWZO.

schließlich nach Wittingau (Třeboň) in die Grablege der Primogenitur überführt. ${ }^{11}$ Der Bau einer Familiengruft für die von Karl Philipp zu Schwarzenberg begründete Sekundogenitur im Schlosspark zu Worlik verzögerte sich bis 1861/64. ${ }^{12}$ Erst im Januar 1865 konnte der testamentarischen Fügung des Fürsten entsprochen werden. ${ }^{13}$

Das 25 Jahre nach dem Sieg über Napoleon auf dem von Winckler erworbenen Grundstück aufgestellte Denkmal bestand nicht allein aus einem Block aus Lausener Granit (Abb. 1). ${ }^{14}$ Der Hügel, auf dem es steht, war als Grabhügel konzipiert und von

11 Rainold (wie Anm. 10), S. 7-9, 28; Prokesch von Osten, Anton Graf: Denkwürdigkeiten aus dem Leben des Feldmarschalls Fürsten Carl zu Schwarzenberg. Wien 1823, S. 310-312; SchwARZENBERG, Karl Fürst: Feldmarschall Fürst Schwarzenberg. Der Sieger von Leipzig. Wien-München 1964, S. 429.

12 Weihe am 15. Oktober 1864 durch den Prager Erzbischof. BEZEcNÝ, Zdeněk: Schwarzenbergové a jejich Orlík v 19. století [Die Familie Schwarzenberg und ihr Worlik im 19. Jahrhundert]. In: Jihočeský sborník historický 68 (1999), S. 129-145, hier S. 137.

13 Schwarzenberg (wie Anm. 11), S. 432.

14 „DEM FÜRSTEN / KARL VON SCHWARZENBERG / DEM FÜHRER / DER AM 18. OKT. 1813 AUF DEN EBENEN VON LEIPZIG / FÜR EUROPAS FREIHEIT KÄMPFENDEN SCHAREN / SETZTEN DIESEN DENKSTEIN SEINE GATTIN MARIANNE / UND SEINE SÖHNE FRIEDRICH, KARL, EDMUND.“ Die Inschrift auf der Rückseite nennt die Lebensdaten Schwarzenbergs „GEB. DEN 15. APRIL 1771 IN WIEN / GEST. DEN 15. OKTOBER 1820 IN LEIPZIG“. Der Historisch-topographische Wegweiser in die Umgegend und auf die Schlachtfelder von Leipzig nebst ausführlicher Beschreibung der großen Völkerschlacht. Leipzig ${ }^{2} 1844$ [ $\left.{ }^{1} 1835\right]$, S. 21 zitiert das Wort „Oktober“ bzw. „Okt.“ der Inschrift mit einem „,c“. So noch WoInovich, Emil von: Kulm, Leipzig, Hanau 1813. Wien 1813 


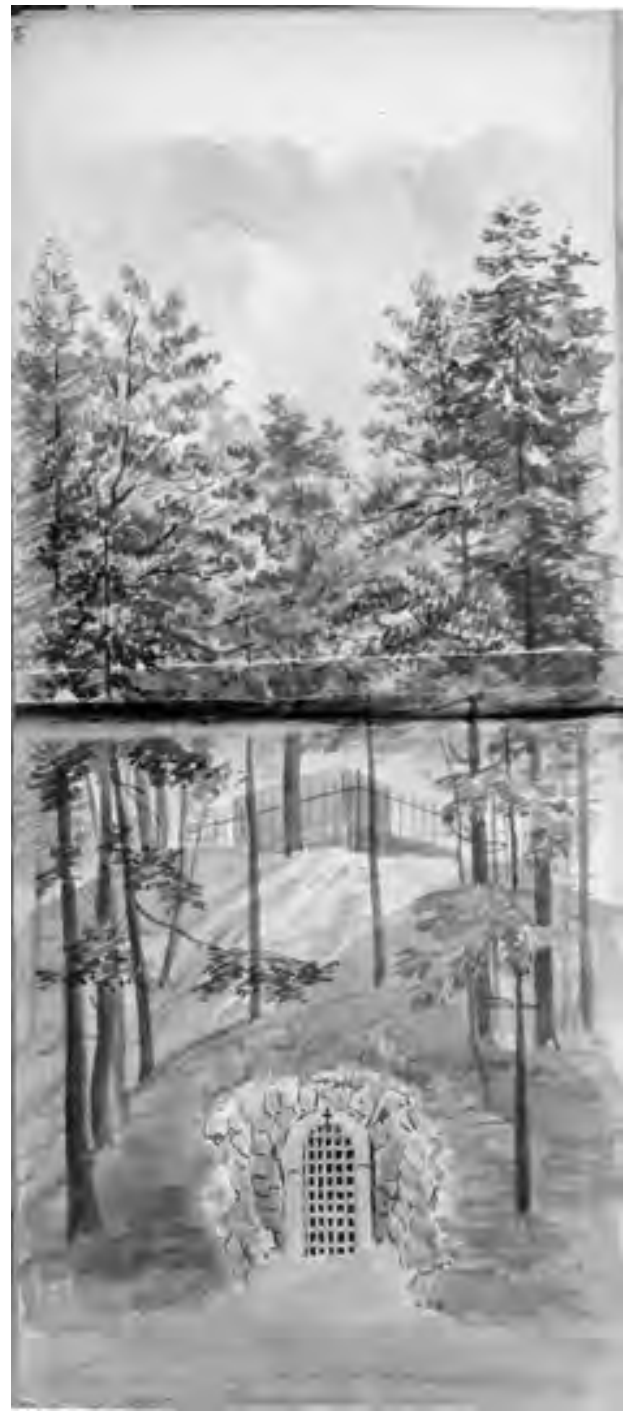

Abb. 4 Ossarium im Grabhügel des Schwarzenberg-Denkmals. Foto: Stadtgeschichtliches Museum Leipzig.
Eichen umstanden. Hinter dem Denkmal fiel das Gelände sechs Meter tief ab, um Zugang zu einem Ossarium zu schaffen, dessen Portal aus Feldsteinen aufgemauert war (Abb.4). Die Schädel und Gebeine, die im Inneren der Grotte zu sehen waren, sollen österreichischen Soldaten gehört haben, die ursprünglich in einem Massengrab im Schmidt'schen Garten in Liebertwolkwitz beigesetzt waren. ${ }^{15}$ Als sich die österreichische Delegation im Oktober 1913 am Denkmal versammelte, war der Zugang zur Grotte bereits vermauert, ${ }^{16}$ doch das Konzept einer Ruhestätte für Gefallene, deren Gedenkstein ihrem Feldherrn gewidmet ist, war noch erkennbar.

Möglicherweise hat schon ein unmittelbar nach der Völkerschlacht angelegter Grabhügel über einem Massengrab die Standortwahl des späteren Schwarzenberg-Denkmals mitbestimmt. Aus Paris zurückkehrende Kosaken und Sachsen hatten hier am 18. Oktober 1814 einen Feldgottesdienst abgehalten - die erste in Leipzig begangene Gedenkfeier zur Völkerschlacht. ${ }^{17}$

Als der ,Verein zur Feier des 19. October“ im Jahre 1847 auf dem höchsten Punkt des Monarchenhügels, östlich der Chaussee nach Grimma, einen gusseisernen Obelisken aufstellte, trug er damit einer veränderten Gewichtung der Ereignisse durch die Öffentlichkeit Rech-

(1813-1815, Österreich in den Befreiungskriegen, Bd. 3), S. 57. Seit dem Zweiten Weltkrieg fehlen die seitlich am Block aufgehängten Kränze aus Bronze. Diese Hinweise auf „spätere Überarbeitungen“ nur bei Cottin, Markus/Klank, Gina/Kretzschmar, Karl-Heinz/Kürschner, Dieter/Petzold, Ilona: Leipziger Denkmale. Beucha 1998, S. 178 (K.-H. Kretzschmar).

15 Leipziger Tageblatt, Festnummer zum 18.10.1913.

16 Staatsarchiv Leipzig, 20024 Kreishauptmannschaft Leipzig, Nr. 164, fol. 33r, Ortsbegehung in Meusdorf am 20.9.1913.

17 Leipziger Tageblatt, Festnummer zum 18.10.1913. 
Abb. 5 Denkmal auf dem Monarchenhügel, aufgerichtet vom „Verein zur Feier des 19. October" 1847, Feldsteinsockel 1863 ergänzt. Foto: C. Forster.

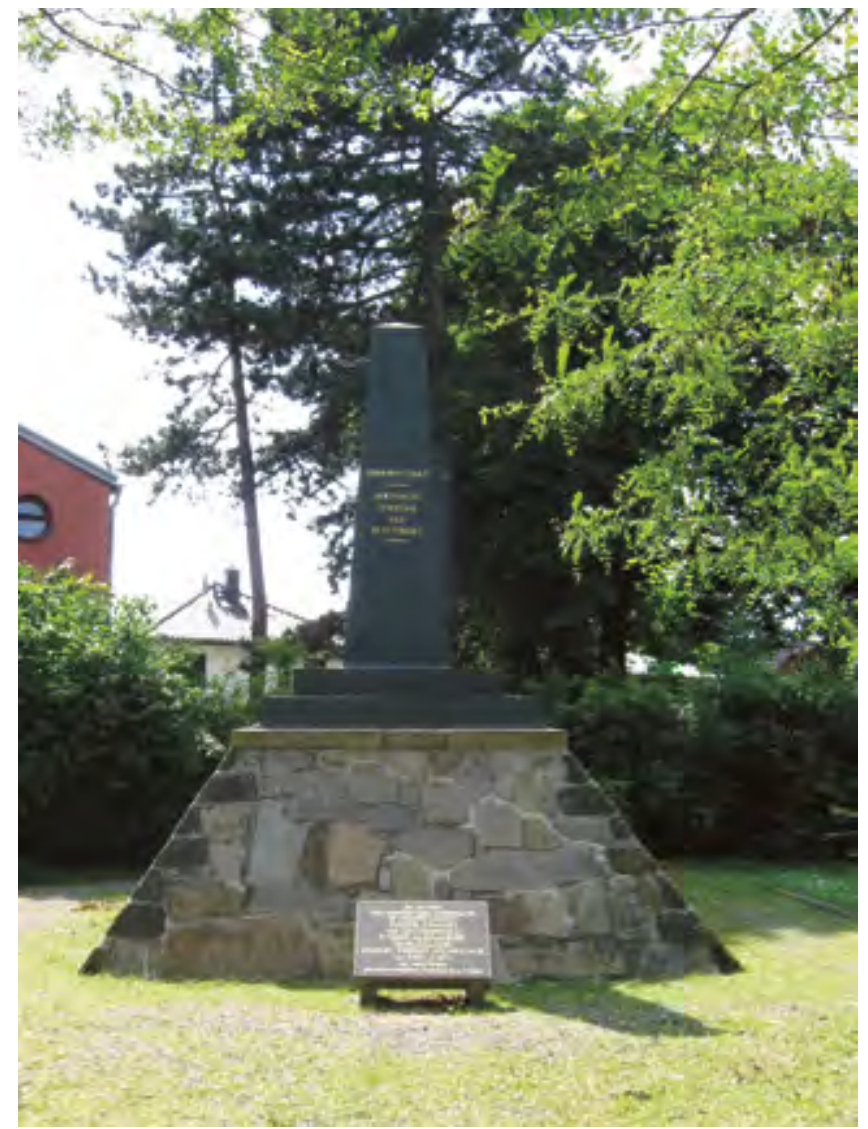

nung (Abb. 5). ${ }^{18}$ Zwar hat sich das auf dem Gemälde „Siegesmeldung“ von Johann Peter Krafft (1817) ${ }^{19}$ dargestellte Ereignis - Schwarzenberg kommt vom Schlachtfeld auf Zar Alexander I. von Russland, König Friedrich Wilhelm III. von Preußen und Kaiser Franz I. von Österreich zugeritten, um den Sieg der verbündeten Armeen zu verkünden - nie zugetragen, schon weil sich Schwarzenberg den ganzen Nachmittag über bei den Monarchen aufgehalten hatte. ${ }^{20}$ Doch darf die mythenbildende Wirkung

18 Gusseisenplatten laut Signatur hergestellt von „C\&G. HARKORT IN LEIPZIG.“ (Carl und Gustav Harkort); Feldsteinsockel ergänzt 1863; Einfassung mit 126 Kanonenkugeln 1952/53 beseitigt. CoTtin, Markus/Kretzschmar, Karl-Heinz/Kürschner, Dieter/Petzold, Ilona: Leipziger Denkmale, Bd. 2. Beucha 2009, S. 94 f. (K.-H. Kretzschmar).

19 Johann Peter Krafft: Die Siegesmeldung nach der Schlacht bei Leipzig am 18. Oktober 1813, Öl auf Leinwand, 1817, bezahlt von den niederösterreichischen Ständen, Wien, Heeresgeschichtliches Museum.

20 Prokesch von Osten (wie Anm. 11), S. 211 f.; Apel, Theodor: Tabellarische Zusammenstellung der Kriegsereigniße bei Leipzig im October 1813. Leipzig 1866, S. 48; GüNTHER, Felix: Die Schlüsselstellung Markkleeberg in der Völkerschlacht bei Leipzig. Die Kampfhandlungen im Raume Cröbern - 
des Gemäldes nicht unterschätzt werden: Mehr noch als die wenigen Monumente, die der österreichische Kaiser zum Andenken an den Sieg von Leipzig in Auftrag gab, prägten die Gemälde von Krafft die österreichische Erinnerung nachhaltig, weil sie wieder und wieder reproduziert und zitiert wurden und ,an den Jahrestagen der Schlacht [im Wiener Militär-Invalidenhaus] öffentlich zugänglich" waren. ${ }^{21}$ Schließlich fanden sich sogar „Augenzeugen“, die den Ort einer Siegesmeldung durch Schwarzenberg auf dem Leipziger Monarchenhügel wiedererkannt haben wollten. ${ }^{22}$ Nach der Aufrichtung des Obelisken an der bezeichneten Stelle befand sich das Schwarzenberg-Denkmal in einer untergeordneten Position, und die örtliche Topografie scheint die Figurenkomposition von Kraffts „Siegesmeldung“ widerzuspiegeln. Erst seit dem Bau von Einfamilienhäusern auf dem Monarchenhügel hat sich das Verhältnis wieder umgekehrt, da diese den Obelisken abschirmen, während die Grünanlage, die es umgibt, das Schwarzenberg-Denkmal von der Prager Straße her gut einsehbar macht.

Schwarzenberg selbst hatte nach der unmittelbaren Erfahrung der Schlacht den Wunsch verspürt, im Schlosspark seiner Residenz eine Kapelle zu errichten. Aus Jena unterrichtete er am 23. Oktober 1813 seine Frau Marianne, die während seiner Abwesenheit die Anlage des Landschaftsparks überwachte, von seinem „Project“: „Ich bin entschlossen, irgendwo [in Worlik] eine einfache, aber niedliche Capelle erbauen zu lassen, zu dem Andenken der großen Ereignisse bei Leipzig; es müßte eine anmuthige Pflanzung angelegt werden; am 18. October müßte alle Jahre ein Tedeum abgehalten, dann ein ländliches Fest gefeiert werden, bei welchem alle Invaliden der Herrschaft gespeiset und beschenkt würden. Den Tag darauf würden Messen für die an diesen Tagen verblichenen Krieger abgelesen “. ${ }^{23}$ In diesen Zeilen äußert sich wenige Tage nach der Leipziger Völkerschlacht das Entsetzen des Oberkommandierenden der alliierten Armeen über die hohen Verluste. Nicht allein Schwarzenberg fand es angemessen, die Nachwelt mittels einer Kapelle an den verlustreichen Sieg über Napoleon zu erinnern. ${ }^{24}$ Unter dem Eindruck einer Besichtigung des Schlachtfeldes schlug der Journalist Carl Bertuch vor, in der Nähe der Quandt'schen Tabaksmühle, des Standquartiers Napoleons am Tag seiner Niederlage, ein Nationaldenkmal in Gestalt einer Kapelle zu errichten. „Ein großer freyer Platz würde die Kapelle ... umgeben, wo an jedem achtzehnten October den gefallenen Helden ein Seelenamt gehalten, das Bündnis der Ewigkeit

Markkleeberg - Dölitz - Connewitz in der Zeit vom 12. bis 19. Oktober. Markkleeberg-Leipzig 1938, S. 94; Schwarzenberg (wie Anm. 11), S. 248.

21 Telesko, Werner: Kulturraum Österreich. Die Identität der Regionen in der bildenden Kunst des 19. Jahrhunderts. Wien 2008, S. 49; FrodL-SchneEmann, Marianne: Johann Peter Krafft 1780-1856. Monographie und Verzeichnis der Gemälde. Wien-München 1984, S. 42, 44, 139 f., Kat.-Nr. 76.

22 Historisch-topographischer Wegweiser (wie Anm. 14), S. 121.

23 Schwarzenberg (wie Anm. 11), S. 251.

24 Die St. Karls-Kapelle (abgegangen) wurde 1815/16 beim Dorf Groß-Wir (Velký Vír) erbaut, SchwarZenberg (wie Anm. 11), S. 388, 410; BezecnÝ (wie Anm. 12), S. 130. Die kleine, ein Steinkreuz beherbergende Kapelle im heutigen Schlosspark nahe der Gruft wurde nach dem Tod des 1914 in Vukovar gefallenen Karl V. Fürst zu Schwarzenberg von seiner Witwe zum Gedenken an die Befreiungskriege errichtet, vgl. Schwarzenberg (wie Anm. 11), S. 433. 
erneuert, und ... den Völkern fortdauernden Frieden, Ruhe und Eintracht verkündigt" würden, schrieb er vom Wiener Kongress am 18. Oktober 1814. ${ }^{25}$ Noch der Entwurf, den der russische Konsul in Leipzig, Wilhelm von Freygang, zusammen mit Christian Ludwig Stieglitz und Carl Heinrich Aster 1824 vorlegte, sollte in erster Linie der Gefallenenehrung einen liturgischen Rahmen bieten. ${ }^{26}$ Je länger aber die Schlacht zurücklag, desto stärker traten die mit dem Totengedenken verknüpften christlichen Elemente in den Hintergrund, wenn darüber diskutiert wurde, welches architektonische Mal das Leipziger Schlachtfeld auszeichnen sollte. So blieb es 100 Jahre nach der Schlacht dem halbstaatlichen russischen Projekt überlassen, das Gedenken an die eigenen Gefallenen mit einem Sakralbau zu verknüpfen, in den auch - anders als in das Völkerschlachtdenkmal - Gebeine überführt wurden.

\section{Die Österreicher-Denkmale und ihre Ikonografie}

Ursprünglich wollte der Thronfolger auch ein Denkmal im Leipziger Stadtteil Lößnig besuchen, das kurz zuvor zu Ehren der Österreicher, die ihr Leben bei der Völkerschlacht ließen, errichtet worden war (Abb. 6). Da ihm das Leipziger Festprogramm für zwei feierliche Akte keine Zeit ließ, übernahm der Kriegsminister, Feldzeugmeister Alexander Krobatin, diese Aufgabe. ${ }^{27}$ Vier weitere Österreicher-Denkmale wurden der Obhut der Stadt Leipzig am 2. Dezember 1913, am Tage der Vollendung des 65. Regierungsjahres von Kaiser Franz Joseph, übergeben: ${ }^{28}$ Eines steht vor der Genezarethkirche in Paunsdorf, eines außerhalb von Holzhausen an einer Straßengabelung, eines auf dem Rembrandtplatz (ehem. Merveldtplatz) in Lößnig und eines unmittelbar westlich der Weißen Elster im Stadtteil Kleinzschocher. Ein fünftes, das an der Wegkreuzung Markkleeberg-Auenhain/Crostewitz-Wachau stand, ist dem Braunkohletagebau zum Opfer gefallen. ${ }^{29}$

25 Bertuch, Carl: Die Kapelle der Eintracht auf dem Schlachtfelde von Leipzig. Wien-Weimar 1814, S. 7.

26 Ausdrücklich „Entwurf eines zum Andenken der Schlacht von Leipzig zu errichtenden (nicht Sieges), sondern Totenmonuments" betitelter Plan für eine neogotische kreuzförmige Kapelle auf dem Monarchenhügel, Wustmann, Gustav: Aus Leipzigs Vergangenheit. Bd. 1-3. Leipzig 1885-1909, hier Bd. 2 (1898), S. 395 f.; Hildebrand, Karl: Die früheren Versuche zur Ausführung eines Völkerschlachtdenkmals und ihre Gegenüberstellung zum fertigen Denkmal. In: Leipziger Kalender 1913 (1913), S. 121-136, hier S. 131.

27 Neues Wiener Tagblatt, Nr. 288, 20.10.1913, S. 10: „Nach dieser würdigen kleinen Feier [am Schwarzenberg-Stein] bekränzte unser Kriegsminister im sogenannten Merveldtpark, in einer Gegend, wo viele Österreicher gefallen, einen vom Maria Theresienorden zu ihrer Ehrung aufgestellten Obelisken, wie deren mehrere auf andern Punkten des Schlachtfeldes zur Aufstellung gelangten.“

28 Leipziger Allgemeine Zeitung, Nr. 281, 3.12.1913; Leipziger Neueste Nachrichten, Nr. 335, 4.12.1913; Leipziger Tageblatt, Nr. 612, 2.12.1913, Nr. 614, 3.12.1913 und Nr. 615, 4.12.1913.

291913 war das Denkmal dem Grundeigner, Herrn von der Crone, zur Obhut übergeben worden. Mit der Auflösung des Wachauer Gutsbezirks 1923 kam es unter die Verwaltung der Gemeinde OetzschMarkkleeberg. Kurz vor Weihnachten 1922 hatten Unbekannte einige der Eckfestons gestohlen, vorsorglich wurden daher am 26.2.1923 die restlichen Bronzeteile abmontiert und eingelagert. Darüber 


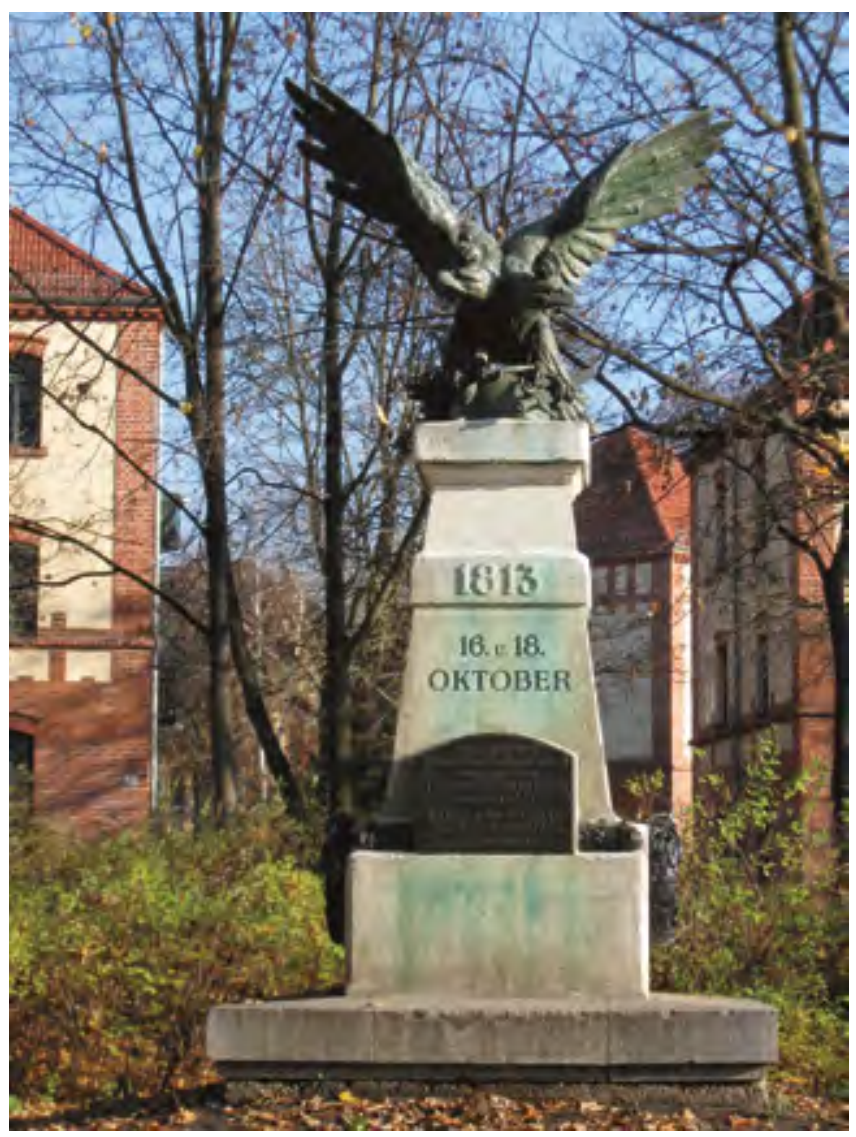

Abb. 6 Österreicher-Denkmal in Leipzig-Lößnig, Rembrandtplatz (ehem. Merveldtplatz). Foto: C. Forster.

Es sind fünf baugleiche Denkmale, etwa vier Meter hohe Pfeiler aus istrischem Kalkstein mit geböschten Seiten, deren fein profilierte Deckplatte eine bronzene Halbkugel trägt, auf der in geduckter Haltung ein doppelköpfiger Adler steht, der mit seinen Krallen ein Schwert am Abgleiten hindert. Die Schauseite präsentiert über dem Sockelblock eine Inschriftentafel, über den Sockelseiten hängen Bronzekränze. Ihre Aufhängung,

erging am 10.3.1923 Mitteilung an den Militär-Maria-Theresia-Orden, der am 4.4. um Begleichung der Rechnung des Schlossermeisters gebeten wurde. Am 16.3.1938 feiert die NSDAP-Ortsgruppe Österreichs ,Anschluss“ am Markkleeberger Denkmal. Als der wegen ,politischer Unzuverlässigkeit“" entlassene Schulleiter von Markkleeberg-Mitte, Weigand, vorschlug, die Umgebung des Denkmals zur 125-Jahr-Feier der Völkerschlacht neu zu bepflanzen, gaben sich der Oberbürgermeister und der Kulturreferent Felix Günther, der mit der Publikation GüNTHER (wie Anm. 20) hervortrat, empört und wurden ihrerseits aktiv (Abb. 9). Nach der abmontierten Inschriftentafel fahndete man vergeblich und musste sie rekonstruieren. Auch diese Kosten übernahm der Orden in Wien. 1940 und 1941 entgingen die Metallteile der Beschlagnahme, 1942 oder später jedoch nicht mehr. Vgl. Staatsarchiv Leipzig, 20611 Stadt Markkleeberg 1569/I. 1975 musste das Denkmal dem Tagebau Espenhain weichen, nur die Ersatztafel ist erhalten (Abb. 11). 


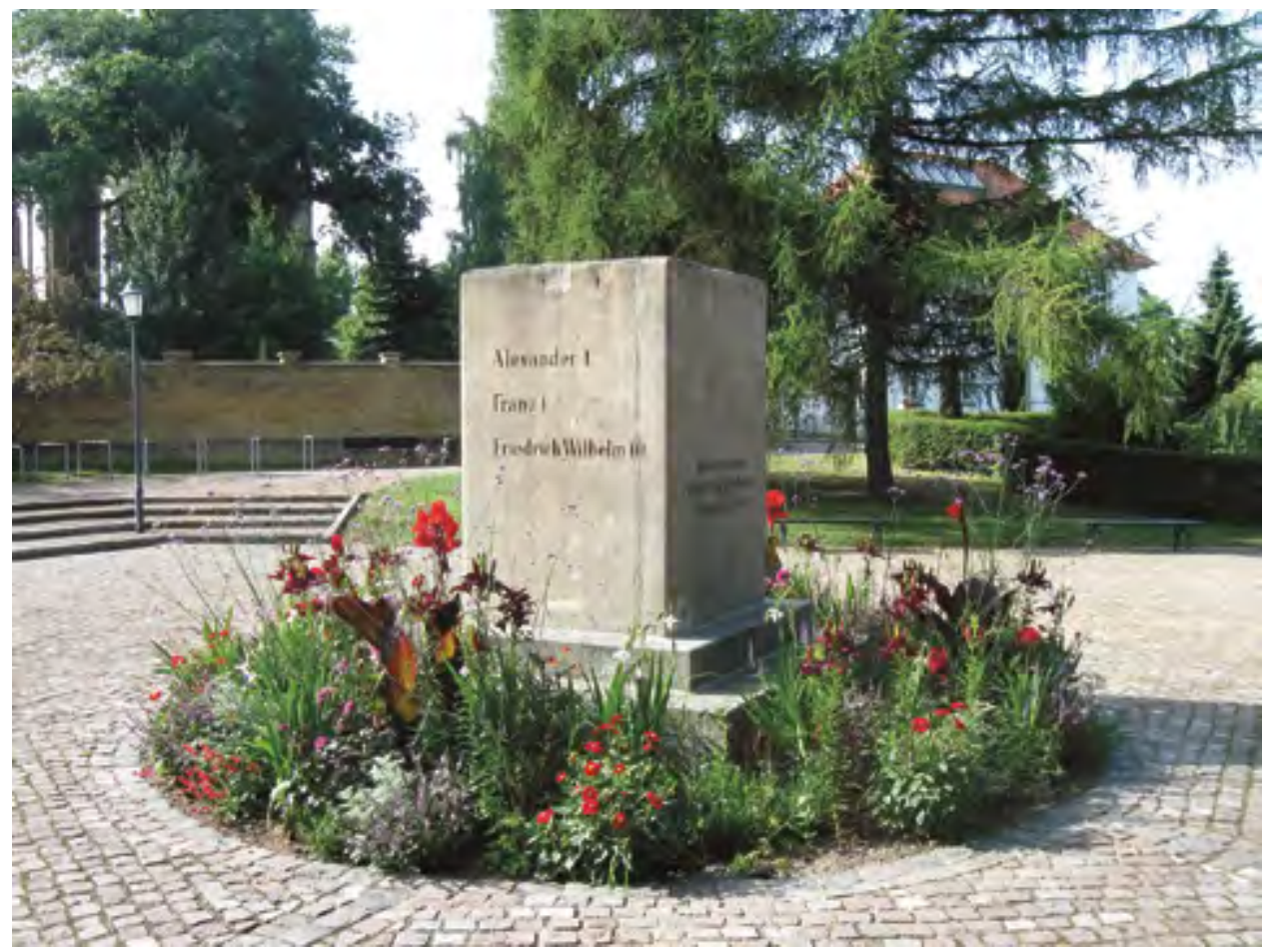

Abb. 7 Wachtberg-Denkmal mit Inschrift „Standpunkt der drey Monarchen“. - „Alexander I., Franz I., Friedrich Wilhelm III.“. - „Den 16ten October 1813“. Gestiftet 1854, seit 1982 Wachau, Kirchplatz. Foto: C. Forster.

die Inschriftentafel und eine Steintafel mit der Datierung MCMXIII auf der Rückseite ragen über die Kante des Sockels hinaus, während auf seinen Ecken gekrümmte Eichenlaubkränze aufliegen. Alle metallenen Teile wurden aus der Bronze von 1813 erbeuteten Geschützen gefertigt. Auf allen vier Seiten eines blockförmigen Zwischengesimses im oberen Drittel des Pfeilers ist die Jahreszahl 1813 erhaben aufgebracht. Über der Bronzetafel verdeutlicht eine Datumsangabe, auf welche Vorgänge während der mehrtägigen Schlacht um Leipzig die Inschrift Bezug nimmt. Die Inschriften der Bronzetafeln machen deutlich, dass die Denkmale den Gefallenen von konkret bezeichneten Armeeeinheiten gewidmet sind; auf sie wird zurückzukommen sein.

Es fällt auf, dass die fünf Obelisken weder formal noch hinsichtlich ihres Standortes auf die bereits existierenden Leipziger Denkmale Bezug nehmen, insbesondere nicht auf diejenigen, die der „Verein zur Feier des 19. October“ gestiftet hatte, um sämtliche Feldherrnhügel der Völkerschlacht zu besetzen (Abb. 7). Zwar ist der Obelisk ein gängiges Motiv für Sieger- und Gefallenenmale, auch im Kontext der Befreiungskriege. ${ }^{30}$

30 Z.B. Caspar David Friedrichs Denkmalsentwürfe, vgl. KLugE, Hans-Joachim: Caspar David Friedrich: Entwürfe für Grabmäler und Denkmäler. Berlin 1993, S. 152-165, Nr. 29-31. 


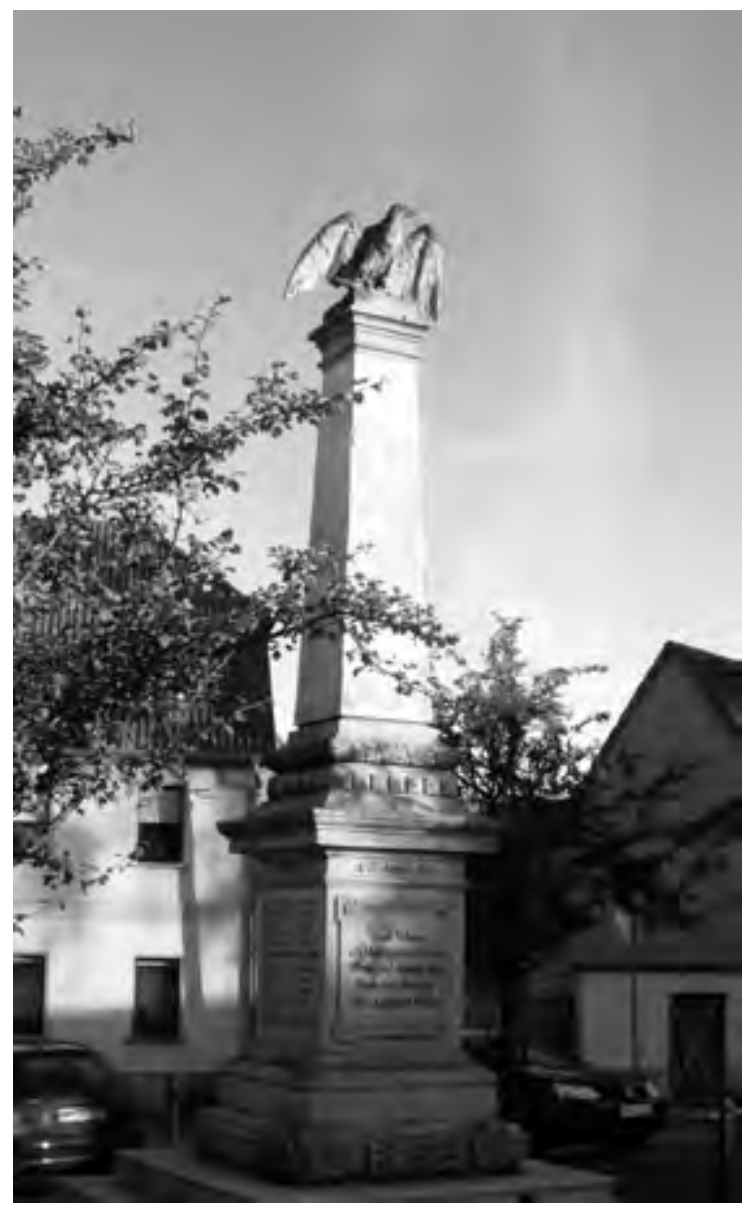

Abb. 8 Auerstedt, Kriegerdenkmal für die Gefallenen von 1866 und 1870/71. Foto: C. Forster.

Österreichischerseits wurde ein Obelisk in 1825 in Arbesau (Varvažov u Telnice) im Teplitzer Tal verwendet, um General Hieronymus von Colloredo-Mansfeld zu ehren, der entscheidend dazu beigetragen hatte, Napoleon an einem Einfall in Böhmen zu hindern. ${ }^{31}$ Der den Obelisken bekrönende Adler nimmt in Leipzig jedoch nicht die triumphale Haltung an wie in Arbesau oder auch in Schöngrabern. ${ }^{32}$ Seine Gestaltung lässt zwei Deutungen zu. 1. Er breitet seine Flügel aus, um anzuzeigen, dass er die Gefallenen unter seine Fittiche nimmt, eine allegorische Umsetzung der alten habsburgischen Devise sub umbra alarum tuarum (Ps 17,8), die auch den geduckten Adler auf dem Denkmal für Kaiser Franz Joseph im Park der Theresianischen Militärakademie

31 Ehnl, Maximilian: Schlacht bei Kulm. Wien 1913 (Kriege unter der Regierung des Kaisers Franz: Befreiungskrieg 1813 und 1814. Einzeldarstellungen der entscheidenden Kriegsereignisse 4), bes. S. 107-196.

32 Zum Granitobelisk von 1908 Telesko (wie Anm. 21), S. 478. 
in Wiener Neustadt erklären würde, das 1912 aufgestellt wurde. ${ }^{33}$ 2. Er hebt zum Abflug auf die Stadt Leipzig an, wie um die bevorstehende Eroberung anzukündigen. Wie man mit der Ausrichtung des Adlers eine nachträgliche teleologische Geschichtskonstruktion vornimmt, ließ sich am Kriegerdenkmal für die Auerstedter Gefallenen von 1866 und 1870/71 studieren (Abb. 8). Auf diesem Denkmal aus dem Jahre 1905 breitet der nach Westen weisende preußische Wappenvogel seine Flügel aus, er ist im Begriff, sich aufzuschwingen, wobei eine Inschrift am Sockel erläutert: „Preussens Aar flog / über Auerstedts Gefilde / nach Sedan“. Mit Genugtuung wird die Kapitulation der französischen Armee in Sedan 1870 als Revanche für die verheerende Niederlage der Preußen von 1806 gewertet und als Bedingung für die „Wiederaufrichtung des Deutschen Reiches". ${ }^{34}$

Nicht bei allen Österreicher-Denkmalen sind die k. u. k. Adler auf die nahe Stadt ausgerichtet; das abgegangene Denkmal von Markkleeberg stand nördlich der Kreuzung Auenhainer Straße/Verbindung Cröbern-Wachau; um den Vorübergehenden zur Lektüre der Inschriftentafel einzuladen, musste der Adler nach Süden blicken (Abb. 9, 10 und 11). Doch auch ohne eine konsequent zentripetale Anordnung bilden die Österreicher-Denkmale einen Kranz von baulichen Zeichen mit dem Ziel, das Großereignis Völkerschlacht als eine Abfolge militärischer Erfolge und Rückschläge darzustellen. Am Nachzeichnen eines Prozesses hatte sich schon ein älteres, räumlich viel weiter ausgreifendes „Netzwerk“ von Denkmalen der Befreiungskriege versucht. Die Rede ist von Schinkels gusseisernen Fialen mit Eisernem Kreuz, die seit 1817/18 die nach preußischem Verständnis wichtigsten Etappen des Niederringens Napoleons kennzeichnen: Großgörschen bei Lützen (Abb. 12), ein Sieg für Napoleon, aber als erste Schlacht der Befreiungskriege am 2. Mai 1813 bedeutsam, Haynau (Chojnów, 1945 beseitigt, zum 26. Mai 1813), Großbeeren (zum 23. August 1813), bei Wahlstatt (Legnickie Pole, 1945 beseitigt), um an die Schlacht an der Katzbach (Kaczawa) am 26. August 1813 zu erinnern, Arbesau (Varvažov, zum 30. August 1813), NiedergörsdorfDennewitz (zum 6. September 1813) und schließlich Plancenoit (Waterloo, 18. Juni 1815), wo Napoleon in seiner letzten Schlacht unterlag. Sie alle sind durch die Verwendung des gleichen Materials und des gleichen neogotischen Stils ideell mit dem zentralen Denkmal auf dem Kreuzberg in Berlin verbunden, das einige Jahre später verwirklicht wurde. ${ }^{35}$

In Leipzig hatte Theodor Apel den Hergang der Schlacht gründlich erforscht und durch die Aufstellung kleiner Positionsmarken aus Sandstein im Gelände nachvollziehbar gemacht. Bis zu seinem Tod 1867 waren 44 „Apelsteine“ gesetzt und mit Inschriften versehen, ,welche den Namen des Führers, der hier befehligte, die Anzahl seiner Truppen, den Namen der Schlacht, in welcher sie auftraten, die genaue Angabe der

33 GeIssL, Gerhard: Denkmäler in Wiener Neustadt. Orte des Erinnerns. Berndorf 2013, S. 13.

34 Vollständig lautet die Inschrift: „Ihren Söhnen / den Mitkämpfern für die / Wiederaufrichtung des / Deutschen Reiches / Die dankbare Heimat.“

35 Nungesser, Michael: Das Denkmal auf dem Kreuzberg von Karl Friedrich Schinkel. Berlin 1987, bes. S. 75-77. 


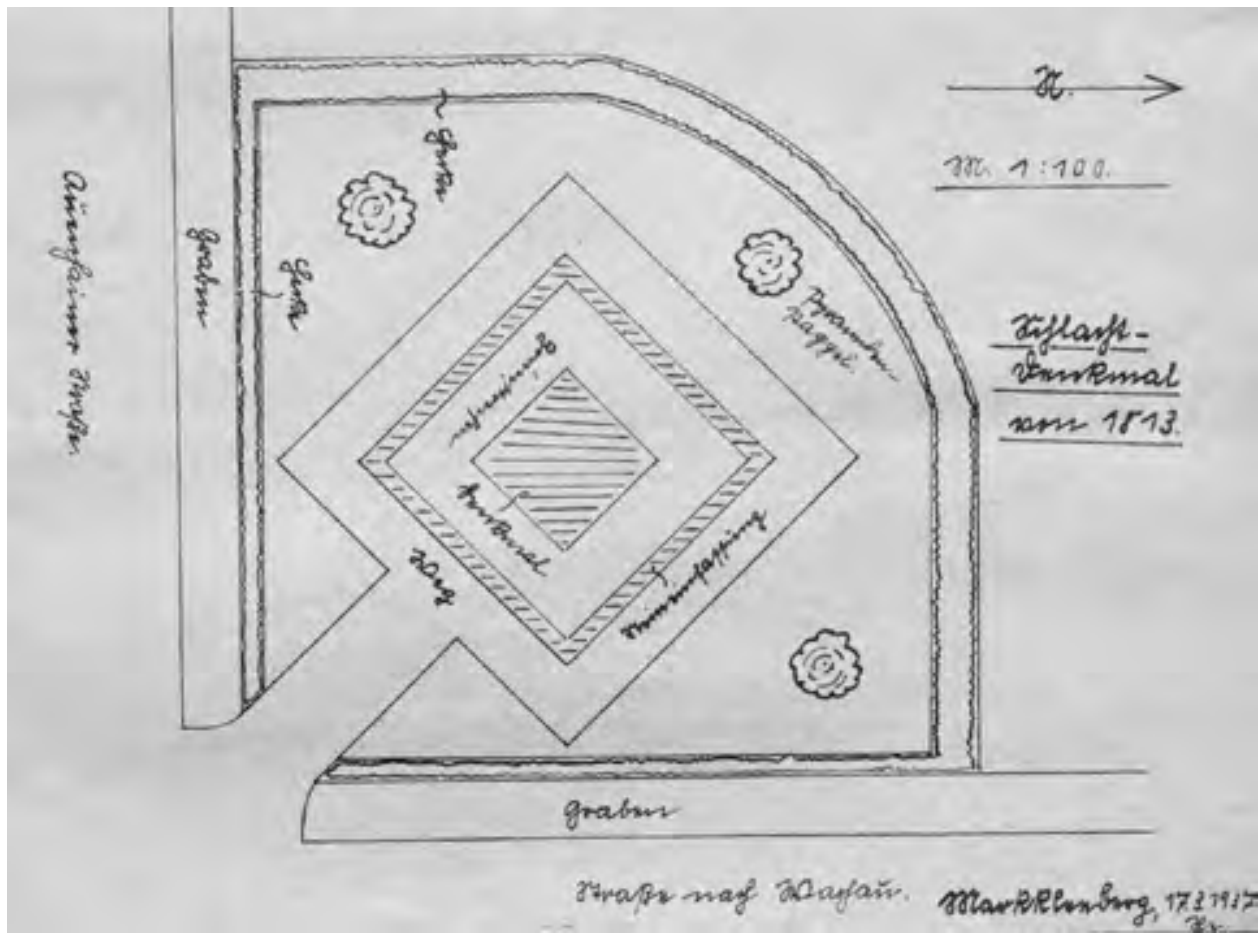

Abb. 9 Entwurf zur Platzgestaltung um das Österreicher-Denkmal bei Markkleeberg 1938. Foto: Sächsisches Staatsarchiv Leipzig.
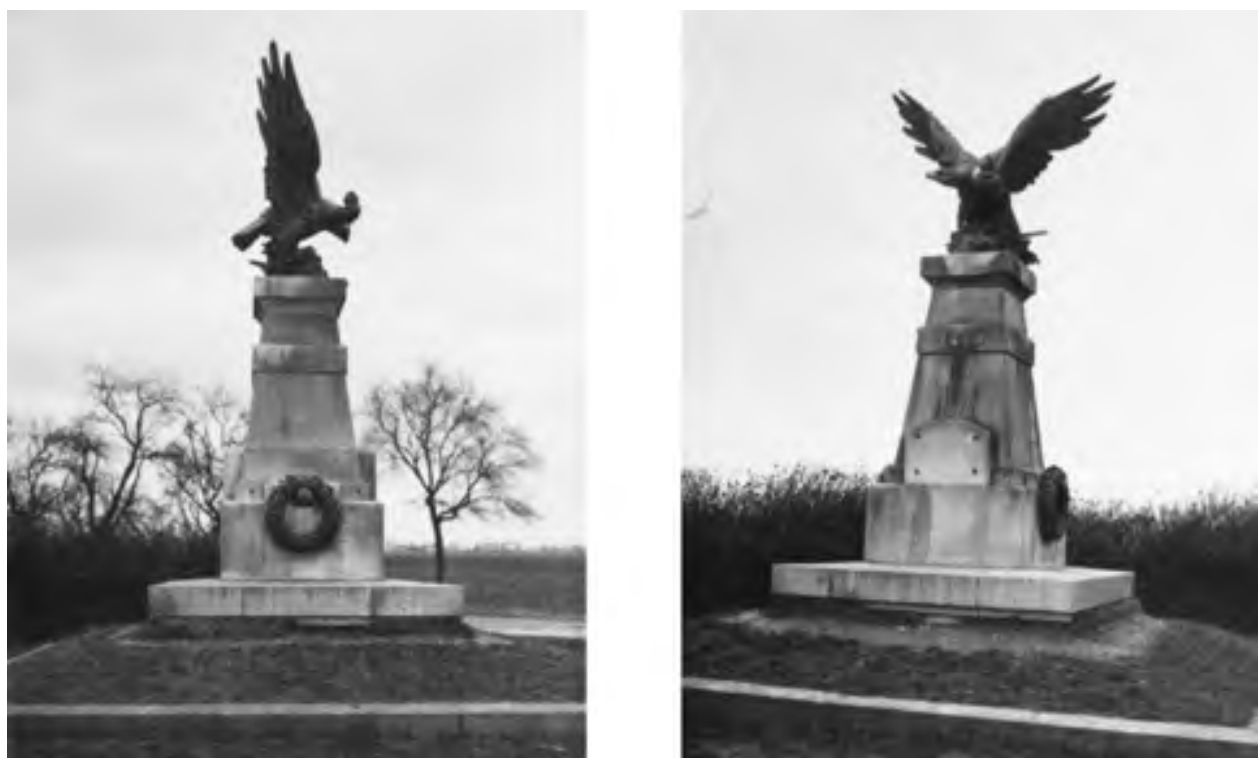

Abb. 10 Österreicher-Denkmal zwischen Markkleeberg und Auenhain. Foto: Sächsisches Staatsarchiv Leipzig. 


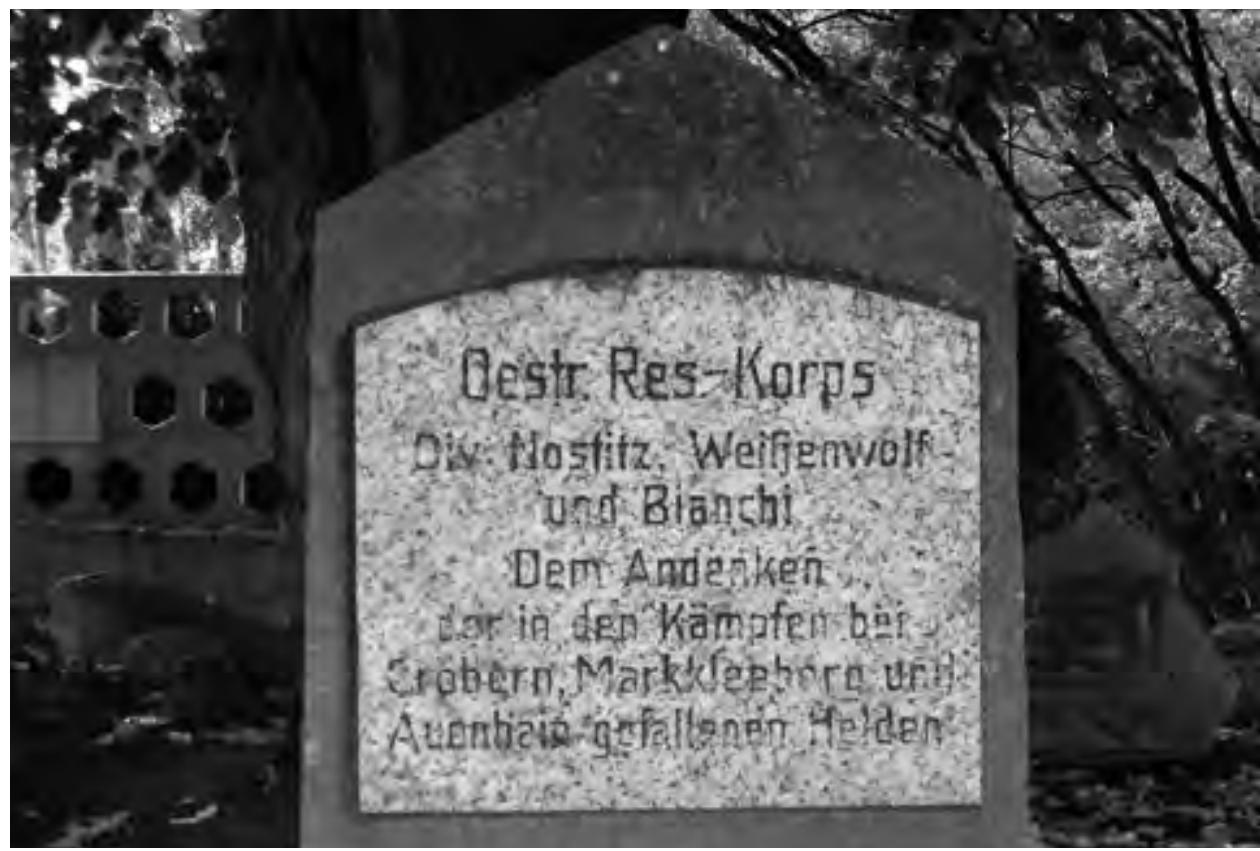

Abb. 11 Die 1938 ersetzte Inschriftentafel, seit dem Abbau des Markkleeberger Denkmals einzig verbliebener Rest, aufgestellt auf einem Hügel über einem Massengrab im ehem. Wachauer Gut. Foto: C. Forster.

Abb. 12 Karl Friedrich Schinkel, Denkmal für die preußischen Gefallenen der Schlacht von Großgörschen am 2. Mai 1813, 1818/19 auf dem Monarchenhügel südlich von Großgörschen aufgestellt, 1985 restauriert und umgesetzt. Foto: C. Forster.

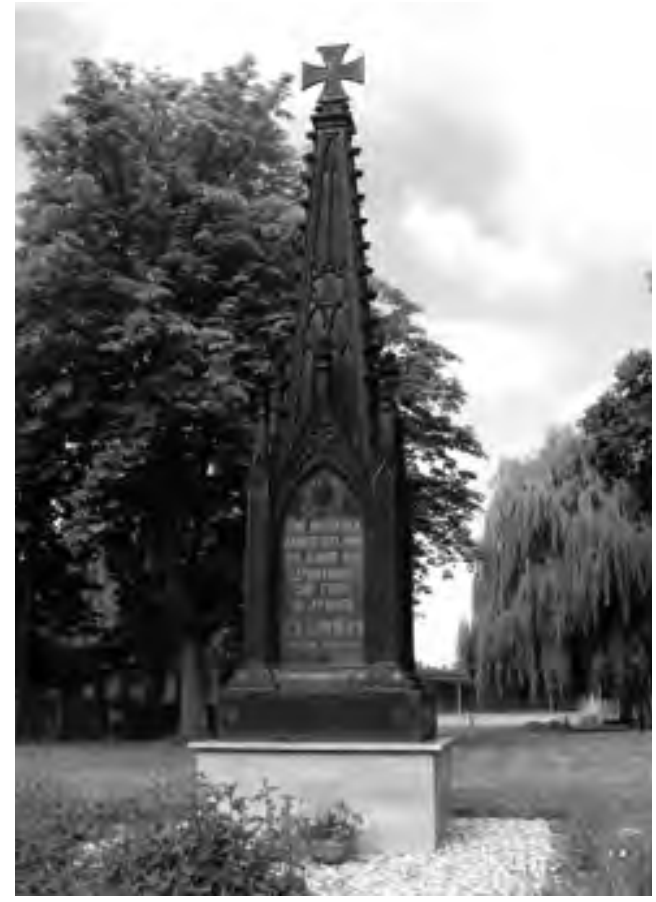


Himmelsgegenden und der Front enthielten.“36 Dieses „Netz“ war von einem Unparteiischen über die Leipziger Schlachtfelder geworfen worden und berücksichtigte die napoleonischen Stellungen und die der Verbündeten gleichermaßen.

\section{Planung, Ausführung und Akteure}

Die Österreicher-Denkmale sollten nur einen bestimmten Ausschnitt des Geschehens beleuchten. Ihre Planung und ihre Baugeschichte lassen sich aus den Akten gut nachvollziehen.

Nachdem 1902 ein Aufruf in der „Neuen Hamburger Zeitung“ zum Bau eines Denkmals für die bei der Völkerschlacht gefallenen Österreicher ohne Wirkung geblieben war ${ }^{37}$ hatten die Gesuche, die der Eschendorfer Pfarrer Hans Krieger (1873-1961) kurz vor der Leipziger Hundertjahrfeier bei Kaiser Franz Joseph I. einreichte, Erfolg. ${ }^{38}$ Krieger sollte zur Festausgabe der „Leipziger Neuesten Nachrichten“ am 18. Oktober 1913 einen Artikel beisteuern, in dem er mit scharfen Worten geißelte, dass sich nach der Völkerschlacht niemand gefunden habe, die zahlreichen Massengräber zu kennzeichnen: „Die Gräber sind zum größten Teil vergessen.“39 Insbesondere machte er darauf aufmerksam, dass ,kein einziges Denkmal [...] auf dem linken Pleißenufer der vielen tapfer gefallenen Oesterreicher [gedenkt]. ${ }^{640}$ Ob seine Motivation, nach Wien zu schreiben, nur aus Pietätsempfinden oder aus einem großdeutschen Nationalismus erwuchs, muss offen bleiben. ${ }^{41}$

36 ApEL, Theodor: Führer auf die Schlachtfelder Leipzigs im October 1813 und zu deren Marksteinen. Leipzig 1863, S. 2. Zu den Apelsteinen: Cotтin u.a. (wie Anm. 14), S. 125-151 (K.-H. Kretzschmar); POSER, Steffen: Hiob 38,11. Bis hierher sollst du kommen und nicht weiter; hier sollen sich legen deine stolzen Wellen. Denkmale erzählen über die Leipziger Völkerschlacht. Beucha 1998 (Leipziger Hefte 13), S. 87-137.

37 Hinweis im Protokoll der 63. Vorstandssitzung des Deutschen Patriotenbundes am 10.4.1902, Stadtarchiv Leipzig, Deutscher Patriotenbund zur Errichtung eines Völkerschlachtdenkmals bei Leipzig 1 (ehem. Kap. 35, Nr. 1775), fol. 152.

38 Österreichisches Staatsarchiv, Kriegsarchiv, Exhibitenprotokoll 1913, Nr. 200, 202, 227. Vgl. auch Leipziger Neueste Nachrichten, Nr. 335, 4.12.1913: „Zur Aufstellung der österreichischen Völkerschlacht-Gedenksteine“.

39 KRIEGER, Hans: Erhaltene Gräber aus den Tagen der Völkerschlacht. In: Deutschlands Freiheitsdom. Gedenkblatt der Leipziger Neuesten Nachrichten zur Weihe des Völkerschlachtdenkmals, 18. Oktober 1913. Leipzig 1913, S. 12-13, hier S. 12.

40 Krieger (wie Anm. 39), S. 13.

411896 hatte Krieger den sozialdemokratischen Journalisten Edgar Steiger wegen der Veröffentlichung zweier Kurzdramen angezeigt, und Steiger wurde in der Folge vom Leipziger Reichsgericht zu viereinhalb Monaten Gefängnis wegen Gotteslästerung verurteilt, vgl. RegLER-BeLLingER, Brigitte: Edgar Steiger 1858-1919. Leben und Werk des deutsch-schweizerischen Schriftstellers. Norderstedt 2004, S. 129-132. Nach dem Ersten Weltkrieg driftete Krieger vollends ins rechtsradikale Lager ab und wurde 1929 wegen Beleidigung der Republik verurteilt. Er hatte einen offenen Brief an den wegen Mordes verurteilten Führer der Schwarzen Reichswehr, Paul Schulz, verfasst und behauptet, Schulz' Verurteilung habe auf „Lügen“ beruht, Allgemeen Handelsblad, 27.1.1929. 
Am 12. August 1913 ging dem Kaiser eine Kostenberechnung für die Leipziger Österreicherdenkmale zu, daher musste der mit dem Entwurf beauftragte Major des Ingenieursoffizierskorps Gustav König inzwischen Pläne vorgelegt haben. Mit der Ausführung wurde der Militärische Maria-Theresien-Orden beauftragt, dessen Kassa auch die Kosten übernahm. Am 28. August stellte das Kriegsministerium 125 Pfund Bronze gegen 25 Heller per Kilogramm zur Verfügung. Am gleichen Tag traf aus Ischl die Bewilligung zum Bau ein. ${ }^{42}$ Dass es sich bei dem Material um Geschützbronze von Kanonen, die 1813 erbeutet wurden, handelte, lässt sich heute nur noch aus einem Bericht der „Leipziger Allgemeinen Zeitung“ herauslesen, da die Inventare des Wiener Arsenals während des Zweiten Weltkriegs verbrannt sind. ${ }^{43}$ Schon am 29. August kündigte die österreichisch-ungarische Gesandtschaft in Dresden dem sächsischen Staatsminister für innere und äußere Angelegenheiten, Graf Vitzthum von Eckstädt, die Anreise zweier mit dem Denkmalsbau beauftragter Offiziere an. Am 3. September gab der Minister Anweisung an Gemeinden und Polizeibehörden, die Herren zu unterstützen. ${ }^{44}$ An den folgenden Tagen müssen Ortsbegehungen durch die österreichischen Offiziere, Ordensgreffier Feldmarschallleutnant Karl Edler von Kailer und Major Gustav König, stattgefunden haben, denn am 6. September diskutierte der Leipziger Stadtrat das Vorhaben und genehmigte den Bau eines Denkmals auf dem Merveldtplatz in Lößnig und in Kleinzschocher. Außerdem entsprach der Rat dem Wunsch der österreichisch-ungarischen Regierung, für den Unterhalt der Denkmale aufzukommen und gärtnerische Anlagen auszuführen. ${ }^{45}$ Noch am selben Tag erarbeitete die Städtische Gartendirektion Skizzen für beide Standorte.

Das österreichisch-ungarische Anliegen kam im richtigen Moment: Nicht nur waren an beiden Standorten in aktuellen Bebauungsplänen öffentliche Parkflächen vorgesehen. Schon im März 1913 war der Beschluss ergangen, dass zwei der in Lößnig auf dem Areal der Gemeinnützigen Baugesellschaft entstandenen Straßen nach Merveldt und Colloredo benannt werden sollten, zwei Generälen in österreichischen Diensten während der Kriege gegen Napoleon. ${ }^{46}$ Der Bauplatz in Kleinzschocher gehörte der Stadt zwar noch nicht, sein Erwerb war aber geplant, und der Noch-Eigner des Ritterguts, Baron von Tauchnitz, gab seine Zustimmung unverzüglich. ${ }^{47}$ Am 16. und 27. September kamen das Baumaterial und die von Fritz Zerritsch gegossenen Bronzeteile aus Wien mit dem Zug an. ${ }^{48}$ Die Errichtung der Denkmale lag nun in der Verantwortung des Leipziger Oberbaurats Otto Wilhelm Scharenberg. Am 23. September setzte Oberbürgermeister Dittrich den Kreishauptmann davon in Kenntnis, dass auch in Paunsdorf,

42 Österreichisches Staatsarchiv, Kriegsarchiv, Exhibitenprotokoll 1913, Nr. 257, S. 264.

43 Leipziger Allgemeine Zeitung, Nr. 281, 3.12.1913: „Weihe der österreichischen Denkmäler in Leipzig und Umgebung“. - 325 Kanonen erbeuteten die Verbündeten während der Schlacht, so WoINOVICH (wie Anm. 14), S. 86.

44 Stadtarchiv Leipzig, Kap. 26A, Nr. 98.

45 Stadtarchiv Leipzig, Kap. 26A, Nr. 98 (Gesamtratsbeschluss Nr. 2115).

46 Stadtarchiv Leipzig, Kap. 26A, Nr. 98 (Drucksache Nr. 399/1913 v. 8.9.1913); Kap. 24, Nr. 2484.

47 Stadtarchiv Leipzig, Kap. 26A, Nr. 98 (Briefwechsel v. 6.9. und 7.9.1913).

48 Österreichisches Staatsarchiv, Kriegsarchiv, Exhibitenprotokoll 1913, Nr. 277. 


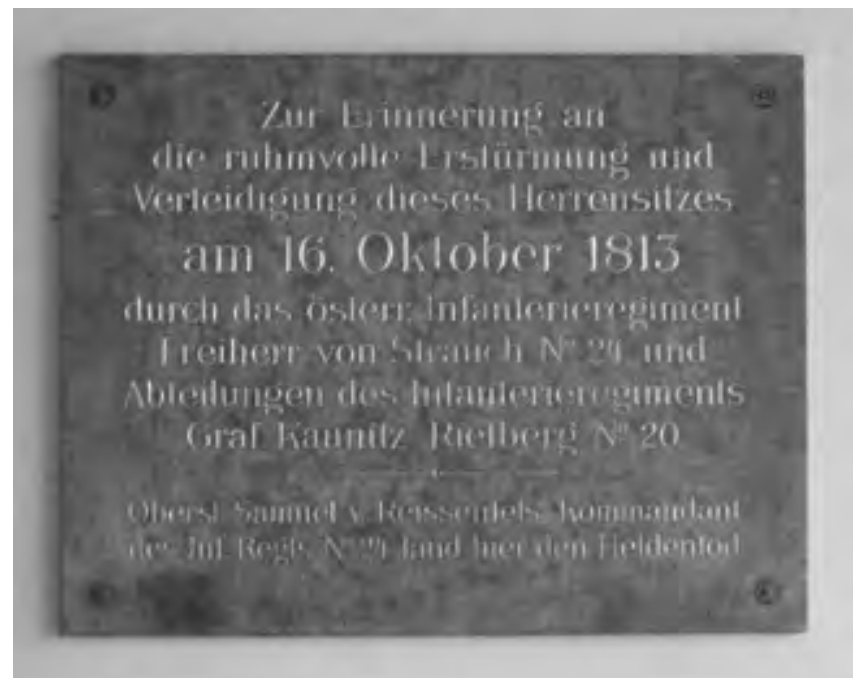

Abb. 13 Gedenktafel im Torhaus des ehem. Rittergutes Dölitz. Foto: C. Forster.

Markkleeberg und im Schloss Dölitz Denkmale geplant seien. Nachdem Rittergutsbesitzer von Winckler in Dölitz nur eine Gedenktafel anbringen wollte (Abb. 13), wurde der fünfte Standplatz in Holzhausen ausfindig gemacht. Dittrich resümierte: „Die österreichischen Herren haben nach ungefähr einwöchigem Aufenthalt Leipzig wieder verlassen und gedenken Mitte Oktober zur Übernahme der Denkmäler wieder hierher zurückzukehren." "49

Am 29. September ging eine offizielle Stellungnahme zu dem Bauvorhaben an Wiener und Leipziger Zeitungen, die etwa von der „Leipziger Abend-Zeitung“ am 4. Oktober abgedruckt wurde. ${ }^{50}$ Aus Anlass der Jahrhundertfeier der Völkerschlacht habe Kaiser Franz Joseph die Errichtung von „Erinnerungszeichen für die in dieser denkwürdigen Schlacht gefallenen österreichischen Krieger in Leipzig“ angeordnet. „Durch die Schaffung dieser Denkmäler soll dem bisher bestandenen fast vollständigen Mangel an Ehrenzeichen, welche den rühmlichen und entscheidenden Anteil der österreichischen Truppen an den Waffenerfolgen der verbündeten Armeen auch äußerlich zum Ausdruck bringen, abgeholfen werden. Abgesehen von den mächtigen Denkmälern, welche gegenwärtig die Pietät der Bewohner des Deutschen Reiches und Rußlands in dem Völkerschlachtdenkmale und der russischen Gedächtniskirche den Manen ihrer an der Schlacht beteiligt gewesenen Vorfahren errichtet haben, findet der Besucher des Schlachtfeldes auf vielen Punkten desselben Denkmäler und kleinere Gedenksteine, welche die Erinnerung an die Aufmarschräume und Kampfplätze der an der Schlacht beteiligt gewesenen Korps und Gruppen festhalten sollen. Außer dem der Persönlichkeit des Führers der Verbündeten, Feldmarschall Fürsten Schwarzenberg, von seiner Familie gewidme-

49 Stadtarchiv Leipzig, Kap. 26A, Nr. 98 (Schreiben v. 23.9.1913).

50 Österreichisches Staatsarchiv, Kriegsarchiv, Exhibitenprotokoll 1913, Nr. 292. - Leipziger AbendZeitung Nr. 231, 4.10.1913. 
ten Denkmale bei Meusdorf aber geben nur einzelne kaum mehr erkennbare und an entfernten, verbauten oder historisch belanglosen Stellen gelegene Steine Zeugnis von dem Anteil der österreichischen Truppen an diesem welthistorischen Siege.“

Das geringschätzige Urteil, das hier über die „Apelsteine“ verhängt wird, verfehlt die Intention ihres Schöpfers, da es Apel um sachliche Rekonstruktion eines komplexen Geschehens gegangen war, weshalb er in Ergänzung zu den schon vorhandenen Gedenksteinen des „Vereins zur Feier des 19. October" auf den Feldherrnhügeln alle jene „Punkte“ kennzeichnete, „welche die Anführer mit ihren Heerhaufen einnahmen, die am Entscheidensten in das Getriebe der Schlacht eingriffen. “51 Die Verlautbarung in der „Abend-Zeitung“ zeigt nun aber, dass Österreich-Ungarns Bauvorhaben darauf abzielte, sich bei den Teilnehmern der Einweihungsfeier des Völkerschlachtdenkmals wie auch bei künftigen Besuchern Leipzigs als die dritte Partei der antinapoleonischen Koalition ins Gedächtnis zu rufen. Durch die deutschen und russischen Initiativen war Kaiser Franz Joseph I. unter Zugzwang geraten. Kaum dürfte er die bislang verpasste Gelegenheit zur nationalen Selbstverherrlichung als Defizit empfunden haben, vielleicht aber den Umstand, dass man der preußischen Deutung der Ereignisse von 1813 nichts entgegengesetzt hatte. Übertrumpfen wollte er den deutschen oder den russischen Gedenkbau nicht. Vielmehr wollte man dezent die historischen Fakten sprechen lassen.

\section{Topografie der Völkerschlacht aus militärhistorischer, insbesondere österreichischer Perspektive}

Bei der Standortwahl ließen sich die Delegierten des Maria-Theresien-Ordens von rein militärischen Gesichtspunkten leiten, sollten die Denkmale doch jene Frontabschnitte kennzeichnen, an denen Verbänden der Böhmischen Armee entweder Durchbrüche gelungen waren oder an denen sie besonders große Verluste erlitten hatten. ${ }^{52}$ Als Entscheidungshilfe diente das Manuskript des vom k. u. k. Kriegsarchiv vorbereiteten Bandes „Feldzug von Leipzig““.53 Eine daraus destillierte „Orientierende Skizze über die Völkerschlacht bei Leipzig mit besonderer Berücksichtigung des Anteils der k. k. Truppen" mit guten Planbeilagen zu den Schlachtfeldern von Wachau und Leipzig wurde dem Gefolge Franz Ferdinands auf die Fahrt nach Leipzig mitgegeben. ${ }^{54}$ In dieser Handreichung heißt es abschließend: „Wenn am Fuße des Völkerschlachtdenkmals die Vertreter aller jener Heere versammelt sein werden, die vor hundert Jahren auf den gesegneten Gefilden von Leipzig ihre Fahnen entrollten, dann dürfen die Sendboten Österreichs mit berechtigtem Stolze ihrer Vorfahren gedenken, denn der

51 Apel (wie Anm. 36), S. 2.

52 Nach Leipziger Abend-Zeitung, Nr. 231, 4.10.1913.

53 Hoen, Maximilian von: Feldzug von Leipzig. Wien 1913 (Kriege unter der Regierung des Kaisers Franz. Befreiungskrieg 1813 und 1814. Einzeldarstellungen der entscheidenden Kriegsereignisse 5).

54 Und findet sich im Nachlass des k. k. Kämmerers Franz Graf Folliot de Crenneville-Poutet, Österreichisches Staatsarchiv, Haus-, Hof- und Staatsarchiv, SB FA Folliot-Crenneville 286. 


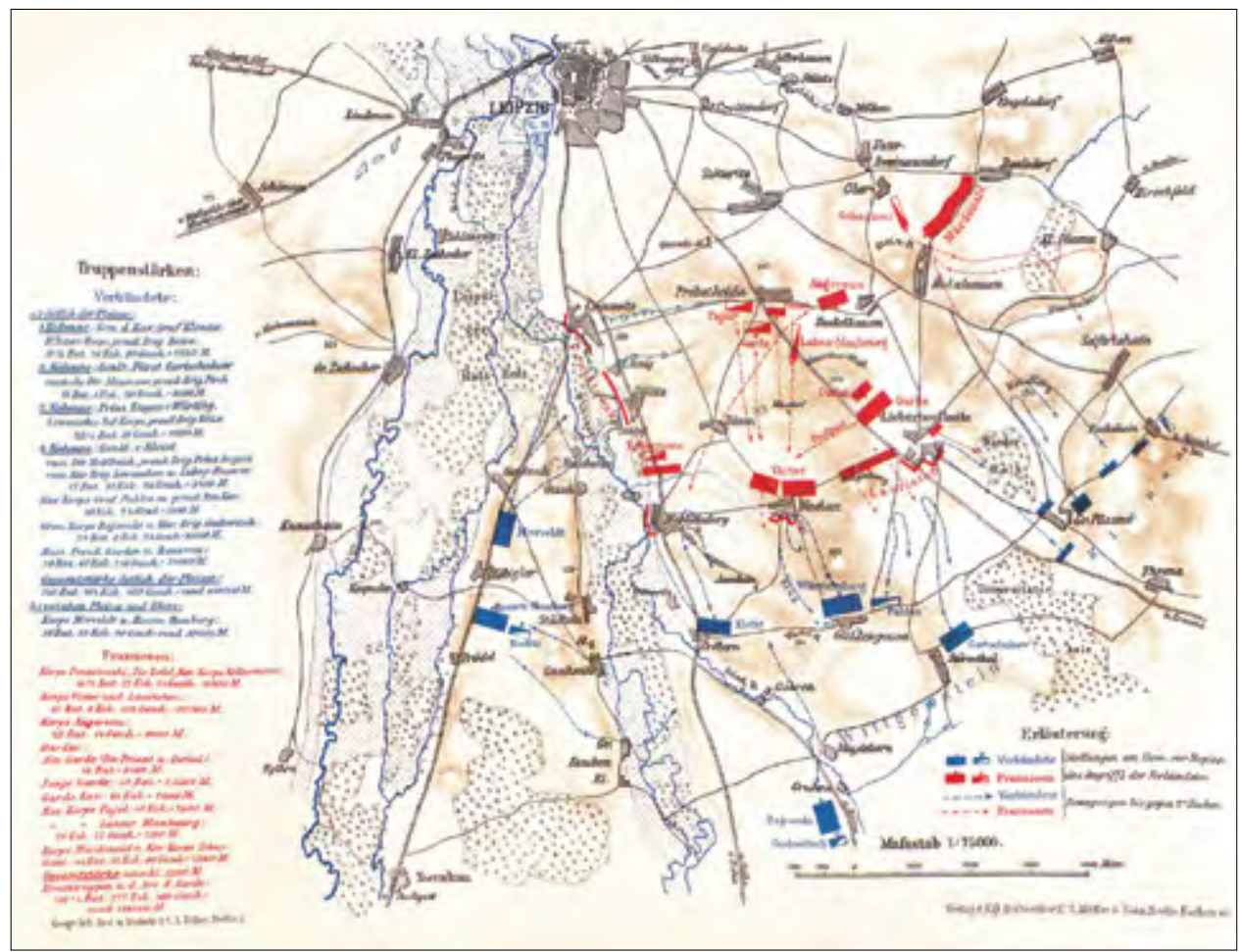

Abb. 14 Truppenaufstellung im Süden Leipzigs am 16. Oktober 1813, aus dem Buch von Rudolf Friederich: Die Befreiungskriege 1813-1815. Bd. 2: Der Herbstfeldzug 1813. Berlin 1912.

Anteil, den die k. k. Truppen an der Schlacht bei Leipzig genommen haben, war groß und ruhmvoll!"“55

Diese Aussage sollte am Ort des Geschehens in den Denkmalen verankert werden. Um dies nachvollziehen zu können, wird im Folgenden der auszeichungswürdige Anteil skizziert, den die auf den Inschriftentafeln angeführten Einheiten und Kommandeure an der Schlacht hatten.

Einfach gesagt hatte die Strategie der Verbündeten darin bestanden, Napoleon mit vereinten Kräften zu schlagen und ihm bis dahin keine Gelegenheit zu geben, alliierte Armeen einzeln niederzuringen. ${ }^{56}$ Anfang Oktober 1813 strebten die Schlesische Armee Blüchers, die Nordarmee Bernadottes, die Hauptarmee Schwarzenbergs und die russische (polnische) Reservearmee Bennigsens aus verschiedenen Richtungen auf Leipzig

55 Orientierende Skizze über die Völkerschlacht bei Leipzig mit besonderer Berücksichtigung des Anteils der k. k. Truppen. Wien o.J. [1813], S. 9.

56 Das Folgende nach Hoen (wie Anm. 53) unter Berücksichtigung von Günther (wie Anm. 20). APEL (wie Anm. 20) und Poser (wie Anm. 36) sind insbesondere in Bezug auf die Ereignisse am 18. Oktober auf dem linken Flügel der Verbündeten nicht verlässlich. 
zu, wo sie Napoleon einzuschließen und zu vernichten hofften. Die Hauptarmee rückte dabei von Süden her an (Abb. 14). Ihr standen auf einer Frontlinie von Connewitz bis Markkleeberg und weiter über den Kellerberg, Wachau und Galgenberg bis Liebertwolkwitz drei französische Korps gegenüber. Die zur Aufklärung vorgeschickte Kavallerie unter General Wittgenstein entfesselte am 14. Oktober das Reitergefecht von Liebertwolkwitz. ${ }^{57}$ Dabei bedrohte das 4. Österreichische Korps unter General Johann Graf von Klenau die linke Flanke der Verteidiger im Bereich Liebertwolkwitz und Kolmberg. Am Ende des Tages stabilisierte sich die Position der Angreifer auf der Linie Gautzsch-Cröbern-Güldengossa-Fuchshain, woraus sich die Disposition für die Schlacht bei Wachau am 16. Oktober ergab. Schwarzenbergs Plan sah vor, den Gegner im Süden auf breiter Front anzugreifen und mit dem 2. Österreichischen Armeekorps unter General Maximilian von Merveldt in seine linke Flanke zu stoßen. Dazu mussten Merveldts Verbände auf das rechte Pleißeufer wechseln, doch sollte ihnen dies weder in Connewitz noch in Lößnig gelingen.

\section{Markkleeberg}

\section{OKTOBER}

Oesterr. Res.-Korps / Div. Nostitz, Weißenwolf / und Bianchi. / Dem Andenken / der in den Kämpfen bei Cröbern, Markkleeberg und / Auenhain gefallenen Helden.

Erste Erfolge der preußischen und russischen Angriffskolonne in Markkleeberg (Abb. 9, 10 und 11) und auf dem Kellerberg und der von Prinz Eugen von Württemberg geführten Angriffskolonne auf Wachau wurden durch die überlegene Artillerie des Gegners zunichtegemacht. Bei einem massiven Gegenangriff brachen die Franzosen und Polen unter Poniatowski durch, besetzten die Ebene zwischen Markkleeberg und Auenhain und trieben die russische Kavallerie bis Cröbern vor sich her. Napoleon ließ in der Stadt die Glocken läuten, um den vermeintlich greifbaren Sieg zu verkünden. Doch auf Druck Zar Alexanders hatte Schwarzenberg am frühen Nachmittag österreichische Reserven, die zwischen Elster und Pleiße standen, in Bewegung gesetzt, die Kürassier-Division unter Johann Nepomuk von Nostiz-Rieneck, die Ungarn-Division unter Friedrich von Bianchi und die Grenadier-Division unter Nikolaus Ungnad von Weissenwolff. Mit einer Kürassier-Attacke auf den Feldern zwischen Cröbern, Crostewitz, Auenhain und Kellerberg konnte Nostitz das französische Vordringen aufhalten. Damit wendete sich das Blatt. Nachdem ein französischer Durchbruchsversuch bei Güldengossa an russischer Gardekavallerie gescheitert war, gelang es der

57 Karte zum Reitergefecht auf der Basis der Sächsischen Meilenblätter bei SEYFERT, Friedrich: Die Völkerschlacht bei Leipzig vom 14. bis 19. Oktober 1813. Dresden 1913 (Deutsche Schlachtfelder 5), Bl. 1. 
Division Weissenwolff zusammen mit Grenadieren des russischen Generals Rajewski schließlich, das Vorwerk Auenhain zurückzuerobern. Bianchi war den im südlichen Markkleeberg gegen eine Übermacht ausharrenden Preußen zu Hilfe gekommen und rückte zeitweilig bis Dölitz und Dösen vor. Als Merveldt dies gewahrte, wagte er vom Schloss Dölitz, einem Brückenkopf links der Pleiße, den die Österreicher schon am Morgen des 16. Oktober den Polen Poniatowskis entwenden konnten, einen Ausfall, bei dem er gefangen genommen wurde. Napoleon schickte ihn am 17. Oktober mit einem Waffenstillstandsangebot zu den verbündeten Monarchen und ordnete bald darauf den Rückzug an.

\section{Lößnig}

\section{6. u. 18. OKTOBER}

General der Kavallerie / Friedrich Erbprinz von Hessen-Homburg / Oesterr. Reservecorps / 1. Korps: Feldzeugmeister Grf. Colloredo / 2. Korps: General der Kav. Frh. von Merveldt. / Dem Andenken der in den Kämpfen um / Connewitz, Lößnig, Dölitz und Dösen / gefallenen Helden.

Für den Angriff am 18. Oktober war eine 1. Kolonne unter Friedrich von HessenHomburg aus seinen bewährten Divisionen Bianchi, Weissenwolff und Nostitz sowie dem am Vortag eingetroffenen 1. Korps unter Feldzeugmeister Hieronymus von Colloredo-Mansfeld und dem 2. Korps Merveldts gebildet worden, welches von Ignaz von Lederer interimsmäßig geführt wurde (Abb. 6). Von Auenhain aus rückte der Großteil der Truppen östlich der Pleiße auf gleicher Höhe wie die 2. (russische) Kolonne von Barclay de Tolly vor. Ein erster Sturm auf Lößnig, Dölitz und Dösen war so erfolgreich, dass Napoleon einer Division seiner Jungen Garde einzugreifen befahl. Der französische Gegenstoß konnte erst in der Weinteichsenke östlich von Markkleeberg aufgehalten werden. Schwarzenberg musste angesichts der massiven Gegenwehr fürchten, „Napoleon wolle ... alle seine Kräfte gegen die Hauptarmee werfen und einen Durchbruch nach Süden versuchen“ ${ }^{58}$ weshalb er Gyulai vom linken Pleißeufer abberief, um dem linken Flügel zu Hilfe zu kommen. Bis Gyulai in Gautzsch eingetroffen war, hatten sich die Österreicher wieder bis Dölitz und Dösen vorgekämpft. Lederer, der auf der linken Seite der Pleiße verblieben war, unterstützte die Angreifer vom Dölitzer Schloss aus. An der Raschwitzer Brücke konnte er wegen der massiven Verteidigung von Connewitz nichts ausrichten. Im weiteren Verlauf wogte die Schlacht um den Höhenrücken nördlich von Dösen und bis Sonnenuntergang um das Dorf Lößnig. ${ }^{59}$ Poniatowski hielt aber Connewitz und blockierte

58 Hoen (wie Anm. 53), S. 603.

59 Seyfert (wie Anm. 57), S. 166: „Erst als Feldzeugmeister Graf Colloredo zwei Regimenter der Division Greth persönlich zum Sturm heranführte, fiel Lößnig in die Hände der Österreicher.“ In Hoens 
weiterhin die Straße nach Leipzig. Erst nachts räumten Polen und Franzosen in aller Stille die Frontstellungen und zogen sich auf die Vorstädte zurück, um den allgemeinen Rückzug zu decken.

\section{Holzhausen}

\section{4., 16. u. 18. OKTOBER}

Oesterr. viertes Korps / General der Kav. Graf Klenau. / Dem Andenken der in den / Kämpfen um Liebertwolkwitz, Kolmberg, / Seifertshain, Holzhausen u. Zuckelhausen / gefallenen Helden.

Klenaus Kolonne erhielt am 16. Oktober den Auftrag, auf Liebertwolkwitz und den Kolmberg vorzurücken und eine Umklammerung an der rechten Flanke abzuwehren (Abb. 15). Das Tempo des Gegners unterschätzend, besetzte Klenau den Kolmberg nur mit zwei Bataillonen und zwölf Geschützen. General Jacques MacDonald stürmte den Hügel, ließ Schanzen anlegen und starke Artillerie in Stellung gehen, die ihm in dieser günstigen Position einen taktischen Vorteil bringen sollte. Am Ende des Tages konnten die Österreicher den verlustreichen Kampf um Seifertshain für sich entscheiden, die Franzosen hielten Liebertwolkwitz.

Am 18. Oktober war Klenaus 4. Österreichisches Korps der am Spätabend des Vortags eingetroffenen russischen Reservearmee unter General Levin August von Bennigsen unterstellt. Diese 3. Angriffskolonne hatte den Raum zwischen Seifertshain und Paunsdorf zu sichern und die Verbindung mit der Nordarmee Bernadottes herzustellen. Schnell stellte sich heraus, dass Napoleon seine Stellungen nach hinten verlegt hatte, um die Front zu verkürzen. Umso verbissener musste um Holzhausen und Zuckelhausen gekämpft werden, denn MacDonald hatte für seine Artillerie auf dem Steinberg erneut eine beherrschende Position gefunden, die er zunächst auch noch als Rückzugsort für die aus beiden Dörfern weichenden Truppen hielt. Am Nachmittag hielten die Franzosen die Linie Probstheida, Stötteritz und Zweinaundorf. Klenau sollte es trotz fortgesetzter Beschießung nicht gelingen, Stötteritz einzunehmen. Am 19. Oktober zog sich MacDonalds Korps auf Leipzig zurück.

Darstellung hat diese Anekdote keinen Eingang gefunden. GüNTHER (wie Anm. 20), S. 93, Anm. 374 stellt mit Bezug auf Aster, Heinrich: Die Gefechte und Schlachten bei Leipzig im October 1813. Bd. 1-2. Dresden 1852-1856 klar: ,Aster behauptet irrtümlicherweise II. 172, der österreichische Angriff sei bis zum (alten, heute verschwundenen) Connewitzer Kirchhofe (Gelände der jetzigen Connewitzer Kirche) vorgetragen worden. Aus den österreichischen Berichten geht hervor, daß die Sturmtruppen nicht weit über Lößnig hinausgekommen sind.“ 


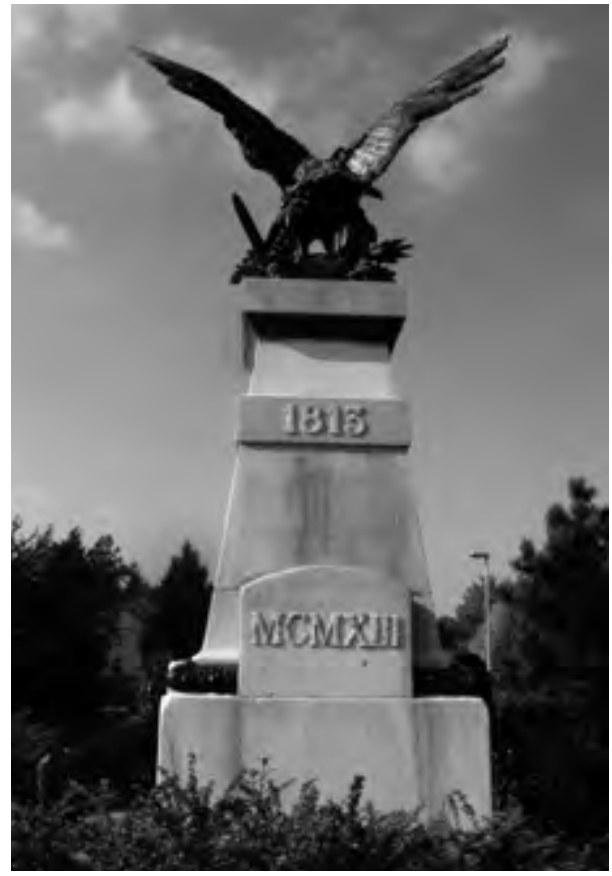

Abb. 15 Österreicher-Denkmal in LeipzigHolzhausen, von Osten. Foto: C. Forster.

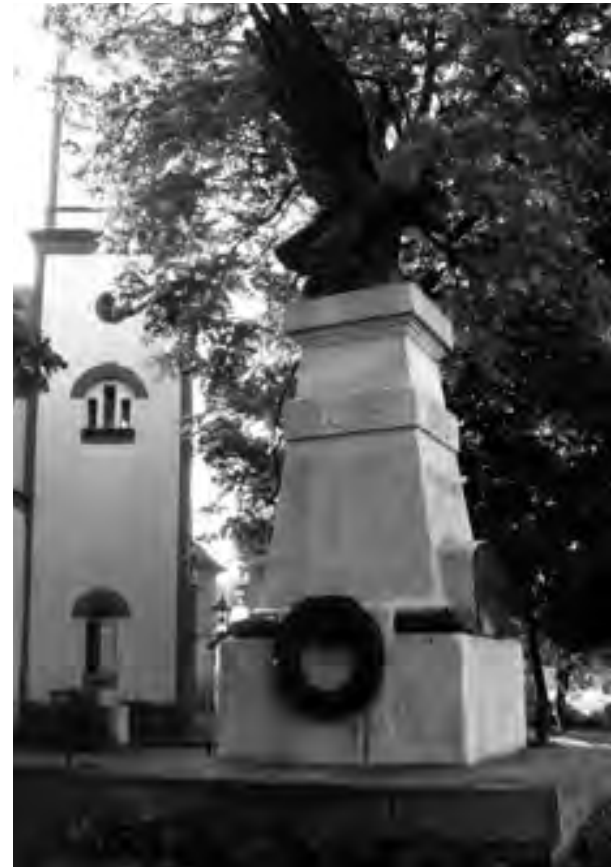

Abb. 16 Österreicher-Denkmal in LeipzigPaunsdorf. Foto: C. Forster.

\section{Paunsdorf}

\section{OKTOBER}

Oesterreichische / zweite leichte Division / Feldmarschalleutnant Graf Bubna. / Dem Andenken der in den / Kämpfen um Paunsdorf u. Mölkau / gefallenen Helden.

Beim Gefecht um Leipzig am 18. Oktober war die 2. Leichte Division unter Ferdinand Graf von Bubna und Lititz Bennigsens russisch-polnischer Reservearmee angegliedert (Abb. 16). Ihre Aufgabe bestand darin, Paunsdorf einzunehmen, um den Verteidigungsring um Leipzig zu durchbrechen, oder den Franzosen solange zuzusetzen, bis die Nordarmee des Kronprinzen von Schweden eintraf. Den Österreichern gelang es mehrmals, in Paunsdorf einzufallen, doch wurden sie stets zurückgeworfen. Erst nachdem von Norden das Korps Bülow herangerückt war und den Artilleriebeschuss verstärkte und eine sächsische Division, die bei Stünz im 2. Treffen stand, zu den Verbündeten übergelaufen war, musste General Reynier Paunsdorf aufgeben und sich auf Sellerhausen zurückziehen. Nach der Einnahme Paunsdorfs wandte Bubna sich nach Süden und eroberte zusammen mit der russischen Avantgarde Mölkau. 
Hoen beklagte die relativ dürftige Quellenlage zum Einsatz Bubnas, um zu schließen: „An der Tatsache kann aber nicht vorübergegangen werden, daß die Division Bubna an der Ostfront von Leipzig bis 2 Uhr nachmittags allein den Kampf bestritt, französische Streitkräfte auf sich zog und zu Gunsten der anderen Gefechtsabschnitte dort zähe festhielt." “60

\title{
Kleinzschocher
}

\author{
16. u. 18. OKTOBER
}

Oesterr. 3. Korps / Feldzeugmeister Graf Gyulai / 1. Leichte Division Feldmarschalleutnant / Prinz Moritz Liechtenstein / Detachement Oberstlt. Frh. v. Simbschen. / Dem Andenken der in den Kämpfen bei Lindenau, Zschocher u. Schleussig / gefallenen Helden.

Am 16. Oktober näherten sich das 3. Österreichische Korps unter Ignaz Graf Gyulai und die 1. Leichte Division unter Moritz Fürst Liechtenstein Leipzig von Markranstädt her. Gyulai war auf der Hauptetappenlinie Napoleons vorgerückt, um den Nachzug von Verstärkungen zu unterbinden. Jetzt sollte er Leipzig von Westen her angreifen (Abb. 17-18). Er schickte einen linken Flügel unter Prinz Philipp von Hessen-Homburg gegen Leutzsch und einen rechten Flügel unter Liechtenstein gegen Groß- und Kleinzschocher. Das zur Armeeabteilung Merveldts gehörende Bataillon Gradiskaner Nr. 8 unter Oberstleutnant Joseph von Simbschen unterstützte Liechtenstein von Schleußig aus mit Flankenfeuer. Gyulai selbst rückte auf der Chaussee gegen Lindenau vor. Das Dorf war anfangs verhältnismäßig schwach besetzt, aber durch eine Mauer und Erdschanzen geschützt. Nachdem die erste Einnahme Lindenaus schon an der feindlichen Artillerie scheiterte, war dort während des zweiten Sturms, den Hessen-Homburg unternahm, die unüberwindliche Verstärkung eines gan-

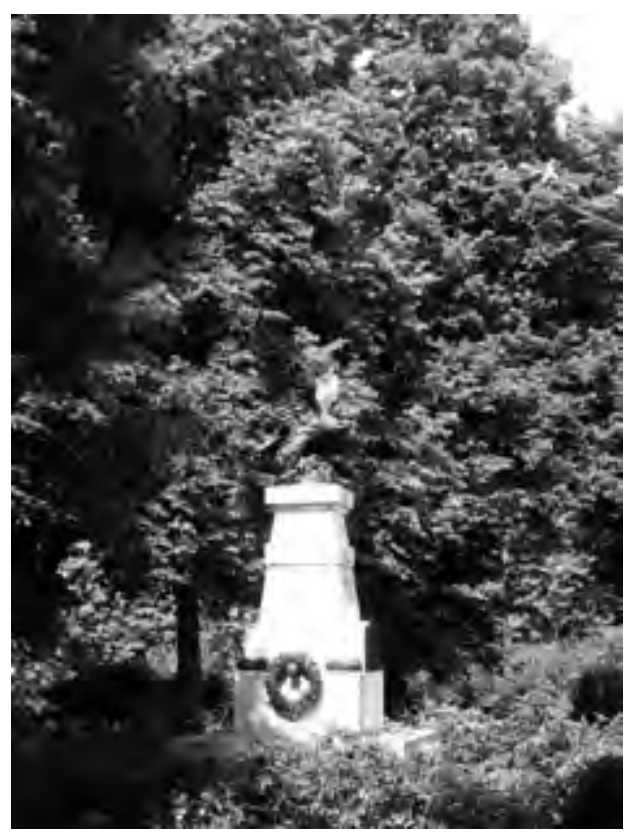

Abb. 17 Österreicher-Denkmal in Leipzig-Kleinzschocher. Foto: C. Forster.

60 Hoen (wie Anm. 53), S. 625. 


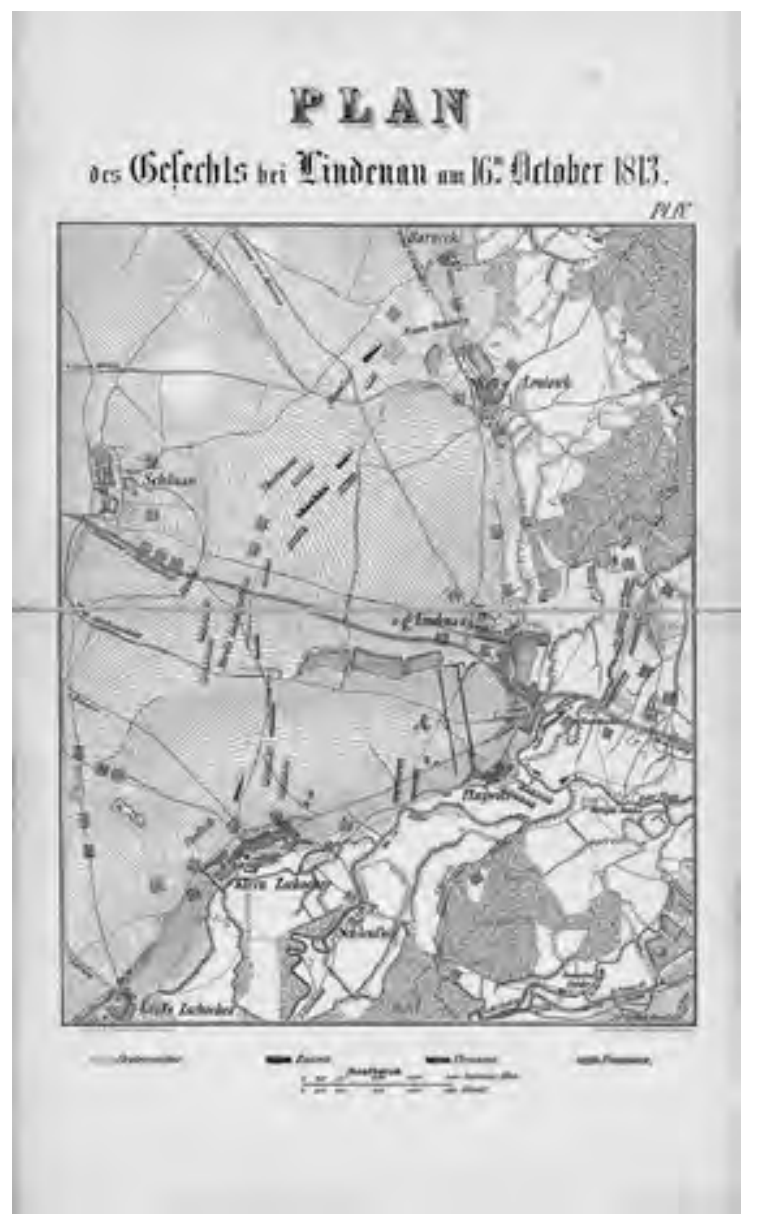

Abb. 18 „Plan des Gefechts bei Lindenau am 16 n October 1813", aus dem Buch von Heinrich Aster: Die Gefechte und Schlachten bei Leipzig im October 1813. Bd. 1-2. Dresden 1852-1856, PI. IV (auf der Grundlage der Sächsischen Meilenblätter, nicht geordnet).

zen Korps unter General Henri-Gatien Bertrand eingetroffen. Dieser wehrte die Österreicher ab und ging zum Gegenangriff über. Am Abend hielt Gyulai noch immer die Linie Leutzsch-Kleinzschocher. Am Morgen des 18. Oktober unternahm Bertrand zur Sicherung des Abzugs einen erfolgreichen Angriff auf Kleinzschocher. Bevor auch Schleußig in feindliche Hände fiel, verbrannte Simbschen die Brücke, die beide Orte über die Elster verband. Gyulai wurde von Schwarzenberg zum südlichen Gefechtsfeld abgezogen, während Bertrand entlang der Chaussee aufmarschierte. Dadurch war Napoleons Rückzug gesichert. ${ }^{61}$

Für das Denkmal in Kleinzschocher, das allgemein dem Kampf um den Leipziger Westen gewidmet war, wurde an der Elsterbrücke gegenüber Schleußig ein Ort gefunden, der durch die heroische Tat eines österreichischen Offiziers eine besondere Bedeutung gewonnen hatte. In seiner Rede bei der Einweihungsfeier am 2. Dezember 1913

61 Vgl. Hoen (wie Anm. 53), S. 578-586, 608-613. 
betonte der Ordensgreffier von Kailer, dass mit der Wahl des Standorts Oberstleutnant Simbschen geehrt werden solle, der durch das Halten von Schleußig und der Brücke die Franzosen gezwungen hatte, ihren Rückzug ausschließlich über den Rannischen Steinweg zu nehmen..$^{62} 1815$ hatte der junge Offizier dafür das Ritterkreuz des MilitärMaria-Theresien-Ordens erhalten. ${ }^{63}$ In der Tat wäre ein Abzug über die Alte Pleiße und durch das Ratsholz am Vormittag des 18. Oktober, als Simbschen die Brücke in Brand steckte, für die im Süden stehenden französischen Truppen noch eine Option gewesen. Das im Handstreich genommene Schloss Dölitz ist ein zweiter Ort, an dem das Gedenken an eine herausragende österreichische Leistung wachgehalten werden konnte, doch hatte sich der Eigentümer von Winckler nur zur Anbringung einer Tafel durchringen können (Abb. 15). Zu den vier weiteren Österreicher-Denkmalen sind keine vergleichbaren Äußerungen von Kailers überliefert.

Vergegenwärtigt man sich den Hergang der Schlacht, stellt sich heraus, dass die Denkmale bei Markkleeberg und Holzhausen inmitten eines ehemaligen Gefechtsraumes platziert sind. Das Paunsdorfer Objekt hat neben der Pfarrkirche des Dorfes eine auch langfristig prominente Position inne, und das Lößniger Objekt steht neben der 1813 stark umkämpften Bornaischen Straße an einem Punkt, bis zu dem die Österreicher vor dem 19. Oktober wahrscheinlich gar nicht vorgedrungen waren. Der bei der Stadterweiterung geplante Park an dieser Stelle bot sich als Kulisse für das Denkmal einfach an.

\section{Schluss}

Die vom Militär-Maria-Theresien-Orden errichteten Doppeladler-Monumente sind keineswegs als Siegesmarken zu verstehen. An verschiedenen Frontabschnitten aufgestellt, bezeugen sie die Teilnahme österreichischer Kontingente und lassen durch ihre Verteilung um Leipzig die erfolgreiche Strategie der Einkesselung erkennen, die Schwarzenbergs Generalstabschef Josef Wenzel Radetzky von Radetz entwickelt hatte. ${ }^{64}$ Sämtliche in den Inschriften genannte Korps- und Divisionskommandanten waren Träger des Militärischen Maria-Theresien-Ordens. Fünf von ihnen - Nostitz, Bianchi, Friedrich Erbprinz von Hessen-Homburg, Weissenwolff und Bubna - hatten diese Auszeichnung ebenso wie Oberstleutnant Simbschen für ihren hervorragenden Einsatz während der Leipziger Völkerschlacht erworben. ${ }^{65}$ Die in den Widmungs-

62 Leipziger Tageblatt, Nr. 614, 3.12.1913.

63 Hirtenfeld, Jaromir: Der Militär-Maria-Theresien-Orden und seine Mitglieder, Bd. 1-4. Wien 1857, hier Bd. 2, S. 1241 mit der ungesicherten Überlieferung: „Selbst Fürst Poniatowsky suchte in dieser Gegend einen Ausweg und ertrank“. Vgl. Hoen (wie Anm. 53), S. 656: ,auch Poniatowski hatte nach der Aussage seines gefangenen Ordonnanzoffiziers einen Ausweg über Schleußig gesucht“".

64 Zuletzt Mitterer, Kurt Anton: Die Rolle Österreichs im Feldzug 1813. In: 1813. Kampf um Europa. Die Österreicher in der Völkerschlacht bei Leipzig. Ausst.-Kat. Historisches Torhaus Markkleeberg. Hg. v. Wolfgang Gerlach und Rainer Baumann. Markkleeberg 2013, S. 16-27, bes. S. 16-20.

65 Hirtenfeld (wie Anm. 63), Bd. 2, S. 1145-1158, 1231-1235; vgl. Hoen (wie Anm. 53), S. 666 f. 
zeilen genannten Kämpfe waren besonders verlustreich und hatten sich meist über mehrere Tage hingezogen. An den hohen Blutzoll sollte erinnert werden, denn die große Zahl der Gefallenen legitimierte Österreichs Anteil an der Neugestaltung Europas nach dem Sieg über Napoleon. In ähnlicher Weise brachte sich 1913 auch die russische Seite in den Gedenkwettbewerb mit Deutschland ein, argumentierte dabei aber mit konkreten Zahlen, um zu verdeutlichen, dass die Truppen des Zaren bei den Kämpfen um Leipzig zwischen dem 16. und dem 19. Oktober 1813 die meisten Verluste unter allen Verbündeten erlitten hatten. Freilich werden auf den Steintafeln an den Portalflanken der Russischen Gedächtniskirche die nach militärischer Konvention so genannten „Verluste“, die Tote, Verwundete, Gefangene und Vermisste umfassen, irrtümlich mit Gefallenen gleichgesetzt. ${ }^{66}$ Auch auf österreichischer Seite hatte das Leipziger Völkerschlachtdenkmal und die auftrumpfende deutschnationale Rhetorik, die seinen Bau begleitete, Verärgerung hervorgerufen. Dem großspurigen Bauwerk des Deutschen Patriotenbundes setzte man klugerweise ein militärisch-sachliches Konzept entgegen. Seitens der Leipziger Stadt- und der Kreisverwaltung war man dem österreichischen Bauvorhaben von Anfang an hilfreich entgegengekommen.

Am Tag der Einweihung des Völkerschlachtdenkmals verlegte Franz Ferdinand die österreich-ungarische Feier dennoch nicht an die eigens zu diesem Anlass errichteten Denkmale des Maria-Theresien-Ordens, sondern an den Schwarzenberg-Stein, der schon seit 1838 auf dem sogenannten Monarchenhügel in Meusdorf das Gedenken an den Oberkommandierenden der alliierten Armeen auf sich zog. Der Grund dürfte nicht darin zu suchen sein, dass nur eines der Österreicher-Denkmale (in Lößnig) rechtzeitig zum 18. Oktober fertiggestellt war. Für die Doppelmonarchie Österreich-Ungarn besaß das Meusdorfer Denkmal den größeren Repräsentationswert, auch und gerade wegen der fortgesetzten Kritik an Schwarzenbergs Befehlen, seinen Einschätzungen der Lage und seiner Führung vonseiten der preußischen und kleindeutschen Historienschreibung der Völkerschlacht. ${ }^{67}$ Der Erzherzog-Thronfolger, der militärischen Hierarchien große Bedeutung beimaß, dürfte in Oberbefehlshaber Schwarzenberg auch einen Amtsvorgänger geehrt haben, nachdem er am 17. August 1913 von Franz Joseph I. zum „Generalinspektor der gesamten bewaffneten Macht" ernannt worden war.

66 „In diesen Schlachten / fielen: / 22000 Russen / 16000 Preußen / 12000 Oesterreicher / 300 Schweden.“ Die absoluten Zahlen decken sich im Falle der Russen und Preußen mit dem „Verlustausweis der Verbündeten" bei Hoen (wie Anm. 53), Anhang VI und sind für die schwedischen Verluste nach unten zu korrigieren (215). Die österreichischen Verluste beziffert HoEn (wie Anm. 53), Anhang V auf 419 Stabs- und Oberoffiziere und 14.541 Unteroffiziere und Mannschaften (ohne das Reitergefecht bei Liebertwolkwitz am 14.10.1813).

67 Vgl. Woinovich (wie Anm. 14), S. 45, 98, 132; Hoen, Maximilian von: Der Festartikel „Leipzig“ im Berliner „Militär-Wochenblatt“" vom 18. Oktober 1913. In: Streffleurs Militärische Zeitschrift 90 (1913), S. 1773-1786; Mitterer (wie Anm. 64), S. 16 f. 


\title{
Die Archäologie der Völkerschlacht bei Leipzig 1813
}

\author{
Thomas Westphalen
}

An vier Tagen im Oktober 1813 entschied die Niederlage Napoleons vor Leipzig über das Schicksal Europas. Obwohl heute zu großen Teilen im Stadtbild Leipzigs aufgegangen, kann der Verlauf der Schlacht an zahlreichen Denkmälern und (wenigen) archäologischen Befunden nachgezeichnet werden.

Berührungspunkte zwischen dem Geschehen während der Napoleonischen Kriege im Allgemeinen und der Völkerschlacht im Einzelnen einerseits und der sächsischen Landesarchäologie andererseits zu finden, ist im 200. Jubiläumsjahr der Völkerschlacht bei Leipzig eine reizvolle Aufgabe. Um es gleich vorweg zu sagen, neue Beiträge, die das Geschehen zwischen dem 14. und 19. Oktober 1813 zu erklären versuchen, vermag die Archäologie nicht zu liefern. Zu dicht ist die Überlieferung, die, sich aus Zeitzeugenberichten, überlieferten Befehlen, Statistiken, Zeichnungen, Gegenständen und Memoiren zusammensetzend, ein nahezu lückenloses und minutiöses Bild des Ablaufes der Kampfhandlungen zu zeichnen ermöglicht. Und: $\mathrm{Zu}$ groß ist die Überformung des im Herbst 1813 noch weitestgehend agrarisch geprägten Leipziger Umlandes, das durch Eingemeindungen und intensivste urbane Überprägung längst Teil der Großstadt geworden ist. Außerdem ist zu bedenken, dass mit einer unmittelbar von Kampfhandlungen betroffenen Operationsfläche von knapp 400 Quadratkilometern die Völkerschlacht eine größere Fläche einnahm als die meisten Schlachten des Ersten Weltkriegs. Allein die südliche Frontlinie hatte am 16. Oktober 1813 eine Länge von ca. 15 Kilometer.

Dennoch gibt es die Berührungspunkte: Funde von Kanonen- oder Gewehrkugeln und Uniformteilen waren nicht selten. Immer wieder stieß man auf Skelette von Gefallenen und Pferden. In den Ostakten des Landesamtes für Archäologie stammt die älteste Nachricht aus Leipzig-Schönefeld, wo 1936 unter dem Pflaster der Bergerstraße gefundene Skelette als Opfer der Völkerschlacht identifiziert wurden. Wie hoch die Dunkelziffer ist, lässt sich nicht verlässlich sagen. Bereits 1824 begann man mit gezielter Nachsuche auf dem nördlichen Schlachtfeld, als Ritter Max von Sternburg die Fruchtbarkeit seiner Ländereien um Lützschena mit den gemahlenen Knochen der Begrabenen zu verbessern suchte. „Die Knochenlieferungen“ (mit denen er seine dafür aus England importierte Knochenmühle betrieb) „wurden meist von armen Leuten besorgt, die sie in Leipzigs Umgebung, wo in dem Jahr 1813 viele Tausend der gefallenen Krieger begraben [...], in ansehnlicher Quantität gesammelt." " Über das Landschaftsbild des Schlachtfeldes geben die entsprechenden Sächsischen Meilenblätter Auskunft. Dieses Kartenwerk wurde unter Napoleon vollendet und war einer der Gründe für dessen

1 Sternburg, Max von: Landwirtschaftliche Beschreibung des Ritterguts Lützschena bei Leipzig mit seinen Gewerbezweigen. Leipzig 1842, S. 73. 
strategische Überlegenheit, gab es doch eine verlässliche und großmaßstäbliche topografische Übersicht über das Schlachtfeld. Heute sind die drei Ausgaben, die als Kriegsbeute auch in Paris und Berlin aufbewahrt wurden, eine wichtige Grundlage für die Inventarisation archäologischer Denkmäler, da heute verschwundene Grabhügel, Burgwälle, Hohlwege, Schäfereien etc. als damals militärisch wichtige Geländemarken minutiös aufgenommen wurden. In den Jahren nach der Schlacht ist mit den zahllosen Grabstellen ein weiteres Landschaftselement hinzugekommen. Gerade Massengräber, in denen häufig Dutzende Gefallener oder mehrere Pferdekadaver verscharrt wurden, müssen dem Offenland streckenweise das Bild einer endlosen Hügelgräberlandschaft und natürlich denjenigen, die die Gräber fledderten, Anhaltspunkte für die erfolgreiche Suche gegeben haben.

Der Bau der Bundesautobahn 38, die zum Teil durch das „südliche Schlachtfeld“ führt, zeigte, dass angesichts der enormen Opferzahlen die Funddichte ausgesprochen dünn ist. Auf einer Strecke von ca. fünf Kilometer lagen lediglich 19 Pferdebestattungen und ein verscharrter Soldat, obwohl hier am 16. Oktober Tausende Menschen und ungezählte Pferde ihr Leben ließen.

Aufschluss über die am Geschehen direkt oder indirekt Beteiligten geben die Funde von insgesamt fünf Grabstellen mit insgesamt 137 Bestatteten, die nach 1993 archäologisch und zum Teil auch anthropologisch untersucht wurden.

Der jüngste, 2011 getätigte Fund mit mindestens zehn Bestattungen dürfte der Schlacht von Möckern am 16. Oktober zuzuordnen sein. An der ehemaligen Flurgrenze zwischen den Dörfern Möckern und Gohlis gelegen, wurden die offensichtlich sehr jungen Individuen recht zügig in die angelegte Grabgrube geworfen (Abb. 1). Aus dem Befund wurden mehrere Uniformknöpfe und die Überreste eines Tornisters geborgen. Ein Knopf gehörte zu der Uniform des 1. Regiments der französischen Marine-Artillerie, das als Eliteeinheit bei der Verteidigung Möckerns durch die Preußen aufgerieben wurde. Die wenigen Kleidungsreste lassen darauf schließen, dass die Toten entweder gar nicht oder allenfalls spärlich bekleidet beigesetzt wurden.

Reste eines Massengrabes zunächst unbekannter Zeitstellung wurden Anfang April 2008 bei Bauarbeiten im Zuge der Erweiterung des Leipziger Zoos entdeckt und anschließend vom Landesamt für Archäologie Sachsen ausgegraben. Diese Fundstelle liegt im Bereich des ehemaligen Gutes Pfaffendorf nördlich der Leipziger Altstadt. Aufgrund der weit fortgeschrittenen Ausbaggerungsarbeiten und erheblicher Störungen durch die Verlegung einer Kabeltrasse in den 1960er Jahren, bei denen das Grab westlich durchschnitten wurde, ließ sich die Form der Grabgrube nicht mehr erkennen. Erhalten und ausgegraben wurde ein etwa dreieckiger Ausschnitt mit einer maximalen Kantenlänge von drei Metern. Dokumentiert wurden insgesamt 19 ganz oder teilweise geborgene menschlichen Skelette sowie ein weitgehend erhaltener ca. fünfjähriger Hengst. Außer den menschlichen Überresten wurden zudem Knöpfe, Kleidungsreste und eine Münze geborgen.

Die anthropologisch-paläopathologische Bearbeitung erfolgt im Rahmen mehrerer Lehrveranstaltungen an den Universitäten Leipzig und München und ist noch nicht abgeschlossen. 
Die Geschlechts- und Altersverteilung unterscheidet sich vollständig von zeitgleichen ländlichen oder städtischen Bevölkerungsgruppen: Nachgewiesen wurden bislang elf Männer, zwei Frauen und ein nicht geschlechtsbestimmbares Individuum. Die Hälfte der bislang untersuchten Individuen verstarb unter 20 Jahren, nur ein Mann erreichte ein Alter von über 40 Jahren. Bei den nicht zuzuordnenden Skelettelementen ist oft nur eine grobe Altersschätzung möglich.

Die Todesursache konnte bislang nur bei zwei Individuen bestimmt werden: Ihre Schädel zeigten Spuren eines scharfen Traumas bzw. Schusswunden. Die anderen verstarben wahrscheinlich an nicht am Knochen nachweisbaren Verletzungen oder Krankheiten. Die Zahl der bisher beobachteten Knochenbrüche ist gering: Zwei Männer wiesen gut verheilte Schlüsselbeinfrakturen auf, ein anderer einen gut verheilten Bruch des Oberschenkels. Schlechte Zahnhygiene konnte bei allen Individuen in Form von dicken Zahnsteinbelägen und Kieferentzündungen belegt werden. Hinzu kamen ausgedehnte kariöse Defekte und intravitale Zahnverluste. Entzündungen der Nasennebenhöhlen wurden bei vielen Toten beobachtet. Von schwerwiegenden Infektions-

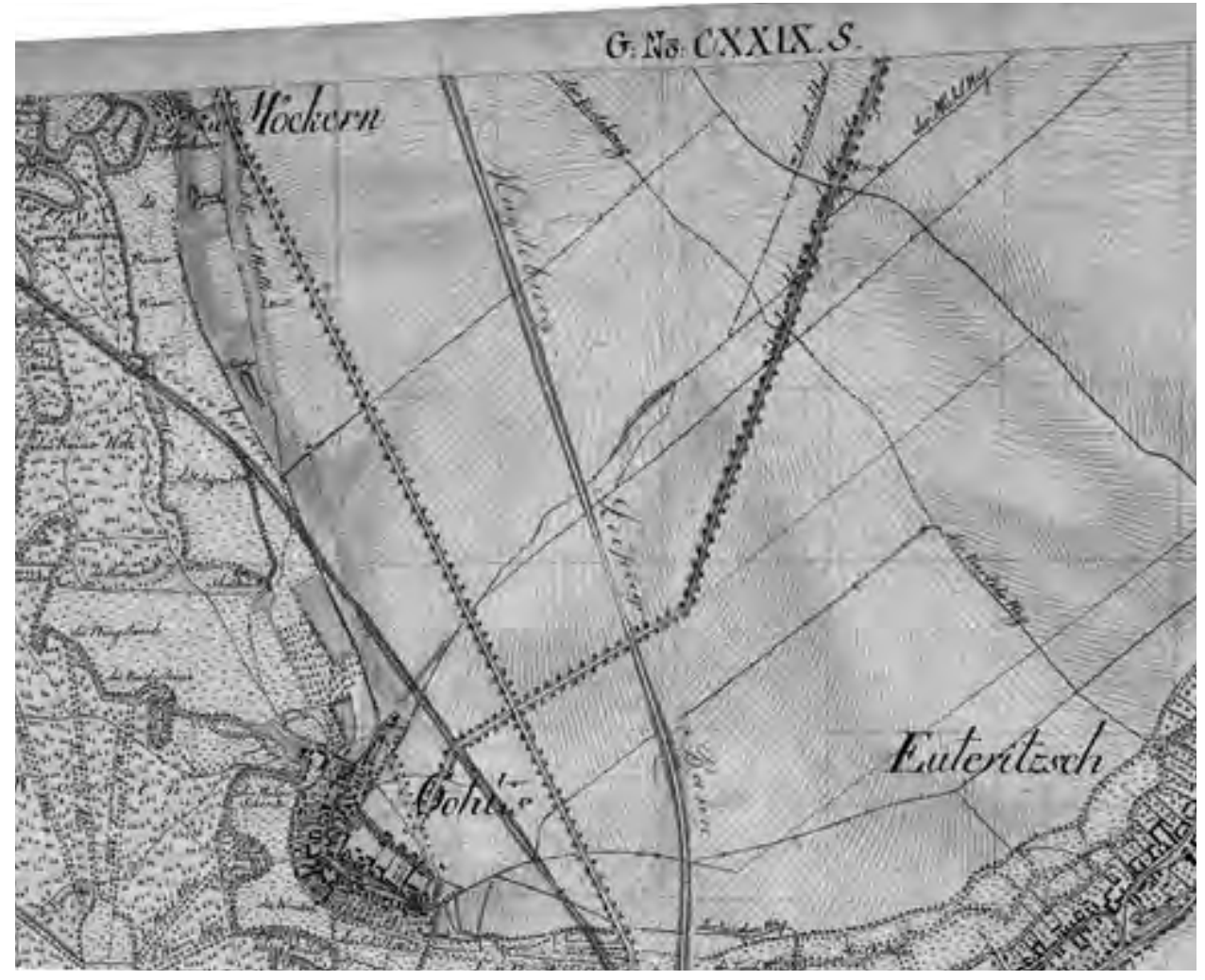

Abb. 1 Lage des Massengrabes Gohlis und Pferdebestattungen südlich von Lindenthal. Kartengrundlage sind die Blätter F 3 und F 7 des Freiberger Meilenblattes. Bearbeitung: Sven Kretzschmar, Thomas Westphalen, Landesamt für Archäologie Sachsen. 
krankheiten ist bei einem jüngeren Individuum eine Wirbelsäulentuberkulose nicht auszuschließen.

Degenerative Veränderungen, vor allem der Wirbelsäule, waren allgemein üblich, Jugendliche und junge Erwachsene litten an der Scheuermann'schen Erkrankung (Abb. 2). Die Ansatzstellen von Bändern und Muskeln zeigten bereits bei Jugendlichen extreme Überlastung, insbesondere im Schulterbereich. ${ }^{2}$

Wer waren nun diese Toten? Die Tatsache, dass wir es hier überwiegend mit jungen Männern mit deutlichen Spuren von Überlastung zu tun haben, weist zusammen mit den gefundenen Uniformresten darauf hin, dass im Bereich des Gutes Pfaffendorf überwiegend Soldaten bestattet wurden. Das weitgehende Fehlen von akuten Traumata deutet möglicherweise auf Lazarettinsassen, die an akuten Infektionen wie z.B. Cholera, Typhus, aber auch an Verletzungen, Blutvergiftung und Ähnlichem verstorben sein könnten. Es ist nicht unwahrscheinlich, dass wir es mit den Toten aus einem der beiden Lazarette auf dem Gut Pfaffendorf zu tun haben, die ab Juni 1813 eingerichtet wurden. Eines stand unter Leitung des jungen Leipziger Anatomieprofessors Carl Gustav Carus. Er selbst erkrankte nach der Völkerschlacht in seinem Lazarett an Typhus, überlebte und hat davon eindrucksvoll in seinen Lebenserinnerungen berichtet. ${ }^{3}$ Um den Lazarettbetrieb ungefährdet fortzusetzen, wurden die Toten nördlich außerhalb der Gutsgebäude bestattet.

Einer der gefundenen Uniformknöpfe trug die Ziffern „48“. Das „48ème Régiment d'Infanterie de Ligne“" war jedoch zuletzt 1806 in Leipzig und während der Völkerschlacht in Hamburg stationiert. ${ }^{4}$ Ob einzelne Soldaten (oder Ausrüstungsgegenstände) dennoch an der Schlacht teilnahmen, muss offenbleiben. Um der Ausbreitung von Seuchen vorzubeugen, wurde das Massengrab vom Leipziger Zoo nach abgeschlossener Belegung mittels Kalk abgedeckt.

Bereits 1996 konnten auf dem Gelände des ehemaligen Georgenhospitals zwischen modernen Kellern drei Massenbestattungen mit insgesamt 96 Bestatteten dokumentiert werden (Abb. 3). Auch gab die anthropologische Untersuchung ${ }^{5}$ einen Einblick in die mangelhaften Verhältnisse, denen nicht nur verwundete Soldaten, sondern auch die Stadtbevölkerung ausgesetzt waren. Zwar dominieren junge männliche Individuen Soldaten, die häufig Verletzungen am Skelett aufwiesen. Daneben wurden aber auch Kinder- und Frauenskelette identifiziert und damit ein deutlicher Hinweis auf die beginnende Typhusepidmie gegeben, der im Herbst 1813 insgesamt weitere 30.000 Menschen

2 TeEgen, Wolf-Rüdiger: Ein Massengrab napoleonischer Zeit aus Leipzig II: Erste Untersuchungen zur Anthropologie und Paläopathologie. Poster, Tagung „Schlachtfeld und Massengrab - Spektren interdisziplinärer Auswertung von Orten der Gewalt“", Brandenburg, 21.-24. November 2011 (für den Tagungsband eingereicht). Zusammenfassung in: http://www.1636.de/wp-content/uploads/2011/11/ Abstracts.pdf, S. 41 (26.05.2013).

3 CARus, Carl Gustav: Lebenserinnerungen und Denkwürdigkeiten. Bd. 1-2. Leipzig 1865, hier Bd. 1.

4 Teegen (wie Anm. 2).

5 ZINK, Albert, u.a.: Abschlußbericht der anthropologischen/paläo-pathologischen Untersuchungen zu den Ausgrabungen beim „Hotel Stadt Leipzig“. In: Arbeits- und Forschungsberichte zur sächsischen Bodendenkmalpflege 39 (1997), S. 207-226. 


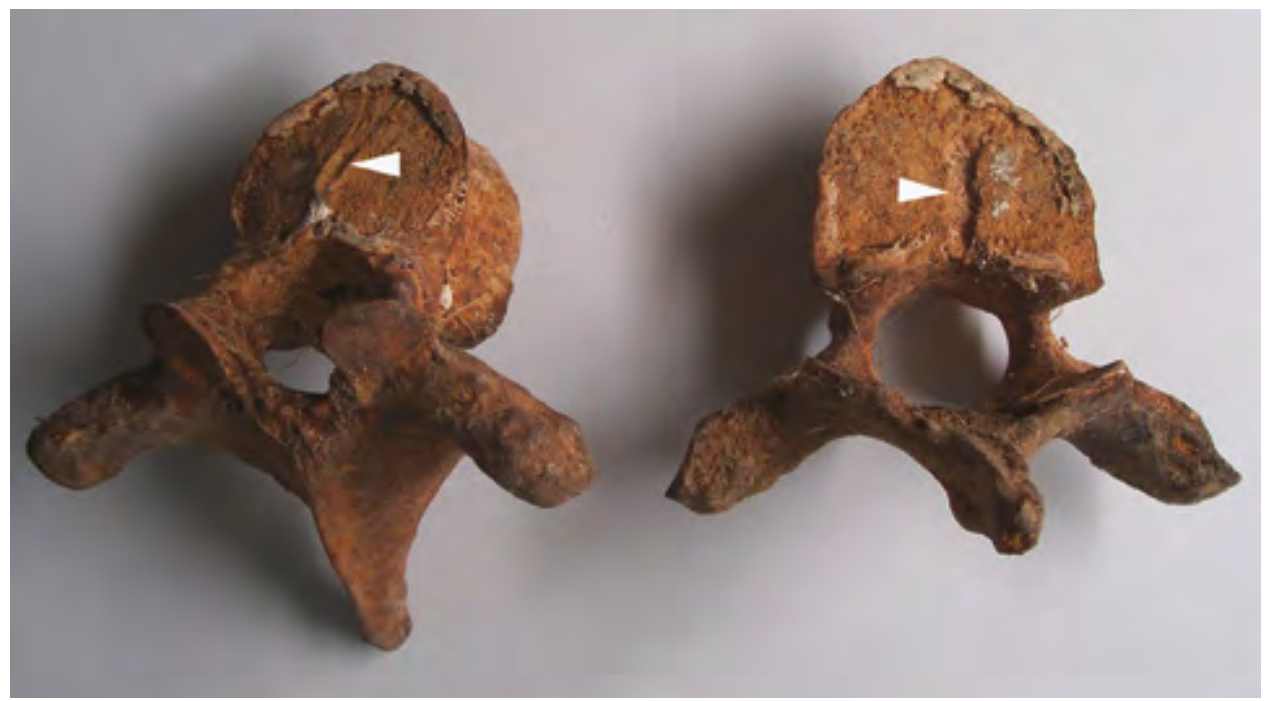

Abb. 2 Jugendlicher mit Verdacht auf die Scheuermann'sche Erkrankung. Gut erkennbar sind die sogenannten Schmorl'schen Knorpelknoten (Pfeile), an denen aufgrund einer Fehlbelastung Bandscheibengewebe in die Wirbelkörper gedrückt wurde. Foto: W.-R. Teegen.

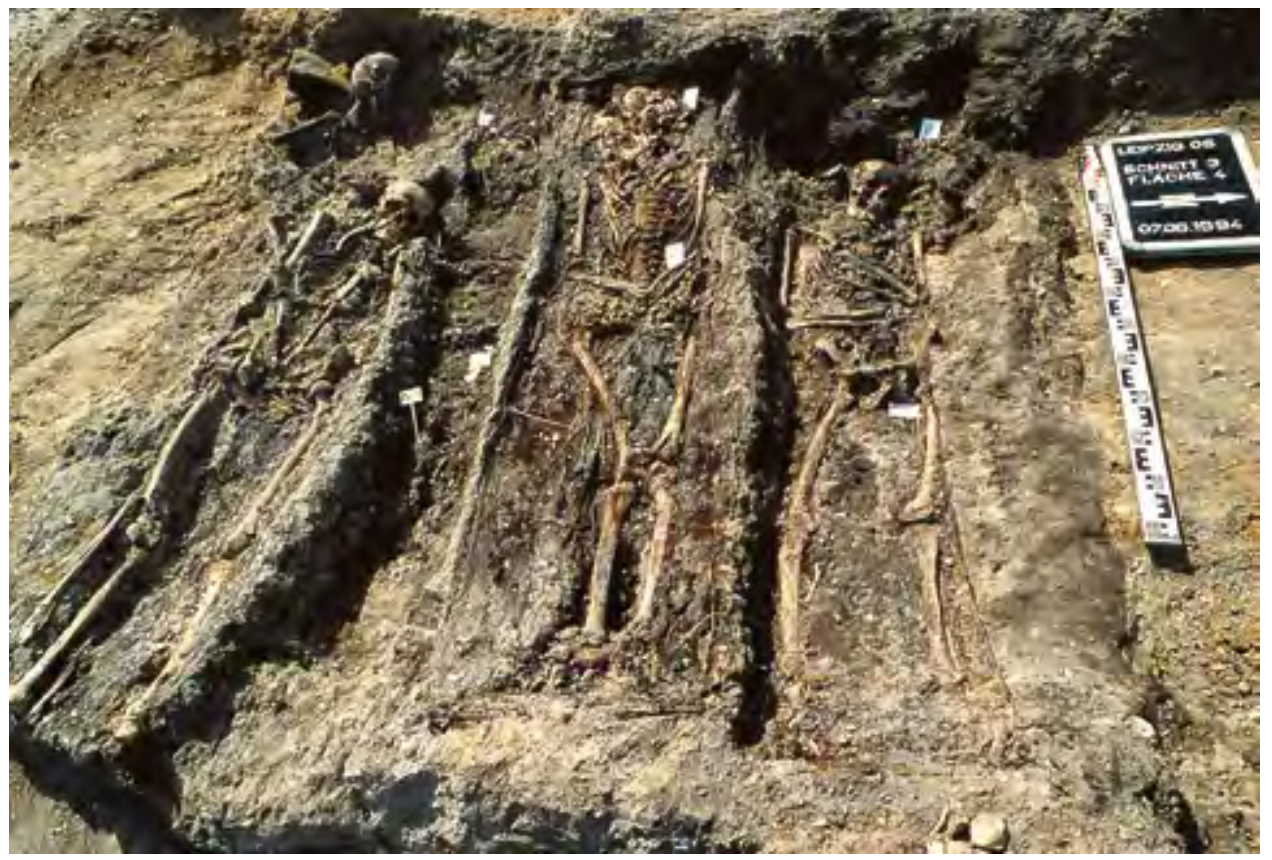

Abb. 3 Blick von Norden in die rechteckige Grube eines Massengrabes aus dem Georgenhospitals. Im unteren Bereich waren die Toten übereinanderliegend in einfachen Holzsärgen bestattet. Foto: Landesamt für Archäologie Sachsen. 


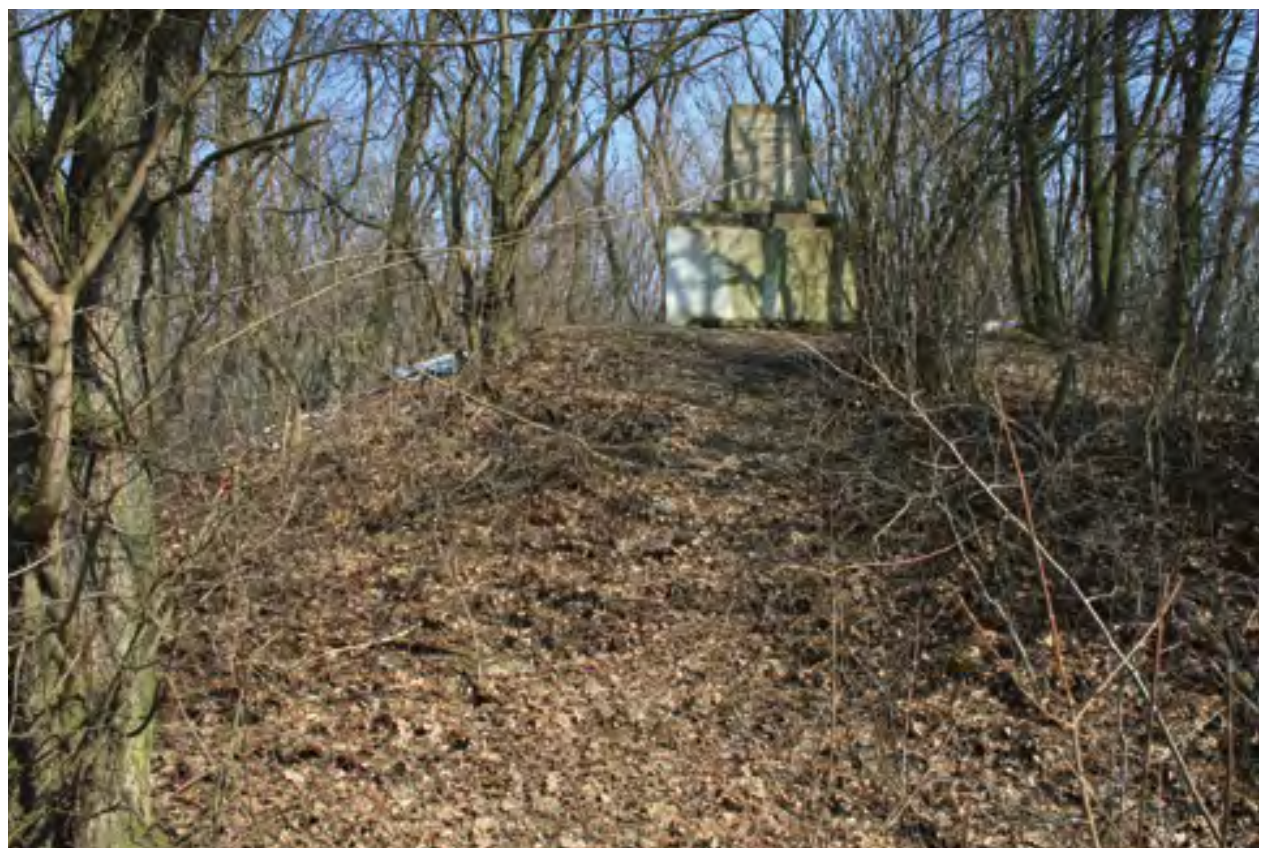

Abb. 4 Der Kolmberg bei Holzhausen war am 16. Oktober einer der Brennpunkte des Kampfgeschehens. Daran erinnert das pyramidenförmige MacDonald-Klenau-Denkmal. Foto: Thomas Westphalen.

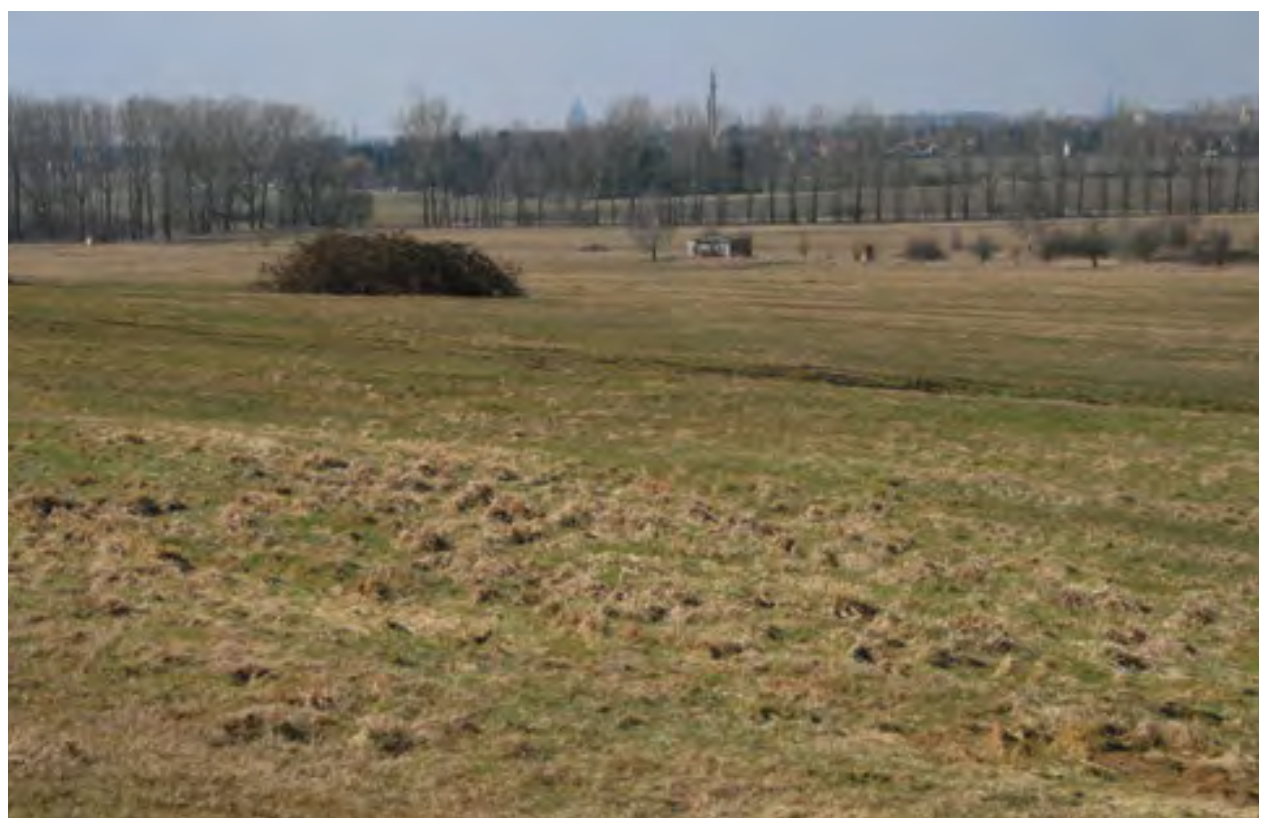

Abb. 5 Die Landmarken der Völkerschlacht - Blick vom Kolmberg, Ort des Geschehens am 16.10.1813, zum Völkerschlachtdenkmal auf den Kampfplatz vom 18.10. zum City-Hochhaus nahe des Grimmaischen Tores, erstürmt am 19.10.1813. Foto: Thomas Westphalen. 
zum Opfer fielen. Im Georgenhospital bestattete man die Leichen zunächst in Särgen, später wurden die nackten Leichname einfach in die Gruben gelegt - ein deutlicher Hinweis auf die sich anbahnende Katastrophe, in deren Folge dann auch in der wohlhabenden Messestadt die Särge zur Mangelware wurden.

Als letzter Berührungspunkt zwischen der Völkerschlacht und Archäologie ist der Schutz der Lokalitäten, soweit dies heute noch möglich ist, von großem gemeinschaftlichem Interesse. Als „,südliches Schlachtfeld“ sind einige Feldschläge zwischen Wachau und Liebertwolkwitz als Flächendenkmal ausgewiesen. Trotz vermehrter Gewerbeansiedlungen vermittelt hier die nahezu ebene Agrarlandschaft immer noch einen Eindruck vom Landschaftsbild der Völkerschlacht mit dem Galgenberg im Zentrum. Ein weiterer Brennpunkt des Geschehens am 16. Oktober war der weiter östlich gelegene Kolmberg. Die damals von größter Bedeutung gewesene Anhöhe wird heute von zwei benachbart liegenden Deponien überragt. Dennoch verrät der Blick von der Anhöhe nach dem nahe gelegenen Seifertshain, warum Erstürmung, Verteidigung und Befestigung für die Franzosen so wichtig war, ließ sich doch von dem 200 Meter langen Plateau ein größerer Abschnitt der österreichischen Front wirksam kontrollieren und konnten Angriffe gegen die nahe gelegenen Stellungen der Alliierten durchgeführt werden. Trotz Sandabbau und Bewaldung sind die am 16. und 17. Oktober von Sappeuren aufgeschütteten Befestigungen im LIDAR-Höhenmodell als den Hügel fassender Wall deutlich zu erkennen (Abb. 4, 5).

Im archäologischen Kontext wird es zweifelsohne auch künftig weitere Funde geben, die im Zusammenhang mit der Völkerschlacht zu sehen sind. Fundstellen sind dabei in allen Gebieten in und um Leipzig zu erwarten. 
Open Access @ 2016 by Böhlau Verlag GmbH \& Cie, Köln Weimar Wien 
Bilder der Völkerschlacht: Medien und Erinnerung 
Open Access @ 2016 by Böhlau Verlag GmbH \& Cie, Köln Weimar Wien 


\title{
Heldensturz
}

\section{Deutsche, englische und russische Napoleon-Karikaturen zur Völkerschlacht von Leipzig}

\author{
Dagmar Burkhart
}

\section{Visualisierung eines Desasters}

\begin{abstract}
„An Leipzig biss sich der Pariser Nuss-Knacker die Zähne aus“ - so lautet die Bildbotschaft einer anonymen deutschen Napoleon-Karikatur (Abb. 1), die nach der Völkerschlacht 1813 entstanden ist. Napoleon Bonaparte, der noch 1805 - wie auf einer englischen Karikatur von James Gillray dargestellt ${ }^{1}$ - zusammen mit William Pitt die Erdkugel verspeiste („The Plumb-pudding in Danger“), der noch 1808 in den „Bildungsblättern für die Jugend“ in einem „Historischen Sinnräthsel“ wegen seiner Eroberungen mit größtem Herrscherlob bedacht worden war, dieser zum Übermenschen Stilisierte hat sich nach seinem gescheiterten Russlandfeldzug und seiner Niederlage bei Leipzig als besiegbar erwiesen (Abb. 2). Er wird nun auf einem deutschen Spottbild (Abb. 3) von seinem kleinen Sohn, dem König von Rom, gewarnt, sich an der Erdkugel nur den Magen nicht zu verderben; er wird auf einer russischen Karikatur ${ }^{2}$ samt seinen Generälen wie ein Hase, Symbol der Feigheit, gejagt, und auf der Radierung „Hasenhetze“ von Johann Michael Voltz noch dazu durch einen gereimten Text verspottet:
\end{abstract}

Es war einst ein gewaltiger Held, / So sich der Große nannte. / Bei Leipzig nahm er's Fersengeld / Als eine Brück' verbrannte. // Auch gab's ein unbezwinglich Heer, / Unendlich aufgeblasen. / Doch sieh, ein Cosak knallte sehr, / Da wurden's lauter Hasen. // Drob lacht nun wohl die ganze Welt, / Freut sich der Dinge Wende. / Das Große Reich der Hasen fällt, / Der Spaß hat jetzt ein Ende. $^{3}$

1 Napoleon - Genie und Despot. Ideal und Kritik in der Kunst um 1800. Ausst.-Kat. Max Liebermann Haus. Hg. v. Gisela Vetter-Liebenow. Hannover 2006, S. 59. Das Wortspiel „plum(b)-pudding“ verweist auf „Blei“ (plumb) und setzt damit die Erde mit einer Kanonenkugel in Beziehung.

2 BuKreEva, Elena: Russkaja karikatura ėpochi Otečestvennoj vojny 1812 goda [Die russische Karikatur in der Epoche des Vaterländischen Kriegs]. Moskau 2012, S. 48.

3 Ein Exemplar der Voltz'schen Karikatur (kolorierte Radierung, 17,1 x 19,9 cm) befindet sich im Stadtgeschichtlichen Museum Leipzig (Inv. Nr. VS 2008). 


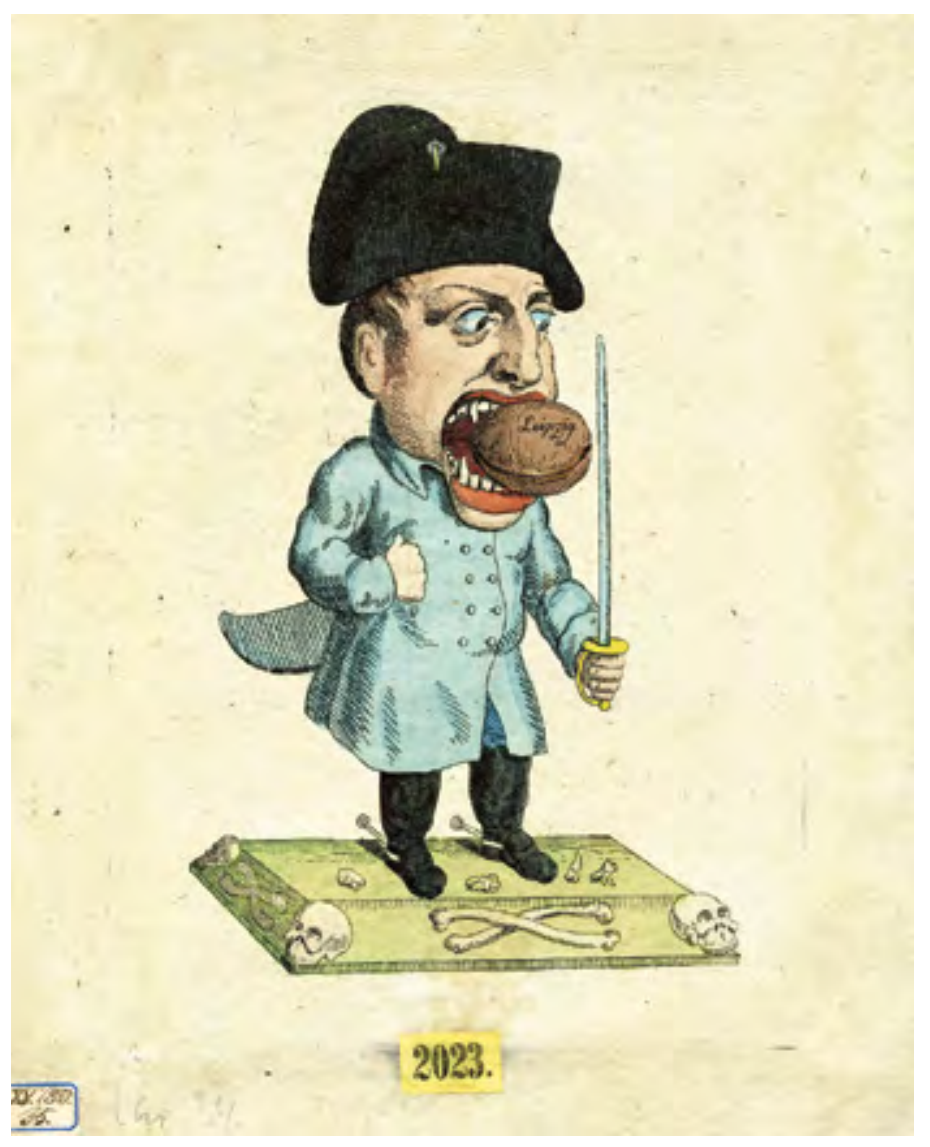

Abb. 1 Unbekannter Künstler (deutsch): Der Pariser Nussknacker, 1813/14, kolorierte Radierung, 21,5 x, 15,4 $\mathrm{cm}$. Stadtgeschichtliches Museum Leipzig.

Schließlich tischt auf einer Karikatur von Charles Williams der Proviantmeister den „kleinen Knochen“ Boney, Spottname für Bonaparte, auf - als Leckerbissen für Europa: „Caterer's - Boney Dish'd - a bonne bouche for Europa“: Um einen runden Tisch sind die uniformierten Herrscher Europas versammelt: Russland, Österreich, Preußen, Schweden und England. Dahinter stehend Personifizierungen der Staaten Württemberg, Bayern, Niederlande, der Schweiz und Italiens. Alle unterhalten sich über das auf einer großen Platte servierte Gericht, das sie untereinander aufteilen wollen: in der Mitte kniend und wild gestikulierend der zwergenhafte Napoleon, umgeben von seinen Marschällen und Generälen als Garnierung. Am rechten Bildrand steht weinend der alte König von Sachsen, der betet, nicht das Schicksal Napoleons erleiden zu müssen und von den übrigen Mächten , verspeist‘ zu werden ${ }^{4}$ - so die durch Sprechblasen verdeutliche Bildbotschaft.

4 Ereigniskarikaturen. Geschichte in Spottbildern 1600-1930. Hg. v. Siegfried KessemeIER. Münster 1983, S. 176. 


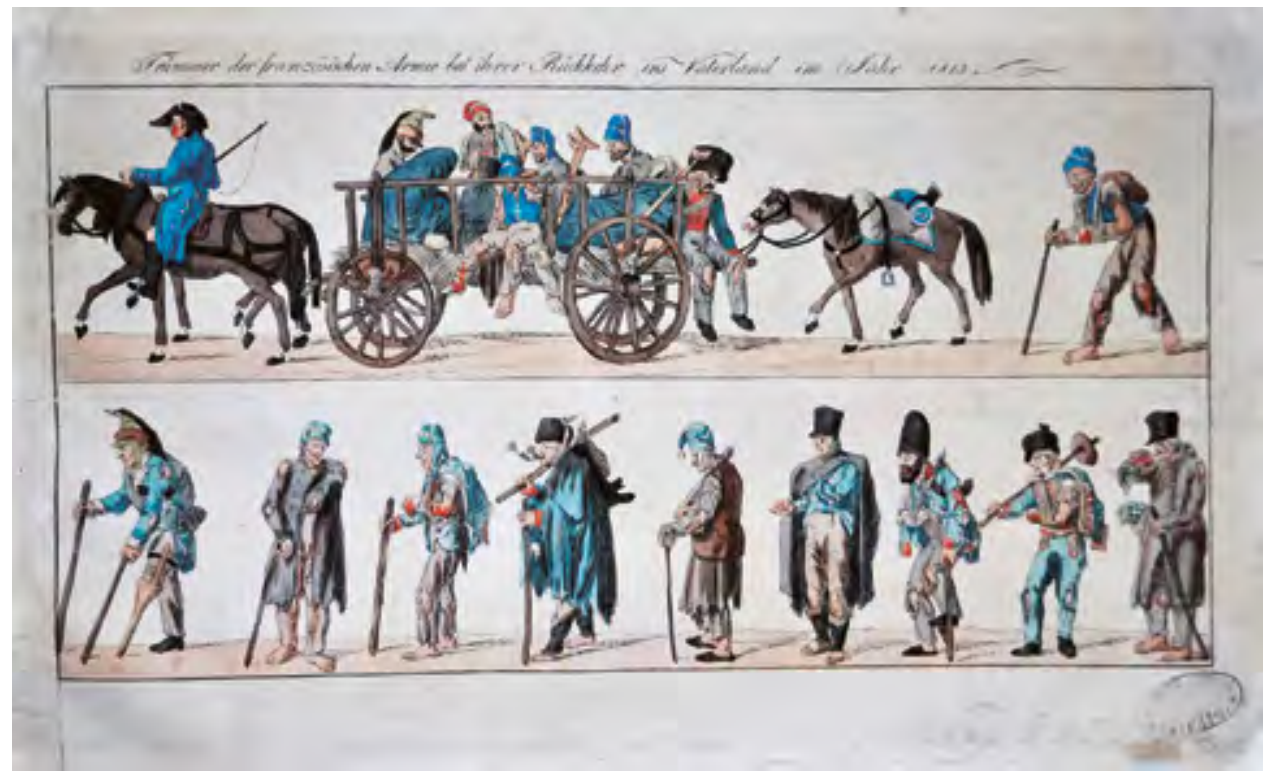

Abb. 2 Christian Heinrich Geißler: Die Trümmer der französischen Armee bey ihrer Rückkehr ins Vaterland im Jahr 1813, Leipzig 1813, kolorierte Radierung. 21 x 34,5 cm. Stadtgeschichtliches Museum Leipzig.

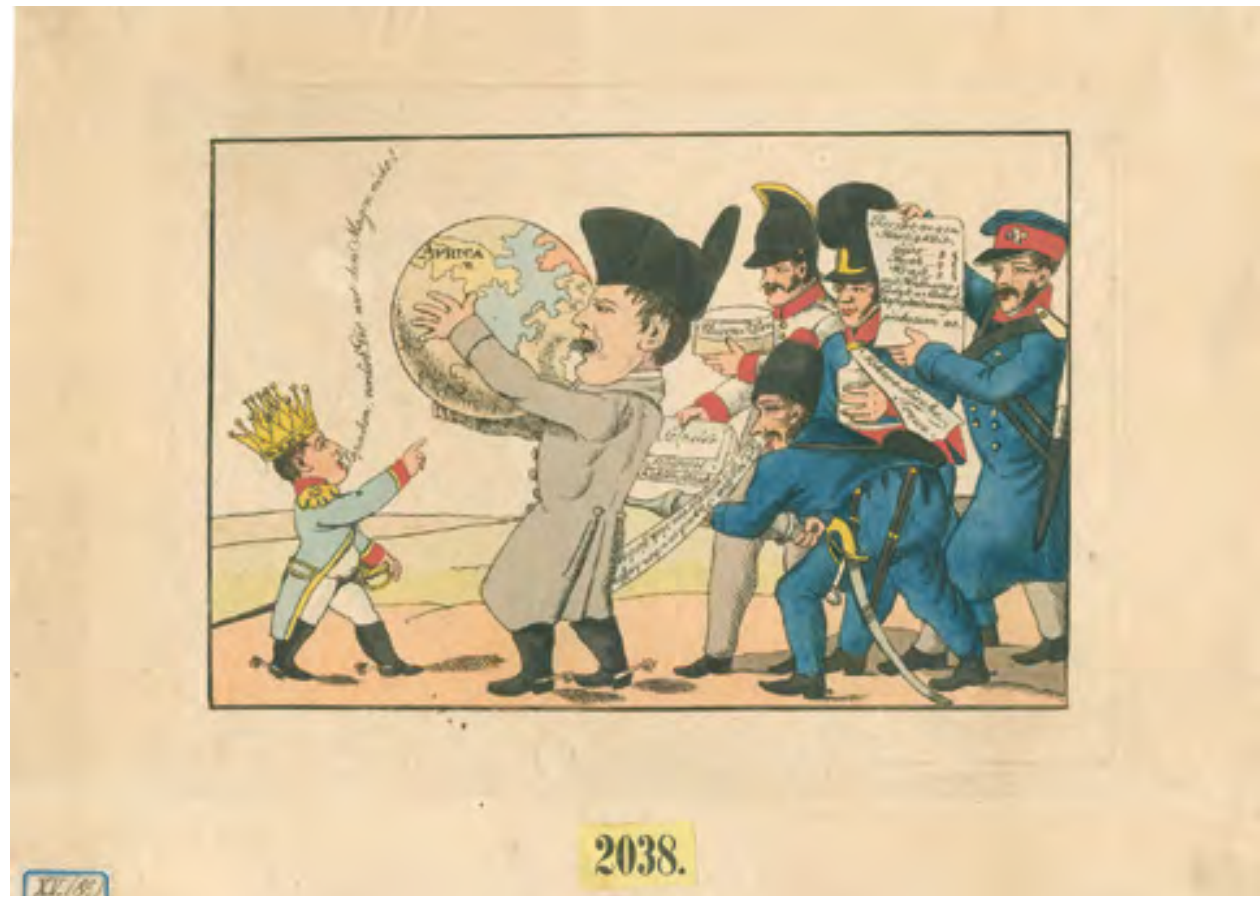

Abb. 3 Unbekannter Künstler: Papachen, verdirb dir nur den Magen nicht, 1813/14, kolorierte Radierung, 13,3 x 18,7 cm. Stadtgeschichtliches Museum Leipzig. 


\section{Das Bild als Dokument und Mittel der Kommunikation}

Im Gegensatz zur Kunstgeschichte, die eine qualitative Ikonografie nach ästhetischen Kriterien betreibt, ist Bildmaterial (Wandmalerei, Einblattdrucke etc.) für die Ethnologie bzw. Kulturanthropologie in erster Linie Dokument und Kommunikationsmittel. Die ethnologische Bildforschung fokussiert daher ihre Betrachtung und Analyse auf folgende Aspekte:

- Bildstruktur und Motivik (Bildsequenz, Einzelbild, Bildpaare, Kontrastbilder; Motive),

- Bildbotschaft (religiöse, moralische, soziale, politische),

- Bildveränderung (Weitergabe, lokale und soziale Anpassung, Funktionstausch),

- Bildstabilität und Bildvariation (eine Bildidee, mehrere Bildvariationen und -botschaften),

- Bild-Text-Relation (Über- oder Untertitelung, Textblock, Erläuterungsblatt) sowie

- Bild-Funktion und Vermittlung im historischen Kontext.

Der schwedische Ethnologe Nils-Arvid Bringéus, auf den diese Systematik zurückgeht, betont, die „Bildlore“ müsse „wie die Folkloristik eine internationale Richtung erhalten“, ,alle sozialen Grenzen überschreiten in Hinblick auf Bildproduktion wie Bildkonsum“ und „mit einer unbeschnittenen Zeitperspektive arbeiten, rückwärts und vorwärts. ${ }^{\text {"5 }}$ Im Sinne dieser bildwissenschaftlichen Forschung sind auch die Karikaturen zu behandeln: als eine primär bildliche Form der Satire, die sich als parteiische Kritik an bestehenden politischen Verhältnissen versteht und als Waffe in gesellschaftlichen Auseinandersetzungen verwendet wird. Die Karikatur als operativ-polemisches Genre zur pointierten politischen Meinungsäußerung übertreibt, spitzt zu und verzerrt charakteristische Züge eines Ereignisses oder einer Person, um durch diese Verzerrung bzw. Verfremdung den Rezipienten zum Nachdenken zu bewegen und zur Abstellung der Missstände anzuregen.

\section{Konjunkturen der Karikaturen}

Seit seiner Ernennung zum Ersten Konsul der Französischen Republik und seiner Krönung zum Kaiser rückte Napoleon in das Blickfeld der Karikatur. Die Spottblätter bilden einen eindrucksvollen Kontrast zu den idealisierten Gemälden eines von Bonaparte systematisch inszenierten Herrscherkults. Zwischen 1797 und 1815 sind über 2.000 Napoleon-Karikaturen erschienen, bis 1813 jedoch vorwiegend in England. Dort hatte sich nach Einführung der konstitutionellen Monarchie „ein liberaler Umgang mit Presse- und Meinungsfreiheit etabliert, wie er in den anderen europäischen Ländern auf Grund der Zensur nicht denkbar war. Die Mitglieder des Hofes, Minister und Parlamentarier standen unter öffentlicher Beobachtung und wurden gegebenen-

5 BRINGÉUs, Nils-Arvid: Volkstümliche Bilderkunde. München 1982, S. 14 f. 
falls auch kritisiert. “6 In diesem günstigen Klima florierte die Karikatur als Form der politischen Meinungsäußerung und erlangte seit Ende des 18. Jahrhunderts eine über die Landesgrenzen reichende Wirkung. Karikaturen der Künstler James Gillray, Thomas Rowlandson oder Vater und Sohn Isaac und George Cruikshank wurden in den Auslagen ihrer Londoner Verleger präsentiert und konnten als (preiswertere) schwarzweiße oder als kolorierte Versionen gekauft bzw. abonniert werden. Und auch die deutschen Leser der von 1798 bis 1815 in Weimar herausgegebenen Zeitschrift „London und Paris“ erreichten englische Karikaturen, etwa 1805 „The Plumb-Pudding in Danger", versehen mit einem zehn Seiten langen Kommentar des Redakteurs Karl August Böttiger.

Die typischen Verfahren der Karikatur - Verfremdung und Deformation - wurden durch die englischen Karikaturisten in den folgenden Jahren vielfältig entwickelt und verfeinert. Die Blätter sind reich an Allusionen, Wortspielen, Symbolen und Metaphern. Personen und Ereignisse werden so kontextualisiert, dass sich der historische Background und politische Konfliktbereiche auf eine pointierte wie unterhaltsame Weise mitteilen. Napoleon reagierte auf solche Spottbilder mehr als indigniert. Er hatte sogar geplant, einen Passus in den Vertrag von Amiens aufzunehmen, der es ihm ermöglicht hätte, Karikaturisten wie Mörder und Fälscher zu behandeln und ihre Auslieferung zu verlangen. ${ }^{7}$

In Russland, wo Wochenblätter wie „Der russische Bote“ das Nationalgefühl schürten, thematisieren die etwa 200 Napoleon-Karikaturen von Ivan Ivanovič Terebenev, Aleksej Gavrilovič Venecianov, Ivan Alekseevič Ivanov u.a. in erster Linie den schmählichen Rückzug der 1812 geschlagenen Truppen Napoleons und ihre Vertreibung durch die heroisch agierende Landbevölkerung und Kosaken. Stilistisch macht sich der Einfluss englischer Vorbilder bemerkbar, doch gibt es zahlreiche Karikaturen, die in der Tradition der populären Einblattdrucke (lubok) stehen. Die Blätter wurden in Moskau, Kiew und St. Petersburg auf Messen und Kirchplätzen vertrieben, sie waren im Wochenblatt „Sohn des Vaterlandes“ abgedruckt, wurden auf Jahrmärkten verkauft oder durch Hausierer (ofeni) in die Provinz getragen.

„Alles zu Druckende gehört vor die Censur", heißt es im preußischen Zensuredikt von $1788 .{ }^{8}$ Erst während der Befreiungskriege, als sich der Untergang des „Universalmonarchen" abzeichnete und sich für kurze Zeit (bis 1816) die Zensur lockerte, konnten auch in Deutschland Karikaturen gegen Napoleon erscheinen. Nach der Niederlage der multinationalen Grande Armée in Russland, vor allem aber nach der desaströsen Völkerschlacht fanden die deutschen Propagandablätter reißenden Absatz. Ihre Ventilwirkung und ihr Einfluss auf das Nationalgefühl in allen Bevölkerungsschichten

6 Napoleon (wie Anm. 1), S. 8.

7 Fuchs, Eduard: Die Karikatur der europäischen Völker. 2 Bde. Berlin 1901-1903, hier Bd. 1: Vom Altertum bis zur Neuzeit. Berlin ${ }^{3} 1904$ [1901], S. 177.

8 Scheffler, Sabine/Scheffler, Ernst: So zerstieben geträumte Weltreiche. Napoleon I. in der deutschen Karikatur. Stuttgart 1995, S. 14. 
waren beträchtlich. Die Völkerschlacht bei Leipzig vom 16. bis 18. Oktober 1813 bedeutet für die Napoleon-Wahrnehmung zweifellos einen Wendepunkt:

Den lange ersehnten Frieden in Europa hatte Napoleon ebenso wenig zustande gebracht wie eine Erneuerung des Reiches. Was man gemeinsam mit Napoleon nicht zu erlangen vermochte, schien nunmehr aber im Kampf gegen ihn in greifbare Nähe zu rücken. Die alliierten Truppen verfolgten die Grande Armée nach deren Niederlage bei Leipzig bis auf französisches Territorium. Und in der öffentlichen Meinung Deutschlands begann jetzt ein deutlich negatives Napoleon-Bild zu dominieren. ${ }^{9}$

Unverkennbar war dies etwa in den „Deutschen Blättern“, die von 1813 bis 1816 in Leipzig erschienen und vor allem, wie der Redakteur betonte, „den so finstern und blutdürstigen Charakter des Tyrannen" ${ }^{\text {"10 }}$ entlarven wollten. Verleger war Friedrich Arnold Brockhaus; redigiert wurden sie in Altenburg. Besonders augenfällig zeigte sich die veränderte Napoleon-Wahrnehmung im visuellen Bereich, bei den Karikaturen. Selbst bekannte Künstler wie Johann Gottfried Schadow oder der auch als Karikaturist wirkende E.T.A. Hoffmann beteiligten sich an dem Bilderkampf in den von Napoleon besetzten Gebieten vor allem Norddeutschlands und Preußens. Viele Karikaturisten wollten aber in Hinblick auf die Zensurbehörde lieber anonym bleiben.

Die deutschen Karikaturen, die in hohen Auflagen erschienen und ihr Publikum über den Buch- und Bilderhandel sowie Schaufenster und Lesezirkel erreichten, sind überwiegend kleinformatig, um die Distribution zu erleichtern. Charakteristisch ist eine häufig im Stil der populären Bilderbögen gehaltene Formensprache und Narration. Sprichwörter, Redensarten und doppeldeutige Ausdrücke spielen eine relevante Rolle. Die charakteristischen Stilmittel der Figurenverzerrung im Bildteil finden sich bei den deutschen Blättern allerdings weniger als bei den englischen und russischen, dafür wird Napoleon häufiger im Textteil verspottet bzw. geächtet.

\section{Als Besiegter verspottet, als Todbringer geächtet}

Die Karikaturen, die im Vorfeld oder in Zusammenhang mit der Völkerschlacht entstanden sind, lassen sich nach zwei Motivkomplexen klassifizieren: Im ersten Komplex sind burleske Spottbilder versammelt, welche Napoleon als Besiegten, Gejagten und Feigling verhöhnen. So wird er beispielsweise zusammen mit unreinen oder verachteten Tieren wie Schwein, Ziege(nbock), Ratte, Hase und Krebs dargestellt;

9 GreiLING, Werner: „Feuergenie des Jahrhunderts“ oder „blutdürstiger Tyrann“? Die Schlacht bei Jena 1806 und das Napoleon-Bild 1797-1815. In: Leipziger Universitätsreden N. F. 106 (2009), S. 38-65, hier S. 50.

10 Ebd. 
als Verlierer, dessen Weltherrschaftsträume wie Seifenblasen zerstoben, ${ }^{11}$ oder sogar als einer, der „die Hosen voll hat“. ${ }^{12}$ Die zweite Karikaturenklasse ist wegen ihrer moralisch wertenden Dimensionen und ihrer Vanitas-Aspekte die bedeutsamere. Hier finden sich jene Blätter, auf denen Napoleon als Tränen-, Leid- und Todbringer geächtet wird, der einen bis dahin nie gesehenen Leichenberg verschuldet hat. Als Bildelemente dieses thanatologischen Diskurses fungieren visualisierte Affekte wie Aggressivität oder Blutgier und Dingsymbole wie Waffen, Funeralobjekte, Leichen, Knochen, abgebrochene Zähne, Tränen, Blut ${ }^{13}$, Totenschädel und Skelette. Ein sinnfälliges Beispiel bietet die Karikatur „Der Pariser Nussknacker“ (Abb. 1): Napoleon, der mit blutrünstigem Gesichtsausdruck, einen Säbel in der Hand, auf einer mit Knochen bestückten Grabplatte stehend, die harte Nuss „Leipzig“ zu knacken versucht hat und sich daran - eine realisierte Metapher - die Zähne ausbeißt, d.h. scheitert. In der semantischen Aussage vielschichtiger zeigt sich die kolorierte Radierung „Der Universalmonarch", die 1814 in Berlin zu einem nicht unerheblichen Preis von 16 Groschen verkauft wurde. ${ }^{14}$ Napoleon sitzt auf einem Thron aus namentlich gekennzeichneten Schädeln seiner prominentesten Opfer; Lorbeerkranz und Vertragsdokumente haben Feuer gefangen; am Horizont sind brennende Ortschaften zu sehen; aus dem Himmel schleudern drei schwarze Adler (allegorisch für Österreich, Preußen und Russland) Blitze auf den Kaiser, der aus einem ihm gereichten Pokal „Thränen des Jammers" trinkt. Die (ein Spottbild von 1809 aktualisierende) Karikatur erschien mit einem Beiblatt, aus dessen gereimtem Text - gleichsam ein negatives Gegenstück zu dem eingangs erwähnten preisenden „Sinnräthsel“ von 1808 - der auf dem ,blutigen Thron" Sitzende erraten werden soll. Auf einer anderen anonymen deutschen Karikatur, die zum Inventar des Kupferstichkabinetts Dresden gehört, ist ein Schädeldenkmal für Napoleon als blutrünstigem Tiger dargestellt. Und auf einer ,Sein Denckmal“ betitelten Radierung blickt ein Januskopf-Napoleon von einem Schädelsockel gleich-

11 „Die große Seifenblase“, unbekannter Künstler, deutsch, 1814, kolorierte Radierung, Transparentbild, 17,8 x 16,7 cm, Stadtgeschichtliches Museum Leipzig. Abb. in: Helden nach Maß. 200 Jahre Völkerschlacht bei Leipzig. Ausst.-Kat. Stadtgeschichtliches Museum Leipzig. Hg. v. Volker RodEKAmP. Leipzig 2013, S. 216.

12 „Der Rückzug oder Die Folgen des russischen Abführmittels“. Abb. in: Claudon-AdHemar, Catherine: Populäre Druckgraphik Europas: Russland. München 1975, Abb. 85. Vgl. auch BuRkHART, Dagmar: Text-Bild-Relationen und ihre kulturanthropologische Dimension in russischen Bilderbögen. In: Text und Bild, Bild und Text. DFG-Symposion 1988. Hg. v. Wolfgang Harms. Stuttgart 1990, S. 296-308, Abb. 142-152, und Peltzer, Marina: Imagerie populaire et caricature: La graphique politique antinapoléonienne en Russie et ses antécédents pétroviens. In: Journal of the Warburg and Courtauld Institutes 48 (1985), S. 189-221.

13 Tränen und Blutströme, von Napoleon verursacht, werden etwa auf der russischen Karikatur „Eine alte Frau deutet Napoleon seinen Traum von den drei Gläsern“ (Bukreeva, wie Anm. 2, S. 36) oder auf den deutschen Radierungen „Das Schlachthaus“, 1813, und „Das große Rabengastmahl bei Leipzig“" (Christian H. Geißler zugeschrieben), thematisiert.

14 Napoleon (wie Anm. 1), S. 177. Der Verweis am unteren Rand, der die Karikatur auf den 21. Oktober 1813 datiert und als Publikationsort London nennt, ist fiktiv und sollte vermutlich die deutschen „Zensurbehörden irreführen, sicher aber auch an die Niederlage Napoleons in der Völkerschlacht im Oktober 1813 bei Leipzig erinnern.“ 


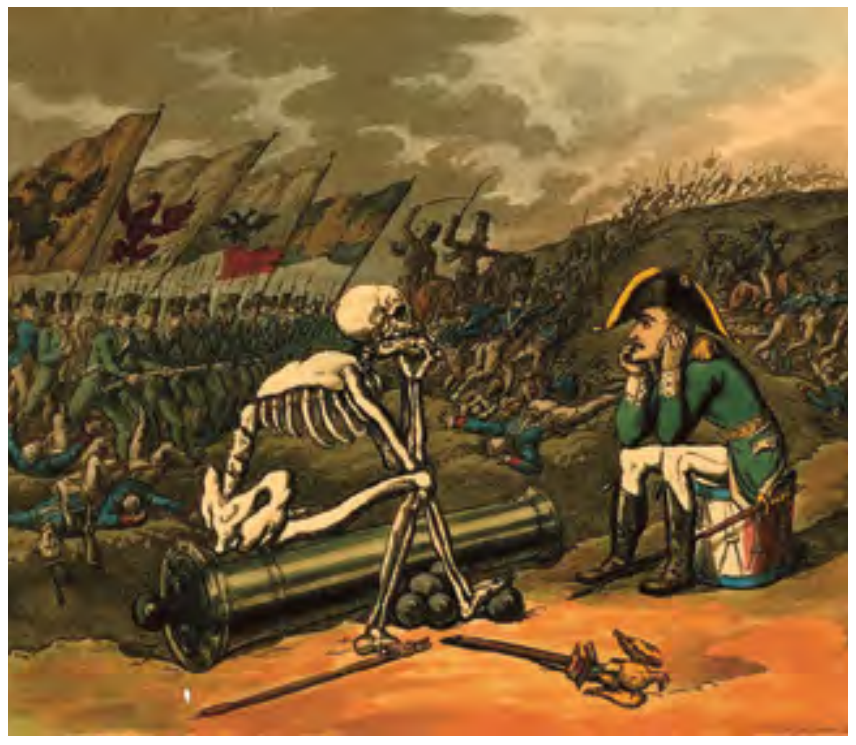

Abb. 4 Nach Thomas

Rowlandson: Death and Napoleon. The Two Kings of Terror, 1813/14, kolorierte Radierung, 48 x 30,7 cm. Stadtgeschichtliches Museum Leipzig.

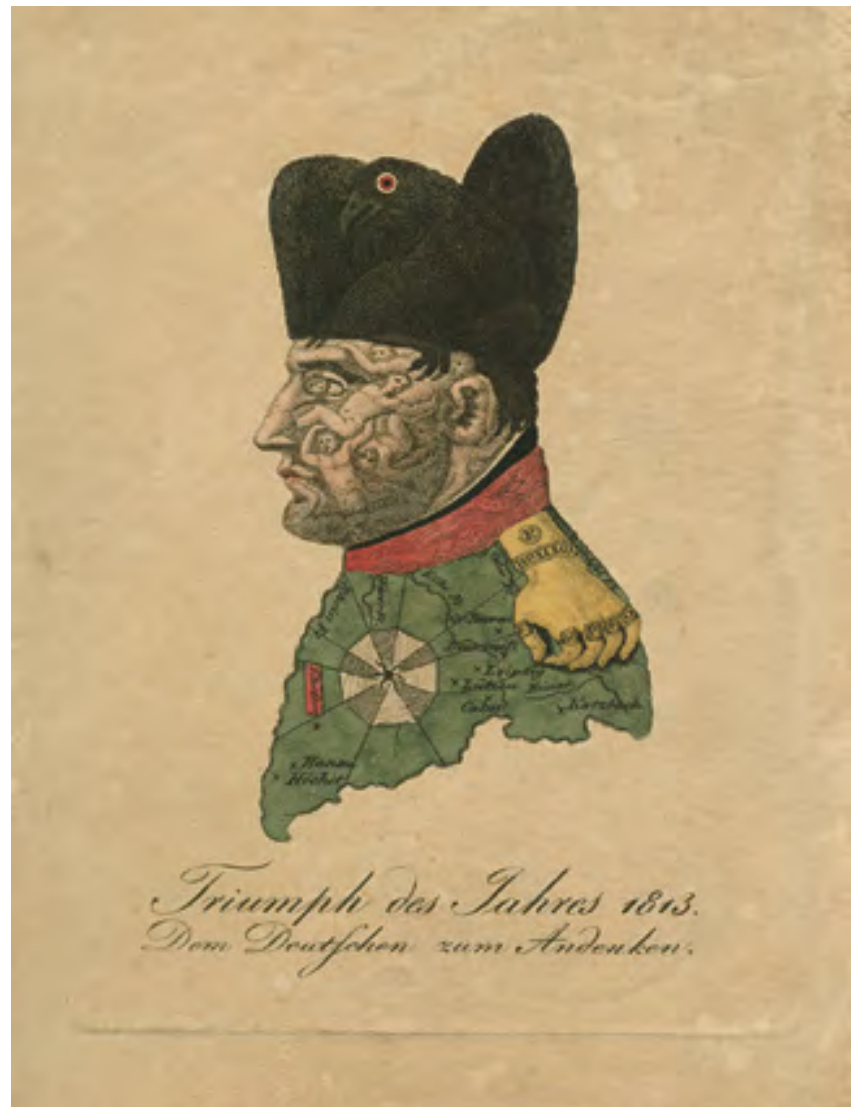

Abb. 5 Johann Michael Voltz: Triumph des Jahres 1813, 1814, kolorierte Radierung, 13 x $9,5 \mathrm{~cm}$. Stadtgeschichtliches Museum Leipzig. 
zeitig rechts auf das verwüstete Deutschland und links auf das (noch) blühende Frankreich. ${ }^{15}$ Schließlich sitzen auf einem englischen Transparentbild ,The two kings of terror" (Abb. 4), nämlich Napoleon und der Tod, auf dem Schlachtfeld in Denkerpose einander gegenüber: Durch die identifizierende Nähe wird Napoleon zur Personifikation des Thanatos.

Die erfolgreichste Napoleon-Karikatur indes erschien Ende des Jahres 1813 nach der als Triumph über den Todbringer gefeierten Schlacht bei Leipzig. Napoleon, „Bevollmächtigter der Höllenliga, kommandierender General der Legionen von Skeletten, zurückgelassen in Moskau, Smolensk, Leipzig“, wird von dem Kupferstecher Johann Michael Voltz aus Nördlingen als sogenannter „Leichenkopf“" karikiert (Abb. 5). Die Verleger dieser kolorierten Radierung, die Gebrüder Henschel, kündigten sie in den „Berliner Nachrichten“ vom 9. Dezember 1813 an mit den Worten: „Eine überraschende Allegorie in Brief-Format mit der Unterschrift: Triumph des Jahres 1813. Den Deutschen zum Neuenjahr 1814 ist so eben erschienen und bei uns couleurt à $6 \mathrm{Gr}$. Courant zu haben." Innerhalb einer Woche wurden in Berlin 20.000 Exemplare des aus Leichendarstellungen zusammengesetzten Napoleon-Profilkopfes verkauft. Eine Vorlage für die Radierung lieferte wohl Gottfried Arnold Lehmanns Gemälde „Napoleon Le Grand“ von 1806. Dieses weitgehend naturgetreue Porträt-Bildnis wurde auf Gebrauchsgegenstände gedruckt, etwa auf Schnupftabaksdosen, und fand auch in Kupferstichen weite Verbreitung.

Anlässlich einer Neuauflage von Voltzens „Leichenkopf“, dieser „Wahren Abbildung des Eroberers" - der Bildtitel spielt mit der Redensart „,sein wahres Gesicht zeigen“ brachten die Gebrüder Henschel 1814 einen Bilderläuterungstext auf einem separatem Blatt heraus, welcher der Entschlüsselung der Bildsemantik dienen sollte:

Der Hut ist Preussens Adler, welcher mit seinen Krallen den Grossen gepackt hat und ihn nicht mehr loslässt. Das Gesicht bilden einige Leichen von denen Hunderttausenden, welche seine Ruhmsucht opferte. Der Kragen ist der grosse Blutstrom, welcher für seinen Ehrgeiz so lange fliessen musste. Der Rock ist ein Stück der Landcharte des aufgelössten Rheinbundes. An allen darauf zu lesenden Orten verlohr er Schlachten. Das rothe Bändchen bedürfte des erklärenden Ortes wol nicht mehr [gemeint ist der ergebnislose ,Fürstenkongress “ 1808 in Erfurt -D.B]. Der grosse Ehrenlegionsorden ist ein Spinnengewebe, dessen Fäden über den ganzen Rheinbund ausgespannt waren; allein in der Epaulette ist die mächtige Gotteshand ausgestreckt, welche das Gewebe zerreisst, womit Deutschland umgarnt war und die Kreuzspinne vernichtet, die da ihren Sitz hatte, wo ein Herz seyn sollte. ${ }^{16}$

15 Helden nach Maß (wie Anm. 11), S. 226. Es handelt sich um ein Transparentbild, das, gegen Licht gehalten, einen verborgenen anderen als den manifesten Bildinhalt zeigt: „Beim Anfang des Jahres 1814“, wie es im Untertitel heißt, geht rechts die Sonne von 1813 unter, die Häuser sind wieder aufgebaut und die Felder bestellt, während links die Sonne von 1814 blutrot über Frankreich aufgeht, Städte brennen und Soldaten durch das Land reiten.

16 Napoleon (wie Anm. 1), S. 124. 
Der grotesk-verfremdete „Leichenkopf“ ist vom Typus her ein sogenanntes Kompositbild im Stil der semantisch komplexen, manieristischen Bilder der Spätrenaissance. Am bekanntesten sind die Kompositbilder von Giuseppe Arcimboldo, z.B. Allegorien der Elemente (Wasser, Erde, Feuer, Luft) oder der vier Jahreszeiten, die Allegorie „Der Bibliothekar", dessen Kopf aus Büchern und Staubwedeln besteht, oder das 1591 entstandene Porträt Kaiser Rudolphs II. als Vertumnus, komponiert aus Erntefrüchten, reifen Ähren und Blumen in Anspielung auf den römischen Gott der Verwandlung und Fülle.

Arcimboldo wurde vielfältig imitiert. $\mathrm{Zu}$ diesen zahlreichen „Arcimboldesken“ gehört ein aus Menschenkörpern komponiertes Porträtbild, das in mehreren Versionen kursierte. Eine davon findet sich im Innsbrucker Ferdinandeum - das Missing Link zwischen Voltzens „Leichenkopf“-Karikatur und Arcimboldos allegorischen Kompositionen? Es handelt sich um ein „Herodes“ betiteltes Kompositbild (Abb. 6), Öl auf Holz, wahrscheinlich im 17. Jahrhundert entstanden. ${ }^{17}$ Auf der ersten Signifikantenebene ist es zusammengesetzt aus (ineinander verschlungen gemalten) Kinderleichen in Anspielung auf den Kindermord von Bethlehem, für den König Herodes im Matthäusevangelium 2,16 verantwortlich gemacht wird, der in der Folge zur Inkarnation des Bösen stilisiert wurde. Auf der sekundären Signifikantenebene wurden die Komponenten zum Porträt im Profil komponiert: Der Kindermörder trägt gleichsam seinen Charakter und seine bösen Taten in der Physiognomie - das Gesicht des Blutherrschers als Massengrab. Und diese höchst affektive Bildbotschaft vermittelt auch der Voltz'sche Napoleon als „Leichenkopf“: Bonaparte ist einer, der „über Leichen geht“ - so lautet die realisierte Metonymie, oder „Wo Napoleon - da Leichen“.

$\mathrm{Zu}$ den 23 deutschen „Leichenkopf“-Versionen zählen Bildmutationen, auf denen die Kinderleichen - eine expressive Steigerung der Rezeptionslenkung - „entfleischt“ werden und zu Skeletten mutieren. ${ }^{18}$ In anderen Varianten der „Leichenkopf“-Karikatur tritt die todbringende Kreuzspinne „Napoleon“ vergrößert aus ihrem Netz hervor, wodurch sich Motivverbindungen ergeben etwa zu Thomas Rowlandsons Karikatur „The Corsican Spider in His Web“ (1808) und einer anonymen deutschen Karikatur von 1814 (Germanisches Nationalmuseum, Nürnberg), auf der Napoleon, als Spinne dargestellt, von den „vereinten Kräften“ vernichtet wird.

Einige satirische Blätter haben über die deutschen Grenzen hinaus gewirkt, allen voran der „Leichenkopf“. Die Karikatur wurde in England, Frankreich, Italien, Russland,

17 Das auf Holz gemalte Ölgemälde gelangte nach brieflicher Auskunft des Ferdinandeums im Jahr 1943 als Teil eines umfangreichen Legats des Innsbrucker Juweliers Bernhard Höfel in die Sammlungen des Tiroler Landesmuseums. Wo sich das „Herodes“-Gemälde vor der Schenkung befand, lässt sich nicht zurückverfolgen. Offenbar waren differierende, auch Öl-auf-Leinwand-Versionen des „Herodes" mit unterschiedlichen Kopfbedeckungen in Umlauf, die Voltz gekannt haben konnte. Noch 1964, 1996 und 2006 tauchen sie bei Auktionen auf. Erwähnt wird 20 Jahre nach der Völkerschlacht ein „Herodes“-Bild bei dem Zisterzienser-Mönch und Historiker Malachias Koll. Im Kunstkabinett des Stifts Heiligenkreuz, das er beschreibt, befand sich seiner Aussage nach „ein gemahlter Kopf des Herodes ganz aus kleinen Kindern zusammengesetzt“ (in: Das Stift Heiligenkreuz in Österreich. Wien 1834, S. 54).

18 Der Kunsthistoriker Bredekamp spricht hier von „Totentanz“ und „Knochengesicht“ (BREDEKAMP, Horst: Thomas Hobbes - Der Leviathan. Berlin 2006, S. 148). 
Abb. 6 Nachahmer Giuseppe Arcimboldos: Herodes, 17. Jh., Öl auf Holz, 45,6 x $34 \mathrm{~cm}$. Tiroler Landesmuseum, Ferdinandeum, Innsbruck.

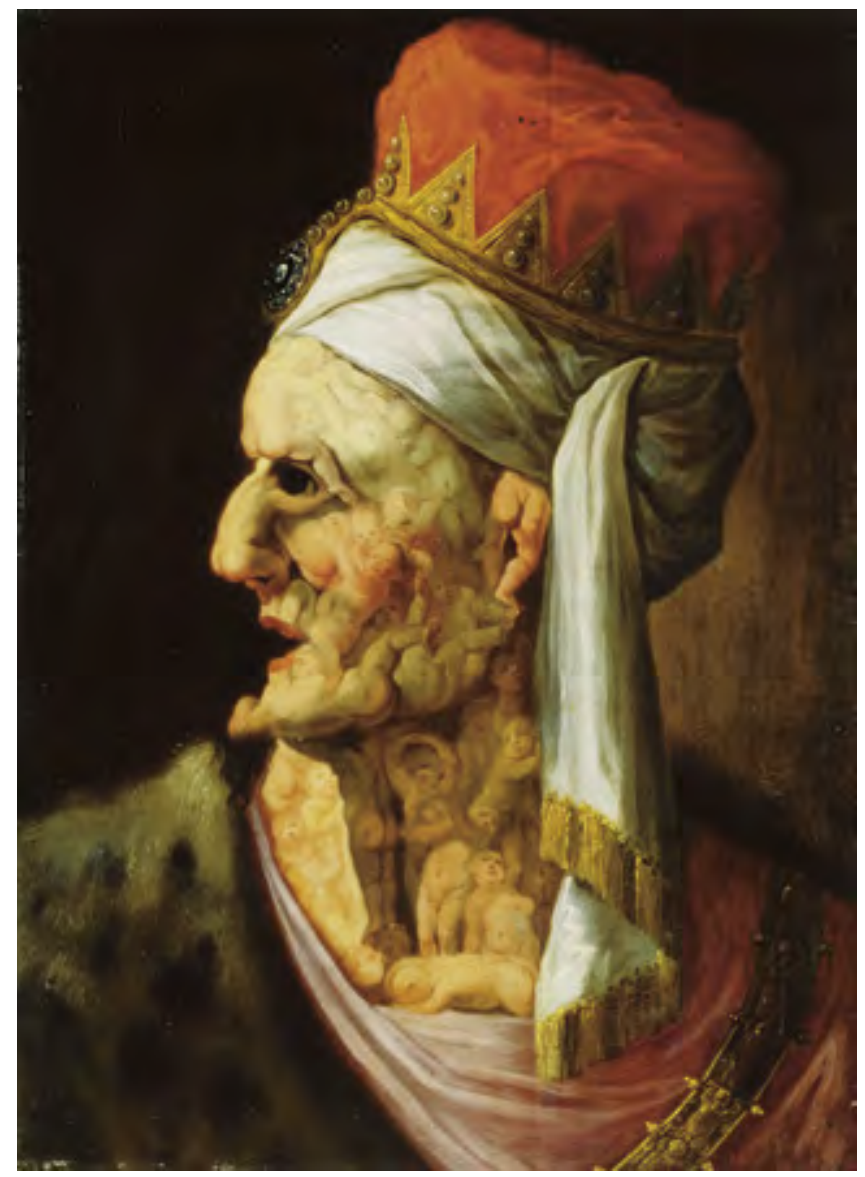

Holland, Schweden, Spanien und Portugal nachgedruckt und übersetzt, beispielsweise ins Russische. Der Bilderläuterungstext weicht in Details von der deutschen Version $\mathrm{ab}$, ohne diese jedoch zu verfälschen:

Das Gesicht ist aus Leichen zusammengesetzt, die Bekleidung aus einer Landkarte komponiert, auf der die aus dem derzeitigen Krieg berühmten Schlachtenorte gekennzeichnet sind, der Kragen bildet ein blutiges Meer ab, welches ein Schiff verschluckt. Das Band der Ehrenlegion wird dargestellt durch einen roten Streifen, auf dem anstelle des Wortes Erfurt die jüngste französische Devise „Ehre fort“ geschrieben steht. Den Stern bildet ein Spinnennetz, und auf der Schulter liegt statt einer Epaulette die schwer lastende Hand der Nemesis (der Rachegöttin). All dies krönt in Gestalt einer Kopfbedeckung ein Adler, dessen Auge dem Hut als Kokarde dient und dessen Klauen die Haare darstellen. ${ }^{19}$

19 Bukreeva (wie Anm. 2), S. 17. Übersetzung: Dagmar Burkhart. 


\section{Das "Lied vom Ende"}

Napoleon-Karikaturen wirken nicht nur in der Gebrauchsgrafik weiter (etwa als Motiv einer Postkarte des Illustrators Horst Eckert aka Janosch), sondern auch als Zitat in der Kunst: beispielsweise in dem großformatigen Gemälde „Als ich die Völkerschlacht malen wollte" von dem Maler der alten Leipziger Schule Bernhard Heisig (1925-2011), das er 1985, also noch zu DDR-Zeiten, fertigstellte. In diesem hochkomplexen Antikriegsbild, das im Museum der bildenden Künste Leipzig ausgestellt ist, hat er nicht nur visuell eine Verbindungslinie von der Völkerschlacht zum Ersten und Zweiten Weltkrieg gezogen, sondern auch - siehe den zentralen Totenschädel - das Vanitas-Thema generell aufgegriffen und mit dem thanatologischen Völkerschlacht- und Napoleon-Diskurs verbunden. Zur Sinnpotenzierung dienen ihm nicht zuletzt Karikaturen, die er zitiert oder auf die er anspielt: erstens Napoleon als blutrünstiger, aber erfolgloser „Leipzig-Nussknacker“ bzw. zweitens „Napoleon und die Weltkugel", ein Motiv, das sowohl in der englischen Karikatur wie auch in der russischen und deutschen politischen Grafik eine Rolle spielt: Auf einer von den Gebrüdern Henschel herausgegebenen Radierung etwa ist Napoleon dargestellt als ein von Blitzen getroffener Höllenhund auf der Erdkugel, ${ }^{20}$ und auf einer russischen Karikatur mit dem Titel „Napoleonova deržost' zavladet' celym svetom“ (Napoleons Dreistigkeit, die ganze Welt zu beherrschen) ${ }^{21}$ ist dem nach der Weltkugel (speziell Russland) greifenden und von einem russischen Soldaten mit dem Beil bedrohten Napoleon der Satz „Ich nehme alles“ in den Mund gelegt. Schließlich wendet sich das Blatt, und nun wird Napoleon auf einer anonymen deutschen Karikatur zur Völkerschlacht (Spruchband: „Helft, die große Kugel erdrückt mich!“) selbst von der dicht mit Armeen besetzten Weltkugel bedroht und ins offene Grab gestürzt. Das satirische Blatt trägt den signifikanten Titel „Lied vom Ende“, ${ }^{22}$ und diese Bildbotschaft ist es wohl, die auch Bernhard Heisig bei der Gestaltung seines Schlachtengemäldes beschäftigte, nämlich: „War 1813 das Ende vom Lied?“

20 Der Cerberus, Berlin 1814. In: Rodekamp (wie Anm. 11), S. 210.

21 Abb. in: Bukreeva (wie Anm. 2), S. 39.

22 „Das Lied vom Ende“, 1814. Abb. in: Helden nach Maß (wie Anm. 11), S. 212. 


\title{
„Das Volk steht auf, der Sturm bricht los!“
}

\section{Die Napoleonischen Kriege als Mobilisierungsressource im NS-Spielfilm - das Beispiel „Kolberg“}

\author{
Lars Karl
}

\begin{abstract}
Ihr werdet doch nicht schlechter sein wollen, als Eure Väter waren? Wagt Ihnen zu gleichen! Ihr habt ein Beispiel, nun gebt ein Beispiel! (Gneisenau in seiner Ansprache vor den Bürgern von Kolberg)
\end{abstract}

30. Januar 1945 - das nationalsozialistische „Großdeutsche Reich“ geht seinem Untergang entgegen. Im Osten hat die Rote Armee die Oder erreicht, im Westen stehen die Alliierten kurz vor dem Rhein. In Frankreich sind nur noch einzelne, zu „Festungen" ausgebaute Orte in deutscher Hand, darunter La Rochelle - der letzte U-BootBunker am ehemaligen „Atlantikwall“, der von zahlenmäßig haushoch überlegenen alliierten Truppen eingeschlossen ist. An diesem Tag wirft dort ein einsames deutsches Flugzeug einen Fallschirm ab. An ihm schwebt eine „Wunderwaffe“ der deutschen Propaganda ganz besonderer Art: der Film „Kolberg“ (Abb. 1). ${ }^{1}$

Der parallel dazu geführte Funkspruchwechsel zwischen Joseph Goebbels und dem Kommandanten der Atlantikfestung mutet gespenstisch an und kündet vom Realitätsverlust, der sich aufseiten des Reichspropagandaministers inzwischen eingestellt haben musste. Goebbels' Botschaft lautete:

Ich habe Ihnen eine erste Kopie des soeben fertiggestellten Farbfilms „Kolberg“ zur Uraufführung in ihrer Festung am 30. Januar 1945 übersandt. Der Film ist ein künstlerisches Loblied auf die Tapferkeit und Bewährung, die bereit ist, auch die größten Opfer für Volk und Heimat zu bringen. Er wird also seine würdigste Uraufführung im Zeichen der engen kämpferischen Verbundenheit von Front und Heimat bei den Männern erfahren, die die in diesem Film dargestellten Tugenden der ganzen Nation vorleben. Möge der Film Ihnen und Ihren tapferen Soldaten als ein Dokument der unerschütterlichen Standhaftigkeit eines Volkes erscheinen, das in diesen Tagen eines weltumspannenden Ringens, eins geworden mit der kämpfenden Front, gewillt ist, es den großen Vorbildern seiner ruhmvollen Geschichte gleichzutun. ${ }^{2}$

1 Die militärische Lage der seit Langem völlig eingeschlossenen „Festung“ La Rochelle war im Januar 1945 so absurd wie die Aufführung von „Kolberg“. Sie war wie die anderen „Atlantikfestungen“ sowie der gesamte „Atlantikwall“ nach der alliierten Invasion in der Normandie im Juni 1944 auch geografisch jenseits jeder funktionalen Bedeutung für den Kriegsverlauf. Während die Alliierten bereits längst deutsches Kernland erreicht hatten, wurde La Rochelle bis zum letzten Kriegstag „ehrenvoll“ gehalten (Kapitulation am 9. Mai 1945, 00.01 Uhr). Vgl. HellwinKEL, Lars: Hitlers Tor zum Atlantik. Die deutschen Kriegsmarinestützpunkte in Frankreich 1940-1945. Berlin 2012, S. 154-181.

2 Zit. nach Leiser, Erwin: „Deutschland erwache!“ Propaganda im Film des Dritten Reichs. Reinbek bei Hamburg 1968, S. 105. 


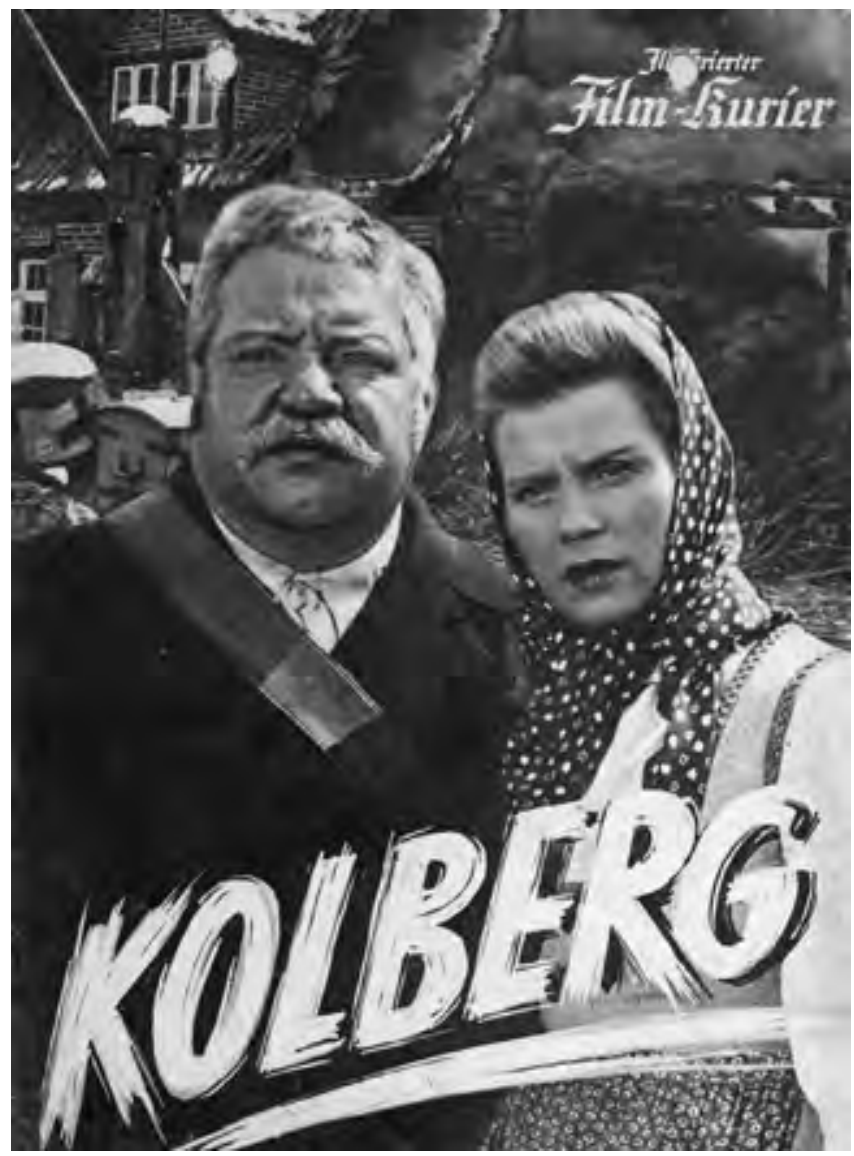

Abb. 1 Illustrierter Filmkurier: Kolberg.

Obwohl die unmittelbare Wirkungsmächtigkeit der Propagandaaktion auf die seit Monaten in der Festung eingeschlossenen Soldaten fraglich erscheinen mag, schien sie Form, Inhalt und Botschaft des Films angemessen: Die - nach den Worten Klaus Kreimeiers - „megaloman-todessüchtige Durchhalteproduktion Kolberg“ gilt in der Filmgeschichtsschreibung in der Tat als sogenannter „Durchhaltefilm“ par excellence. ${ }^{3}$ Der folgende Beitrag unternimmt den Versuch, diese These im Hinblick auf den Entstehungskontext des Films sowie auf dessen geschichtspolitisch nutzbare Narrative zu hinterfragen und dessen Wirkung im entsprechenden zeithistorischen Bezug erinnerungskulturell zu verorten. Da der intendierte Interpretationshorizont von „Kolberg“ im Wesentlichen ein historischer ist, soll der Funktion von „Geschichte“ im nationalsozialistischen (Propaganda-)Film sowie der Darstellung der Napoleonischen Kriege in selbigem dabei besondere Beachtung geschenkt werden.

3 Kreimer, Klaus: Die UFA-Story. Geschichte eines Filmkonzerns. München 1992, S. 323. 


\section{Preußen als ein Phoenix aus der Asche: Die Napoleonischen Kriege im NS-Film}

Die unmittelbar auf die politische Geschichte bezogenen Historienfilme des „Dritten Reiches" behandeln vorzugsweise drei Zeiträume: ${ }^{4}$ das Preußen Friedrichs des Großen, vor allen im Siebenjährigen Krieg (1756-1763); Preußen im Kampf gegen Napoleon (1805-1813); Preußen und die Gründung des Deutschen Reiches (1860-1880); dazu vereinzelt das Wilhelminische Reich unter Einschluss des Ersten Weltkriegs. Thematisch gemeinsam ist ihnen der Argumentationsstrang, dass sich Preußen respektive Deutschland gegen Feinde, die es umzingeln und in seiner Existenz gefährden bzw. die Nations- und Reichswerdung verhindert wollen, militärisch behaupten muss. Die im Film dargestellten preußisch-deutschen Tugenden entstehen gewissermaßen aus der Unausweichlichkeit dieses aufgezwungenen Abwehr- und Selbstbehauptungskampfes. Dieser historische Diskurs der tödlichen Bedrohung von außen läuft auf ein Opfern der Individualinteressen zugunsten der Einordnung in die Gesellschaft (Volksgemeinschaft) und die Unterordnung unter eine lenkende und befehlende Autorität (Führerprinzip) hinaus. Die propagierten Tugenden sind folglich soldatische - der Pflichterfüllung, des Kampfes - unter Einschluss der Todesbereitschaft. Durchgängig vorhanden ist die Konstellation des „einsamen Befehls und des gläubigen Gehorsams“, wie Peter Regel zu „Der Choral von Leuthen“ (1933; R.: Carl Froehlich) feststellt. ${ }^{5}$

Niederlage und Unterdrückung in der napoleonischen Zeit stehen oftmals in Kontrast zur glorifizierten Ära König Friedrichs II. (1740-1786). Vor allem verglich das Kino des Nationalsozialismus dessen wagemutiges und beharrliches Vorgehen im Siebenjährigen Krieg mit der zaghaften und unglückseligen Haltung König Friedrich Wilhelms III. (1797-1840). Um an vergangene Größe anzuknüpfen, imaginieren die Filme ein „preußisches Echo“, das es anzustreben gelte. Ermessen werden konnte es an übermenschlich agierenden Individuen, charismatischen Führern oder Feldherrengenies. So entstanden mehrere Filmbiografien über Blücher, den Sieger von Waterloo, und Yorck, der durch seine Bündnisaufkündigung die Wende in der preußischen Kriegspolitik einleitete. Mit der Inszenierung von Märtyrern verband sich der Appell an den Opfermut des Einzelnen: Die Niederlage bewirkte, dass Preußen sich wieder auf seine Tugenden besann. Gezeigt hätte sich dies schon in zahlreichen vorbildhaften Einzelfällen in der schwärzesten Stunde. ${ }^{6}$

Im Falle von „Kolberg“ lässt sich der Beginn des Filmprojekts auf das Jahr 1943 datieren: Am 18. Februar, rund zwei Wochen nach der Kapitulation der 6. Armee bei

4 SChENK, Irmbert: Geschichte im NS-Film. Kritische Anmerkungen zur filmwissenschaftlichen Suggestion der Identität von Propaganda und Wirkung. In: montage/av 3/2 (1994), S. 73-98, hier S. 75.

5 Regel, Helmut: Die Fridericus-Filme der Weimarer Republik. In: Preußen im Film. Eine Retrospektive der Stiftung Deutsche Kinemathek. Hg. v. Axel Marquardt und Heinz Rathsack. Reinbek bei Hamburg 1981, S. 124-134, hier S. 132.

6 Koller, Wolfgang: Historienkino im Zeitalter der Weltkriege. Die Revolutions- und Napoleonischen Kriege in der europäischen Erinnerung. Paderborn u.a. 2013, S. 163-164. 
Stalingrad, schwur Goebbels im Berliner Sportpalast die deutsche Bevölkerung auf den „totalen Krieg" ein. Zeitgleich suchte der Reichspropagandaminister unermüdlich nach Vorlagen für den Kulturbetrieb, die für stimmungsstützende Maßnahmen geeignet schienen. Die Tatsache, dass diesbezüglich für Goebbels insbesondere Filmprojekte oberste Priorität genossen, erklärt sich aus seinem bekanntermaßen obsessiven Glauben an die Wirkungsmöglichkeiten des Films. Vor diesem Hintergrund erging am 1. Juni 1943 der entsprechende schriftliche Auftrag aus dem Reichpropagandaministerium Adressat war Veit Harlan, der zu den erfolgreichsten Filmemachern des „Dritten Reiches“ zählte und als solcher von Goebbels persönlich protegiert wurde. Über die propagandistische Zielrichtung einer Verfilmung des populären, „volkstümlichen“ und daher potenziell vielversprechenden Stoffes des Widerstands der Stadt Kolberg gegen die französische Blockade notierte Goebbels:

In diesem Film soll Harlan ein Beispiel des Mannesmuts und der Widerstandskraft einer Bürgerschaft auch unter verzweifelten Verhältnissen geben. Dieser Film wird vor allem in den Luftkriegsgebieten eine große Lehre darstellen. Er soll ganz auf historische Tatsachen aufgebaut werden. ${ }^{7}$

Im Rahmen der angestrebten „geistigen Kriegführung“ hatte Goebbels die pommersche Hafenstadt Kolberg geradezu als Pars pro toto für den deutschen Verteidigungsund Widerstandswillen auserkoren. Der historische Kampf um die Festungsstadt, der aufgrund seiner nationalpatriotischen Tradierung vielen Deutschen geläufig war, schien hervorragend geeignet, um die „Nun, Volk, steh' auf, und Sturm, brich’ los“Parole aus der „Sportpalastrede" ${ }^{\text {8 }}$ vom Februar 1943, die fortan das propagandistische Leitmotiv bis zum Kriegsende darstellte, filmisch zu transportieren (Abb. 2). Schließlich war diese bewusst an den Anfang des Theodor-Körner-Gedichts „Männer und Buben"von 1813 angelehnt worden und sollte somit geschichtspolitisch explizit eine Kontinuitätslinie zu den Napoleonischen Befreiungskriegen bilden. ${ }^{9}$

7 Eintrag vom 7.5.1943. In: Die Tagebücher von Joseph Goebbels. Teil II. Hg. v. Elke FröHLICH u.a. Bd. 1-15, hier Bd. 8. München 1996, S. 225.

8 Vgl. dazu: Fetscher, Iring: Joseph Goebbels im Berliner Sportpalast 1943: „Wollt ihr den totalen Krieg?““. Hamburg 1998; Kegel, Jens: „Wollt Ihr den totalen Krieg?“ Eine semiotische und linguistische Gesamtanalyse der Rede Goebbels' im Berliner Sportpalast am 18. Februar 1943. Tübingen 2006.

9 Die Volksmassen marschieren in der Kulisse des „Breslau im Jahre 1813“ und bringen den hadernden preußischen König schließlich dazu, den Aufruf „An mein Volk“ zu signieren. Die kostümierten Komparsen lässt Harlan allerdings nur die erste Zeile des achtstrophigen Liedes singen - und das sowohl in merkwürdiger Neu-Intonierung als auch in martialischer Redundanz. Das im Körner-Lied tatsächlich tragende, achtmal wiederholte Motiv „Bist doch ein ehrlos erbärmlicher Wicht / Ein deutsches Mädchen küsst dich nicht / Ein deutsches Lied erfreut dich nicht / Und deutscher Wein erquickt dich nicht" ist im Film nicht existent. Die Filmdramaturgie verfährt mit der historischen Vorlage damit genauso radikal verkürzend wie es Goebbels zum Abschluss seiner berüchtigten „Sportpalastrede“ getan hatte: „Nun, Volk, steh auf, und Sturm, brich los!“ Es ist damit also dezidiert der Reichspropagandaminister, der dem filmisch erzählten weltgeschichtlichen Moment von 1813 die Worte gibt und so für seine gewaltsame Körner-Adaption von 1943 nachträgliche Legitimation und Verstärkung schafft. Vgl. 
Abb. 2 Umschlag zur Sportpalastrede von Josef Goebbels. Reichspropagandaleitung der NSDAP.

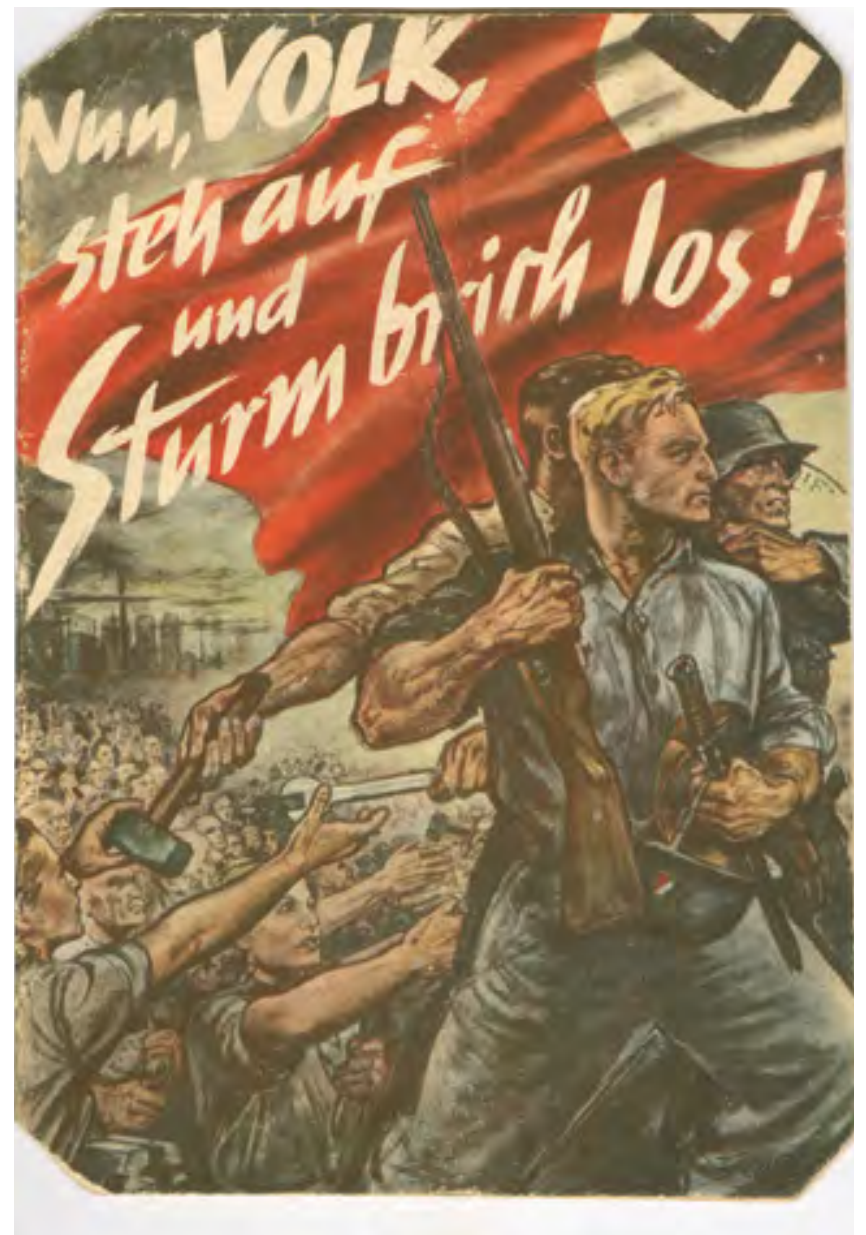

Der Film „Kolberg“ glorifiziert eine historische Begebenheit aus den Tagebuchaufzeichnungen des Bürgerrepräsentanten Nettelbeck, der diese einige Jahre später in einem autobiografischen Zusammenhang veröffentlichte. ${ }^{10}$ Gegen Ende des Vierten Koalitionskrieges (1806/07) erfolgte die Belagerung der Ostseestadt Kolberg durch die französischen Truppen. Verteidigt von den eingeschlossenen Bewohnern unter der Führung von Festungskommandant Gneisenau, Freikorpsführer Schill sowie Bür-

Demantowsky, Marko: Kolberg (1945). In: http:/www5.rz.ruhr-uni-bochum.de:8620/ng4/mam/content/kolberg_1945_.pdf (25.06.2014).

10 Vgl.: Joachim Nettelbeck, Bürger zu Colberg. Eine Lebensbeschreibung. Drittes Bändchen. Mit einem Plan der Gegend um Kolberg. Hg. v. J. Ch. L. Haken. Leipzig 1823. Der Band beschreibt die Jahre ab 1783 und damit auch die Belagerung von 1807. Zur Vita vgl. Vogt, Martin: Nettelbeck, Joachim. In: Neue Deutsche Biographie (NDB). Bd. 1-25, hier Bd. 19. Berlin 1999, S. 83 f.; ein Sammelwerk mit umfangreichem Literaturverzeichnis bietet: Joachim Nettelbeck. Hg. v. Peter JANCKE. Hamburg 1988. 
gerrepräsentant Nettelbeck, konnte sich die Festung bis zum Friedensschluss halten. Berichte und Gerüchte um diesen „Erfolg“ gerieten bereits wenig später zu einem legendenhaft-übersteigerten Narrativ, welches im politischen Kräftespiel des 19. Jahrhunderts verschiedene Formen annehmen sollte.

Aufgrund des stark fiktionalen Charakters des Films sind literarische Vorlagen nicht durchgängig genau zu bestimmen. Der Kolberg-Stoff ist schon von Paul Heyse verarbeitet worden. ${ }^{11}$ Harlan kannte das Stück jedoch nach eigener Aussage „nicht genau“. Zudem wurde auf eine Erwähnung dieser literarischen Vorlage im Film verzichtet, da der Autor im 20. Jahrhundert stark an Ansehen eingebüßt hatte und darüber hinaus - für die Nationalsozialisten wichtiger - über einen ,nichtarischen“ Hintergrund verfügte. ${ }^{12}$ Genauer dagegen dürfte Harlan das Schauspiel „Die letzte Festung“ von Werner Deubel bekannt gewesen sein, das im Januar 1944 im Deutschen Theater in Berlin zur Aufführung kam. Im Mittelpunkt dieses Schauspiels steht Gneisenau. Harlans Liebesgeschichte zwischen Schill und Marie ähnelt der Figurenkonstellation Schill/Klothilde; im Schauspiel wird Klothilde v. Loucadou jedoch auf den Wällen von Kolberg durch eine Granate getötet. ${ }^{13}$

\section{Breslau - Kolberg - Breslau, oder: „Kolberg“ und die Geschichte}

Der Inhalt des Harlan'schen Monumentalwerks ist schnell erzählt. Im Breslau des Jahres 1813 möchte Gneisenau den widerstrebenden König Friedrich Wilhelm III. von Preußen dazu überreden, das Volk angesichts der Niederlage Napoleons in Russland zu den Waffen zu rufen, und argumentiert mit dem Beispiel von Kolberg im Jahre 1806/07: Die Stadt Kolberg wird von den Preußen besetzenden Armeen Napoleons aufgefordert, sich zu unterwerfen. Der Festungskommandant Oberst Loucadou will sich ergeben, aber Bürgerrepräsentant Nettelbeck fordert die Verteidigung bis zum Äußersten. Nettelbeck wird daraufhin wegen Unbotmäßigkeit zum Tode verurteilt, Rittmeister Schill aber setzt Nettelbecks Entlassung aus der Haft durch und stellt eine

11 Heyse, Paul: Colberg. Historisches Schauspiel in fünf Akten. Berlin 1868.

12 Harlan hatte wohl begonnen, bereits vor der offiziellen Beauftragung durch Goebbels vom 1. Juni 1943 am Drehbuch zu arbeiten: „,Kolberg“ war kein dichterisch hochwertiger, aber es war wenigstens auch keiner von den antisemitischen Stoffen. Ich dachte sofort an das Theaterstück von Paul Heyse, das ich allerdings nicht genau kannte. Goebbels behauptete kurzerhand, Heyse sei Jude gewesen, und ich dürfe mich keinesfalls auf sein Theaterstück stützen. [...] Ich bekam den Befehl, mich bei der Abfassung des Drehbuches genau an die Geschichte Nettelbecks, Gneisenaus und die Geschehnisse von $1807 \mathrm{zu}$ halten. Ich sollte eine Liebesgeschichte dazu erfinden, wie ich das für den Film ,Der große König‘ getan hatte.“ In: HarLan, Veit: Im Schatten meiner Filme. Gütersloh 1966, S. 181; Vgl. auch BonTer, Urszula: Paul Heyse. Hofdichter und Publikumsschriftsteller. In: Die höchste Ehrung, die einem Schriftsteller zuteilwerden kann. Deutschsprachige Nobelpreisträger für Literatur. Hg. v. Krzysztof Ruchniewicz und Marek Zybura. Dresden 2007, S. 61-88; zur Vita vgl. Martini, Fritz: Heyse, Paul. In: Neue Deutsche Biographie (NDB). Bd. 1-25, hier Bd. 9. Berlin 1972, S. 100-102.

13 Kanzog, Klaus: „Staatspolitisch besonders wertvoll“. Ein Handbuch zu 30 deutschen Spielfilmen der Jahre 1934 bis 1945. München 1994, S. 356-366, hier S. 362. 
Bürgerwehr auf. Die heldenhafte Maria, Schwester von Schills Kriegskamerad Friedrich, mit der Schill nicht nur durch die gemeinsame nationale Gesinnung verbunden ist, reist nach Königsberg zum König von Preußen, erreicht aber nur die Königin, um für die Stadt um einen neuen Kommandanten zu bitten. Als sie nach Kolberg zurückkehrt, hat Gneisenau dort schon das Kommando übernommen und sich den eigensinnigen Nettelbeck zum treuen Helfer gemacht. Dieser wiederum feuert die Kolberger mit Durchhaltereden an, den in überlegenen Massen anstürmenden Franzosen zu widerstehen. Eine Meuterei französischer Offiziere, die am Durchhaltewillen der Kolberger verzweifeln, macht der Belagerung ein Ende. Breslau 1813: Gneisenau diktiert dem Monarchen den Aufruf „An mein Volk“: „Aus Asche und Trümmern wird sich ein neues Volk erheben, ein neues Reich. ${ }^{\text {14 }}$

Diese Rahmenhandlung des Films, der Dialog zwischen Gneisenau und Friedrich Wilhelm III. im Schloss von Breslau, war nach Aussage von Veit Harlan ein „eigener Einfall“" von Goebbels gewesen. ${ }^{15}$ Für den Reichspropagandaminister war es keine Frage, dass der Film nicht mit der Einstellung der Kämpfe um Kolberg enden konnte, denn diese war eine Folge des Waffenstillstands von Tilsit (21. Juni 1807), der kaum als Ruhmesblatt in der deutschen Geschichte interpretiert werden konnte und somit nichts hergab, das sich zu einem heroischen Narrativ hätte umcodieren lassen. Preußen verlor im Friedensvertrag vom 9. Juli 1807 die Hälfte seines Territoriums: sämtliche Besitzungen westlich der Elbe und die meisten der nach 1772 annektierten polnischen Gebiete; Danzig wurde Freie Stadt. Die Rahmenhandlung von 1813 gab dem Film die Wendung, die nationalistische wie propagandistische Bedürfnisse zu befriedigen in der Lage war. Die Szene von 1813 und der Entschluss des Königs, das Volk zu mobilisieren, sollten den Blick des Zuschauers prospektiv auf die Völkerschlacht bei Leipzig, den Sieg über Napoleon sowie die anschließende Befreiung Deutschlands lenken. Das auch zeitgenössisch weitläufig bekannte historische Faktum, dass zwischen Kolberg und Breslau sechs Jahre lagen, die für nationalistische Gemüter durchaus das Beiwort „schmachvoll“" trugen, wird verwischt, indem die Ereignisse des Jahres 1807 direkt auf das heroische Jahr 1813 projiziert werden. Damit wird suggeriert, dass es niemals zu den Befreiungstaten von 1813 hätte kommen können, wenn die Rückzüge und Niederlagen von 1807 nicht so heldenhaft und siegreich gewesen wären.

Entsprechend der geschichtspolitischen Intention des Films sind die Rollen nah an den ausgewählten historischen Protagonisten ausgerichtet. Der Ortskommandant Loucadou (gespielt von Paul Wegener) ist der Ansicht, dass Napoleon es für überflüssig hielte, Truppen ins entlegene Kolberg zu schicken, nachdem diese bereits in Preußens Hauptstadt Berlin einmarschiert waren. Die Vorschläge des Bürgerrepräsentanten Nettelbeck (verkörpert von einem voluminös-väterlichen Heinrich George) in Bezug auf die mangelhafte Einlagerung des Proviants werden von ihm entrüstet zurückgewiesen,

14 Eine detaillierte Skizzierung des Handlungsverlaufs findet sich in: Hitlerjunge Quex, Jud Süss und Kolberg. Die Propagandafilme des Dritten Reiches. Dokumente und Materialien zum NS-Film. Hg. v. Rolf Giesen und Manfred Hobsch. Berlin 2005, S. 452-457.

15 Harlan (wie Anm. 12), S. 190. 
worin sich einmal mehr sein Desinteresse an den überlebensnotwendigen Bedürfnissen der Stadtbewohner offenbart. Ebenso wenig enerviert ihn der beharrliche Tadel von Leutnant Schill (Gustav Diessl), der eben erst schwer verwundet mit einer kleinen Einheit die Stadt erreichte, am maroden Zustand ihrer militärischen Verteidigungsanlagen. Als Schill mit sachkundigem Beistand Nettelbecks schließlich versucht, die Bürger auf einen drohenden Angriff der Armee Napoleons vorzubereiten, antwortet Loucadou mit der selbstgefälligen Haltung eines konservativen Offiziers - der Krieg sei nun einmal „Sache der Armee“ und Zivilisten daher weder befugt noch geeignet, sich am Kampfgeschehen zu beteiligen.

Diese ausgesprochen negative Illustration der Figur des Ortskommandanten rekurriert auf die Überlieferungen Nettelbecks und wird von der Forschung inzwischen infrage gestellt. ${ }^{16}$ Indes lag Loucadou mit seiner Prognose, dass Napoleon nicht vorhatte, Kolberg einzunehmen, vollkommen richtig: Der Kaiser der Franzosen verlangte schriftlich die Subordination unter seine Befehlsgewalt - eine damals durchaus übliche Vorgehensweise, um eine überflüssige Gefährdung militärischer und ziviler Ressourcen zu vermeiden.

Nettelbeck stellte diesen Appell beim Rat der zehn führenden Bürger der Stadt zur Diskussion, ohne gleichwohl den geringsten Zweifel an seiner Intention aufkommen zu lassen, das napoleonische Diktat scharf zurückweisen zu wollen. Erst als dies schließlich geschehen war, setzten sich die französischen Truppen von Süden her in Marsch, um Kolberg gewaltsam zu unterwerfen. Nettelbecks persönliche „Standhaftigkeit“ und seine stark subjektiv geprägte Perspektive auf die zeitgenössischen Ereignisse ließen im frühen 19. Jahrhundert den Mythos um „Kolberg“ heranreifen - für Goebbels und die nationalsozialistische Filmindustrie ein geradezu vorbildlicher Ausgangsstoff.

So wird am Handlungsablauf des Harlan'schen Werkes die tagespolitische Intention der NS-Propaganda unter dem Deckmantel ,historischer“ Abläufe deutlich sichtbar. Denn nicht nur der im weiteren Verlauf des Films auf Betreiben Nettelbecks durch den jüngeren Gneisenau ersetzte Stadtkommandant Loucadou wird als Feigling, dessen Verhalten von Dummheit zeugt, charakterisiert. Jeder, der in Erwägung zieht, mit der Kapitulation vor den heranrückenden feindlichen Armeen sein Eigentum schützen zu wollen, gilt als eigensüchtiger Überläufer. Da diese Geisteshaltung im Film ohnehin nur von den Protagonisten des egoistischen Großbürgertums vorgetragen wird, lässt „Kolberg“ eine wertfreie Erörterung der Situation im Sinne eines Schutzes aller Beteiligten erst gar nicht entstehen, da der Heldentod als „freier deutscher Bürger“ dem Fortleben unter dem Regime eines ausländischen Tyrannen selbstverständlich unwidersprochen zu präferieren ist.

Im wahrsten Sinne des Wortes tonangebend für eine unmissverständliche Lesart des Films ist die Sprache Nettelbecks, kombiniert mit Heinrich Georges Verkörperung eines „Übervaters“, deren Wirkung durch ihre geschickte Argumentation sicherlich nicht zu leugnen war. Nicht „Hurra-Patriotismus“ oder militärischer Überschwang sind seine

16 So etwa bei Bauer, Frank: Kolberg 13. März - 2. Juli 1807. Ein preußischer Mythos. Potsdam 2007; zur Biografie vgl. Vogt (wie Anm. 10), S. 83 f. 
Motivation, sondern eine aus patriarchalischer Besonnenheit gespeiste Sachlichkeit, die sich einzig am Wohlergehen der Bewohner ,seiner“ Stadt orientiert - und dabei wie selbstverständlich den an sich offensichtlichen Tatbestand verwässert, dass seine Intention erst die (per se vermeidbare) militärische Auseinandersetzung mit den napoleonischen Truppen in die Wege leitet. Vor diesem Hintergrund scheint Goebbels' Forderung nachvollziehbar, verschiedene Szenen mit Bildern von Tod, Verwundung und sonstigen Kriegsfolgen herauszuschneiden, da diese das von Nettelbeck entworfene Bild des omnipotenten Schutzherrn beim Zuschauer sicherlich merklich infrage gestellt hätten.

In der durch den Film „Kolberg“ betriebenen Geschichtsverfälschung wird die zeitgenössische propagandistische Intention umso deutlicher: Man redet vom Volksheer und meint Volkssturm, und die Sprache des Königs und die Loucadous soll als die Rhetorik der deutschen Generalität verstanden werden. Diese kann in ihrer standesdünkelhaften Verbohrtheit den (aus der Sicht der NS-Führung notwendigen) Interventionen von Parteioberen in militärische Angelegenheiten nur mit Misstrauen, Unbehagen und offenem Widerstand begegnen. In Harlans Film werden somit nun noch einmal - gewissermaßen in historischer Verkleidung - die zeitgenössischen Prestige- und Führungskämpfe zwischen Wehrmacht und SS, Generalstab und Parteistrategen ausgetragen zugunsten der Partei. ${ }^{17}$

Darüber hinaus sind die Beispiele für realhistorische Geschichtsklitterung Legion. ${ }^{18}$ Der Sturm auf Kolberg wurde nicht eingestellt, weil die französische Artillerie wie ein Söldnerheer meuterte, sondern weil ein preußischer Kurier aus Tilsit am 8. Juli eintraf und General Louis Henri Loison jede Möglichkeit nahm, den Waffenstillstand, der ihm bereits seit dem 28. Juni bekannt war, noch länger zu ignorieren. Oberst Loucadou war nicht der defätistische, schwache Offizier, den der Film aus ihm macht, sondern ein eher konservativer, vielleicht etwas zögerlicher Stadtkommandant, der seine Festung „klassisch“" verteidigen wollte. Nettelbeck wurde niemals von ihm unter Arrest gesetzt und zum Tode verurteilt - Loucadou hatte damit wohl nur gedroht, um ihn einzuschüchtern. Ebenso begann der Kampf um Kolberg bereits unter Loucadou und nicht, wie der Film glauben machen will, unter dem ,jungen“ Gneisenau. Tatsächlich war der historische Gneisenau (1760-1831) bei der Übernahme dieses Kommandos bereits 47 Jahre alt und somit sogar einige Jahre älter als der im Film bereits als leicht greisenhaft skizzierte König Friedrich Wilhelm III. (1770-1840). Der wiederum bekam den Aufruf „An mein Volk“ auch nicht von Gneisenau diktiert, sondern bediente sich dazu eines Ghostwriters, wahrscheinlich des Staatsrats Theodor Gottlieb von Hippel. Auch verschweigt der Film schamhaft eine schwedische Fregatte und eine englische Brigg, die von See aus die militärischen Operationen der Belagerten mit wirkungsvollem Geschützfeuer unterstützten.

17 Zur Konkurrenz der „Waffenträger“ im „Dritten Reich“ vgl. FöRsTER, Jürgen: Die Wehrmacht im NSStaat: Eine strukturgeschichtliche Analyse. München ${ }^{2} 2009$ [ ${ }^{12007], ~ S . ~ 71-92 . ~}$

18 Die hier angeführte Skizze erhebt keinen Anspruch auf Vollständigkeit. Vgl. dazu EITNER, Hans-Jürgen: Kolberg ein preußischer Mythos 1807/1945. Berlin 1999. 
Gänzlich fiktiv die historisch nicht belegte Familie des Bauern Werner, deren Tochter Maria (gespielt von Kristina Söderbaum) neben Nettelbeck zur tragenden Figur der Filmhandlung wird. Auch steht sie hier für jeden nationalsozialistischen Frauentypus gleichermaßen - die blonde Unschuld vom Lande, die treue Geliebte des Soldaten, die tapfere Kämpferin und die aufopferungsvolle Bürgerin. ${ }^{19}$ Während eine Fülle unterschiedlich gezeichneter männlicher Protagonisten die Szenerie beherrscht, kommen außer ihr nur wenige Frauen in schwach skizzierten Nebenrollen vor. Wahrscheinlich war auch hier der Gedanke ausschlaggebend, in der Filmhandlung möglichst wenige Zivilisten umkommen zu lassen, weshalb sich die pausbäckige, immer frisch geschminkte Maria allen Widrigkeiten erfolgreich entgegensetzt, um dabei konsequent von ihren männlichen Begleitern als „kleines Mädel“, „Fräuleinchen“ und „Frauenzimmerchen“ bezeichnet zu werden. Eine Einschätzung, der sie stets mit frechem Augenaufschlag und gespielt devotem Verhalten zu begegnen weiß.

\section{„Jetzt können wir zusammen sterben“: Der Endkampf als zentrale Botschaft}

Das Ende der Beschießung der eingekesselten Stadt resultiert im Film aus einer Meinungsverschiedenheit unter den beteiligten französischen Offizieren, ursächlich war dafür indes der im Juli 1807 unterzeichnete „Frieden von Tilsit“, der die Hochphase von Napoleons Herrschaft einläutete. Letzten Endes blieb der zähe Widerstand der Kolberger Bürgerschaft ohne jegliche Bedeutung für die anstehenden Verhandlungen, die Zerstörung ihrer Stadt somit für die politischen Folgen des Krieges ein bedeutungsloses Opfer. Dies verschweigt die Harlan'sche Produktion, indem sie aus der Perspektive Gneisenaus den Mythos eines moralisch wie militärisch zweckvollen Widerstands der (Zivil-)Bevölkerung gegen einen weit überlegenen Gegner kultiviert. Gneisenaus Appell ist eingebettet in die bereits erwähnte, auf den März des Jahres 1813 datierte zweiteilige Rahmenhandlung zu Beginn und am Ende des Films - und richtet sich an König Friedrich Wilhelm III., um ihn zur Unterzeichnung des historischen Aufrufs „An mein Volk“ zu motivieren. Dieser Aufruf, in dem die Einheit von Krone, Staat und Volk beschworen wurde, resultierte in der Einführung der allgemeinen Wehrpflicht und in der Aufstellung eines Volksheeres. Daneben bildeten sich freiwillige Jägerverbände und Freikorps. Zudem wandte sich zum ersten Mal in der Geschichte ein preußischer Monarch direkt an sein Volk. ${ }^{20}$ Dieses ist im Film bereits in Massen vor dem Fenster aufmarschiert, nur noch auf die Instruktionen seines Mo-

19 Zur Rolle der Frau und dem offiziellen Frauenbild im Nationalsozialismus vgl. Harvey, Elisabeth: Der Osten braucht Dich! Frauen und nationalsozialistische Germanisierungspolitik. Hamburg 2010; KompIsch, Kathrin: Täterinnen. Frauen im Nationalsozialismus. Köln 2008; Kramer, Nicole: Volksgenossinnen an der Heimatfront. Mobilisierung, Verhalten, Erinnerung. Göttingen 2011; Volksgenossinnen: Frauen in der NS-Volksgemeinschaft. Hg. v. Sybille Steinbacher. Göttingen 2007.

20 Vgl. dazu Stamm-Kuhlmann, Thomas: König in Preußens großer Zeit. Friedrich Wilhelm III., der Melancholiker auf dem Thron. Berlin 1992, S. 372. 
narchen wartend. Somit soll die Sequenz einen repräsentativen Bezug zu den Menschen im Deutschland des Katastrophenjahres 1944 darstellen, die ebenfalls zum finalen Widerstand, zum „Endkampf“ zu mobilisieren waren.

Den bedeutsamsten Mobilisierungs- und Disziplinierungsversuch stellt in diesem Zusammenhang sicherlich der „Deutsche Volksturm“ dar, dessen erste Verbände bereits auf einen Führererlass vom 25. September 1944 hin aufgestellt worden waren. ${ }^{21}$ Die öffentliche Bekanntgabe und massive Propagierung dieser Entscheidung erfolgte jedoch nicht zufällig am 18. Oktober 1944, dem 131. Jahrestag der Völkerschlacht zu Leipzig (Abb. 3). Es war das erste Mal, dass Heinrich Himmler, Reichsführer SS und Chef der deutschen Polizei sowie Befehlshaber des Ersatzheeres, eine Rundfunkansprache im Krieg hielt; zudem nahm er in Königsberg den ersten Appell von Einheiten des „Deutschen Volkssturms“" ab. Die historische Legitimationsgrundlage dieser Entscheidung schien offensichtlich: Erst der Landsturm, so argumentierte Himmler, habe die Voraussetzungen des großen strategischen Sieges über Napoleon geschaffen, aus notdürftig Bewaffneten seien „,fanatische Freiheitskämpfer“ geworden. „Wie damals im Freiheitskrieg der Landsturm“, fuhr er fort, „,so hat heute der Volkssturm die Aufgabe, überall dort, wo der Feind unseren Heimatboden betritt [...], ihn fanatisch anzupacken, festzuhalten und ihn womöglich aufzureiben.“ Die Feinde hätten indes zu lernen: „Jeder Kilometer, den sie in unser Land vordringen wollen, wird sie Ströme ihres Bluts kosten.“ Jeder Häuserblock, jeder Busch werde von Männern, Knaben und Greisen verteidigt. Deutschland zu erobern, heiße für den Gegner, nationalen Selbstmord zu begehen. Zum Einsatz komme nun „,des Reiches stärkste Wunderwaffe“, „seines Volkes Aufgebot voll Tapferkeit und Fanatismus“, kurzum: „die Armee von Deutschlands größten Idealisten“.22 Nach einem von der NSDAP ausgegebenen propagandistischen Aufruf an alle ,waffenfähigen Männer im Alter von 16 bis 60 Jahren“ verfolgte er das Ziel, den „Heimatboden“ des Deutschen Reiches zu verteidigen, „,bis ein die Zukunft Deutschlands und seiner Verbündeten und damit Europas sichernder Frieden gewährleistet" sei. ${ }^{23}$

Konsequenterweise ist das Argumentationsziel des Filmes „Kolberg“ die Vermittlung der Idee, dass in schweren Kriegszeiten „das ganze Volk“ wehrfähig gemacht werden müsse. Deshalb erklärt Schill dem kompromisslerischen Kommandanten Loucadou:

In den Bürgern liegt die Rettung des Vaterlandes, auf ihren Mut und auf ihre Haltung kommt es an. Wenn eine Festung belagert wird, dann gibt es keinen Unterschied mehr zwischen Bürgern und Soldaten.

21 Zur Geschichte des „Volkssturms“ vgl. Yelton, David K.: Hitler’s Volkssturm. The Nazi Militia and the Fall of Germany 1944-1945. Lawrence 2002; Ders: The SS, NSDAP, and the Question of Volkssturm Expansion. In: The Impact of Nazism. New Perspectives on the Third Reich and its Legacy. Hg. v. Alan E. Steinweis und Daniel Rogers. Lincoln 2003, S. 167-181.

22 Völkischer Beobachter, 19.10.1944. Zit. nach: Henke, Klaus-Dieter: Die amerikanische Besetzung Deutschlands. München ${ }^{2} 1996$ [1995], S. 128.

23 Zit. nach: 1945. Das Ende des Krieges. Hg. v. Gerd R. Ueberschär und Rolf-Dieter MüLLER. Darmstadt 2005, S. 160-161. 


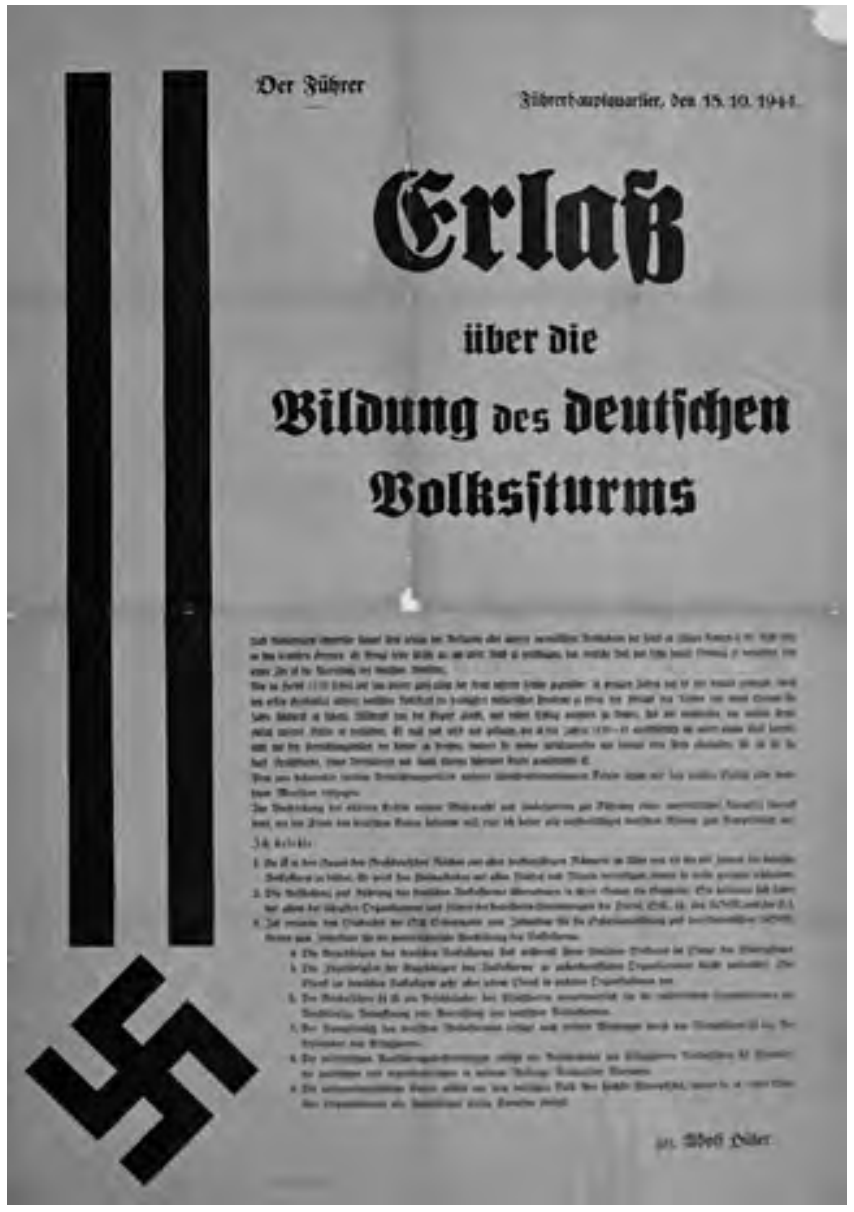

Abb. 3 Plakat: Erlass über die Bildung des deutschen Volkssturms.

Für ihn aber ist das „Kriegführen“ - im Gegensatz zu Loucadou, der darin nur ein „Handwerk“ sieht - eine „Sache des Herzens“: „Und die Kolberger haben Herz. Sie lieben ihre Stadt und ihre Heimat." So kann Gneisenau gegenüber König Friedrich Wilhelm III. den Standpunkt vertreten, dass „Nettelbecks wehrhafte Bürgerschaft, das Volk von Kolberg“, den Militärs erst die Möglichkeit gegeben hat, die Festung zu halten, und dass dessen Bürgerschaft Preußen in schwerer Stunde rettete. Für Gneisenau ist die Verteidigung Kolbergs die „Geburtsstunde der deutschen Freiheit“, denn damals sei der „Gedanke eines Volksheeres“ aufgegangen. In der Tat hatte die hier zum Ausdruck gebrachte Vorstellung der Volkssouveränität die „Fürsten und Könige“ während der Befreiungskriege (und danach) außerordentlich beunruhigt und sie zu einer rigorosen Restaurationspolitik veranlasst. 
Die hier skizzierte Argumentationslinie entwickelt sich im Film entlang der filmischen Konstruktion dreier für die NS-Ideologie zentraler Normen. ${ }^{24}$ An erster Stelle steht als höchster Wert die Heimat. ${ }^{25}$ Dabei geht es allerdings keinesfalls um persönliches Eigentum. Als der Reeder Gollnow bereit ist, den Eid auf Napoleon zu leisten, schlägt ihm Nettelbeck vor, mit dem Schiff nach Bornholm oder Schweden zu fahren: „Oder bilden Sie sich etwa ein, wir werden unsere schöne alte Stadt preisgeben, bloß damit Ihr wertvolles Eigentum unangetastet bleibt?"

Zum zweiten ist ein einmal geleisteter Eid absolut verbindlich und unverbrüchlich. Das macht Nettelbeck dem französischen Kommissionär klar: „Aber die freien Bürger der alten Hansestadt Kolberg wollen sich lieber unter den Trümmern ihrer Mauern begraben lassen als ihren Eid auf ihren König und Herren brechen.“"

Ebenso absolut gesetzt wird die (militärische) Disziplin, was auch der Bürgerrepräsentant Nettelbeck zunächst noch lernen muss. Gneisenau lässt ihn von Anfang an über die Verbindlichkeit dieser Norm nicht im Zweifel: „Disziplinlosigkeit wird unter meiner Führung mit den schärfsten Strafen belegt.“ Seine „Feuerprobe“ besteht Nettelbeck, indem er einen Straßengraben wieder aufreißen lässt, den zuvor Loucadou auszuheben und wieder zuzuschütten befohlen hatte: „Es tut mir leid, dass ich euch die doppelte Arbeit machen lassen muss, aber Befehl ist Befehl!" Er handelt dabei gegen bessere Einsicht, und Gneisenau weiß, dass Nettelbecks Maßnahme, den Straßengraben zuschütten zu lassen, richtig war. Gleichwohl besteht er auf der Ausführung seines Befehls:

Ja, was meinen Sie wohl, was daraus wird, wenn jeder nur den Befehl ausführen würde, den er für richtig hält? Zugegeben, im vorigen Falle hatten Sie recht. Aber kommt es denn darauf an? Dann wären wir ja auf dem besten Wege zur Anarchie.

Fraglos übertrifft die Stilisierung des nationalen Überlebenskampfes gegen Kriegsende - selbst gemessen an nationalsozialistischen Standards - noch alles bis dahin filmisch Inszenierte. Als die Lage für die Verteidiger aussichtslos wird, erklärt Nettelbeck:

Am Ende - Schande? [...] wir sind hier groß geworden [...] Wir lassen doch nicht los. Und wenn wir uns mit unseren Nägeln in unseren Boden einkrallen, an unsere Stadt, wir lassen nicht los, ne! Da muss man uns die Hände einzeln abhacken. Oder uns erschlagen, einen nach dem anderen.

24 Vgl. dazu Kanzog (wie Anm. 13), S. 356-366, hier S. 363-365.

25 Zur Forschung zum deutschen Heimat-Begriff vgl. BAusinger, Hermann: Heimat in einer offenen Gesellschaft. Begriffsgeschichte als Problemgeschichte. In: Die Ohnmacht der Gefühle. Heimat zwischen Wunsch und Wirklichkeit. Hg. v. Jochen Kelter. Weingarten 1986, S. 76-90; Bastian, Andrea: Der Heimat-Begriff. Eine begriffsgeschichtliche Untersuchung in verschiedenen Funktionsbereichen der deutschen Sprache. Tübingen 1995, S. 117-146; NeumaYer, Michael: Heimat. Zu Geschichte und Begriff eines Phänomens. Kiel 1992, S. 6-62; ApplEgate, Celia: A Nation of Provincials. The German Idea of Heimat. Berkeley u.a. 1990. 
Die Begriffe Schande oder Ehrverlust sind hier in extremster Form übersteigert. Appelle zur bedingungslosen Selbstaufopferung reichen nicht mehr aus. Das Volk verwandelt sich ganz im Sinne nationalsozialistischer Blut-und-Boden-Ideologie in einen pflanzlichen Organismus, der im Boden lebt und gedeiht, durch feindliche Eroberung aber herausgerissen wurde, was ihm zwangsläufig seine Lebensgrundlage entzog. Als die Belagerer das Feuer einstellen, wird in „Kolberg“ ein blühender Baum als Sinnbild für die Zukunft der Stadt ins Bild gerückt. Die abstrakten Begrifflichkeiten Schande und Ehre werden somit durch biologische Kollektivsymbolik gestützt. Der Film suggeriert, dass erst das preußische Ethos in Form von Kampfgeist und Opfermut den Wiederaufstieg des Landes ermöglichte. Die französischen Gegner bekommen diesen bereits früh zu spüren: „Les Prussiens se battent comme des lions“. Auch wenn diese Stärke noch nicht zum Sieg reicht, unterstreichen diese Metaphern, dass die Fremdherrschaft nicht gerechtfertigt sei und nur von kurzer Dauer sein würde. ${ }^{26}$

\section{Die preußische Madonna und der korsische Weltenlenker: Erinnerte historische Personen}

Eine Reihe politischer und militärischer Akteure wurde besonders häufig in Historienfilmen zu den Napoleonischen Kriegen verkörpert. In Deutschland zählen hierzu drei Opfer der antinapoleonischen Aufstände und Feldzüge, die als Ikonen der „nationalen Erhebung" erinnert wurden. Andreas Hofer stand an der Spitze der Rebellion des Jahres 1809 gegen die bayerisch-französische Besatzungsmacht. Ferdinand von Schill stellte sich im gleichen Jahr mit seinem Regiment gegen die französischen Truppen im Königreich Westphalen. ${ }^{27}$ Theodor Körner, der sich den Lützower Jägern anschloss, gelangte durch seine Gedichte über die Befreiungskriege und die tödliche Verwundung, die er darin erfuhr, zu Berühmtheit. Die populärste deutsche Kinofigur in Filmen über die Napoleonischen Kriege war allerdings Königin Luise. Sie wurde nicht nur als liebevolle Landesherrin und Vorzeigemutter verehrt, sondern trägt aufgrund ihres Bittgangs zum französischen Kaiser im ostpreußischen Tilsit, ihres Patriotismus und frühen Todes ebenfalls Merkmale eines Märtyrermythos in sich. Die Reformanstrengungen Hardenbergs, Steins, Gneisenaus, Scharnhorsts oder Clausewitz' in Heer, Verwaltung, Politik und Recht blieben in deutschen Filmproduktionen indessen weitestgehend unerwähnt. So ist die Figur Gneisenaus in „Kolberg“ konsequenterweise als jugendlich charismatischer Heißsporn und Anpeitscher angelegt und keinesfalls als besonnener Reformer. ${ }^{28}$

26 Vgl. Koller (wie Anm. 6), S. 165.

27 Zur Mythenbildung um die Person Ferdinand von Schills vgl.: Für die Freiheit - gegen Napoleon: Ferdinand von Schill, Preußen und die deutsche Nation. Ausst.-Kat. Pommersches Landesmuseum Greifswald u.a. Hg. v. Veit Veltzke. Köln u.a. 2009.

Vgl. Koller (wie Anm. 6), S. 98 f. 
Auch die Konstellation, die den entscheidungsschwachen König seiner Gattin Luise als Fürsprecherin der „Kriegspartei“ gegenüberstellt, rekurriert im Falle „Kolbergs“ auf filmisch verfestigte Narrative aus der Zwischenkriegszeit. Insbesondere die Spielfilmproduktionen „Yorck“ (1931; R.: Gustav Ucicky) und „Luise, Königin von Preußen“ (1931; R.: Carl Froelich) erwiesen sich als Träger einer hagiografischen Tradition, die in dem Werk Harlans ihren Höhepunkt fand: Friedrich Wilhelm III. erscheint als gehemmter und willensschwacher Monarch, der erst durch seine Gemahlin und einen Kranz von Reformkräften - Stein, Hardenberg und Scharnhorst, im Falle „Kolbergs“ Gneisenau zur Auseinandersetzung mit Napoleon gedrängt werden muss.

Während der Film „Kolberg“ also auf der Handlungsebene im Wesentlichen einer bereits kanonisierten Luise-Legende folgt, liegt das Hauptcharakteristikum bei Harlan indes eher auf der visuellen Ebene, im Sinne einer komplett entrückten Darstellung der preußischen Königin. Um in den letzten Kriegswochen beim Zuschauer die größtmögliche emotionale Wirkung zu erzielen, fungiert die preußische Monarchin als diejenige Protagonistin, die den bis zum Tode bedrängten, aber von unbezwingbarem Durchhaltewillen beseelten Kolbergern ihre tiefe Zuneigung entgegenbringt: „Es sind nur noch wenige Edelsteine in unserer Krone geblieben. Kolberg ist einer davon.“ Auffällig ist in dieser Szene die in höchstem Maße stilisierte Inszenierung Luises als reglose und gestenfreie Heiligengestalt mit verklärtem Blick, begleitet von engelhaftem Chorgesang. Als Deutschland bereits in Schutt und Asche lag, beschworen die Nationalsozialisten hier noch den Glauben an das Unmögliche. Die Aura der Führergestalt vermag Wunder zu bewirken, sollte die Aussage lauten. ${ }^{29}$

Napoleon-Darstellungen im nationalsozialistischen Deutschland lassen sich - ebenso wie im faschistischen Italien - als Bezugnahmen auf die allgegenwärtigen Führerfiguren Adolf Hitler und Benito Mussolini lesen. Glaubt man den Aussagen von Veit Harlan, zollte auch Hitler Napoleon „höchste Achtung“ ${ }^{30}$ Die Figur Napoleons fungierte also gewissermaßen als zukunftsweisender Eroberer. Allerdings tritt er in den meisten deutschen Filmen der dreißiger Jahre, die über Aufstände gegen die französische Herrschaft und die Befreiungskriege entstanden, in denen Napoleon bekämpft wird, konsequenterweise gar nicht erst in Erscheinung. ${ }^{31}$ Den letzten Auftritt auf der Bühne des NSRegimes hatte der Korse allerdings in „Kolberg“. Unter anderem ist er hier in einer kurzen Sequenz am Grabe Friedrichs des Großen in Potsdam zu sehen, wo er dem militärischen Genie seinen Respekt zollt: „Serais-je là si tu vivais encore?“ Dieser Ausspruch ist einem realgeschichtlich bezeugten Moment entlehnt und verweist auf die welthistorische Größe des Eroberers - wenngleich der Kaiser der Franzosen im weiteren Verlauf des Films im Kontext der Belagerung Kolbergs als Prüfstein für die Wider-

29 Zur Kinofigur Luise vgl. ebd., S. 125-127, hier S. 126.

30 Harlan (wie Anm. 12), S. 182.

31 So etwa in „Der Rebell“ (1932; R.: Kurt Bernhardt, Luis TrenKER), „Theodor Körner. Ein Deutsches Heldenlied“ (1932; R.: Carl Boese, Rudolf WALtHER-Fein), „Yorck“(1931; R.: Gustav UCickY) und „Der höhere Befehl“ (1935; R.: Gerhard LAMPRECHT). 
standskraft der Preußen fungiert. ${ }^{32}$ In die Darstellung des militärischen Gegners gehen allerdings dezidiert negative Charakterzuschreibungen mit ein: Die französischen Soldaten erscheinen als disziplinlos und verroht, die Kommandeure als jähzornig und unorganisiert. Die fremden Truppen ergehen sich nach der Besatzung fremder Gutshöfe in wilden Zechgelagen. ${ }^{33}$

Schließlich ist es auch der Film „Kolberg“, in dem der patriotische Enthusiasmus der Massen wahrscheinlich am unmittelbarsten in Szene gesetzt wurde. Zu Zeiten, als der Zweite Weltkrieg sich auf deutschem Boden abspielte und das NS-Regime mit dem Einsatz des „Volkssturms“ den Vormarsch der Alliierten glaubte aufhalten zu können, galt das Hauptaugenmerk hier konsequenterweise den Zivilisten. Die Landwehr der Befreiungskriege wurde vom untergehenden NS-Regime als historisches Vorbild für die Mobilisierung des „Volkssturms“ eingespannt. Der „losbrechende Sturm“, die „wilde Begeisterung, die Preußen durchtobt“, der „große elementare Ausbruch des Volkswillens" - es sind zumeist naturhafte Metaphern, die in einschlägigen Filmen des Öfteren auf die konstruierten Kollektividentitäten Volk oder Preußen angewandt wurden: „Sie suggerieren, dieses Kollektiv sei eine eigenständige lebendige Gestalt mit der Energie von Naturgewalten. Faszination und zugleich Ehrfurcht vor der ,Masse' als einer Art

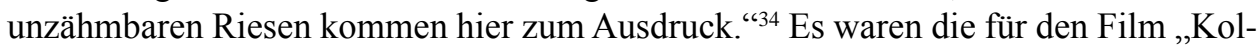
berg“ Verantwortlichen, welche die eher abstrakte Begrifflichkeit „Volk“ in der Massenszene in Breslau am plakativsten zu vermitteln suchten.

\section{Fazit: "Kolberg" - kein "Durchhaltefilm", sondern Denkmal für die Ewigkeit?}

Die außergewöhnliche politische Bedeutung, welche „Kolberg“ aus Sicht des Reichspropagandaministers zukam, wird aus den gewaltigen materiellen wie personellen Ressourcen ersichtlich, die vonseiten des Staates für das Projekt mobilisiert wurden, sowie an den einschneidenden Handlungs- und Entscheidungsvollmachten, die dem Regisseur vonseiten des Regimes zugestanden worden waren. „Ich hatte Macht über Generäle“, konstatierte Harlan nach Kriegsende in einem Interview, „wenn sie nein sagten, wurde ja gesagt ...“35 Demnach ,sei der ausdrückliche Befehl des Führers, daß für diesen Film das Militär in jeder notwendigen Menge eingesetzt werden dürfe; auch daß mir jegliches Material zur Verfügung stehen solle." ${ }^{\text {"36 }}$ In jedem Falle sollte die Produktion eine absolute Spitzenstellung auf der kulturpolitischen Agenda dieser

32 Vgl. Keitz, Ursula von: Der Idealheld des Monumentalfilms: Napoleon in der Kinematographie. In: Mythen der Nationen - Völker im Film. Hg. v. Rainer RotнeR. Berlin 1998, S. 250-266, hier S. 262 f.; Koller (wie Anm. 6), S. 103-107, hier S. 105 f.

33 Zu Besatzungsbildern im NS-Film vgl. ebd., S. 182-184, hier S. 184.

34 Ebd., S. 168.

35 30. Januar 1945. Kolberg, ein zeitgeschichtliches Dokument. Hg. v. AtLas Filmverleir. Frankfurt/M. 1965, S. 10.

36 Harlan (wie Anm. 12), S. 184. 
Tage innehaben - Harlan skizzierte deren Gigantomanie später mit den Worten: „Sowohl Hitler wie Goebbels mußten von der Idee besessen gewesen sein, daß ein solcher Film ihnen mehr nützen konnte, als etwa eine gewonnene Schlacht in Rußland.“"37

Film-, trick-, pyro- und kameratechnisch waren für „Kolberg“ konsequenterweise sämtliche verfügbaren Register zu ziehen. Veit Harlan probierte bei diesem Film - von dem er wusste, dass es vorläufig sein letzter sein würde - alles aus, was er an entsprechenden Innovationen zu diesem Zeitpunkt noch parat hatte, so zum Beispiel neue Techniken für Sprengungen. Nach eigenen Angaben dirigierte er zeitweise die gesamte Szenerie von einem Fesselballon aus..$^{38} 10.000$ Kostüme wurden aus deutschen Theatern zusammengetragen, für die Abdankungsszene Kaiser Franz' II. die echten Reichsinsignien zur Verfügung gestellt, welche von 20 Detektiven zu bewachen waren. Etwa 30 Pyrotechniker waren damit beschäftigt, die Gefechte durch Scheingranaten und Rauchwolken so realistisch wie möglich erscheinen zu lassen. Den Fluss Persante ließ Veit Harlan durch eigens gegrabene Kanäle in die Niederungen um Kolberg herum so einfließen, dass die Stadt von Wasser eingeschlossen schien. Die Dreharbeiten mussten aufgrund von Luftangriffen immer wieder pausieren - um Schauspieler und Filmcrew im Falle von Bombenalarm zu schützen, wurde auf dem Drehgelände eigens ein Splittergraben ausgehoben. ${ }^{39}$

Auch mit Blick auf die Produktionskosten erwies sich das Filmprojekt somit schon bald als eines der Superlative und die ursprüngliche Kostenkalkulation von Goebbels vom 4. Juli 1943, nach der höchstens 4 Millionen Reichsmark zu bewilligen waren, als hinfällig. Je nach zitierter Quelle verschlang der Film 8,5 bis 8,8 Millionen Reichsmark und somit in etwa acht Mal so viel, wie eine durchschnittliche Produktion damals kostete. Die Tatsache, dass dieser gewaltige materielle und finanzielle Ressourcenaufwand trotz der immer kritischer werdenden Situation an allen Kriegsfronten und der damit einhergehenden Rationierungen betrieben wurde, spricht zweifelsohne für die herausragende propagandistische Bedeutung, die dem Filmprojekt vonseiten des Regimes eingeräumt worden war. $^{40}$

37 30. Januar 1945 (wie Anm. 35), S. 10. Anhand der entsprechenden Tagebuchaufzeichnungen von Goebbels lassen sich die einzelnen Etappen der Filmgenese sehr gut nachzeichnen - die Fülle der Einträge offenbart zugleich den Stellenwert, den „Kolberg“ für den Propagandaminister hatte: „Selten wird Produktionsgeschichte so anschaulich, wird so offenbar, wie Goebbels von ganz oben, trotz extremer Überlastung im Krieg, steuerte, kontrollierte, plante, Drehbücher bis ins Detail ausrichtete. Nirgendwo sonst inszeniert sich Goebbels selbst so stark als Produzent und oberster künstlerischer Leiter.“ Moeller, Felix: Der Filmminister. Goebbels und der Film im Dritten Reich. Berlin 1998, S. 295.

38 Vgl. Harlan (wie Anm. 12), S. 184-186.

39 Vgl. Klaus, Ulrich J.: Deutsche Tonfilme. Filmlexikon der abendfüllenden deutschen und deutschsprachigen Tonfilme nach ihren deutschen Uraufführungen. Jahrgang 1944/45. Bd. 1-15, hier Bd. 13. Berlin u.a. 2002, S. 79.

40 Eine detaillierte Darstellung des Entstehungs- und Produktionsprozesses findet sich bei KuTZ, Jens P.: Veit Harlans Kolberg. Der letzte „Großfilm“ der Ufa. In: http://www.jenspeterkutz.de/analyse.html (03.09.2014). 
Folgt man den Zahlen Harlans, so wirkten bei den Dreharbeiten trotz angespannter Kriegslage bisweilen 187.000 deutsche Soldaten als Statisten sowie 6.000 Pferde mit. Diese Angaben scheinen jedoch weit übertrieben. ${ }^{41}$ Bei Betrachtung der einschlägigen Massenszenen im Film und unter Berücksichtigung der realen Sachzwänge ist wohl die Vermutung naheliegender, dass etwa 5.000 Wehrmachtssoldaten und zwischen 2.000 und 3.000 Pferde eingesetzt wurden - eine Zahl freilich, die angesichts der von Monat zu Monat prekärer werdenden Situation an der Ostfront immer noch gewaltig erscheint. Eine interessante Fußnote: Einen Großteil der Kavallerie stellten russische Kosakenverbände, die sonst (wahrscheinlich) unter dem Kommando der sogenannten „Russischen Befreiungsarmee“ Andrej Vlasovs standen.

Die ursprüngliche Zeitplanung, nach der die Dreharbeiten an „Kolberg“ zum 13. Mai 1944 abgeschlossen sein sollten, war vor dem Hintergrund der sich ständig verschlechternden Rahmenbedingungen des Krieges ebenso unrealistisch wie der Wunsch des Reichspropagandaministers, das Endprodukt im Winter 1943/44 auf die Leinwände der verbliebenen deutschen Filmtheater zu bringen. Endlich abgeschlossen waren die Dreharbeiten indes erst im Juli 1944. Als auch die Schnittbearbeitung Anfang Dezember beendet werden konnte, zeigte sich Goebbels sowohl künstlerisch als auch inhaltlich äußerst zufrieden mit dem Resultat und sah nur an wenigen Stellen und in marginalem Umfang etwas Änderungsbedarf. ${ }^{42}$ Diesem wurde jedoch nicht im gewünschten Maße entsprochen, und am 23. Dezember äußerte der Reichspropagandaminister nun erstmals unmissverständliche Einwände in Bezug auf das Harlan'sche Monumentalwerk. Im Zentrum der Kritik standen dabei vor allem die allzu realitätsnah verfilmten Kriegsleiden - ausufernde Schlachtenszenen und erbarmungslose Metzeleien, erschütternde Bilder der leidenden Zivilbevölkerung aus dem in Feuerstürmen untergehenden Kolberg. All diese Einstellungen erinnerten wohl allzu eindringlich an den Kriegshorror der unmittelbaren Gegenwart und liefen daher Goebbels' Intention, dem Zuschauer ein (Vor-)Bild des heldenhaften Abwehrkampfes einer am Ende siegreichen (!) Festungsstadt

41 Ulrich Gehrke führt hierzu aus: „Der Abzug von 187.000 Mann von der im Sommer 1944 schwer ringenden Ostfront [...] wäre, so wirklich stattgefunden, ein solcher Skandal, dass er nicht nur von der Zwecksetzung, sondern allein von den Dimensionen her, nicht der Aufmerksamkeit der Nachbarverbände entgehen konnte, noch weniger der ersten kritischen Betrachtung des Frontgeschehens im Osten nach Kriegsende. Unter der wachsenden Anspannung an allen Fronten gilt das auch für etwa andernorts abgezogene geringere Verbände."Vgl. GeHrKe, Ulrich: Heinrich George. Anfang und Ende in Kolberg. Hamburg 2005, S. 68.

42 Ein Erwin Leiser skizziert die Streichliste wie folgt:,,1. Kürzung aller monströsen Schlachten- und Stadtszenen zu Gunsten der Handlung unter den bekannten Persönlichkeiten, 2. Beseitigung der Gebärszenen von dem Verbringen der schwangeren Frau in das Haus des Bürgervorstehers bis zu der Szene nach der Geburt des Kindes und dem Wegbringen von Mutter und Kind aus dem Haus, 3. Kürzung der hysterischen Ausbruchszenen des Bruders Klaus, 4. Kürzung der Audienz-Szenen bei der Königin Luise durch Wegnahme von je 1 oder 2 Großaufnahmen der Frau v. Meyendorff und von Frau Söderbaum, 5. Kürzung der Unterredungsszene zwischen Gneisenau und Nettelbeck über die Befehlsgewalt in Kolberg. Beseitigung der Sätze, daß er (Gneisenau) die alleinige Verantwortung trüge.“ Außerdem forderte Goebbels für den Schluss des Films die Ersetzung des ihm unliebsamen Luther-Chorals „Ein feste Burg ist unser Gott“ durch das nach 1807 entstandene (und damit unhistorische) „Niederländische Dankgebet“. In: LeISER (wie Anm. 2), S. 111. 
zu liefern, diametral entgegen - und waren daher sicherlich nicht dazu geeignet, beim Publikum heroische Gefühle und Siegesentschlossenheit zu fördern.

Schließlich wurde der Tag der „Reichsuraufführung“ von Kolberg auf den 30. Januar 1945 terminiert - der symbolträchtige zwölfte Jahrestag der nationalsozialistischen Machtergreifung. Die Premiere sollte, der herausragenden Bedeutung des Filmprojektes angemessen, in der Reichshauptstadt Berlin stattfinden. Der repräsentative Ufa-Palast am Zoologischen Garten war infolge alliierter Luftangriffe bereits vollständig zerstört, sodass die Premierengäste spontan in den (noch) unversehrten Tauentzien-Palast und in das Ufa-Theater am Alexanderplatz eingeladen wurden. Es war den Veranstaltern nur mit knapper Not gelungen, zur Feier des Tages ein kaltes Büfett - Thunfisch und ein paar Büchsen Ölsardinen - zu organisieren, welches nach der Filmpremiere eiligst verzehrt wurde - von einem besorgten Publikum, welches gern vor dem zu erwartenden Bombardement den nächtlichen Weg nach Hause gefunden haben wollte. Vor diesem Hintergrund hinterließ die Aufführung des Films bei den Anwesenden ein „Gefühl der Verlassenheit und der Eiseskälte“. ${ }^{43}$

Dagegen waren die Rezensionen von Kolberg in der ,gleichgeschalteten“ nationalsozialistischen Presse erwartungsgemäß überschwänglich. Als paradigmatisch ist in diesem Zusammenhang eine Besprechung im Zentralorgan der NSDAP, dem „Völkischen Beobachter“, vom 31. Januar 1945 zu werten, deren Grundtenor stellvertretend für die offizielle Rezeption in den letzten Kriegsmonaten gelten kann:

Diesen Film im Frieden zu sehen, hieße die Stadt Kolberg und ihre Bürger als Vorbild bewundern. Ihn in diesem Krieg sehen, bedeute ein Gleichnis, ein Beispiel für uns selber. [...] Der Film „Kolberg" ist ein großer Film, sonst hätte man es ihm nicht vergönnt, am 30. Januar und noch dazu dieses bedeutungsvollen Jahres aufgeführt zu werden. ${ }^{44}$

Obgleich „Kolberg“ sowohl in der Reichshauptstadt Berlin als auch in der belagerten Atlantikfestung La Rochelle seine Premiere feierte, kam der Film zu spät, um die von ihm erwartete propagandistische Wirkung noch erfüllen zu können. Die noch im Oktober 1944 geäußerte Absicht, ihn zeitgleich mittels einer großen Anzahl an Kopien in den bedeutendsten Städten des Reiches anlaufen zu lassen, um damit möglichst schnell die erwünschte Breitenwirkung zu erzielen, war angesichts des raschen Vordringens der alliierten Truppen bereits gänzlich unrealistisch. Die Realität des Krieges

43 Zit. nach Kahlenberg, Friedrich P.: Preußen als Filmsujet in der Propagandasprache der NS-Zeit. In: Preußen im Film (wie Anm. 5), S. 135-163, hier S. 162.

44 „Kolberg - ein Film? Ein Beispiel!“ In: Völkischer Beobachter, 31.1.1945. Es war nur folgerichtig, dass der Film rasch mit dem höchsten Prädikat „Film der Nation“ ausgezeichnet wurde - eine Würdigung, die seit ihrer Einführung im Jahre 1935 nur fünf Filme erhielten. Insgesamt vereinte „Kolberg“ mehr Prädikate als jede andere Filmproduktion des Dritten Reiches zuvor: neben „Film der Nation“ galt sie als „Staatspolitisch und künstlerisch besonders wertvoll“, „Kulturell wertvoll“, „Volkstümlich wertvoll“", „Anerkennenswert“, „Volksbildend“ und „Jugendwert“. Vgl. KAnzog (wie Anm. 13), S. 356. 
hatte die militärische Fiktion überholt, und die Filmwirklichkeit musste an den Tatsachen der sich abzeichnenden deutschen Niederlage zerbrechen.

Goebbels aber war indes keinesfalls bereit, die propagandistische Katastrophe des Harlan'schen Monumentalepos in allen Konsequenzen anzuerkennen. Er wurde hingegen, so ließe sich spekulieren, selbst zum Opfer des von ihm geschaffenen Mythos. Akribisch verfolgte der Reichspropagandaminister in mehreren Einträgen den allmählichen Fall des gegenwärtigen Kolbergs im Zweiten Weltkrieg. Dabei fällt auf, dass er diesen Ausschnitt tatsächlicher, aktueller Geschichte nach dem Muster des von ihm geplanten und zensierten Films wahrnahm - wobei anzumerken ist, dass Darstellungen der militärischen Lage in diesem Tagebuch sonst üblicherweise nach der StenografieNiederschrift der Berichte angefertigt wurden, welche der Verbindungsoffizier des Oberkommandos der Wehrmacht täglich überbrachte. Am 6. März 1945 heißt es:

Der Kampfkommandant von Kolberg - wenn man ihm diesen Titel überhaupt zuerkennen will hat beim Führer den Antrag gestellt, Kolberg kampflos dem Feind zu übergeben. Der Führer hat ihn gleich ab- und einen jungen Offizier an seine Stelle gesetzt. Haben denn diese verkommenen Generäle überhaupt kein geschichtliches Empfinden und Verantwortungsgefühl, und hat ein Kampfkommandant von Kolberg zur jetzigen Zeit viel mehr den Ehrgeiz, einem Lucadou als einem Gneisenau nachzueifern? ${ }^{45}$

In doppelter Weise an den Film denkt Goebbels auch am 19. März, nachdem die Rote Armee Kolberg eingenommen hatte:

Die Stadt, die sich mit einem so außerordentlichen Heroismus verteidigt hat, konnte nicht mehr gehalten werden. Ich will dafür sorgen, daß die Räumung von Kolberg nicht im OKW-Bericht verzeichnet wird. Wir können das angesichts der starken psychologischen Folgen für den KolbergFilm augenblicklich nicht gebrauchen. ${ }^{46}$

Das filmische Trugbild einer siegreichen Schlacht um Kolberg erschien dem Reichspropagandaminister offenbar relevanter als das immer unabwendbar werdende Faktum einer militärischen Niederlage des „Dritten Reiches“, welches sich tatsächlich und in unvermeidbarer Konsequenz vor aller Augen abzeichnete. ${ }^{47}$ Fast gewinnt man

45 GoebBels, Joseph: Tagebücher 1945. Die letzten Aufzeichnungen. Hamburg 1977, S. 126.

46 Ebd., S. 304.

47 Am 4. März 1945 erreichten sowjetische Panzerspitzen den Stadtrand beim Kautzenberg. Aus Kolberg wurde heftige Gegenwehr geleistet, um die in der Stadt eingeschlossenen Soldaten und Flüchtlinge ausschiffen zu können. Kolberg wurde dabei nicht zur „Festung“, sondern lediglich zum „Festen Platz" erklärt. Funktionsfähige Festungsanlagen gab es hier - nach Johannes Voelker - seit 1873 nicht mehr. Lediglich 3.300 deutsche Soldaten und Volkssturm-Angehörige standen einer erdrückenden sowjetisch-polnischen Übermacht gegenüber. Sowjets und Polen machten sich später den KolbergMythos ebenfalls zunutze und übertrieben die militärische Stärke der deutschen Seite um ein Vielfaches, um die Bedeutung ihres Sieg zu erhöhen. Trotzdem wurde bei den Kämpfen um die Stadt vom 5. bis 18. März 1945 in der Schlacht um Ostpommern Kolberg zu 90 Prozent zerstört, während es gelang, die Bevölkerung größtenteils auf dem Seeweg zu evakuieren (70.000 Menschen). Am 18. 
den Eindruck, als ginge es ihm nicht mehr um den ohnehin unrealistischen Endsieg, sondern darum, sich und sein Deutschland für die historische Nachwelt zu stilisieren und zu inszenieren. Worum es in diesem Wunschdenken ging, war womöglich nicht mehr ein konkreter Sieg, sondern nur noch oder allenfalls ein posthumer Sieg, ein Endzeit-Sieg des Nachruhms, gleichsam der „Effekt in der Geschichte“. Und wo wäre solch ein Wunschdenken besser zu erfüllen als in einem Film? Ist „Kolberg“ vielleicht - gerade in Anbetracht seiner besonderen Entstehungs-, Zensur- und Rezeptionsgeschichte - gar kein Durchhaltefilm für den Zweiten Weltkrieg, sondern ein propagandistischer Historienfilm für die Zukunft im Rückblick auf die Geschichte, eben die filmische Glorifizierung der totalen Niederlage Deutschlands im Jahre 1945?

Schließlich endet der letzte Spielfilm über die Geschichte Preußens, bevor das „Dritte Reich“ in Schutt und Asche fiel, mit den eindringlichen Worten Gneisenaus an den zögernden König Friedrich Wilhelm, so wie sie aus nationalsozialistischer Perspektive im Jahre 1813 in Breslau hätten vorgetragen werden können: Der König möge an sein Volk einen Aufruf zum Kriege verfassen und damit ,[...] die Fesseln endgültig abschütteln. Das Volk steht auf zur kommenden Völkerschlacht, Majestät, der Sturm bricht los!“ Die Naheinstellung der Kamera auf den preußischen Militärführer blendet auf die bewegten kampfbereiten Massen auf den Straßen über, bevor Gneisenau mit entrücktem Blick beschwörend fortfährt: „Aus Asche und Trümmern wird sich, wie ein Phoenix, ein neues Volk erheben. Ein neues Reich“. Das Ziel der Befreiung von den „Fesseln“ der Fremdherrschaft war verknüpft mit der Vorstellung einer schon zwangsläufigen, reinigenden Zerstörung der Gegenwart vor dem Anbruch einer neuen Zeit. ${ }^{48}$

Die Nationalsozialisten waren nicht nur von ihrer eingebildeten Mission besessen, sondern auch von dem Bild, das sie in der Geschichte abgeben würden - nicht unbedingt in den kommenden Jahrzehnten, aber sicherlich in den kommenden Jahrhunderten. Ihre Großbauten, vom Nürnberger Parteitagsgelände bis zu den Autobahnen, wurden nicht zuletzt nach Maßgabe ihres „Ruinenwertes“ konzipiert: Noch nach langer Zeit sollten sie von der „Größe“ des Reiches künden und bewundert werden wie die Hinterlassenschaften des alten Ägyptens oder des antiken Roms. Aus Einsicht in die militärische Überlegenheit des Gegners einfach zu kapitulieren, hätte das „grandiose“ Bild zerstört. Wenn das germanische Weltreich im „historischen Kampf“ den „Mächten des Bösen“ unterlag, dann nicht auf banalem Wege, sondern angemessen bombastisch. Wenn nicht totaler Sieg und totale Macht zu erringen waren, dann sollte wenigstens die Katastrophe von so überwältigendem Ausmaß sein, dass man noch nach Jahrhunderten von ihr spräche. Und mit Blick auf „Kolberg“ sieht es so aus, als sei dies den Nationalsozialisten auch bis heute gelungen.

März 1945 wurde der Widerstand aufgegeben. Zum erinnerungskulturellen Fortleben des KolbergMythos in Polen vgl. Culbert, David: „Kolberg“: Film, Filmscript and Kolobrzeg Today. In: The Historical Journal of Film, Radio and Television 14/4 (1994), S. 449-466.

48 Koller (wie Anm. 6), S. 152. 
Open Access @ 2016 by Böhlau Verlag GmbH \& Cie, Köln Weimar Wien 


\title{
István Széchenyi vor Leipzig
}

\section{Heldenstory und Soldatengeschwätz}

\author{
Stephan Krause
}

\begin{abstract}
Hiszen nyelvében él a nem ... / ha kell ha nem KAF, Überallesbadeni nyelvtanászok ${ }^{1}$

Noch steht mir die Wand von Fakten gegenüber, wo kein Durchkommen ist. Man kann die Sache ein wenig beschleunigen und rascher erzählen.

Es braucht nicht viel Kunst, die Geschichte zu überreden, einen Zahn zuzulegen. Es genügt ein Gerücht, sie in Wallung zu bringen. Volker Braun, Die hellen Haufen ${ }^{2}$
\end{abstract}

Die vorliegende Untersuchung widmet sich István Széchenyis Teilnahme an der Völkerschlacht bei Leipzig. Damit wird eine Episode aus Széchenyis Biografie ins Zentrum gestellt, die nur sehr geringfügig für seinen äußerst bedeutenden Status als historische Figur verantwortlich ist. Biografische Prominenz kommt dem Geschehen nur dadurch zu, dass sie im Rückblick der Lebensbeschreibung zur bedeutsamen Gegebenheit erhoben wird, nicht aber aus ihm selbst heraus. ${ }^{3}$ Széchenyis Bedeutung für und in Ungarn geht nicht auf militärischen Ruhm zurück.

Im Mittelpunkt dieser literaturwissenschaftlich inspirierten Untersuchung steht folglich umso mehr die Funktionsweise der Narrative ${ }^{4}$, mit denen die Episode zur

1 KovÁcs, András Ferenc: Überallesbadeni nyelvtanászok [Überallesbadener Grammatiker]. In: DERs.: Überallesbadeni dalnokversenyek. (Burleszkek és szatírák). Kolozsvár [Cluj Napoca] 2005, S. 52-53, hier S. 53. Die deutsche Übersetzung dieser Verse bleibt ohne die Doppeldeutigkeit des Originals: „Denn in seiner Sprache lebt das Nein/Geschlecht ..., / ob es nötig ist oder nicht.“ Kovács' Verse beziehen sich auf einen Széchenyi zugeschriebenen Ausspruch, nach dem die Nation (,nemzet") in ihrer Sprache lebe. Kovács aber lässt die zweite Hälfte des Wortes fort und schafft so Anspielung und Irritation zugleich. Das erste ,nem` kann beide in der Übersetzung angegebenen Bedeutungen haben. Soweit nicht anders angegeben, stammen im Folgenden alle Übersetzungen vom Verfasser.

2 Braun, Volker: Die hellen Haufen. Erzählung. Berlin 2011, S. 30-31.

3 Kontextualisieren ließe sich dieser Befund noch mit dem Begriff der Präfiguration, wie ihn Hans Blumenberg in seinem posthum erschienenen Text Präfiguration. Arbeit am politischen Mythos (Berlin 2014, besonders S. 9-17) vorgeschlagen hat. Allerdings müsste hier von einer gewissermaßen ,umgekehrt gedachten Präfiguration“ ausgegangen werden. Denn Széchenyis Leipziger Schlachtbeteiligung wird erst vor dem Hintergrund seiner weit später erlangten politisch-historischen Bedeutung zum mit biografischer Bedeutsamkeit aufladbaren Begebnis.

4 Die exemplarische Textgrundlage dieser Untersuchung bilden die Versionen bei: ZichY, Antal: Gróf Széchenyi István életrajza (1791-1860) [Lebensbeschreibung Graf István Széchenyis (1791-1860)]. Hg. v. Sándor Szilágyi. Bd. 1-2. Budapest 1896-1897 (Magyar Történeti Életrajzok 12./13. Jg.); Nosziczi Thurzó, Kálmán: Gróf Széchenyi István szerepe a lipcsei csatában [Graf István Széche- 
Heldengeschichte aufbereitet wird. Gefragt wird hier nicht so sehr, was die jeweiligen Einzelgeschichten als Faktisches erzählen (können), sondern mehr, wie die zumindest zum Teil unwägbare Bedeutung eines durch Széchenyi ausgeführten Kurierauftrages narrativ zur schlachtentscheidenden Episode erhoben wird. Auf diese Weise erhalten die im Folgenden betrachteten Texte einschließlich einer Spielfilmszene den Status parallel nebeneinander stehender Untersuchungsgegenstände, deren Betrachtung in ihrem synchronen Vorliegen erfolgt.

Mit István Széchenyi wird eine der bekanntesten Figuren der ungarischen Geschichte und vielleicht die bedeutendste des 19. Jahrhunderts in Ungarn behandelt. Seine Bedeutung zeigt sich nicht nur an der Breite der über ihn und seine politischen, wirtschaftlichen, gesellschaftlichen und wissenschaftlichen Aktivitäten publizierten Fachliteratur oder an der Tatsache, dass etwa die aktuellen ungarischen Wirtschaftsförderungs- und Infrastrukturprogramme Új Széchenyi terv (Neuer Széchenyi-Plan) bzw. Széchenyi 2020 heißen. ${ }^{5}$ Dies lässt sich auch an der (eher alltäglichen) Tatsache ablesen, dass es in beinahe jeder ungarischen Ortschaft eine Straße gibt, die nach Széchenyi benannt ist. Die zeitgenössischen Künstler Attila Bujdosó, Zoltán Csík-Kovács und Gábor Papp haben für das ungarische Durchschnittsdorf eine Statistik zur Häufigkeit von Straßennamen angelegt. Darin überholt Lajos Kossuth (1802-1894), Széchenyis wichtigster politischer Gegner in den 1840er Jahren, ${ }^{6}$ diesen allerdings mit klarem Vorsprung. Den ersten Platz belegt unangefochten Sándor Petöfi (1823-1849). Weder Kossuth noch

nyis Rolle in der Völkerschlacht bei Leipzig]. In: Hadtörténelmi Közlemények Nr. 3 (1914), S. 335 362; Hegedüs, Loránt: Gróf Széchenyi regénye és éjszakája [Graf István Széchenyis Roman und Nacht]. Budapest 1933; Viszota, Gyula: Gróf Széchenyi István mint katona. (Második közlemény.) [Graf István Széchenyi als Soldat (Zweiter Teil.)]. In: Irodalomtörténeti közlemények 52/3 (1942), S. 132-155; Silagi, Denis: Der größte Ungar. Stephan Széchenyi. Wien u.a. 1967; Fekete, Sándor: Széchenyi István [István Széchenyi]. Budapest 1968; SuRÁNYI, Miklós: Egyedül vagyunk. Széchenyi István életregénye [Wir sind allein. István Széchenyis Lebensroman]. 2 Bde. Budapest 1982; FARKAS, Miklós: Ein Kurierreiter in der Völkerschlacht. In: Leipziger Blätter 18 (1991), S. 36; SzENTKIRÁLYI, Elemér: Graf István Széchenyi auf dem Weg in die Politik. Der Lebensabschnitt bis zum Erscheinen des ,Hitel'. I. Teil. In: Ungarn-Jahrbuch 19 (1991), S. 89-141; OplatKa, Andreas: Graf Stephan Széchenyi. Der Mann, der Ungarn schuf. Wien 2004, besonders Kap. 3; Topor, István: Tudod-e, milyen hőstettet hajtott végre a „népek csatájában“ Gróf Széchenyi István? [Weißt Du, welche Heldentat Graf István Széchenyi in der „Völkerschlacht“ vollbrachte?]. In: http://korok.webnode.hu/news/tudod-emilyen-hostettet-hajtott-vegre-a-nepek-csatajaban-grof-szechenyi-istvan-/ (12.10.2013); sowie eines der drei Themen für den durch das Militärgeschichtliche Museum und die Organisation Nemzeti Vágta [Nationaler Galopp] veranstalteten Malwettbewerb für Grundschüler unter dem Titel „A legnagyobb magyar hőstettei ...“ [„„Die Heldentaten des größten Ungarn ..."]: 2. Villám lovas [Blitzreiter]. In: http://vagta.hu/rajzpalyazat/2010/_html/tortenetek.html\#villam_lovas (23.03.2014. Link ist abgeschaltet), und schließlich der Spielfilm A hídember (Im Schatten der Brücke, Ungarn 2002; Regie: Géza Bereményi).

5 Vgl. etwa die im Internet geschalteten Antragsportale: http://ujszechenyiterv.hu/ (Ungarisch; 12.05.2014) und www.szechenyi2020.hu (Ungarisch; 12.05.2014).

6 Széchenyi stritt im Parlament und in Zeitungsartikeln anhaltend mit Kossuth über dessen für Ungarn verfolgte revolutionäre Reformpolitik, zu der u.a. die Unabhängigkeit von Österreich zählte. Széchenyi sah mit Sorge auf die durch Kossuth unterstützte Magyarisierungspolitik in den ungarischen Reichsteilen. Beide sind aber als ungarische Nationalhelden zu sehen. 
Abb. 1 Der Apelstein Nr. 22 an der Saalfelder Straße in Leipzig erinnert an die durch General Ignác Gyulay (1763-1831) kommandierte Armee, die in der Völkerschlacht 1813 als Verbindungsglied zwischen Schwarzenbergs Hauptarmee und Blüchers Truppen fungierte. Sie hatte eine Stärke von 17.000 Mann. István Széchenyi gehörte jedoch direkt zu Schwarzenbergs Stab.

Foto: Stephan Krause.

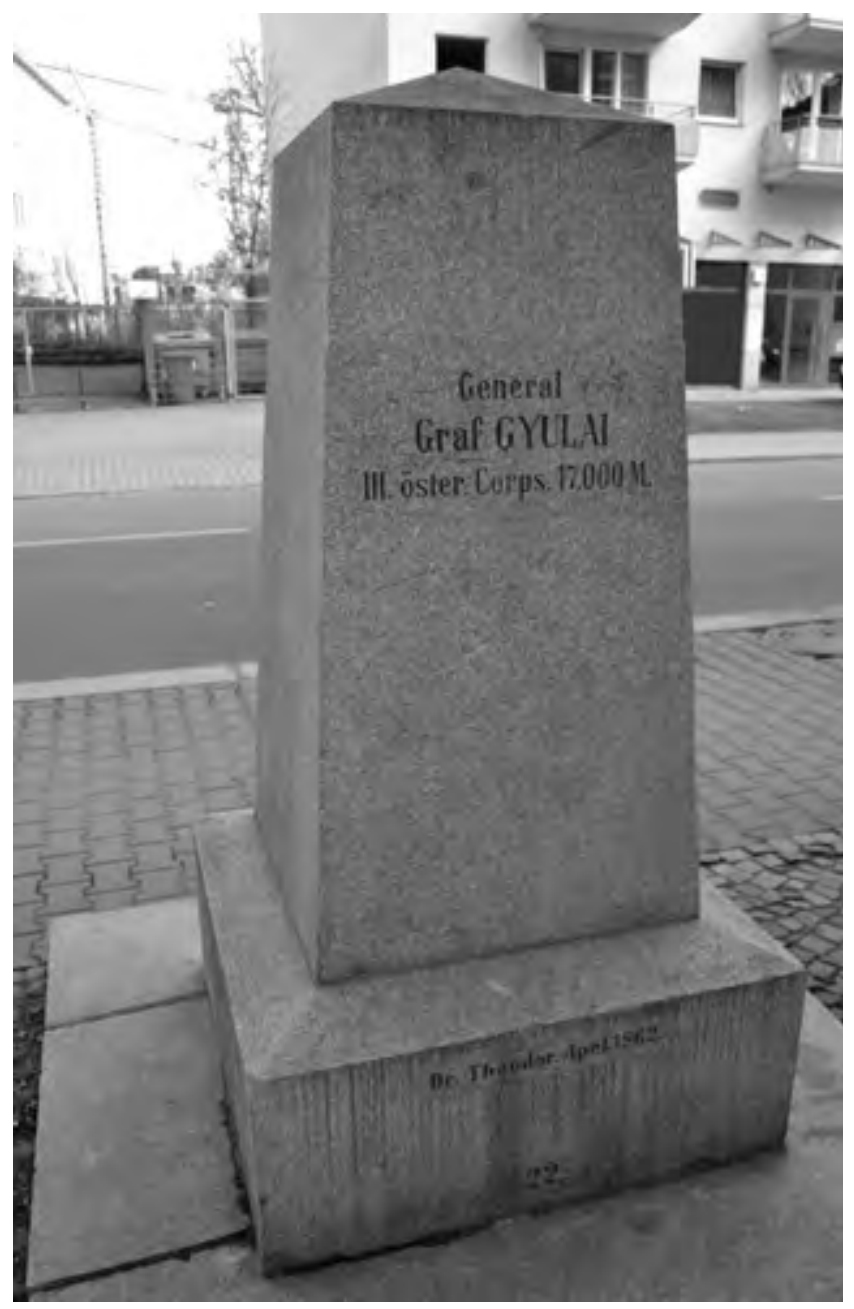

Széchenyi reichen an den Dichter heran. ${ }^{7}$ Diese Namhaftigkeit Széchenyis rührt von seinem historischen, gesellschaftlichen und politischen Einfluss auf Ungarns Geschicke her. So ist die Bedeutung seiner Rolle kaum zu überschätzen.

Széchenyis Vita lässt sich unter Berücksichtigung des Kontextes von 1813 in der folgenden Weise skizzieren: István Széchenyi, Sohn des Grafen Ferenc Széchényi und der Gräfin Julianna Festetics, wurde am 21. September 1791 in Wien geboren. Wie seine Brüder Pál und Lajos trat er 1808 ins Militär ein. 1813 stand der 22-jährige István Széchenyi als Rittmeister (ung. kapitány) bzw. Ordonnanzoffizier (ung. parancsőrtiszt)

7 Vgl. die Grafik Átlagtelepülés [Durchschnittsgemeinde] in: Bujdosó, Attila/DE Vet, Annelys: Magyarország szubjektív atlasza. Budapest 2011, S. 167. 
in Diensten des Feldmarschalls Karl Philipp zu Schwarzenberg und nahm an kriegerischen Auseinandersetzungen mit dem napoleonischen Heer teil, an der Schlacht bei Dresden (26. und 27. August 1813) und an der Völkerschlacht bei Leipzig (16. bis 19. Oktober 1813). Széchenyi gehörte damit nicht zu dem von Ignaz Graf Gyulay befehligten 3. Armeekorps, sondern war Schwarzenberg direkt unterstellt (Abb. 1).

István Széchenyi wurde im Ungarn des 19. Jahrhunderts zu einer der entscheidenden politisch-historischen Figuren. Ab 1825 betätigte er sich aktiv als gewandter und talentierter Politiker, in den 1840er Jahren im beständigen parlamentarischen und publizistischen Streit mit dem revolutionär denkenden Lajos Kossuth. Von Letzterem stammt trotz unausgesetzter politischer Rivalität in grundsätzlichen Fragen der Zukunft Ungarns der Ausspruch Széchenyi sei „der größte Ungar“:

Die Heimatliebe verflüchtigte sich beim Grafen Széchenyi dennoch nicht in müßigem Jammern. Mit seiner Hand am Puls der Epoche, verstand er deren Regungen genau. Deshalb nenne ich ihn den größten Ungarn; weil (selbst wenn dies jemand widerlegte) ich in unserer Historie niemanden kenne, über den wir sagen würden, dass sein Handeln mit auf Jahrhunderte angelegter Wirkung genau rechtzeitig kam. ${ }^{8}$

Kossuths geradezu prophetische Einschätzung seines Zeitgenossen steht paradigmatisch für Széchenyis Status in der ungarischen Geschichte seit dem 19. Jahrhundert. Széchenyi setzte sich für den kulturellen, wissenschaftlichen und wirtschaftlich-politischen Aufschwung Ungarns und den Aus- und Aufbau einer verlässlichen Infrastruktur wie kein anderer ein, und zwar mit seinem Geist, seiner Person und seinem Vermögen. Ein modernes Ungarn ist ohne Széchenyi mithin nicht zu denken. Die Gründung der Ungarischen Akademie der Wissenschaften (MTA) 1827 geht auf seine Initiative zurück. Für die ihr vorausgehende ungarische Gelehrtengesellschaft stellte er ein Jahreseinkommen seiner Besitzungen zur Verfügung. Im selben Jahr rief er das Nemzeti Kaszinó (Nationales Casino) ins Leben, das sich den Londoner Clubs vergleichen ließe. Im Kaszinó wurden gesellschaftliche, wirtschaftspolitische und allgemeine politische Fragen diskutiert. Für Széchenyi war dies ein Ort, über den er seinen Ideen zur Fortentwicklung Ungarns, deren Vorbilder er auf Reisen nach England fand, Einfluss verschaffen wollte. Das bekannteste Bauwerk, das auf Széchenyi zurückgeht, ist die erste feste Donaubrücke zwischen den Stadthälften Pest und Buda: Die Széchenyi Lánchíd (Kettenbrücke) wurde 1839-1849 erbaut. Doch trotz dieser Erfolge (und vielleicht wegen der ihm [auch persönlich] in den Weg gestellten Hindernisse?) verschlechterte sich Széchenyis Gesundheitszustand immer mehr. Ab 1848 bis zu seinem Freitod am 8. April 1860 lebte er in der Görgen-Heilanstalt in Döbling (Stadtteil von Wien).

Széchenyis Stellung in der ungarischen Geschichte und auch sein Einfluss liegen demnach nicht in seiner Kühnheit als gefeierter Kriegsheld begründet, auch wenn dies

8 Kossuth, Lajos: Felelet Gróf Széchenyi Istvánnak Kossuth Lajostól [Anwort an Graf István Széchenyi von Lajos Kossuth]. Pest 1841, S. 17. 
das von Ádám Pálóczi Horváth ${ }^{9}$ (1760-1820) früh ${ }^{10}$ auf ihn verfasste Gedicht An Graf István Széchenyi aus der Ungarischen Heimat nahezulegen scheint:

István! Du Spross deiner strahlenden Vorfahren

Den der eitle Hauch des Hochmuts nicht reizt

Den noch der aus den Seelen der Sieben Stammesfürsten eingesogene

Hunnische Feuer-Geist entflammt!

Dein Ruf kündet Stolz; schwingt sich beflügelt

Hoch auf der Heimat Gipfel: Auf ihre patriotischen Hoffnungen

Aus deinem Herzen, viel ohnmächtige Seelen Gewalt-

Besiegende Erz-Stücke setzten.

$[\ldots]$

Und für solche Verdienste, die bisher

Kein anderer sich auf solchem unbetretnen Wege erwarb;

$\mathrm{Zu}$ deiner wahren Treue ewiger Zier, erhebt sich

Eine vieltausend Jahre haltende Säule. ${ }^{11}$

Der hymnische Ton des Textes erhebt Széchenyi als Helden zur Übergröße. Ein konkretisierbarer Verweis auf Széchenyis Teilnahme an der Völkerschlacht aber fehlt. Der Bezug dieses als Quasi-Heldenlied geschriebenen Gedichtes auf Széchenyis Schlachtteilnahme bleibt kursorisch und ist im Zusammenhang mit dem Entstehungsjahr allenfalls ableitbar. Allein in einem Eintrag im Pallas Nagy Lexikona (Großes PallasLexikon) von 1911, einem zeitgenössischen Standardnachschlagewerk, findet sich der Hinweis, der Text sei ein Lob auf Széchenyis Heldentum in der Völkerschlacht. ${ }^{12}$

Der ungarische Militärhistoriker Kálmán Nosziczi Thurzó legt in seiner eingehend recherchierten Untersuchung über Graf István Széchenyis Rolle in der Völkerschlacht

9 Pálóczi Horváth steht trotz seines beständigen Kontaktes mit bedeutenden Dichtern wie Ferenc Kazinczy (1759-1831) oder Mihály Csokonai Vitéz (1773-1805) eher in deren Schatten und ist weniger einflussreich in dieser Epoche.

10 Dem trägt etwa József Némeths Hinweis Rechnung, das Gedicht sei interessant, weil „Széchenyi 1817 in der ungarischen Öffentlichkeit noch nahezu unbekannt war.“ NÉMETH, József: Pálóczi Horváth Ádám petrikeresztúri évtizede (1811-1819) [Ádám Pálóczi Horváths Petrikeresztúrer Jahrzehnt (1811-1819)]. Magyar Árion. Tanulmányok Pálóczi Horváth Ádám műveiröl. Hg. v. István Csörsz Rumen und Béla Hegedús. Budapest 2011, S. 75-88, hier S. 81.

11 Auszug (erste, zweite und letzte Strophe) aus: PÁlóczi Horváth, Ádám: Gróf Széchenyi Istvánnak a Magyar Hazábúl [1817] [An Graf István Széchenyi aus der Ungarischen Heimat [1817]]. In: Felsőmagyarországi Minerva Nr. 2 (1830), S. 154-155.

12 „Es gibt eigentlich keine zweite Figur, dessen Handeln die ungarische Dichtung so dauerhaft und mit so lebendiger Sympathie begleitete wie eben Széchenyi. [...] Ádám Pálóczi Horváth eröffnet diese Reihe mit seinem 1817 verfassten Gedicht An Graf István Széchenyi aus der Ungarischen Heimat, das sein Heldentum* in der Leipziger Schlacht belobigt.“ Széchenyi a magyar költészetben. In: Pallas Nagy Lexikona [Internetausgabe], Bd. XIV. In: http://mek.oszk.hu/00000/00060/html/095/pc009589. html (16.04.2014). (*Im Originaltext steht an dieser Stelle das Wort „hőség“, das so geschrieben eigentlich „Hitze“ bedeutet. Dies dürfte ein Tippfehler sein. Gemeint war wohl hösiség, eine Form des Wortes hösiesség, das „Heldentum“ bedeutet.) 
bei Leipzig (1914) eine detaillierte Darstellung von Széchenyis Agieren am 17. und 18. Oktober 1813 in der Völkerschlacht bei Leipzig vor. So genau Nosziczi Thurzó argumentiert und so sehr er die ihm vorliegenden Fakten prüft, scheint er am Schluss dennoch nicht um die Verdeutlichung seines (persönlichen?) Anliegens herumzukommen. Er formuliert es mit einer Geste der Beglaubigung seiner eigenen Ausführungen und beruft sich nur an dieser Stelle seines Textes zitatweise auf seinen Gegenstand, d.h. Széchenyi selbst:

In diesen Zeilen leiteten mich die Überzeugung und das Wissen, dass in dem Kranz zu Széchenyis ehrendem Gedenken nur saubere Blätter ihren Platz verdienen. / Er selbst schrieb: „Il n’y a pas de bonheur sans vertu ..."; und auch wir schätzen die soldatische Erinnerung an den größten Ungarn nur dann hoch genug, wenn wir ihn mit seiner wahren Tugend aufrufen. ${ }^{13}$

Diese pathetisch gefärbten Zeilen sind eine indirekte und mit moralischer Überzeugung vorgetragene Reaktion Nosziczi Thurzós. Diese Einlassung deutet an, dass gerade aufgrund der (historisch-politischen) Bedeutung der Figur Széchenyi die Erinnerung an ihn den Sanktionen besonderer (faktischer) Korrektheit unterliegt. Der freilich unausgesprochene - interdiskursive Verweis, den Nosziczi Thurzós Bemerkung enthält, zeigt ein zentrales Problem an. Zwar drückt der Autor seine versteckte Diagnose in einem Modus der (Selbst-)Beglaubigung aus, doch ist es lohnenswert, die Ehrenkranz-Metapher ernst zu nehmen, die Nosziczi Thurzó verwendet. Denn offenbar bezieht er sich auf gerüchteweise oder als scheinbare „Kriegsheldenlegenden“ und als „Soldatengeschwätz“14 bezeichnete Erzählungen über István Széchenyis entscheidende (bei Nosziczi Thurzó ebenfalls zum Teil infrage gestellte) Rolle kurz vor Beginn der entscheidenden Angriffe der verbündeten Truppen auf die napoleonische Armee in der Völkerschlacht.

Dieser widersprüchliche Zusammenhang aus Faktischem, tatsachengebundenen (d.h. militärgeschichtlichen und räumlich-praktischen) Faktoren und den fiktionalen und/ oder legendenhaften Narrativen ist Gegenstand dieser Untersuchung. Als Problem scheint es in der erwähnten Perspektive des (Militär-)Historikers auf, der sich freilich entschieden auf die Seite der von ihm aufschlussreich organisierten (faktischen) Details schlägt. Der Széchenyi-Biograf Andreas Oplatka hat hierfür feuilletonistisch von „romantische[m] Beiwerk" ${ }^{\text {"15 }}$ an der Erzählung über Széchenyis Kurierritt am Vorabend der Völkerschlacht gesprochen. Dies wirft die Frage nach den Arabesken des historisch rückgebundenen Narrativs auf, die das Geschehen wohl mehr verdecken, als es zur Sprache zu bringen. Denn im Lichte der vorgetragenen Fakten meldet Nosziczi Thurzó Zweifel daran an, dass Széchenyis Rolle jene weltgeschichtlichen Auswirkungen hatte, die ihm eine Vielzahl seiner Biografen zugestehen bzw. andichten. Diese Rolle lautet knapp gefasst meist folgendermaßen: Széchenyi habe mit der Ausführung eines von

13 Nosziczi Thurzó (wie Anm. 4), S. 362.

14 Eigentlich: „harctéri pletyka“ (Soldatengeschwätz), wörtlich „Schlachtfeldgequatsche“.

15 Oplatka (wie Anm. 4), S. 52. 
Schwarzenberg beauftragten Kurierrittes den Ausgang der Völkerschlacht entscheidend zugunsten der Alliierten beeinflusst.

Die verschiedenen Narrative zu diesem Ritt Széchenyis über das Leipziger Schlachtfeld - so die These hier - projizieren die Bedeutung, die Wirkung und den Einfluss der späteren Széchenyi-Figur auf den bei der Völkerschlacht gerade 22-jährigen Ordonnanzoffizier. Damit prädominiert die narrativ-biografische Konstruktion der Figur Széchenyi als fiktionalisierter Held der Erzählungen. Die bis hin zur Heldenlegende ausgeschmückte Überhöhung von Széchenyis Rolle in der Völkerschlacht speist sich somit aus dem Status und der exponierten Position, die ihm aufgrund seines politischen und gesellschaftlichen Handelns post festum zugeschrieben wurde. Den vorliegenden narrativen Varianten des Kurierrittes bei der Völkerschlacht ist die Bedeutung Széchenyis als nationale Ikone substanziell eingeschrieben. Grundlage dieser Perspektivierung ist also diese ikonisierte Figur, zu der István Széchenyi als Gedächtnisinhalt - zumal nationaler - gemacht wird und nicht die epistemologisch kompliziertere Frage nach dem Zustandekommen und der sichtbar gemachten Entwicklung in einer Lebensbeschreibung. Der Ansatz zur Rekonstruktion von Széchenyis Handeln am 17. und 18. Oktober 1813 vor und um Leipzig, den etwa Nosziczi Thurzó anbietet, greift dieses Problem jedoch nicht auf, sondern bemüht sich um eine eher metaphorisch behauptete denn als solche auffindbare oder gar darstellbare „Wahrheit“". Deren Konstruktionscharakter wird allerdings weder von Nosziczi Thurzó noch in einer der übrigen Darstellungen zu Széchenyis Kurierritt auch nur thematisiert. Dies nährt nicht so sehr den Verdacht der Kolportage, die ohnehin anzunehmen bleibt. Aber es unterstützt die Mutmaßung (beinahe bis hin zur Gewissheit), dass die je als faktuale Berichte gegebenen Narrative sich vor ein(em) Geschehen drängen, dessen faktisches Vorgehen sie gerade zu berichten angeben. Denn es ist ein Brief von Széchenyis Schwager Ferdinand Zichy an dessen Eltern, der das Zeugnis sein dürfte, mit dem die Geschichte in die Welt kam. Die dort ausgeführten Angaben aber beruhen wiederum nur auf Erzählungen, die Zichy in den Oktobertagen 1813 bei Leipzig gehört hatte:

Es ist mir unbegreiflich dass Stepherl nichts erzählte, ergo werde ich es thun [...]. - Stepherl wurde von Fürst Schwarzenberg den 16-ten auf den 17-ten Nachts zum F[eldmarschall] Blücher gesendet um selben zur Schlacht am 18-ten zu laden. (diess ist die Art bey uns die Herrn politisch zum Dinee zu bitten) er entledigte sich seines Auftrages, und hatte den Befehl an Blücher gebracht auch den Kronprinzen von Schweden dazu zu invitieren. - Blücher und noch mehr Kreisenau verzweifelte an der Möglichkeit diesen unentschlossenen Halbnarren [...] zu diesen Schritt zu bewegen; da fasste Stepherl seinen Entschluss und sprach zu Blücher: Geben mir Euer Excellenz ein Pferd: Die Antwort war: Was wollen sie machen junger Mensch? Ant[wort] Ich bewege den Kronprintzen zu den Marsche koste es was es wolle. Diess gefiel dem alten Krieger, er gab ihm ein Pferd und seinen Seegen zu dieser nöthigen Unternehmung. Stepherl reitet zum Kronprinzen und findet vor den Quartir desselben mehrere Preussische Officiers, er eröffnet ihnen seine Absicht, den Kronprinzen im Nahmen der beyden Kaisers und des Königs von Preussen gegen Leipzig zu laden, der eine dieser Officiers der ihm befragte ob er den Auftrag dazu hätte, welches Stepherl ihm gestand dass er ihm nicht hatte sondern höchstens seinen Kopf risquire, der ihm für das all- 
gemeine Wohl nicht feil wäre, erwiederte darauf: Junger Mann sie wagen viel ich werde sie selbst anmelden. Der Anmelder war ein Prinz von Preussen, dessen Zunahme ich vergessen. Stepherl spricht unerschrocken den Kronprinzen an, der Kronprinz - schlägt den Marsch ab, entschuldigt sich und macht alle art von Seitensprünge. Stepherl verliert die Contenance nicht und bittet sich schriftlich aus, dass er ihm die Einladung der 3 Monarchen nach Leipzig gebracht, der Kronprinz giebt sie, fangt späther an zu stutzen, ruft Stepherl zurück, beruft einige Generäle Stepherl schreibt ihm den Weg an, der Kronprinz marschiert, trift noch zu rechter Zeit ein und entscheidet die Schlacht von Leipzig die unwiederbringlich verloren gewesen wäre. Verzeihe, dass ich die Sache nicht so beschreiben kann, wie ich sie weiss, aber das ganze Hauptquartier Schwarzenberg kann dir die Geschichte bestättigen. Dies That ist mehr werth als alle in diesen Krieg geschehen. ${ }^{16}$

Die Zeugenschaft, die der Brief vermeintlich vermittelt, ja aus deren Perspektive er berichtet und die durch die abschließenden Sätze an Glaubhaftigkeit gestärkt werden sollen, ist die Zeugenschaft an der Erzählung und an der Authentizität von deren mündlicher Weitergabe. Der Brief zeugt mithin für diese Weitergabe, nicht für das Geschehen selbst. Im Brief wird diese Funktion auch angesprochen. Was Széchenyi selbst für wenig oder nicht berichtenswert erachtete und was als Story unter den Soldaten mündlich kursierte, soll nun schriftlich mitgeteilt werden. Der Schreiber macht sich selbst zum Berichterstatter, der sein Handeln offensichtlich auch reflektiert, zum einen, indem er Széchenyis vermeintliches Versäumnis als eigene Motivation angibt, und zum anderen, da er sich auf seine (mündlichen) Quellen im alliierten Hauptquartier beruft, das dort Gehörte verschriftlicht und Széchenyis Handeln zudem mit einem (militär)historischen Superlativ versieht. Dem Briefschreiber aber scheint gerade diese mündliche Kolportage nicht ausgereicht zu haben, sodass er sich - davon ,ermüdet"? - niedersetzte, um das Geschehen schriftlich mitzuteilen, möglicherweise gar, um die Weitergabe der Story zu sichern. ${ }^{17}$ Auch dies bezeichnet die (selbstermächtigende) Eingangsformel. Nosziczi Thurzó weist allerdings nach, dass Zichy in der fraglichen Zeit zwar auf dem Schlachtfeld bei Leipzig war, jedoch andernorts bei seiner Einheit, sodass er Széchenyi, etwa im Hauptquartier im Schloss Rötha (Abb. 2), nicht begegnet sein kann: „Wie der Ton, der Inhalt des Briefes zeigen, hatte sein Schreiber von Széchenyis Leipziger Rolle nur gehört. “18

16 Zichy Nándor levele nejéhez, Széchenyi Zsófiához, Lampertheim/Rhein, 15.11.1813 [Brief Ferdinand Zichys an seine Frau Zsófia Széchenyi, Lampertheim/Rhein, 15.11 .1813 (Auszug)]. In: SzéchenYI, István: Gróf Széchenyi István munkái [Graf István Széchenyis Werke]. Hg. v. Magyar Tudományos Akadémia. Bd. 9, Gróf Széchenyi István levelei IV. Gróf Széchenyi István levelei szülőihez. Hg. v. Antal Zıсну. Budapest 1896, S. 142-143 (im Original deutsch; Rechtschreibung und Hervorhebungen wie im Original).

17 Einen „Augenblick der Ermüdung“, den Hans Blumenberg in dem Moment erkennt, da durch Homers Niederschreiben seiner Epen die Schriftlichkeit einsetzt, scheint auch dieser Brief zu bezeichnen, wenn wohl auch mit geringerer historischer Reichweite in der Wirkung. Vgl. zur „Ermüdung“: BLuMENBERG, Hans: Arbeit am Mythos. Frankfurt/M. ${ }^{5} 1996$ [1979], S. 168-169.

18 Nosziczi Thurzó (wie Anm. 4), S. 356 (Hervorhebung im Original). 


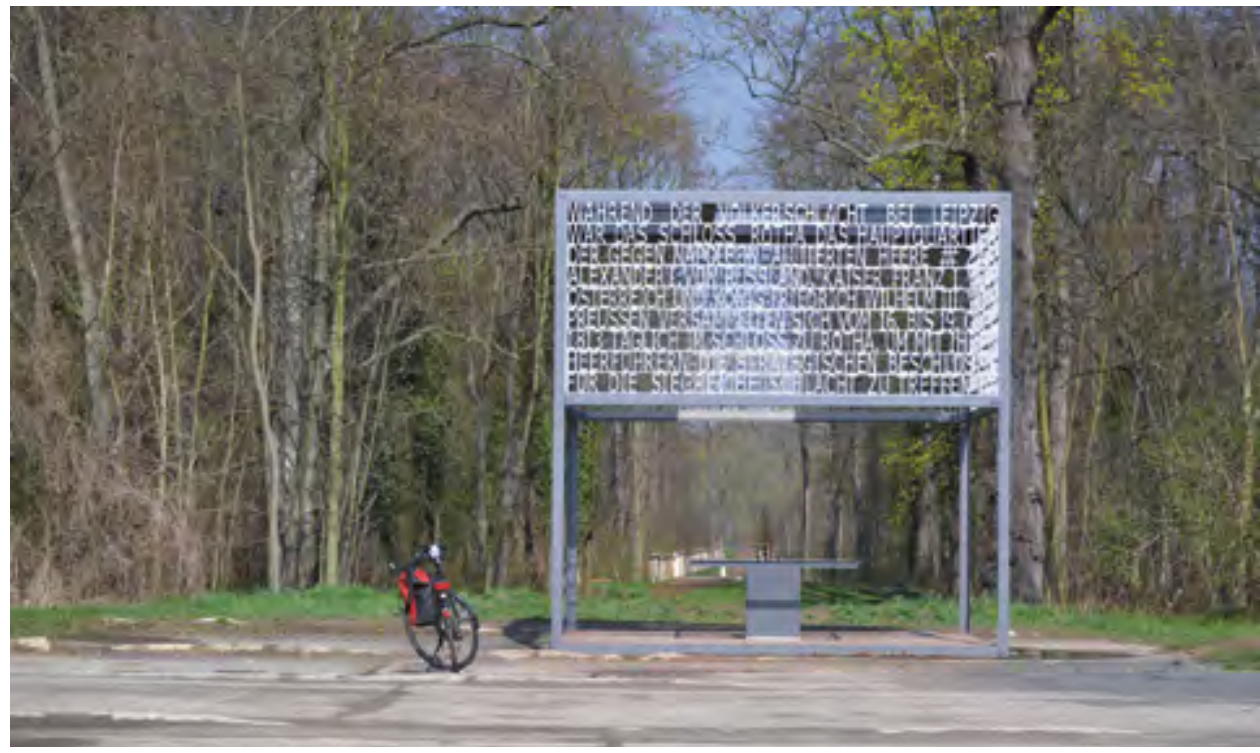

Abb. 2 Schloss Rötha wurde 1968 gesprengt. Heute befindet sich an jener Stelle dieses Denkmal, das an die Funktion des Schlosses als Hauptquartier der Alliierten in der Völkerschlacht erinnert. Foto: Stephan Krause.

Abb. 3 Die Karte zeigt die Routen, die István Széchenyi möglicherweise auf dem Hin- und Rückweg zwischen Schloss Rötha und Blüchers Lager genommen hat (strichpunktierte Linien). Außerdem eingezeichnet sind die Stellungen der Alliierten (umrandete Linien) und der Franzosen (schwarze Linien) jeweils am 17. Oktober abends und am 18. Oktober vormittags. Reproduktion aus: Hadtörténelmi Közlemények Nr. 3 (1914).

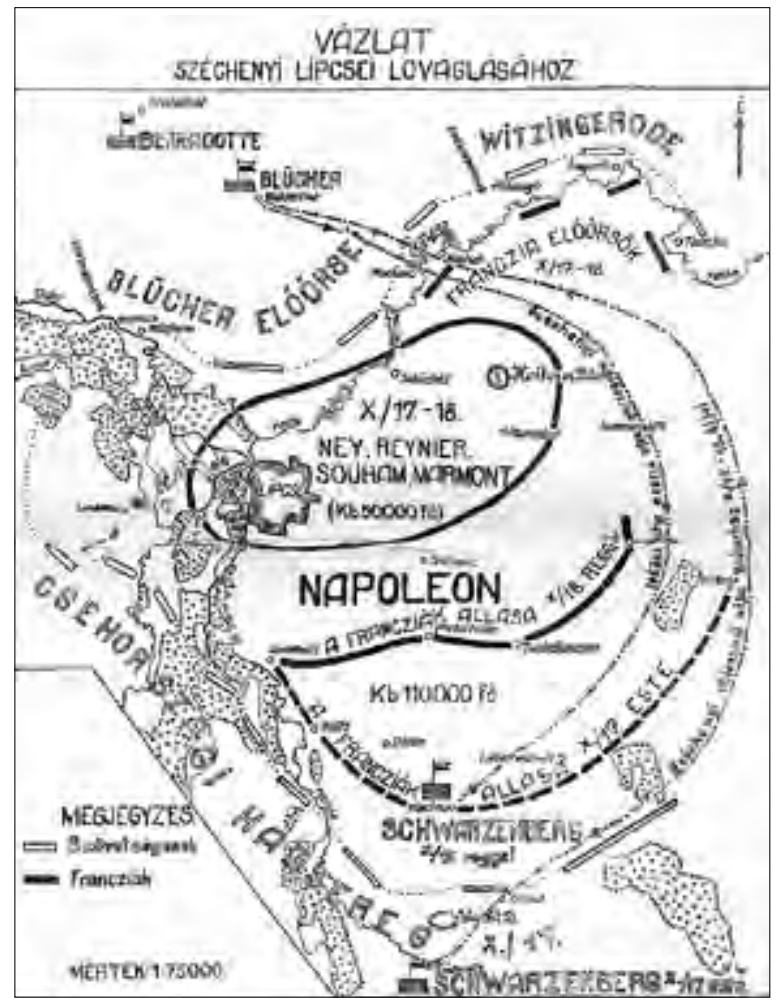


Das Gerüst der Geschichte von István Széchenyis Leipziger Schlachtbeteiligung ließe sich demnach etwa folgendermaßen umreißen: Schwarzenberg, dessen Hauptquartier sich südlich von Leipzig in Rötha befand, habe Blücher, der mit seinen Truppen nordwestlich bei Schkeuditz stand, am Vorabend der Hauptschlacht mitteilen wollen, dass der Angriff gegen Napoleon am nächsten Morgen (18. Oktober) geführt werde, und habe ihn zur Beteiligung einladen wollen. Als Schwarzenbergs Ordonnanzoffizier habe Széchenyi diese Botschaft Blücher zu überbringen gehabt. Er sei gegen Abend zu einem Ritt auf die andere Seite des Schlachtenortes jenseits der feindlichen Linien aufgebrochen, habe Blücher in Lindenau angetroffen und Schwarzenbergs Brief überbracht. Dann sei Széchenyi zu Bernadotte, dem schwedischen Kronprinzen und Kommandanten der Nordarmee, geritten, dem er dessen Zusage zur Beteiligung an der Schlacht abgerungen habe. Bernadotte zu überzeugen, war notwendig, da dessen Streitmacht mächtig und damit schlachtentscheidend war, dieser sich jedoch wankelmütig bzw. zögerlich verhalten hatte (Abb. 3). ${ }^{19}$ Der Vorgang lässt zunächst nicht auf eine soldatische oder strategische Leistung schließen, die in ihrer Einzigartigkeit und Wirkung hervorzuheben wäre, zumal Széchenyi des Öfteren Kurierdienste für Schwarzenberg auszuführen hatte ${ }^{20}$ und Zweifel an dieser Version der Begegnung mit Bernadotte angebracht sind. Delbrück/Pertz dokumentieren die am 18. Oktober 1813 in Breitenfeld zwischen Blücher und Bernadotte geschlossene Vereinbarung. Darin wird zwar ein „Hauptmann Graf Scezeny [sic!]“21 erwähnt, der Schwarzenbergs Einladung zum Angriff überbracht habe, doch dürfte die Übereinkunft der beiden Heerführer das entscheidende Moment für die schwedische Beteiligung an der Schlacht gewesen sein ${ }^{22}$ :

Früh um acht Uhr ward der Vertrag über die Führung der beiden Heere abgeschlossen. Er lautete ins Deutsche übersetzt dahin: „Nachdem der Feldmarschall Fürst Schwarzenberg durch den Hauptmann Graf Scezeny [sic!] angekündigt hatte, daß Ihre Majestäten der Kaiser Alexander, der Kaiser von Oesterreich und der König von Preußen den Feind anzugreifen beabsichtigen, und den Wunsch hegen, daß das Nordheer und das Schlesische Heer zu diesem großen Unternehmen mitwirken; und da General Blücher infolge der ihm dazu gewordenen Einladung sich in das Hauptquartier des Kronprinzen begeben hatte, so ist man dahin übereingekommen: / 1. Der General Blücher wird dem Kronprinzen von Schweden 30.000 Mann seines Heeres, Infanterie, Cavallerie und Artillerie geben; mit diesen dem Nordheer vereinigten Truppen unter des Kronprinzen Führung wird die Armee des Kaisers Napoleon über Taucha angegriffen. Mit seinen übrigen Truppen wird General Blücher die Stellung vor Leipzig behaupten und in dem Augenblick,

19 Ulmann, Heinrich S.: Geschichte der Befreiungskriege 1813 und 1814. Bd. 2. Berlin u.a. 1915, S. 228-232; SeYFert, Friedrich: Die Völkerschlacht bei Leipzig vom 14. bis 19. Oktober 1813. Dresden 1913 (Deutsche Schlachtfelder. Ereignisse und Wanderfahrten. Hg. v. Alfred Brabant. Bd. 5), S. 146-150; Delbrück, Hans/Pertz, Georg H.: Das Leben des Feldmarschalls Grafen Neidhardt von Gneisenau, Bd. 1-5, hier Bd. 3 (8. Juni bis 31. Dezember 1813). Berlin 1869, S. 467, wo von „AnmaBung und hartnäckige[m] Starrsinn des Kronprinzen“ die Rede ist.

20 S. auch Oplatka (wie Anm. 4), S. 50.

21 Delbrück/Pertz (wie Anm. 19), S. 467.

22 S. Ulmann (wie Anm. 19), S. 229. 
wo die Schlacht allgemein seyn wird, mit seiner ganzen Anstrengung sich der Stadt zu bemächtigen suchen. / 2. Falls der Kaiser Napoleon mit seiner ganzen Macht auf das Schlesische und das Nordheer fallen sollte, werden beide Heere gemeinschaftlich fechten, bis dahin, daß das große Heer ihnen zu Hülfe kommt. In diesem letzten Falle werden der Kronprinz und General Blücher zusammen handeln und die beiden Oberfeldherrn sich über alle ihre Operationen vereinigen. / Breitenfeld, am 18. October 1813, Morgens 8 Uhr." ${ }^{\text {23 }}$

Dem stehen die Geschichte(n) über Széchenyis Kurierauftrag gegenüber, die den jungen Ordonnanzoffizier vor allem als kühnen Reiter ausweisen, von dessen Mission der Sieg der Alliierten in der Völkerschlacht abhängig gewesen sei. Eine wechselseitige Negation des Dokumentes durch die Storys ${ }^{24}$ bzw. der Geschichten durch das Dokumentarische zu verfolgen aber brächte nicht mehr zutage als ebendiesen Prozess reziproken Ausschließens des von dem/der einen Bezeichneten durch das/die jeweils andere.

Als Funktion dieser Narrative lässt sich ausmachen, dass sie jeweils ein Széchenyi zugeschriebenes (soldatisches) Heldentum generieren, das sich freilich weniger aus dem Vorgang selbst erklären lässt. Denn gerade der tatsächliche Einfluss von Széchenyis Handeln auf den (bekannten) Ausgang der Völkerschlacht bleibt eher unklar. Mithin verstärkt sich vielmehr der Verdacht, die fiktional-narrative Gestaltung nutze den Status, der der Figur Széchenyi nachträglich zugekommen ist. Diesen bestimmt der biografische Rückblick, in den das Narrativ (welche Version davon immer) funktional integriert wird. So wird der Leipziger Ritt in ein mit deutlichem historischem Abstand entstandenes Széchenyi-Bild eingepasst. Kossuths Diktum von Széchenyi als dem ,größten Ungarn“25 bestimmt dessen ikonische Dimension. Mit dieser retrospektiv mächtigen Zuordnung von Bedeutung schwindet beinah jedes Moment des Dokumentarischen, da die Episode nur mehr zur Bestätigung der (historiografisch belegten wie auch national-narrativ inszenierten) Größe Széchenyis benutzt wird. Mit diesem Einsatz der Episode werden sowohl eine weltgeschichtliche Bedeutung als auch Széchenyis dementsprechende Rolle behauptet. Durch die narrativ gerichtete Verwendung wird nicht erst die Genese des Heldenstatus sichtbar, sondern dieser steht von vornherein fest, sodass die Heldentat dann nur als eine solche erzählt werden kann. D.h., die Erzählungen von Széchenyis Botenritt stehen unter der Bedingung, diesen als historische Tat zu sanktionieren, da der historiografische und biografische Status des Handelnden es vermeintlich erfordert. Mithin trifft für die Episode zumindest teilweise zu, was Hans Blumenberg - freilich

23 Delbrück/Pertz (wie Anm. 19), S. 467-468.

24 Der deutsche Plural weist das Wort als Terminus aus und deutet zugleich an, dass sich darin die Prominenz des Erzählten über die Richtigkeit des Faktischen zu stellen beabsichtigt; ganz als folge dies Goethes Diktum: „Wahrscheinlichkeit ist die Bedingung der Kunst, aber innerhalb des Reiches der Wahrscheinlichkeit muß das Höchste geliefert werden, was sonst nicht zur Erscheinung kömmt. Das Richtige ist nicht sechs Pfennige wert, wenn es weiter nichts zu bringen hat." GoEtHE, Johann Wolfgang v.: Relief von Phigalia. In: Ders.: Sämtliche Werke, Bd. 1- 45, hier Bd. 31 [1818]. Hg. v. Curt NocH. Berlin 1925, S. 294-296, hier S. 295.

25 Kossuth (wie Anm. 8). 
mit Blick auf den Mythos - als „Geschichtswerdung der Geschichten“26 beschrieben hat. Denn die Mehrzahl der Erzählungen behauptet das Narrativ als Geschichte und weniger als fiktionale Erzählung. Széchenyis weltgeschichtliche Rolle wird so durch die Darstellungsweise und die Perspektivierung des Geschehens in der Retrospektive des Biografischen erzeugt. Die Darstellungsweise aber wäre, sofern dem Vorgang der welthistorische Stellenwert zukäme, eng an das (belegbare) Handeln Széchenyis zu binden. Der weltgeschichtlich entscheidende Moment, in den der Held eingreifen kann, erweist sich als Konstruktion, die erst die Ersetzung des Historisch-Faktischen durch die narrative Performanz der Erzählungsvarianten von Széchenyis (vermeintlich) heldenhaftem Tun erlaubt. Geschichte ist demnach nicht das Geschehen, auf das die Erzählungen vermeintlich stupend verweisen, sondern das Geschehen, das in dem Erzählen selbst vorliegt. Indem der Fokus des Narrativs auf den dezisiven Moment gerichtet wird, privilegiert es die Bedeutsamkeit des so hervorgehobenen Faktors und des augenblicklichen Umschlags. Das Gros der nachfolgenden Vorgänge und Entwicklungen wird so zurückführbar auf einen Zusammenhang, der das Geflecht der undurchschaubar vielen Zusammenhänge der Völkerschlacht narrativ ersetzt. Die Frage „Was wäre, wenn (nicht)?" bestimmt die so geschaffene narrative Realität. Nicht die Dokumentation eines zusammenhängenden Vorgangs liegt in deren Interesse, sondern die Bestätigung des bestehenden Status der Figur Széchenyi, für deren ja bereits vorhandene Ikonizität die Erzählung von dem Leipziger Kurierritt eigentlich gar nicht (mehr) benötigt würde.

$\mathrm{Zu}$ Beginn des (bisher einzigen) Széchenyi-Films A hídember (Im Schatten der Brücke $^{27}$, Ungarn 2002; Regie: Géza Bereményi) wird die ikonische Disposition der

26 Blumenberg, Arbeit am Mythos (wie Anm. 17), S. 163.

27 Leider leitet der deutsche Verleihtitel fehl. Unverständlich bleibt, warum nicht die wörtliche Übersetzung des Originaltitels, „Der Brückenmann“, gewählt wurde, was in Ungarn zudem ein Begriff ist. Der Film soll vor allem die Lebens- und Wirkungsgeschichte des István Széchenyi erzählen. Die Errichtung der Kettenbrücke war eines seiner Projekte. - Zur Gesamteinschätzung des Films A hídember, der von der ersten Orbán-Regierung mit 1,6 Mrd. Forint (ca. 5,2 Mio. €) gefördert wurde: „Der ungarische Regisseur Géza Bereményi malt ein opulentes, romantisches Gemälde über István Széchenyis heroisches Leben. Sein zugleich tragisch umschattetes und von Zwiespältigkeiten geprägtes Leben im 19. Jahrhundert steht stellvertretend für Ungarns Weg in die nationale Unabhängigkeit.“ WOPPERER, Michael: Kritik [zu Im Schatten der Brücke]. In: http://www.filmreporter.de/kino/9698Im-Schatten-der-Bruecke (17.05.2014). Dies trifft sich durchaus mit Einschätzungen in der ungarischen Kritik, die allerdings meist viel drastischer ausfallen. So spricht Gusztáv Schubert von einem „Scheitern“ des Films, den er in seiner ausführlichen Besprechung als „langatmig und langweilig“ bezeichnet. Schubert, Gusztáv: Lobogónk, Széchenyi [Unser Banner, Széchenyi.]. In: http://www. filmvilag.hu/xereses_aktcikk_c.php?\&cikk_id $=2566 \&$ gyors_szo $=\% 257 \mathrm{Ch} \% 25$ EDdember\&start $=0$ (12.04.2014). S. in diesem Zusammenhang auch die kritische Betrachtung zweier Historiker in einem Gespräch über den Film: ERdöDy, Gábor/Gerö, András/Minancsik, Zsófia: A leggyengébb láncszemek [Die schwächsten Kettenglieder]. [Gespräch]. In: http://www.filmvilag.hu/xereses_aktcikk_c. php?\&cikk_id=2567\&gyors_szo=\%257Ch\%25EDdember\&start=0 (12.04.2014). Beinahe noch deutlicher wird eine Premierenkritik in dem Portal film.hu, in der es als Fazit heißt $A$ hídember sei „ein schlechter Film. Er ruhe in Frieden." A hídember - Eperjes elszabadul a képregény-reformkorban [Der Brückenmann - Erperjes befreit sich in der Comic-Reformepoche]. In: http://magyar.film.hu/ filmhu/premier/a-hidember-eperjes-elszabadul-a-kepregeny-reformkorban-filmnevjegy-premier.html (12.04.2014). Bereits bei Drehbeginn äußerte sich der Regisseur in einem Gespräch mit einem sehr 


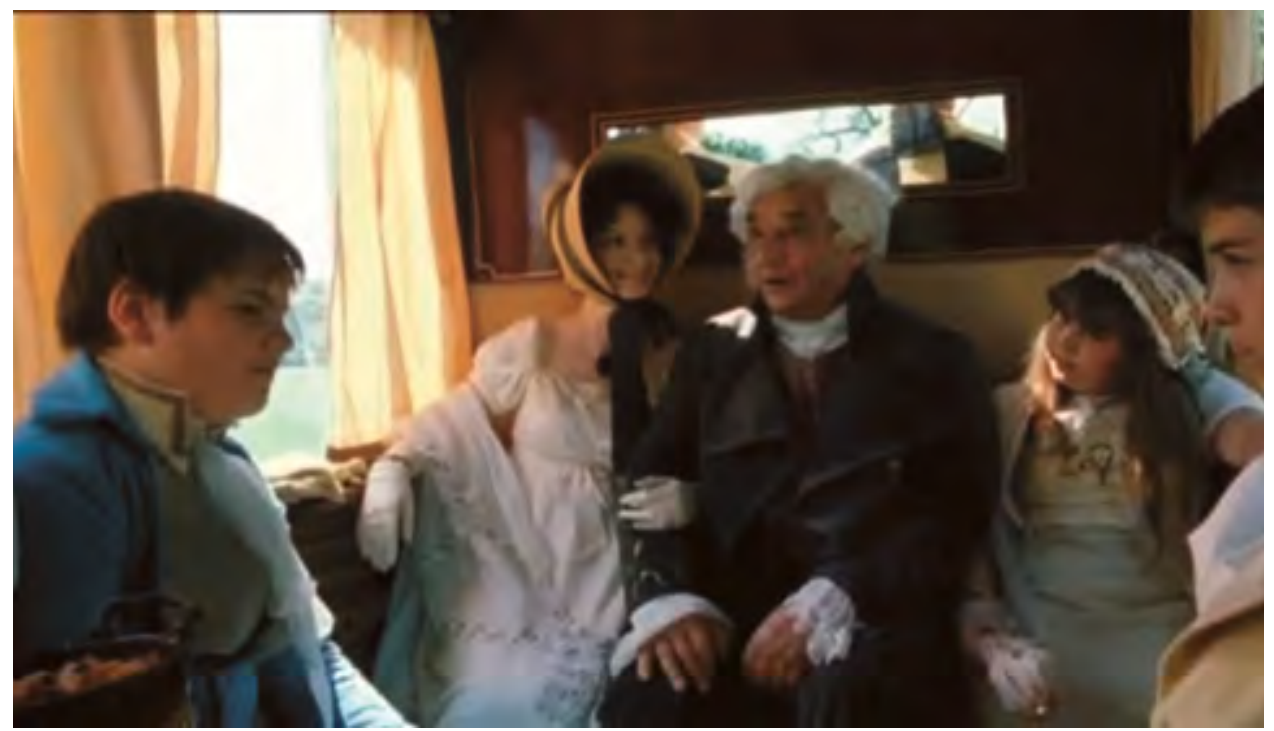

Abb. 4 Still aus dem Spielfilm A hídember (2002). Dialogszene in der Kutsche mit dem Grafen Károly Zichy. Die Frau im Bild ist Crescence Seilern (Zichys, nach dessen Tod Széchenyis Gattin). Felícia Zichy ist in dieser Einstellung nicht zu sehen.

Titelfigur pointiert dargeboten. ${ }^{28}$ Széchenyi tritt als eine Art Reitakrobat in Husarenuniform $^{29}$ auf. Aus dem Off wird dazu Unrühmliches über ihn berichtet, er sei ein Luftikus. Dies sagt Graf Károly Zichy während einer Kutschfahrt (Abb. 4). Zwischen Zichy und einer der mit ihm reisenden Damen ${ }^{30}$, Felícia Zichy, entsteht ein Dialog, der dies konterkarieren soll:

verqueren Vergleich über seine Hauptfigur: „Gern würde ich einen Film über einen Mafioso machen. [...] Genauer, über den Mythos, der ihn umweht. Doch ich habe nun mal Széchenyi bekommen ... Einen besseren Mythos.“ Bereményi, Géza/Székely, Gabriella: A Széchenyi terve [Der SzéchenyiPlan]. [Gespräch]. In: http://www.filmvilag.hu/xereses_aktcikk_c.php?\&cikk_id=3046\&gyors_ $\mathrm{szo}=\% 257 \mathrm{Ch} \% 25 \mathrm{EDdember} \& s t a r t=0$ (12.04.2014). Balázs Barta schließt seine Kritik in dem wichtigen Wochenmagazin Magyar Narancs mit der Einschätzung, A hídember sei nicht der größte Film Bereményis. Vgl. BARTA, Balázs: Désiré történelemórája [Désirées Geschichtsstunde]. In: http://magyarnarancs.hu/zene2/film_beremenyi_geza_a_hidember-59000 (12.04.2014).

$28 \mathrm{Vgl} .:,[\ldots]$ sporadic attempts to deconstruct Széchenyi's solemn historical figure and provide instead a flesh-and-blood and somewhat moot personality can be also tracked down in the plot, but these remain (or became?) subordinate to the political aim." Носк, Beáta: Gendered Artistic Positions and Social Voices. Politics, Cinema, and the Visual Arts in State-Socialist and Post-Socialist Hungary. Stuttgart 2013 (Forschungen zur Geschichte und Kultur des östlichen Mitteleuropa Bd. 42), S. 160.

29 Széchenyi gehörte 1813 einem böhmischen Ulanenregiment an: Viszota (wie Anm. 4), S. 132-136, und SZÉNTKIRÁlYi (wie Anm. 4), S. 114.

30 Darunter ist seine Frau Crescence Seilner, die nach Zichys Tod Széchenyis Frau wurde. 
Felícia Zichy:

Dennoch gewann er für Feldmarschall Schwarzenberg die Völkerschlacht bei Leipzig!

Károly Zichy:

Das ist nur Soldatengeschwätz!

F. Z.:

Er führte den schwedischen Thronerben durch die französischen Stellungen gegen Napoleon!

K. Z.:

Das alles blendet mich aber nicht!

Die Heldenstory gründet auf der vermeintlichen strategischen Überlegenheit der Schüsselfigur Széchenyi und auf seiner singulären Leistung. Worin diese aber genau bestand, ist unerheblich. Denn für den Erfolg der Erzählung viel wichtiger ist die Unentbehrlichkeit von Széchenyi und seinem Kurierritt quer über den Schlachtenort. Das Narrativ sanktioniert diesen Status der Heldenfigur und weist ihr Handeln als entscheidend für den Ausgang des weltgeschichtlichen Momentes aus, sodass Széchenyi noch alle anderen Beteiligten zu überstrahlen scheint.

Den bisher betrachteten Varianten des Narrativs zu Széchenyis Kurierauftrag steht zunächst die Tatsache gegenüber, dass es nur sehr wenige überlieferte Äußerungen von Széchenyi selbst gibt, die den Leipziger Ritt betreffen oder gar schildern, ja mehr noch, die vorhandenen Erwähnungen sind eher vage. Sie lassen weder belastbare Rückschlüsse auf die konkreten Vorgänge zu, noch handelt es sich letztlich um subjektiv genaue Erlebnisberichte, anhand derer sich die kursierenden gewissermaßen überprüfen ließen; zumal davon auszugehen ist, dass es für einen Großteil des Kurierrittes keinen anderen Zeugen als Széchenyi selbst gegeben haben dürfte. Im Tagebuch ${ }^{31}$ werden Leipzig und die Völkerschlacht einmal erwähnt:

Bei der Schlacht von Leiptzig componire ich einen Roman, - von Weg abschneiden, Todtgeschossenen [!] Pferd, - den ich Schwarzenberg, Metternich und wer es hören will, debutire - -, kein wahres Wort --, Mich wundert es, dass man mich, als einen impertinenten Lügner nicht abgeschaft hat - und die Leute mich in ihrer Gesellschaft noch litten, und mit mir Umgang pflegten.

Dass ich mich mit meinen [!] Succes, prahlte, mich sogar in details einliess -

Endlich über diese Sache, mit der grössten Eitelkeit dem Fürsten Schwarzenberg eine Confidenz machte.$-^{32}$

Széchenyi bezichtigt sich selbst der Prahlerei oder zumindest, eine übertriebene Geschichte erzählt zu haben. Dies schreibt er zudem immerhin 17 Jahre nach der Schlacht nieder. Nicht nur trägt der Eintrag zu den Umständen des Leipziger Rittes nichts Substanzielles bei, sondern es fehlt bis auf zwei ungenaue Hinweise auch der

31 Széchenyis Tagebuch setzt erst 1814 ein.

32 SzÉChENYI, István: [Auszug aus dem Tagebucheintrag vom 29. Juli 1830.] In: Ders.: Összes munkái [Sämtliche Werke]. Hg. v. Magyar Történelmi Társulat. Bd. XIII. Naplói [Tagebücher]. Bd. 4, 18301836. Hg. v. Gyula Viszota. Budapest 1934, S. 90 (im Original deutsch). 
eigentliche Inhalt der romanhaften Story. Das Tagebuch schafft so zwar nochmals Evidenz für Széchenyis Anwesenheit in Leipzig, doch bleiben die im Zichy-Brief, in der Biografik und auch im Film kolportierten Versionen der Heldenstory auf sich selbst zurückgeworfen.

Auch Széchenyis zweite Bezugnahme auf den Kurierauftrag enthält nur wenig mehr Informationen. Außerdem besitzt der Hinweis auf die Völkerschlacht vor allem anekdotische Funktion. D.h., diese Erwähnung erfüllt einen rhetorischen Zweck, in dessen Dienst hier auch jede Sachinformation steht. In einer Parlamentsrede nimmt Széchenyi im Oktober 1843 Bezug auf seine Begegnung mit Blücher bei der Völkerschlacht 1813. Széchenyi setzt die aus der Erinnerung erzählte Szene als Pointe ein:

\section{[28. Oktober 1843]}

Es ist heute elf Tage und dreißig Jahre her, [...] dass ich am zweiten Tag der Schlacht von Leipzig in das Lager des Helden Blücher gesandt wurde. Im Morgengrauen kam ich dort an. Als ich hineingehe, finde ich einen seiner Soldaten vor dem Spiegel, der sich eben frisierte und Pomade auftrug. Ich wunderte mich, gehe weiter und finde seinen Adjutanten, wie er sich auch sein Haar richtet. Schließlich gehe ich zu dem alten Siegerhelden hinein. Auch ihn traf ich beim Frisieren vor dem Spiegel an. „Mein Herr!“, sagte ich nach meiner Erinnerung zu ihm, ,ich glaubte, dass ihr mit Schwert und Schießpulver zugange seid; doch sehe ich, dass auch Nachfrage nach Pomade besteht.“ Darauf der Siegerheld: „Wir hoffen heute ein Fest zu feiern, und es gibt viele, die ihre beste Uniform nur zur Parade anlegen; wir wollen bestens gekleidet und möglichst am hübschesten heute in der Schlacht aussehen!“ Und noch am selben Tag gelangten die triumphalen Fahnen des preußischen Generals an die Mauern von Leipzig. ${ }^{33}$

Zwar wird der 17. Oktober 1813 genau bezeichnet, doch gibt es auch hier keine Schilderung der konkreten Ereignisse. Der Hinweis auf die Begegnung mit Blücher und deren Umstände im Kontext der Völkerschlacht mag hier als Hinweis genügt haben. $\mathrm{Ob}$ seine Zuhörer im Pressburger Parlament mit einem Abstand von 30 Jahren auch den weiteren Zusammenhang herstellten, muss offenbleiben. Vermeintlich konnte Széchenyi von der Kenntnis des Narrativs bei seinen Zuhörern ausgehen, sodass er keine genaueren Angaben zu machen brauchte. Mit Blick auf diese Anspielung auf Leipzig und den hier verfolgten rhetorischen Zweck aber lässt sich auch sagen, dass genauere Informationen auch gar nicht nötig gewesen wären. Széchenyis Bezugnahme auf die Begegnung mit Blücher soll die Aufmerksamkeit der Zuhörer auf den Redner Széchenyi und die bevorstehende Parlamentsentscheidung zum Haushalt lenken. Széchenyi nämlich stand festlich gekleidet und mit all seinen Orden vor ihnen. ${ }^{34}$

33 SzÉchenYI, István: [Rede im Parlament am 28.10.1843.] In: Gróf Széchenyi István munkái [Graf István Széchenyis Werke]. Hg. v. Magyar Tudományos Akadémia. Bd. 2, Gróf Széchenyi István beszédei [Reden des Grafen István Széchenyi]. Hg. v. Antal Zıchy. Budapest 1887, S. 418.

34 Széchenyi bezieht sich in seinem Redebeitrag auf seine Kleidung: SzÉCHENYI (wie Anm. 33), S. 418. Darauf weist auch Nosziczi Thurzó hin: Nosziczi Thurzó (wie Anm. 4), S. 345. 
Gut erkennbar wird bis hierher bereits die Bandbreite der narrativen Gestaltungen, mit denen Széchenyis Kuriereinsatz inszeniert wird. Sie reicht vom anekdotisch gehaltenen Zitat durch Széchenyi selbst über biografisch fiktionalisierte Stilisierungen, in denen sich das Narrativ verselbstständigt, bis zur emblematischen Verwendung der Episode im Film und in der Populärkultur. So bildet die Geschichte eines der Themen für einen Malwettbewerb für Grundschulkinder im Jahr 2010 (150. Todesjahr Széchenyis). Neben zwei anderen „Heldentaten Széchenyis“(so der Titel des Wettbewerbs), die sich ebenso in kriegerischen Auseinandersetzungen zugetragen haben sollen, steht hier die Geschichte „Blitzreiter - Galopp zum Sieg über Napoleon“. Darin wird Széchenyis Kurierauftrag zur geschichtsträchtigen Tat erklärt: „István Széchenyi war gerade erst 22 Jahre alt und wirkte bereits an geschichtemachenden Handlungen mit [...]." ${ }^{\text {“35 }}$ Der Text endet mit dem Hinweis, Széchenyi sei etwa vom Zaren Alexander für seine Tat ausgezeichnet worden, doch der Kaiser habe dies versäumt. In einer Online-Zeitschrift für „Freunde der Geschichte“ wird das Gewicht noch deutlicher auf die welthistorische Bedeutung von Széchenyis Mission gelegt: „Die Aufgabe duldete keinen Aufschub, alles hing von ihr ab. ${ }^{\text {"36 }}$ Der Ritt wird auf diese Weise zum entscheidenden Ereignis, an das in den Erzählungen noch das Kriegsglück geknüpft ist. Die Verbindung zwischen der Ausführung des Kurierauftrags durch Széchenyi und dessen Einfluss auf den Schlachtausgang erscheint so als narrative Konstruktion. Dieser Konstruktionscharakter bietet zudem die Möglichkeit, die Erzählung mit anekdotischen Weiterungen zu versehen. So stellt Sándor Fekete die Begegnung zwischen Blücher und Széchenyi in seiner biografischen Erzählung für Jugendliche (1968) fast wie ein Treffen unter alten Bekannten dar und lässt Blücher Széchenyi beispielsweise noch ein Glas Wein anbieten. Auch bei Fekete erhält die Episode jenen großen Effekt, und dessen Kenntnis wird gar dem Handelnden selbst unterstellt: „Als seine Ordonnanz ihm sein Pferd brachte, streckte er [Széchenyi - S.K.] unwillkürlich seine Brust heraus, wie es sich für den Überbringer

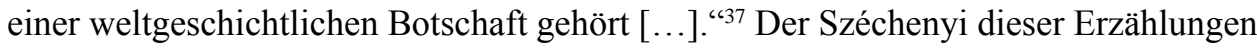
kann gar nicht anders, als sich als heldenhafter Reiter zu erweisen, der im Bewusstsein um seine Verantwortung seine Aufgabe zu erfüllen hat. Solche Konzentration auf den Kurierritt nimmt eine Akzentverschiebung vor, mit der das Zusammenwirken einer Vielzahl von Faktoren zugunsten eines Einzelereignisses zurückgedrängt wird, sodass der Moment eines historisch folgenreichen Umschlags als Narrativ greifbar zu werden scheint, das nicht zuletzt mit nationaler Bedeutung aufladbar ist. Silagi lässt in seiner deutschsprachigen Széchenyi-Biografie (1967) noch eine zurückhaltende Steigerung erkennen: Széchenyi ,glänzte in der Völkerschlacht zu Leipzig [sic!] mit einem Bravourstück, das beinahe schon eine Heldentat war. ${ }^{\text {‘38 }}$ Der Széchenyi-Biograph Antal Zichy hingegen neigt zum Superlativ (1896): „Gezwungenermaßen müssen wir hier unterbrechen, um die auffällige Lücke, die sich eben auf Széchenyis allerwichtigste,

35 Villám lovas (wie Anm. 4).

36 Topor (wie Anm. 4).

37 Fekete (wie Anm. 4), S. 14.

38 Silagi (wie Anm. 4), S. 73. 
von ihm jedoch verschwiegene militärische Tat bezieht, mit Hilfe einer anderen Quelle zu schließen. “39 Zichy zitiert als Beleg aus dem oben erwähnten Brief von Széchenyis Schwager. Loránt Hegedűs entfaltet in seiner Biografie (1933) nationalhistorisches Pathos: „In der großen Wende der Weltgeschichte, die Europas Chronik als Völkerschlacht bei Leipzig bezeichnet, ist der aus dem flaumig weichen Nest aufgeflogene ungarische junge Adler anwesend. "“40 Anhand dieser Einschätzungen zeigt sich auch die politisch-patriotische Verwendung der Geschichte um Széchenyis Kurierritt. Silagi bleibt eher distanziert, während Zichy für den Beleg seines Superlativs auf eine vermeintlich verlässliche Quelle verweist. Hegedüs' Einschätzung verbindet die Metaphorik eines nationalistischen Pathos mit dem weltgeschichtlichen Effekt, sodass der Kurierritt vom vermeintlich kühnen militärischen Einsatz eines Einzelnen umgedeutet wird zur Großtat im Namen der Nation.

Miklós Surányi bietet eine romanhafte Biografie von István Széchenyi (1982). Dort wird die Erzählung vom Leipziger Ritt in einem Gespräch Széchenyis mit seinem älteren Bruder Pál dargestellt, das beide während eines Billardspiels führen. Páls Worte spiegeln dabei die gleiche Übertreibung, die später auch die Sätze kennzeichnet, die im Film A hídember gesprochen werden: Er habe gehört, Steffer ${ }^{41}$ habe die Völkerschlacht bei Leipzig gewonnen. Surányis Széchenyi errötet vor Stolz und beginnt zu berichten. Pál stachelt ihn daraufhin ein zweites Mal an, indem er ihm jenen Brief seines Schwagers Ferdinand Zichy zeigt, vermutlich, damit der Bruder seine noble Bescheidenheit überwindet. Doch die Peripetie der Szene ist eher der Auftritt von Páls Frau Karolina, die von Pál angekündigt wird: „Selbst meine Frau ist keine Ausnahme. Sie verbreitet die Neuigkeit, du hättest in der Völkerschlacht bei Leipzig den Korsen besiegt. Du glaubst das nicht? Frag sie. Hier ist sie. Karolina, hier ist dein Held. Nun fall ihm um den Hals. “42 In Páls Worten kulminiert die narrative Konstruktion des Helden István Széchenyi, zumal in der durch Pál zitierten Sichtweise seiner Frau Karolina. Die Szene enthält so auch die Zuweisung der Geschlechterrollen, in der sich die Überhöhung des schlauen und kräftigen Helden gegenüber der weiblichen Verehrerin wiederholt. Ihre zudem allein weiblich konnotierte Schwäche soll das Heldische der Figur Széchenyi potenzieren, indem Karolina vor ihm umso geringer erscheint: Ihre Funktion ist, Verkünderin seiner Heldentat zu sein. Demgegenüber ließe sich argumentieren, Páls Aufforderung an seine Frau sei ironisch zu verstehen. Der Text setzt sich fort mit der erotischen Inszenierung der Karolina. Denn während sie Billard spielt, werden ihr Körper und ihre Schönheit aus der Perspektive István Széchenyis in Szene gesetzt. Es scheint, als biete sich Karolina ihm an. Mit dieser Sexualisierung der Karolina liefert der Text sie ,ihrem‘ Helden geradezu als erotischen Lohn für seine Taten aus. Surányi legt mit dieser Fiktionalisierung einen unmittelbaren Zusammenhang zwischen Széchenyis als

39 Zichy (wie Anm. 4), S. 67.

40 Hegedüs (wie Anm. 4), S. 50.

41 Auch ,Stepherl‘, Wienerische Koseform von István/Stephan.

42 Surányi (wie Anm. 4), S. 50. 
Heldentat erzähltem Ritt und der (folgenreichen) Liebesbeziehung ${ }^{43}$ zu Karolina nahe. Was die Szene aber außerdem vorführt, ist der Vorgang der Kolportage der Heldenstory. Dabei vermittelt die Episode den Eindruck, als könne sich die Hauptfigur selbst des Erfolgs der Story nicht erwehren. Damit inszeniert Surányis Text, wie die Autorität des Handelnden hinter die (Helden-)Erzählungen zurücktritt. Széchenyi wird von Pál und Karolina mit dem Narrativ konfrontiert und berichtet (auch bei Surányi) doch nichts Wesentliches über seine Rolle in der Völkerschlacht. Vielmehr privilegiert der SurányiText zitatweise die Version aus dem Zichy-Brief.

Ein wie immer rekonstruierbares und/oder belegbares, wahres Geschehen " wird sich aus den unterschiedlichen narrativen Varianten zu Széchenyis Kurierritt schwerlich destillieren lassen. Diese Diagnose ließe sich in ihrer Essenz als Zeichen dafür auffassen, dass es (bisher) nicht gelungen sei, jenes Geschehen zu ergründen. Namentlich die Militärhistorie und die Biografik haben daraus ihre Schlüsse gezogen. So resümiert beispielsweise Gyula Viszota nüchtern: „Diesen zweifellos berühmten Ritt Széchenyis konnte die Militärgeschichte nicht in allen Einzelheiten klären. [...] [M] it Blick auf die genaue Zeit des Rittes, Széchenyis Auftrag und die Route sind die Angaben der Autoren verschieden, ja widersprechen einander." ${ }^{" 44}$ Andreas Oplatka weist darauf hin, dass der genaue Verlauf der Episode ungeklärt sei: „Kein Wort in seinen Berichten nach Hause verlor der Rittmeister dagegen über einen Kurierauftrag, den er am Vorabend der Entscheidungsschlacht ausgeführt hatte. Die Nachwelt hat darüber um so mehr Tinte vergossen, und die Geschichte der tollkühnen Mission gilt bis heute als nicht vollständig geklärt."“5 Diese Einschätzungen benennen die Widersprüchlichkeit (Viszota) der einzelnen Versionen bzw. die Tatsache, dass sich derer viele fänden. Eben hierin dürfte die Wurzel für die Produktivität dieser Geschichte liegen. Denn die Erzählvarianten zu Széchenyis Kurierritt verweisen nicht auf das Fehlen faktischer Klärung (oder gar deren Notwendigkeit), sondern auf das Vorhandensein eines Zu-Erzählenden. Dies zeigt sich noch in den pathetisch überhöhten Varianten der Story, die sich von dem arrivierten Ruhm der Figur Széchenyi herschreiben, mit dem sie auch heute ausgestattet ist. Darin bestimmt weniger Széchenyis historisch einordenbare militärische Rolle im Schlachtgeschehen den Diskurs als weitaus mehr die Projektion einer durch Fiktionalisierung konstruierten Széchenyi-Figur in die historische Konstellation der Völkerschlacht 1813.

43 Oplatka beschreibt die Beziehung zwischen Páls Frau Caroline und István Széchenyi als „lebenslängliches Trauma [in Széchenyis Existenz]“. OplatKa (wie Anm. 4), S. 65.

44 Viszota (wie Anm. 4), S. 150.

45 Oplatka (wie Anm. 4), S. 50. 


\title{
Die irreguläre Kavallerie des Zaren Alexander I. in der Leipziger Völkerschlacht und ihre Darstellungen in Beständen des Staatlichen Historischen Museums Moskau
}

\author{
Elena Bukreeva und Ramil Rachimov
}

Eines der Phänomene der Napoleonischen Kriege war die Existenz nichtrussischer Reiterei in der Armee Zar Alexanders I.: Baschkiren, Mescherjaken, Treptjaren, Kalmücken und Krimtataren. Zusammen mit den Don-, Schwarzmeer-, Orenburger, Ural-, Astrachaner und Bugkosaken bildeten sie die irreguläre Kavallerie (Abb. 1)1.

Die nichtrussischen und Kosakenverbände waren an der Peripherie des riesigen Reiches stationiert und bewachten, auf eigenen Pferden, gekleidet in ihre traditionellen Trachten und ausgerüstet mit Waffen, die oftmals aus dem Mittelalter zu stammen schienen, die Grenzen des russländischen Imperiums. ${ }^{2}$ Der Mangel an leichter Kavallerie sowie die Möglichkeit, Mittel für den Ankauf von Pferden für die Armee einzusparen, führten im 18. Jahrhundert zum Einsatz von Kosaken und nichtrussischer Kavallerie im Nordischen, Siebenjährigen und Russisch-Schwedischen Krieg.

Im 19. Jahrhundert nahmen Baschkiren und getaufte Stavropoler Kalmücken 1807 bei Tilsit ${ }^{3}$ erstmalig am Krieg gegen Napoleon teil (Abb. 2). ${ }^{4}$ Hier erlangte die baschkirische Reiterei ihre von den Franzosen geprägte historische Bezeichnung „Nördliche Amouren" (les amours du nord), die später auch von anderen Europäern und Russen übernommen wurde. Sie beruhte auf der traditionellen Bewaffnung der Baschkiren mit Pfeil und Bogen sowie den kleinwüchsigen baschkirischen Pferden und entstand vermutlich unter Verweis auf Darstellungen des römischen Liebesgottes Amor in der zeitgenössischen Kunst des Empire-Stils.

Dieser Beiname war zunächst herabwürdigenden Charakters und bekam erst im Verlauf des Russlandfeldzuges von 1812 eine gänzlich andere, ehrenvolle Bedeutung. Im Paris des Jahres 1814 nannten die Franzosen die Baschkiren auch „Sibirische Amouren“ (les amours de Sibérie). ${ }^{5}$ Eingang in die russische Literatur fanden die „Nördlichen Amouren“ durch das 1814-1815 von Konstantin Batjuškov verfasste Gedicht „Wan-

1 Staatliches Historisches Museum Moskau (weiter: SHM) 64708/IK-5760.

2 Organisatorisch existierten zu dieser Zeit baschkirisch-mescherjakische Truppenteile und Stavropoler-Kalmücken-Regimenter.

3 Davydov, Denis V.: Til'sit v 1807 godu [Tilsit im Jahre 1807]. In: Sočinenija $v$ trech tomach. (Ežemesjačnoe priloženie k žurnalu „Sever“ za janvar“ 1893). Bd. 1, S. 294-296; Čujkevič, Petr A.: Podvigi kazakov v Prussii [Heldentaten der Kosaken in Preußen]. Sankt Petersburg 1810.

4 SHM 55709/DK, Kiste 17, Mappe 7, Nr. 145.

5 RadožITSKIJ, Ilja T.: Pochodnyje zapiski artillerista, s 1812 po 1816 god [Feldzugsaufzeichnungen eines Artilleristen 1812-1816]. Moskva 1835 (Teil 3: 1814. Vojna vo Francii [Der Krieg in Frankreich]). 


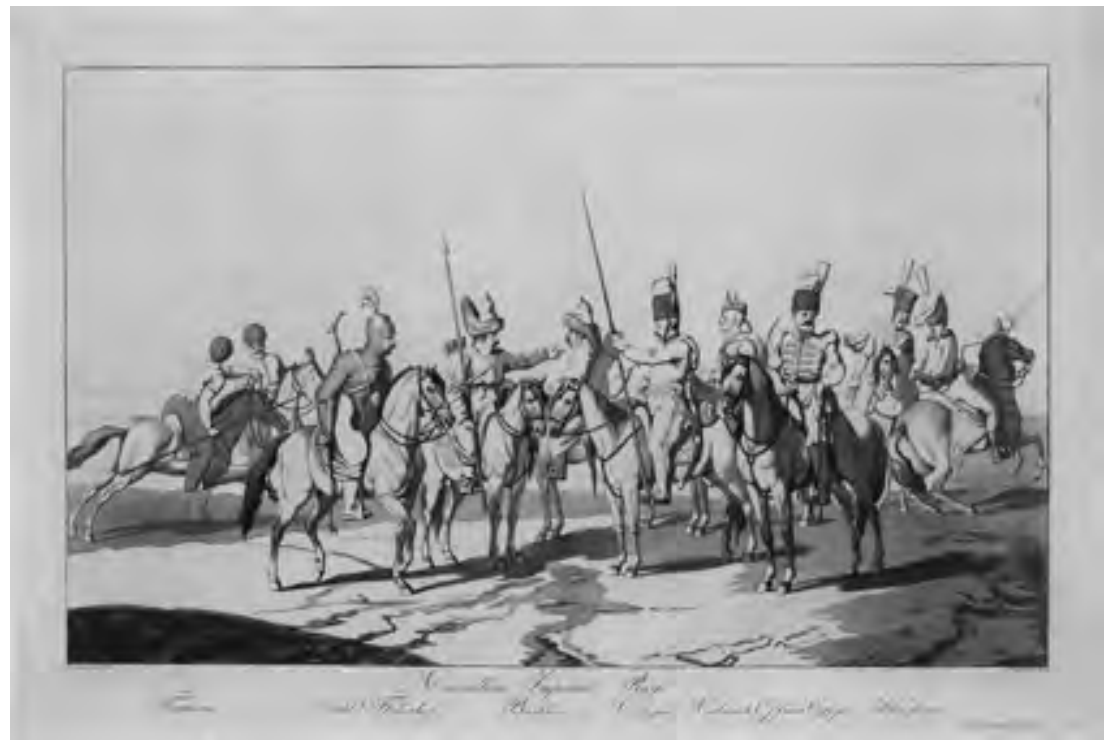

Abb. 1 Russische kaiserliche Kavallerie. Wasserfarbdruck von Kolbe nach einem Original von Meyer. Berlin: Gaspare Weisse \& Comp., 38,0 x 57,0 cm. Staatliches Historisches Museum Moskau.

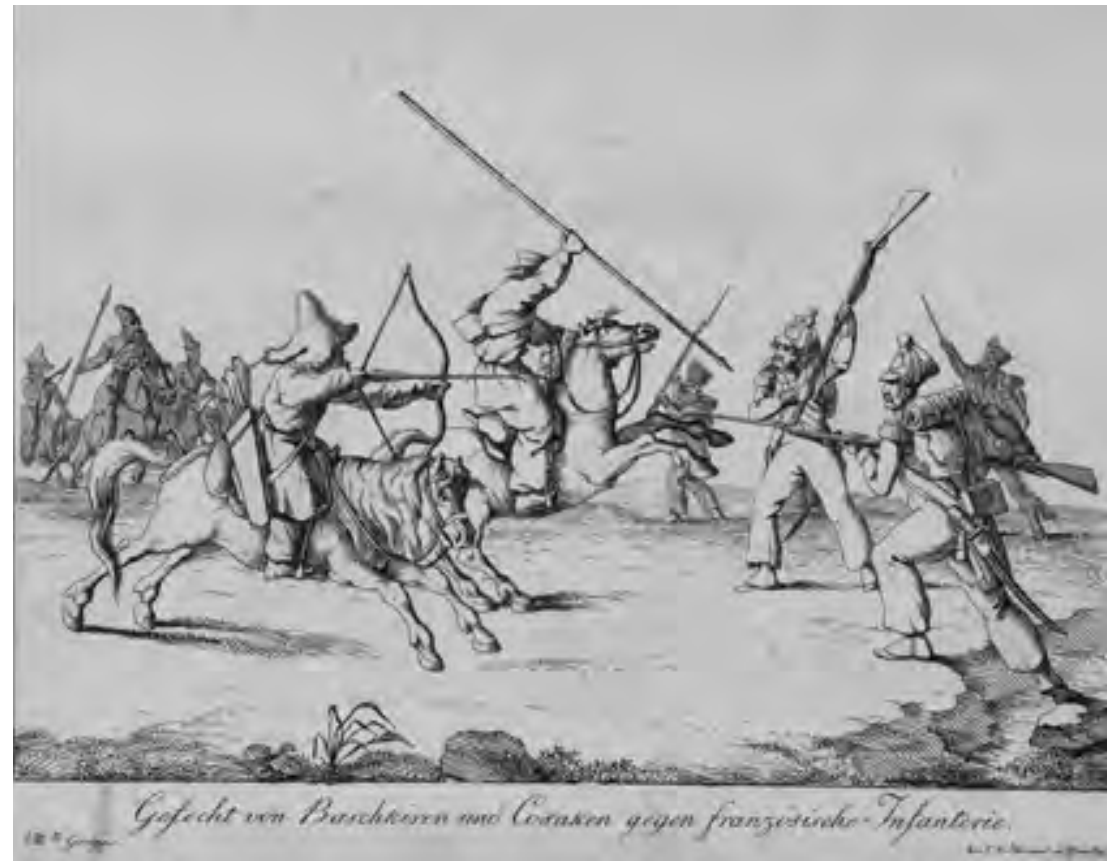

Abb. 2 Gefecht von Baschkiren und Kosaken gegen französische Infanterie. Stich eines unbekannten Künstlers. Dresden: G. Morasch, 18 x 24,6 cm. Staatliches Historisches Museum Moskau. 
derer und Stubenhocker" (russ. Stranstvovatel' i domosed), das 1815 in der sechsten Nummer des Journals „Amphion“ veröffentlicht wurde. In der sowjetischen Historiografie bestätigten diese Bezeichnung die Forschungen von Abubakir Usmanov und Anvar Asfandijarov. Auch der die Ereignisse des Vaterländischen Krieges 1812 darstellende und im Stil des sozialistischen Realismus geschriebene historische Roman Jannybaj Chammatovs, „Nördliche Amouren“, spiegelt die Verankerung dieses Beinamens im öffentlichen Bewusstsein wider. ${ }^{6}$

Während der Feldzüge Napoleons wurden in den Jahren 1812 bis 181420 baschkirische, zwei mescherjakische, zwei treptjarische, vier berittene krimtatarische, zwei kalmückische Kosakenregimenter aus Astrachan und ein aus getauften Kalmücken aus Stavropol bestehendes Regiment aufgestellt, alles in allem 31 Regimenter mit insgesamt 17.000 Mann. Der größte Teil dieser Truppenteile nahm auf die eine oder andere Art und Weise an den Kampfhandlungen im Herbst 1813 in Deutschland teil.

Die nichtrussische Kavallerie ist nicht mit der russischen Landwehr zu verwechseln, die ebenfalls an den Kampfhandlungen 1812-1814 teilgenommen hatte. Die Landwehr wurde auf der Grundlage eines Zaren-Ukas aus Adligen, Bauern und Kleinbürgern, die weder gedient hatten noch über militärische Erfahrungen verfügten, formiert und nur für die Dauer des Krieges aufgestellt. Demgegenüber rekrutierte sich die nichtrussische Kavallerie aus kriegserprobten Völkerschaften mit einer ständigen militärischen Struktur und verfügte über militärisch gut ausgebildete, kampferfahrene Soldaten.

Alle diese nichtrussischen Regimenter hatten, wie die Donkosakenregimenter, einen Personalbestand von 500 Mann und wurden in der Regel von einem Offizier der russischen Armee befehligt. Alle anderen Planstellen, wie der Stellvertreter des Regimentskommandeurs sowie der Quartiermeister und der Regimentsschreiber, wurden mit Vertretern der indigenen Eliten besetzt. ${ }^{7}$ Ein Regiment bestand aus fünf Jessauls (Rittmeistern), fünf Sotniks (Oberleutnante, Kommandeure der Hundertschaften), fünf Chorunžij (Leutnante, Fahnenträger bzw. Einheitskommandeure), zehn Urjadniks (Unteroffiziere, Zugführer) und 500 Soldaten, insgesamt also 530 Mann. Bei den Baschkiren, Tataren und Treptjaren gehörte ein Mullah, bei den Astrachaner Kalmücken ein buddhistischer Mönch zum Regiment. Anstelle eines Fuhrparks wurden Pferde als Tragtiere verwendet.

Grundlegende Schwächen der irregulären Kavallerie waren die höchst unterschiedliche Bewaffnung, unzureichende Kenntnisse über die Taktik der europäischen Armeen und die ungenügende Beherrschung der russischen Sprache. Zu ihren Vorzügen zählten

6 Usmanov, Abubakir N.: Baškirskij narod v Otečestvennoj vojne 1812 goda [Das baschkirische Volk im Vaterländischen Krieg 1812]. Ufa 1964, S. 18-19; AsfandiJarov, Anvar S.: Učastie baškir v vojnach i pochodach Rossii v period kantonnogo upravlenija [Die Teilnahme von Baschkiren an den Kriegen und Feldzügen Russlands zur Zeit der Kantonverwaltung]. In: Iz istorii feodalizma i kapitalizma v Baškirii. Ufa 1971, S. 75-78; Снамматоv, Jannybaj C.: Tenjak amursary. ${ }^{1}$ Ofe 1983 (russische Ausgabe: Ders.: Severnye amury. Ufa 1987, Teil 1-2).

7 Bei den Krimtataren und Kalmücken waren die Regimentskommandeure Offiziere dieser Völker, die in der russischen Armee bereits in höheren Kommandeurs- und Stabsdienststellungen gedient hatten. 


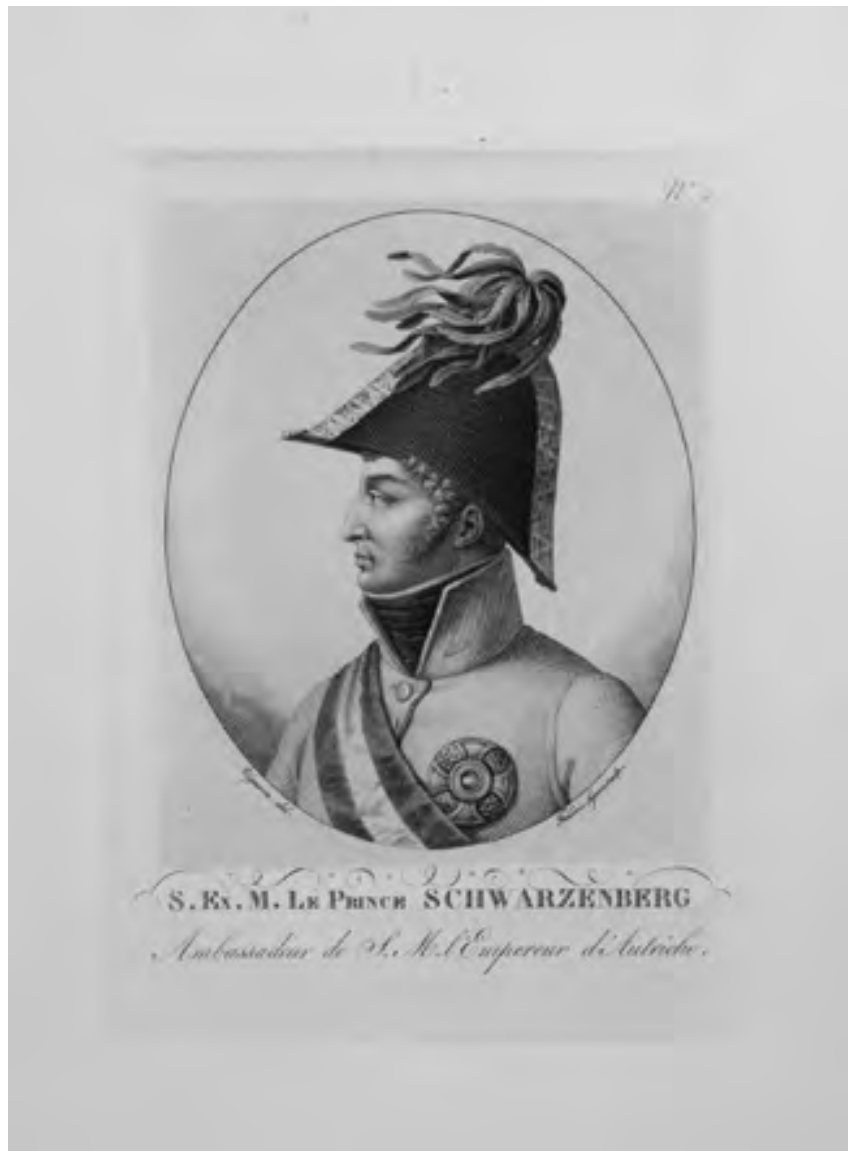

Abb. 3 Generalfeldmarschall Fürst Schwarzenberg. Stich von Frederic Lignon nach einem Original von Vigneron. Frankreich, Beginn des 19. Jahrhunderts, $32,5 \times 26,0$ $\mathrm{cm}$. Staatliches Historisches Museum Moskau.

ihre einheitliche Gliederung, ihre hohe Manövrierfähigkeit, niedrige Kosten für die Staatskasse und die vergleichsweise gute Kampfmoral der Soldaten.

Im Herbst 1813 rückten vier Armeen verbündeter Truppen - Russen, Preußen, Österreicher und Schweden - auf Leipzig vor. Als Oberbefehlshaber der verbündeten Streitkräfte in der Schlacht bei Leipzig trat Karl Philipp Fürst zu Schwarzenberg in Erscheinung (Abb. 3). ${ }^{8}$

\section{Die irreguläre Kavallerie in den Armeen der Verbündeten}

Im Folgenden soll ein kurzer Überblick über die Formationen nichtrussischer Reiterei im Bestand der vier Armeen bei Leipzig gegeben werden. $\mathrm{Zu}$ den drei von Generallleutnant Petr Pahlen befehligten Kavalleriekorps der Böhmischen Armee gehörte das

8 SHM 64709/IK-3744. 
berittene Jevpatorianer Tatarenregiment (Kommandeur: Hauptmann Mamajskij). Im Korps des Generals der Kavallerie Matvej Platov befanden sich das 1. TreptjarenKosakenregiment (Kommandeur: Major Temirov) sowie das 2. (Kommandeur: Major des Orenburger Garnisons-Regiments Kurbatov; baschkirischer Kommandeur: Pochodny Staršina Kajpov) und das 11. Baschkirische Kosakenregiment (Kommandeur: Major Spicyn, baschkirischer Kommandeur: Pochodny Staršina Iskanderov). ${ }^{9}$

Als Begleitschutz des Generals der Kavallerie P. C. Wittgenstein fungierte eine Abteilung des 4. Baschkirischen Kosakenregiments unter der Leitung seines baschkirischen Kommandeurs, Pochodny Staršina (Oberst) Bakirov. Sie bestand aus einem Stabs-, drei Oberoffizieren, drei Halbhundertschaftskommandeuren und 42 baschkirischen Soldaten. ${ }^{10}$ Das restliche Regiment und Teile des 5. Baschkirischen Kosakenregiments unter Führung des Oberstleutnants des Orenburger Garnisonsregiments Tichanovskij bewachten Gefangenenkonvois. Später wurde die Abteilung in kleinere Gruppen aufgeteilt. Das geht aus dem „Verzeichnis über die Anzahl der Verpflegung und Furage erhaltenden Dienstgrade und Pferde in den Regimentern und Artilleriekompanien der Armee des Generals der Kavallerie Graf Wittgenstein" hervor. In ihm findet sich auch die Abteilung des 4. Baschkirischen Kosakenregiments mit drei Offizieren und 19 niederen Dienstgraden wieder. ${ }^{11}$

Eine Hundertschaft des 5. Baschkirischen Kosakenregiments unter dem Befehl des Vojskovoj Saurjad-Staršina (Major) Bikčurin bewachte ab Ende 1812 das Hauptquartier des Generals der Infanterie Michail B. Barclay de Tolly.

Zum Bestand der Nordarmee im Korps des Generaladjutanten Ferdinand von Wintzingerode gehörte das 1. Baschkirische Kosakenregiment (Kommandeur: Major des Pavlograder Husarenregiments Fedor Gagarin).

Das 2. Kalmückenregiment (Kommandeur: Major Tjumen') befand sich im Korps des Generals der Infanterie Baron Fabian von Osten-Sacken der Schlesischen Armee. Im Korps des Generals der Infanterie Alexander Langeron kämpfte das Stavropoler Kalmückenregiment (Kommandeur: Oberstleutnant des Orenburger Garnisonsregiments Diomidij).

In der von Generalleutnant Evgenij Markov befehligten Vorhut der polnischen Armee befanden sich das 9. Baschkirische Kosakenregiment (Kommandeur: Stabshauptmann des Oberural-Garnisonsbataillons Popov, baschkirischer Kommandeur: Urasgulov), in der Abteilung von Generalmajor Kiprian Kreutz das 14. Baschkirische Kosakenregiment

9 Das 2. und 11. Baschkirische Kavallerieregiment wurden aus der polnischen Armee ausgegliedert und der Böhmischen Armee unterstellt.

10 Rossijskij gosudarstvennyj vojenno-istoričeskij archiv, g. Moskva (RGVIA) [Russisches Staatliches Militär-Historisches Archiv], Moskau, Fonds 846, Verzeichnis 16, Akte 4137, Blatt 438; Fonds 103, Verzeichnis 1/208 c, Bündel 46, Akte 3, Blatt 208.

11 Vklad Baškirii v pobedu Rossii v Otečestvennoj vojne 1812 goda. Sbornik dokumentov i materialov meždunarodnoj naučno-praktičeskoj konferencii [Der Beitrag der Baschkiren zum Sieg Russlands im Vaterländischen Krieg 1812. Material- und Dokumentensammlung zur internationalen Konferenz]. Ufa 2012, S. 63; zum 1. September waren in der Abteilung ein Stabs-, drei Oberoffiziere und 17 Soldaten. 
(Kommandeur: Major des Orsker Garnisonsbataillons Seleznjov, baschkirischer Kommandeur: Pochodny Staršina Suragulov). Das 15. Baschkirische Kosakenregiment (Kommandeur: Hauptmann des Orsker Garnisonsbataillons Kondratjev) gehörte zur Abteilung von Generalmajor Michail Bulatov. ${ }^{12}$

Demzufolge befanden sich im Bestand der vier verbündeten Armeen vor Leipzig sechs baschkirische, zwei Kalmücken-, ein Krimtataren- und ein Treptjarenregiment sowie selbstständige Abteilungen zweier baschkirischer Regimenter - in etwa 10,5 Regimenter oder ein Drittel der gesamten nichtrussischen Kavallerie.

Werfen wir nun einen kurzen Blick auf die Geschichte dieser Truppenteile. Das 1. Baschkirische Kosakenregiment war im Mai 1811 in Simbirsk aufgestellt und im Juni nach Serpuchov verlegt worden; im April 1812 traf es in Vilna (Vilno, Vilnius) ein. Im Vaterländischen Krieg von 1812 zog sich das Regiment, im Bestand der Nachhut des Kosakenkorps Matvej Platovs kämpfend, von Grodno (Hrodna) über Smolensk nach Borodino zurück. Im Herbst nahm es an Partisanenaktionen rund um Moskau und anschließend an der Verfolgung der sich zurückziehenden Grande Armée teil. 1813 war es an der Belagerung Danzigs (Gdańsk), an der Befreiung Berlins und den Kampfhandlungen bei Jüterbog, Wittenberg, Herzberg und Dessau beteiligt. Später kämpfte das Regiment in Holland und Frankreich und beendete seinen Kampfesweg in Paris. Am 27. Dezember 1813 zählte das Regiment noch zwei Stabs-, 17 Oberoffiziere, 25 Urjadniks und 273 baschkirische Reiter.

Ebenfalls im Mai 1811 war das 2. Baschkirische Kosakenregiment formiert und im Juli 1812 der Vorhut des Generaladjutanten Karl Lambert in der 3. Observationsarmee unterstellt worden. Es kämpfte gegen sächsische und österreichische Truppen bei Kobrin (Kobryn), Slonim, am Westlichen Bug, am Fluss Sisloč und in Volkovysk (Vaukavysk). 1813 war es an der Befreiung Warschaus beteiligt, ehe es in den Gefechten bei Görlitz, Reichenbach und Bautzen eingesetzt wurde. Während des Frankreichfeldzugs erfüllte es Aufgaben im Bereich der Straßensicherung. Am 2. August 1814 verfügte das Regiment über zwei Stabs-, 13 Oberoffiziere, acht Halbhundertschaftskommandeure, 415 baschkirische Reiter, einen Mullah, einen Schreiber, der Arabisch und Russisch beherrschte, und einen Soldaten „für Schreibsachen“ (d.h. zur Führung des russischen Schriftverkehrs), 412 Reit- und 440 Lastpferde.

Das 9. Baschkirische Kosakenregiment war im September 1812 in der Festung Novovozdvižensk im Orenburger Gouvernement aufgestellt und im Oktober nach Nižnij Novgorod verlegt worden, wo es zu der von Generalleutnant Petr Tolstoj befehligten Landwehr des Wolgagebiets stieß. 1813 kämpfte es bei Freiberg und Meißen, 1814 gehörte es zusammen mit dem 1. Baschkirischen Kosakenregiment zur Vorhut der angreifenden Armeen und zog in Paris ein.

12 Nach offiziellen Dokumenten befand sich das 15. Regiment in dieser Zeit vor Dresden. Aus Dokumenten des Archivs der Russischen Gedächtniskirche in Leipzig geht hervor, dass das Regiment an der Völkerschlacht teilnahm und anschließend nach Dresden zurückkehrte, wo es bis zur Kapitulation der französischen Garnison stationiert war. Siehe auch: Kaufmann, K.-H.: Baškiriskie polki pod Leipcigom [Baschkirische Regimenter in der Völkerschlacht von Leipzig]. In: Vklad Baškirii (wie Anm. 11), S. 133-134. 
Das im September 1811 gegründete 11. Baschkirische Kosakenregiment verlegte man im Oktober nach Nižnij Novgorod, und es wurde Petr Tolstoj unterstellt. Zusammen mit der Pensaer Landwehr nahm das Regiment an den Kämpfen um Warschau teil. Im Dezember übernahm es Aufgaben der Straßensicherung und zur Bewachung von Gefangenenkonvois. Bei der Rückkehr in die Heimat im Jahre 1814 zählten zum Regiment der Kommandeur, sein Stellvertreter, ein Stabsoffizier, drei Jessaule, fünf Hundertschaftskommandeure, fünf Chorunžij, sieben Halbhundertschaftskommandeure, ein Regimentsmullah, ein Quartiermeister und 421 baschkirische Reiter.

Das 14. Baschkirische Kosakenregiment war im September 1812 in den Baschkirensiedlungen des Sakmaratals formiert und im Oktober nach Nižnij Novgorod zu Graf Tolstoj in Marsch gesetzt worden. Im Mai 1813 ging das Regiment in den Bestand der polnischen Armee über, wo es sich im September über Gießhübel, Dohna und Dresden nach Leipzig durchkämpfte. Im Januar 1813 verfügte das Regiment noch über zwei Stabsoffiziere, fünf Jessaule, fünf Hundertschaftskommandeure, fünf Chorunžij, zwölf Halbhundertschaftskommandeure, einen Regimentsmullah, einen Schreiber, einen Quartiermeister und 500 baschkirische Reiter.

Im September 1812 aufgestellt, wurde das 15. Baschkirische Kosakenregiment gleichfalls nach Nižhnij Novgorod verlegt und dort dem Oberkommando von Graf Tolstoj unterstellt. Im Herbst 1813 nahm es an Gefechtshandlungen um Dresden teil, wonach es 1814 zum Bestand des Belagerungskorps von Hamburg gehörte.

Die baschkirischen Kosakenregimenter waren nicht uniformiert. Ihre Bewaffnung bestand aus Pfeil und Bogen sowie Lanzen, vereinzelt waren Säbel und Feuerwaffen in Form von Gewehren und Pistolen vorhanden. Ein Großteil der Ausrüstung bestand aus erbeuteten Waffen.

Das Jevpatorianer tatarische Reiterregiment war 1808 aufgestellt worden und nahm im Bestand der 3. Observationsarmee am Russlandfeldzug gegen Napoleon von 1812 teil und kämpfte bei Brest-Litovsk, Kobrin, Gorodečno und Luboml. 1813 stand es in den Schlachten von Kalisch, Lützen, Bautzen seinen Mann, von August bis Oktober kämpfte es in der selbstständigen Abteilung des Generalmajors Karl Knorring bei Schönewalde, Peterswalde und Kulm. Eine Besonderheit der Krimtataren war ihre einheitliche Uniformierung, bestehend aus einem Čekmen' (Wams) aus schwarzem, gewalktem Tuch, Pumphose und tatarischer Flügelkappe. Die Bewaffnung bestand aus Lanzen, Pistolen, Säbeln, Gewehren sowie tatarischen Langmessern.

Das Stavropoler Kalmückenregiment wurde im Mai 1811 formiert. Im Russlandfeldzug Napoleons von 1812 kämpfte es im Korps Platovs bei Mir und Romanov. Anschließend gehörte es zum „Fliegenden Korps“ des Generaladjutanten Wintzingerode und schlug sich zwischen Smolensk und Moskau mit dem Gegner. Im Herbst nahm das Regiment an der Verfolgung der sich zurückziehenden französischen Armee und den Kämpfen um Vilna teil.

1813 kämpften die Kalmücken (Abb. 4) ${ }^{13}$ vor Danzig, Berlin und belagerten die Festungen Küstrin und Glogau. Vom 20. April bis 22. Mai war das Stavropoler Kalmü-

13 SMH 64708/IK 7536. 


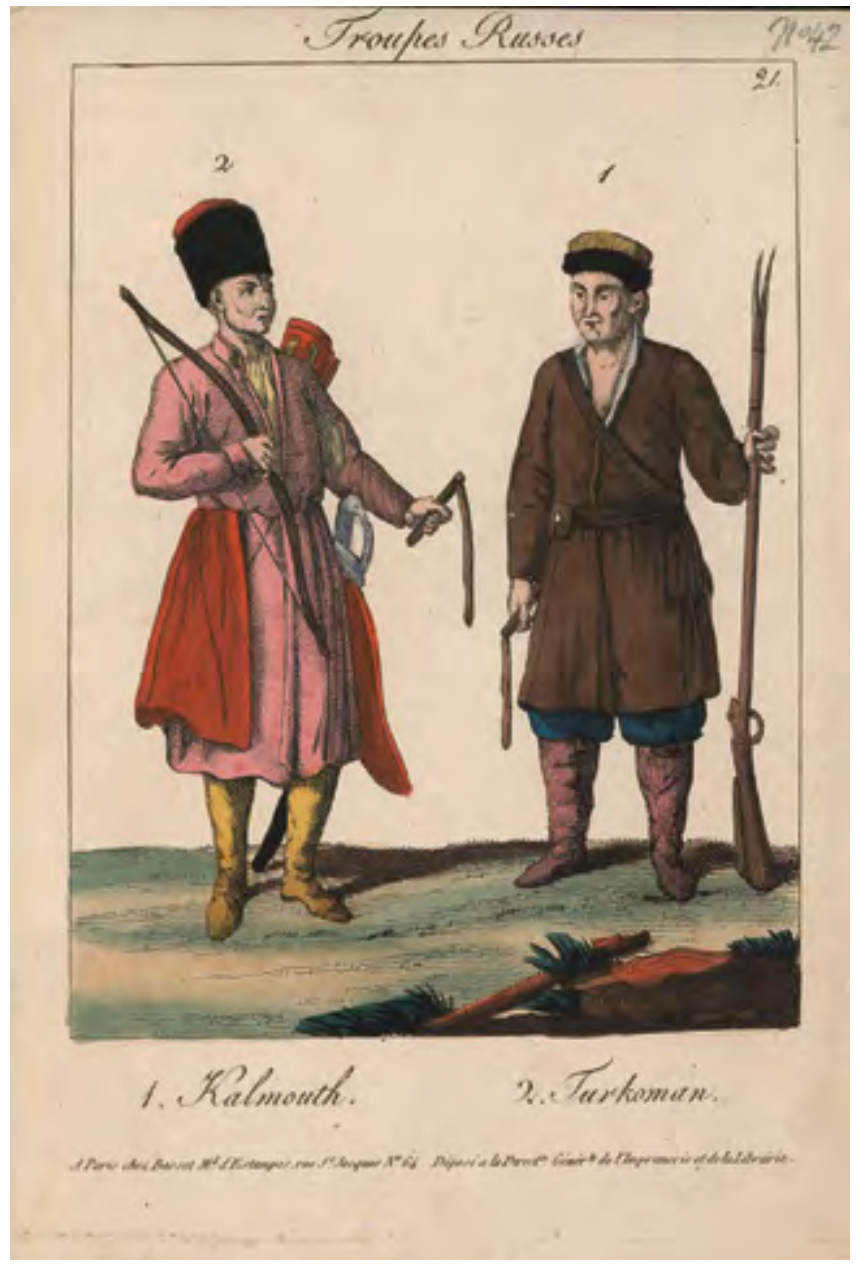

Abb. 4 Unbekannter Künstler: Kalmücke, Turkmene, 1815. Blatt aus der Serie von Paul-André Basset, „Troupes Étrangères". Paris 1815. Aquarell-Radierung, 21,9 x $14,0 \mathrm{~cm}$. Staatliches Historisches Museum Moskau.

ckenregiment an den Schlachten von Lützen, Dresden und Bautzen beteiligt, im Herbst 1813 stand es im Gefecht um die Städte Löbau, Hochkirch, Pirna, Zinna, Süptitz und Schilda. Anfang August zählte das Regiment 349 Mann: elf Oberoffiziere, 18 Urjadniks, 320 Kosaken und 380 Pferde. $^{14} 1814$ war es Teil der Belagerungstruppen der Festungen von Mainz und Kastel.

Das 1811 aufgestellte 2. Kalmückenregiment sammelte im Kriegsjahr 1812 Kampferfahrungen in den Gefechten um die Ortschaft Prušany (Pružany) und nahm Brest sowie Slonim im Sturm. 1813 kämpfte es bei Vengrov (Węgrów), Liv (Liw), Tschenstochau (Częstochowa) und Krakau. Nach dem Waffenstillstand war es bei der Schlacht

14 Maksimov, Konstantin N./Otschirov, Utash B.: Kalmyki v napoleovskich vojnach [Kalmücken in den Napoleonischen Kriegen]. Elista 2012, S. 357. 
an der Katzbach sowie in den Gefechten bei Görlitz, Reichenbach, Meißen und Großenhain zu finden.

Die Regimenter sowohl getaufter als auch buddhistischer Kalmücken verfügten über eigene, von den Donkosaken kopierte Uniformen. Beide Regimenter besaßen eine Truppenfahne, die es bei anderen Truppenteilen der nichtrussischen Kavallerie nicht gab. Die Bewaffnung bestand aus Lanzen, Säbeln und Karabinern.

Das 1. Teptjarische Regiment war bereits 1798 aufgestellt worden. Die Teptjaren waren eine in Baschkirien lebende Mittelschicht und rekrutierten sich in ethnischer Hinsicht aus Baschkiren, Tataren, Tschuwaschen, Mari, Mordwinen und Udmurten. Die teptjarischen Regimenter nahmen eine Zwischenstellung zwischen regulärer und irregulärer Kavallerie ein. Sie verfügten über einheitliche Uniformen nach dem Muster der Orenburger Kosaken und Standardbewaffnung (Lanzen mit Wimpeln, Säbel und Karabiner). Als Dienstzeit waren 15 Jahre festgelegt.

Das Teptjarische Regiment stieß 1812, zusammen mit der Garde-SchwarzmeerHundertschaft, als erstes auf die auf das russische Ufer übersetzenden Franzosen. Danach zog es sich in Nachhutgefechten von Wilna nach Borodino zurück. Ein Teil des Regiments kämpfte in der Schlacht von Borodino, der andere Teil schloss sich von der Armee im Hinterland aufgestellten Partisaneneinheiten an und operierte eigenständig im Gouvernement Kaluga.

Im Jahr 1813 führte das Regiment Kampfhandlungen bei Großgörschen, Bautzen und Reichenbach. Im Herbst 1813 stand es in den Schlachten an der Katzbach, bei Löwenberg, Altenburg und Chemnitz. Nach Leipzig verfolgten die Teptjaren die zurückweichende Armee des Gegners. 1814 befand sich ein Teil bei der Belagerung von Mainz, das Regiment war an den Schlachten von Brienne-le-Château, La Rothière, Arcis-surAube und Fère-Champenoise sowie der Einnahme von Paris beteiligt.

Von zehn Regimentern nahmen sechs am Feldzug gegen Napoleon von 1812 und am Frühjahrsfeldzug 1813 in Deutschland teil. Über diese Truppenteile schrieb der französische General Marcellin de Marbot (Abb. 5) ${ }^{15}$ in seinen Memoiren:

Diese neu Eingetroffenen, den Franzosen noch Unbekannten, waren von ihren Kommandeuren, die fast so ungebildet wie sie selbst waren, dermaßen aufgestachelt worden, dass wir uns bei ihrer Annäherung zur Flucht wandten. Sie konnten es kaum erwarten, Feindberührung zu haben, und vom ersten Tag ihres Eintreffens in den Stellungen vor unseren Truppen stützten sie sich in unzähliger Masse auf unsere Soldaten, wurden aber überall durch Gewehrfeuer empfangen [...] und ließen eine große Zahl an Getöteten auf dem Felde zurück. Diese Verluste schienen sie keineswegs zu beeindrucken. Sie bewegten sich ohne jegliche Ordnung, nutzen jede sich nur bietende Übersetzstelle, galoppierten wie ein Wespenschwarm pausenlos um uns herum, entwischten überall und waren für uns nur sehr schwer einzuholen. Als dies aber unseren Kavalleristen gelang, töteten sie erbarmungslos eine Vielzahl an Baschkiren, da unsere Lanzen und Säbel einen gewaltigen Vorteil gegenüber ihren Pfeilen hatten. Da die Angriffe dieser Barbaren nicht aufhörten und die Russen sie noch durch Husarenabteilungen verstärkten, um die von den Baschkiren an einigen

15 SHM 64708/IK 3639. 


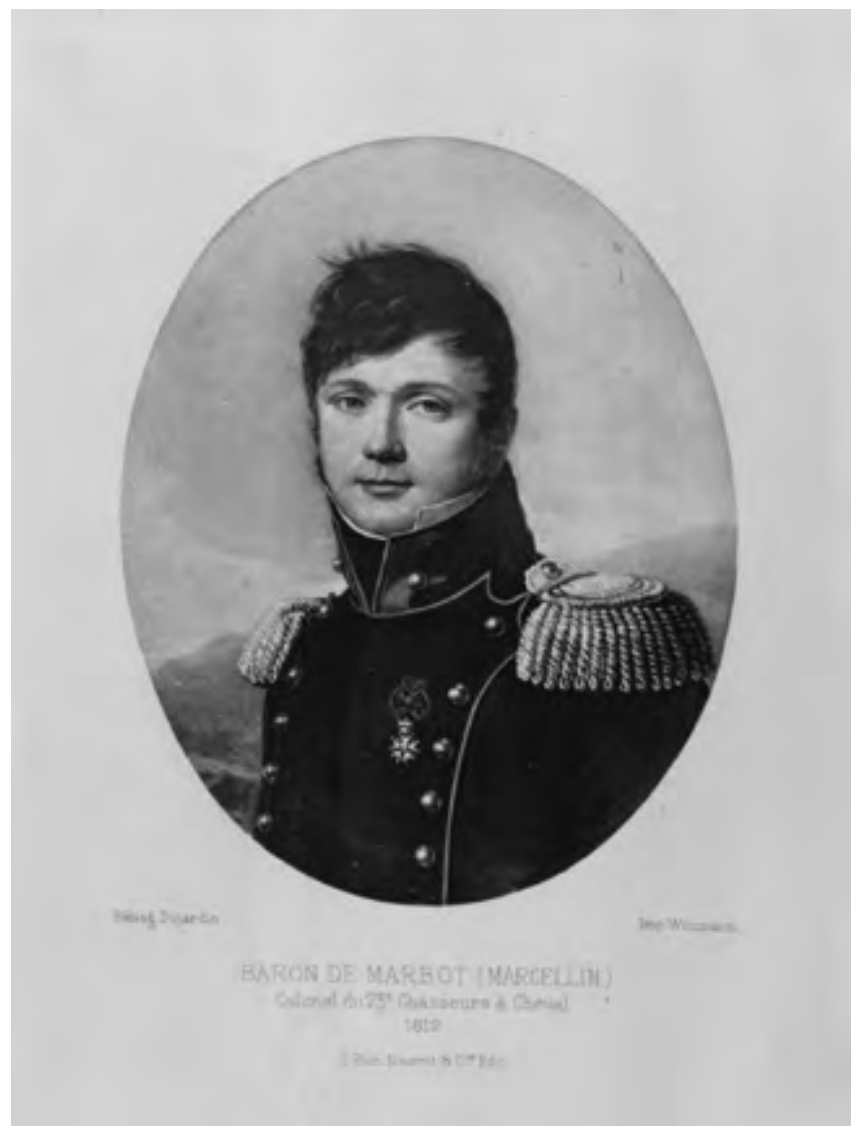

Abb. 5 General Marcellin Marbot. Kupferlichtdruck Dujardin, 1891, Paris, E. Plon, $15,0 \times 11,5 \mathrm{~cm}$. Staatliches Historisches Museum Moskau.

Punkten unserer Linien gestiftete Verwirrung auszunutzen, befahl der Kaiser den Generalen, die Wachsamkeit zu verdoppeln und öfters unsere vorgeschobenen Posten aufzusuchen. ${ }^{16}$

\section{Die Nördlichen Amouren in der bildenden Kunst}

In der Abteilung für darstellende Kunst des Staatlichen Historischen Museums in Moskau gebührt neben den die Ereignisse des Jahres 1812 widerspiegelnden grafischen Blättern auch der Darstellung der am Feldzug gegen Napoleon von 1812 und den Auslandsfeldzügen von 1813-1814 beteiligten irregulären Truppenteile besondere Beachtung. Über 100 Radierungen, die Kosaken, Kalmücken, Tataren, Baschkiren und andere Völkerschaften des russländischen Imperiums darstellen, fanden

16 Marbot, Marcellin: Memuary generala barona de Marbot [Franz.: Memoires du général baron de Marbot. ${ }^{1}$ Paris 1891]. Moskva 2005, S. 660-661 (Übersetzung aus dem Russischen: K. Kaufmann). 


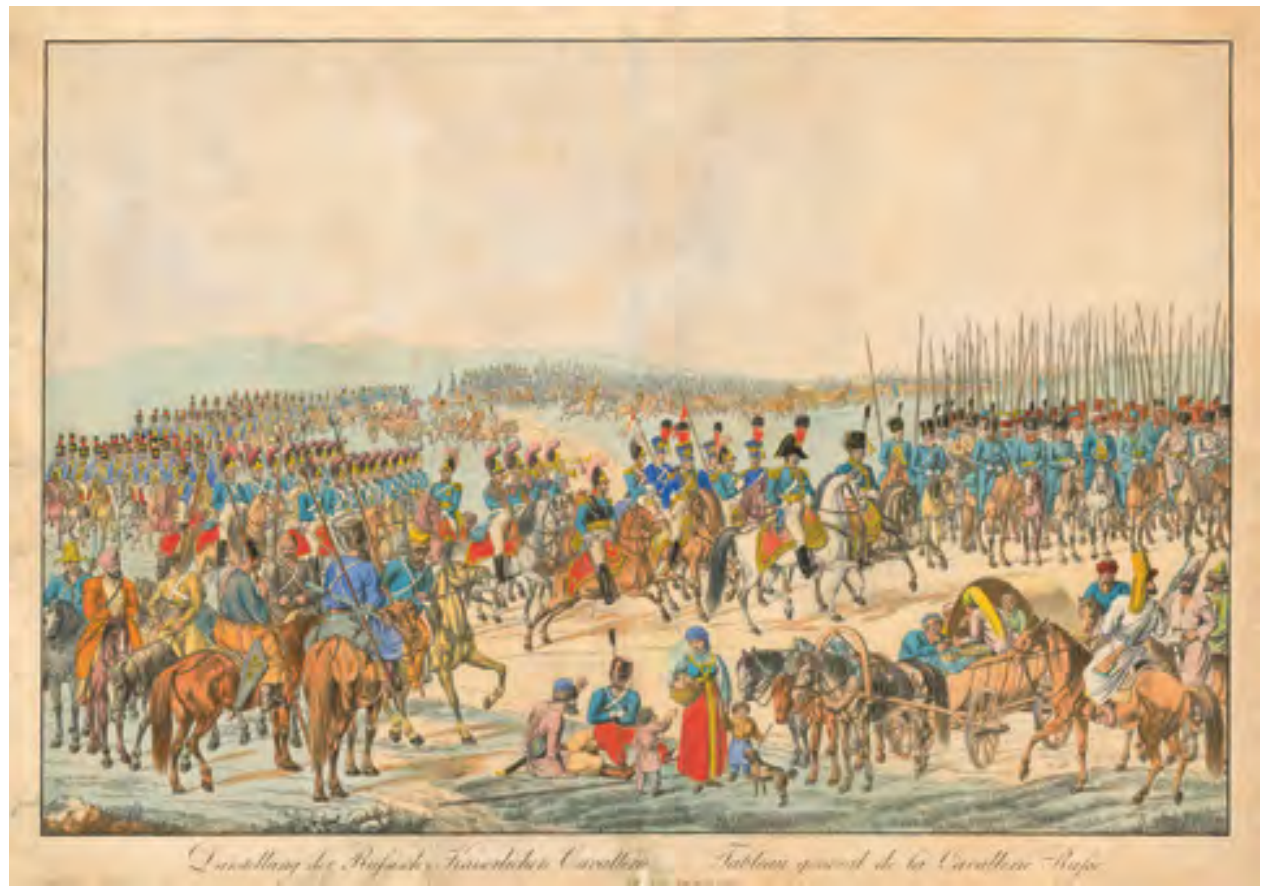

Abb. 6 Russische kaiserliche Kavallerie. Stich nach einem Original von Wilhelm Kobell. Aquarell-Radierung. Wien: Artaria \& Comp., 51,5 x 72,2 cm. Staatliches Historisches Museum Moskau.

sich in den Sammlungen bekannter Kunstliebhaber des 20. Jahrhunderts, wie Petr Ščukin, Ivan S. Kolodejev, Aleksej P. Bachrušin, Pavel J. Daškow. In einer gesonderten Mappe werden Stiche aufbewahrt, die ausschließlich der Leipziger Völkerschlacht gewidmet sind.

Die Zeichnung „Haupttabelle der russischen Kavallerie“ zeigt russländische Reiterei auf dem Marsch. Ein General inspiziert irreguläre Kavallerie. Er ist im Kreis von Stabsoffizieren, Hornisten, Dragonern, Husaren und berittener Artillerie (im Hintergrund) dargestellt. Rechts sind Uralkosaken, im Vordergrund Baschkiren, Kalmücken und eine Marketenderin zu sehen. Die von einem deutschen Meister geschaffene Zeichnung „Russische kaiserliche Kavallerie“ wurde im ersten Viertel des 19. Jahrhunderts in Berlin gedruckt (Abb. 6). ${ }^{17}$

Richten wir nun unser Augenmerk auf einzelne Vertreter irregulärer Truppenteile der russisch-imperialen Armee. In erster Linie waren dies Kosaken. Eine anonyme französische Radierung zeigt eine Gruppe von drei Reitern. ${ }^{18}$ Der deutsche Maler Zim-

17 SНМ 42949 И III-36273.

18 SMH ADK 112231/46/I-III-72545. „Drei Kosakenoffiziere“. Radierung nach einer Original-Zeichnung eines französischen Offiziers. (Aus dem Museum des Jahres 1812). 


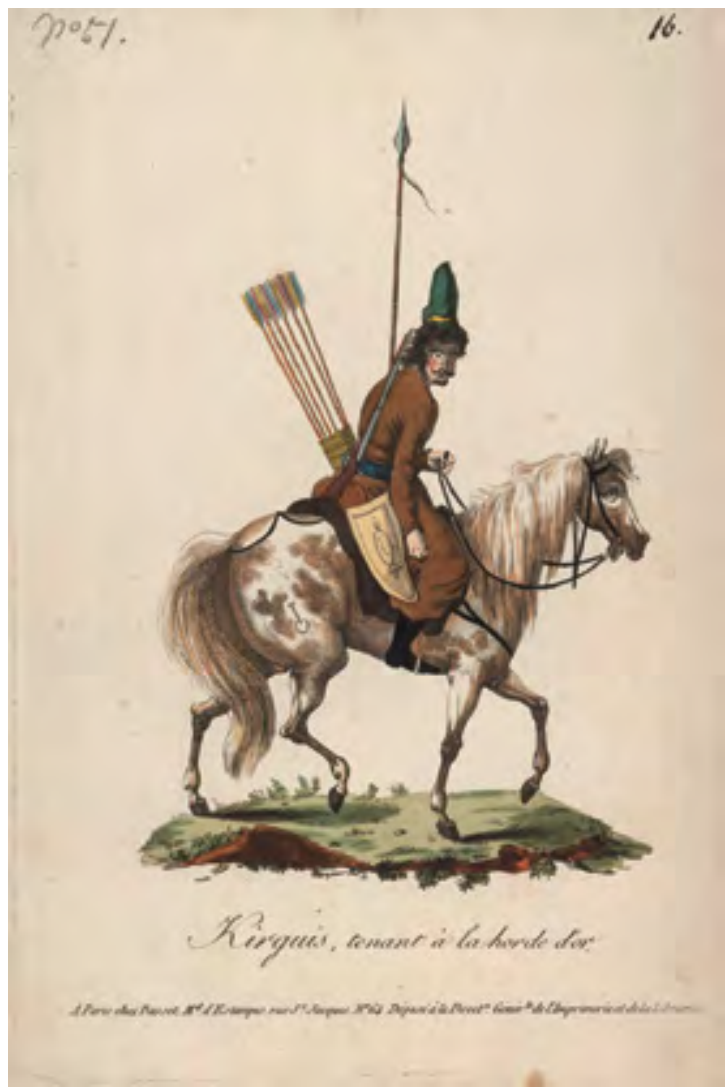

Abb. 7 Kirguis tenant à la horde d'or. Unbekannter Künstler, 1818. Blatt aus der Serie von Paul-André Basset, „Troupes Étrangères". Paris 1815. AquarellRadierung, 21,9 x 14,0 cm. Staatliches Historisches Museum Moskau.

mermann (Vorname unbekannt) gravierte nach einem unbekannten Original ein Biwak von Kosaken und Kalmücken in der Umgebung von Berlin. ${ }^{19}$

Die Darstellung von Kosakenregimentern der russländischen Armee in der Epoche der Napoleonischen Kriege war bei ausländischen Künstlern, die mit ihnen in Kontakt kamen, ein sehr beliebtes Thema.

In der Abteilung der Bildenden Künste des Moskauer Historischen Museums werden Hunderte von grafischen Blättern aufbewahrt, die den kleinen Völkerschaften des Reiches gewidmet sind. Davon seien hier drei Zeichnungen aus der französischen Serie „Russische Truppen“ des Herausgebers Paul-André Basset von 1815 ausgewählt. Sie zeigen einen Nogaier Tataren, Kirgisen (Abb. 7), Kalmücken und Turkmenen. Die Grafiken sind vor allem deshalb interessant, weil sie die Sichtweise eines Ausländers auf die ethnischen Volksgruppen des russländischen Imperiums, deren Sitten und Gebräu-

19 SHM ADK 64708/IK-2408a. „Kosakenlager“. Radierung von Zimmermann. Berlin: L. Wittich. 34,3 x 41,8 cm. Aus der Sammlung von Ivan Chr. Kolodejev. 
Abb. 8 Alexander Orlowski: Baschkire zu Pferde, 1818. Papier, Rötel, italienischer Bleistift, 55,5 x 43,0 cm. Staatliches Historisches Museum Moskau.

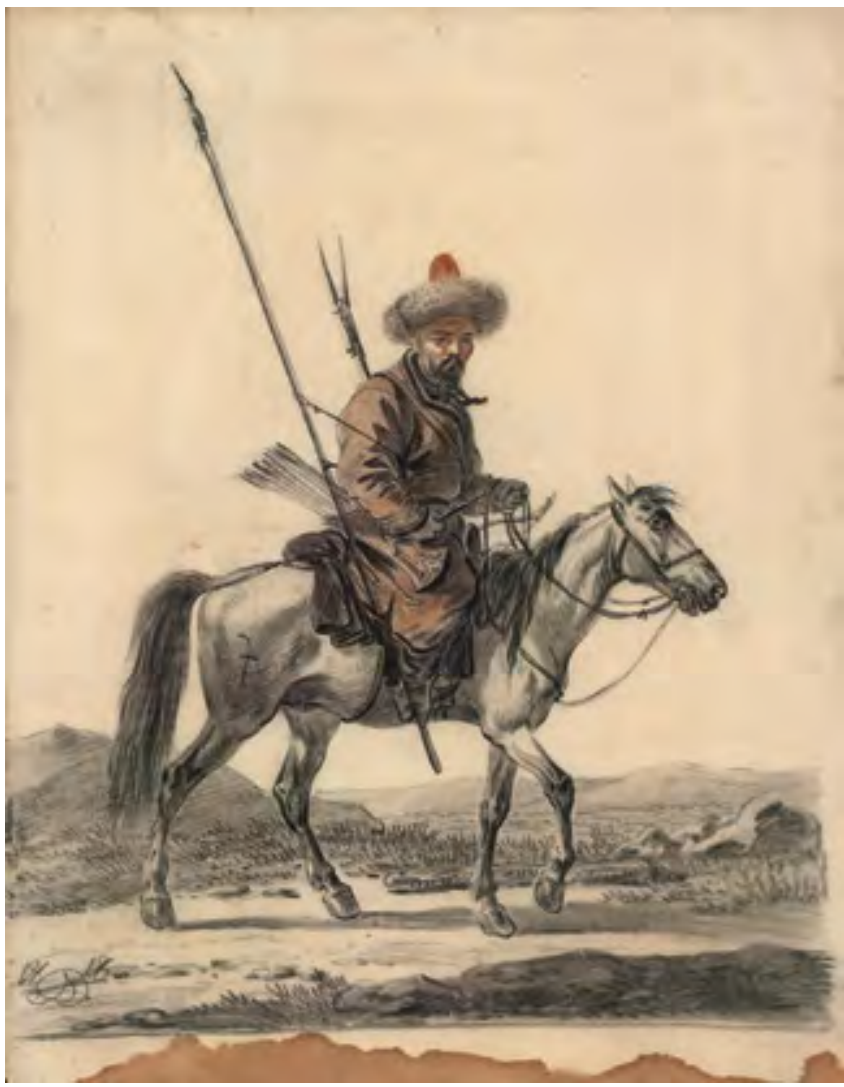

che, Trachten und Uniformen wiederspiegeln. ${ }^{20}$ Den größten Teil dieser Sammlung bilden Blätter mit der Darstellung von Baschkiren.

Am häufigsten wurden baschkirische Reiter von einem russischen Maler polnischer Abstammung, Alexander Orłowski, dargestellt. ${ }^{21}$ Er war auch der Erste, der lange vor

20 „Tatare-nogais“. Stich von Frédéric Dubois nach einer Zeichnung von Claude-Louis Desrais (17461816) Aquarell-Radierung. Blatt 49; „Kirguis tenant à la horde d'or“. Stich eines unbekannten Künstlers. Aquarell-Radierung. Blatt 34 (SHM 64708/IK 5737); „Kalmücke, Turkmene“. Stich eines unbekannten Künstlers. Aquarell-Radierung, Blatt 54, aus der Serie von Drucken von Paul-André Basset, „Troupes Étrangères“. Paris 1815.

21 Alexander Orlowski (russ. Aleksandr Ossipovič Orlovskij), geb. 1777 in Warschau, gest. 1832 in St. Petersburg. Maler, Zeichner, Graveur, Lithograph, Porträtist, Karikaturist, Illustrator. Zu seinen Auftraggebern in Warschau zählte Fürst Józef Poniatowski. Seit 1802 lebte und arbeitete er in St. Petersburg. Zu Orlowski siehe: RovinskiJ, Dmitrij A.: Podrobnyj slovar‘ russkich gravirovannych portretov [Detailliertes Lexikon russischer Porträt-Gravuren]. Bd. 1. Moskva 2006, S. 507, 574; KonDAKov, Sergej N.: Spisok russkich chudožnikov k Jubilejnomu spravočniku Imperatorskoj Akademii chudožestv [Verzeichnis russischer Künstler zum Jubiläumsnachschlagewerk der Imperialen Akademie der Künste]. Moskva 2002, S. 162; Korostin, Aleksej F.: Načalo litografii v Rossii. 18161818 [Der Anfang der Lithographie in Russland. 1816-1818]. Moskva 1943; ACARKIna, Esfir' N.: 
den Ereignissen von 1812 Baschkiren zeichnete. Noch 1807-1809 begab er sich auf Studienreise durch das Land, um das russische Dorf sowie das Leben nichtrussischer Völkerschaften wie Kalmücken, Kirgisen, Baschkiren und Kurden kennenzulernen. Im Ergebnis dieser Reise entstand eine Vielzahl von Skizzen über deren Alltagsleben. In dieser Periode war die Darstellung von Kosaken und Nomaden bevorzugtes Thema Orlowskis. Einige Arbeiten widmete der Künstler den Baschkiren: „Baschkirische Reiter“, „Baschkirischer Reiter“, „Bogenschießender Baschkire“ sowie das Gemälde „Baschkire“. ${ }^{22}$ Im Zeichnungsfundus des Moskauer Historischen Museums wird eine Originalzeichnung Orlowskis, „Baschkire zu Pferde“ (Abb. 8), aufbewahrt, auf der die besondere Begabung des Zeichners, Feinheiten der Bekleidung und Bewaffnung von Nomadenvölkern bildlich wiederzugeben, erkennbar ist. Dazu gehören Köcher und Pfeile, Futteral und Bogen, wattierte Umhänge und Mäntel, pelzverbrämte hohe Kopfbedeckungen und Mützen mit Ohren- und Nackenschutz. ${ }^{23}$ Auf dem Stich eines unbekannten deutschen Künstlers ist eine Schlacht von Kosaken und Baschkiren mit französischen Soldaten zu sehen. Vorne erblickt man einen aus dem Köcher schießenden Baschkiren; im Hintergrund erkennt man Umrisse von Figuren von Kosaken und Baschkiren, die durch ihre charakteristischen Kopfbedeckungen erkennbar sind. ${ }^{24}$

Die farbliche Gestaltung der Radierungen entsprach dabei nicht immer der Realität. Das zeigt sich bei den die Ereignisse zu Anfang des Jahres 1813 chronologisch darstellenden Doppelradierungen, deren erste die Grafik „Russen belagern Danzig“ (Abb. 9) war. $^{25}$

Die Radierungen waren im ersten Viertel des 19. Jahrhunderts in Deutschland in hohen Auflagen gedruckt worden und verkauften sich glänzend in Europa und Russland. 1911 erwarb das Moskauer „Museum des Jahres 1812“, welches im Jahre 1912 zum Jubiläum des Feldzuges gegen Napoleon eröffnet wurde, insgesamt 25 Blatt dieser Serie. An dieser Stelle seien vier Stiche ausgewählt, um die Aufmerksamkeit auf deren Farbgebung zu richten. Vor allem die von Künstler zu Künstler variierenden Unterschiede in der Handkolorierung geben diesen Blättern ihren besonderen Wert. So zeigt sich deutlich, dass ein Künstler die Radierungen gefertigt, andere Meister aber deren Kolo-

Aleksandr Ossipovič Orlovskij. Moskva 1971; Solovjev, Vladimir D: Russkie chudožniki XVIII-XX vekov: Spravočnik [Russische Künstler des 18. bis 20. Jahrhunderts: Nachschlagewerk]. Dnepropetrovsk 1996, S. 210; Gosudartsvennaja Tretjakovskaja galereja. Živopis' XVIII-XIX vekov, 7 Bde. Bd. 3: Katalog sobranija. Živopis' pervoj poloviny XIX veka [Staatliche Tretjakov-Galerie, SammlungsKatalog. Die Malerei des 18. u. 19. Jahrhunderts, 7 Bände. Band 3: Malerei in der ersten Hälfte des 19. Jahrhunderts]. Moskva 2005, S. 242-243.

22 Abgebildet in: Gosudarstvennyj Russkij muzej. Živopis. Pervaja polovina XIX veka [K-Ja] [Staatliches russisches Museum. Malerei. Erste Hälfte des 19. Jahrhunderts. K-Ja]. Sankt Petersburg 2007, S. 103.

23 SHM ADK 73464/I-II- 6704. (Aus alten Zugängen, 1932).

24 SHM ADK 55709/DK Kiste 17, Akte 7/145. „Baschkiren und Kosaken im Gefecht mit französischer Infanterie“. Radierung eines unbekannten Künstlers. Dresden. G. Morasch. 18 x 24,6 cm. (Aus der Sammlung von P. K. Daškov).

25 SHM ADK 64709/IK-2008; 4264. (Aus dem Museum des Jahres 1812). 


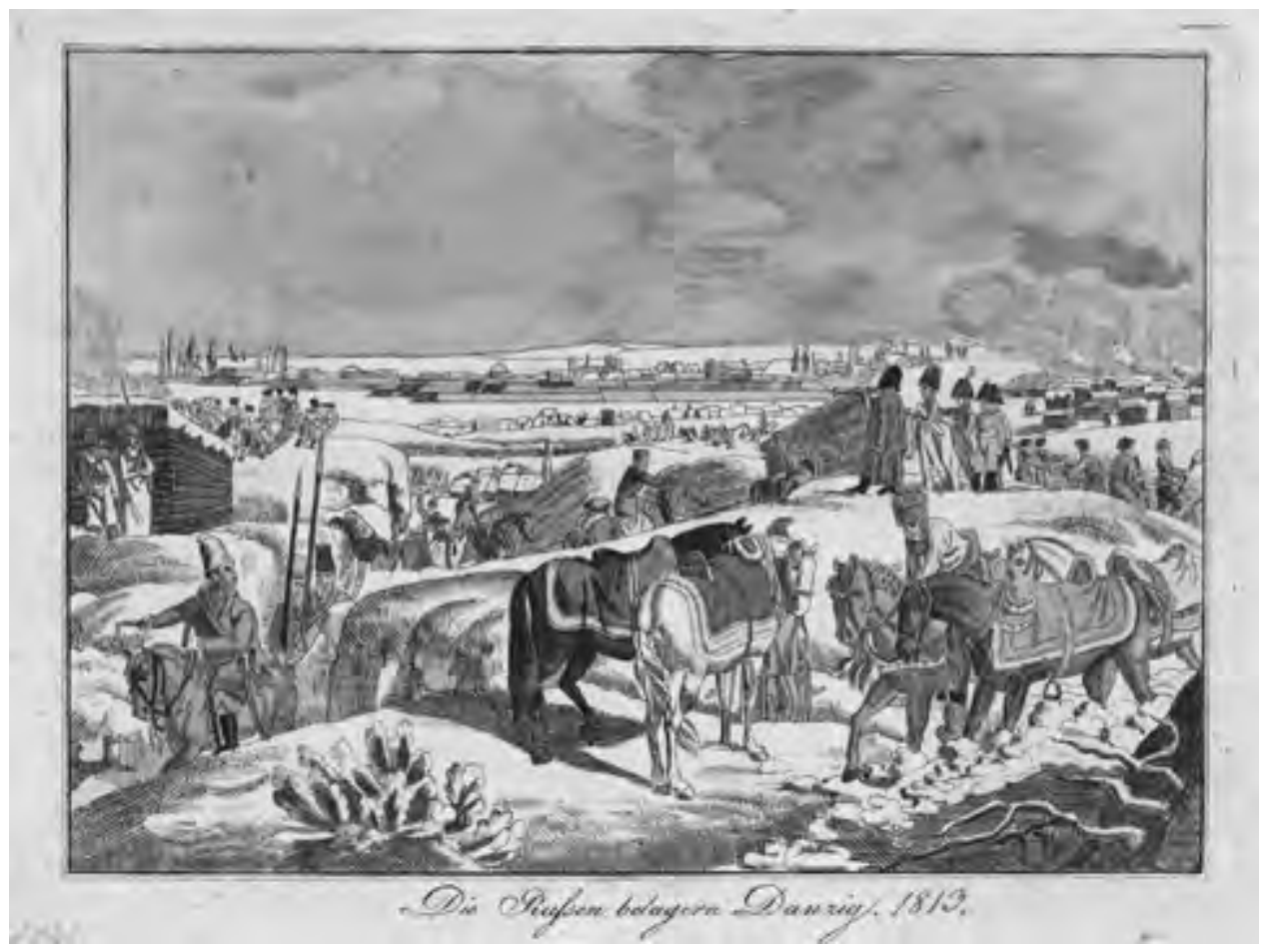

Abb. 9 Russen belagern Danzig. Stich eines unbekannten Künstlers, Deutschland, erstes Viertel des 19. Jahrhunderts, 19,0 x 26,8 cm. Staatliches Historisches Museum Moskau.

rierung entsprechend ihrem Wissensstand, oftmals ohne Kenntnis der Uniformfarben der russischen Armee, übernommen hatten.

Die archivierten Listen über Beförderung und Auszeichnung von Offizieren und Soldaten der baschkirischen Kosakenregimenter führen Belege über die Teilnahme der irregulären Kavallerie an der Schlacht bei Leipzig. ${ }^{26}$ Neben diesen Listen veranschaulichen auch Werke zeitgenössischer Künstler aus den Sammlungen des Moskauer Historischen Museums, wie der Einsatz nichtrussischer Kavallerie an der Völkerschlacht von Leipzig vonstattenging.

Die in einem volkstümlichen Stil von einem unbekannten Künstler geschaffene Radierung „Die Völkerschlacht bei Leipzig“ ist mit umfangreichen schriftlichen Erläuterungen versehen (Abb. 10). ${ }^{27}$ Ein anderer Stich mit der Darstellung der Völkerschlacht bei Leipzig ist eine Arbeit des deutschen Malers Carl Heinrich Rahl nach einem Origi-

26 RSMHA, Fonds103, Verzeichnis 1/208a, Bündel 0, Akte 86, Blatt 35.

27 SHM ADK 77002/I-III-26680. 


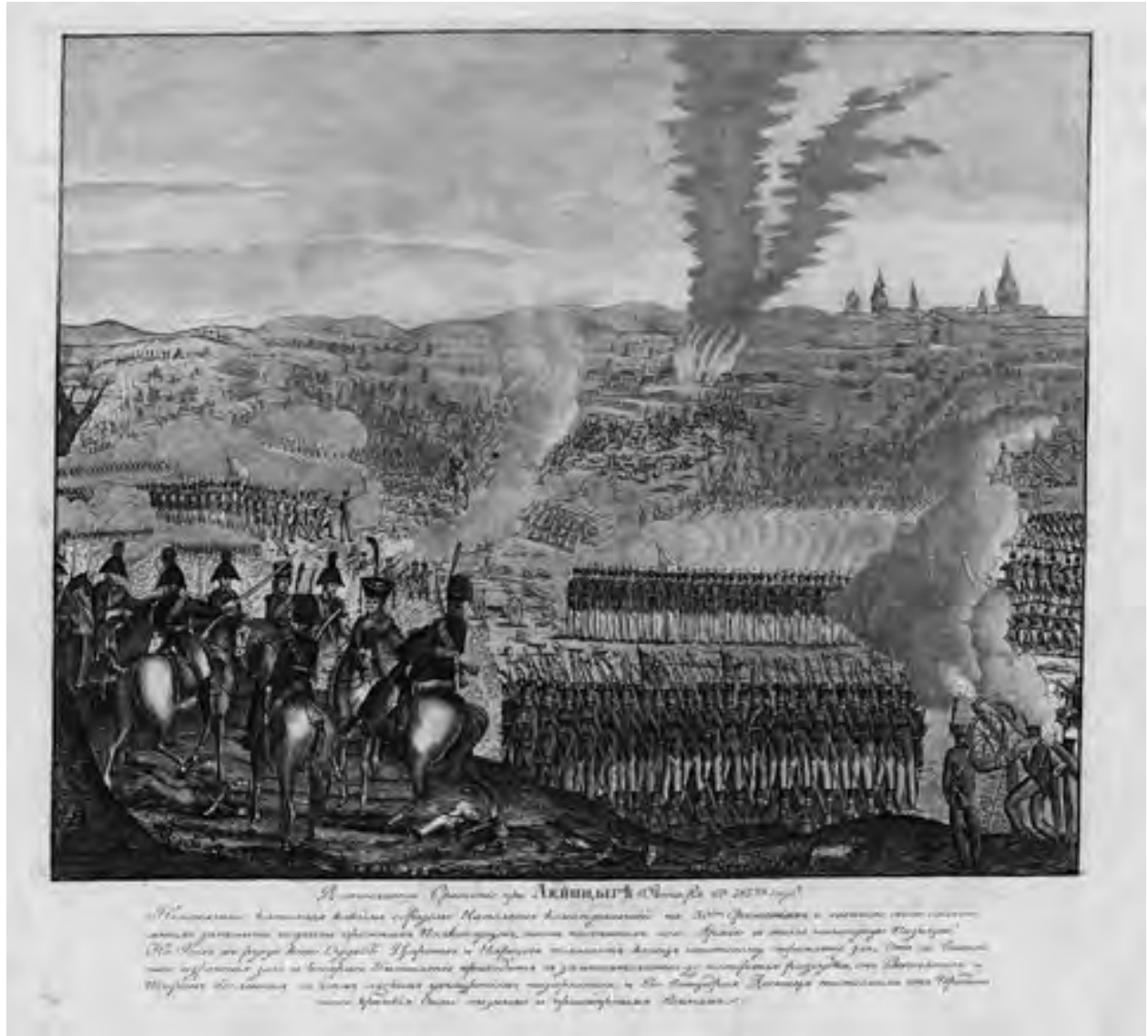

Abb. 10 Die Völkerschlacht bei Leipzig. Bilderbogen (Lubok), erstes Jahrzehnt des 19. Jahrhunderts, 38,3 x 41,5 cm. Staatliches Historisches Museum Moskau.

nal von Johann Adam Klein. ${ }^{28}$ Die populären Blätter wurden in Massenauflagen vom Verlag „Artaria“ in Wien vertrieben.

Neben den Werken der Druckgrafik verfügt das Historische Museum Moskau auch über zwei Originalblätter, die den Leipziger Ereignissen gewidmet sind. Eines von ihnen ist die Zeichnung „Die Schlacht von Leipzig“ eines unbekannten Künstlers aus den Sammlungen des Moskauer Kunstliebhabers Aleksej Petrovič Bachrušin. ${ }^{29}$

28 SHM ADK 64709/IK-1982. „Die große Völkerschlacht bei Leipzig“. Radierung von C. H. Rahl nach einem Original von J. A. Klein. Wien: Artaria \& Comp., 44,8 x 54,5 cm. (Aus dem Museum des Jahres 1812).

29 SHM ADK 42949/I-II-2309 „Die Schlacht von Leipzig“. Skizze eines unbekannten Künstlers, Papier, Tusche, Tinte, Pinsel, Feder. 1816-1818. 47 x 69,5 cm. (Aus der Sammlung von A.P. Bachrušin). 


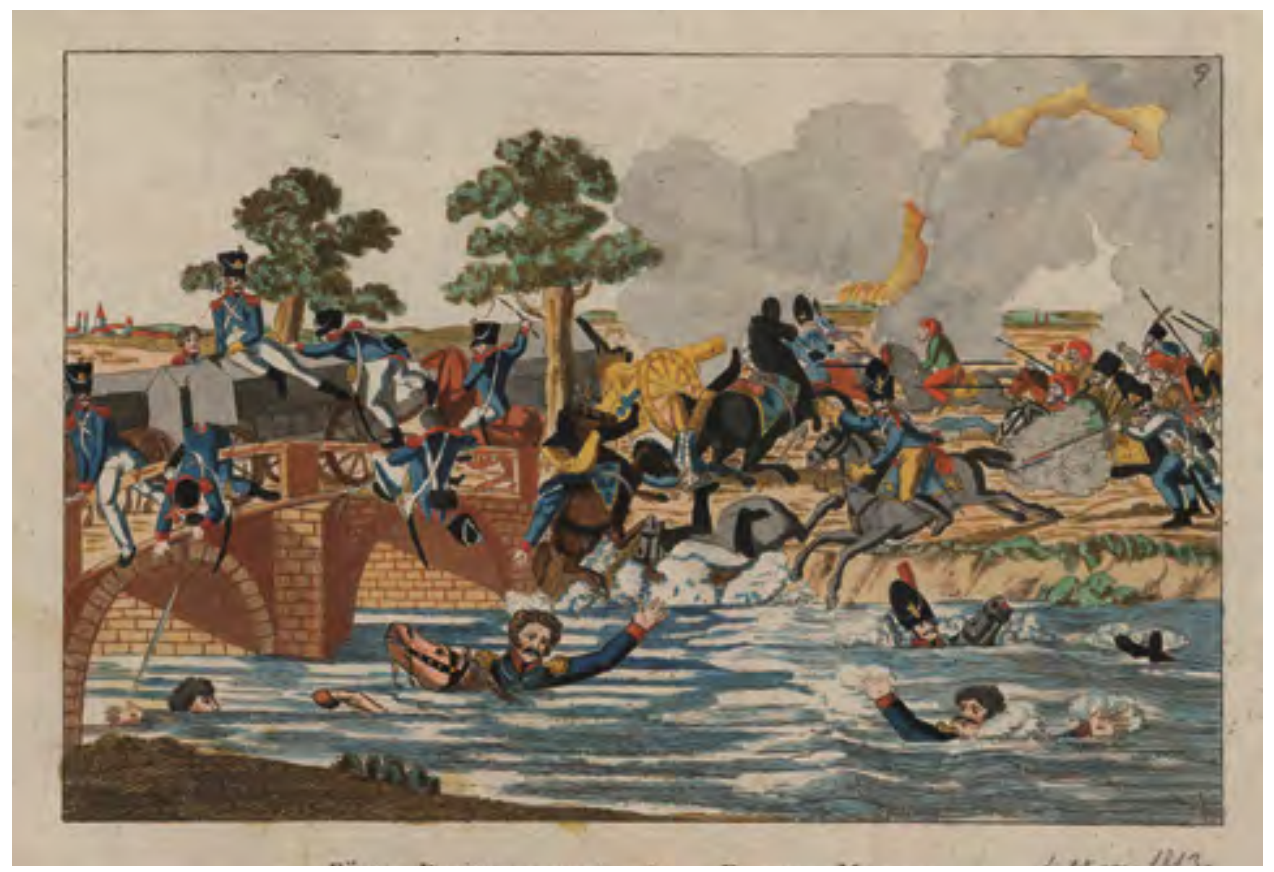

Abb. 11 Kaiserlich-französischer Reichsmarschall Fürst Poniatowski. Stich eines unbekannten Künstlers nach einer Aquarell-Radierung. Wien: Schönberg, erstes Viertel des 19. Jahrhunderts, 22 × $36 \mathrm{~cm}$. Staatliches Historisches Museum Moskau.

Die zweite, dicht mit Aquarell und Gouache bemalte Zeichnung „Kampf um dem Leipziger Fleischerplatz“"30, ist vom deutschen Aquarellmaler Christian Geißler unterzeichnet und zeigt das Zusammentreffen der Vorhuten aller vier verbündeten Armeen gegen Mittag des 19. Oktober in der Stadt.

Wie bekannt, kam an diesem Tag Fürst Józef Poniatowski beim Überqueren der Elster ums Leben. Auch dieses Ereignis fand seine Widerspiegelung in der bildenden Kunst. ${ }^{31}$ Nach den Unterschriften zu urteilen, wurde die Radierung von einem unbekannten Künstler in volkstümlichen Manier geschaffen und in Österreich gedruckt (Abb.11).

Das einzige der Schlacht bei Leipzig gewidmete Bild auf Leinwand in den Sammlungen des Moskauer Historischen Museums entstammt dem Pinsel eines der bekanntesten russischen Schlachtenmaler, Vladimir Ivanovič Moškov (1792-1839). ${ }^{32}$

30 SHM ADK 77002/И II-29172. Ch. G. Geißler „Kampf um den Fleischerplatz in Leipzig am 19. Oktober 1813“. Um 1813. Papier, Aquarell, Gouache, Tusche, Feder, 45,5 x 78,0 cm.

31 SHM ADK 64709/IK-4252. (Aus dem Museum des Jahres 1812).

32 SHM ADK 68257/I-I5667. Moškov, V. I. „Die Schlacht auf den Wachauer Höhen vor Leipzig“. Öl auf Leinwand, nach 1815. 126 x $236 \mathrm{~cm}$. (Aus dem Miltärhistorischen Museum, Moskau). 
Die irreguläre Reiterei des russischen Zaren nahm äußerst aktiv an den Napoleonischen Kriegen 1812-1814 teil. Es kann davon ausgegangen werden, dass für die Mehrzahl dieser nichtrussischen Kavalleristen die Begriffe „Ehre“ und „Treue“ zu Zar und Vaterland keine leeren Worthülsen darstellten. Sie begriffen ihre Teilnahme an den Napoleonischen Kriegen nicht als Untertanenpflicht, sondern als Einsicht in die Notwendigkeit, ihre Heimat zu schützen. Sie erfüllten ihre militärischen Aufgaben zusammen mit der Armee, den Kosaken, der Landwehr und den Truppen der Verbündeten dort, wo sie das Oberkommando eingesetzt hatte, und ließen die Stunde des Sieges näher rücken. Eine der herausragenden Episoden dieses Kampfes war die Völkerschlacht von Leipzig. ${ }^{33}$

Übersetzung aus dem Russischen von Karl-Heinz Kaufmann

33 Die Autoren bedanken sich für die Unterstützung bei der Vorbereitung der vorliegenden Beitrags bei Oberstleutnant a.D. Karl-Heinz Kaufmann sowie den Mitarbeitern des Staatlichen Historischen Museums Moskau E. A. Lukjanov und N. A. Perevezenceva für die Bereitstellung der Originale. 


\section{Autorenverzeichnis}

Arnold Bartetzky, Dr., Kunsthistoriker, seit 1995 wissenschaftlicher Mitarbeiter, seit 2011 Fachkoordinator für Kunstgeschichte am Geisteswissenschaftlichen Zentrum Geschichte und Kultur Ostmitteleuropas (GWZO) an der Universität Leipzig (anfangs in Berlin). Forschungsschwerpunkte: Architektur, Städtebau, Denkmalpflege sowie politische Ikonografie im 19.-21. Jahrhundert; Architektur der Renaissance und des Manierismus nördlich der Alpen. Jüngste Buchveröffentlichung: Die gerettete Stadt. Architektur und Stadtentwicklung in Leipzig seit 1989. Erfolge, Risiken, Verluste. Leipzig 2015.

Elena M. Bukreeva, Dr., Historikerin, leitende wiss. Mitarbeiterin am Staatlichen Historischen Museum Moskau. Forschungsschwerpunkte: Innen- und Außenpolitik Russlands im 19.-20. Jahrhundert; Genealogie; Sammeltätigkeit. Jüngste Publikation: Parižskie sobytija vesny 1814 goda v gravjurach i litografijach iz sobranija Gosudarstvennogo istoričeskogo muzeja [Pariser Ereignisse des Frühjahrs 1814 in Stichen und Lithografien aus den Sammlungen des Staatlichen Historischen Museums]. In: Iz Tauragè do Pariža (k 200-letiju Zagraničnych pochodov russkoj armii). Kaliningrad 2013, S. 108-116.

Dagmar Burkhart, Prof. Dr., Kulturanthropologin und Philologin, von 1985 bis 1995 Professorin an der Universität Hamburg (Slawische Literaturen und Popularkultur), von 1995 bis 2002 Geschäftsführende Direktorin des Instituts für Slawistik an der Universität Mannheim. Forschungsschwerpunkte: Kultursemiotik; Vergleichende Literaturwissenschaft; Intermedialität. Jüngste Buchpublikation: Hautgedächtnis. Mit einem Vorwort von Volker Steinkraus. Hildesheim, New York 2011.

Marina Dmitrieva, Dr., Kunsthistorikerin, seit 1996 wissenschaftliche Mitarbeiterin am Geisteswissenschaftlichen Zentrum Geschichte und Kultur Ostmitteleuropas (GWZO) an der Universität Leipzig. Forschungsschwerpunkte: Kunstgeschichte der Moderne in Zentral- und Osteuropa; Renaissance nördlich der Alpen; politische Ikonografie im 20.-21. Jahrhundert. Jüngste Buchpublikation: Italia v Sarmatii. Puti Renessansa v Vostočnoj Evrope [Italien in Sarmatien. Die Wege der Renaissance im Östlichen Europa]. Moskau 2015.

Christian Forster, Dr., Kunsthistoriker, seit 2011 wissenschaftlicher Mitarbeiter am Geisteswissenschaftlichen Zentrum Geschichte und Kultur Ostmitteleuropas (GWZO) an der Universität Leipzig. Forschungsschwerpunkte: Architektur des frühen und hohen Mittelalters; Antikenrezeption; christliche Ikonografie. Jüngste Buchpublikation: Die Architekturfragmente aus dem ehemaligen Kloster Lorsch (Arbeiten der Hes- 
sischen Historischen Kommission NF 28; Bamberger Beiträge zur Archäologie des Mittelalters und der Neuzeit 2). Hg. zus. mit Heiko Brandl. Darmstadt 2016.

Karen Hagemann, Prof. Dr., Historikerin, seit 2005 Kenan Distinguished Professor of History an der University of North Carolina, Chapel Hill. Forschungsschwerpunkte: Deutsche und Europäische Geschichte des späten 18. bis 20. Jahrhunderts. Jüngste Buchpublikation: Revisiting Prussia's Wars against Napoleon: History, Culture, and Memory. Cambridge 2014.

Dietlind Hüchtker, PD Dr., Historikerin, seit 2003 wissenschaftliche Mitarbeiterin, seit 2014 Projektleiterin am Geisteswissenschaftlichen Zentrum Geschichte und Kultur Ostmitteleuropas (GWZO) an der Universität Leipzig. Forschungsschwerpunkte: Geschlechter- und Kulturgeschichte, Europäische Geschichte. Jüngste Buchpublikation: Geschichte als Performance. Politische Bewegungen in Galizien um 1900. Frankfurt/M., New York 2014.

Karsten Holste, Dr., Historiker, seit 2007 wissenschaftlicher Mitarbeiter am Institut für Geschichte der Martin-Luther-Universität Halle-Wittenberg. Forschungsschwerpunkte: Polnische und preußische Geschichte im 18. und 19. Jahrhundert; Adelsgeschichte, Stadtgeschichte, politische Ideengeschichte. Jüngste Buchpublikation: In der Arena der preußischen Verfassungsdebatte. Adlige Gutsbesitzer der Mark und Provinz Brandenburg 1806-1847. Berlin 2013.

Lars Karl, Dr., Historiker, von 2011 bis 2015 wissenschaftlicher Mitarbeiter am Geisteswissenschaftlichen Zentrum Geschichte und Kultur Ostmitteleuropas (GWZO) an der Universität Leipzig, im akademischen Jahr 2015/16 Junior Fellow am Alfried Krupp Wissenschaftskolleg Greifswald. Forschungsschwerpunkte: Kulturgeschichte Osteuropas und des Kaukasus; Geschichtspolitik und Erinnerungskultur; Mediengeschichte Russlands und der Sowjetunion. Jüngste Buchveröffentlichung: Cinema in Service of the State. A Comparative Perspective on East Germany and Czechoslovakia, 1945-1960. Hg. zus. mit Pavel Skopal. Oxford, New York 2015.

Stephan Krause, Dr., Literaturwissenschaftler (Hungarologie, Germanistik, Romanistik (F)), seit 2012 wissenschaftlicher Mitarbeiter am Geisteswissenschaftlichen Zentrum Geschichte und Kultur Ostmitteleuropas (GWZO) an der Universität Leipzig. Forschungsschwerpunkte: ungarischsprachige und deutschsprachige Literatur in ihren ostmitteleuropäischen Kontexten; Literatur und Körper; Literatur und Ästhetik in der Romantik. Jüngste Buchpublikation: Leibesvisitationen. Der Körper als mediales Politikum in den (post)sozialistischen Kulturen und Literaturen. Hg. zus. mit Torsten Erdbrügger. Heidelberg 2014.

Ruth Leiserowitz, apl. Prof. Dr., Historikerin, seit 2009 stellv. Direktorin am Deutschen Historischen Institut Warschau. Forschungsschwerpunkte: Transnationale 
Geschichte Osteuropas im 19. Jahrhundert; Baltische und Jüdische Geschichte; Netzwerke von Wissenschaftlern im Warschau des 19. Jahrhunderts. Jüngste Buchpublikation: Polnische Militärärzte im zarischen Imperium. Räume und Spannungsfelder zwischen Warschau und Port Arthur. München, Boston 2015.

Ramil N. Rachimov, Dr., Historiker, seit 2013 leitender wissenschaftlicher Mitarbeiter am Russländischen Institut für Strategische Studien (RISI) in Ufa. Forschungsschwerpunkte: Nationalitätenpolitik des Russischen Reiches; Militärdienst der nichtrussischen Völker in der russländischen Armee; Geschichte der Napoleonischen Kriege. Jüngste Buchpublikation: Na službe u „Belogo zarja“. Voennaja služba nerusskich narodov jugo-vostoka Rossii v 18. - pervoj polovine 19. veka [Im Dienste des „Weißen Zaren“. Militärdienst der nichtrussischen Völker der südöstlichen Gebiete Russlands vom 18. bis Anfang des 19. Jahrhunderts]. Moskau 2014.

Thomas Topfstedt, Prof. Dr. habil., Kunsthistoriker, lehrte am Institut für Kunstgeschichte der Universität Leipzig, emeritiert 2012. Forschungsschwerpunkte: Architektur- und Städtebaugeschichte mit Schwerpunkten im 19. und 20. Jahrhundert. Buchpublikationen: Stadtdenkmale im Osten Deutschlands. Leipzig 1994; Geschichte der Leipziger Universitätsbauten im urbanen Kontext. Hg. zus. mit Michaela Marek. Leipzig 2009.

Hans-Christian Trepte, Dr., Literaturwissenschaftler (Slavistik, Anglistik, Polonistik), Übersetzer polnischer Literatur ins Deutsche, wissenschaftlicher Mitarbeiter am Institut für Slavistik der Universität Leipzig. Forschungsschwerpunkte: Polnische und tschechische Literatur und Kultur; weltweites Exil; Sprachwechsel. Jüngste Buchpublikation: Flüsse. Kultur und Literatur der Wasserwege. Hg. zus. mit Elmar Schenkel. Leipzig 2015.

Stefan Troebst, Prof. Dr. habil., Historiker und Slavist, seit 1999 Professor für Kulturgeschichte des östlichen Europa an der Universität Leipzig und stellv. Direktor des Geisteswissenschaftlichen Zentrums Geschichte und Kultur Ostmitteleuropas (GWZO) ebendort. Forschungsschwerpunkte: Geschichtspolitik und Erinnerungskultur in Europa; Geschichte von Völkerrecht und internationalen Beziehungen; frühneuzeitliche Geschichte Nordosteuropas; moderne Geschichte Südosteuropas; Kulturgeschichte Ostmitteleuropas. Jüngste Buchpublikation: Erinnerungskultur Kulturgeschichte - Geschichtsregion. Ostmitteleuropa in Europa. Stuttgart 2013.

Thomas Westphalen, Dr., Dipl.-Geogr., seit 1993 Mitarbeiter des Landesamtes für Archäologie Sachsen, Leiter der Abteilung ,archäologische Denkmalpflege“. Forschungsschwerpunkte: Stadtkernarchäologie, Archäologie des slawischen Mittelalters, praktische Denkmalpflege. Buchpublikation: Zwischen Schloss und Neumarkt. Archäologie eines Stadtquartiers in Dresden (= Archaeonaut 8). Landesamt für Archäologie Sachsen, Dresden 2008. 
Agnieszka Zabłocka-Kos, Prof. Dr., Architekturhistorikerin und Architektin, seit 2010 Professorin am Institut für Kunstgeschichte der Universität Wrocław (Breslau). Forschungsschwerpunkte: Architektur und Städtebau im 19. und 20. Jahrhundert in Mitteleuropa mit besonderer Berücksichtigung der nationalen Problematik; Wiederaufbau und Nachkriegsmoderne; Erinnerungsorte und Geschichtspolitik im internationalen Vergleich. Buchpublikation: Zrozumieć miasto. Centrum Wrocławia na drodze ku nowoczesnemu city 1807-1858 [Die Stadt verstehen. Das Stadtzentrum von Breslau auf dem Weg zur modernen City 1807-1858]. Wrocław 2006. 


\section{Abbildungsnachweise}

\section{Hagemann}

Abb. 1-6: Stadtgeschichtliches Museum Leipzig.

\section{Troebst}

Abb. 1: (c) picture-alliance/dpa.

\section{Trepte}

Abb. 1: Kazimierz Olszański: Juliusz Kossak. Wrocław-Warszawa-Kraków 1988, Abb. 429; Abb. 2: Artur Korczak-Siedlecki; Abb. 3: Paweł Gorszczyński.

\section{Zabłocka-Kos}

Abb. 1: Sammlung Verlag Via Nova, Wrocław; Abb. 2: Privatsammlung; Abb. 3: Sammlung Małgorzata Urlich-Kornacka, Wrocław; Abb. 4: Katalog der Historischen Ausstellung. Breslau 1913, Abb. I; Abb. 5: Jerzy Kos; Abb. 6: Sammlung Muzeum Ceramiki, Boleslawiec, Sign. MCB/R/162/82c.

\section{Bartetzky}

Abb. 1: wikipedia.org; Abb. 2: wikimedia.org; Abb. 3: Theodor Lindner: Der Krieg gegen Frankreich und die Einigung Deutschlands. Zur 25jährigen Wiederkehr der Gedenktage von 1870/71. Berlin 1895; Abb. 4: Arnold Bartetzky; Abb. 5: Zeitschrift für Bauwesen 29 (1879); Abb. 6: wikipedia.org/Daderot; Abb. 7: Postkarte um 1912; Abb. 8: National Archives of Australia.

\section{Topfstedt}

Abb. 1, 3-6: Matthias Topfstedt; Abb. 2, 7, 8: Deutschlands Denkmal der Völkerschlacht, das Ehrenmal seiner Befreiung und nationalen Wiedergeburt. Weiheschrift des Deutschen Patriotenbundes. Hg. v. Alfred Spitzner. Leipzig 1913.

\section{Dmitrieva}

Abb. 1, 4, 5: Stadtarchiv Leipzig; Abb. 2, 6, 8: Marina Dmitrieva; Abb. 3: Rainer Krumrey; Abb. 7: (C) Staatliches A.V. Ščusev Architekturmuseum Moskau, Inv.-Nr. PI-4890; Abb. 9, 10: Stadtgeschichtliches Museum Leipzig.

\section{Forster}

Abb. 1, 5-8, 11-13, 15-17: Christian Forster; Abb. 2: Österreichisches Staatsarchiv, Haus-, Hof- und Staatsarchiv; Abb. 3: GWZO; Abb. 4: Stadtgeschichtliches Museum Leipzig; Abb. 9, 10: Sächsisches Staatsarchiv Leipzig; Abb. 14: Rudolf Friederich: Die Befreiungskriege 1813-1815. Bd. 2: Der Herbstfeldzug 1813. Berlin 1912; Abb. 18: Heinrich Aster: Die Gefechte und Schlachten bei Leipzig im October 1813. Bd. 1-2. Dresden 1852-1856, Pl. IV. 


\section{Westphalen}

Abb. 1, 3: Landesamt für Archäologie Sachsen; Abb. 2: W.-R. Teegen; Abb. 4, 5: Thomas Westphalen.

\section{Burkhart}

Abb. 1-5: Stadtgeschichtliches Museum Leipzig; Abb. 6: Tiroler Landesmuseum, Ferdinandeum, Innsbruck, Inv. Nr. Gem 1380.

\section{Karl}

Abb. 1-3: Stadtgeschichtliches Museum Leipzig.

\section{Krause}

Abb. 1, 2: Stephan Krause; Abb. 3: Hadtörténelmi Közlemények Nr. 3 (1914), S. 350/351; Abb. 4: Still aus dem Spielfilm A hídember (2002).

\section{Bukreeva/Rachimov}

Abb. 1-11: Staatliches Historisches Museum Moskau. 


\section{Register}

\section{Personenregister}

Aleksandr I. (Alexander I.) (Russland) 42, 54, 99, 166, 183, 187, 197, 258, 264, 267

Aleksij, hl. 160, 172

Alexander I. $\rightarrow$ Aleksandr I.

Apel, Theodor 189, 195

Arcimboldo, Giuseppe $224 \mathrm{f}$.

Arndt, Ernst Moritz 35, 37, 101 f., 138-140

Arnsztayn, Franciszek 78

Asfandijarov, Anvar 269

Askenazy, Szymon 83, 90, 93

Aster, Carl Heinrich 23, 185, 199, 202

Bach, Karl Daniel $101 \mathrm{f}$.

Bachrušin, Aleksej Petrovič 277, 282

Bakirov 271

Bär, Adolf 129

Barclay de Tolly, Michail B. 198, 271

Basset, Paul-André 274, 278 f.

Batjuškov, Konstantin 267

Begas, Reinhold 140

Behrens, Christian $145 \mathrm{f}$.

Bell, David 19

Bendekówna, Janina $61 \mathrm{f}$.

Bender, Georg 108, 110

Bendorz, Robert 114

Bennigsen, Levin (Leontij Leontjevič) August Theophil von 87, 196, 200

Benois, Leontij N. 157, 166

Bereményi, Géza 250, 260 f.

Berg, Max 109-111, 113-115, 119 f., 133, 153

Bernadotte, Jean Baptiste 14, 196, 199, 258

Bertrand, Henri-Gatien 202

Bertuch, Carl 184

Białkowski, Antoni 86

Bianchi, Friedrich von 197 f., 203

Bikčurin 271

Blücher, Gebhard Leberecht von 11, 14, 98-108, 117, 119, 122, 196, 229, 251, 255, 257-259, $263 \mathrm{f}$.

Blumenberg, Hans 256, 259

Bondarčuk, Sergej 165

Böttiger, Karl August 219
Brandys, Marian 75, 80

Braun, Volker 249

Bredekamp, Horst 224

Breschnew, Leonid Iljitsch (Leonid Il'ič Brežnev) 44

Brežnev, Leonid Il'ič $\rightarrow$ Breschnew, Leonid Iljitsch

Bringéus, Nils-Arvid 218

Brockhaus, Friedrich Arnold 220

Bronikowski, Mikołaj 83

Brynkus, Józef 82

Bubna und Lititz, Ferdinand von 200 f., 203

Bujdosó, Attila 250

Bulatov, Michail 272

Carus, Carl Gustav 208

Chammatov, Roman Jannybaj 269

Chłapowski, Dezydery $86 \mathrm{f}$.

Chlebnikov, Ivan P. 163

Chruschtschow, Nikita Sergejewitsch (Nikita Sergeevič Chruščëv) 44

Chruščëv, Nikita Sergeevič $\rightarrow$ Chruschtschow, Nikita Sergejewitsch

Clausewitz, Carl Philipp Gottlieb von 240

Colloredo-Mansfeld, Hieronymus von 188, 193, 198

Conrad von Hötzendorf, Franz von 177, 179

Cruikshank, George 219

Cruikshank, Isaac 219

Csík-Kovács, Zoltán 250

Czarnowska, Barbara Bronisława 55, 58

Czubaty, Jarosław 85

Dąbrowski, Jan Henryk 81, 86, 91

Daškow, Pavel J. 277

Dębicka, Waleria 55

Delbrück, Hans 258

Desrais, Claude-Louis 279

Deubel, Werner 232

Diessl, Gustav 234

Diomidij 271

Dittrich, Rudolf 177, 193 f. 
Dmitrieva, Ol'ga Petrovna 167

Dmowski, Roman $59 \mathrm{f}$.

Dobraczyński, Jan 80 f., 94

Dodel, Friedrich Wilhelm 156, 163, 166, 172

Doflein, Karl 141

Donskoj, Dmitrij $41 \mathrm{f}$.

Dubois, Frédéric 279

Dumas, Alexandre 94

Eckert, Horst 226

Eggers, Friedrich 129

El'cin, Boris Nikolaevič $\rightarrow$ Jelzin, Boris

Nikolajewitsch

Emeljanov, Nikolaj S. 163

Engel, Ludwig 141

Enke, Otto 170

Erll, Astrid 159

Eugen von Württemberg 197

Fekete, Sándor 264

Festetics, Julianna 251

Filaret, Metropolit von Moskau 41

Folliot de Crenneville-Poutet, Franz 195

Franz Ferdinand von Österreich-Este

(Erzherzog) 156, 172, 177, 179, 195, 204

Franz I. von Österreich 183, 187

Franz Joseph I. (Österreich) 185, 188, 192, 194 f., 204

Fredro, Aleksander 81

Freygang, Wilhelm von 185

Friedrich August I. (Sachsen) 20, 31, 180

Friedrich August III. (Sachsen) 156

Friedrich Wilhelm III. (Preußen) 11, 51, 98 f., 103, 107, 109, 117 f., 124, 127 f., 183, 187, 229, 232 f., 235 f., 238, 241, 247

Friedrich Wilhelm IV. (Preußen) 105, 123

Friedrich, Caspar David 187

Friedrich von Hessen-Homburg 198, 203

Friedrich II. (Preußen) 229, 241

Froehlich, Carl 229

Frolov, Vladimir 163

Fuller, Margaret 57

Gagarin, Fedor 271

Gąsiorowski, Włacław 54

Gates, David 31

Gehrke, Ulrich 244

Geißler, Christian Heinrich 34 f., 217, 221, 283
George, Heinrich $233 \mathrm{f}$.

Gertzówna (häufig: Gertz), Wanda 62 f.

Gillray, James 215, 219

Gneisenau, August Neidhardt von 7, 13, 101, 227, 231-236, 238-241, 244, 246 f.

Goebbels, Joseph 13, 227, 230-235, 243 f., 246

Goethe, Johann Wolfgang von 259

Goldschab, Karl August 24 f.

Gorbačëv, Michail Sergeevič $\rightarrow$ Gorbatschow, Michail Sergejewitsch

Gorbatschow, Michail Sergejewitsch (Michail Sergeevič Gorbačëv) 44

Górski, Artur 75

Grabowski, Jozef 86

Grautoff, Ferdinand Heinrich $21 \mathrm{f}$.

Gulbinowicz, Henryk 117

Günther, Felix 186

Gyulai, Ignaz 198, 201 f.

Hardenberg, Karl August von 100, 240 f.

Harkort, Carl 183

Harkort, Gustav 183

Harlan, Veit 13, 230, 232-236, 241-244, 246

Hauptmann, Gerhart 107, 111, 114 f., 119

Hegedüs, Loránt 265

Heisig, Bernhard 226

Henckel von Donnersmarck, Wilhelm Ludwig Viktor 104

Henschel, Gebrüder, 223, 226

Hertz, Jan Adolf 93

Heyse, Paul 232

Himmler, Heinrich 237

Hippel, Theodor Gottlieb von 235

Hitler, Adolf 44, 241, 243

Hoen, Maximilian von 201

Hoenisch, Ernst 172

Höfel, Bernhard 224

Hofer, Andreas 240

Hoffmann, E. T. A. (Ernst Theodor Amadeus) 220

Hoffmann, Josef 146

Homer 256

Horváth, Ádám Pálóczi 253

Humboldt, Wilhelm von 100

Hussell, Christian 25

Iskanderov 271

Ivanov, Ivan Alekseevič 219 
Janion, Maria 86, 91

Jaroslavskij, Emel'jan 42 f.

Jelzin, Boris Nikolajewitsch (Boris Nikolaevič El'cin) $44 \mathrm{f}$.

Jurgenev, Andrej 163

Kaczyński, Lech Aleksander 75

Kailer, Karl Edler von 193, 203

Kajpov 271

Kazinczy, Ferenc 253

Keghel, Isabelle de 45

Kiliński, Jan 81

Kisielewska, Julia 81

Klein, Johann Adam 282

Klenau, Johann von 197, 199, 210

Kluczycka, Józefa 55

Knorr, Johann Friedrich 102

Knorring, Karl 273

Koch, Karl Wilhelm Otto 140

Kołaczkowski, Klemens 86

Koll, Malachias 224

Kolodejev, Ivan S. 277

Kondratjev 272

König, Gustav 193

Körner, Theodor 37, 230, $240 \mathrm{f}$.

Korzon, Tadeusz 79

Kościuszko, Tadeusz 11, 53, 55, 72, 79-81, 84, 91

Kossak, Juliusz 73

Kossuth, Lajos 250, 252, 259

Kovács, András Ferenc 249

Krafft, Johann Peter 183 f.

Kreimeier, Klaus 228

Kreis, Wilhelm 141, 153

Kreutz, Kiprian 271

Krieger, Hans 192

Krobatin, Alexander 185

Krüger, Frederike 51

Kučma/Kutschma, Leonid 43

Kudašev, Nikolaj 163

Kugler, Bernhard 126

Kurbatov, Major 271

Kutuzov, Michail 41 f., 120-122

Lambert, Karl 272

Łańcucki, Wincenty 76

Langeron, Alexander 271

Langhans, Karl Ferdinand 103
Lechoń, Jan 78

Lederer, Hugo 145

Lederer, Ignaz von 198

Lehmann, Gottfried Arnold 223

Leiser, Erwin 244

Leljanov, Ivan P. 166, 172

Leśniewski, Sławomir 82

Libera, Zdzisław 86

Liechtenstein, Moritz 201

Lindner, Theodor 125-127

Loison, Louis Henri 235

Loucadou, Klothilde von 232

Loucadou, Ludwig Moritz 232, 234 f., 237-239

Luise von Mecklenburg-Strelitz (Luise von Preußen) 128-130, 240 f., 244

Lukaschenko, Alexander (Aljaksandr Ryhoravitč Lukašenka) 43

Lukašenka, Aljaksandr Ryhoravitč $\rightarrow$ Lukaschenko, Alexander

Lützow, Ludwig Adolf Wilhelm von 107, 117

MacDonald, Jacques 199, 210

Mai, Hartmut 157

Mamajskij 271

Mann, Thomas 38

Marbot, Marcellin de $275 \mathrm{f}$.

Markov, Evgenij 271

Masner, Karl 108-110, 114 f.

Matting, Paul 114

Meinecke, Friedrich 38

Merveldt, Maximilian von 193, 197 f., 201

Metternich, Klemens Wenzel Lothar von 262

Metzner, Franz 145-147, 149-153

Meyendorff, Frau von 244

Miciński, Tadeusz 78

Mickiewicz, Adam 56, $82 \mathrm{f}$.

Minin, Kuz'ma 41 f., 45

Monten, Dietrich Heinrich Maria 79

Morawska, Zuzanna 90, 93-96

Moškov, Vladimir Ivanovič 283

Moszczeńska, Iza 60

Müffling, Karl von 8

Müller-Gerhardt, Rudolph 152

Musin, Aleksandr 165

Mussolini, Benito 241

Napoleon Bonaparte 7-11, 13, 17 f., 20-24, 26, 28, 31-34, 41 f., 59, 71 f., 75, 80, 82-85, 
87, 89, 91 f., 96, 98 f., 114 f., 117, 124, 126 f., 131, 134, 139, 154, 160, 162, 166, 175, 180 f., 184, 188 f., 193, 196-199, 201 f, 204 f., 215 f., 218-224, 226, 232-234, 236 f., 239-241, 258 f., 262, 264, 267, 269, 273, 275 f., 280

Napoleon III. $126 \mathrm{f}$.

Naumann, Max 143, 154

Naumann, Robert 25

Németh, József 253

Nervi, Pier Luigi 117

Nettelbeck, Joachim 13, 231-236, 238 f., 244

Nevskij, Aleksandr 41-43

Niebuhr, Barthold Georg 103

Niemcewicz, Julian Ursyn 77

Nikolaus I. (Russland) 107

Nipperdey, Thomas 154

Nora, Pierre 159

Nostiz-Rieneck, Johann Nepomuk von 197

Oplatka, Andreas 254, 266

Oppman, Artur (Pseudonym: Or-Ot) $78 \mathrm{f}$.

Orłowski, Alexander (Aleksandr Ossipovič Orlovskij) 279

Osten-Sacken, Fabian von 271

Pahlen, Petr 270

Papi, Tereza 94

Papp, Gábor 250

Pertz, Georg H. 258

Petőfi, Sándor 250

Pfann, Paul 141, 144

Pflugk-Harttung, Julius von 17

Piłsudska, Aleksandra 62

Piłsudski, Józef 59, 61 f., 64

Piotrowiczowa, Marja 57

Pitt, William 215

Plater, Emilia 54-58, 63 f., 66

Platov, Matvej 271-173

Plautier, Familie 106

Plečnik, Jože 146

Poelzig, Hans 110-113, 118-120

Pokrovskij, Vladimir Aleksandrovič 156-158, 160, 163, 166-168, 170

Poniatowski, Andrzej 80

Poniatowski, Józef Anton(i) 10 f., 71-83, 85, 87, 91-97, 117 f., 197 f., 203, 279, 283

Poniatowski, Stanisław August 71, $80 \mathrm{f}$.
Popov 271

Požarskij, Dmitrij 41 f., 45

Prądzyński, Ignacy 11, 80

Prochaska, Eleonore 51 f., 57

Prus, Bolesław 88

Przyborowski, Walery Jerzy 90, 95 f.

Pustowójtówna, Anna Henryka 58

Putin, Vladimir 44-46

Quensel, Paul 129

Radetzky von Radetz, Josef Wenzel 203

Radziwiłł, Józef 72

Rahl, Carl Heinrich $281 \mathrm{f}$.

Rauch, Christian Daniel 103

Regel, Peter 229

Reil, Johann Christian 28

Reinhardt, Max 107

Reynier, Jean Louis Ebenezer von 200

Rieth, Otto 141

Rogaliński, Adelsfamilie 57

Romanov, russische Dynastie 41, 171

Romanov, Kyrill Vladimirovič 156, 171

Romanov, Michail Aleksandrovič 41, 45

Rosov, Konstantin 172

Rowlandson, Thomas 219, 222, 224

Rudolph II. (HRR) 224

Saarinen, Eliel $132 \mathrm{f}$.

Šavel'skij, Georgij Ivanovič 160

Schadow, Johann Gottfried 120, 220

Schaede, Bernhard 141

Scharenberg, Otto Wilhelm 193

Scharnhorst, Gerhard Johann David von 101, $240 \mathrm{f}$.

Schaudt, Emil 145

Schenk, Frithjof Benjamin 43

Scherrer, Jutta $44 \mathrm{f}$.

Schill, Ferdinand von 13, 231-234, 237, 240

Schinkel, Karl Friedrich 102 f., 120, 124, 127, 131, 189, 191

Schlosser, Ludwig Wilhelm Gottlob 23

Schmitthenner, Paul 111

Schmitz, Bruno 131, 140-142, 145-147, 153

Schnabel, Franz 51

Schubert, Gusztáv 260

Schulz, Paul 192

Schwarzenberg, Edmund Leopold Friedrich 181 
Schwarzenberg, Friedrich Karl 181

Schwarzenberg, Karl Philipp 12, 14, 17, 80, 177-181, 183 f., 194, 196-198, 202-204, 252, 255 f., 258, 262, 270

Schwarzenberg, Karl (V.) 177 f., 181, 184

Schwarzenberg, Marianne 181, 184

Ščukin, Petr 277

Seilner, Crescence 261

Sekulski, Henryk 82

Seleznjov 272

Servaes, Franz 149

Ševič, Ivan 163

Sienkiewicz, Henryk 88

Silagi, Denis $264 \mathrm{f}$.

Simbschen, Joseph von 201-203

Smoleński, Władysław 79

Söderbaum, Kristina 236, 244

Spaeth, Karl 141

Spicyn 271

Spitzner, Alfred 131

Stalin, Josef (Iosif) 42, $44 \mathrm{f}$.

Stegmann, Natali 60

Steiger, Edgar 192

Stein, Heinrich Friedrich Karl vom und zum $240 \mathrm{f}$.

Sternburg, Max von 205

Stieglitz, Christian Ludwig 185

Stillfried-Alcántara, Rudolf von 126

Strack, Johann Heinrich 105

Straßberger, Ernst Wilhelm 26 f., 29 f., 34

Suchodolski, January 72

Suchomlinov, Vladimir Aleksandrovič 170 f., 175

Sułkowski, Józef 75

Suragulov 272

Surányi, Miklós $265 \mathrm{f}$.

Suvorov, Aleksandr $41 \mathrm{f}$.

Świderski, Jędrzej 93

Széchényi, Ferenc 251

Széchenyi, István 13 f., 250-266

Széchenyi, Karolina 265 f.

Széchenyi, Lajos 251

Széchenyi, Pál 251, 265 f.

Szelągowski, Adam 79

Tauchnitz, Christian Karl Bernhard 193

Temirov 271

Terebenev, Ivan Ivanovič 219
Thieme, Clemens 12, 115, 130, 140 f., 143 f., 153, 179

Thorvaldsen, Bertel 73 f., 103

Thurzó, Kálmán Nosziczi 253-256, 263

Tichanovskij 271

Tjumen' 271

Tolstoj, Petr $272 \mathrm{f}$.

Tomjuk, Aleksej 156 f., 163

Ton, Konstantin 166

Traugutt, Romuald 81

Trufanov, Nikolaj Ivanovič 162

Tschammer, Richard 159, 170

Ucicky, Gustav 241

Ungnad von Weissenwolff, Nikolaus 197 f., 203

Urasgulov 271

Usbeck, Oskar 141

Usmanov, Abubakir 269

Vasilij III. Ivanovič (Russland) 171

Vater, Auguste 33

Venecianov, Aleksej Gavrilovič 219

Vignon, Alexandre Pierre 102

Viszota, Gyula 266

Vitéz, Mihály Csokonai 253

Vitzthum von Eckstädt, Christoph Johann Friedrich 193

Voelker, Johannes 246

Voltz, Johann Michael 215, 222-224

Wajda, Andrzej 73

Watanabe-O'Kelly, Helen 48

Wegener, Paul 233

Weidenbach, Georg 159, 170

Weinbrenner, Friedrich 131, 138-140, 151

Wenk, Ernst 141

Werner, Anton von 127

Wilhelm I. (Deutsches Reich) 124 f., 127-129, 131

Wilhelm II. (Deutsches Reich) 38, 134, 142, 156, 172, 177-179

Williams, Charles 216

Winckler, Johann Ernst von 180 f., 194, 203

Wintzingerode, Ferdinand von 271, 273

Wittgenstein (Sayn-Wittgenstein), Ludwig Adolf Peter zu 197, 271

Woronicz, Jan Paweł 76 
Yorck von Wartenburg, Johann David Ludwig 229

Zagórska, Aleksandra 63

Zedlitz-Trützschler, Carl Eduard von 101

Żeromski, Stefan 73

Zerritsch, Fritz 193
Zichy, Antal 264 f.

Zichy, Ferdinand 255 f., 265

Zichy, Károly $261 \mathrm{f}$.

Zichy, Felícia $261 \mathrm{f}$.

Zimmermann (Vorname unbekannt) 278

Zola, Émile 94

Żubrowa (auch: Żubr), Joanna 53-55, 58

\section{Ortsregister}

Abu Simbel 151

Altenburg 220, 275

Arbesau (tsch. Varvažov) $188 \mathrm{f}$.

Arcis-sur-Aube 97, 275

Astrachan 269

Auenhain $\rightarrow$ Markkleeberg

Auerstedt 20, 131, $188 \mathrm{f}$.

Bad Ischl 193

Bagrationowsk $\rightarrow$ Preußisch Eylau

Bautzen 21, 272-275

Belgrad (serb. Beograd) 179

Beograd (serb.) $\rightarrow$ Belgrad

Berlin 12 f., 22, 36, 43, 47, 87, 108, 119, 124, 126-131, 140-142, 147, 189, 206, 221, 223, 230, 232 f., 245, 272 f., 277 f.

- Charlottenburg 141

- Karlshorst 43

Bolesławiec (poln.) $\rightarrow$ Bunzlau

Borodino 97, 272, 275

Breitenfeld $\rightarrow$ Leipzig

Breslau (poln. Wrocław) 11, 22, 98, 101-105, 107-110, 113-122, 133, 153, 230, 232 f., 242, 247

Brest (auch: Brest-Litovsk) $273 \mathrm{f}$.

Brest-Litovsk $\rightarrow$ Brest

Brienne-le-Château 275

Brüssel 146

Buda $\rightarrow$ Budapest

Budapest

- Buda 252

- Pest 252

Bunzlau (poln. Bolesławiec) $120 \mathrm{f}$.

Canberra $132 \mathrm{f}$.
Charlottenburg $\rightarrow$ Berlin

Chemnitz 275

Chojnów (poln.) $\rightarrow$ Haynau

Connewitz $\rightarrow$ Leipzig

Cröbern $\rightarrow$ Markkleeberg

Crostewitz $\rightarrow$ Markkleeberg

Częstochowa (poln.) $\rightarrow$ Tschenstochau

Danzig (poln. Gdańsk) 116, 233, 272 f., 280 f.

Dennewitz 189

Dessau 272

Döbling $\rightarrow$ Wien

Dobra 57

Dohna 273

Dölitz $\rightarrow$ Leipzig

Dösen $\rightarrow$ Leipzig

Dresden 22 f., 82, 158, 193, 221, 252, 272-274

Eschendorf 192

Espenhain $\rightarrow$ Rötha

Fère-Champenoise 275

Frankfurt/Main 123

Freiberg 272

Fuchshain 197

Gautzsch $\rightarrow$ Markkleeberg

Gdańsk (poln.) $\rightarrow$ Danzig

Gießhübel 273

Glogau (poln. Głogów) 273

Głogów (poln.) $\rightarrow$ Glogau

Gohlis $\rightarrow$ Leipzig

Görlitz 272, 275

Gorodečno 273

Grimma 180, 182 
Grodno (auch: Hrodna) 272

Groß-Wir (tsch. Velký Vír) 184

Großbeeren 22, 189

Großenhain 275

Großgörschen $\rightarrow$ Lützen

Großpösna 24

- Güldengossa 197

- Seifertshain 199, 211

Großzschocher $\rightarrow$ Leipzig

Güldengossa $\rightarrow$ Großpösna

Halle/Saale 28

Hamburg 145, 208, 273

Haynau (poln. Chojnów) 189

Herzberg 272

Hochkirch 274

Holzhausen $\rightarrow$ Leipzig

Hrodna $\rightarrow$ Grodno

Ischl $\rightarrow$ Bad Ischl

Jena 20, 90, 131, 184

Jüterbog 272

Kalisch (poln. Kalisz) 273

Kalisz (poln.) $\rightarrow$ Kalisch

Karlshorst $\rightarrow$ Berlin

Kastel 274

Kiew (ukr. Kyjiv) 219

Kleinzschocher $\rightarrow$ Leipzig

Koblenz 140

Kobrin (auch: Kobryn) 272 f.

Kobryn $\rightarrow$ Kobrin

Kolberg (poln. Kołobrzeg) 13, 227-236, 238-247

Kołobrzeg (poln.) $\rightarrow$ Kolberg

Kolomenskoe $\rightarrow$ Moskau

Krakau (poln. Kraków) 60, 72, 76, 90, 92, 95, 274

Kraków (poln.) $\rightarrow$ Krakau

Krieblowitz (poln. Krobielowice) 99, 105 f.

Krobielowice (poln.) $\rightarrow$ Krieblowitz

Kulm 273

Kostrzyn (poln.) $\rightarrow$ Küstrin

Küstrin (poln. Kostrzyn) 273

Kyjiv (ukr.) $\rightarrow$ Kiew

La Rochelle 13, 227, 245
La Rothière 275

Legnickie Pole (poln.) $\rightarrow$ Wahlstatt

Leipzig 7-14, 17, 20-39, 75 f., 80, 82 f., 85, 87, 94 f., 97 f., 100, 102, 108, 110, 115, 117, 122 f., 130-132, 137-143, 145-173, 175-189, 192-196, 199-206, 208, 211, 215, 220 f., 223, 226, 233, 237, 249, 251-256, 258, 262-265, 267, 270, 272 f., 275, 277, 281-284

- Breitenfeld 259

- Connewitz 197-199

- Dölitz 180, 194, 198, 203

- Dösen 198

- Gohlis $206 \mathrm{f}$.

- Großzschocher 23

- Holzhausen 185, 194, 199 f., 203, 210

- Kleinzschocher 185, 193, $201 \mathrm{f}$.

- Leutzsch $201 \mathrm{f}$.

- Liebertwolkwitz 24, 181 f., 197, 199, 204, 211

- Lindenau 201, 258

- Lößnig 185 f., 193, 197-199, 203 f.

- Lützschena 205

- Meusdorf 12, 177 f., 180, 195, 204

- Möckern 206

- Mölkau 200

- Paunsdorf 185, 193, 199 f., 203

- Probstheida 199

- Schleußig 201-203

- Sellerhausen 200

- Stötteritz 199

- Stünz 200

- Zuckelhausen 199

- Zweinaundorf 199

Lemberg (poln. Lwów, ukr. Lviv) 59, 61-64, 79

Leutzsch $\rightarrow$ Leipzig

Liebertwolkwitz $\rightarrow$ Leipzig

Lindenau $\rightarrow$ Leipzig

Liv (poln. Liw) 274

Livadia 171

Löbau 274

Lodz (poln. Łódź) 54

Łódź (poln.) $\rightarrow$ Lodz

London 221, 252

Lößnig $\rightarrow$ Leipzig

Löwenberg (poln. Lwówek Śląski) 275

Luboml (ukr. Ljuboml') 273 
Lützen 21, 189, $273 \mathrm{f}$.

- Großgörschen 189, 191, 275

Lützschena $\rightarrow$ Leipzig

Lviv (ukr.) $\rightarrow$ Lemberg

Lwów (poln.) $\rightarrow$ Lemberg

Lwówek Śląski (poln.) $\rightarrow$ Löwenberg

Maciejowice 79

Mainz $274 \mathrm{f}$.

Markkleeberg 185 f., 189-191, 194, 197 f., 203

- Auenhain 185, 190, 197 f.

- Cröbern 189, 197

- Crostewitz 185, 197

- Gautzsch 197 f.

- Raschwitz 198

- Wachau 185, 187, 189, 191, 195, 197, 211

Meißen 272, 275

Meusdorf $\rightarrow$ Leipzig

Minden 140

Mir 273

Möckern $\rightarrow$ Leipzig

Mölkau $\rightarrow$ Leipzig

Moskau (russ. Moskva) 8, 12, 14, 41-43, 45 f., 114, 156, 160, 163, 166, 168, 171 f., 219, 223, 267 f., 270, 272-274, 276-284

- Kolomenskoe 12, 159 f., 170 f.

Moskva (russ.) $\rightarrow$ Moskau

München 141, 206

New York 173

Niedergörsdorf 189

Nižnij Novgorod 41, 45, 272 f.

Nördlingen 223

Novovozdvižensk 272

Nürnberg 224, 247

Orlík nad Vltavou $\rightarrow$ Worlik

Paris 56, 65, 72, 99, 102, 139, 144, 182, 206, 215 f., 219, 221, 267, 272, 275 f.,

Paunsdorf $\rightarrow$ Leipzig

Pest $\rightarrow$ Budapest

Peterswalde (tschech. Petrovice) 273

Pfaffendorf 206, 208

Pirna 274

Posen (poln. Poznań) 90, 110, 116

Poznań (poln.) $\rightarrow$ Posen

Preußisch Eylau (heute: Bagrationowsk) 90
Probstheida $\rightarrow$ Leipzig

Prušany (Pružany) 274

Puschkin $\rightarrow$ Zarskoe Selo

Raschwitz $\rightarrow$ Markkleeberg

Raszyn 78, 97

Reichenbach 272, 275

Rom 215, 247

Rötha 256-258

- Espenhain 186

Schilda 274

Schleußig $\rightarrow$ Leipzig

Schlüsselburg 157

Schönewalde 273

Schöngrabern 188

Sedan 126, 131, 189

Seifertshain $\rightarrow$ Großpösna

Sellerhausen $\rightarrow$ Leipzig

Simbirsk (heute: Uljanowsk) 272

Slonim 272, 274

Smolensk 75, 223, 272 f.

Somosierra 97

Sowetsk $\rightarrow$ Tilsit

St. Petersburg 120, 156 f., 163, 166, 170, 219, 279

Stalingrad $\rightarrow$ Wolgograd

Stavropol 267, 269, 271, 273

Stettin (poln. Szczecin) 116

Stötteritz $\rightarrow$ Leipzig

Stünz $\rightarrow$ Leipzig

Süptitz 274

Szczecin (poln.) $\rightarrow$ Stettin

Theben $151 \mathrm{f}$.

Tilsit (heute: Sowetsk) 235, 240, 267

Tivoli 106

Trebnitz (poln. Trzebnica) 99

Třeboň (tsch.) $\rightarrow$ Wittingau

Trzebnica (poln.) $\rightarrow$ Trebnitz

Tschenstochau (poln. Częstochowa) 53, 274

Uljanowsk $\rightarrow$ Simbirsk

Varvažov (tsch.) $\rightarrow$ Arbesau

Valkaviskas (lit.) $\rightarrow$ Vaukavysk

Vaukavysk (lit. Valkaviskas, poln. Wołkowysk, russ. Volkovysk) 272 
Velký Vír (tsch.) $\rightarrow$ Groß-Wir

Vengrov (poln. Węgrów) 274

Versailles 131

Vilna (russ.) $\rightarrow$ Wilna

Vilnia (weißruss.) $\rightarrow$ Wilna

Vilnius (lit.) $\rightarrow$ Wilna

Volkovysk (russ.) $\rightarrow$ Vaukavysk

Vukovar 184

Wachau $\rightarrow$ Markkleeberg

Wahlstatt (poln. Legnickie Pole) 98 f., 189

Warschau (poln. Warszawa) 53, 55, $59 \mathrm{f}$.,

72-77, 79 f., 90, 92, 97, 157, 272 f., 279

Warszawa (poln.) $\rightarrow$ Warschau

Waterloo 189

Węgrów (poln.) $\rightarrow$ Vengrov

Wieluń 54

Wien 10, 80, 146 f., 149, 179, 184, 186, 189, 192 f., 251 f., 265, 282

- Döbling 252
Wilna (jidd. Wilne, lit. Vilnius, poln. Wilno, russ. Vilna, weißruss. Vilnia) 63, 272 f., 275

Wilne (jidd.) $\rightarrow$ Wilna

Wilno (poln.) $\rightarrow$ Wilna

Wittenberg 272

Wittingau (tsch. Třeboň) 181

Wolgograd (1925-1961: Stalingrad) 230

Wołkowysk (poln.) $\rightarrow$ Vaukavysk

Worlik (heute: Orlík nad Vltavou) 180 f., 184

Wrocław (poln.) $\rightarrow$ Breslau

Zamość 53, 97

Zarskoe Selo (heute: Puschkin) 157

Zinna 274

Zuckelhausen $\rightarrow$ Leipzig

Zweinaundorf $\rightarrow$ Leipzig 
Open Access @ 2016 by Böhlau Verlag GmbH \& Cie, Köln Weimar Wien 


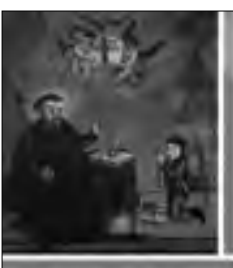

OIE KUNST DER ARMENIER IM OSTLICHEN CUROPA

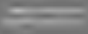

MARINA DMITRIEVA, BÁLINT KOVÁCS (HG.)

\section{DIE KUNST DER ARMENIER IM ÖSTLICHEN EUROPA}

(ARMENIER IM ÖSTLICHEN EUROPA -

ARMENIANS IN EASTERN EUROPE, BAND 2)

Der vorliegende Band versammelt Beiträge von Kunsthistorikern, Bauforschern, Ethnologen und Historikern zur Rolle der Armenier in der frühneuzeitlichen Kunstgeschichte Zentral- und Osteuropas. Behandelt werden sakrale Malerei und illuminierte Handschriften, Architektur und Städtebau, Kunsthandwerk und -sammlungen. Den geografischen Rahmen bilden dabei die heutigen Staaten Polen, Ukraine, Belarus, Rumänien, Moldova und die Russländische Föderation. Die von armenischen Künstlern geschaffenen Werke spiegeln ihre multiethnische und plurikonfessionelle Umgebung wider, ohne dabei ihre ursprünglichen Traditionen aus Mittlerem Osten und Kleinasien zu verleugnen.

2014. 256 S. 27 FARB. UND 28 S/W-ABB. GB. $170 \times 240$ MM.

ISBN 978-3-412-21107-3

BÖHLAU VERLAG, URSULAPLATZ I, D-50668 KÖLN, T:+49 22I 9I3 90-O INFO@BOEHLAU-VERLAG.COM, WWW.BOEHLAU-VERLAG.COM | WIEN KÖLN WEIMAR 


\section{VISUELLE GESCHICHTSKULTUR}

HERAUSGEGEBEN VON STEFAN TROEBST

IN VERBINDUNG MIT ARNOLD BARTETZKY, STEVEN A. MANSBACH UND MAKGORZATA OMILANOWSKA

EINE AUSWAHL

BD. 1 | ARNOLD BARTETZKY, MARINA DMITRIEVA, STEFAN TROEBST (HG.)

\section{NEUE STAATEN - NEUE BILDER?}

VISUELLE KULTUR IM DIENST STAATLICHER SELBSTDARSTELLUNG IN ZENTRAL- UND OSTEUROPA SEIT 1918 UNTER MITARBEIT VON

THOMAS FICHTNER.

2005. X, 364 S. 177 S/W- UND 16 FARB.

ABB. AUF 88 TAF. GB.

ISBN 978-3-412-14704-4

BD. 2 | ULF BRUNNBAUER,

STEFAN TROEBST (HG.)

\section{ZWISCHEN AMNESIE UND NOSTALGIE}

DIE ERINNERUNG AN DEN

KOMMUNISMUS IN SÜDOSTEUROPA

2007. VI, 308 S. 37 S/W-ABB. UND 9 TAB.

GB. | ISBN 978-3-412-13106-7

BD. 3 | MARTIN AUST, KRZYSZTOF

RUCHNIEWICZ, STEFAN TROEBST (HG.)

\section{VERFLOCHTENE ERINNERUNGEN}

POLEN UND SEINE NACHBARN

IM 19. UND 20. JAHRHUNDERT

2009. VII, 285 S. 33 S/W-ABB. GB

ISBN 978-3-412-20292-7

BD. 4 | JACEK FRIEDRICH

\section{NEUE STADT IN ALTEM GEWAND}

DER WIEDERAUFBAU DANZIGS

1945-1960

2010. VIII, 276 S. 105 S/W-ABB. AUF

48 TAF. GB. | ISBN 978-3-412-20312-2
BD. 5 | JUTTA FAEHNDRICH

EINE ENDLICHE GESCHICHTE

DIE HEIMATBÜCHER DER

DEUTSCHEN VERTRIEBENEN

2011. XII, 303 S. 36 S/W-ABB. GB.

ISBN 978-3-412-20588-1

BD. 6 | MARTINA BALEVA

\section{BULGARIEN IM BILD}

DIE ERFINDUNG VON NATIONEN

AUF DEM BALKAN IN DER KUNST

DES 19. JAHRHUNDERTS

2012. 294 S. 123 S/W- UND

19 FARB. ABB. GB.

ISBN 978-3-412-20687-1

BD. 7 | ELENA TEMPER

\section{BELARUS VERBILDLICHEN}

STAATSSYMBOLIK UND NATIONS-

BILDUNG SEIT 1990

2012. 332 S. 52 S/W-ABB. UND 22 FARB.

ABB. GB. | ISBN 978-3-412-20699-4

\section{BD. 8 | JENNY ALWART}

MIT TARAS ŠEVČENKO STAAT MACHEN ERINNERUNGSKULTUR UND GESCHICHTSPOLITIK IN DER UKRAINE VOR UND NACH 1991

2012. 220 S. 25 S/W- UND 22 FARB. ABB GB. | ISBN 978-3-412-20769-4

BÖHLAU VERLAG, URSULAPLATZ I, D-50668 KÖLN, T:+49 22I 9I3 90-O INFO@BOEHLAU-VERLAG.COM, WWw.BOEHLAU-VERLAG.COM | WIEN KÖLN WEIMAR 


\section{VISUELLE GESCHICHTSKULTUR}

BD. 9 | ARNOLD BARTETZKY

NATION - STAAT - STADT

ARCHITEKTUR, DENKMALPFLEGE UND VISUELLE GESCHICHTSKULTUR VOM 19. BIS ZUM 21. JAHRHUNDERT 2012. 276 S. 69 S/W- UND 177 FARB. ABB. GB. | ISBN 978-3-412-20819-6

BD. 10 | AGNIESZKA GASIOR (HG.)

\section{MARIA IN DER KRISE}

KULTPRAXIS ZWISCHEN KONFESSION UND POLITIK IN OSTMITTELEUROPA 2014. 388 S. 81 S/W- UND 47 FARB. ABB. GB. | ISBN 978-3-412-21077-9

BD. 11 | ARNOLD BARTETZKY,

RUDOLF JAWORSKI (HG.)

\section{GESCHICHTE IM RUNDUMBLICK}

PANORAMABILDER IM ÖSTLICHEN EUROPA

2014. 213 S. 24 S/W- UND 70 FARB. ABB. GB. | ISBN 978-3-412-22147-8

BD. 12 | ARNOLD BARTETZKY, CHRISTIAN DIETZ, JÖRG HASPEL (HG.)

\section{VON DER ABLEHNUNG ZUR}

ANEIGNUNG? DAS ARCHITEKTONISCHE ERBE DES SOZIALISMUS IN MITTEL- UND OSTEUROPA

FROM REJECTION TO APPROPRIATION? THE ARCHITECTURAL HERITAGE OF SOCIALISM IN CENTRAL AND EASTERN EUROPE

2014. 297 S. 43 S/W- UND 175 FARB. ABB. GB. | ISBN 978-3-412-22148-5

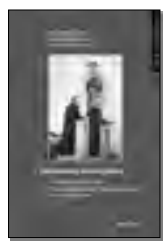

BD. 13 | AGNIESZKA GASIOR, AGNIESZKA HALEMBA, STEFAN TROEBST (HG.) GEBROCHENE KONTINUITÄTEN TRANSNATIONALITÄT IN DEN ERINNERUNGSKULTUREN OSTMITTELEUROPAS IM 2O. JAHRHUNDERT

2014. 352 S. 51 S/W- UND 12 FARB. ABB. GB. | ISBN 978-3-412-22256-7

BD. 14 I STEFAN ROHDEWALD

\section{GÖTTER DER NATIONEN}

RELIGIÖSE ERINNERUNGSFIGUREN IN SERBIEN, BULGARIEN UND MAKEDONIEN BIS 1944

2014. 905 S. 18 S/W- UND 10 FARB. ABB. GB. | ISBN 978-3-412-22244-4

BD. 15 | MARINA DMITRIEVA,

LARS KARL (HG.)

\section{DAS JAHR 1813, OSTMITTELEUROPA}

\section{UND LEIPZIG}

DIE VÖLKERSCHLACHT ALS

(TRANS)NATIONALER ERINNERUNGSORT

2016. 299 S. 49 S/W- UND 4 O FARB. ABB GB. | ISBN 978-3-412-50399-4 


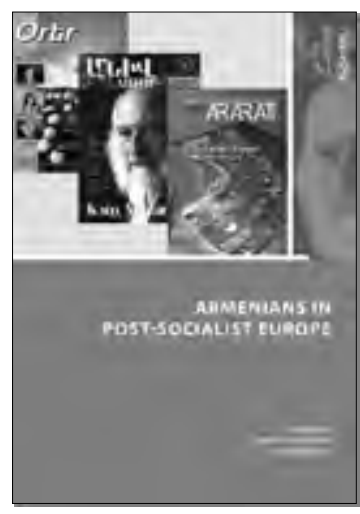

KONRAD SIEKIERSKI,

STEFAN TROEBST (EDS.)

\section{ARMENIANS IN POST-SOCIALIST} EUROPE

(ARMENIER IM ÖSTLICHEN EUROPA -

ARMENIANS IN EASTERN EUROPE, BAND 3)

This volume presents articles on the modern Armenian diaspora in postsocialist Europe, including the Baltic States, Belarus, Bulgaria, the Czech Republic, Hungary, Moldova, Poland, Romania, Russia and Ukraine. Specialists from the fields of cultural anthropology, sociology, and area studies offer their insights into current developments of Armenian communities which, although located within common post-socialist timespace, differ from one another significantly in terms of their historical background, identity politics, and socio-cultural characteristics.

2016. 237 S. GB. $170 \times 240$ MM | ISBN 978-3-412-50155-6

BÖHLAU VERLAG, URSULAPLATZ I, D-50668 KÖLN, T: + 49 22I 9I3 90-O INFO@BOEHLAU-VERLAG.COM, WWW.BOEHLAU-VERLAG.COM | WIEN KÖLN WEIMAR 


\section{VISUELLE GESCHICHTSKULTUR | BAND 15}

In Anknüpfung an die vielfältige historische Erforschung der Kommemorierung von Kriegen sowie der damit einhergehenden Formen von Erinnerungspolitik widmet sich dieser Sammelband einer Thematisierung des Völkerschlachtereignisses in den Gedächtniskulturen Ost(mittel)europas. Konkreten Anlass dazu bot das Leipziger Doppeljubiläum: jenes der Schlacht im Jahre 1813 sowie das der Einweihung des Völkerschlachtdenkmals im Jahre 1913. Im Zentrum stehen dabei kultur- und erinnerungsgeschichtliche Perspektiven - mit einem Schwerpunkt auf jeweiligen nationalen Narrativen und daran hängenden Mythenbildungen. Auch finden mediale Aufbereitungen des Ereignisses in Literatur, bildender Kunst und Film besondere Berücksichtigung.

Marina Dmitrieva arbeitet als Kunsthistorikerin am GWZO e.V. an der Universität Leipzig. Ihre Forschungsschwerpunkte sind Kunstgeschichte der Moderne in Zentral- und Osteuropa, Renaissance nördlich der Alpen, politische Ikonografie im 20.-21. Jahrhundert.

Lars Karl ist Historiker an der Universität Leipzig mit den Forschungsschwerpunkten Kulturgeschichte Osteuropas und des Kaukasus, Geschichtspolitik und Erinnerungskultur, Filmgeschichte Russlands und der Sowjetunion. 